\title{
Chelate Ligands for the Stabilisation of Low-Valent Main Group Compounds
}

\author{
Dissertation \\ zur Erlangung des mathematisch-naturwissenschaftlichen Doktorgrades \\ „Doctor rerum naturalium“ \\ der Georg-August-Universität Göttingen
}

im Promotionsprogramm

der Georg-August University School of Science (GAUSS)

vorgelegt von

Johannes Kretsch

aus Stuttgart

Göttingen, 2021 


\section{Betreuungsausschuss:}

Prof. Dr. Dietmar Stalke, Institut für Anorganische Chemie

Prof. Dr. Franc Meyer, Institut für Anorganische Chemie

\section{Mitglieder der Prüfungskommission:}

Referent: $\quad$ Prof. Dr. Dietmar Stalke, Institut für Anorganische Chemie

Korreferent: $\quad$ Prof. Dr. Franc Meyer, Institut für Anorganische Chemie

Weitere Mitglieder der Prüfungskommission:

Prof. Dr. Manuel Alcarazo, Institut für Organische und Biomolekulare Chemie

Prof. Dr. Ricardo Mata, Institut für Physikalische Chemie

Dr. Matthias Otte, Institut für Anorganische Chemie

Jun.-Prof. Dr. Johannes Walker, Institut für Organische und Biomolekulare Chemie

Tag der mündlichen Prüfung: 25.08.2021 
Die vorliegende Arbeit wurde unter Anleitung von Prof. Dr. Dietmar Stalke am Institut für Anorganische Chemie der Georg-August-Universität Göttingen im Zeitraum vom 01.01.2016 bis 30.06.2021 angefertigt. 
Für meine Familie 


\section{TABLE OF CONTENTS}

List of Abbreviations

Compound Index ix

1 Introduction 1

1.1 Low-valent group 13 complexes 1

$\begin{array}{lll}1.1 .1 & \text { Aluminium } & 1\end{array}$

$\begin{array}{llr}1.1 .2 & \text { Gallium } & 8\end{array}$

$\begin{array}{lll}1.1 .3 & \text { Indium } & 12\end{array}$

$\begin{array}{lll}\text { 1.1.4 Thallium } & 14\end{array}$

1.2 NacNac related ligands and complexes 16

1.3 Scope 23

2 Results and Discussion $\quad 24$

2.1 Important Structural Features 25

2.2 Complexes based on bis(benzoxazol-2-yl)methanide 27

2.2.1 Synthesis of bis(benzoxazol-2-yl)methane $\left(\mathrm{Box}_{2} \mathrm{CH}_{2}\right) \quad 27$

2.2.2 Group 1 complexes of bis(benzoxazol-2-yl)methanide 27

2.2.3 Group 13: Alumnium bis(benzoxazol-2-yl)methanide complexes 35

2.3 Complexes based on bis(4-methyl-benzoxazol-2-yl)methane 38

2.3.1 Synthesis of bis(4-methyl-benzoxazol-2-yl)methane ligand 38

$\begin{array}{lll}\text { 2.3.2 } & \text { Group } 1 \text { bis(benzoxazol-2-yl)methanide } & 38\end{array}$

2.3.3 Group 13 bis(4-methyl-benzoxazol-2-yl)methanide complexes 41

2.4 Complexes based on Bis(4-benzhydryl-benzoxazol-2-yl)methane scaffold 68

$\begin{array}{lll}\text { 2.4.1 Ligand Synthesis } & 68\end{array}$

$\begin{array}{lll}\text { 2.4.2 Group 1 Complexes } & 73\end{array}$

2.4.3 Group 13 Complexes 92

3 Summary \& Outlook $\quad 102$

4 Experimental Part $\quad 110$

$\begin{array}{lll}4.1 & \text { Work Techniques and Experimental Setups } & 110\end{array}$

4.1.1 Handling of Air- and Moisture-Sensitive Compounds 110

4.1.2 Preparation and Workup of Starting Materials 111

$\begin{array}{lll}4.1 .1 & \text { Elemental Analyses } & 111\end{array}$

$\begin{array}{lll}4.1 .2 & \text { IR Spectroscopy (ATR) } & 111\end{array}$

$\begin{array}{lll}4.1 .3 & \text { Mass Spectrometry } & 111\end{array}$

4.1.4 NMR Techniques and Experiments $\quad 112$

4.1.4.1 ${ }^{1}$ H-DOSY-ECC-MW Estimation: Sample Preparation and Measuring Parameters 112

$\begin{array}{lll}\text { 4.1.4.2 } & { }^{1} \mathrm{H} \text { NMR Water Titration Experiments } & 113\end{array}$

4.1.5 Computational Details of Electronic Structure Analyses 113

4.1.6 Single Crystal X-ray Diffraction Experiments 113

$\begin{array}{lll}\text { 4.1.6.1 Crystal Selection and Handling } & 113\end{array}$

$\begin{array}{lll}\text { 4.1.6.2 Data Collection and Processing } & 114\end{array}$

$\begin{array}{lll}\text { 4.1.6.3 Structure Solution and Refinement } & 114\end{array}$

$\begin{array}{lll}\text { 4.1.6.4 Treatment of Disorder } & 115\end{array}$ 
4.1.7 Complex based on bis(benzoxazol-2-yl)methanide 117

4.1.8 Complex based on bis(4-methyl-benzoxazol-2-yl)methanide 122

4.1.9 Synthesis of bis(4-benzhydryl-benzoxazol-2-yl)methane 136

4.1.10 Complex based on bis(4-benzhydryl-benzoxazol-2-yl)methanide 145

5 Appendix 167

$\begin{array}{lll}5.1 & \text { Crystallographic Data } & 168\end{array}$

$\begin{array}{lll}5.2 & \text { Crystallographic Cooperation } & 208\end{array}$

5.3 DOSY Data 212

5.4 UV/Vis Spectroscopy 213

5.5 Fluorescence measurements 214

5.6 Experimental setup and methodology for $\mathrm{p} K_{\mathrm{a}}$ determination 218

5.7 Differential Scanning Calorimetry (DSC) 220

5.8 Monoanionic $(E, E)-,(Z, E / E, Z)-$ or $(E, E)-\left({ }^{4-B^{2} h} B_{0 x} C H\right)$ isomers of 28a-i 222

6 References 223 


\section{LIST OF ABBREVIATIONS}

$\AA$

Adam

ATR

CIP

CS

CSD

CCDC

C.N.

$\mathrm{DAB}$

DCM

dev.

Dipp

DMAP

DMSO

DOSY

DSE

ECC

ED

EI

ESI

$\mathrm{Et}_{2} \mathrm{O}$

EtOAc

equiv.

ecx.

GUI

HMBC

HMDS

HOMO

HSAB

HSQC

ipp

${ }^{i} \mathrm{Pr}$

IR

LIFDI

LUMO

$\mathrm{M}$

$\mathrm{MHz}$

MS

MW
Ångstrom

Adamantyl

Attenuated Total Reflection

Contact Ion Pair

Compact Spheres / Compact Spherical

Cambridge Structural Database

Cambridge Crystallographic Data Base

Coordination Number

Diazabutadiene

Dichloromethane

Deviation(s)

2,6-Diisopropylphenyl

4-Dimethylaminopyridine

Dimethylsulfoxide

Diffusion-Ordered Spectroscopy

Dissipated Spheres and Ellipsoids

External Calibration Curve

Expanded Discs

Electron Ionization

Electrospray-ionization

Diethyl ether

Ethyl acetate

Equivalent(s)

excess

Graphical User Interface

Heteronuclear Multiple Bond Correlation

Hexamethyldisilazane

Highest Occupied Molecular Orbital

Hard and Soft Acids and Bases

Heteronuclear Single Quantum Correlation

2-Isopropylphenyl

Isopropyl

Infrared

Liquid Injection Field Desorption Ionization

Lowest Unoccupied Molecular Orbital

Molar

Megahertz

Mass Spectrometry

Molecular Weight 
$\mathrm{m} / \mathrm{z}$

$\mathrm{NacNac}$

NBO

${ }^{n} \mathrm{BuLi}$

NMR

NOESY

NPA

NRT

PMDETA

ppm

Py

RMS(D)

sof.

SSIP

${ }^{t} \mathrm{Bu}$

${ }^{t} \mathrm{BuLi}$

THF

TMEDA

TMS

XRD

YLD

Z
Mass/charge ratio

$\beta$-Diketiminate

Natural Bonding Orbital

n-Butyllithium

Nuclear Magnetic Resonance

Nuclear Overhauser Enhancement Spectroscopy

Natural Population Analysis

Natural Resonance Theory

$N, N, N, N$, $N$ "'-Pentamethyldiethylenetriamine

Parts per million

Pyridyl

Root Mean Square (Deviation)

Site Occupation Factor

Solvent-Separated Ion Pair

tertiary-Butyl

tertiary-Butyllithium

Tetrahydrofurane

$N, N, N^{\prime}, N$ '-Tetramethylethylene-1,2-diamine

Tetramethylsilane

$\mathrm{X}$-ray diffraction

Yield

Charge 


\section{COMPOUND INDEX}

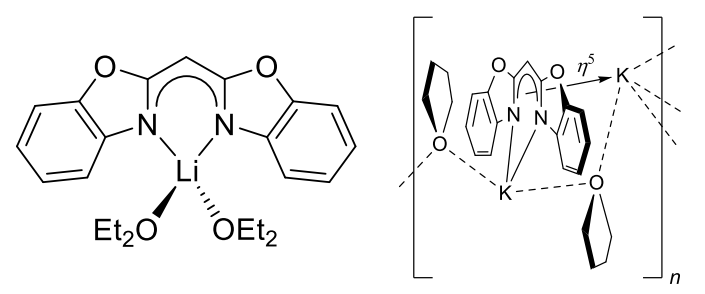

1<smiles></smiles>

4

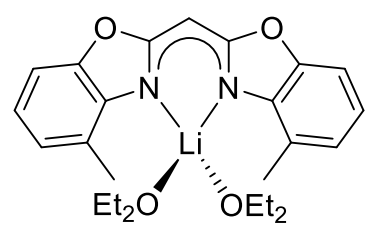

6

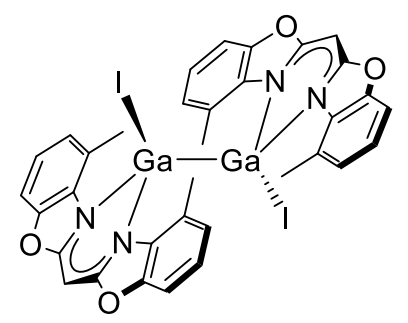

$8 a$

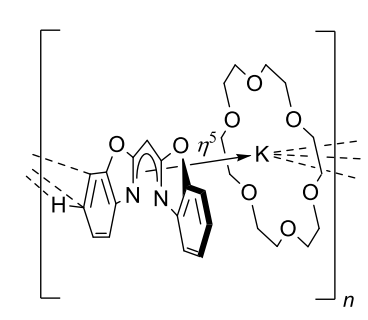

3

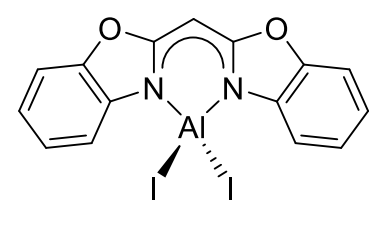

5

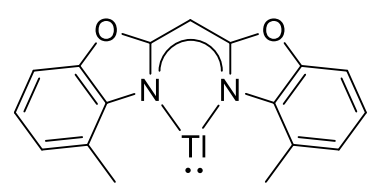

7

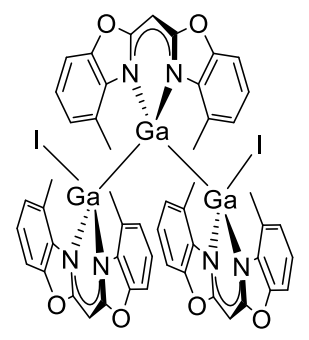

$8 b$

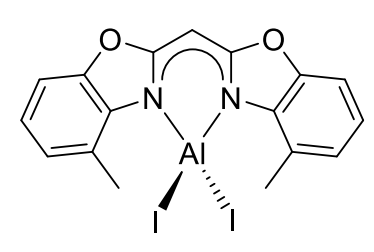

9

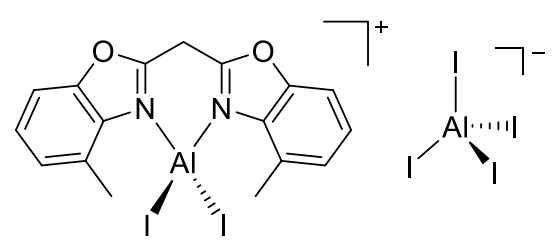

10

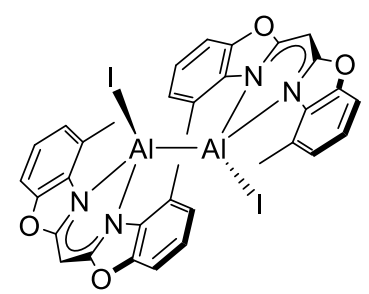

11 


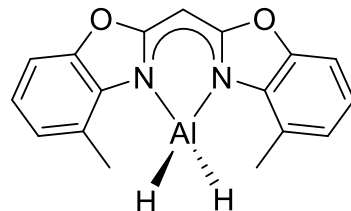

12

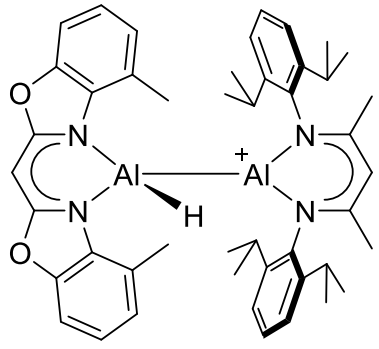

$\left[\mathrm{B}\left(\mathrm{C}_{6} \mathrm{~F}_{5}\right)_{4}\right]^{-}$

14

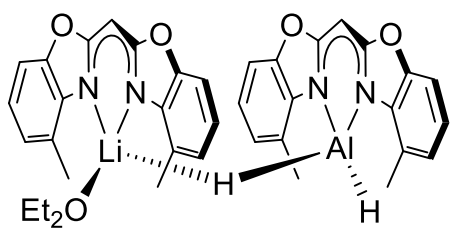

$12 a$

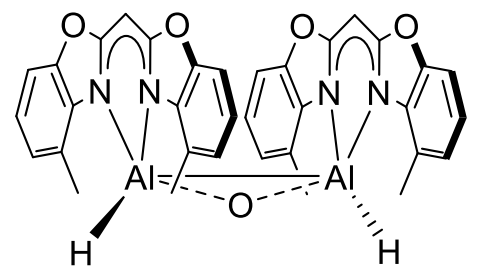

$15 a \quad 15 b$

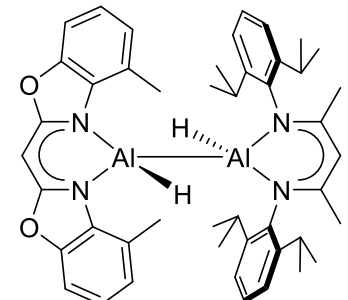

13

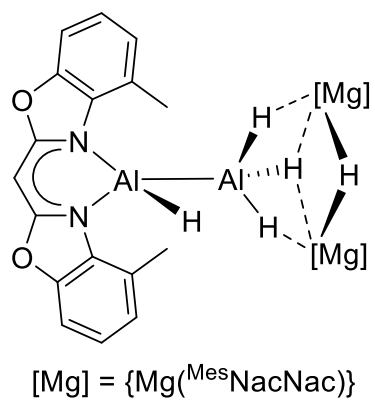

$15 c$

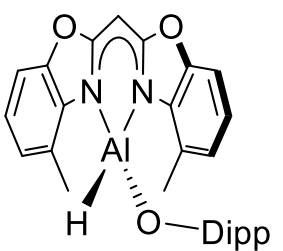

16

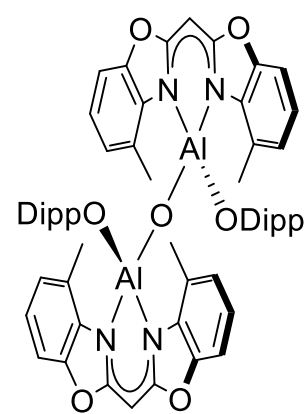

17<smiles>COc1ccccc1N[R6](=O)OC(C)(C)C</smiles>

18<smiles>COc1cccc(C(O)(c2ccccc2)c2ccccc2)c1NC(C)(C)C</smiles>

$19 a$<smiles>COc1cccc2c1NC(=O)OC2(c1ccccc1)c1ccccc1</smiles>

19b<smiles>COc1cccc(C(c2ccccc2)c2ccccc2)c1N</smiles>

20 


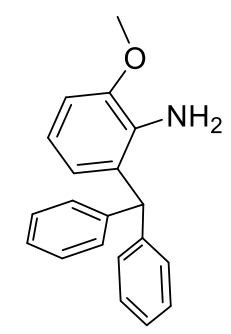

21

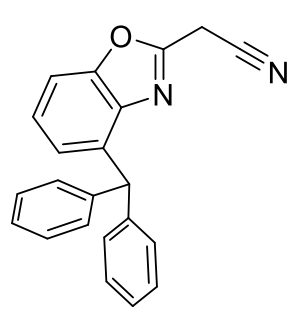

22

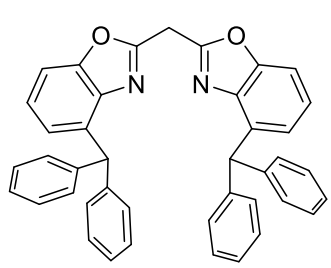

23

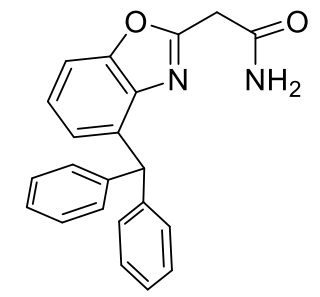

$23 a$

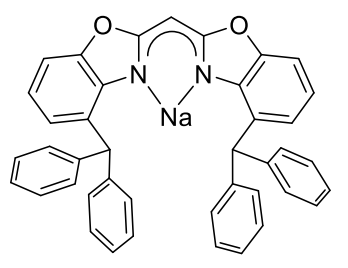

24

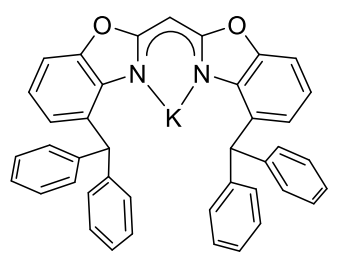

25

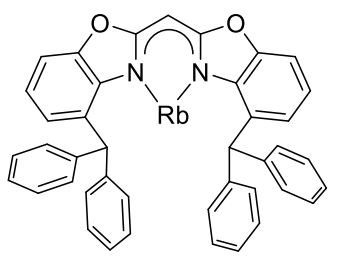

26

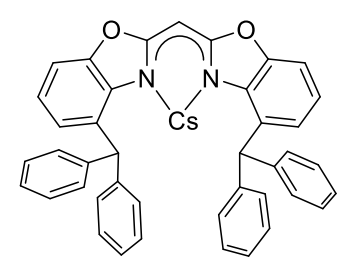

27

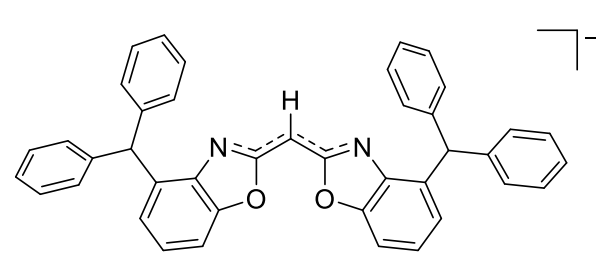

[K@18-crown-6] $]^{+}$

28

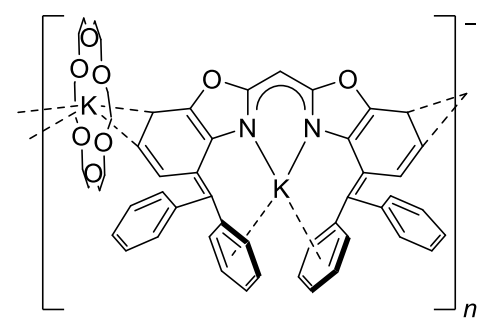

$n\left[(\mathrm{THF})_{2} \mathrm{~K} @ 18-\text { crown-6] }\right]^{+}$

29

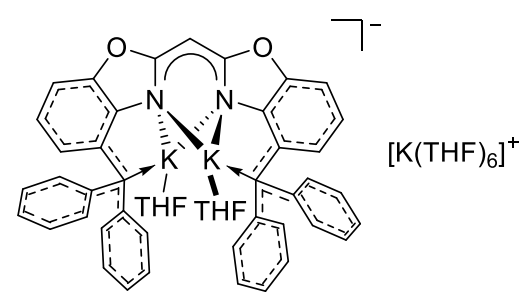




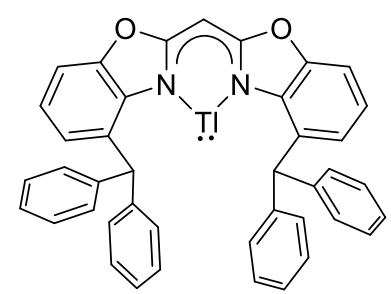

32

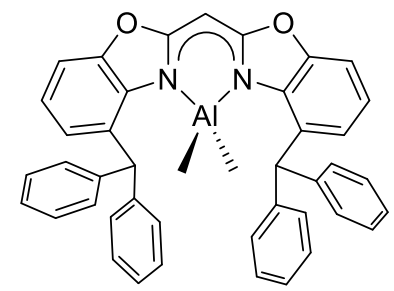

35

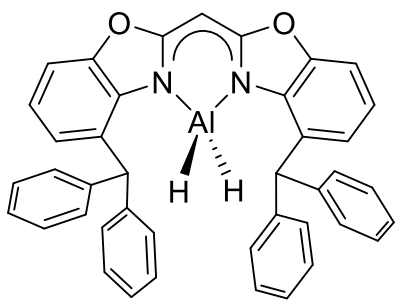

38

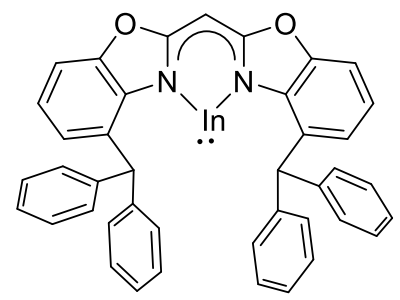

33

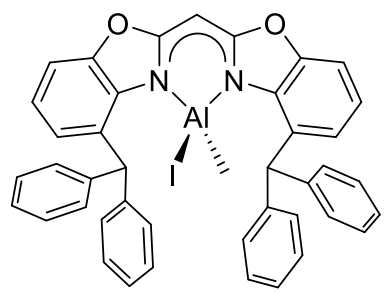

36

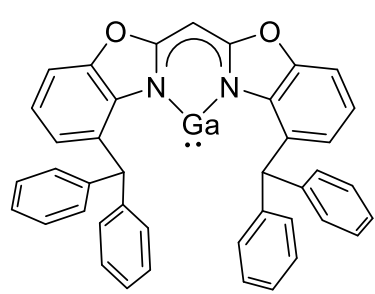

34

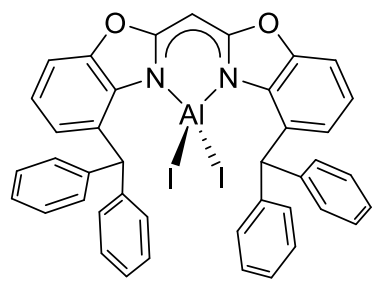

37

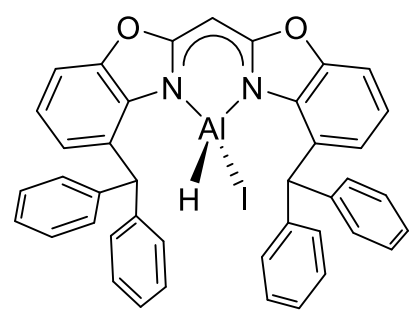

39 
Major parts of this Ph.D. thesis have been published separately:

[1] J. Kretsch, Anne Kreyenschmidt, R. Herbst-Irmer, D. Stalke, "Alkali metal complexes based on bisheterocyclomethanide ligands", Dalton Trans. 2018, 36, 12606-12612. ${ }^{[1]}$

[2] J. Kretsch, R. Herbst-Irmer, D. Stalke, "Aluminum(III) Halide Complexes based on a Bis(benzoxazol-2-yl)methane Ligand”, Z. Anorg. Allg. Chem. 2018, 14, 657-660. ${ }^{[2]}$

[3] J. Kretsch, I Koehne, Märt Lõkov, Ivo Leito, D. Stalke, "Bis(benzoxazol-2-yl)methanes Hounding NacNac: Varieties and Applications in Main Group Metal Coordination”, Eur. J. Inorg. Chem. 2019, 28, 3258-3264. ${ }^{[3]}$

[4] J. Kretsch, Anne Kreyenschmidt, Timo Schillmöller, R. Herbst-Irmer, D. Stalke, "Mixed LowValent Alanes from the Bis(4-methyl-benzoxazol-2-yl)methanide Ligand", Inorg. Chem. 2020, 59, 13690-13699. ${ }^{[4]}$

[5] J. Kretsch, A. Kreyenschmidt, T. Schillmöller, M. Lõkov, R. Herbst-Irmer, I. Leito, D. Stalke, "Bis(4-benzhydryl-benzoxazol-2-yl)methane - from a Bulky NacNac Alternative to a Trianion in Alkali Metal Complexes", Chem. Eur. J. 2021, 27, 9858-9865. ${ }^{[5]}$

[6] J. Kretsch, A. Kreyenschmidt, T. Schillmöller, C. Sindlinger, R. Herbst-Irmer, D. Stalke, "Group 13 Heavier Carbene Analogs Stabilized by the Bulky Bis(4-benzhydryl-benzoxatol-2yl)methanide Ligand", Inorg. Chem. 2021, 60, 7389-7398. ${ }^{[6]}$ 



\section{INTRODUCTION}

In 1825 Hans Christian Ørstedt, a Danish chemist, isolated aluminium for the first time. ${ }^{[7]}$ Two years later, Friedrich Wöhler invented a new synthesic process for the pure synthesis of aluminium in which aluminium chloride was reduced with three equivalents of potassium. ${ }^{[8]}$ Another milestone for the utilisation of aluminium was the independent and almost simultaneous invention of the HallHéroult process, named by Charles Martin Hall and Paul Héroult in $1866 .{ }^{[9]}$ Since then, aluminium, which is the third most common element on the earth's crust (7.57 wt\%) after oxygen (49.4 wt\%) and silicon (25.8 wt\%), has become one of the most versatile metals. ${ }^{[8]}$ In 2019, about 63.7 million metric tons of raw aluminium were primarily produced by fused-salt electrolysis requiring ca. $848 \mathrm{TWh},{ }^{[10]}$ which is roughly $3 \%$ of the worldwide generated electricity. ${ }^{[11]}$

Although aluminium mainly occurs in the oxidation state + III, several complexes have been isolated that comprise aluminium $+\mathrm{II}$ ions. ${ }^{[12]}$ The isolation of $\mathrm{Al}^{\mathrm{I}}$ species is even more challenging caused by their thermodynamic instability, and can only be achieved by the introduction of sterically demanding ligand systems. ${ }^{[13]}$ In past decades, numerous aluminium compounds in low oxidation states have been synthesised. Especially alanediyls, ${ }^{[14]}$ dialuminium species ${ }^{[15]}$ incorporating single or multiple bonds as well as aluminium(I) anions (aluminyl anions), ${ }^{[16]}$ show promising behaviour in small molecule activation and therefore might be considered as predecessors of future main group catalysts. This work will focus on ligands, which form $\mathrm{N}$-heterocyclic carbene-like analogues of aluminium (alanediyls) and its heavier homologues gallium, indium, and thallium.

\subsection{Low-valent group 13 complexes}

\subsubsection{Aluminium}

In 2000, the group of Roesky et al. published the $\beta$-diketiminate based [ $\left.\mathrm{Al}^{\mathrm{I}}\left({ }^{\mathrm{Dipp}} \mathrm{NacNac}\right)\right]$ (Al-I) $\left({ }^{\text {DippNacNac }}=\left(\{\text { DippNCMe }\}_{2} \mathrm{CH}\right)\right.$, Dipp $\left.=2,6-{ }^{i} \mathrm{Pr}_{2} \mathrm{C}_{6} \mathrm{H}_{3}\right)$ complex, which had been prepared by reduction of corresponding aliuminium(III) diiodide species. ${ }^{[14 a]}$ This was the first monomeric carbenoid $\mathrm{Al}^{\mathrm{I}}$ complex to be synthesised and characterised by single crystal XRD experiments. A few years later, Cui et al. synthesised the related aluminium(I) complex $\left(\left[\mathrm{Al}^{\mathrm{I}}\left(\left\{\mathrm{DippNC}^{t} \mathrm{Bu}\right\}_{2} \mathrm{CH}\right)\right]\right)$ with tert-butyl instead of methyl groups at the NacNac scaffold. ${ }^{[14 b]}$ Computational investigations on alanediyls incorporating differing NacNac ligands ( $\left.\{R \mathrm{NCR}\}_{2} \mathrm{CH}\right), R=\mathrm{H}, \mathrm{Me}, \mathrm{Ph}$, or Dipp; $R^{\prime}=\mathrm{H}$, $\mathrm{Me}$ ) unveiled a substantial positive charge on the metal centre and heavily polarised Al-N bonds (Figure 1-1). ${ }^{[14 a, 17]}$ The singlet-triplet energy separation in these model compounds was calculated to be in the range of 34.3 to $45.7 \mathrm{kcal} / \mathrm{mol} \cdot{ }^{[18]}$ In general, the $\mathrm{HOMO}$ of $\left[\mathrm{Al}^{\mathrm{I}}\left(\{R \mathrm{NCR}\}_{2} \mathrm{CH}\right)\right]$ consists of an sp-like hybridised singlet lone pair of electrons at the cation. Furthermore, a formally vacant porbital on $\mathrm{Al}^{\mathrm{I}}$, orthogonal to the heterocycle and associated with the LUMO+1, causes a 


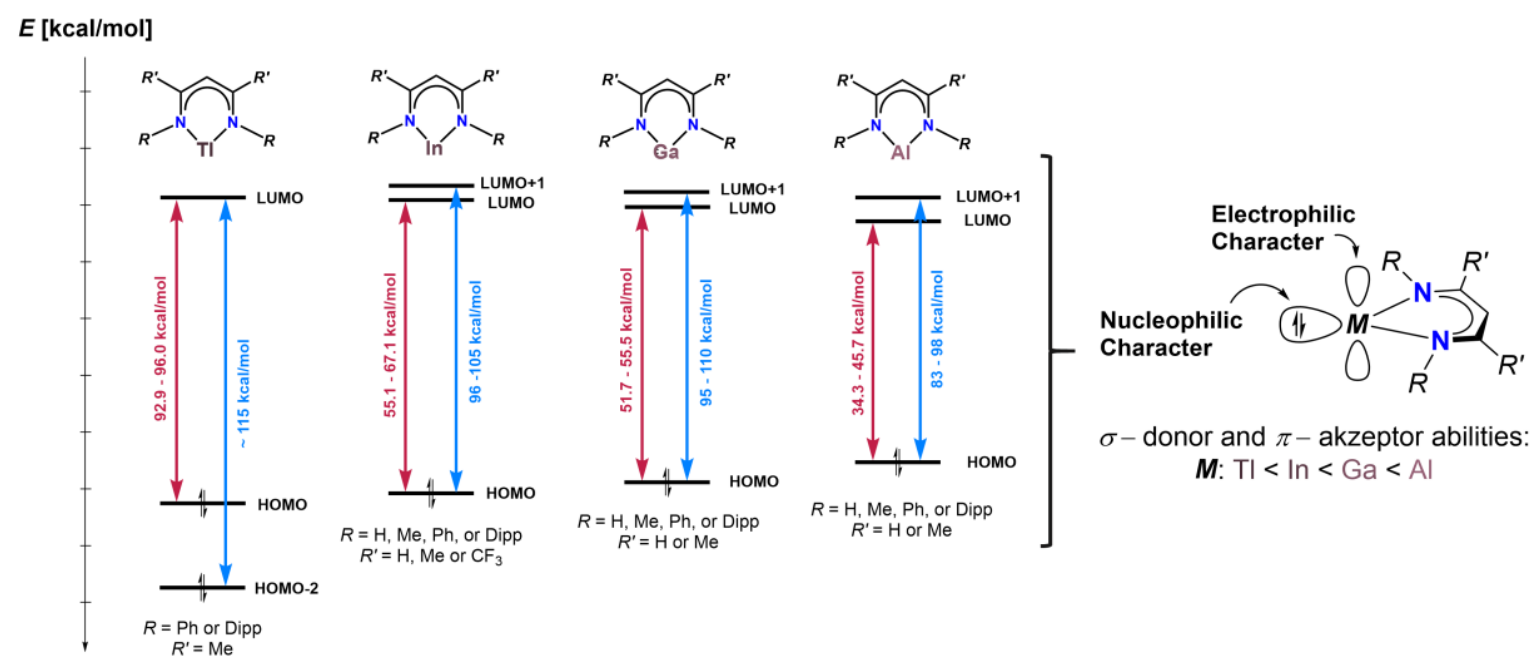

Figure 1-1. Calculated frontier orbitals of $\left[M\left(\{R \mathrm{NCR}\}_{2} \mathrm{CH}\right)\right]\left(M=\mathrm{Tl}\right.$, In, Ga, Al) (left). ${ }^{[13,30-33]}$ Electrophilic and nucleophilic character of NHC analogues (right).

HOMO-LUMO+1 gap of $83-98 \mathrm{kcal} / \mathrm{mol}$. As a result, a nucleophilic and an electrophilic character of the alanediyls, were expected and later proven, especially on [ $\left.\mathrm{Al}^{\mathrm{I}}\left({ }^{\text {(ipp }} \mathrm{NacNac}\right)\right](\mathrm{Al}-\mathrm{I})$, in numerous experiments. In the last two decades, the unique properties of alanediyls Al-I were explored by different groups. Hence, the following paragraphs shall give an overview of reactions of $\left[\mathrm{Al}^{\mathrm{I}}\left({ }^{\mathrm{Dipp}} \mathrm{NacNac}\right)\right](\mathrm{Al}-\mathrm{I})$ with diverse organic substrates.

Recently, Crimmin and his co-workers published various reactions in which $\left[\mathrm{Al}^{\mathrm{I}}\left({ }^{\mathrm{Dipp}} \mathrm{NacNac}\right)\right]$ (AlI) was applied for small molecule activation. Among other things, it could be shown that carbon chain growth from $\mathrm{C} 1$ to $\mathrm{C} 3$ and $\mathrm{C} 4$ is accomplished by sequential reaction of $\mathrm{CO}\left(\mathrm{Al}-\mathrm{II}\right.$ ) and $\mathrm{CO}_{2}$ (Al-IIb) with alanediyl Al-I (Figure 1-2) in the presence of a transition metal carbonyl complex $\left[\mathrm{W}(\mathrm{CO})_{6}\right](\mathrm{Al}-\mathrm{II}) \cdot{ }^{[19]}$ Moreover, Crimmin et al. reported on the reversible reaction (Figure 1-2, Al-III) of terminal or strained alkenes like norbornene (Al-IIIa), ethylene, propylene, hex-1-ene, and allylbenzene (Al-IIIb) in benzene under mild conditions. ${ }^{[20]}$ In previous studies, Nikonov and co-workers have demonstrated the oxidative addition (Figure 1-2, Al-IV) of diverse H-X bonds (X $=\mathrm{H}, \mathrm{B}, \mathrm{C}, \mathrm{Si}, \mathrm{N}, \mathrm{P}, \mathrm{O})$ to one equiv. of $\left[\mathrm{Al}^{\mathrm{I}}\left(\mathrm{(ipp}^{\mathrm{Dip}} \mathrm{NacNac}\right)\right](\mathrm{Al}-\mathrm{I})$. Here, heating to $70^{\circ} \mathrm{C}$ was required for the addition of hydrogen or $\mathrm{Cp}^{\star} \mathrm{H}$, whereas the reaction of model substrates $\mathrm{HBPin}, \mathrm{H}_{3} \mathrm{SiPh}$, $\mathrm{HO}^{i} \mathrm{Pr}, \mathrm{H}_{2} \mathrm{~N}^{t} \mathrm{Bu}$ as well as $\mathrm{H}_{2} \mathrm{NPh}$ and the monomeric compound Al-I already occurred at ambient temperature. In further studies, Crimmin et al. and Nikonov et al. investigated the oxidative addition of relatively robust $\mathrm{sp}^{2}$ and $\mathrm{sp}^{3} \mathrm{C}-\mathrm{F}$ bonds and alanediyl Al-I. ${ }^{[21]}$ In the case of polyfluorinated benzene substrates (Figure 1-2, Al-V), the ease of $\mathrm{C}\left(\mathrm{sp}^{2}\right)-\mathrm{F}$ oxidative addition decreases as the degree of fluorination diminishes. In addition, the position of the substituted fluorine atoms influences the reactivity of the $\mathrm{C}-\mathrm{F}$ bond in the order of ortho > meta > para. ${ }^{[22]}$ The cleavage of $\mathrm{C}\left(\mathrm{sp}^{3}\right)-\mathrm{F}$ bonds have been observed in the reaction of flourocyclo- or 1-fluorohexane with Al-I in benzene and resulted in corresponding fluoro aluminium (Figure 1-2, Al-V) species, respectively. ${ }^{[23]}$ 


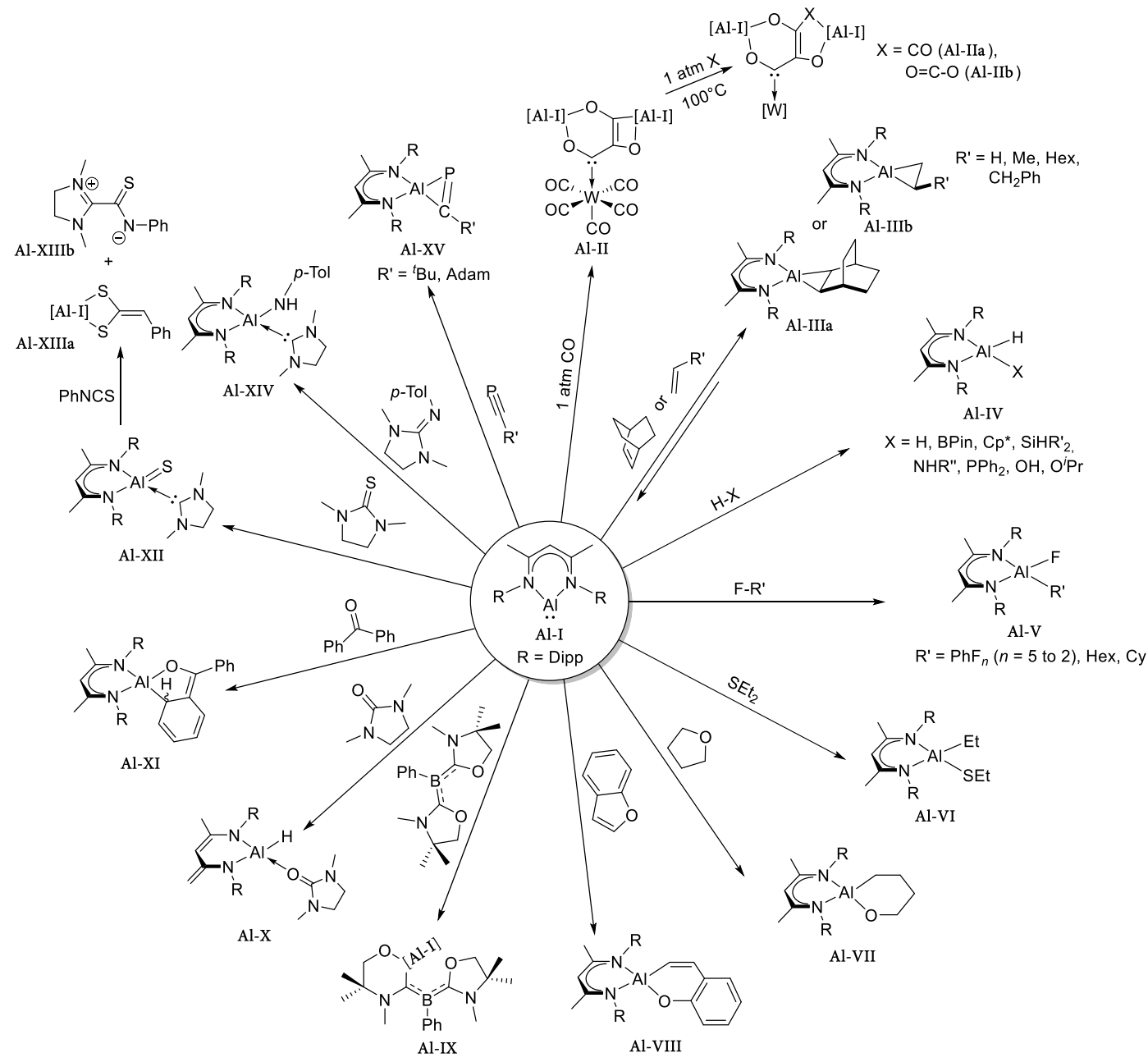

Figure 1-2. Small molecule activation (Al-II/IV) and reactions of organic substrates (Al-III to Al-XV) and carbenoid $\left[\mathrm{Al}^{\mathrm{I}}\left({ }^{\text {Dipp NacNac }}\right)\right](\mathrm{Al}-\mathrm{I})$.

The first example of a $\mathrm{C}\left(\mathrm{sp}^{3}\right)-\mathrm{S}$ bond activation by a main-group element has been observed for diethyl sulphide, that reacted to $\left.\left[(\mathrm{Et})(\mathrm{EtS}) \mathrm{Al}^{\mathrm{III}}{ }^{\mathrm{Dipp}} \mathrm{NacNac}\right)\right]$ (Figure 1-2, Al-VI) in benzene at $50^{\circ} \mathrm{C} \cdot{ }^{[24]}$ The $\mathrm{C}-\mathrm{O}$ bond activation of THF and the monomeric complex Al-I proceed smoothly at ambient temperature leading to a cyclic alkoxide derivative (Figure 1-2, Al-VII). ${ }^{[22]}$ The oxidative addition of diethyl ether has hitherto not been detected, ${ }^{[22]}$ while benzofuran and Al-I are slowly transformed to six-membered metallocycle Al-VIII (Figure 1-2) upon heating to $80^{\circ} \mathrm{C}^{[23]}$ Worth mentioning is also the insertion of one equiv. alanediyl $\mathrm{Al}-\mathrm{I}$ into the $\mathrm{C}-\mathrm{O}$ bond of $\mathrm{R}_{2} \mathrm{BPh}(\mathrm{R}=$ oxazol2-ylidene) in toluene at room temperature that might be viewed as an $\mathrm{Al}, \mathrm{N}, \mathrm{O}$ mixed heterocyclic carbene (Figure 1-2, Al-IX) coordinated to a boron centre or an anionic (amino)(boryl)carbene coordinating an aluminium(III) fragment. ${ }^{[25]}$ Furthermore, the reaction of cyclic urea (O=SIMe; SIMe $=\mathrm{C}\left\{\mathrm{NMeCH}_{2}\right\}_{2}$ ) and Al-I resulted in an unexpected adduct of urea coordinating to a HAlNacNac (Figure 1-2, Al-X) fragment. The formation of this hydride derivative Al-X was calculated to proceed via a bimolecular mechanism in which either the basic aluminium(I) centre or

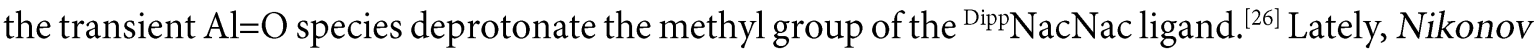
et al. have described the conversion of Al-I and one equiv. benzophenone affording a ketylate species (Figure 1-2, Al-XI), which again experiences cyclisation reactions with unsaturated substrates, e.g., 
quinoline or phenyl nitrile. ${ }^{[27]}$ Interestingly, the reaction of cyclic thioureas and $\left[\mathrm{Al}^{\mathrm{I}}\left({ }^{\mathrm{Dipp}} \mathrm{NacNac}\right)\right]$ (Al-I) resulted in oxidative cleavage of the $\mathrm{C}=\mathrm{S}$ bond and the formation of carbene-stabilised terminal aluminium sulphide compound (Figure 1-2, Al-XII). ${ }^{[28]}$ The $\mathrm{Al}=\mathrm{S}$ bond of $\mathrm{Al}-\mathrm{XII}$, which is supported by DFT calculations, undergoes facile cycloaddition of phenyl isothiocyanate to afford aluminium heterocycle XIIIa as well as the zwitterionic by-product Al-XIIIb. ${ }^{[28]}$ In 2017, Nikonov et al. published the first example of a $\mathrm{C}=\mathrm{N}$ splitting accomplished by $\left[\mathrm{Al}^{\mathrm{I}}\left({ }^{\text {Dipp NacNac}}\right)\right](\mathrm{Al}-\mathrm{I}) \cdot{ }^{[29]} \mathrm{Here}$, oxidative cleavage of cyclic guanidine TolN=SIMe yielded a carbene-coordinated amido $\mathrm{Al}^{\mathrm{III}}$ complex

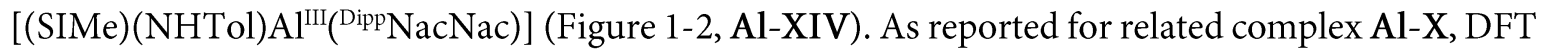
calculations unveiled that this reaction most likely proceeds via a bimolecular mechanism whereby one methyl group of a second complex Al-I is deprotonated. ${ }^{[29]}$ Another example, showing the unique properties of [ $\left.\mathrm{Al}^{\mathrm{I}}\left({ }^{\mathrm{Dipp}} \mathrm{NacNac}\right)\right](\mathrm{Al}-\mathrm{I})$ was reported by Stephan and co-workers in 2019. ${ }^{[30]}$ Their findings revealed that phosphaaluminirenes (Figure 1-2, Al-XV) featuring an unsaturated three-membered AlCP ring are formed via [1+2] cycloaddition of Al-I with phosphaalkynes. The three-centred $2 \pi$-electron species (Al-XV) display ring enlargement reactions with substrates, e.g., selenium, benzophenone, or -nitrile at ambient temperature due to their high ring strain. ${ }^{[30]}$

Apart from the reaction of Al-I with organic substrates, several reactions of Al-I and (semi)metal compounds have been reported. Thereby, alanediyl Al-I can either act as a carbene-like ligand or as strong a reducing agent. The carbenoid character of it has been observed in the reaction of Al-I and the strong Lewis acidic tris(pentafluorophenyl)borane leading to $\left[\left(\mathrm{C}_{6} \mathrm{~F}_{5}\right)_{3} \mathrm{~B} \leftarrow \mathrm{Al}^{\mathrm{I}}\left({ }^{\mathrm{Dipp}} \mathrm{NacNac}\right)\right]$ (Figure 1-3, Al-XVI).

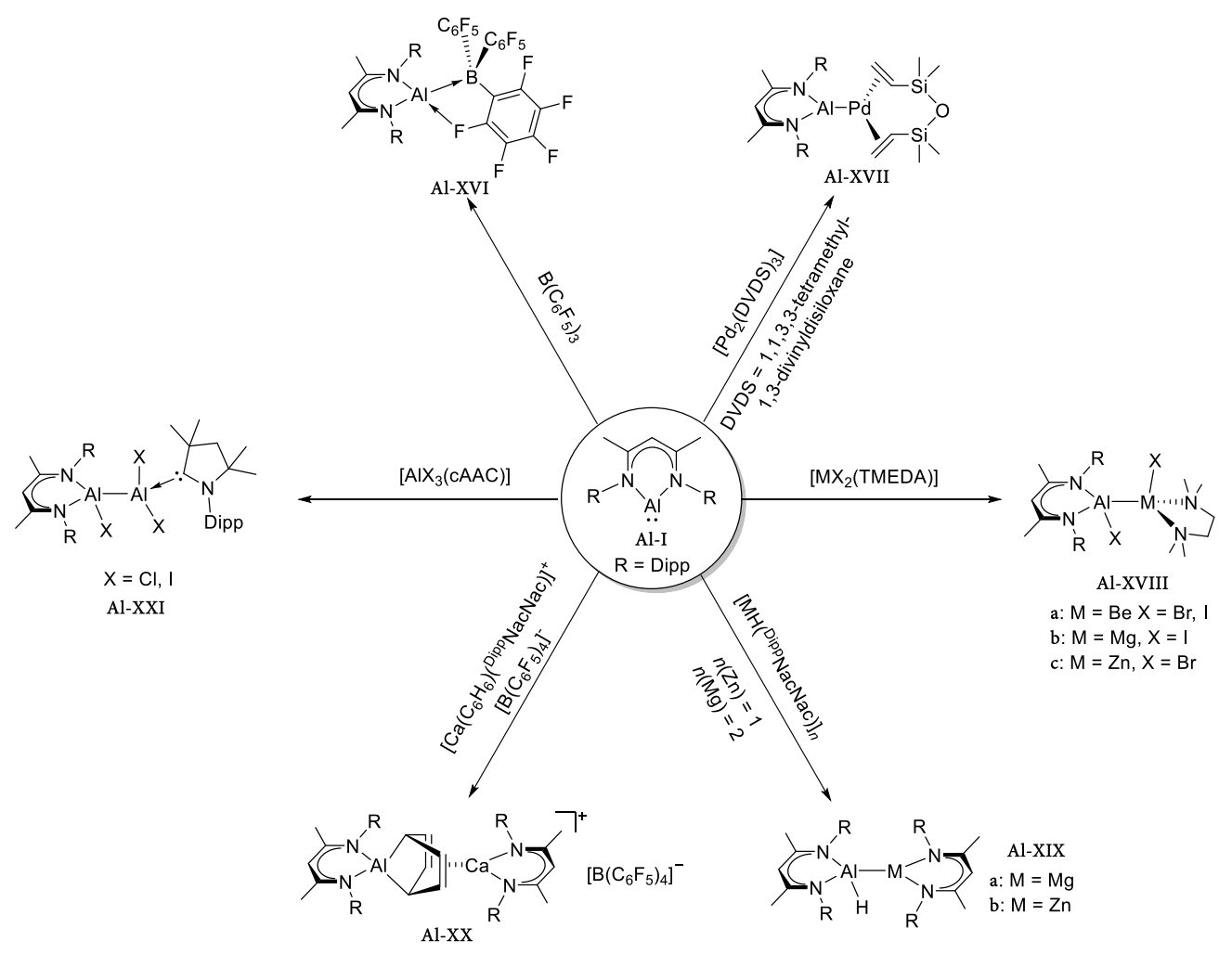

Figure 1-3. Structures of complexes based on $\left[\mathrm{Al}^{\mathrm{I}}\left({ }^{\mathrm{Dipp}} \mathrm{NacNac}\right)\right](\mathrm{Al}-\mathrm{I})$. 
The solid-state structure of $\mathrm{Al}-\mathrm{XVI}$ incorporates $\left[\mathrm{Al}{ }^{\mathrm{I}}\left({ }^{\mathrm{Dipp}} \mathrm{NacNac}\right)\right](\mathrm{Al}-\mathrm{I})$ as a $\sigma$-donor ligand to the $\mathrm{B}\left(\mathrm{C}_{6} \mathrm{~F}_{5}\right)_{3}$ fragment, that concurrently donates electron density from one ortho-fluoro atom of one $\mathrm{C}_{6} \mathrm{~F}_{5}$ group into the empty LUMO+1, which is high in p-character and localised at $\mathrm{Al}^{\left[{ }^{[31]}\right.}$ Another example for the carbenoid character of Al-I is [(DVDS)Pd-Al $\left.{ }^{I}{ }^{\mathrm{Dipp}} \mathrm{NacNac}\right)$ ] (DVDS = 1,1,3,3tetramethyl-1,3-divinyldisiloxane), where the $\mathrm{Al}^{\mathrm{I}}$ complex acts as a terminal ligand (Figure 1-3,

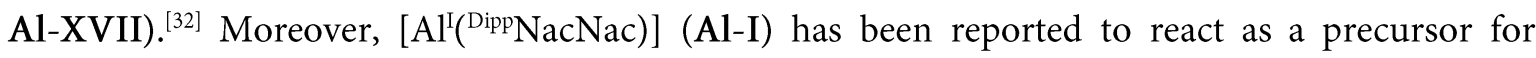
aluminium-metal compounds that are generated by oxidative insertion of the aluminium(I) ion into a $\mathrm{M}-X$ bond $(X=\mathrm{Cl}, \mathrm{Br}, \mathrm{I}, \mathrm{H}) .{ }^{[21]}$ The addition of Al-I and [BeX $\left.(\mathrm{TMEDA})\right](X=\mathrm{Br}, \mathrm{I})$ resulted, for instance, in [(TMEDA)XBe-AlX $\left.\left({ }^{\text {Dipp } N a c N a c}\right)\right]$ (Figure 1-3, Al-XVIIIa), which comprises an unsupported Be-Al bond. ${ }^{[33]}$ Molecular structures of the latter compound, as well as the isostructural magnesium (Figure 1-3, Al-XVIIIb) and zinc (Al-XVIIIc) complexes, were formed by reaction with $\left[\mathrm{MgI}_{2}(\mathrm{TMEDA})\right]$ and $\left[\mathrm{ZnBr}_{2}(\mathrm{TMEDA})\right]$. Here, the aluminium-metal bonds are significantly longer than the sum of single bond covalent radii of the two elements. ${ }^{[33]}$ Within the last years, Harder et al. described the reaction of neutral $\mathrm{Al}^{\mathrm{I}}$ heterocycle (Al-I) with hydride complexes $\left[\mathrm{MgH}\left({ }^{\mathrm{Dipp}} \mathrm{NacNac}\right)\right]_{2}$ and $\left[\mathrm{ZnH}\left({ }^{\text {(ipp }} \mathrm{NacNac}\right)\right]$, which yielded dimeric compounds [( $\left.\left.{ }^{\text {Dipp }} \mathrm{NacNac}\right) M-\mathrm{AlH}\left({ }^{\text {Dipp }} \mathrm{NacNac}\right)\right](M$ $=\mathrm{Mg}$ (Al-XIXa), Zn (Al-XIXb)). Surprisingly, the reaction of unactivated arenes, i.e., benzene, toluene, or p-xylene and Al-I with a catalytic amount of $\left[\mathrm{CaH}_{2}\left({ }^{\text {Dipp }} \mathrm{NacNac}\right)\right]$ resulted in $\mathrm{C}\left(\mathrm{sp}^{2}\right)-\mathrm{H}$ bond activation or aluminiation. These conversions might be explained by a concerted arene activation of the nucleophilic $\mathrm{Al}$ and the Lewis acidic $\mathrm{Ca}$ centre. Furthermore, Harder and co-worker tried to synthesise the donor-acceptor complex [( $\left.\left.{ }^{\text {Dipp }} \mathrm{NacNac}\right) \mathrm{Ca} \leftarrow \mathrm{Al}^{\mathrm{I}}\left({ }^{\mathrm{Dipp}} \mathrm{NacNac}\right)\right]$ via reaction of cationic $\left[\mathrm{Ca}\left(\mathrm{C}_{6} \mathrm{H}_{6}\right)\left({ }^{\text {Dipp }} \mathrm{NacNac}\right)\right]^{+}\left[\mathrm{B}\left(\mathrm{C}_{6} \mathrm{~F}_{5}\right)_{4}\right]^{-}$and $\mathrm{Al}-\mathrm{I}$ at room temperature. However, this reaction attempt led to the dearomatisation of benzene or rather the formation of dianionic $\mathrm{C}_{6} \mathrm{H}_{6}{ }^{2-}$ that is bridging the Ca- and $\mathrm{Al}^{\mathrm{III}}{ }_{-}{ }^{\mathrm{Dipp}} \mathrm{NacNac}$ fragments (Figure 1-3, Al-XX). ${ }^{[34]}$ The comproportionation reaction of aluminium(III) complex cAAC: $\rightarrow \mathrm{AlX}$ (cAAC $=$ cyclic alkyl amino carbene; $X=\mathrm{Cl}, \mathrm{I}$ ) and Al-I resulted in asymmetric dialuminium complex [cAAC: $\left.\rightarrow X_{2} \mathrm{Al}^{\mathrm{II}}-\mathrm{Al}^{\mathrm{II}} X\left({ }^{\text {(ippNacNac}}\right)\right](\mathrm{Al}-$ $\mathrm{XXI}) .{ }^{[35]}$ The Al-Al bond lengths in both species Al-XXI are reduced compared to symmetric dialanes caused by the relaxation of the electrostatic repulsion between the aluminium ions. ${ }^{[35]}$

The first symmetrical dialuminium compound $\left[\left(\left\{\mathrm{Me}_{3} \mathrm{Si}\right\}_{2} \mathrm{CH}\right)_{2} \mathrm{Al}^{\mathrm{II}}-\mathrm{Al}^{\mathrm{II}}\left(\mathrm{CH}\left\{\mathrm{SiMe}_{3}\right\}_{2}\right)_{2}\right]$ possessing an $\mathrm{Al}-\mathrm{Al}$ single bond was published by Uhlet al. in $1988 .{ }^{[36]}$ On this basis, a large number of symmetrical and asymmetrical single-bonded aluminium complexes have been isolated in the past decades. In general, these $\mathrm{Al}-\mathrm{Al}$ compounds (Figure 1-4) exhibit a tetrameric $\mathrm{Al}_{4} R_{4}(R=$ alkyl, aryl, silyl or amide $)^{[13 a, 37]}(\mathrm{A})$ or dimeric $R_{2} \mathrm{Al}-\mathrm{Al} R_{2}(R=\text { alkyl, aryl, silyl and halide })^{[15 a, 38]}(\mathrm{B})$ form. Furthermore, dimeric Lewis base adducts $R_{2} L_{b} \mathrm{Al}-\mathrm{Al} L_{b} R_{2}$ ( $L_{b}=$ Lewis base; $R=$ alkyl, amide, silyl and halide) ${ }^{[15 e, 39]}$ (C) or compounds comprising a donor-acceptor type interaction $R \mathrm{Al} \rightarrow \mathrm{Al}^{\prime}{ }_{3}\left(R=\mathrm{Cp}^{*} ; R^{\prime}=\mathrm{C}_{6} \mathrm{~F}_{5}\right)^{[40]}$ (D) have been described. These compounds show single Al-Al bonds in the range of 2.5 to $2.95 \AA .{ }^{[41]}$ 
<smiles></smiles>

A

$\mathrm{R}=$ alkyl, aryl silyl, amide<smiles>[R][Al]([R])[Al]([R])[R]</smiles>

B

$\mathrm{R}=$ alkyl, aryl, silyl, halide<smiles>[R][Y]([R])([R])[N+]([R])([R])[3H]</smiles>

C

$L_{b}=$ Lewis base
$R=$ alkyl, amide, silyl, halide<smiles>[R][AlH][N+]([R])([R])[R]</smiles>

D

$\mathrm{R}=\mathrm{Cp}^{*}$ $\mathrm{R}^{\prime}=\mathrm{C}_{6} \mathrm{~F}_{5}$

Figure 1-4. Differtent types of aluminium compounds possessing an $\mathrm{Al}-\mathrm{Al}$ single bond.

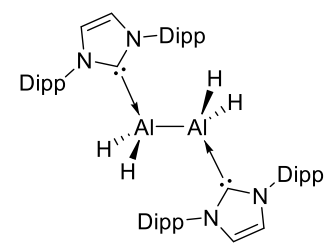

Al-XXII

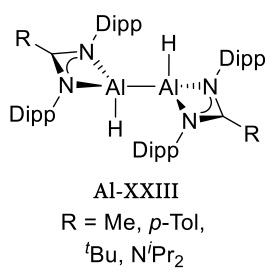

${ }^{t} \mathrm{Bu}, \mathrm{N}^{\mathrm{P}} \mathrm{Pr}$

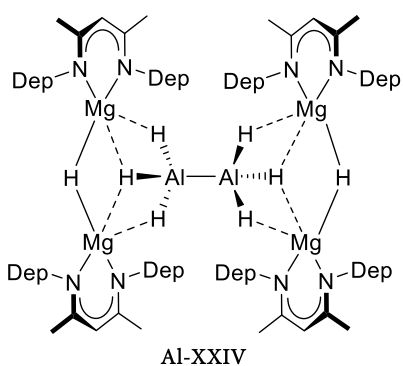

Al-XxIV

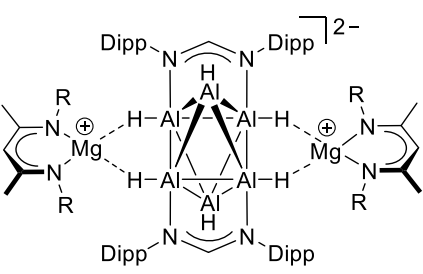

$\mathrm{Al}-\mathrm{XXV}$

$\mathrm{R}=$ Mes, 2,6-Dep, 2,6-Xyly

Figure 1-5. Low-oxidation aluminium hydride complexes synthesised by reduction with dimeric $\left[\operatorname{Mg}^{\mathrm{I}}\left({ }^{R} \mathrm{NacNac}\right)\right]_{2}(\mathrm{R}=$ Dipp, Dep, Mes) complexes.

One example of a complex with an $\mathrm{Al}-\mathrm{Al}$ single bond, which was published in the last decade, is the (bis)carbene adduct [(IDipp) $\mathrm{H}_{2} \mathrm{Al}-\mathrm{AlH}_{2}$ (IDipp)] (IDipp = 1,3-bis-(2,6-diisopropylphenyl) imidazolin-2-ylidene) (Figure 1-5, Al-XXII). This dialane $\left(\mathrm{Al}_{2} \mathrm{H}_{2}\right)$ and $[(L) \mathrm{HAl}-\mathrm{AlH}(L)](\mathrm{Al}-\mathrm{XXIII})$ $\left(L=\left(\{\mathrm{DippN}\}_{2} \mathrm{CR}\right), R=\mathrm{Me}, p\right.$-tolyl, $\left.{ }^{\mathrm{t}} \mathrm{Bu}, \mathrm{N}^{\mathrm{i}} \mathrm{Pr}_{2}\right)$ were synthesised by Stasch and Jones et al. via direct hydrogen atom transfer to the dimeric reduction agent $\left[\mathrm{Mg}^{\mathrm{I}}\left({ }^{\mathrm{Dipp}} \mathrm{NacNac}\right)\right]_{2} \cdot{ }^{\left[{ }^{42]}\right]}$ Moreover, using $\mathrm{Mg}^{\mathrm{I}}$ reagents and aluminium hydride species led to the dialanate dianion [ $\mathrm{H}_{3} \mathrm{Al}^{\mathrm{II}}-$ $\left.\mathrm{Al}^{\mathrm{II}} \mathrm{H}_{3}\right]\left[(\mu-\mathrm{H})\left\{\mathrm{Mg}^{\mathrm{II}}\left({ }^{\mathrm{Dep}} \mathrm{NacNac}\right)\right\}_{2}\right]_{2}^{[43]}$ (Dep = 2,6-diethylphenyl) (Al-XXIV), which is the valence isoelectronic analogue to ethane, or $\left[\mathrm{Al}_{6}^{\mathrm{I}} \mathrm{H}_{6}(\text { Fiso })_{2}\right]\left[\mathrm{Mg}^{\mathrm{II}}\left({ }^{\mathrm{R}} \mathrm{NacNac}\right)\right]^{[44]}$ (Fiso $=\left(\mathrm{HC}\{\mathrm{NDipp}\}_{2}\right) ; \mathrm{R}=$ Mes, Depp, 2,6-xylyl) (Al-XXV) possessing a hypercloso-hexaalane cluster core.

The isolation of complexes inheriting group 13 multiple bonds (Figure 1-6), especially an $\mathrm{Al}=\mathrm{Al}$ bond, is difficult due to their Lewis acidity and their significant singlet diradical character. In the early 1990s, efforts were made to isolate multiple-bonded aluminium complexes. First examples of

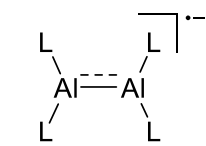

Al-XXVI

$\mathrm{L}=\mathrm{CH}\left(\mathrm{SiMe}_{3}\right)_{2}$,

2,4,6- $-\mathrm{Pr}_{3} \mathrm{C}_{6} \mathrm{H}_{2}$

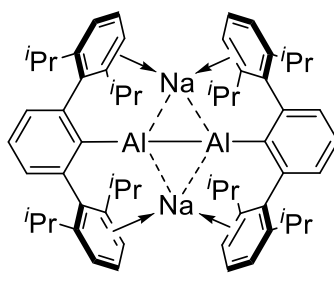

Al-XXVII

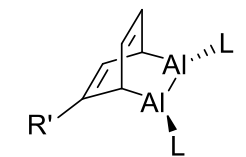

Al-XXVIII

$\mathrm{L}=\mathrm{C}_{6} \mathrm{H}_{3}-2,6-\left(\mathrm{C}_{6} \mathrm{H}_{2}-\right.$

2,4,6-i $\left.\mathrm{Pr}_{3}\right)_{2}$ $\mathrm{R}^{\prime}=\mathrm{H}, \mathrm{Me}$

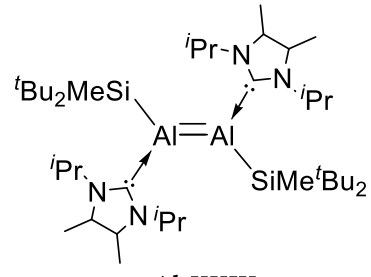

Al-XXIX

Figure 1-6. Complexes comprising an aluminium multiple bond. 
such complexes containing a formal bond order $>1$ are the radical monoanionic species $\left[(L)_{2} \mathrm{AlAl}(L)_{2}\right]^{--}$(Figure 1-6, Al-XXVI) $\left(L=\mathrm{CH}\left\{\mathrm{Me}_{3} \mathrm{Si}\right\}_{2}, 2,4,6-{ }^{i} \mathrm{Pr}_{3} \mathrm{C}_{6} \mathrm{H}_{2}\right)^{[38,45]}$ or the dianionic complex $\left[\mathrm{Na}_{2}\{(L) \operatorname{AlAl}(L)\}\right]\left(L=\mathrm{C}_{6} \mathrm{H}_{3}-2,6-\left(\mathrm{C}_{6} \mathrm{H}_{2}-2,4,6-{ }^{-} \mathrm{Pr}_{3}\right)_{2}\right)$ (Al-XXVII $)^{[15 \mathrm{~d}]}$. The groups of Power and Tokitoh published the synthesis of bicyclo masked dialumenes ${ }^{[15 c, 15 g]}$, which are formed by $[4+2]$ cycloaddition of a dialumene intermediate and toluene or benzene (Al-XXVIII). Recently, the first synthesis of a neutral $\mathrm{Al}=\mathrm{Al}$ complex $\left[\mathrm{Al}\left(\mathrm{I}^{\mathrm{i} P r}\right)\left({ }^{t} \mathrm{Bu}{ }_{2} \mathrm{MeSi}\right)\right]_{2}(\mathrm{Al}-\mathrm{XXIX})$ was achieved by Inoue and co-workers through reduction of NHC base-stabilised di-tbutyl(methyl)silyl-substituted $\mathrm{Al}^{\mathrm{III}}$ halide precursor. ${ }^{[15 \mathrm{~h}]}$ The solid-state structure of the $\mathrm{Al}_{2}$ fragment shows a trans-planar geometry with the shortest Al-Al distance (2.394(2) $\AA$ ) hitherto measured within a molecular dialuminium species. DFT calculations revealed that the HOMO-1 is an Al-Al $\sigma$-bond, while the HOMO correlates to an aluminium $\pi$-bond. ${ }^{[13 e, 15 \mathrm{~h}]}$

The novel class of nucleophilic (amido) aluminyl anions was accessed by Aldridge and Goicoechea et al. in 2018 (Figure 1-7). ${ }^{[16 a]}$ The two-electron reduction of the neutral aluminium(III) precursor complex with an excess of potassium graphite generated $\left[\mathrm{K}_{2}\{\mathrm{Al}(\mathrm{NON})\}_{2}\right](\mathrm{Al}-\mathrm{XXX})(\mathrm{NON}=4,5-$ bis(2,6-diisopropylanilido)-2,7-di-butyl-9,9-dimethylxanthene). DFT calculations using the same method as for neutral [ $\left.\mathrm{Al}^{\mathrm{I}}\left({ }^{\text {(ipp }} \mathrm{NacNac}\right)\right](\mathrm{Al}-\mathrm{I})$ demonstrated that the HOMO energy of Al-XXX is notably higher $(-108 \mathrm{kcal} / \mathrm{mol},-4.70 \mathrm{eV}) \cdot{ }^{[14 \mathrm{a}, 16 \mathrm{a}]}$ Additionally, the lone pair shows a somewhat higher aluminium 3p orbital contribution in relation to Al-I (Al-XXX: 24\%; I: 10\%). Therefore, the aluminyl anion acts as an aluminium(I) nucleophile which was confirmed by reaction with appropriate electrophiles, e.g., $\mathrm{HX}$ or $\mathrm{MeI}$ that yielded compounds containing $\mathrm{Al}-\mathrm{H}$ or $\mathrm{Al}-\mathrm{C}$ bonds, respectively. In the last two years, two further potassium aluminyl complexes featuring bidentate ligands have been published by Coles et al. $\left(\left[\mathrm{K}_{2}\left\{\mathrm{Al}\left(\{R \mathrm{NSiMe}\}_{2} \mathrm{O}\right)\right\}_{2}\right] ; R=2,6-{ }^{i} \mathrm{Pr}_{2} \mathrm{C}_{6} \mathrm{H}_{3}\right)^{[16 c]}(\mathrm{Al}-\mathrm{XXXI})$ as well as Hill and McMullin et al. $\left(\left[\mathrm{K}_{2}\left\{\mathrm{Al}\left(\mathrm{DippNSiMe} \mathrm{CH}_{2}\right)_{2}\right\}_{2}\right]\right)^{[16 \mathrm{dd}]}(\mathrm{Al}-\mathrm{XXXI})$. More recently, Yamashita and Kinjo reported of alkyl substituted aluminyl compounds [K(toluene) ${ }_{2}-$ $\left.\operatorname{Al}\left\{\left(\mathrm{C}\left(\mathrm{SiMe}_{3}\right)_{2} \mathrm{CH}_{2}\right)_{2}\right\}\right]^{[16 \mathrm{e}]} \quad(\mathrm{Al}-\mathrm{XXXII})$ and $\left[\mathrm{K}(12 \text {-crown-4 })_{2}\right]\left[\mathrm{Al}\left(\mathrm{AdN}-\mathrm{CH}=\mathrm{CH}-\mathrm{C}\left(\mathrm{CMe}_{3}\right)_{2}\right)\right]^{[16 f]}$
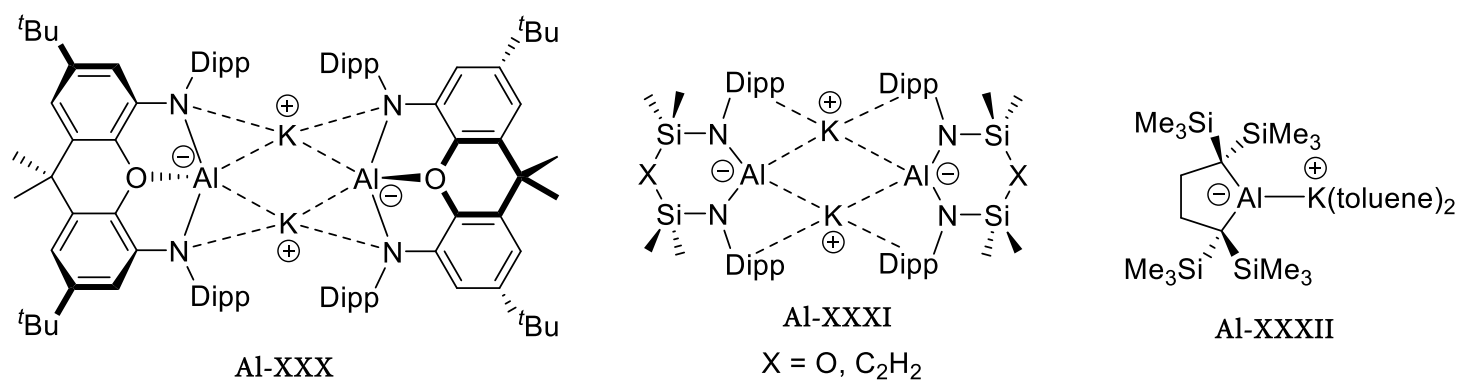

$\mathrm{X}=\mathrm{O}, \mathrm{C}_{2} \mathrm{H}_{2}$

Al-XXXII

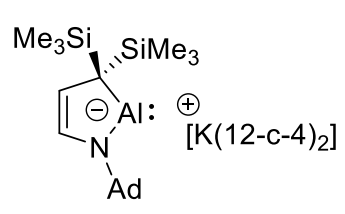

Al-XXXIII

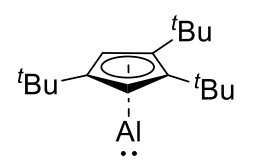

Al-XXXIV

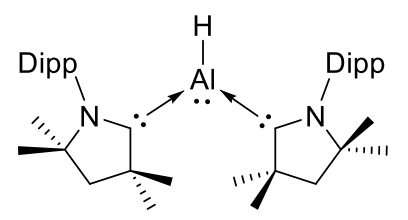

Al-XXXV

Figure 1-7. Diamido (Al-XXX/XXXI) and alkyl (Al-XXXII/XXXIII) substituted aluminyl anion complexes. Monomeric $\left[\mathrm{Al}^{\mathrm{l}} \mathrm{Cp}^{3 \mathrm{t}}\right]\left(\mathrm{Cp}^{3 \mathrm{t}}=1,2,4\right.$-tri-tbutylcyclopenta-dienyl) (Al-XXXIV) as well as cAAC stabilised aluminium(I) hydride (Al-XXXV) complex. 
(Adam = 1-adamantyl) (Al-XXXIII), which were obtained via reduction of dialumanes. The amido and alkyl based aluminyl complexes exhibit huge potential in small molecule activation, e.g., greenhouse gases $\left(\mathrm{N}_{2} \mathrm{O}\right.$ or $\left.\mathrm{CO}_{2}\right)$ leading to anionic monoaluminoxane species. ${ }^{[16 g, 46]}$ Another example of the emerging field of aluminium(I) compounds is marked by the first room temperature stable monomeric cyclopentdienylaluminium derivative $\left[\mathrm{Al}^{\mathrm{I}} \mathrm{Cp}^{3 t}\right] \quad(\mathrm{Al}-\mathrm{XXXIV}) \quad\left(\mathrm{Cp}^{3 \mathrm{t}}=1,2,4\right.$-tritbutylcyclopenta-dienyl) which was isolated by Braunschweig and co-workers. ${ }^{[4]}$ Furthermore, the group of Braunschweig isolated a cAAC stabilised complex $\left[\mathrm{HAl}^{\mathrm{I}}(\mathrm{cAAC})_{2}\right](\mathrm{Al}-\mathrm{XXXV})(\mathrm{cAAC}=$ cyclic (alkyl)(amino)carbene) that can be handled under ambient conditions. Computational and experimental analyses showed that $\mathrm{Al}-\mathrm{XXXV}$ is best described as an $\mathrm{Al}(\mathrm{I})$ hydride with nonnegligible open-shell $\mathrm{Al}(\mathrm{III})$ singlet diradical character. ${ }^{[48]}$

\subsubsection{Gallium}

In comparison to aluminium(I) complexes, heavier gallium(I) compounds tend to be more stable towards disproportionation. Nonetheless, the thermodynamically preferred oxidation state of gallium is +III, and therefore bulky ligand platforms are indispensable for stabilising $\mathrm{Ga}^{\mathrm{I}}$ ions ${ }^{[21,49]}$ In recent decades, numerous complexes or metalloid cluster compounds have been synthesised incorporating gallium $+\mathrm{I}$ or $+\mathrm{II}$ centres. Therefore the focus of this chapter shall be on nitrogenbased ligands. ${ }^{[49 \mathrm{~d}]}$ The compounds are generally synthesised via salt-metathesis reaction or reduction by strong reducing agents (alkali metals) of $\mathrm{Ga}^{\mathrm{II}}$ or $\mathrm{Ga}^{\mathrm{III}}$ precursors. The most prevalent $\mathrm{Ga}^{\mathrm{I}}$ source for salt-metathesis reactions is pale green "GaI" which is obtained in an ultrasonically activated reaction of neat gallium and half equiv. of diiodine at $>30^{\circ} \mathrm{C} .{ }^{[50]}$ Raman spectroscopy revealed that the "GaI" powder consists of a mixture of gallium sub-iodides, while $[\mathrm{Ga}]_{2}\left[\mathrm{Ga}_{2} \mathrm{I}_{6}\right]$ is the predominant species. ${ }^{[51]}$ Besides, salt-metathesis reactions with Lewis acids are accompanied by disproportionation reactions leading to $\mathrm{Ga}(\mathrm{II}), \mathrm{Ga}(\mathrm{III})$, or mixed valence products.

Hitherto, bi- and tridentate nitrogen ligand platforms have been used to synthesise neutral or anionic gallium(I) complexes. Monomeric four-membered gallium(I) N-heterocycles $\left[\mathrm{Ga}^{\mathrm{I}}\left(\{\mathrm{DippN}\}_{2} Y\right)\right]^{[52]}$ $\left(Y=\mathrm{CNCy}_{2}, \mathrm{PPh}_{2}\right.$ ) (Figure 1-8, Ga-I) have been prepared by salt-metathesis reaction of "GaI" and the corresponding lithium precursor in toluene. Additionally, a wide variety of dimeric $\mathrm{Ga}^{\mathrm{II}}$ and mixed-valent complexes based on four-membered guanidinate or amidinate ligands have been

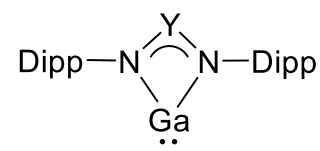

Ga-I $\mathrm{Y}=\mathrm{CNCY}_{2}$ $\mathrm{PPh}_{2}$

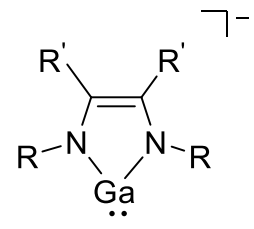

Ga-II

$$
\mathrm{R}={ }^{t} \mathrm{Bu}, \mathrm{R}^{\prime}=\mathrm{H} \text {; }
$$

$R=$ Dipp, $R^{\prime}=H, M e$

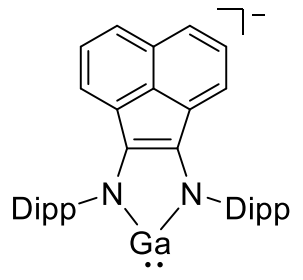

Ga-III<smiles></smiles>

Ga-IV

a: $Y=\mathrm{CMe}$

b: $Y=C^{t} B u$ c: $\mathrm{Y}=\mathrm{PPh}_{2}$

Figure 1-8. Four-, five- and six-membered gallium(I) $N$-heterocycles. 
reported by Linti and Stasch. ${ }^{[52 c, 53]}$ The subclass of five-membered anionic gallium(I) heterocycles $\left[\mathrm{Ga}^{\mathrm{I}}(L)\right]^{-}\left(L: \mathrm{DAB}=\left\{R N C R^{\prime}\right\}_{2}, R={ }^{\mathrm{t}} \mathrm{Bu}\right.$, Dipp, $\mathrm{R}^{\prime}=\mathrm{H}, \mathrm{Me}$; BIAN $=\{$ DippNC $\left.\} \mathrm{C}_{10} \mathrm{H}_{6}\right)$ (Figure 1-8, GaII/III), which are valence isoelectronic to imidazolylidene-NHCs, represent the most developed to date. These NHC analogous, which reductions with alkali metals can afford, have been isolated either as contact ion pairs or ion-separated species. The steric bulk and nucleophilicity of [:Ga $\left.\mathrm{Ga}^{\mathrm{I}}(\mathrm{DAB})\right]^{-}$are contributing factors to its ability as a ligand to stabilise different main group elements and low-valent transition metal complexes. ${ }^{[18,54]}$ In 2000, Power and co-worker reported on the first monomeric sixmembered gallium(I) NHC analogue [ $\left.\mathrm{Ga}^{\mathrm{I}}\left({ }^{\mathrm{Dipp}} \mathrm{NacNac}\right)\right]$ (Figure 1-8, Ga-IVa), that was obtained by salt-metathesis reaction of the lithiated $\beta$-diketiminate species and "GaI" salt. ${ }^{[55]}$ Since then, two other carbenoid six-membered $N$-heterocycles $\left[\mathrm{Ga}\left(\{\mathrm{Dipp} Y\}_{2} \mathrm{CH}\right)\right]\left(Y=\mathrm{C}^{t} \mathrm{Bu}, \mathrm{PPh}_{2}\right)(\mathrm{Ga}-\mathrm{IVb} / \mathrm{c})$ have been isolated using the same synthetic route. ${ }^{[18,56]}$

Computational studies of various model compounds, e.g., $\left[\mathrm{Ga}^{\mathrm{I}}\left(\{R \mathrm{NCR}\}_{2} \mathrm{CH}\right)\right](R=\mathrm{H}, \mathrm{Me}, \mathrm{Ph}$, Dipp; $R^{\prime}=\mathrm{H}, \mathrm{Me}$ ) revealed their electronic structures to be similar to the lighter aluminium congeners (Figure 1-1). However, higher singlet-triplet energy separations (51.7-55.5 kcal/mol) and a lower energy of the metal lone pair are observed for $\mathrm{Ga}^{\mathrm{I}}$ species. ${ }^{[17]}$ Calculations revealed that the p-orbital is associated with the LUMO+1, while a slightly increased HOMO-LUMO+1 gap of 95 to $110 \mathrm{kcal} / \mathrm{mol}$ has been determined. ${ }^{[17 \mathrm{a}, 17 \mathrm{c}, 17 \mathrm{~d}, 56]}$ Especially, the $\left[\mathrm{Ga}^{\mathrm{I}}\left({ }^{\text {(ipp }} \mathrm{NacNac}\right)\right](\mathrm{Ga}-\mathrm{IVa})$ displays remarkable thermal stability $\left(T_{\text {decomp. }}>150^{\circ} \mathrm{C}\right.$ ), which is most likely caused by the bulkiness of the ligand, that provides kinetic protection to the $\mathrm{Ga}^{\mathrm{I}}$ centre. ${ }^{[21,57]}$ The chemistry of Ga-IVa is characterised by its weaker reducing capacity compared to alanediyl Al-I. ${ }^{[18]}$ Thus carbenoid $\left.\left[\mathrm{Ga}^{\mathrm{I}}{ }^{\text {Dipp }} \mathrm{NacNac}\right)\right](\mathrm{Ga}-\mathrm{IVa})$ has particularly been utilised as Lewis base in the formation of complexes with dative bonds between $\mathrm{Ga}$ and p- or d-block metals. The reaction of $\mathrm{B}\left(\mathrm{C}_{6} \mathrm{~F}_{5}\right)_{3}$ and Ga-IVa showed, that the gallium centre of gallanediyl Ga-IVa seems to develop a greater nucleophilicity than related ligands like $\mathrm{GaCp}^{*}, \mathrm{GaR}\left(R=\mathrm{C}_{6} \mathrm{H}_{3}-2,6-\left(\mathrm{C}_{6} \mathrm{H}_{2}-2,4,6-{ }^{i} \mathrm{Pr}_{3}\right)_{2}\right)$ or AlCp${ }^{*}$, but it appears to be less electrophilic than alane diyl Al-I (Figure 1-9). ${ }^{[58]}$ Therefore, the gallium-boron

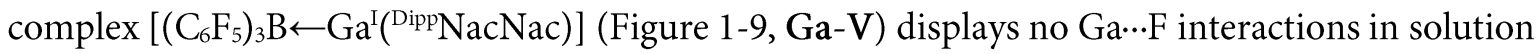
or solid-state. ${ }^{[58]}$ This is in tune with the higher Lewis acidity of aluminium compared to gallium. Nonetheless, a weak back $\pi$-donation from nitrogen to the vacant p-orbital of the Ga centre has been suggested for $\left[R^{\prime} \mathrm{N}=\mathrm{Ga}\left({ }^{\text {Dipp }} \mathrm{NacNac}\right)\right]\left(R^{\prime}=2,6-\mathrm{Trip}_{2} \mathrm{C}_{6} \mathrm{H}_{3}\right)$ (Figure 1-9, Ga-VI) proceeding from spectroscopic, crystallographic as well as computational studies. ${ }^{\left[{ }^{[9]}\right]}$ The $\left[\mathrm{Ga}^{\mathrm{I}}\left({ }^{\text {(ipp NacNac})] ~(G a-I V a)}\right.\right.$ can act as an insertion or cleavage agent for metal complexes due to its unique properties. In these insertion reactions, the isolated gallyl metal(loid) compounds ([SM]GaX(DippNacNac), $[S M]=$ metal(loid) fragment) have been described as intermediates of more thermodynamically favourable gallium(III) complexes $\left[\mathrm{Ga}^{\text {III }} X_{2}\left({ }^{\text {Dipp }} \mathrm{NacNac}\right)\right]^{[18]}$ As an example, Fischer and co-worker have synthesised the $\mathrm{Bi}=\mathrm{Bi}$ complex $\left[\mathrm{BiGa}\left(\mathrm{O} R^{\prime}\right)\left({ }^{\mathrm{Dipp} N a c N a c}\right)\right]_{2}\left(R^{\prime}=\mathrm{SO}_{2} \mathrm{CF}_{3}, \mathrm{C}_{6} \mathrm{~F}_{5}\right)(\mathrm{Ga}-\mathrm{VII})$ via oxidative addition of the $\mathrm{Bi}-\mathrm{O}$ to Ga-IVa and subsequent elimination of $\left[\mathrm{Ga}(\mathrm{OR})_{2}\left({ }^{\left.\left({ }^{\mathrm{Dipp}} \mathrm{NacNac}\right)\right]} .^{[60]}\right.\right.$ The distibene analogous $\left[\mathrm{SbGaX}\left({ }^{\mathrm{Dipp} N a c N a c}\right)\right]_{2}\left(X=\mathrm{Cl}, \mathrm{NMe}_{2}\right)(\mathrm{Ga}-\mathrm{VIIIa})$ were synthesised by reduction with two equiv. Ga-IVa and $\mathrm{Sb} X_{3}$ (Figure 1-9). ${ }^{[61]}$ Heating a toluene solution of this gallium-stabilised dimers at elevated temperatures resulted in a butterfly-like tetraantimony $\left[\left\{\left(\mu, \eta^{1: 1}\right.\right.\right.$ $\left.\left.\mathrm{Sb}_{4}\right) \mathrm{GaX}\left({ }^{\text {(ipp NacNac) }}\right\}_{2}\right]$ (Figure 1-9, Ga-VIIIb) complex. ${ }^{[61]}$ Apart from these examples, multiple 
complexes have been obtained by the reaction of Ga-IVa and pnicogenic (i.e., P to Bi) or telluric precursors. Among these reactions, the fully reversible and temperature-dependent insertion of $\mathrm{Ga}$ IVa into $E_{2} \mathrm{Et}_{4}(E=\mathrm{Sb}, \mathrm{Bi})$ was reported by Schulz and co-workers (Figure 1-9, Ga-IX). ${ }^{[62]}$ Interestingly, the analogous reaction of Al-I exclusively yielded $\left[\mathrm{Al}\left(\mathrm{SMEt}_{2}\right)_{2}\left({ }^{\mathrm{Dipp}} \mathrm{NacNac}\right)\right](S M=\mathrm{Sb}$, Bi). ${ }^{[62]}$ The reaction of $\mathrm{CpSbCl}_{2}$ and two equiv. of NHC-like heterocycle Ga-IVa led to multiple products, among other things, the radical species $\left[\mathrm{Sb}\left\{\mathrm{GaCl}\left({ }^{\mathrm{Dipp}} \mathrm{NacNac}\right)\right\}_{2}\right](\mathrm{Ga}-\mathrm{Xa})$ which afterwards could be reduced $\left(\mathrm{KC}_{8}\right)$ to the first complex [( $\left.\left.\left.{ }^{\text {Dipp }} \mathrm{NacNac}\right) \mathrm{Ga}=\mathrm{Sb}-\mathrm{GaCl}\left({ }^{\text {Dipp }} \mathrm{NacNac}\right)\right\}\right](\mathrm{Ga}-\mathrm{Xb})$ incorporating a $\mathrm{Ga}=\mathrm{Sb}$ double bond $(2.535 \AA) .{ }^{[63]}$ The significant $\pi$-backdonation from the $\mathrm{Sb}$ to the $\mathrm{Ga}$ atom was confirmed by NMR spectroscopic and computational analyses. In addition, various heavy-metal complexes bearing $\mathrm{Ga}-M$ bonds have been synthesised using Ga-IVa as a reducing agent. The reaction of two equiv. Ga-IVa and $\mathrm{CuX}_{2}(X=\mathrm{Br}$, OTf $)$ afforded dimeric complex $\left[\mathrm{XCuGa}\left({ }^{\text {Dipp }} \mathrm{NacNac}\right)\right]_{2}(\mathrm{Ga}-\mathrm{XI})$ that exhibits a relatively short $\mathrm{Cu}^{\mathrm{I}} \cdots \mathrm{Cu}^{\mathrm{I}}$ interaction $(2.277(3) \AA) \cdot{ }^{[64]}$ Furthermore, the reaction of sterically demanding pentaarylcyclopentadienyl nickel halide complex $\left[(\mu-\mathrm{Br}) \mathrm{NiCp}^{R^{\prime}}\right]_{2}\left(\mathrm{Cp}^{R^{\prime}}=\mathrm{C}_{5}\left\{\mathrm{C}_{6} \mathrm{H}_{4}-4-\mathrm{Et}\right\}_{5}\right)$ and $\mathrm{Ga}-\mathrm{IVa}$ resulted in $\left[\left({ }^{\text {Dipp NacNac}}\right) \mathrm{Ga}(\mu-\mathrm{Br}) \mathrm{NiCp} \mathrm{p}^{R^{\prime}}\right]$ (Ga-XIIa), which comprises a halide-bridged $\mathrm{Ni}-\mathrm{Ga}$ bond. The further reduction of this complex with $\mathrm{KC}_{8}$ yielded the first $17 \mathrm{VE}$ open-shell nickel gallanediyl complex [( $\left.\left.{ }^{\mathrm{Dipp}} \mathrm{NacNac}\right) \mathrm{GaNiCp}^{R^{\prime}}\right]$

(Ga-XIIb) that features two electron-rich metal ions in the oxidation state $+\mathrm{I}^{[65]}$

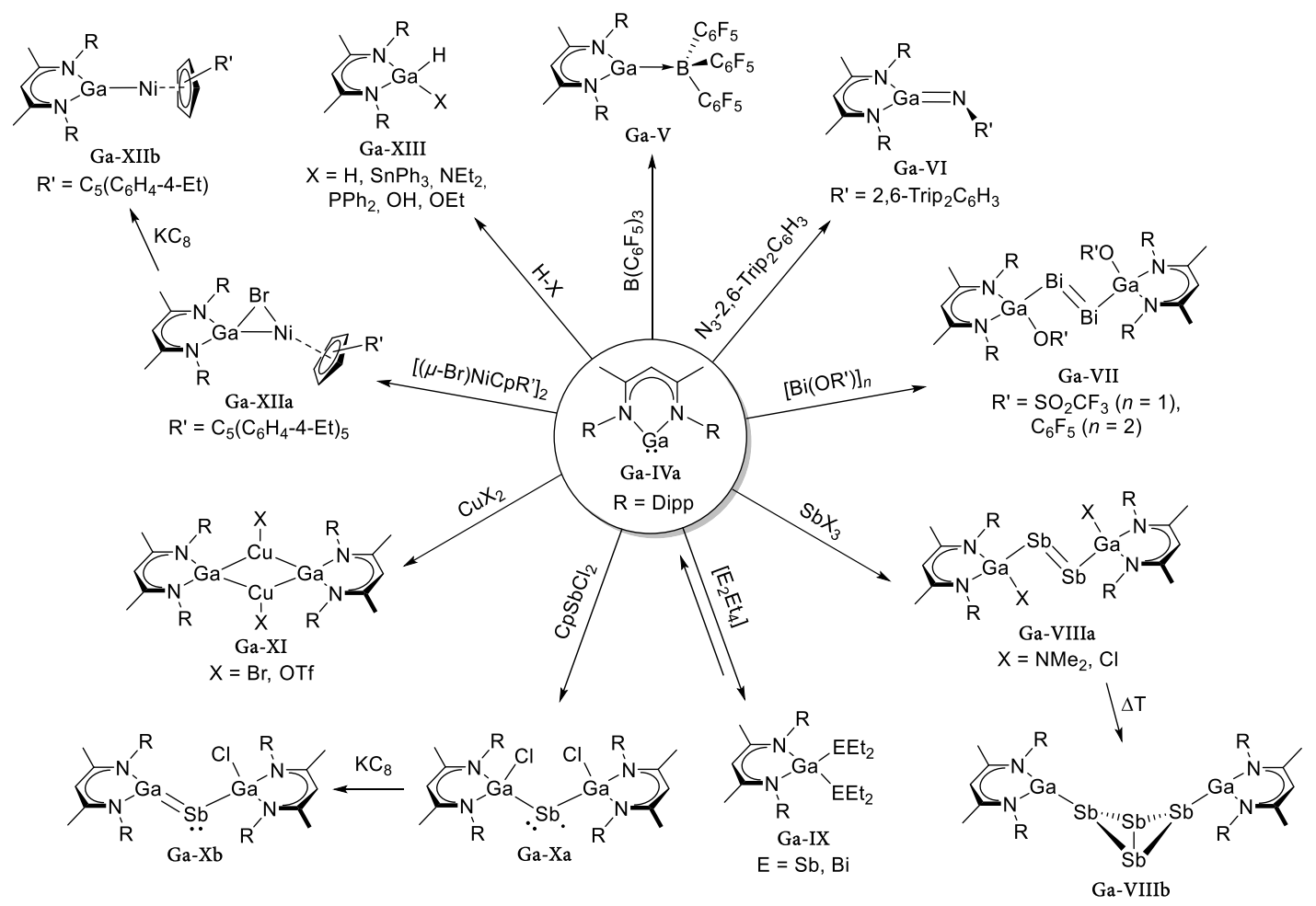

Figure 1-9. Reaction of different substrates (Ga-V to XIII) and carbenoid [Ga' $\left.\left.{ }^{\mathrm{I}}{ }^{\mathrm{Dipp}} \mathrm{NacNac}\right)\right]$ (Ga-IVa).

Additionally, the $\left[\mathrm{Ga}^{\mathrm{I}}\left({ }^{\mathrm{Dipp}} \mathrm{NacNac}\right)\right]$ (Ga-IVa) complex undergoes, as described for its lighter aluminium congener Al-I, facile oxidative additions of substrates including an $\mathrm{H}-X(X=\mathrm{H}, \mathrm{Sn}, \mathrm{O}$, $\mathrm{N}, \mathrm{P}$ ) bond. Thus, Linti and co-workers reported that the addition of corresponding precursors formed gallium hydride complexes [GaHX $\left({ }^{\text {Dipp NacNac })]}\left(X=\mathrm{H}, \mathrm{SnPh}_{3}, \mathrm{NEt}_{2}, \mathrm{PPh}_{2}, \mathrm{OH}, \mathrm{OEt}\right)\right.$ 
(Ga-XIII). ${ }^{[66]}$ More recently, Nikonov et al. published the in situ oxidation of Ga-IVa by nitrous or pyridine oxide that generated a labile oxide species $\left[\mathrm{O}=\mathrm{Ga}\left({ }^{\mathrm{Dipp}} \mathrm{NacNac}\right)\right]$. This putative intermediate facilitates the $\mathrm{C}-\mathrm{H}$ bond cleavage of aliphatic (cyclohexanone, benzophenone, DMSO) and pyridine, comprising hard donor sites. ${ }^{[67]}$

In 2021, Kretschmer et al. reported on a dinuclear gallanediyl complex $\left[\mathrm{Ga}_{2}{ }^{\mathrm{I}}(L)\right](L=$ \{DippNCMeCHCMeN\}$\}_{2}-1,2-\mathrm{Cy}$ ) with a constrained alignment of the metal centres in close proximity (Scheme 1-2). The isomerisation of the bimetallic gallacyles causes a reactive $\mathrm{Ga}-\mathrm{Ga}$ bound species with a significantly smaller HOMO-LUMO gap. Based on this, concerted C-F bond cleavage of hexa-, penta-, or 1,2,3,4-tetrafluorobenzene formed [FGa-GaAr $\left.{ }^{\mathrm{F}}(L)\right]$. Instead, the
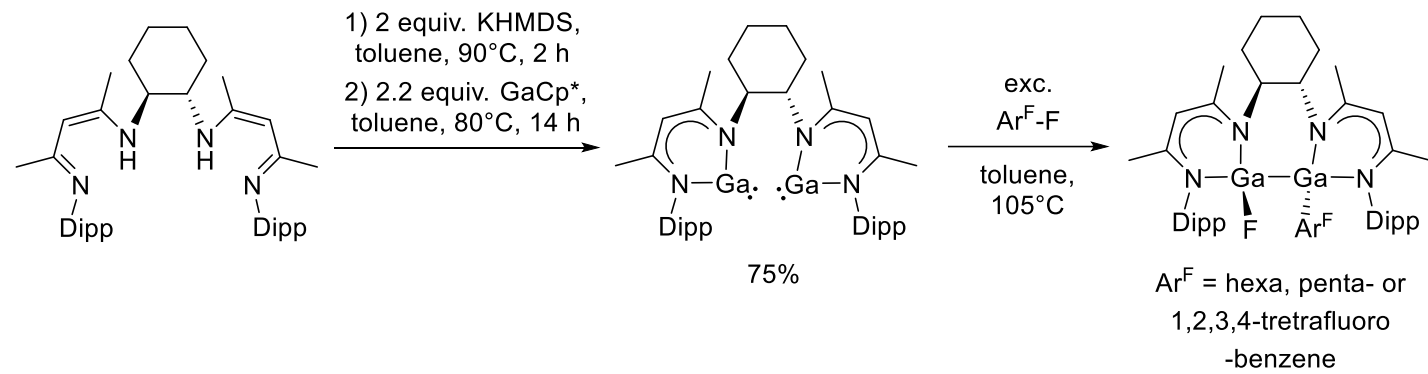

Scheme 1-2. Synthesis of dinuclear gallanediyl and subsequent C-F bond activation.

oxidative addition at the mononuclear counterpart $\left[\mathrm{Ga}^{\mathrm{I}}\left({ }^{\mathrm{Dipp}} \mathrm{NacNac}\right)\right]$ is kinetically disfavoured and therefore emphasising the crucial role of the cooperativity of the bimetallic complex. ${ }^{[68]}$ Iwasawa and co-workers have recently reported a promising approach to stabilise and utilise gallanediyls as a spectator supporting ligand in transition-metal complexes (Scheme 1-1). ${ }^{[69]}$ The multidentate pincertype ligands $\left(6,6\right.$ '" $-\left({ }^{i} \mathrm{Pr}_{2} \mathrm{P}\right)_{2}-2,2^{\prime}: 6$ ', 2"'-terpyridine) enables the coordination of the $\mathrm{GaCl}_{2}$ fragment and subsequent reduction of the $\mathrm{Ga}^{\mathrm{III}}$-species with $\left[\mathrm{Ir}^{\mathrm{I}} \mathrm{Cl}(\operatorname{cod})\right]_{2}$ ( $\operatorname{cod}=1,5$-cycloctadiene). The synthesised $\mathrm{PGa}{ }^{\mathrm{I}} \mathrm{P}-\mathrm{Ir}$ complexes facilitate unique structures and reactivities, while the gallylene ligand, which exerts a high electron-donating nature, stays intact. ${ }^{[69]}$

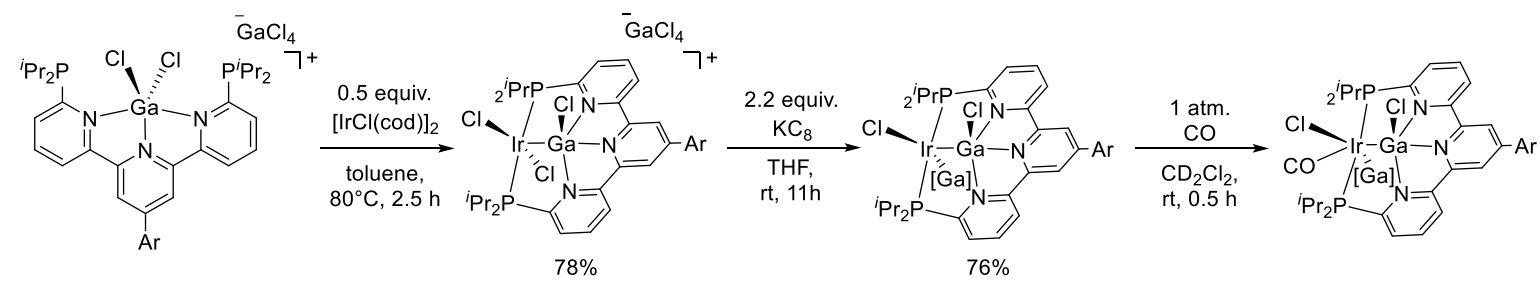

Scheme 1-1. Synthesis of Ir complexes having a pincer-type gallanediylne ligand and the reaction of with carbon monoxide. 


\subsubsection{Indium}

In contrast to the lighter triele elements, indium(I) halides $\operatorname{In} X(X=\mathrm{Cl}, \mathrm{Br}$ or I $)$ are stable concerning disproportionation in the solid-state at ambient temperature and, therefore, commercially available. The halides are negligible soluble in aliphatic and aromatic solvents, whereas disproportionation to indium metal and higher oxidation state species occurs in most donor solvents at ambient temperature. ${ }^{[49 \mathrm{~d}]}$ To enable the reaction nevertheless, indium(I) bromide mixtures in TMEDA/toluene, which are stable concerning disproportionation at low temperatures $\left(T<-20^{\circ} \mathrm{C}\right)$, have been prepared and could be used for synthesis. ${ }^{[70]}$ Alternatively, indium(I) salts have been utilised, e.g., $\operatorname{In}\left[\mathrm{O}_{3} \mathrm{SCF}_{3}\right], \operatorname{In}\left[\mathrm{BF}_{4}\right]$, or $\operatorname{In}\left[E F_{6}\right](E=\mathrm{P}$, As, or $\mathrm{Sb})$, which are soluble in aliphatic and aromatic solvents. In particular, the triflate species features a significant synthetic potential. ${ }^{[71]}$

As reported for gallium(I), the bi- and tridentate ligand scaffolds with a pnicogen donor have been successfully applied in stabilising indium(I) complexes. Salt elimination reactions of alkali metal amidinate, (phospha)guanidinates or diiminophosphinate precursors, and indium(I) salt have led to numerous indium compounds (Figure 1-10, In-I/II). ${ }^{[18,49 \mathrm{~d}, 52 c]}$ The result of these reactions is heavily dependent on the bulkiness of the ligand backbone. In the case of less sterically demanding substituents, partial disproportionation or the formation of complexes, which can be described as localised imido-amide complexes including an $\operatorname{In}^{\mathrm{I}}$ centre exhibiting additional $\eta^{1}-N, \eta^{3}$-arene interactions (In-I).
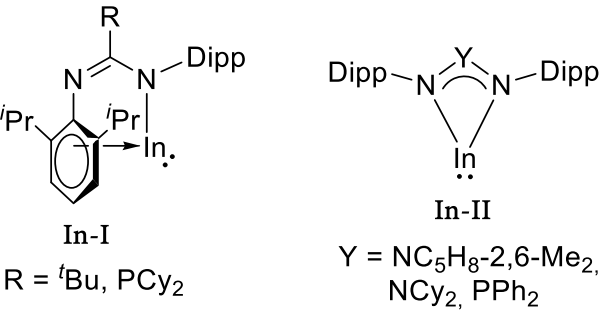

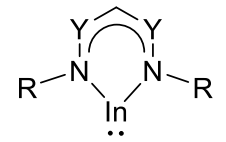

In-III

$\mathrm{R}=\mathrm{Dipp}, \mathrm{Y}=\mathrm{CMe}_{\mathrm{C}} \mathrm{CCF}_{3}$

$\mathrm{R}=\mathrm{Dipp} / \mathrm{C}_{6} \mathrm{H}_{3}-2-\mathrm{OMe}, \mathrm{Y}=\mathrm{CMe}$

$\mathrm{R}=\mathrm{Dipp}, \mathrm{Y}=\mathrm{PPh}_{2}$

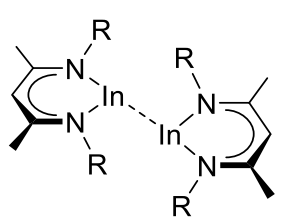

In-IV

$\mathrm{R}=$ Mes, $\mathrm{C}_{6} \mathrm{H}_{3}-2,6-\mathrm{Me}_{2}$

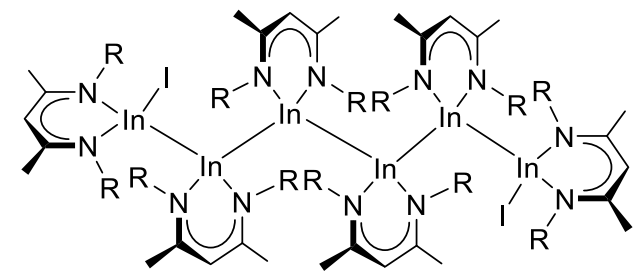

In-V

$\mathrm{R}=3,5-x y l y l$

Figure 1-10. Complexes four- and six-membered indium(I) heterocycles.

The $\kappa^{2}-N, N$-chelation is most likely evaded owing to the narrow bite angle of these ligands in this coordination mode and the size of the indium ion. ${ }^{[49 \mathrm{~d}]}$ For instance, the guanidinate ( $\left.\{\text { DippN }\}_{2} \mathrm{CNCy}_{2}\right)$ or diiminophosphinate $\left(\{\mathrm{DippN}\}_{2} \mathrm{PPh}_{2}\right)$ enforce the formation of four-membered heterocycles (In-II). Computational studies demonstrate that the HOMO is basically a metal-based lone pair high in s-character while the LUMO of the guanidinate or LUMO+1 of the diiminophosphinate is essentially p-orbital at the indium orthogonal to the heterocycle plane. ${ }^{[52 a, 52 c]}$ The synthesis of anionic five-membered indium heterocycles could so far not be accomplished. 
However, several neutral six-membered indium(I) heterocycles (In-III to V) based on NacNac or PNacPNac ligands have been synthesised and characterised. ${ }^{[49,56,57]}$ Bulkier NacNac scaffolds, e.g., ${ }^{\text {Dipp } N a c N a c, \text { prefer monomeric species }}{ }^{[17 c, 72]}$ (In-III) in the solid-state, whereas less sterically demanding ligands tend to form dimeric complexes ${ }^{[73]}$ (In-IV). The long In …In distance (3.1967(4) $\AA$ and 3.3400(5) $\AA$ ) in these dimers indicate a relatively weak metal-metal interaction. Computational analyses showed that $<2 \mathrm{kcal} / \mathrm{mol}$ are necessary to dissociate the dimeric species into monomeric singlet fragments. ${ }^{[73 a]}$ Consequently, pulse gradient spin echo NMR experiments carried out in noncoordinating solvents show that in solution their monomers are formed. ${ }^{[736]}$ Interestingly, the reaction of InI and in situ generated potassium complex of less bulky $\beta$-diketiminate ligands yielded a hexameric indium $\left[(L) \operatorname{In}\{\operatorname{In}(L)\}_{4} \operatorname{InI}(L)\right]\left(L=\left(\{3,5 \text {-xylyl-NCMe }\}_{2} \mathrm{CH}\right)\right.$ complex (Figure 1-10, InV). ${ }^{[74]}$ This unique linear mixed-valence species, which is the result of competing salt elimination and disproportionation reaction, incorporates four internal $\operatorname{In}^{\mathrm{I}}$ centres and two terminal $\left\{\operatorname{In}^{\mathrm{II}} \mathrm{I}(L)\right\}$ fragments. Computational investigations on monomeric six-membered indium(I) heterocycles $\left[\operatorname{In}^{\mathrm{I}}\left(\{R \mathrm{NCR}\}_{2} \mathrm{CH}\right)\right]\left(R=\mathrm{H}, \mathrm{Me}, \mathrm{Ph}, \mathrm{Dip} ; R^{\prime}=\mathrm{H}, \mathrm{Me}, \mathrm{CF}_{3}\right)$ have shown their electronic structures to be similar to those of the lighter $\mathrm{Al}$ and $\mathrm{Ga}$ congeners (Figure 1-1). ${ }^{[17 \mathrm{a}, 17 \mathrm{c}, 17 \mathrm{~d}]}$ However, the singletriplet separation of the carbenoid indium complexes $(55.1-67.1 \mathrm{kcal} / \mathrm{mol})$ is somewhat higher in energy. ${ }^{[17 b, 17 \mathrm{~d}, 75]}$ For all these NacNac-based complexes, the indium lone pair is essentially associated with the HOMO, whereas the empty p-orbital of the metal is represented by the LUMO+1. According to calculations on closely related $\left[\operatorname{In}^{\mathrm{I}}(\mathrm{PNacPNac})\right]$, a change of the ligand backbone resulted in $\mathrm{p}$ orbital associated with $\mathrm{LUMO}+3$, while the In-based lone pair still correlates with the HOMO. ${ }^{[56]}$

In general, the indium(I) heterocycles are poorer Lewis bases and weaker $\pi$-acids than their $\mathrm{Al}^{\mathrm{I}}$ or $\mathrm{Ga}^{\mathrm{I}}$ analogues. Thus, no coordination complexes incorporating a neutral six-membered $\left[\operatorname{In}^{\mathrm{I}}(\mathrm{NacNac})\right]$ have so far been reported. Although the oxidative insertion of $\left[\operatorname{In}^{\mathrm{I}}\left({ }^{R} \mathrm{NacNac}\right)\right](R=$ Dipp, Mes) into the Fe-I bond of $\left[\mathrm{CpFeI}(\mathrm{CO})_{2}\right]$ occurred under mild conditions resulting in a In ${ }^{\text {III }}$ complex $\left(\left[\mathrm{CpFe}(\mathrm{CO})_{2}\left\{\operatorname{InI}\left({ }^{R} \mathrm{NacNac}\right)\right\}\right]\right) \cdot{ }^{[76]}$ Moreover, Hill et al. published the cleavage reaction of an indium diyl and alkyl halides generating $\left[\operatorname{In} R X\left({ }^{\text {Dipp }} \mathrm{NacNac}\right)\right]\left(R={ }^{i} \mathrm{Pr},{ }^{t} \mathrm{Bu} ; X=\mathrm{Br}, \mathrm{I}\right) \cdot{ }^{[77]}$

More recently, the indium(I) biscarbenoid was synthesised comprising a four-membered indacycle due to intra- and intermolecular In-In interactions. ${ }^{[78]}$ The oxidative addition of oxygen towards this complex resulted in a planar $\operatorname{In}_{4} \mathrm{O}_{2}$ ring in that the indium atoms have a formal oxidation state of $+\mathrm{II}$. A similar reaction with sulfur yielded an eight-membered ring incorporating four indium(III) and four sulfides in an alternating fashion. ${ }^{[79]} U$ sing the dianionic $\mathrm{NON}^{\text {Dipp }}\left(\mathrm{NON}^{\text {Dipp }}=\left(\left\{\left\{^{\text {Dipp }} \mathrm{NSiMe}_{2}\right\}_{2} \mathrm{O}\right)^{2-}\right)\right.$ ligand, that could also be utilised to stabilise the diamido substituted aluminyl anion, ${ }^{[16 c]}$ Coles and co-worker prepared the heavier indyl anions $\left[\left(\mathrm{THF}_{2} \mathrm{Li}\right) \operatorname{In}^{\mathrm{I}}\left(\mathrm{NON}^{\text {Dipp }}\right)\right]$ and separated ion pair $[\mathrm{K}([2.2 .2] \mathrm{crypt})]^{+}\left[\operatorname{In}^{\mathrm{I}}\left(\mathrm{NON}^{\mathrm{Dipp}}\right)\right]^{-}$. Reaction of latter species and $\left[\mathrm{MCl}\left({ }^{\mathrm{Mes}} \mathrm{NacNac}\right)\right](M=\mathrm{Zn}, \mathrm{Cd})$ afforded heterobimetallic In- $M$ complexes. ${ }^{[80]}$ Furthermore, the reactivity of these compounds with organic azides $R-\mathrm{N}_{3}(R=$ Mes, Dipp, $\mathrm{Ph})$ were investigated, showing that different reaction pathways are accessible with the outcome dependent on the steric demand of the azide and ligand substituents. ${ }^{[81]}$ 


\subsubsection{Thallium}

Descending group 13 from aluminium to the heavier elements, the most common or stable oxidation state changes from +3 to +1 . Because of the inert pair effect, especially, $\mathrm{Tl}^{\mathrm{I}}$ ion features a nonbonding $6 \mathrm{~s}^{2}$ lone pair that does not engage in bonding or hybridisation (Figure 1-1). ${ }^{[18]}$

The large $\mathrm{Tl}^{\mathrm{I}}$ ion tends to form weak $\mathrm{Tl}$-arene interactions; hence, no low-valent four-membered metallacylces have been reported. $^{[18]}$ All reactions of Dipp-substituted amidinates or (phospha)guanidinates alkali complexes with $\mathrm{Tl}^{\mathrm{I}}$ salts led to extremely air-sensitive formal fivemembered heterocycles of $\eta^{1}-N, \eta^{3}$-arene-chelated type (Figure 1-11, Tl-I). ${ }^{[82]}$ Even the biphenyl- and terphenyl-substituted triazenes based thallium complexes (Tl-II) that appear to form fourmembered $N, N^{\prime}$-chelated heterocycles show thallium arene interactions. ${ }^{[83]}$

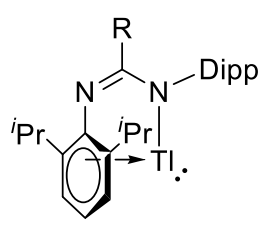

Tl-I

$\mathrm{R}=\mathrm{NCy}_{2}, \mathrm{~N}^{\mathrm{i}} \mathrm{Pr}_{2}$

${ }^{t} \mathrm{Bu}$

$\mathrm{PCy}_{2}$

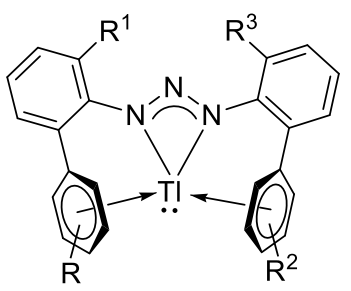

Tl-II

$$
\begin{gathered}
R=R^{2}=2,4,6-{ }^{i} \mathrm{Pr}, \mathrm{R}^{1}=\mathrm{R}^{3}=\mathrm{H} \\
\mathrm{R}=\mathrm{R}^{2}=2,4,6-\mathrm{Me}, \mathrm{R}^{1}=2,4,6-\mathrm{Me}_{3} \mathrm{C}_{6} \mathrm{H}_{2}, \mathrm{R}^{3}=\mathrm{H} \\
\mathrm{R}=\mathrm{R}^{2}=3,5-\mathrm{Me}, \mathrm{R}^{1}=\mathrm{R}^{3}=3,5-\mathrm{Me}_{2} \mathrm{C}_{6} \mathrm{H}_{3}
\end{gathered}
$$

Figure 1-11. Thallium(I) complexes based on aryl-substituted amidinates, (phospha)guanidinates (Tl-I) and triazenes (Tl-II).

On the other hand, six-membered heterocycles containing $\mathrm{Tl}^{\mathrm{I}}$ ion have appeared in literature and can easily be synthesised via salt metathesis reactions. ${ }^{[18]}$ In the solid-state most of these complexes feature a monomeric structure ${ }^{[56,84]}$ (Tl-III), however, less steric groups, e.g., xylyl in the ligand

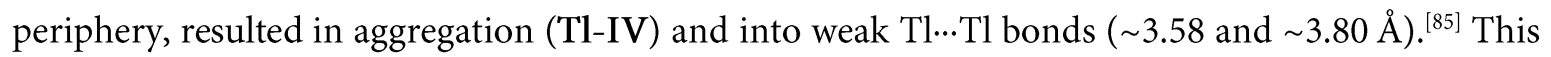
metal-metal interaction was also observed in some dinuclear thallium diyl complexes based on bis(Nacnac) reported by Kretschmer and co-workers (Tl-V). ${ }^{[86]}$ The Tl...Tl interaction was found to be depending on the rigidity or rather flexibility of the bridging unit.<smiles>[R]C1=[Y]=C([R])N([R])[Tl]=[Y]1[H]</smiles>

Tl-III

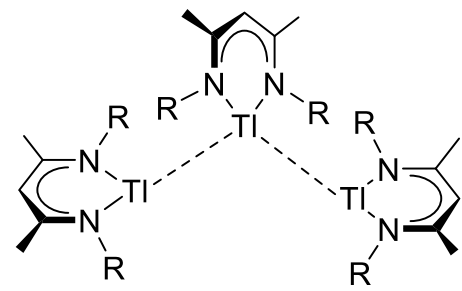

Tl-IV

$\mathrm{Y}=\mathrm{CMe}, \mathrm{R}=\mathrm{Dipp}, \mathrm{R}^{\prime}=\mathrm{H}$;

$Y=\mathrm{CMe}, \mathrm{R}=2,6$-xylyl, $\mathrm{R}^{\prime}=\mathrm{H}$;

$\mathrm{Y}=\mathrm{CPh}, \mathrm{R}=\mathrm{SiMe}_{3}, \mathrm{R}^{\prime}=\mathrm{H}$;

$\mathrm{Y}=\mathrm{CH}, \mathrm{R}=\mathrm{Dipp}, \mathrm{R}^{\prime}=\mathrm{Ph}$;

$\mathrm{Y}=\mathrm{PPh}_{2}, \mathrm{R}=\mathrm{Dipp}, \mathrm{R}^{\prime}=\mathrm{H}$

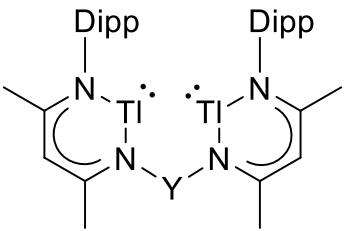

Tl-V

$\mathrm{Y}=\mathrm{Et}, 1,2-\mathrm{Cy}, 1,2-\mathrm{Ph}$,

1,3-Ph, 1,4-Ph, 2,6-Py, $o$-Tol ${ }_{2} \mathrm{O}, m$-xylyl

Figure 1-12. Six-membered thallium(I) complexes based on different NacNac derivatives. 
Considering the low energy of thallium associated lone pairs in these compounds, the coordination and redox chemistry are and most likely will not be developed any further. Nevertheless, thallium precursors have already been utilised as precursors in salt elimination reactions for transition metal complexes, e.g., copper(I) NacNac complexes. ${ }^{[87]}$ 


\subsection{NacNac related ligands and complexes}

Remarkable results in the field of main group chemistry were the synthesis of low-oxidation-state aluminium(I) ${ }^{[13]}$ (vide infra 1.1.1) and dimeric magnesium(I) ${ }^{[22 a]}$ complexes facilitated by bulky $\beta$-diketiminate ligands, e.g., ${ }^{\text {Dipp } N a c N a c}$. These findings initiated research into other ligand platforms which mimic the coordination abilities of the ubiquitous NacNac ligand, in particular the $\kappa^{2}-N, N-$ coordination of the two imine nitrogen atoms to a metal ion to form six-membered metallaheterocycles.

Starting from the bis(2-pyridyl)methane ligand, that is accessed by heating 2-picolylithium with either 2-bromopryridine or an excess of neat pyridine, ${ }^{[88]}$ complexes incorporating a neutral (\{2Py $\left.\}_{2} \mathrm{CH}_{2}\right)\left(\mathrm{L}^{1} \mathrm{H}\right)$ as well as a monoanionic $\left(\{2-\mathrm{Py}\}_{2} \mathrm{CH}\right)\left(\mathrm{L}^{1}\right)$ ligand have been investigated. In the $1990 \mathrm{~s}$ monomeric $\left[\mathrm{Li}(\mathrm{THF})_{2}\left(\{2-\mathrm{Py}\}_{2} \mathrm{CH}\right)\right]$ and solvent separated contact ion pair [Li(12-crown$\left.4)_{2}\right]^{+}\left[\mathrm{Li}\left(\left(\{2-\mathrm{Py}\}_{2} \mathrm{CH}\right)_{2}\right]^{-}\right.$were accessible via deprotonation reaction with equimolar amounts of ${ }^{n} \mathrm{BuLi}$ solution and bis(2-pyridyl)methane. ${ }^{\left[{ }^{89]}\right.}$ Moreover, the reaction of half equiv. of ${ }^{n} \mathrm{BuLi}$ solution and one equiv. $\left\{2-\mathrm{Py}_{2} \mathrm{CH}_{2}\right.$ yielded semi-deprotonated $\left[\left(\{2-\mathrm{Py}\}_{2} \mathrm{CH}_{2}\right) \mathrm{Li}\left(\{2-\mathrm{Py}\}_{2} \mathrm{CH}\right)\right]$, containing a lithium atom that is chelated by a neutral as well as a monoanionic ligand. ${ }^{\left[{ }^{[0]}\right.}$ Using the lithiated species $\left[\mathrm{Li}(\mathrm{THF})_{2}\left(\{2-\mathrm{Py}\}_{2} \mathrm{CH}\right)\right]$ salt elimination reactions with $\mathrm{MMe}_{2} \mathrm{Cl}(M=\mathrm{Al}, \mathrm{Ga})$ yielded $\left[\mathrm{AlMe}_{2}\left(\{2-\mathrm{Py}\}_{2} \mathrm{CH}\right)\right]$ (Figure 1-13, $\left.\mathrm{L}^{1}-\mathrm{AlMe}{ }_{2}\right)$ and $\left[\mathrm{Me}_{2} \mathrm{Ga}\left(\{2-\mathrm{Py}\}_{2} \mathrm{CH}\right)\right]\left(\mathrm{L}^{1}-\mathrm{GaMe}_{2}\right)$, which show a distorted tetrahedral coordination of the metal ion. ${ }^{[1]}$ In 2015 , the reaction of neutral bis(2pyridyl)methane and $\mathrm{MCl}_{3}\left(M=\mathrm{Al}\right.$ to In) was published by Tuononen and co-workers. ${ }^{[2]}$ It was found, that aluminium and gallium salts formed $\left[\mathrm{MCl}_{2}\left(\left\{2-\mathrm{Py}_{2} \mathrm{CH}_{2}\right)_{2}\right]^{+}\left[\mathrm{MCl}_{4}\right]^{-}\left(\mathrm{L}^{1} \mathrm{H}-\mathrm{MCl}_{2}\right)\right.$ or $[M(\{2-$ Py $\left.\left.\}_{2} \mathrm{CH}_{2}\right)_{2}\right]^{+}\left[\mathrm{MCl}_{4}\right]^{-}\left(\left\{\mathrm{L}^{1} \mathrm{H}\right\}_{2}-\mathrm{MCl}_{2}\right)$ depending on the solvent and the ratio of starting materials, while in case of indium chloride only $\left[\mathrm{InCl}_{3}\left(\left\{2-\mathrm{Py}_{2} \mathrm{CH}_{2}\right)\right]\left(\mathrm{L}^{1} \mathrm{H}-\mathrm{InCl}_{3}\right)\right.$ could be isolated.
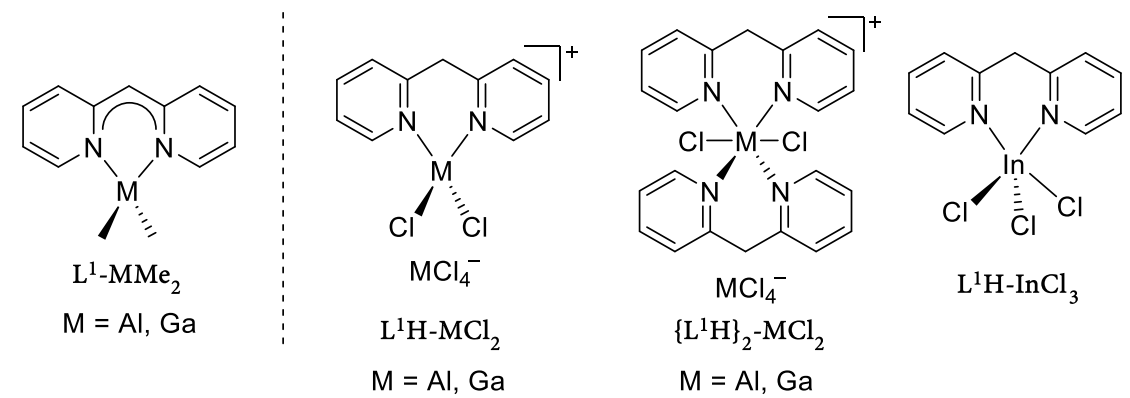

$\mathrm{L}^{1} \mathrm{H}-\mathrm{InCl}_{3}$

Figure 1-13. Group 13 complexes based on monoanionic bis(2-pyridyl)methanide (left) and neutral bis(2pyridyl)methane (right) ligand.

In further research, the backbone, more precisely the methylene bridging unit between the two pyridyl groups, was substituted by valence isoelectronic group 15 moieties $\mathrm{NH}, \mathrm{PH}$, or AsH (Figure $\left.1-14, \mathrm{~L}^{2} \mathrm{H}\right)$. Based on these so-called Janus Head ligands that feature an additional binding site at the backbone numerous main group metal complexes $\left[M R_{2}\left(\{2-\mathrm{Py}\}_{2} E\right)\right](M=\mathrm{Li}, \mathrm{Cs}, \mathrm{Al}, \mathrm{Ga}, \mathrm{In}, \mathrm{Tl}$; $\left.R=\mathrm{THF}, \mathrm{Me}, \mathrm{Et}, E=\mathrm{N},{ }^{\left[{ }^{[93]}\right.} \mathrm{P},{ }^{[93 c, 94]} \mathrm{As}{ }^{[95]}\right)$ with differing coordination modes were obtained. ${ }^{\left[{ }^{[1,}, 93 b\right]}$ Herein, harder group 13 metal ions are prone to form monomers $\left[M \mathrm{Me}_{2}\left(\{2-\mathrm{Py}\}_{2} \mathrm{~N}\right)\right](M=\mathrm{Al}$ and 
Ga) (Figure 1-14, $\mathrm{L}^{2}-\mathrm{MMe}_{2}$ ) with the two endocyclic imine nitrogen donors of the pyridyl groups in a $(Z, Z)$-configuration. The heavier and softer indium and thallium complexes, on the other hand, resulted in dimeric $(E, E)-\left[\operatorname{InMe}_{2}\left(\{2-\mathrm{Py}\}_{2} \mathrm{~N}\right)\right]_{2}\left(\mathrm{~L}^{2}-\mathrm{InMe}_{2}\right)$ and polymeric $(Z, E)-\left[\mathrm{TlMe}_{2}\left(\left\{2-\mathrm{Py}_{2} \mathrm{~N}\right)\right]_{n}\right.$ $(n \rightarrow \infty)\left(\mathrm{L}^{2}-\mathrm{TlMe}_{2}\right)$.

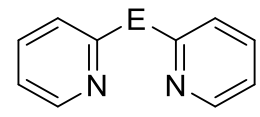

$\mathrm{L}^{2} \mathrm{H}$

$\mathrm{E}=\mathrm{NH}, \mathrm{PH}, \mathrm{AsH}$

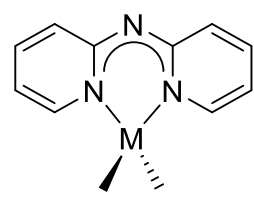

$\mathrm{L}^{2}-\mathrm{MMe}_{2}$ $\mathrm{M}=\mathrm{Al}, \mathrm{Ga}$

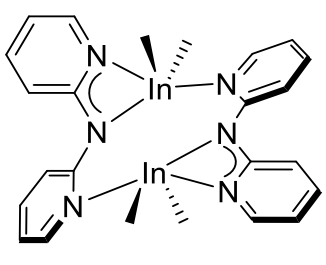

$\mathrm{L}^{2}-\mathrm{InMe}_{2}$

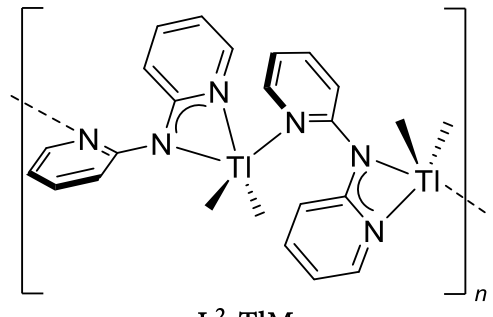

$\mathrm{L}^{2}-\mathrm{TlMe}_{2}$

Figure 1-14. Monomeric (Al, Ga), dimeric (In), and polymeric thallium (Tl) dimethyl group 13 metal complexes of the di(pyridyl)aminide ligand.

In the last two decades, the pyridiyl groups were exchanged by benzannulated oxazoline or thiazole sidearms leading to several symmetrical and asymmetrical ligand platforms (Figure 1-15, $\mathrm{L}^{3} \mathrm{H}$ ). The group 15 homologue bis(benzothiazol-2-yl)phosphane $\left(\left\{\mathrm{C}_{6} \mathrm{H}_{4} \mathrm{NCS}\right\}_{2} \mathrm{PH}\right)$ was prepared like the corresponding 2-pyridyl substituted congener by reductive cleavage of P-aryl bond in the starting material $\left(\left\{\mathrm{C}_{6} \mathrm{H}_{4} \mathrm{NCS}\right\}_{3} \mathrm{PH}\right)$ in the presence of lithium and subsequent hydrolysis. The neutral and monoanionic phosphanide ligand scaffolds offer diverse feasible coordination motifs caused by the three different donor sites (N, P, and S) in the ligand periphery. According to the HSAB concept by Pearson the different metal ions can be addressed by the ligand's donor atoms. ${ }^{[96]}$ Theoretical calculations and charge density analyses on $\left\{\mathrm{C}_{6} \mathrm{H}_{4} \mathrm{NCS}\right\}_{2} \mathrm{PH}$ demonstrated that the formation of an $\mathrm{NH}$ tautomer to be energetically favoured over the proton residing at the phosphorus atom and respective $\mathrm{PH}$ tautomer. Moreover, the $\mathrm{NH}$ species was found to be stable only in $\mathrm{Et}_{2} \mathrm{O}$, while the dilution in other solvents induced a hydrogen shift to the phosphorus linker atom leading to ligand scrambling. Nonetheless, the bis(benzothiazol-2-yl)phosphane ligand was utilised in the coordination chemistry of the main group ( $\mathrm{Li}, \mathrm{Cs}$ ) and transition metals (Fe, $\mathrm{Mn}, \mathrm{Cd}, \mathrm{Zn}$ ), which display different coordination modes caused by the differing HSAB character of integrated N, P and $\mathrm{S}$ donor bases. ${ }^{[96]}$ Bis(benzheterocyclo)amine ligands $\left(\left\{{ }^{4-R} \mathrm{C}_{6} \mathrm{H}_{3} \mathrm{NCX}\right\}_{2} \mathrm{NH} ; R=\mathrm{H}, \mathrm{Me}, \mathrm{OMe} ; X=\mathrm{S}\right.$, O) were generated via condensation reaction of two equiv. 2-aminobenzheterocycles and 1.4 equiv. of phenol under formation of ammonia at $50^{\circ} \mathrm{C} \cdot{ }^{[97]}$ Single crystal XRD experiments demonstrated that the $(Z, E)$-arrangement of the bis-heterocyclic substituted amines is preferred over other configurational isomers in the solid-state. Furthermore, the 4-substituted derivates favour the pure endocyclic tautomer (-NH- bridging unit) over the exocyclic imine-enamine tautomers, which was mainly observed ( $\mathrm{NH}$ pointing out of coordination pocket) for the unsubstituted bis(benzheterocyclo)amine. ${ }^{[976]}$ Reaction of the bis(benzothiazolyl)amine ligands and trimethyl aluminium led to $\left[\mathrm{AlMe}_{2}\left(\left\{{ }^{4-R} \mathrm{C}_{6} \mathrm{H}_{3} \mathrm{NCS}\right\}_{2} \mathrm{~N}\right)\right](R=\mathrm{H}, \mathrm{Me})$ (Figure 1-15, $\left.\mathrm{L}^{3}-\mathrm{AlMe}_{2}\right)$ or $\left[\mathrm{AlMe}_{2}\left(\left\{{ }^{4-\mathrm{MeO}^{-}} \mathrm{C}_{6} \mathrm{H}_{3} \mathrm{NCS}\right\}_{2} \mathrm{~N}\right) \mathrm{AlMe}_{3}\right]\left(\mathrm{L}^{3}-\mathrm{Al}_{2} \mathrm{Me}_{5}\right)$, respectively. Additionally, homoleptic transition metal complexes $\left[M\left(\left\{{ }^{4-\mathrm{H}} \mathrm{C}_{6} \mathrm{H}_{3} \mathrm{NCS}\right\}_{2} \mathrm{~N}\right)_{2}\right](M=\mathrm{Co}, \mathrm{Ni}, \mathrm{Zn}, \mathrm{Hg})^{[98]}\left(\left\{\mathrm{L}^{3}\right\}_{2}-\mathrm{M}\right)$ and heteroleptic 
$\left[M Y_{n} L\left(\left\{{ }^{4-\mathrm{H}} \mathrm{C}_{6} \mathrm{H}_{3} \mathrm{NCS}\right\}_{2} \mathrm{~N}\right)\right]\left(M=\mathrm{Ni}, Y_{1}=\mathrm{MeOH}, L=\mathrm{OAc} ;{ }^{[98]} M=\mathrm{Ru}, Y_{1}=\mathrm{Cl}, L=\right.$ p-cymene; $^{[99]} M=$ Re, $Y_{2}=\mathrm{CO}, L=\left(\left\{{ }^{4-\mathrm{H}} \mathrm{C}_{6} \mathrm{H}_{3} \mathrm{NCS}\right\}_{2} \mathrm{~N},{ }^{[100]} 2-\mathrm{MeNOC}_{6} \mathrm{H}_{4}{ }^{[101]}\right)$ were reported.

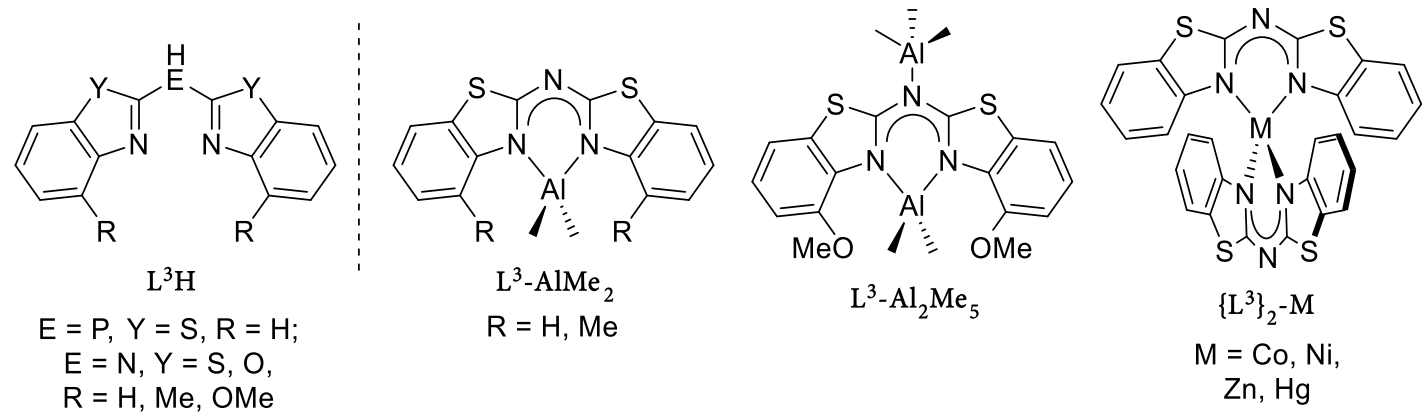

Figure 1-15. Benzanullated symmetrical and asymmetrical phosphane and amine ligand platforms (left, $\left.\mathrm{L}^{3} \mathrm{H}\right)$. Methyl aluminium complexes $\left(\mathrm{L}^{3}-\mathrm{AlMe}_{2}, \mathrm{~L}^{3}-\mathrm{Al}_{2} \mathrm{Me}_{5}\right)$ as well as homoleptic transition metal complexes $\left(\left\{\mathrm{L}^{3}\right\}\right.$ M) containing monoanionic $\left\{{ }^{4-\mathrm{R}} \mathrm{C}_{6} \mathrm{H}_{3} \mathrm{NCS}\right\}_{2} \mathrm{~N}$ derivatives.

The formal replacement of the amine linker unit at the ligand backbone by a methylene group gives access to bis(benzheterocyclo)methane ligands. In the last decades, our group especially focused on designing benzannulated methane platforms suitable for main-group complexes. Within this progress, novel synthetic routes for the unsubstituted symmetrical bis(benzimidazol)-, bis(benzoxazol)- and bis(benzothiazol)methane ligands were investigated. The synthesis of bis(benzothiazol-2-yl)methane $\left(\left\{\mathrm{C}_{6} \mathrm{H}_{4} \mathrm{NCS}\right\}_{2} \mathrm{CH}_{2}\right)$ was first reported by Mills. ${ }^{[102]}$ Since then, several alternative synthetic approaches were developed. ${ }^{[103]}$ Among others, the synthesis of $\left\{\mathrm{C}_{6} \mathrm{H}_{4} \mathrm{NCS}_{2} \mathrm{CH}_{2}\right.$ was accomplished via cyclocondensation reaction of two equiv. of 2-aminothiophenol and one equiv. of malononitrile in ethanol by heating under reflux. Upon deprotonation of the acidic methylene bridge by organic group 13 metal reagent corresponding complexes $\left[M X_{2}\left(\left\{\mathrm{C}_{6} \mathrm{H}_{4} \mathrm{NCS}\right\}_{2} \mathrm{CH}\right)\right]\left(M X_{2}=\right.$ $\mathrm{AlMe}_{2}, \mathrm{AlMeCl} ; \mathrm{GaMe}_{2}$ ) (Figure 1-16, $\mathrm{L}^{3}-\mathbf{M}$ ) were prepared. ${ }^{[104]}$ Each of these complexes exhibits a nearly planar arrangement while the metal fragment is coordinated by the conjugated NacNac-like moiety. The range of group 13 metal compounds $\left[M \mathrm{Me}_{2}\left(\left\{\mathrm{C}_{6} \mathrm{H}_{4} \mathrm{NCY}\right\} \mathrm{CH}\left\{\mathrm{C}_{6} \mathrm{H}_{4} \mathrm{NCS}\right\}\right)\right](Y=\mathrm{O}, M=$ $\left.\mathrm{Al}, \mathrm{Ga}\left(\mathrm{L}^{4}-\boldsymbol{M}\right) ; Y=\mathrm{NMe}, M=\mathrm{AlMe}_{2}\left(\mathrm{~L}^{5}-\mathbf{M}\right)\right)$ was further expanded, starting from asymmetrically substituted methane derivates, which were accessible by the condensation reaction of (2benzothiazol-2-yl)acetonitrile and 2-aminophenol or $\mathrm{N}$-methylphenylenediamine in polyphosphoric acid at elevated temperatures. ${ }^{[105]}$
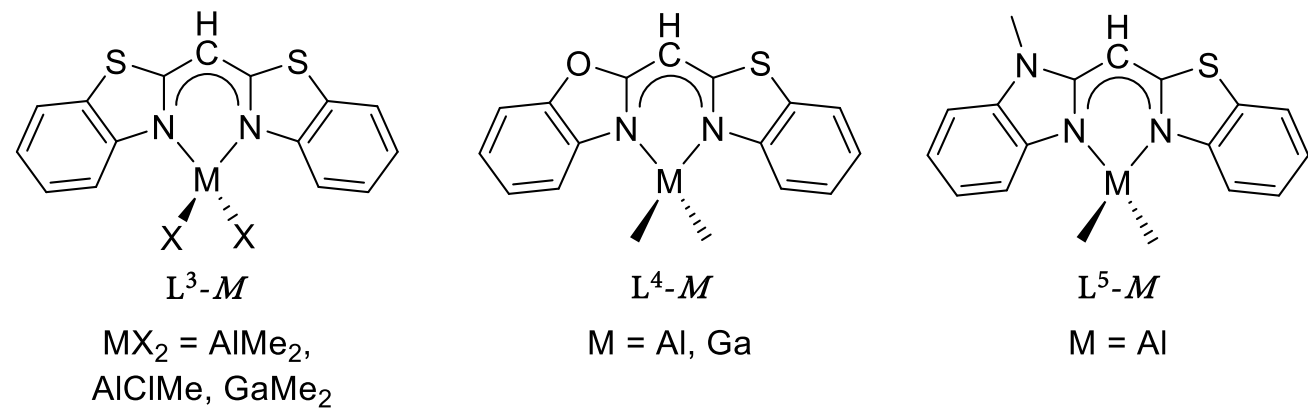

AlCIMe, $\mathrm{GaMe}_{2}$

Figure 1-16. Group 13 metal complexes based on symmetric bis(benzothiazol-2-yl) $\left(\mathrm{L}^{3}-\boldsymbol{M}\right)$ and asymmetric bis(benzheterocyclo)methanide ( $\left.\mathrm{L}^{4}-\mathbf{M}, \mathrm{L}^{5}-\mathbf{M}\right)$ ligands. 
However, bis(benzoxazol-2-yl)methane derivatives are so far probably the most advanced and widely used class of benzannulated methane ligands. In general, their synthesis was accomplished by cyclocondensation reaction of two equiv. substituted 2-aminophenol and one equiv. of a suitable linker at elevated temperatures. ${ }^{[103,104]}$ Herein, activated linker like the ethylbisimidate dihydrogenchloride (Scheme 1-3) have proven useful to obtain corresponding ligands in adequate yields. ${ }^{[3]}$<smiles>[R]c1cc([R])c(N)c(O)c1</smiles><smiles>CCOC(C/C(N=NC(=O)O)=N\O)=NO</smiles><smiles>[R]c1cc([R])c2nc(Cc3nc4c([R])cc([R])cc4o3)oc2c1</smiles>

$$
\begin{gathered}
R=R^{\prime}=H: 56 \% \\
R=M e, R^{\prime}=H: 44 \% \\
R=R^{\prime}={ }^{i} \operatorname{Pr}: 43 \% \\
R=R^{\prime}={ }^{t} \text { Bu: } 18-21 \%
\end{gathered}
$$

Scheme 1-3. General synthesis of bis(benzoxazol-2-yl)methane derivatives based on ethylbisimidate dihydrogenchloride.

Starting from unsubstituted bis(benzoxazol-2-yl)methane $\left(\mathrm{Box}_{2} \mathrm{CH}_{2}\right)$ group 13 complexes $\left[M X_{2}\left(\mathrm{Box}_{2} \mathrm{CH}\right)\right]\left(M X_{2}=\mathrm{AlMe}_{2}, \mathrm{AlMeCl}, \mathrm{GaMe}_{2}\right)\left(\right.$ Figure 1-17, $\left.\left[\mathrm{MX}_{2}\left(\mathrm{Box}_{2} \mathrm{CH}\right)\right]\right)$ were synthesised by well-established deprotonation with corresponding methyl metal precursors in toluene at $0^{\circ} \mathrm{C} \cdot{ }^{[104]}$ Single crystal XRD experiments demonstrated that the metal ions are coordinated in a distorted tetrahedral fashion while the ligand is almost perfectly planar. Additionally, it was proven that neither in solid-state nor solution $\left({ }^{1} \mathrm{H},{ }^{15} \mathrm{~N}-\mathrm{HMBC} \mathrm{NMR}\right)$ coordination of endocyclic oxygen atoms appears. According to measured bond lengths in the NacNac-like $\mathrm{C}_{3} \mathrm{~N}_{2}$ moiety, a delocalisation of the negative charge is to be expected. ${ }^{[104]}$ Thereafter, the sterically more demanding bis(4-methyl-benzoxazol-2yl)methane $\left({ }^{4-\mathrm{Me}} \mathrm{Box}_{2} \mathrm{CH}_{2}\right)$ was metallated by trimethyl group 13 metal $\left(\mathrm{MMe}_{3}, \mathrm{M}=\mathrm{Al}, \mathrm{Ga}\right.$, In) (Figure $\left.1-17,\left[\mathrm{MMe}_{2}\left(\mathrm{Box}_{2} \mathrm{CH}\right)\right]\right)$ as well as differing organoaluminium compounds ( $\left.\mathrm{AlMe}_{2} \mathrm{Cl}, \mathrm{AlEt}_{2} \mathrm{I}\right)$ $\left(\left[\mathrm{MRX}\left(\mathrm{Box}_{2} \mathrm{CH}\right)\right]\right)$ leading to a plethora of monomeric aluminium(III) complexes. ${ }^{[106]}$ Considering the increasing ionic radii of $\mathrm{M}=\mathrm{Al}, \mathrm{Ga}$ to $\mathrm{In}$ an elongation of $\mathrm{M}-\mathrm{N}$ bond lengths and a decreasing

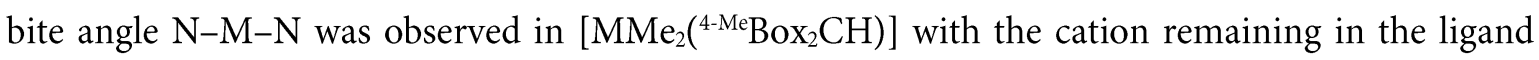
plane. The synthesis of $\left[\mathrm{AlMeI}\left({ }^{4-\mathrm{Me}} \mathrm{Box}_{2} \mathrm{CH}\right)\right]$ was achieved via reaction of the dimethyl aluminium species and an excess of trimethylsilyl iodide at elevated temperatures $\left(>111^{\circ} \mathrm{C}\right)$. Although synthesis of the aluminium diiodide complex $\left[\mathrm{AlI}_{2}\left({ }^{4-\mathrm{Me}} \mathrm{Box}_{2} \mathrm{CH}\right)\right]$, which could be used as a promising precursor for $\mathrm{Al}(\mathrm{I})$ species, was not accomplished. ${ }^{[107]}$ Evaluation of the mono halogenated aluminium(III) complexes demonstrated expanded distances compared to $\left[\mathrm{AlMe}_{2}\left({ }^{4-\mathrm{Me}^{-} \mathrm{Box}} \mathrm{CH}\right)\right]$ while the bite angle $\mathrm{N}-\mathrm{Al}-\mathrm{N}$ is widened. These structural alterations are induced by the partial positive charge at the $\mathrm{Al}^{\mathrm{III}}$ cation caused by the negative inductive effect as well as their reduced electronegativity of the halide atoms with regards to carbon. Thus, the aluminium ion most likely requires less electron density from the coordinating nitrogen atom, whereby the $\mathrm{N}$-Al bond becomes less attractive. ${ }^{[106]}$ All attempts to reduce the partially halogenated and easily accessible $\left[\operatorname{AlEtI}\left({ }^{4-\mathrm{Me}} \mathrm{Box}_{2} \mathrm{CH}\right)\right]$ have not been successful. ${ }^{[107]}$ 

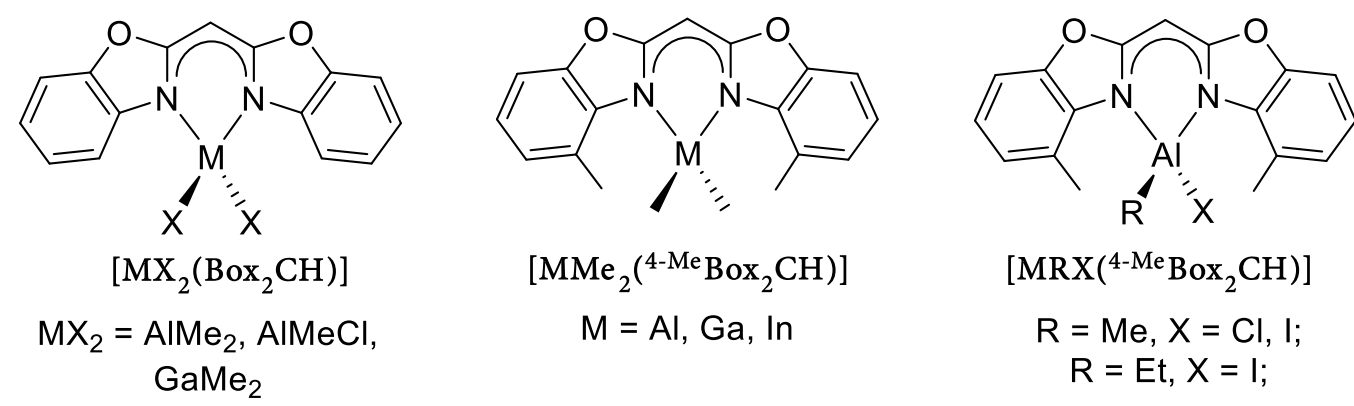

Figure 1-17. Group 13 metal complexes based on unsubstituted (left) and methyl substituted bis(benzoxazol2-yl)methane (middle, right) ligands.

Subsequently, bulkier 4,6-tert-butyl- or 4,6-iso-propyl-substituted bis(benzoxazol-2-yl)methane ligands were developed on the basis of corresponding aminophenol derivatives. ${ }^{[108]}$ Alkali metal complexes $\left[M\left({ }^{4,6-R} \mathrm{Box}_{2} \mathrm{CH}\right)\right]\left(R={ }^{t} \mathrm{Bu}: M=\mathrm{LiTHF}, \mathrm{K} ;{ }^{[108 \mathrm{a}]} \mathrm{R}={ }^{i} \operatorname{Pr}: M=\mathrm{Li}(\mathrm{THF})_{2}, \mathrm{~K}^{[1086]}\right)$ (Figure 1-18) were obtained by concerted deprotonation-metalation reaction with typical alkali-metal reagents. Interestingly, the central lithium cation of $\left[\operatorname{LiTHF}\left({ }^{4,6-B u}{ }^{-B o x}{ }_{2} C H\right)\right]$ (Figure 1-18) is trigonal pyramidally coordinated by the monoanionic ligand and one THF molecule. Here, the fourth coordination site at the metal centre is shielded by the adjacent tert-butyl groups. Therefore the preferred tetrahedral coordination by another THF donor base is prevented. Furthermore, the steric demand of these ligands is revealed by single crystal XRD experiments of corresponding potassium complexes $\left.\left[\mathrm{K}^{4,6-R} \mathrm{Box}_{2} \mathrm{CH}\right)\right]_{n}(n \rightarrow \infty)$ (Figure 1-18), which form solvent-free coordination polymers out of THF solutions. Computational studies of NacNac-based as well as -related lithium complexes $[\mathrm{Li}(\operatorname{Solv})(L)]\left(\right.$ Solv $=$ THF, $\mathrm{Et}_{2} \mathrm{O} ;=L={ }^{4,6-\mathrm{BBu}} \mathrm{Box}_{2} \mathrm{CH},{ }^{[108 \mathrm{a}]}{ }^{4,6-\mathrm{Pr}} \mathrm{Box}_{2} \mathrm{CH}_{,}{ }^{[1086]}{ }^{\mathrm{BBu}} \mathrm{NacNac},{ }^{[109]}$ ${ }^{\text {Dipp }} \mathrm{NacNac}$, $\left.{ }^{[110]}\left\{{ }^{\text {Dipp }} \mathrm{NCNMe}_{2}\right\}_{2} \mathrm{CH}^{[111]}\right)$ gave further insights on their electronic structure. The following trends could be derived from these calculated parameters (NBO, NPA, NRT): Highly substituted bis(benzoxazol-2-yl)methane derivates comprise comparable electronic and donating properties like the usual NacNacs as well as the electron-rich amine-substituted NacNac analogues ( $\left.\left\{{ }^{\text {Dipp }} \mathrm{NCNMe}\right\}_{2} \mathrm{CH}\right)$. The delocalisation of the negative charge within the $\mathrm{C}_{3} \mathrm{~N}_{2}$ moiety, which was already expected from measured bond lengths, is best described by diimino and imino-enamide resonance structures. Moreover, the additional oxygen atoms in the backbone of the methanide derivatives display negative NPA charges similar to the amidic nitrogen atoms in $\left\{{ }^{\text {Dipp }} \mathrm{NCNMe}_{2}\right\}_{2} \mathrm{CH}$. Thus, both oxygen atoms offer sufficient donating capabilities, although a profound charge delocalisation throughout the aryl perimeters can be assumed. 


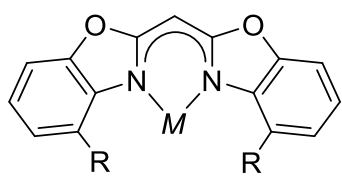

[M( $\left.\left.{ }^{4,6-\mathrm{R}} \mathrm{Box}_{2} \mathrm{CH}\right)\right]$

$\mathrm{R}=4,6{ }^{-} \mathrm{Pr}, \mathrm{M}=\mathrm{Li}(\mathrm{THF})_{2}$ $\mathrm{R}=4,6-{ }^{\mathrm{t}} \mathrm{Bu}, \mathrm{M}=\mathrm{Li}(\mathrm{THF})$

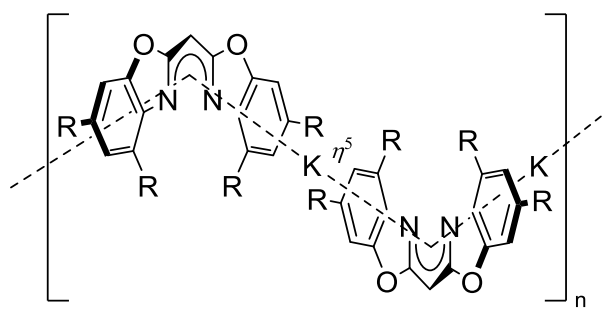

$\left[\mathrm{K}\left({ }^{4,6-\mathrm{R}} \mathrm{Box}_{2} \mathrm{CH}\right)\right]_{n}$ $\mathrm{R}=4,6-{ }^{i} \mathrm{Pr}, 4,6-{ }^{t} \mathrm{Bu}$

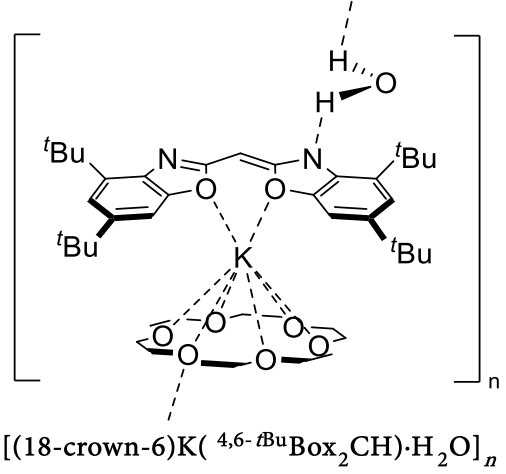

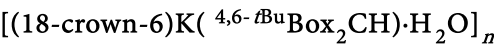

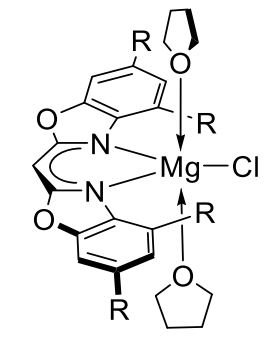

$\left.\left[\mathrm{MgTHF}_{2}{ }^{(4,6-\mathrm{R}} \mathrm{Box}_{2} \mathrm{CH}\right)\right]$

$\mathrm{R}=4,6-{ }^{i} \mathrm{Pr}, 4,6-{ }^{t} \mathrm{Bu}$

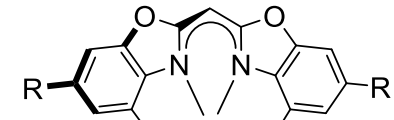

$\mathrm{RR} M \mathrm{RR}$

$\mathrm{R}-$

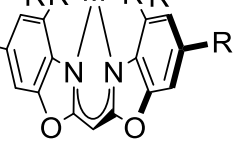

$\left[\mathrm{M}\left({ }^{4,6-\mathrm{R}} \mathrm{Box}_{2} \mathrm{CH}\right)_{2}\right]$

$\mathrm{R}=4,6{ }^{\mathrm{i}} \mathrm{Pr}, 4,6-{ }^{\mathrm{t}} \mathrm{Bu}, \mathrm{M}=\mathrm{Mg}$;

$\mathrm{R}=4,6{ }^{-} \mathrm{Pr}, \mathrm{M}=\mathrm{Ca}(\mathrm{THF}), \mathrm{Sr}(\mathrm{THF})$,

$\mathrm{Ba}(\mathrm{THF})$

Figure 1-18. Alkali and earth alkali complexes comprising bulky bis(4,6-tert-butyl-benzoxazol-2-yl) or bis(4,6iso-propyl-benzoxazol-2-yl)methanide ligands.

An interesting water-containing organopotassium complex $\left[\left(18 \text {-crown-6) } \mathrm{K}\left({ }^{4,6-6 \mathrm{Bu}} \mathrm{Box}_{2} \mathrm{CH}\right) \cdot \mathrm{H}_{2} \mathrm{O}\right]_{n}\right.$ $(n \rightarrow \infty)$ (Figure 1-18) was accessible by deprotonation of bis(4,6-tert-butyl-benzoxazol-2yl)methane ligand with $\mathrm{KH}$ in the presence of incompletely dried crown ether. ${ }^{[12]}$ The obtained crystal structure represents the first example of a bis(oxazol-2-yl)methanide featuring solely Ocoordination to a potassium ion. Furthermore, the water molecule with a site occupation factor of $35 \%$ interacts with an outwards-tilted nitrogen atom resulting in a $2 \mathrm{D}$ hydrogen bond network in the solid-state. There are two maxima in the electron density distribution between the $\mathrm{N}$... O water vector, therefore a double potential hydrogen bond is presumed. One maximum is refined to $21 \%$ occupation, the other to $14 \%$. Considering this, $14 \%$ of the molecular units incorporate a hydrolysed species with an $\mathrm{NH}$ group as well as a hydroxide anion, while $21 \%$ could be assigned to species that hosts an intact water molecule. Additionally, the water-resistance of this unique organopotassium complex was studied by ${ }^{1} \mathrm{H}$ NMR titration experiments and DOSY. The present hydrolysis equilibrium is shifted to the protonated ligand after adding a significant excess of water at ambient temperature. Because of these observations $p K_{\mathrm{a}}$ values (Figure 1-19) of selected benzannulated bis(heterocyclo-2-yl)methane derivatives were determined. ${ }^{[3,113]}$ UV/Vis spectrophotometric titration experiments in acetonitrile unveiled $\mathrm{p} K_{\mathrm{a}}$ values of 26.89(3) for unsubstituted bis(benzoxazol-2-yl)methane as well as 26.16(3) for bis(benzothiazol-2-yl)methane. ${ }^{[114]}$ The slightly lower $\mathrm{p} K_{\mathrm{a}}$ of the sulphur congener might be explained by the less pronounced overlap between carbon $\mathrm{sp}^{2}$ - and sulphur $3 \mathrm{p}$-orbitals compared to the oxygen $2 \mathrm{p}$-orbitals, which display a stronger positive mesomeric effect. ${ }^{[115]}$ Both $\mathrm{p} K_{\mathrm{a}}$ values are notably higher than estimated for $\left\{\mathrm{C}_{6} \mathrm{H}_{4} \mathrm{NCS}\right\}_{2} \mathrm{CH}_{2}$ $(10-20)^{[116]}$ based on 2-benzylbenzo-1,3-thiazole $\left(\mathrm{p} K_{\mathrm{a}}=20.8\right)^{[117]}$ measured in DMSO, which is in 
agreement with the typical relation between $\mathrm{p} K_{\mathrm{a}}$ values in DMSO and acetonitrile. ${ }^{[118]}$ The alkyl groups bound to the aryl system result in an increased positive inductive effect ${ }^{[119]}$ in bis(4-metylbenzoxazol-2-yl)methane and bis(4,6-tert-butyl-benzoxazol-2-yl)methane, which lead to a lower acidity $\left(\mathrm{pK}_{\mathrm{a}}\left({ }^{4-\mathrm{Me}} \mathrm{Box}_{2} \mathrm{CH}_{2}\right)=27.59(3) ; \mathrm{pK}_{\mathrm{a}}\left({ }^{4,6-\mathrm{Bu}}{ }^{-\mathrm{Box}_{2}} \mathrm{CH}_{2}\right)=28.85(3)\right)$ in comparison to unsubstituted $\mathrm{Box}_{2} \mathrm{CH}_{2}$.

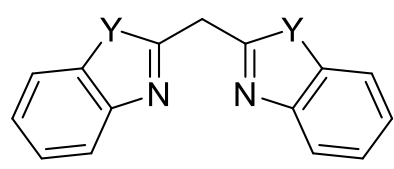

$\mathrm{Y}=\mathrm{O}: \mathrm{p} K_{\mathrm{a}}=26.89(3)$,

$\mathrm{Y}=\mathrm{S}: \mathrm{p} K_{\mathrm{a}}=26.16(3)$

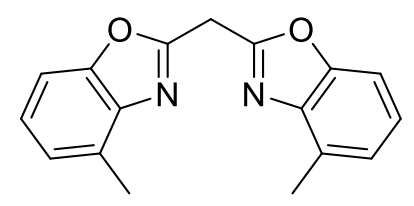

$\mathrm{p} K_{\mathrm{a}}=27.59(3)$

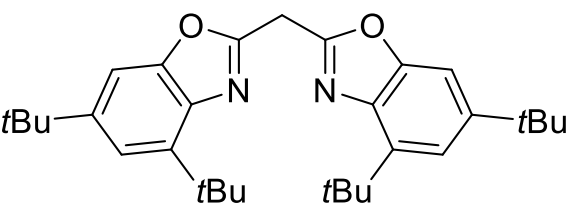

$\mathrm{p} K_{\mathrm{a}}=28.85(3)$

Figure 1-19. $\mathrm{p} K_{\mathrm{a}}$ values of benzannulated methane ligands determined by UV/Vis spectrophotometric titration experiments in acetonitrile.

In 2007 Jones and Stasch et. al. published the first thermally stable magnesium(I) complexes $\left[\mathrm{Mg}^{\mathrm{I}}(L)\right]_{2}$ based on bulky guanidinate $\left(L=\{\mathrm{DippN}\}_{2} \mathrm{CN} R_{2}, R={ }^{i} \mathrm{Pr}, \mathrm{Cy}\right)$ and NacNac ligands $(L=$

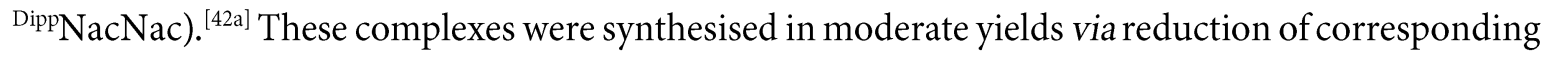
magnesium(II) iodides diethyl etherate precursors and an excess of potassium metal. Considering the similar properties of the $\beta$-diketiminate and the bis(benzoxazol-2-yl)methanide ligand platforms, various attempts to get access to low-valent Group 2 complex of the latter ligand class were carried out in the last five years. ${ }^{[105,108,108 b]}$ Deprotonation of sterically demanding bis(benzoxazol-2yl)methane ligands via Hauser base $\left({ }^{i} \mathrm{Pr}\right)_{2} \mathrm{NMgCl}$ yielded $\left[\mathrm{MgCl}(\mathrm{THF})_{2}\left({ }^{R} \mathrm{Box}_{2} \mathrm{CH}\right)\right]\left(R=4,6-{ }^{i} \mathrm{Pr}, 4,6-\right.$ ${ }^{t} \mathrm{Bu}$ ) (Figure 1-18) including a trigonal bipyramidal coordinated $\mathrm{Mg}^{\mathrm{II}}$ cation. ${ }^{[108 \mathrm{a}, 108 \mathrm{~b}]}$ Reduction attempts were performed with magnesium chloride complex $\left[\mathrm{MgCl}(\mathrm{THF})_{2}\left({ }^{4,6-\mathrm{tBu}} \mathrm{Box}_{2} \mathrm{CH}\right)\right]$ utilising potassium metal or $\mathrm{KC}_{8}$. These reactions have hitherto not afforded a dimeric $\mathrm{Mg}^{\mathrm{I}}-\mathrm{Mg}^{\mathrm{I}}$ species but generated the homoleptic $\left[\mathrm{Mg}\left({ }^{4,6-\mathrm{Bu}} \mathrm{Box}_{2} \mathrm{CH}\right)_{2}\right]$, which is most likely obtained by disproportionation or Schlenk equilibrium type redistribution. ${ }^{[108 a]}$ Besides, the heavier analogues $\left[\mathrm{M}(\mathrm{THF})\left({ }^{4,6-\mathrm{Pr}} \mathrm{Box}_{2} \mathrm{CH}\right)_{2}\right](M=\mathrm{Ca}, \mathrm{Sr}$, and $\mathrm{Ba})$ (Figure 1-18) were obtained by deprotonation of bis(benzoxazole-2-yl) methane ligands with heavier alkaline-earth-metal hexamethyldisilazanes, respectively. Following trends could be observed in the solid-state by descending Group 2 from $\mathrm{Mg}^{\mathrm{II}}$ to $\mathrm{Ba}^{\mathrm{II}}$ : The metal nitrogen $(\mathrm{M}-\mathrm{N})$ bond lengths and the metal dislocation from chelating $\mathrm{C}_{3} \mathrm{~N}_{2}$ plane increase in correlation with ionic radii from $\mathrm{Mg}$ to $\mathrm{Ba}$. The $\mathrm{N}-\mathrm{M}-\mathrm{N}$ bite angles, on the contrary, are decreased in the row $\mathrm{Mg}<\mathrm{Ca}<\mathrm{Sr}<\mathrm{Ba}{ }^{[108 b]}$ Moreover, ${ }^{1} \mathrm{H}$ and ${ }^{13} \mathrm{C}$ NMR spectroscopy of homoleptic $\left[\mathrm{MTHF}_{0-1}\left({ }^{4,6-\mathrm{Pr}} \mathrm{Box}_{2} \mathrm{CH}\right)_{2}\right](\mathrm{M}=\mathrm{Mg}, \mathrm{Ca}, \mathrm{Sr}$, and $\mathrm{Ba})$ (Figure 1-18) indicate an increasing ionic character from $\mathrm{Mg}$ to $\mathrm{Ba}$ resulting in an enhanced charge delocalisation throughout the ligand scaffold. ${ }^{[108 b]}$ 


\section{$1.3 \quad$ Scope}

Reviewing the achievements which have been made in the field of Group 13 metal complexes over the last decades, the main area of research is emerging to the development and utilisation of lowoxidation and/or -valent aluminium compounds. Thereby, alanediyls, dialuminenes and rather novel aluminyl anions exhibit auspicious behaviour in small molecule activation. Up to now, alanediyls, which is a carbene-like analogue, and its heavier homologues were mainly gained from sterically demanding NacNac ligands. To this effect, this work essentially focuses on the exploration of novel ligand platforms facilitating low-valent Group 13 metal compounds.

Starting from bis(2-pyridyl)methane several NacNac alike ligand systems were developed in our group. Thus, alterations of the bridging moiety by isoelectronic groups and therefore connected residues gave rise to various symmetrical and asymmetrical ligands. In recent years the main emphasis has been on symmetrical bis(benzoxzol-2-yl)methane ligands that were straightforwardly synthesised via cyclocondensation of two equivalents 2 -aminophenol derivative and one equivalent of ethylbisimidate dihydrochloride. In comparison to the ubiquitous $\mathrm{NacNac}$ platforms, these ligands possess additional oxygen donor sites, which enable multiple coordination motifs like $N, N^{\prime}$ chelation, and mixed $\mathrm{N}, \mathrm{O}$ - as well as $O, \mathrm{O}^{\prime}$-coordination. Herein, the methylene linker could easily be deprotonated by organometallic reagents due to the close proximity of the endocyclic nitrogen and oxygen atoms. The obtained monoanionic bis(benzoxzol-2-yl)methanides are almost perfectly planar aligned facilitating an ideal orbital overlap of the donor atoms pointing into the coordination pocket and to the corresponding metal fragments. Up to now, no low-oxidation or -valent group 13 complexes on the basis of bis(benzoxzol-2-yl)methanides have been isolated, however, various species containing a $N, N^{\prime}$-chelated triel metal cation ( $\mathrm{Al}, \mathrm{Ga}$, and In) in the oxidation state of $+\mathrm{III}$ could be synthesised.

Hence, the first part of this thesis focuses on the synthesis of low-oxidation or -valent group 13 complexes starting from the unsubstituted bis(benzoxazol-2-yl)methane as well as the bis(4-methylbenzoxazol-2-yl)methane derivative. First, these ligands shall be converted to alkali metal precursor complexes by concerted deprotonation-metalation reactions with group 1 metal organic reagents. With these compounds in hand, heavier low-oxidation state group 13 metallacylces might be accessible by salt elimination reaction with common metal(I) salts. Moreover, dihalide aluminium species should be synthesised and analysed concerning their aptitude as starting material for aluminium(I) compounds.

During our research, we found that despite the steric demand provided by $\mathrm{Pr}$ - or $t \mathrm{Bu}$-residues introduced in proximity to the coordination pocket, low-oxidation main group complexes could so far not be isolated. Thus, we decided to design the even bulkier bis(4-benzhydryl-benzoxzol-2-yl) methane. Based on this novel ligand system group 13 carbene analogues might be accessible, as described in the previous paragraph, via salt elimination or reduction of suitable precursors. 


\section{RESULTS AND Discussion}

Major parts of this chapter have been published in:

[1] J. Kretsch, Anne Kreyenschmidt, R. Herbst-Irmer, D. Stalke, "Alkali metal complexes based on bisheterocyclomethanide ligands", Dalton Trans. 2018, 36, 12606-12612. ${ }^{[1]}$

[2] J. Kretsch, R. Herbst-Irmer, D. Stalke, "Aluminum(III) Halide Complexes based on a Bis(benzoxazol-2-yl)methane Ligand", Z. Anorg. Allg. Chem. 2018, 14, 657-660. ${ }^{[2]}$

[3] J. Kretsch, I Koehne, Märt Lõkov, Ivo Leito, D. Stalke, "Bis(benzoxazol-2-yl)methanes Hounding NacNac: Varieties and Applications in Main Group Metal Coordination”, Eur. J. Inorg. Chem. 2019, 28, 3258-3264. ${ }^{[3]}$

[4] J. Kretsch, Anne Kreyenschmidt, Timo Schillmöller, R. Herbst-Irmer, Ivo Leito, D. Stalke, "Mixed Low-Valent Alanes from the Bis(4-methyl-benzoxazol-2-yl)methanide Ligand", Inorg. Chem. 2020, 59, 13690-13699.[4]

[5] J. Kretsch, Anne Kreyenschmidt, Timo Schillmöller, Märt Lõkov, R. Herbst-Irmer, D. Stalke, "Bis(4-benzhydryl-benzoxazol-2-yl)methane - from a Bulky NacNac Alternative to a Trianion in Alkali Metal Complexes", Chem. Eur. J. 2021, 27, 9858-9865. ${ }^{[5]}$

[6] J. Kretsch, A. Kreyenschmidt, T. Schillmöller, C. Sindlinger, R. Herbst-Irmer, D. Stalke, "Group 13 Heavier Carbene Analogs Stabilized by the Bulky Bis(4-benzhydryl-benzoxatol-2yl)methanide Ligand", Inorg. Chem. 2021, 60, 7389-7398. ${ }^{[6]}$ 


\subsection{Important Structural Features}

To simplify and unify the discussion of solid-state structures and NMR spectra reported within this thesis, a short overview on general ligand numbering (Figure 2-1) should be given in this chapter. The following numberings are applied for the carbon atoms of compounds comprising a bis(benzoazol-2-yl)methane scaffold.
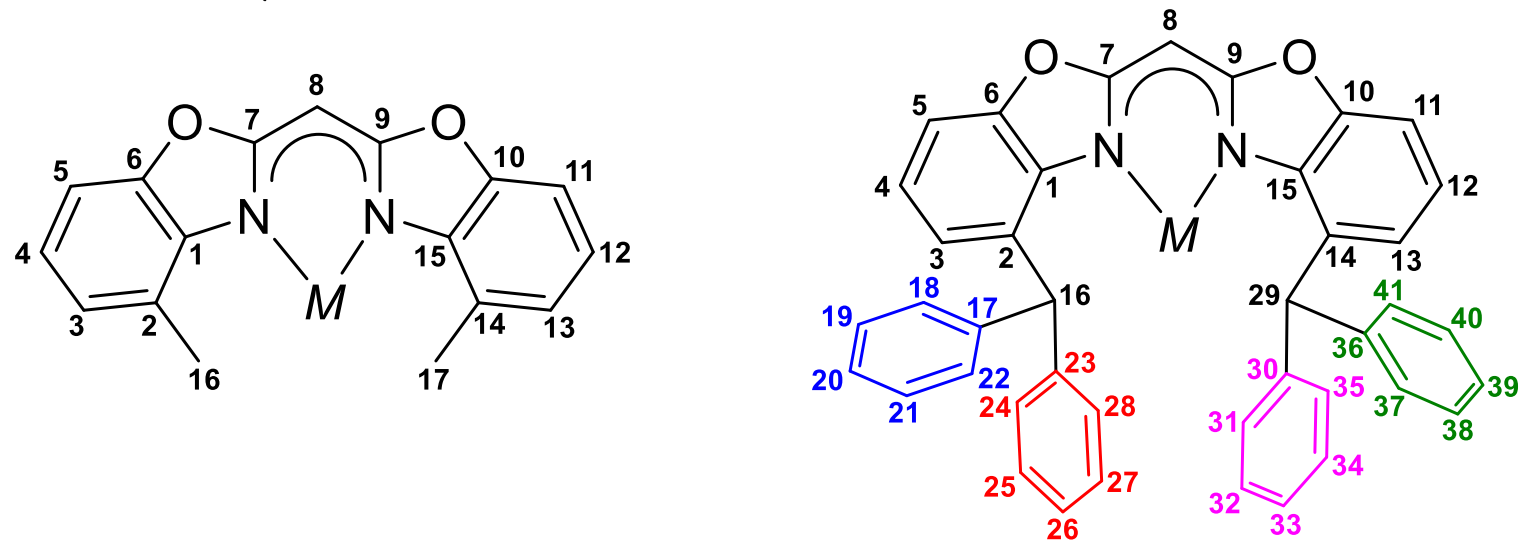

Figure 2-1. Numbering applied for complexes based on ${ }^{4-\mathrm{Me}} \mathrm{Box}_{2} \mathrm{CH}_{2}$ (left) and ${ }^{4-\mathrm{BzhH} 2} \mathrm{Box}_{2} \mathrm{CH}_{2}$ (right) in single $\mathrm{X}$-ray diffraction analyses and NMR spectroscopy.

The nitrogen and oxygen atom linked to arene moiety $\mathrm{C} 1$ to $\mathrm{C} 6$ is labelled $\mathrm{N} 1$ and $\mathrm{O} 1$ while $\mathrm{N} 2$ and $\mathrm{O} 2$ are located next to $\mathrm{C} 10$ to $\mathrm{C} 15$. For compounds of the unsubstituted $\mathrm{Box}_{2} \mathrm{CH}_{2}$ ligand, carbon atoms at position 16 and 17 and numberings can be ignored. Apart from the typical parameters such as bond length and angles two additional features are relevant for the discussion of bis(benzoxazol2-yl)methane based compounds. One of these features is the (butterfly) folding angle, which is spanned by two planes that are constructed by the benzoxazole units (Figure 2-2), respectively. Deprotonation of the methylene group ( $\mathrm{C} 8$ position) results in an extended aromatic ligand framework, which is accompanied by a nearly planar arrangement. This leads to an intersection of ca. $0^{\circ}$ between both heterocycles for an ideally planar conjugated $\pi$-system. Most bis(benzoxazol-2yl)methanide complexes display a $N, N^{*}$-coordination resulting in an increasing folding angle and, consequently, a disruption of the aromatic ligand scaffold.

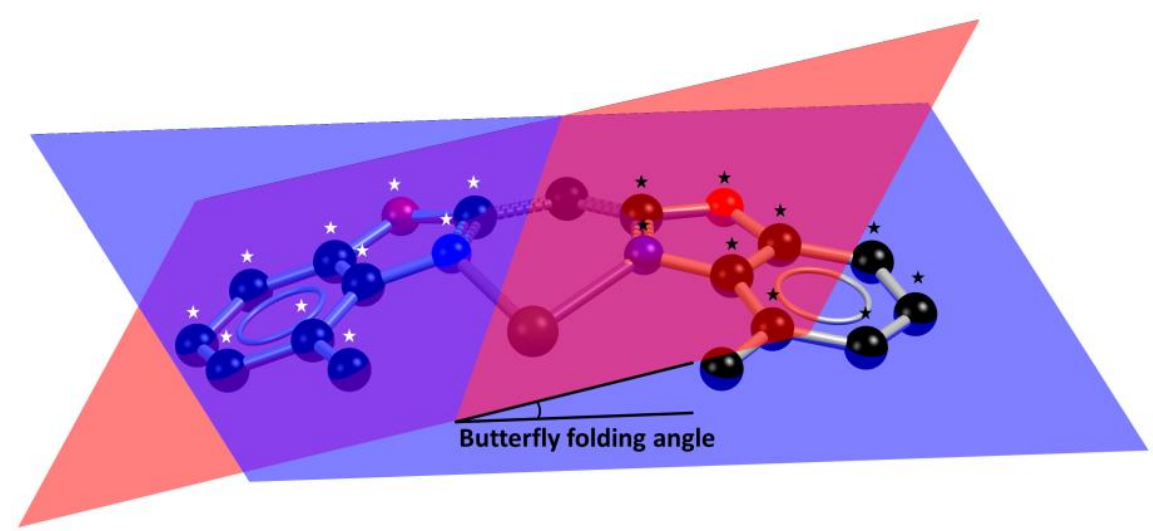

Figure 2-2. The butterfly folding angle of a monoanionic model complex is calculated between two planes that are constructed by atoms marked with white (red) or black stars (blue). 
The second feature is the individual dislocation of metal ion and NacNac-alike $\mathrm{C}_{3} \mathrm{~N}_{2}$ unit $\left(M_{13} \cdots \mathrm{C}_{3} \mathrm{~N}_{2}\right)$. To determine this parameter, a plane is fitted through atom N1, C7, C8, C9 and N2 (Figure 2-3), whereupon the displacement of respective metal fragment and the latter constructed plane is calculated. In general, complexes incorporating smaller ionic radii than potassium $(1.55 \AA$ for octahedral coordination ${ }^{[120]}$ and a $\kappa^{2}-N, N^{c}$-coordination leading to a faint dislocation. In contrast, the deviation of $\mathrm{C}_{3} \mathrm{~N}_{2}$ moiety and cations larger than $\mathrm{K}^{+}$seem to host a deviation $M_{13} \cdots \mathrm{C}_{3} \mathrm{~N}_{2}$ accompanied by coordination of the aromatic $\pi$-system.

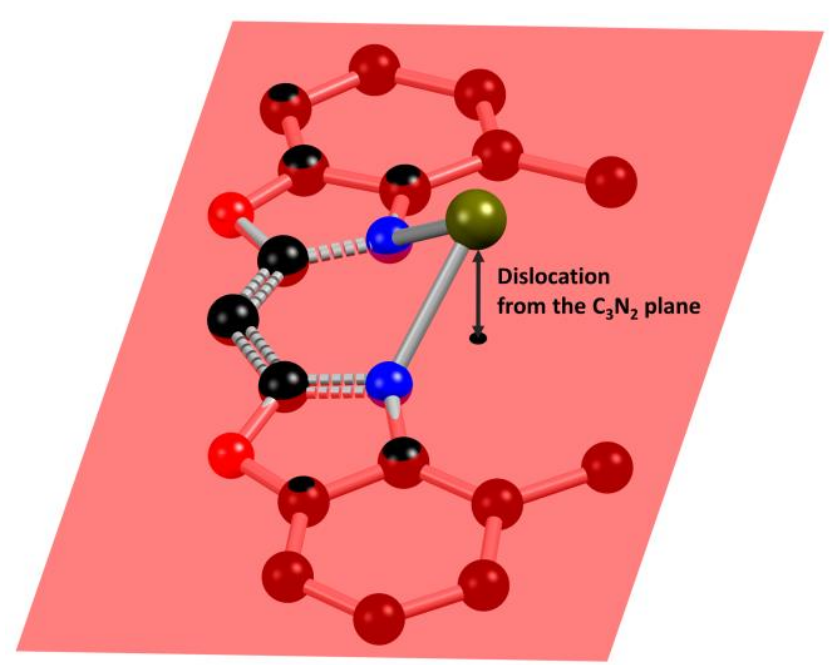

Figure 2-3. Calculation of the metal fragments dislocation in monoanionic bis(benzoxazol-2-yl)methanide complexes. 


\subsection{Complexes based on bis(benzoxazol-2-yl)methanide}

Major parts of this chapter have been published in:

[1] J. Kretsch, Anne Kreyenschmidt, R. Herbst-Irmer, D. Stalke, "Alkali metal complexes based on bisheterocyclomethanide ligands", Dalton Trans. 2018, 36, 12606-12612. ${ }^{[1]}$

[2] J. Kretsch, R. Herbst-Irmer, D. Stalke, "Aluminum(III) Halide Complexes based on a Bis(benzoxazol-2-yl)methane Ligand", Z. Anorg. Allg. Chem. 2018, 14, 657-660. ${ }^{[2]}$

\subsubsection{Synthesis of bis(benzoxazol-2-yl)methane $\left(\mathrm{Box}_{2} \mathrm{CH}_{2}\right)$}

Bis(benzoxazol-2-yl)methane $\left(\mathrm{Box}_{2} \mathrm{CH}_{2}\right)$ was prepared according to the procedures of Ammar ${ }^{[121]}$, Forlani $^{[103 c]}$ and Dauer ${ }^{[104]}$ (Scheme 2-1) to investigate group 13 metallacycles.

2<smiles>Nc1ccccc1O</smiles>

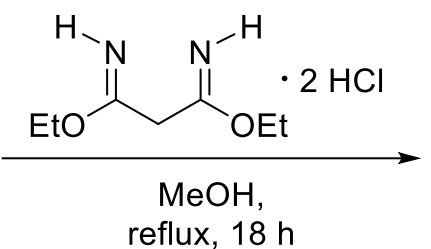
reflux, $18 \mathrm{~h}$

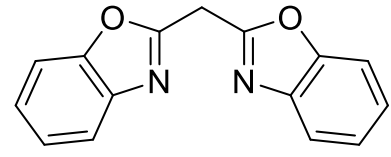

$47 \%$

Scheme 2-1. Synthesis of bis(benzoxazol-2-yl)methane $\left(\mathrm{Box}_{2} \mathrm{CH}_{2}\right)$.

Initially, malononitrile was activated by generating the derived ethylbisimidate dihydrochloride precursor. For that purpose, a solution of $\mathrm{HCl}$ dissolved in 1,4-dioxane was added to a dry solution of malononitrile and ethanol in dioxane at ambient temperature. ${ }^{[122]}$ After the reaction mixture had been stirred overnight, the activated linker was separated by filtration, washed with $\mathrm{Et}_{2} \mathrm{O}$ and dried under reduced pressure. The protonated dihydrochloride salt was subsequently reacted with 2 aminophenol in methanol via two-fold cyclocondensation reaction under the formation of ammonium chloride and ethanol to bis(benzoxazol-2-yl)methane in moderate yields (47\%). ${ }^{[104]}$

\subsubsection{Group 1 complexes of bis(benzoxazol-2-yl)methanide}

Lithium complexes such as $\left[\operatorname{Li}\left(\{\mathrm{NDipp}\}_{2} \mathrm{CMe}\right)\right]^{[53 \mathrm{a}]}$ or $\left[\mathrm{Li}\left({ }^{\mathrm{Dipp}} \mathrm{NacNac}\right)\right]^{[55]}$ were found to be versatile species for the synthesis of low-valent group 13 congeners. Therefore bis(benzoxazol-2-yl)methane was converted to $\left[\mathrm{Li}\left(\mathrm{Et}_{2} \mathrm{O}\right)_{2}\left(\mathrm{Box}_{2} \mathrm{CH}\right)\right](1)$ in $\mathrm{Et}_{2} \mathrm{O}$ by facile deprotonation with a ${ }^{n} \mathrm{BuLi}$ solution at $0^{\circ} \mathrm{C}$ (Scheme 2-2). After the complete addition of a ${ }^{n} \mathrm{BuLi}$ solution, the reaction solution was stirred for $2 \mathrm{~h}$ at ambient temperature. Volatiles were removed under reduced pressure and lithiated species 1 was isolated in high yields (90\%). 


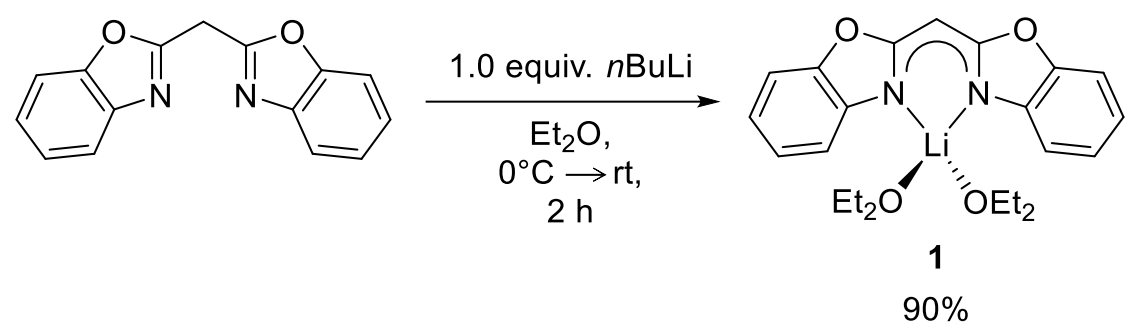

Scheme 2-2. Synthesis of $\left[\mathrm{Li}\left(\mathrm{Et}_{2} \mathrm{O}\right)_{2}\left(\mathrm{Box}_{2} \mathrm{CH}\right)\right](1)$ by deprotonation with ${ }^{\mathrm{n}} \mathrm{BuLi}$ solution in $\mathrm{Et}_{2} \mathrm{O}$. Reprinted with permission from reference ${ }^{[1]}$. Copyright 2018 , Royal Society of Chemistry.

Crystals of 1 suitable for single crystal XRD analysis were grown from a saturated $\mathrm{Et}_{2} \mathrm{O}$ solution at $2^{\circ} \mathrm{C}$. Compound 1 crystallises in the monoclinic space group $P 2_{1} / \mathrm{c}$ with one molecule in the asymmetric unit. The monomeric $\left[\mathrm{Li}\left(\mathrm{Et}_{2} \mathrm{O}\right)_{2}\left(\mathrm{Box}_{2} \mathrm{CH}\right)\right](1)$ comprises a lithium ion that is $\kappa^{2}-N, N^{\prime}-$ chelated by a monoanionic ligand and two $\mathrm{Et}_{2} \mathrm{O}$ molecules in a distorted tetrahedral fashion (Figure 2-4). Both imine nitrogen atoms coordinate the metal ion equidistantly (Li1-N1 1.995(2) $\AA$, Li1-N2 $2.004(2) \AA$ ). The bite angle N1-Li1-N2 of $94.1(1)^{\circ}$ is much more acute than the ideal tetrahedral angle whereas oxygen atoms of diethyl ether molecules and lithium ion form a wider O3-Li1-O4 angle of $102.96(10)^{\circ}$. This is accompanied by distances of Li1-O3 1.980(2) $\AA$ as well as Li1-O4 1.978(2) A, respectively.

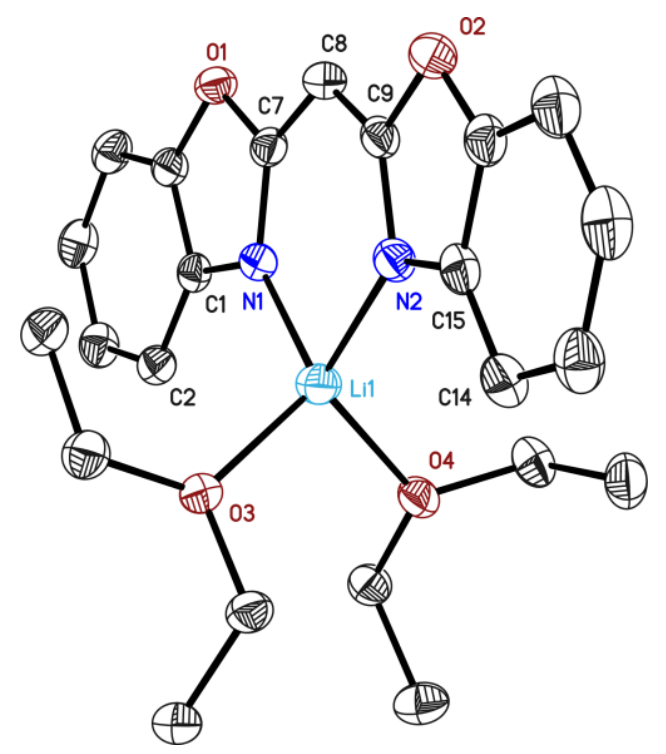

Figure 2-4. Molecular structure of $\left[\mathrm{Li}\left(\mathrm{Et}_{2} \mathrm{O}\right)_{2}\left(\mathrm{Box}_{2} \mathrm{CH}\right)\right]$ (1). Anisotropic displacement parameters are depicted at 50\% probability level. Hydrogen atoms are omitted for clarity. Structural data are reported in Table 2-1 and chapter 5.1.1. Reprinted with permission from reference ${ }^{[2]}$. Copyright 2018, Royal Society of Chemistry.

Furthermore, the NacNac-like $\mathrm{C}_{3} \mathrm{~N}_{2}$ unit in 1 (Table 2-1) exhibits bond length between $1.47 \AA$ $\left(\mathrm{C}\left(\mathrm{sp}^{3}\right)-\mathrm{N}\left(\mathrm{sp}^{3}\right)\right)$ and $1.29 \AA\left(\mathrm{C}\left(\mathrm{sp}^{2}\right)=\mathrm{N}\left(\mathrm{sp}^{2}\right)\right)$ as well as $1.54 \AA\left(\mathrm{C}\left(\mathrm{sp}^{3}\right)-\mathrm{C}\left(\mathrm{sp}^{3}\right)\right)$ and $1.34 \AA$ $\left(\mathrm{C}\left(\mathrm{sp}^{2}\right)=\mathrm{C}\left(\mathrm{sp}^{2}\right)\right)$, indicating a fully conjugated system extended throughout the virtually planar ligand. ${ }^{[123]} \mathrm{A}$ butterfly folding angle (vide supra chapter 2.1) of $8.04(5)^{\circ}$ between both benzoxazole moieties portends a bent ligand. Moreover, the hard lithium ion is almost ideally placed within the central chelating $\mathrm{C}_{3} \mathrm{~N}_{2}$ plane $(0.050(3) \AA)$. This in-plane arrangement is likewise observed in 
monomeric $\left[\mathrm{Li}(\mathrm{THF})_{2}\left\{{ }^{4,6-\mathrm{P} r} \mathrm{Box}_{2} \mathrm{CH}\right)\right]\left(\mathrm{Li} \cdots \mathrm{C}_{3} \mathrm{~N}_{2}: 0.00(3) \text { to } 0.07(5) \AA\right)^{[108 b]}$ The ${ }^{7} \mathrm{Li} \mathrm{NMR}$ spectrum shows a signal at $2.19 \mathrm{ppm}\left(\left[\mathrm{D}_{8}\right] \mathrm{THF}\right)$ which indicates the formation of a single lithium species in solution. In contrast to the uncharged ligand a deshielding and simultaneous downfield shift from the methane $\delta\left(-\mathrm{H}_{2} \mathrm{C}-\right)=4.70 \mathrm{ppm}$ to the methanide bridge $\delta(-H \mathrm{C}-)=4.80 \mathrm{ppm}$ occurs in the ${ }^{1} \mathrm{H}$ NMR spectrum of 1 ([ $\left.\left.\mathrm{D}_{8}\right] \mathrm{THF}\right)$. In addition, the aromatic protons experience an up-field shift. This most likely correlates with an increased electron density at these atoms due to charge delocalization from the $\mathrm{C}_{3} \mathrm{~N}_{2}$ bridge towards the aryl systems in the ligand periphery and indicates mainly $\sigma$ bonding of the electron-rich imine atoms to the lithium cation. ${ }^{[24]}$

Table 2-1. Selected bond lengths $[\AA]$ and angles $\left[{ }^{\circ}\right]$ for complexes 1-3 with the related site occupation factors (sofs.)

\begin{tabular}{|c|c|c|c|}
\hline$\left[\mathrm{M}\left(\mathrm{Box}_{2} \mathrm{CH}\right)\right]$ & $M=\mathrm{Li}\left(\mathrm{Et}_{2} \mathrm{O}\right)_{2}(1)$ & $M=\mathrm{K}(\mathrm{THF})(2)$ & $M=\mathrm{K}(18$-crown-6) \\
\hline $\mathrm{M}-\mathrm{N}$ & $1.995(2), 2.004(2)$ & $2.762(2), 2.754(2)$ & $\begin{array}{l}\text { 3.37(9) (sof. 0.39(3)), } \\
2.87(3)(\text { sof. } 0.82(3))\end{array}$ \\
\hline $\mathrm{M}-\mathrm{O}$ & - & - & $\begin{array}{l}\text { 3.42(5) (sof. 0.61(3)) } \\
2.97(12)(\text { sof. } 0.18(3))\end{array}$ \\
\hline $\mathrm{C} 7-\mathrm{C} 8$ & $1.394(2)$ & $1.403(3)$ & $1.384(4)$ \\
\hline C8-C9 & $1.390(2)$ & $1.403(3)$ & $1.398(3)$ \\
\hline C7-N1 & $1.330(2)$ & $1.318(2)$ & $\begin{array}{l}\text { 1.34(2) (sof. 0.61(3)), } \\
1.33(2) \text { (sof. } 0.39(3) \text { ) }\end{array}$ \\
\hline C9-N2 & $1.333(2)$ & $1.324(2)$ & $\begin{array}{l}1.320(9) \text { (sof. 0.82(3)) } \\
1.35(3) \text { (sof. } 0.18(3) \text { ) }\end{array}$ \\
\hline $\mathbf{N}-\mathbf{M}-\mathbf{N}$ & $94.1(1)$ & $68.35(5)$ & $56(2)$ \\
\hline $\mathrm{M} \cdots \mathrm{C}_{3} \mathrm{~N}_{2}$ plane & $0.050(3)$ & $0.784(3)$ & - \\
\hline Folding angle & $8.04(5)$ & $7.25(7)$ & $18.0(8)$ \\
\hline
\end{tabular}

The syntheses of closely related $\left[\mathrm{K}(\mathrm{THF})\left(\mathrm{Box}_{2} \mathrm{CH}\right)\right]_{n}$ (2) and $\left[\mathrm{K}\left(18 \text {-crown-6) }\left(\mathrm{Box}_{2} \mathrm{CH}\right)\right]_{n}\right.$ (3) $(n \rightarrow \infty)$ was accomplished by the reaction of bis-(benzoxazol-2-yl)methane and potassium hydride (Scheme 2-3). The deprotonation at the acidic linker unit accompanied by the release of hydrogen was already observed at $-30^{\circ} \mathrm{C}$, immediately after the addition of $\mathrm{KH}$. The synthesis of compound 2 was conducted in THF, whereas 3 was synthesised in toluene. Both reactions were allowed to warm to ambient temperature and stirred for about one more day. Subsequently, the reaction mixture was filtered and all volatiles were evaporated. Both complexes could be obtained as an off-white powder in good yields (YLD(2): 97\%, YLD(3): 82\%). 


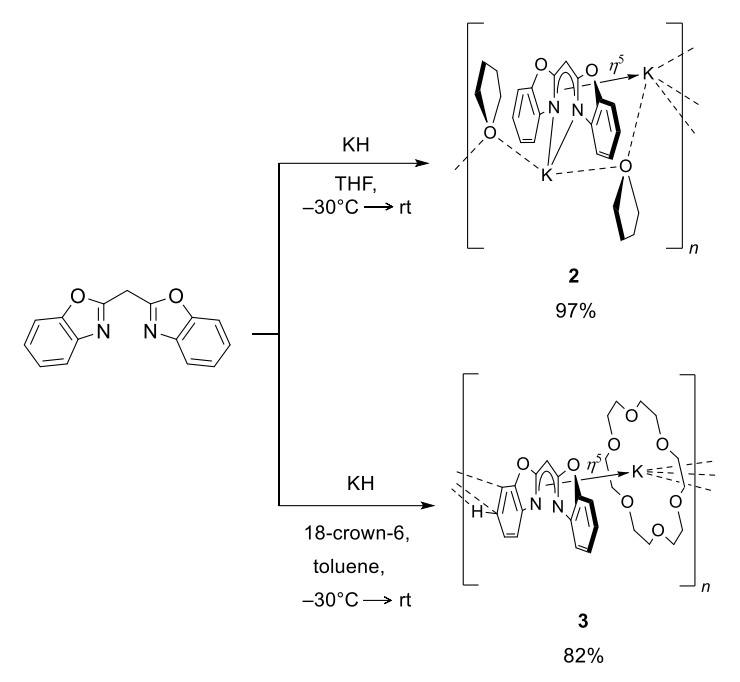

Scheme 2-3. Syntheses of $\left[\mathrm{K}(\mathrm{THF})\left(\mathrm{Box}_{2} \mathrm{CH}\right)\right]_{n}(2)$ and $\left[\mathrm{K}(18-\operatorname{crown}-6)\left(\mathrm{Box}_{2} \mathrm{CH}\right)\right]_{n}(3) \quad(n \rightarrow \infty)$ by deprotonation with $\mathrm{KH}$. Both potassium complexes form 1D coordination polymers in solid-state. Adapted with permission from reference ${ }^{[2]}$. Copyright 2018, Royal Society of Chemistry.

Crystals suitable for single crystal XRD experiments were grown from a concentrated solution of THF (2) and toluene (3), respectively. The tetrahydrofuran complex 2 crystallised in form of yellowish needles in the orthorhombic space group $P n a 2_{1}$ with one molecule in the asymmetric unit. $\left[\mathrm{K}(\mathrm{THF})\left(\mathrm{Box}_{2} \mathrm{CH}\right)\right]_{n}$ (2) forms polymeric zig-zag strands with the potassium ion $N, N^{\prime}$-chelated almost in plane of one ligand and $\eta^{5}$-coordinated to a second structural unit (Figure 2-5). Additionally, the coordination sphere of the potassium cation is saturated by a bridging THF molecule.

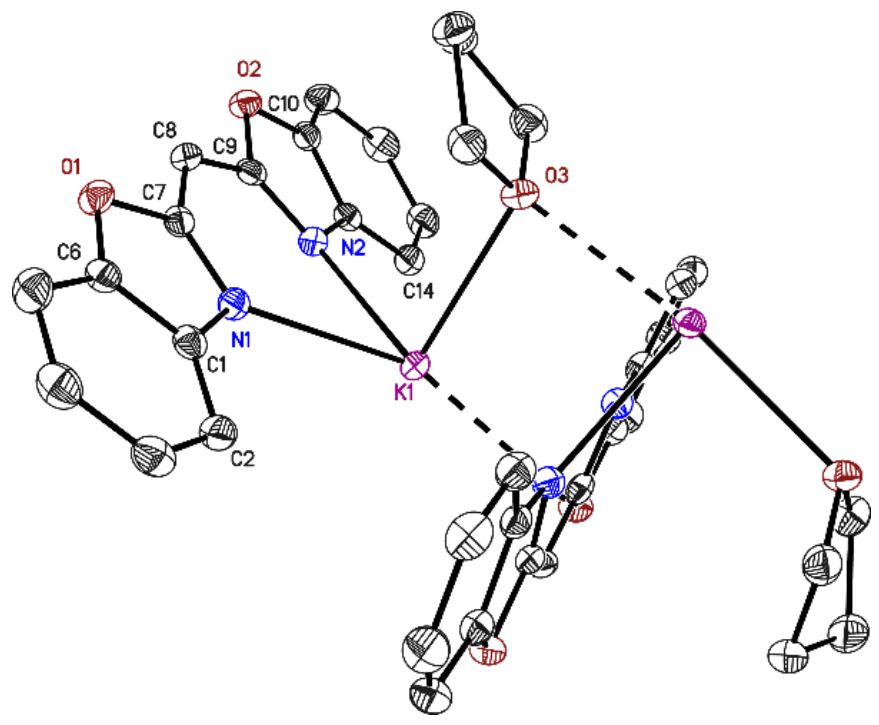

Figure 2-5. Polymeric structure of $\left[\mathrm{K}(\mathrm{THF})\left(\mathrm{Box}_{2} \mathrm{CH}\right)\right]_{n}(2)(n \rightarrow \infty)$. Anisotropic displacement parameters are depicted at 50\% probability level. Hydrogen atoms are omitted for clarity. Structural data are reported in Table 2-1 and chapter 5.1.1. Reprinted with permission from reference ${ }^{[2]}$. Copyright 2018, Royal Society of Chemistry.

This variation in the aggregation and complexation of 1 and 2 can be explained, apart from the different solvents, by the differences in ionic radii $(\mathrm{Li}(\mathrm{C} . \mathrm{N} .=4) 0.59 \AA, \mathrm{K}(\mathrm{C} . \mathrm{N} .=8) 1.51 \AA)^{[120]}$. The "softer" character of the potassium leading to multiple interactions with $\pi$-systems has been reported 
in various publications e.g. $\left[\mathrm{K}_{2}(\mathrm{THF})_{3}\left(\mathrm{C}_{8} \mathrm{H}_{8}\right)\right]^{[125]}$, $\left[\mathrm{K}_{2}(\mathrm{THF})\left(\mathrm{C}_{10} \mathrm{H}_{8}\right)_{2}\right]^{[126]}$ or $\left[\mathrm{K}(\mathrm{THF})_{3}(\mathrm{BPID})\right]^{[127]}$ (BPID = $(1 R, 2 R)-N, N$ '-bis (2-pyridylmethylene) cyclohexane-1,2-diamine). Due to the formation of a conjugated $\pi$-system along with the rehybridisation of the carbon atoms at the methylene bridge from $\mathrm{sp}^{3}$ to $\mathrm{sp}^{2}$ a decrease in C-C bond lengths from 1.489(2) $\AA$ to 1.403(3) $\AA$ in C8-C9 and C7-C8 is observed. ${ }^{[104]}$ However, the distances between N1-C7 1.318(2) $\AA$ as well as N2-C9 1.324(2) $\AA$ are elongate in comparison to the neutral $\mathrm{Box}_{2} \mathrm{CH}$ ligand $(1.286(2) \AA)^{[104]}$. To facilitate the $\eta^{5}$ coordination to a second ligand the cation experiences a strong deviation of 0.784(3) $\AA$ from the $\mathrm{C}_{3} \mathrm{~N}_{2}$-plane, similar structural features were found for corresponding potassium ion in $\left[\mathrm{K}(\mathrm{THF})\left({ }^{4-\mathrm{Me}} \mathrm{Box}_{2} \mathrm{CH}\right)\right]_{n}(1.33 \AA) .{ }^{[128]}$ Moreover, structural parameters like $\mathrm{K}-\mathrm{N}$ distances (2.754(2)2.762(2) $\AA$ ), N-K-N bite angle $\left(68.34(5)^{\circ}\right)$ and the butterfly folding angle $\left(7.25(7)^{\circ}\right)$ between both benzoxazolyl moieties are nearly identical to $\left[\mathrm{K}(\mathrm{THF})\left({ }^{4-\mathrm{Me}} \mathrm{Box}_{2} \mathrm{CH}\right)\right]_{n}{ }^{[128]}$

The related $[\mathrm{K}(18 \text {-crown-6)(Box } 2 \mathrm{CH})]_{n}$ (3) was crystallised in form of pale yellow needles in the orthorhombic space group $P c a 2_{1}$ with one molecule in the asymmetric unit. In contrast to complex 2 , which comprises a solvent shared ion pair, the solid-state structure of 3 reveals the formation of a molecular contact ion pair (Figure 2-6).

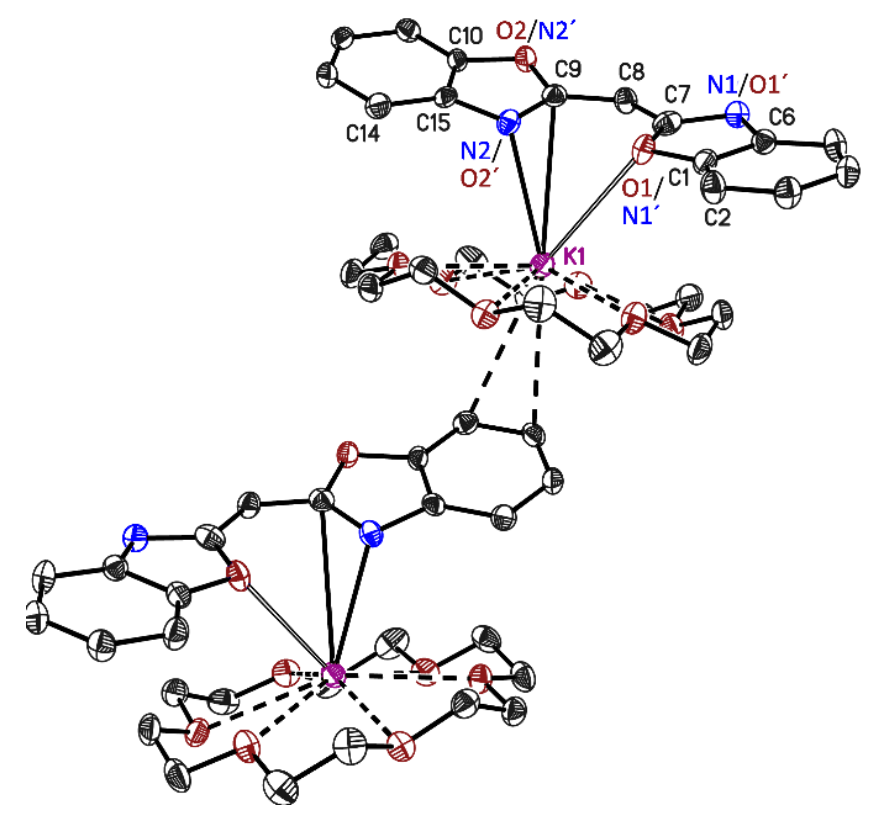

Figure 2-6. Polymeric structure of $[\mathrm{K}(18 \text {-crown-6)(Box } 2 \mathrm{CH})]_{n}$ (3) $(n \rightarrow \infty)$. Anisotropic displacement parameters are depicted at $50 \%$ probability level. Hydrogen atoms are omitted for clarity. Structural data are reported in Table 2-1 and chapter 5.1.1. Reprinted with permission from reference ${ }^{[2]}$. Copyright 2018, Royal Society of Chemistry.

Potassium features a high binding affinity to 18 -crown-6, which results in the formation of a hostguest system. ${ }^{[129]}$ In addition, a slipped $\eta^{5}-\mathrm{C}_{3} \mathrm{~N}_{2}$-coordination of the anionic ligand is formed to one side of the embraced metal, while the other is $\eta^{2}$-coordination to an aryl moiety of an adjacent ligand. This ligand is again $\eta^{5}-\mathrm{C}_{3} \mathrm{~N}_{2}$-coordinated to another cation leading to a metallopolymer. Both of the $\mathrm{N} / \mathrm{O}$ positions are disordered. In the $\mathrm{N} 2 / \mathrm{O} 2$ '-C9 residue, which is closer to the potassium ion (K1N2 2.87(2) $\AA, \mathrm{K} 1-\mathrm{O} 2{ }^{\prime} 2.97(12) \AA$ ), the nitrogen has a much higher occupancy of 82(3)\% relative to the oxygen (sof. 18(3)\%). In the more distant N1'/O1-C7 moiety (K1-N1' 3.37(9) $\AA$, K1-O1 
3.42(5) $\AA$ ) on the other hand the oxygen occupies $61(3) \%$ of the site. In compound 3, the potassium is in demand of the much better nitrogen donor compared to the similar $\left[\mathrm{K}\left(\mathrm{H}_{2} \mathrm{O}\right)(18\right.$ crown-6) $\left.\left(^{4,6-\mathrm{Bu} u} \mathrm{Box}_{2} \mathrm{CH}\right)\right]^{[112]}$ in which the metal is exclusively oxygen coordinated. In the latter compound, an additional THF molecule provides electron density to the metal, which is much more beneficial than a $\eta^{2}$-coordination to the adjacent aryl unit in 3 . Additionally, the rotation around the C7-C8 or C8-C9 bonds in unsubstituted $\left[\mathrm{K}\left(18 \text {-crown-6) }\left(\mathrm{Box}_{2} \mathrm{CH}\right)\right]_{n}\right.$ (3) seems to be facilitated, probably because of the missing residue in $4^{\text {th }}$-position $(\mathrm{C} 2, \mathrm{C} 14)$ of the benzoxazolyl groups. The distances between the potassium cation and the oxygen atoms of 18-crown-6 (2.751(2) to 2.995(2) $\AA$ ) are in good agreement with the average values of related complexes. ${ }^{[130]}$ Furthermore, the successful syntheses of alkali metal complexes 1 to 3 were confirmed by mass spectrometry, elemental analysis, and NMR spectroscopy.

The ${ }^{1} \mathrm{H}-\mathrm{NMR}$ spectra ([ $\left.\left.\mathrm{D}_{8}\right] \mathrm{THF}\right)$ of potassium complex 2 and 3 display a set of signals in the aromatic region from 7.06 to $6.57 \mathrm{ppm}$ that can be assigned to $2-\mathrm{H}$ and $5-\mathrm{H}$ as well as to $11-\mathrm{H}$ and $14-\mathrm{H}$. These signals are shifted up-field in comparison to 7.69-7.27 ppm of the aromatic protons of the neutral $\mathrm{Box}_{2} \mathrm{CH}_{2}$ ligand. Especially, 2- $\mathrm{H}$ and $14-\mathrm{H}$ experience a significant deshielding, which leads to a down-field shift of 7.03-7.01 ppm (2) or 7.06-7.03 ppm (3), respectively. Moreover, the ${ }^{1} \mathrm{H}$ NMR spectra of both potassium species reveal a slightly shielding and up-field shift of the methanide bridge $\Delta \delta=0.06 \mathrm{ppm}\left(\delta(-\mathrm{HC}-)=4.64 \mathrm{ppm}, \delta\left(-\mathrm{H}_{2} \mathrm{C}-\right)=4.70 \mathrm{ppm}\right)$ compared to the free methane derivative. Multiplets that can be assigned to the THF molecule of $\left[\mathrm{K}(\mathrm{THF})\left(\mathrm{Box}_{2} \mathrm{CH}\right)\right]_{n}(2)$ were found at $4.64 \mathrm{ppm}\left(\mathrm{O}-\mathrm{CH}_{2}\right)$ and $1.77 \mathrm{ppm}\left(-\mathrm{CH}_{2}\right)$. In contrast, the methylene groups of 18-crown-6 in $[\mathrm{K}(18 \text {-crown-6)(Box } \mathrm{CH})]_{n}$ (3) were observed at $3.46 \mathrm{ppm}$ according to the chemical shift of comparable compounds. ${ }^{[130 c]}$ Fuelled by the unexpected stability of $\left[\mathrm{K}\left(\mathrm{H}_{2} \mathrm{O}\right)(18\right.$-crown6) $\left.{ }^{4,6-\mathrm{B} B \mathrm{Box}} \mathrm{BoH}_{2} \mathrm{CH}\right]^{[112]}$ towards hydrolysis, we embarked on ${ }^{1} \mathrm{H}-\mathrm{NMR}$ water titration experiments for compounds 2 (Figure 2-7) and 3 (Figure 2-8). For this purpose, well-defined amounts of water $(0.2$ to $0.8 \mu \mathrm{L} ; 0.18$ to 7.21 equiv.) were added to an NMR sample and the effect of successively increasing water content on the complex solution was monitored by ${ }^{1} \mathrm{H}-\mathrm{NMR}$ spectroscopy. Interestingly, the equilibrium of $\left[\mathrm{K}\left(18 \text {-crown-6)( } \mathrm{Box}_{2} \mathrm{CH}\right)\right]_{n}$ (3) and even $\left[\mathrm{K}(\mathrm{THF})\left(\mathrm{Box}_{2} \mathrm{CH}\right)\right]_{n}$ (2) is almost completely on the side of the deprotonated ligand and $\mathrm{H}_{2} \mathrm{O}$ (Scheme 2-4).

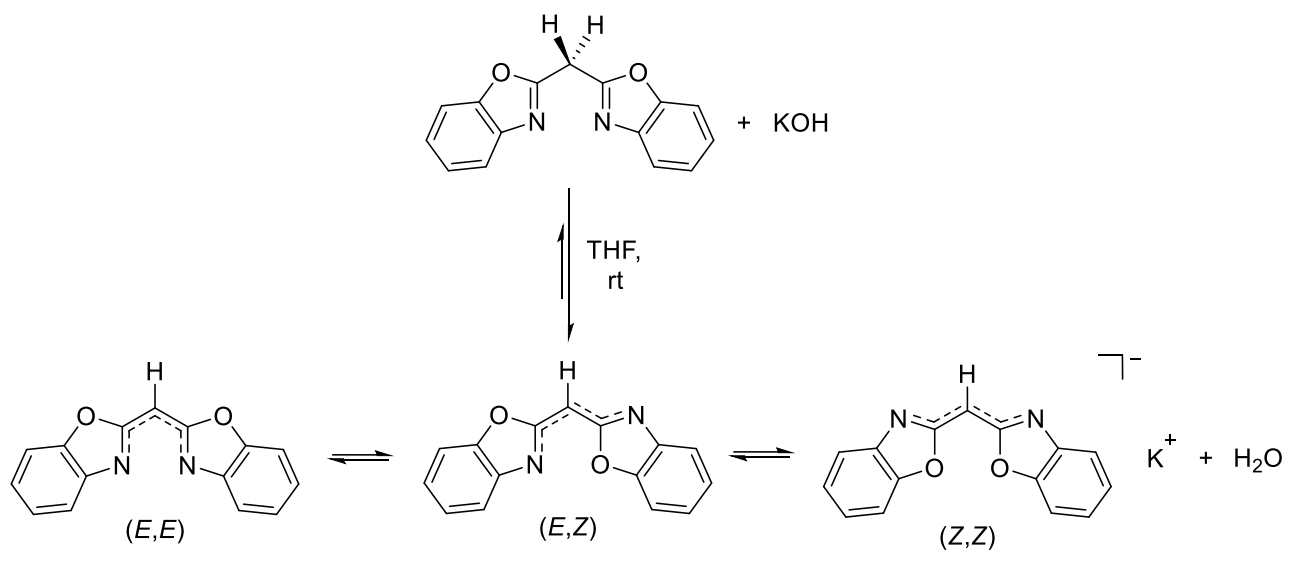

Scheme 2-4. Diastereomers assumed for the protolytic equilibrium of $\mathrm{Box}_{2} \mathrm{CH}_{2}$ and monoanionic $\left(\mathrm{Box}_{2} \mathrm{CH}\right)$ in presence of $\mathrm{KOH}$. 
In this case, the umbrella effect against hydrolysis recently described by Gimbert et al. for complexing a lithium amide of 3-aminopyrrolidine with lithium halides ( $\mathrm{LiCl}, \mathrm{LiBr}$ ) or MeLi cannot be operational. ${ }^{[131]}$ In Figure 2-7 and Figure 2-8 it is shown that even the addition of a vast excess of water marginally affects the chemical shifts as well as the signal line shape of both complexes. In the overlaid spectra of 2 the water signal is first detected at $2.99 \mathrm{ppm}(0.2 \mu \mathrm{L}, 0.18$ equiv. $)$, weakly shifting to $2.86 \mathrm{ppm}$ (2.0-2.4 $\mu \mathrm{L}, 1.80-2.16$ equiv.) and finally observed at $2.95 \mathrm{ppm}(8.0 \mu \mathrm{L}, 7.21$ equiv.). Moreover, a slightly deshielding and shift of $2-\mathrm{H}$ and $14-\mathrm{H}$ towards downfield of $\Delta \delta=0.06 \mathrm{ppm}$ can be observed.

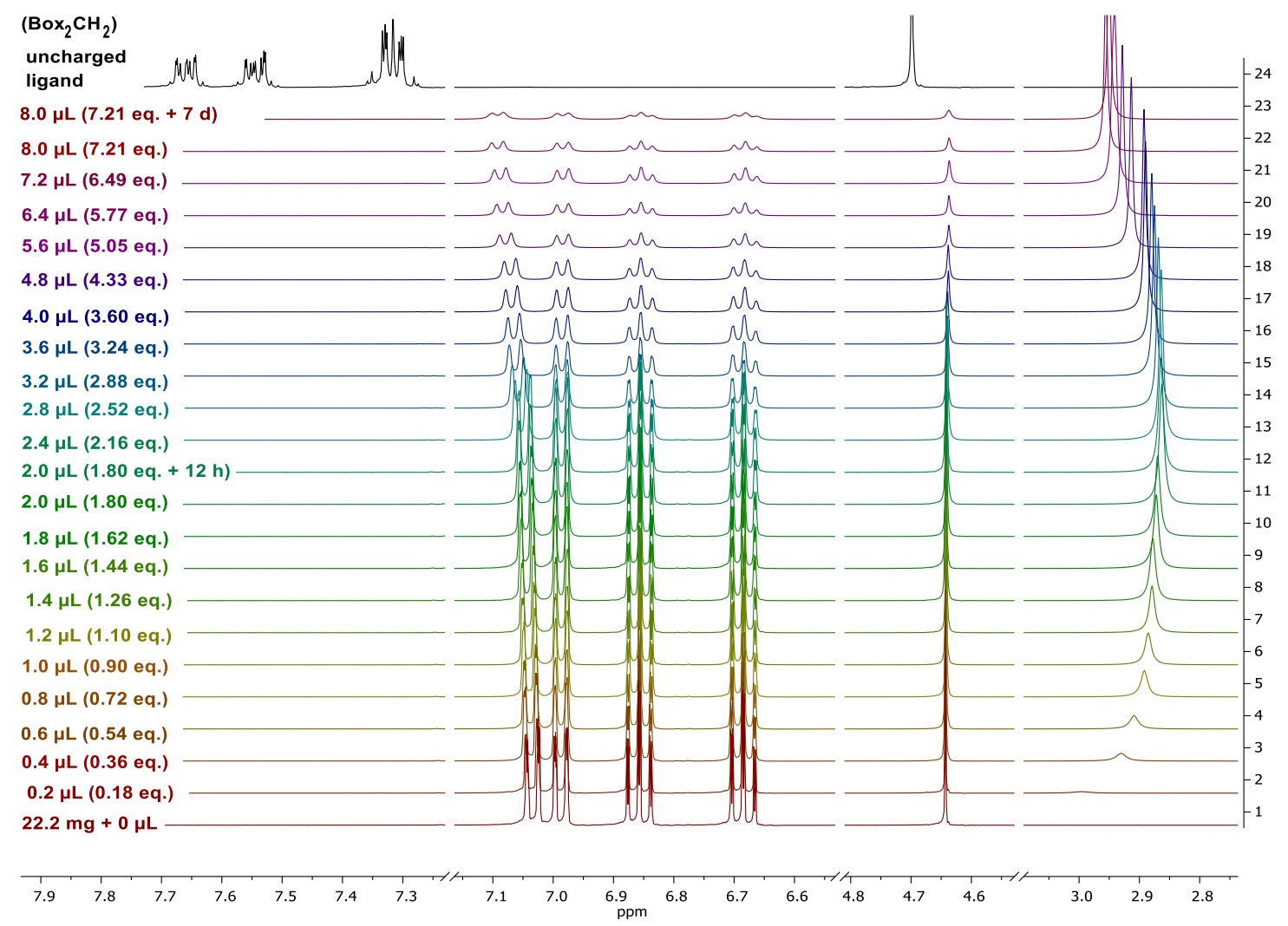

Figure 2-7. Stacked ${ }^{1} \mathrm{H}$ NMR spectra of a titration experiment of $\left[\mathrm{K}(\mathrm{THF})\left(\mathrm{Box}_{2} \mathrm{CH}\right)\right]_{n}(2)$ and water in $\left[\mathrm{D}_{8}\right]$ THF. The ${ }^{1} \mathrm{H}$ NMR spectrum of neutral $\mathrm{Box}_{2} \mathrm{CH}_{2}$ (black) is shown as a reference. 


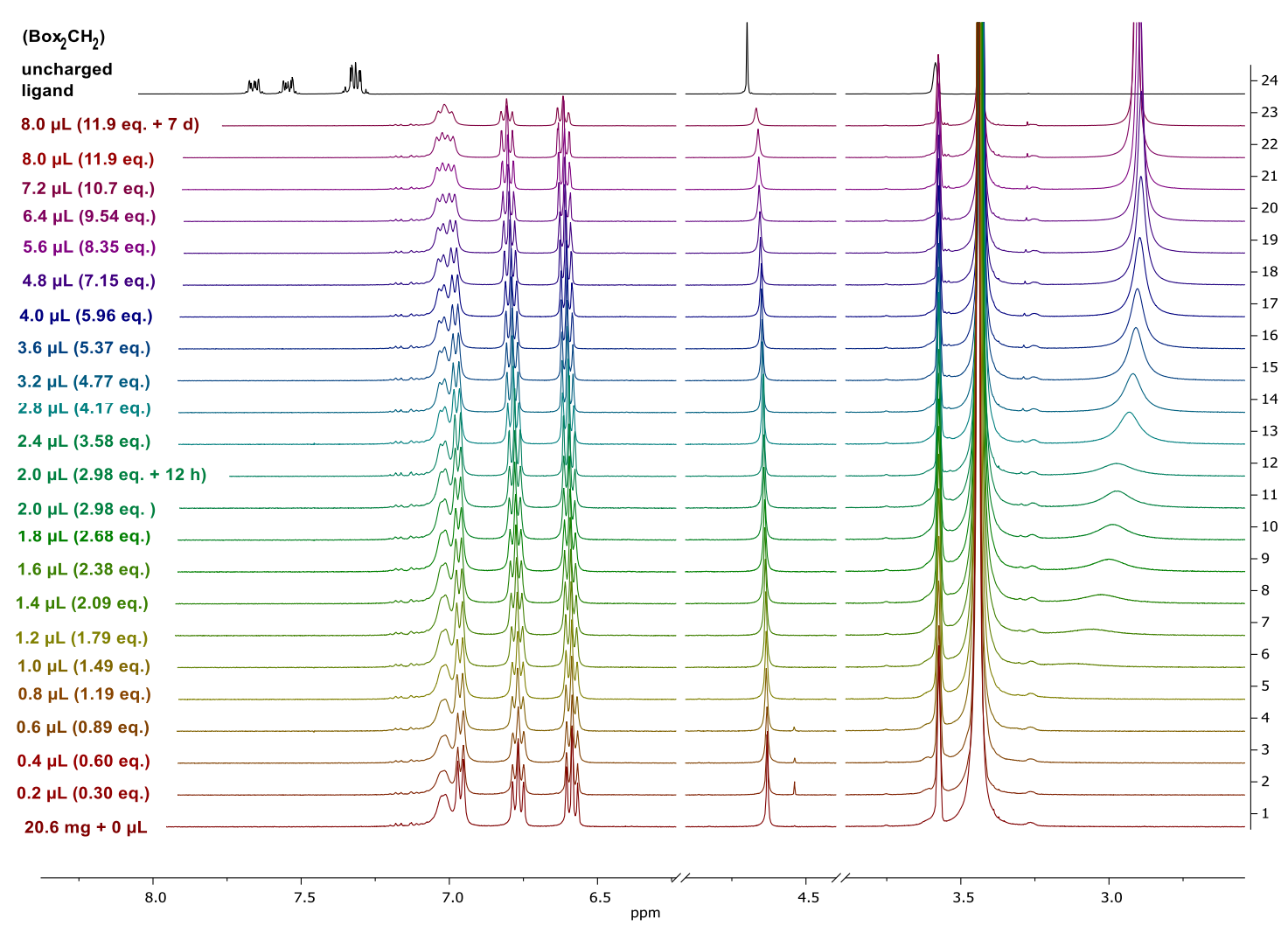

Figure 2-8. Stacked ${ }^{1} \mathrm{H}$ NMR spectra of a titration experiment of $\left[\mathrm{K}\left(18 \text {-crown-6)(Box }{ }_{2} \mathrm{CH}\right)\right]_{n}(3)$ and water in $\left[\mathrm{D}_{8}\right]$ THF. The ${ }^{1} \mathrm{H}$ NMR spectrum of neutral $\mathrm{Box}_{2} \mathrm{CH}_{2}$ (black) is shown as a reference.

Due to a broadening of the signals detected during the titration experiments an exchange of water and both potassium species seems to appear. This was later verified by ${ }^{1} \mathrm{H}-\mathrm{NMR}$ experiment of complex 2 and $\mathrm{D}_{2} \mathrm{O}$ in THF at ambient temperature. Here the $\mathrm{H} / \mathrm{D}$ exchange could be observed by a significant intensity decrease of the methanide linker proton at $4.64 \mathrm{ppm}$. The UV/vis spectrophotometric titration experiments in acetonitrile ${ }^{[114]}$, that were carried out by Märt Lõkov in Ivo Leito's group, revealed a $\mathrm{p} K_{\mathrm{a}}$ value of $26.89(3)^{[3,113]}$ for bis(benzoxazol-2-yl)methane in acetonitrile. The conversion of the $\mathrm{p} K_{\mathrm{a}}$ value from $\mathrm{MeCN}$ to THF by correlation equation resulted in a somewhat lower value of $21 \pm 1 .{ }^{[118,132]}$ An explanation of the hydrolysis stability of species 2 and 3 as well as the reaction of $\left(\mathrm{Box}_{2} \mathrm{CH}_{2}\right)$ and potassium hydroxide to complex 2 (THF), is most likely due to the presence of potassium cations. ${ }^{[133]}$ The formation of ion pairs (contact and solvent-shared ion pairs) or larger aggregates can be assumed in lower polarity solvents as THF or DME. Thereby an ion pair acidity/basicity is observed that deviates from the $\mathrm{p} K_{\mathrm{a}}$ value of $\left(\mathrm{Box}_{2} \mathrm{CH}_{2}\right)$ determined by titration with organic bases 9- $\mathrm{C}_{6} \mathrm{~F}_{5}$-fluorene, (4-Me- $\left.\mathrm{C}_{6} \mathrm{~F}_{4}\right)\left(\mathrm{C}_{6} \mathrm{H}_{5}\right) \mathrm{CHCN}$ and $\left(\mathrm{C}_{6} \mathrm{~F}_{5}\right)\left(\mathrm{C}_{6} \mathrm{H}_{5}\right) \mathrm{CHCN}{ }^{[118]}$ In comparable studies of Olmstead and Bordwell on 1,3-dicarbonyl (acac) compounds, it could be shown, that apart from the cation type, $\mathrm{p} K_{\mathrm{a}}$ and correlating ion-pair association constant ( $\left.\log K_{\mathrm{as}}\right)$ are directly coupled to multiple parameters as the structural or conformational properties of a ligand. ${ }^{[134]}$ With the focus on group 13 complexes, parameters impacting the protolytic equilibrium of complex 2 or 3 have not been further examined. In the following chapter the synthesis and characterisation of aluminium halide complexes starting from $\left[\mathrm{Li}\left(\mathrm{Et}_{2} \mathrm{O}\right)_{2}\left(\mathrm{Box}_{2} \mathrm{CH}\right)\right]$ (1) shall be discussed. 


\subsubsection{Group 13: Alumnium bis(benzoxazol-2-yl)methanide complexes}

Numerous studies have demonstrated that aluminium halide complexes are straightforwardly accessible via salt metathesis of a lithium precursor complex and a corresponding aluminium halide. ${ }^{[135]}$ Thus, lithiated complex (1) and aluminium trichloride or -iodide were reacted in toluene at $0^{\circ} \mathrm{C}$ (Scheme 2-5). After the reaction mixture was allowed to warm to ambient temperature, it was stirred for $\sim 2 \mathrm{~d}$. Volatiles were then removed under reduced pressure and the residue was extracted with toluene. Again, solvents were removed in vacuo and colourless solids of $\left[\mathrm{AlX}_{2}\left(\mathrm{Box}_{2} \mathrm{CH}\right)\right](X=$ $\mathrm{Cl}$ (4), I (5)) were isolated in poor yields. This is probably due to the low-solubility of the dihalido aluminium complexes in alkanes, toluene or diethyl ether, that were also tested as extractants. The extraction of crude $\mathbf{4}$ and $\mathbf{5}$ with THF, which should be eschewed with regard to eventual reduction attempts, resulted in partial coextraction and consequently impurities of lithium halide.

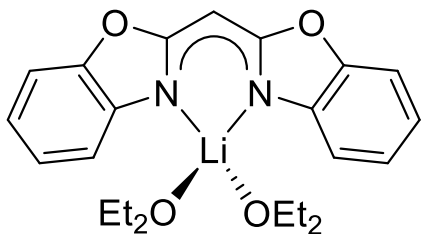

1

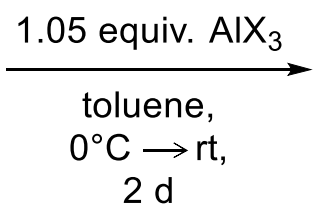

$2 \mathrm{~d}$

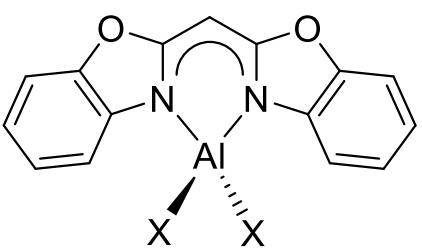

4: $\mathrm{X}=\mathrm{Cl}$, YLD: $17 \%$; 5: $\mathrm{X}=$ I, YLD: $9 \%$.

Scheme 2-5. Synthesis of aluminium halide complex $\left[\mathrm{AlCl}_{2}\left(\mathrm{Box}_{2} \mathrm{CH}\right)\right](4)$ and $\left[\mathrm{AlI}_{2}\left(\mathrm{Box}_{2} \mathrm{CH}\right)\right](5)$.

Crystals suitable for single crystal XRD analysis were obtained out of saturated solutions of 4 and 5 in toluene at $-20^{\circ} \mathrm{C}$ after a few days. Compound 4 crystallises in a monoclinic crystal system with the space group $P 2_{1} / \mathrm{n}$. The mononuclear species consists of an $\mathrm{Al}^{\mathrm{III}}$-cation which is coordinated by the monoanionic ligand and two chloride ions in a distorted tetrahedral fashion (Figure 2-9).
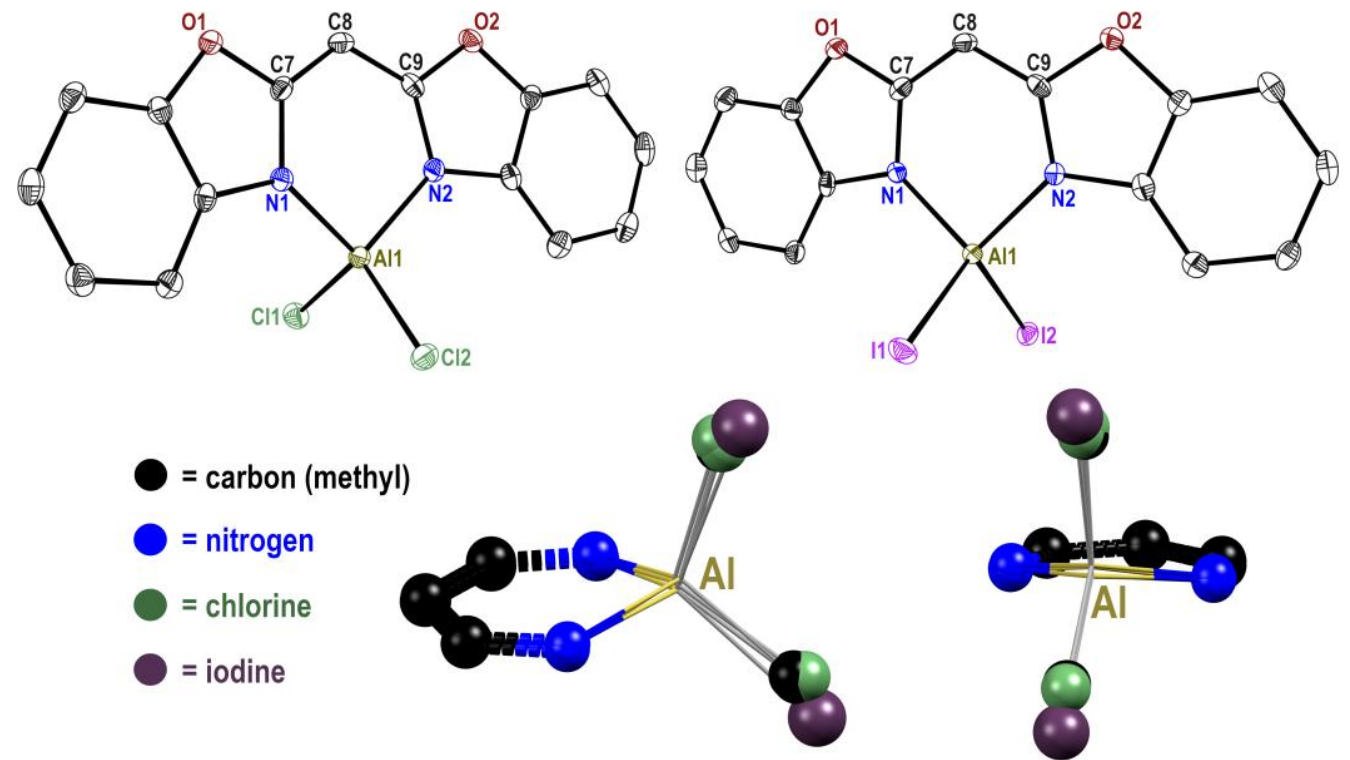

Figure 2-9. Molecular structure of $\left[\mathrm{AlCl}_{2}\left(\mathrm{Box}_{2} \mathrm{CH}\right)\right]\left(4\right.$, top left) and $\left[\mathrm{AlI}_{2}\left(\mathrm{Box}_{2} \mathrm{CH}\right)\right]$ (5, top right). Anisotropic displacement parameters are depicted at 50\% probability level. Hydrogen atoms are omitted for clarity. Two perspectives (bottom) of superimposed $\mathrm{M} \cdots \mathrm{C}_{3} \mathrm{~N}_{2}$ unit of priorly published $\left[\mathrm{AlXMe}\left(\mathrm{Box}{ }_{2} \mathrm{CH}\right)\right]^{[141]}(\mathrm{X}=\mathrm{Me}, \mathrm{Cl})$ as well as complex 4 and 5 . 
Table 2-2. Selected bond lengths $(\AA)$ bond angles $\left(^{\circ}\right)$ of previously published $\left[\mathrm{AlXMe}\left(\mathrm{Box}_{2} \mathrm{CH}\right)\right]^{[104]}(\mathrm{X}=\mathrm{Me}$, $\mathrm{Cl})$ as well as 4 and 5 .

\begin{tabular}{|c|c|c|c|c|}
\hline$\left[M X_{2}\left(\mathrm{Box}_{2} \mathrm{CH}\right)\right]$ & $M X_{2}=\mathrm{AlMe}_{2}$ & $M X_{2}=\mathrm{AlMeCl}$ & $M X_{2}=\mathrm{AlCl}_{2}(4)$ & $M X_{2}=\mathrm{AlI}_{2}(5)$ \\
\hline \multirow[t]{2}{*}{$\mathrm{M}-\mathrm{N}$} & 1.917(2), & $1.8961(17)$ & 1.8713(13), & 1.867(2), \\
\hline & $1.918(2)$ & $1.8899(17)$ & $1.8665(13)$ & $1.869(2)$ \\
\hline \multirow[t]{2}{*}{$\mathrm{M}-\mathrm{X}$} & 1.959(3), & Me: 1.942(12) & 2.1142(9), & 2.5035(9), \\
\hline & $1.950(3)$ & Cl: $2.130(3)$ & $2.1149(9)$ & 2.4994(9) \\
\hline $\mathrm{C} 7-\mathrm{C} 8$ & $1.377(2)$ & $1.385(2)$ & $1.384(2)$ & $1.388(3)$ \\
\hline C8-C9 & $1.383(3)$ & $1.378(2)$ & $1.387(2)$ & $1.380(4)$ \\
\hline C7-N1 & $1.348(3)$ & $1.350(2)$ & $1.3550(18)$ & $1.349(3)$ \\
\hline $\mathrm{C} 9-\mathrm{N} 2$ & $1.344(3)$ & $1.346(3)$ & $1.3509(18)$ & $1.354(3)$ \\
\hline $\mathrm{N}-\mathrm{M}-\mathrm{N}$ & $91.67(9)$ & $94.33(11)$ & $95.34(6)$ & 95.14(9) \\
\hline $\mathrm{X}-\mathrm{M}-\mathrm{X}$ & $115.9(1)$ & 113.3(6) & 111.09(3) & $113.68(3)$ \\
\hline \multirow[t]{4}{*}{$\mathrm{N}-\mathrm{M}-\mathrm{X}$} & 111.5(1), & 114.5(4), & 113.38(4), & 112.31(7), \\
\hline & 111.9(1), & 109.44(9), & 112.47(5), & 110.50(7), \\
\hline & 111.0(1), & 108.8(16), & 112.39(4), & 111.95(7), \\
\hline & $112.4(1)$ & $113.9(4)$ & $111.32(4)$ & 111.86(7) \\
\hline $\mathrm{M} \cdots \mathrm{C}_{3} \mathrm{~N}_{2}$ plane & $0.296(3)$ & $0.181(3)$ & $0.329(2)$ & $0.217(3)$ \\
\hline Folding angle & $9.12(8)$ & $3.7(4)$ & $11.59(10)$ & $6.58(13)$ \\
\hline
\end{tabular}

More precisely, the two imine nitrogen atoms of the bis(benzoxazol-2-yl)methanide (Table 2-2) chelate the metal centre by bond lengths of Al1-N1 1.8713(13) $\AA$ and Al1-N2 1.8665(13) $\AA$, respectively, and a bite angle N1-Al1-N2 of $95.34(6)^{\circ}$. The distances of cation and chloride ions are Al1-Cl1 2.1142(9) $\AA$ and Al1-Cl2 2.1149(9) $\AA$. This is accompanied by angles of Cl1-Al1-Cl2 111.09(3) ${ }^{\circ}, \mathrm{N} 1-\mathrm{Al} 1-\mathrm{Cl} 1113.38(4)^{\circ}, \mathrm{N} 1-\mathrm{Al} 1-\mathrm{Cl} 2112.47(5)^{\circ}, \mathrm{N} 2-\mathrm{Al} 1-\mathrm{Cl} 1112.39(4)^{\circ}$ and N2-Al1$\mathrm{Cl} 2111.32(4)^{\circ}$, slightly larger than the ideal tetrahedral angle. ${ }^{[136]}$ Complex 5 crystallises in space group $P \overline{1}$ with one molecule in the asymmetric unit. Aluminium nitrogen bond lengths and bite angles are similar to the parameters of 4 . Unsurprisingly, the distorted tetrahedral binding situation at the aluminium ion shows somewhat elongated metal halide bonds Al1-I1 2.5035(9) $\AA$ and Al1-I2 $2.4994(9) \AA$ due to the larger ionic radius of iodide $(2.2 \AA)$ in relation to chloride $(1.81 \AA) .{ }^{[20]}$ The NacNac-like structural motif embracing N1, C7, C8 C9 and N2, in both aluminium complexes, exhibits bond lengths between $1.54 \AA\left(\mathrm{C}\left(\mathrm{sp}^{3}\right)-\mathrm{C}\left(\mathrm{sp}^{3}\right)\right)$ and $1.34 \AA\left(\mathrm{C}\left(\mathrm{sp}^{2}\right)=\mathrm{C}\left(\mathrm{sp}^{2}\right)\right)$ as well as $1.47 \AA$ $\left(\mathrm{C}\left(\mathrm{sp}^{3}\right)-\mathrm{N}\left(\mathrm{sp}^{3}\right)\right)$ and $1.29 \AA\left(\mathrm{C}\left(\mathrm{sp}^{2}\right)-\mathrm{N}\left(\mathrm{sp}^{2}\right)\right)$, indicating a highly conjugated system between these atoms. ${ }^{[137]}$ In addition, the $\left(\mathrm{Box}_{2} \mathrm{CH}\right)$ ligand is folded to a butterfly-like conformation while coordinating the aluminium ion. Here folding angles of $11.59(10)^{\circ}(4)$ and $6.58(13)^{\circ}(5)$ were calculated, respectively. In comparison to previously reported $\left[\mathrm{AlMe}_{2}\left(\mathrm{Box}_{2} \mathrm{CH}\right)\right]\left(9.12(8)^{\circ}\right)$ and $\left[\mathrm{AlMeCl}\left(\mathrm{Box}_{2} \mathrm{CH}\right)\right]\left(3.7(4)^{\circ}\right)$, in particular, 4 features a notable deviation from an ideally planar ligand scaffold. ${ }^{[104]}$ This deviations seem to correlate with the dislocations of the metal ions out of the $\mathrm{C}_{3} \mathrm{~N}_{2}$ plane (Figure 2-9 (bottom), Table 2-2). ${ }^{[104]}$ Thus, dichloride aluminium species 4 exhibits a 
distance of $0.329(2) \AA$ while species 5 features a shorter distance of $0.217(3) \AA$. The synthesis of complex 4 and 5 was confirmed by ${ }^{1} \mathrm{H}$ and ${ }^{13} \mathrm{C}$ NMR spectroscopy. The ${ }^{1} \mathrm{H}$ NMR spectra of both aluminium halide complexes reveal a significant deshielding and simultaneous downfield shift of the methanide bridge $\Delta \delta=1.02 \mathrm{ppm}\left(-H \mathrm{C}-5.05 \mathrm{ppm},-\mathrm{H}_{2} \mathrm{C}-4.03 \mathrm{ppm}\right)$ in contrast to the free uncharged ligand. Additionally, the aromatic protons $3-\mathrm{H}$ to $5-\mathrm{H}$ and $11-\mathrm{H}$ to $13-\mathrm{H}$ experience an upfield shift to 6.85-6.69 ppm (4) and 6.87-6.70 ppm (5). This correlates with an increased electron density at these atoms due to charge delocalization from the $\mathrm{C}_{3} \mathrm{~N}_{2}$ unit towards the aryl systems in the ligand periphery. Moreover, $2-\mathrm{H}$ as well as $14-\mathrm{H}$ of $\left[\mathrm{AlCl}_{2}\left(\mathrm{Box}_{2} \mathrm{CH}\right)\right](4)$ show a slight upfield shift to $7.48 \mathrm{ppm}$ whereas corresponding protons of $\left[\mathrm{AlI}_{2}\left(\mathrm{Box}_{2} \mathrm{CH}\right)\right](5)$ experience a downfield shift to $7.74 \mathrm{ppm}$ ( $2-\mathrm{H}$ plus $14-\mathrm{H}$ of $\mathrm{Box}_{2} \mathrm{CH} \delta=7.55 \mathrm{ppm}$ ). A possible explanation for this phenomenon might be the deviation from ideal planarity as well as the distorted conjugated system in the $\mathrm{C}_{3} \mathrm{~N}_{2}$ plane, which results in a closer proximity of the $\mathrm{Al}^{\mathrm{III}}$-ion and the protons in compound 5 . The ${ }^{13} \mathrm{C}$ NMR spectra of 4 and 5 comply with related complexes [ $\left.\mathrm{AlMe}_{2}\left(\mathrm{Box}_{2} \mathrm{CH}\right)\right]$ and $\left[\mathrm{AlMeCl}\left(\mathrm{Box}_{2} \mathrm{CH}\right)\right]$, however, quaternary carbon atoms were not observed on account of the poor solubility of the first two complexes. ${ }^{[104]}$ The mass spectrum (LIFDI[+]) of 4 displays a peak at $\mathrm{m} / \mathrm{z}(\%)=346.0(100)$, which matches the positive charged $\left[\mathrm{AlCl}_{2}\left(\mathrm{Box}_{2} \mathrm{CH}\right)\right]^{+}$fragment. This molecular ion peak exhibits a characteristic isotopic distribution pattern for the two chloride atoms and support the successful synthesis of 4. Corresponding LIFDI spectrum of 5 shows a molecular peak at $m / z(\%)=529.8(100)$, which is based on $\left[\mathrm{AlI}_{2}\left(\mathrm{Box}_{2} \mathrm{CH}\right)\right]^{+}$species. Furthermore, the mass spectra of both aluminium dihalide species 4 and 5 exhibit a peak at $\mathrm{m} / \mathrm{z} 250.1$ owing to $\mathrm{Box}_{2} \mathrm{CH}_{2}$ ligand. Since complex 4 and 5 show low yields and a poor solubility in hydrocarbon solvents, e.g., toluene at room temperature, all attempts to reduce the aluminium dihalide complexes, so far, resulted in intractable products mixture. Thus, we decided to switch to sterically more demanding ligand systems with a higher solubility in corresponding solvents. 


\subsection{Complexes based on bis(4-methyl-benzoxazol-2- yl)methane}

Major parts of this chapter have been published in:

[4] J. Kretsch, Anne Kreyenschmidt, Timo Schillmöller, R. Herbst-Irmer, D. Stalke, "Mixed Low-Valent Alanes from the Bis(4-methyl-benzoxazol-2-yl)methanide Ligand", Inorg. Chem. 2020, $59,13690-13699 .{ }^{[4]}$

\subsubsection{Synthesis of bis(4-methyl-benzoxazol-2-yl)methane ligand}

According to the synthesis of unsubstituted $\mathrm{Box}_{2} \mathrm{CH}_{2}$, the synthesis of bis(4-methyl-benzoxazol-2yl)methane ligand $\left({ }^{4-\mathrm{Me}} \mathrm{Box}_{2} \mathrm{CH}_{2}\right.$ ) (Scheme 2-6, Method $A$ ) was achieved by cyclocondensation reaction of two equivalents of 2-amino-3-methylphenol and one equivalent of activated ethylbisimidate dihydrochloride in moderate yields (YLD: 44\%). ${ }^{[106]}$ Although, the reaction carried out in polyphosphoric acid at $90^{\circ} \mathrm{C}$ for $5 \mathrm{~h}($ Method B) using 2-amino-3-methylphenol and malonic acid (2:1) resulted in slightly higher yields (YLD: 56\%), ${ }^{[106]}$ the ${ }^{4-\mathrm{Me}} \mathrm{Box}_{2} \mathrm{CH}_{2}$ ligand was synthesised according to method $A$ owing to the, in general, more straightforward synthesis and work-up procedures.

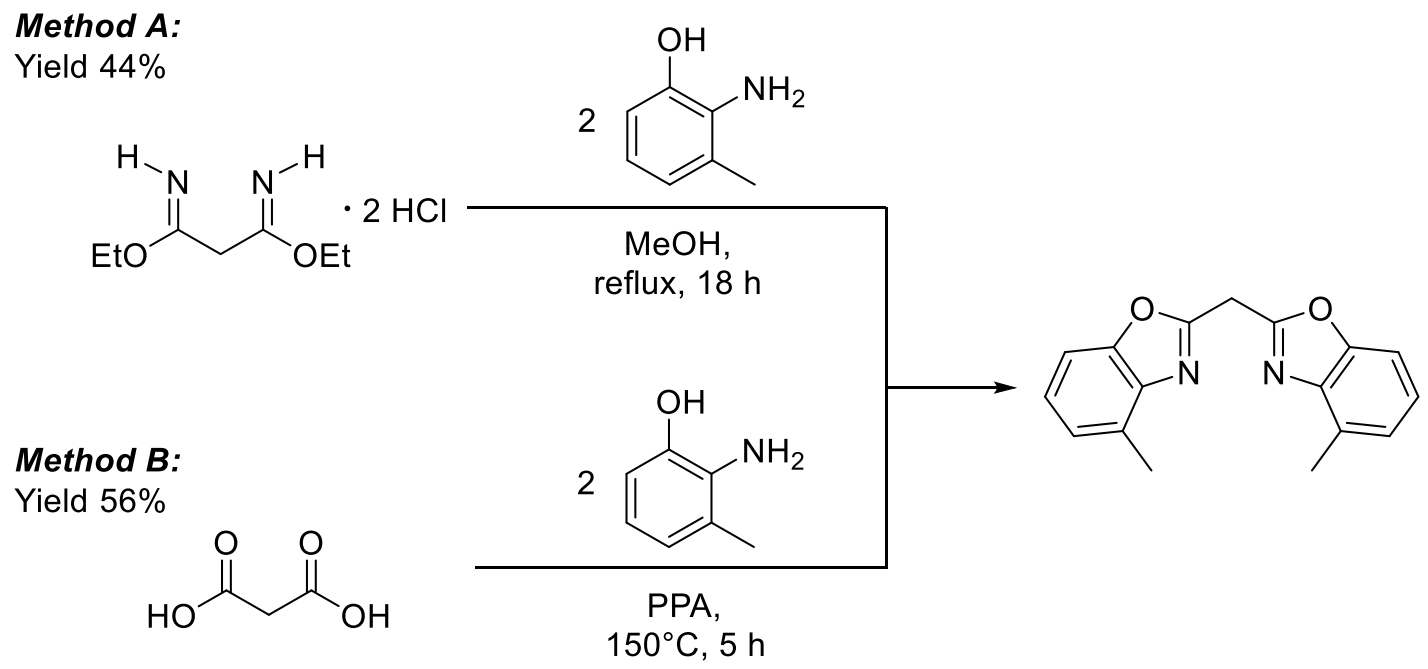

Scheme 2-6. Synthesis routes of bis(4-methyl-benzoxazol-2-yl)methane via activated ethylbisimidate dihydrochloride (Method A) or malonic acid (Method B).

\subsubsection{Group 1 bis(benzoxazol-2-yl)methanide}

Starting from bis(4-methyl-benzoxazol-2-yl)methane a few complexes of group 13 have so far been reported by Dauer and Stalke, e.g., $\left[M_{13} \mathrm{Me}_{2}\left({ }^{4-\mathrm{Me}} \mathrm{Box} 2 \mathrm{CH}\right)\right]\left(M_{13}=\mathrm{Al}, \mathrm{Ga}, \mathrm{In}\right) \cdot{ }^{[106]}$ Moreover, the range

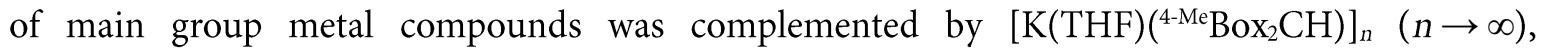
$\left[\mathrm{Mg}\left({ }^{4-\mathrm{Me}} \mathrm{Box}_{2} \mathrm{CH}\right)_{2}\right]$ or $\left[\mathrm{Ca}(\mathrm{THF})_{2}\left({ }^{4-\mathrm{Me}} \mathrm{Box}_{2} \mathrm{CH}\right)_{2}\right]$ published by Koehne and Stalke et al. ${ }^{[128]}$ Based on 
these studies, next chapter focuses on the efficient synthesis of aluminium precursors for lowoxidation and/or -valent complexes and their heavier homologues.

In previous research, salt metathesis reactions were successfully used for the synthesis of various main group complexes. Thus, the bis(4-methyl-benzoxazol-2-yl)methane ligand ( ${ }^{4}-\mathrm{Me}^{\mathrm{B}} \mathrm{Box}_{2} \mathrm{CH}_{2}$ ) was initially converted to lithium precursor $\left[\mathrm{Li}\left(\mathrm{Et}_{2} \mathrm{O}\right)_{2}\left({ }^{4-\mathrm{Me}} \mathrm{Box}_{2} \mathrm{CH}\right)\right](6)$. For this purpose, ${ }^{4-\mathrm{Me}} \mathrm{Box}_{2} \mathrm{CH}_{2}$ was dissolved in diethyl ether and cooled to $0^{\circ} \mathrm{C}$ (Scheme 2-7). At this temperature, one equivalent of a ${ }^{n} \mathrm{BuLi}$ solution in hexane was carefully added while stirring. After the solution had been stirred $15 \mathrm{~min}$ at $0^{\circ} \mathrm{C}$, it was allowed to warm up to ambient temperature and stirred for $2 \mathrm{~h}$. Thereafter, volatiles were removed under reduced pressure and a yellowish-white powder (6) was obtained in high yields (YLD: 86\%).
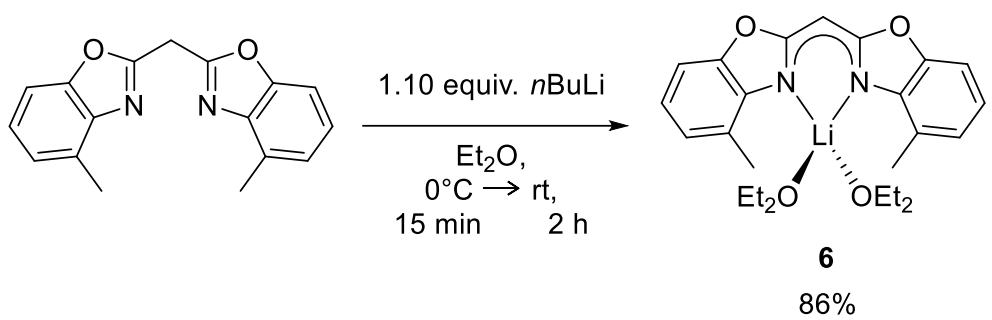

Scheme 2-7. Synthesis of $\left[\mathrm{Li}\left(\mathrm{Et}_{2} \mathrm{O}\right)_{2}\left({ }^{4-\mathrm{Me}} \mathrm{Box}_{2} \mathrm{CH}\right)\right](6)$ by deprotonation with ${ }^{n} \mathrm{BuLi}$ solution in $\mathrm{Et}_{2} \mathrm{O}$.

Crystals suitable for single crystal XRD experiments were grown from a saturated solution of diethyl ether at $2^{\circ} \mathrm{C}$ overnight. These experiments on 6 were carried out at $-73.15^{\circ} \mathrm{C}(200 \mathrm{~K})$ because lower temperatures led to crystal decomposition probably caused by phase transition.

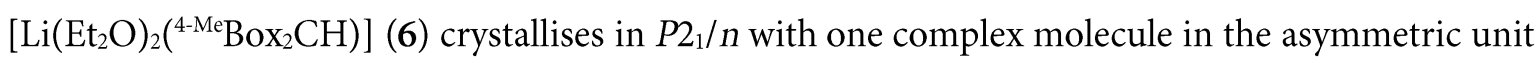
(Figure 2-10, left). As previously described for lithium species 1 , the cation is $\kappa^{2}-N, N^{\prime}$-coordinated by a negatively charged ligand as well as two diethyl ether molecules in a distorted tetrahedral geometry (Figure 2-10, right). The two nitrogen atoms are chelating the lithium ion equidistantly (Li1-N1/2 2.046(6) $\AA$ ) in a bite angle N1-Li1-N2 of $96.4(2)^{\circ}$, which is more acute than the ideal tetrahedral angle. The corresponding bond lengths and angles in $\left[\mathrm{Li}\left(\mathrm{Et}_{2} \mathrm{O}\right)_{2}\left(\mathrm{Box}_{2} \mathrm{CH}\right)\right](1)$ are smaller
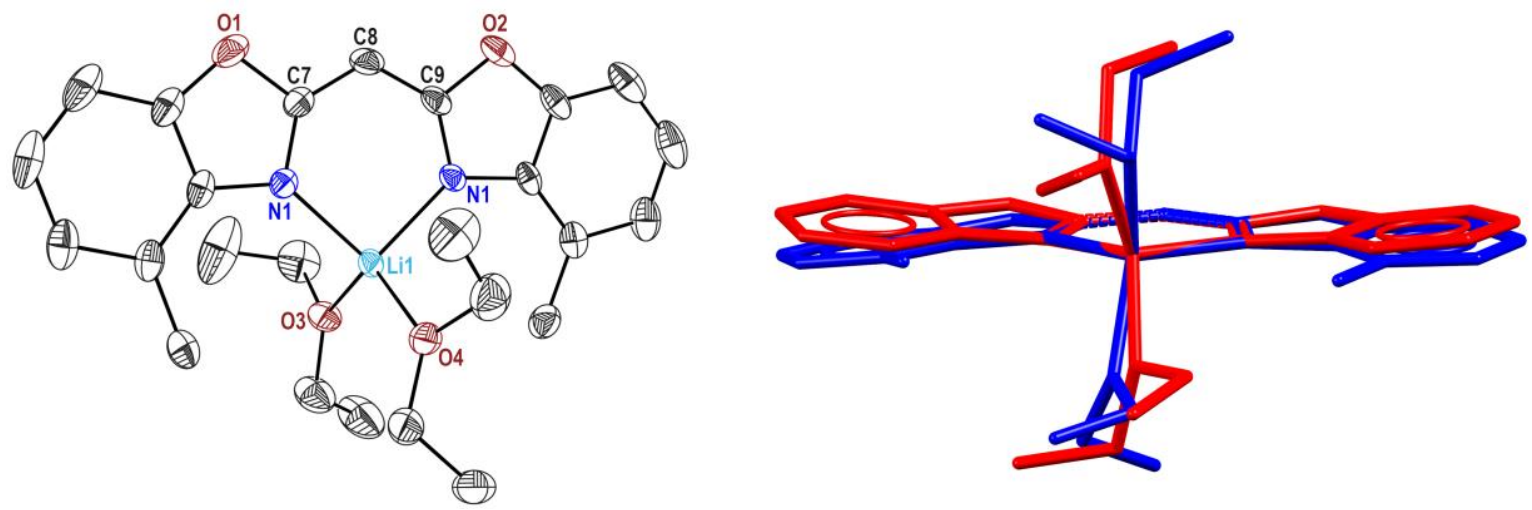

Figure 2-10. Molecular structure of $\left[\mathrm{Li}\left(\mathrm{Et}_{2} \mathrm{O}\right)_{2}\left({ }^{4-\mathrm{Me}} \mathrm{Box}_{2} \mathrm{CH}\right)\right](6)$ measured at $-73.15^{\circ} \mathrm{C}(200 \mathrm{~K})$ (left). Anisotropic displacement parameters are depicted at 30\% probability level. Hydrogen atoms are omitted for clarity. Superimposed molecular structure of $\mathbf{6}$ (right, blue) and unsubstituted lithium species 1 (red). 


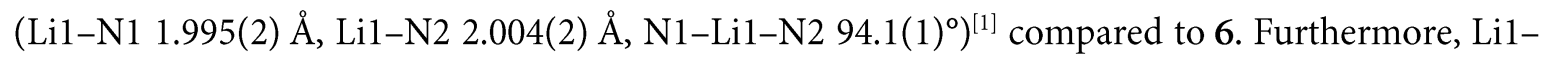
O3 1.982(6) Å and Li1-O4 1.996(6) Å distances are slightly elongated (1: Li1-O3 1.980(2) Å, Li1-O4 $1.978(2) \AA)^{[1]}$ while O3-Li1-O4 is expanded to $\left.115.7(4)^{\circ}(1 \text { : O3-Li1-O4 102.96(10 })^{\circ}\right)^{[1]}$. The lithium atom is only $0.033(7) \AA$ dislocated from the NacNac-like $\mathrm{C}_{3} \mathrm{~N}_{2}$ plane (N1-C7-C8-C9-N2) that is also observed in related lithium bis-benzoxazolyl methane complexes. ${ }^{[3,112]}$ Additionally, the folding angle $6.66(18)^{\circ}$ indicates an almost planar ligand system in which the cation is embedded. The

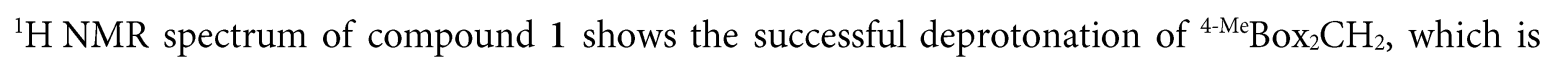
coupled with a downfield shift and a lower integral of the former methane linker unit $\left(\delta\left(-\mathrm{H}_{2} \mathrm{C}-\right) 4.70 \mathrm{ppm}, \delta(-H \mathrm{C}-) 4.80 \mathrm{ppm}\right)$. This is in line with the signals found for the unsubstituted

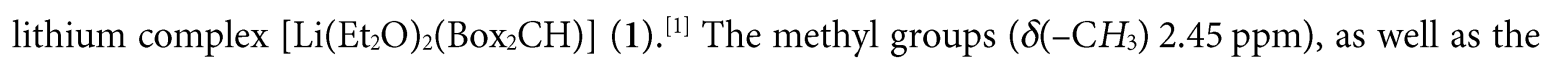
aromatic protons, concurrently experience an increased shielding and an upfield shift. Besides, the ${ }^{7} \mathrm{Li}$ NMR spectrum exhibits a singlet at $2.13 \mathrm{ppm}\left(\left[\mathrm{D}_{8}\right] \mathrm{THF}\right)$, which indicates the formation of a single lithium species in solution at ambient temperature. Accessorily, ${ }^{13} \mathrm{C}$ NMR spectroscopy, mass spectrometry (LIFDI, THF, $\left.\mathrm{m} / \mathrm{z}(\%) 284.0(100)\left[M-2 \mathrm{Et}_{2} \mathrm{O}\right]^{+}\right)$and elemental analysis verified the synthesis of 6 . 


\subsubsection{Group 13 bis(4-methyl-benzoxazol-2-yl)methanide complexes}

Various carbenoid thallium complexes, for instance $\left[\mathrm{Tl}^{\mathrm{I}}\left(L^{6}\right)\right]\left(L^{6}=\left\{\operatorname{DippCN}\left(\mathrm{F}_{3} \mathrm{C}\right)\right\}_{2} \mathrm{CH}^{[17 c]}\right.$, $\left\{\left(\mathrm{SiMe}_{3}\right) \mathrm{NCPh}_{2} \mathrm{CH}^{[84]}\right.$, $\{\mathrm{DippNPPh}\}_{2} \mathrm{CH}^{[56]}$, and $\left.\{\mathrm{DippNCH}\}_{2} \mathrm{CPh}^{[84]}\right)$ have been synthesised by treatment of appropriate alkali metal precursors with an equivalent amount of $\mathrm{Tl}^{\mathrm{I}}$ salt under mild conditions. Based on those publications, thallium complex $\left[\mathrm{Tl}^{\mathrm{I}}\left({ }^{4-\mathrm{Me}}{ }^{\mathrm{Box}}{ }_{2} \mathrm{CH}\right)\right](7)$ was synthesised by facile salt metathesis of the lithiated species 6 and thallium triflate (TlOTf). For this purpose, one equiv. of commercially available $\mathrm{Tl}^{\mathrm{T}} \mathrm{OTf}$ and 6 were separately dissolved in diethyl ether and subsequently cooled to $-30 \mathrm{C}$. Thereafter, both solutions were mixed at low temperature $\left(\mathrm{ca} .-30^{\circ} \mathrm{C}\right)$ under vigorous stirring and warmed to ambient temperature after $\sim 30 \mathrm{~min}$.
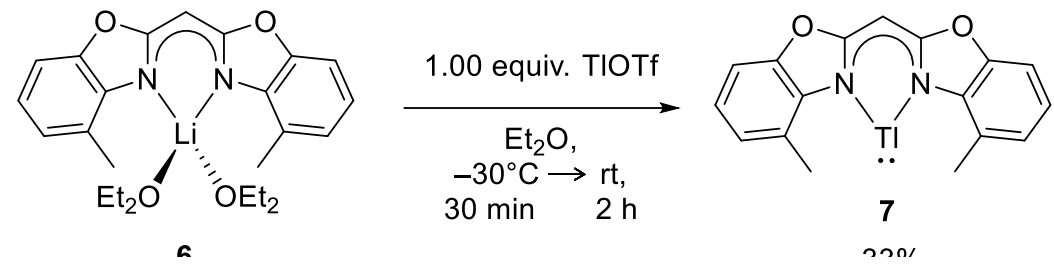

Scheme 2-8: Synthesis of $\left[\mathrm{Tl}^{\mathrm{I}}\left({ }^{4-\mathrm{Me}} \mathrm{Box}_{2} \mathrm{CH}\right)\right]$ (7) via salt metathesis of lithium precursor 6 .

Volatiles were removed after $2 \mathrm{~h}$ and a black-greyish solid was gained. This solid was extracted with toluene, the obtained solution was then concentrated and stored at about $-30^{\circ} \mathrm{C}$. Crystals suitable for single crystal XRD experiments were grown from the saturated toluene solution in moderate yields (YLD: 33\%) after $1 \mathrm{~d}$. The thallium diyl (7) crystallises in the triclinic space group $P \overline{1}$ with one complex and one toluene molecule in the asymmetric unit (Figure 2-11). The monomeric $\left[\mathrm{Tl}^{\mathrm{I}}\left({ }^{4-\mathrm{Me}} \mathrm{Box}_{2} \mathrm{CH}\right)\right](7)$ consists of a $\mathrm{Tl}^{\mathrm{I}}$ cation that is $N, N^{\prime}$-chelated by the negatively charged ligand (Figure 2-11, left). A closer look at the solid-state structure revealed weak noncovalent metal-ligand interactions $^{[83 b]}$ (Figure 2-11, right) similar to $\left[\mathrm{Tl}^{\mathrm{I}}(\mathrm{Piso})\right]^{[82 \mathrm{~b}]}$ (Piso $=\{\mathrm{NR}\}_{2} \mathrm{C}{ }^{t} \mathrm{Bu} ; \mathrm{R}=2,6-$ diisopropylphenyl) or $\left[\mathrm{Tl}^{\mathrm{I}}(\mathrm{NacNac})\right]^{[84]}\left(\mathrm{NacNac}=\left\{\mathrm{N}\left(\mathrm{SiMe}_{3}\right) \mathrm{CPh}\right\}_{2} \mathrm{CH} ;\left\{\mathrm{N}\left(\mathrm{SiMe}_{3}\right) \mathrm{CPh}\right\}_{2} \mathrm{CPh}\right)$.
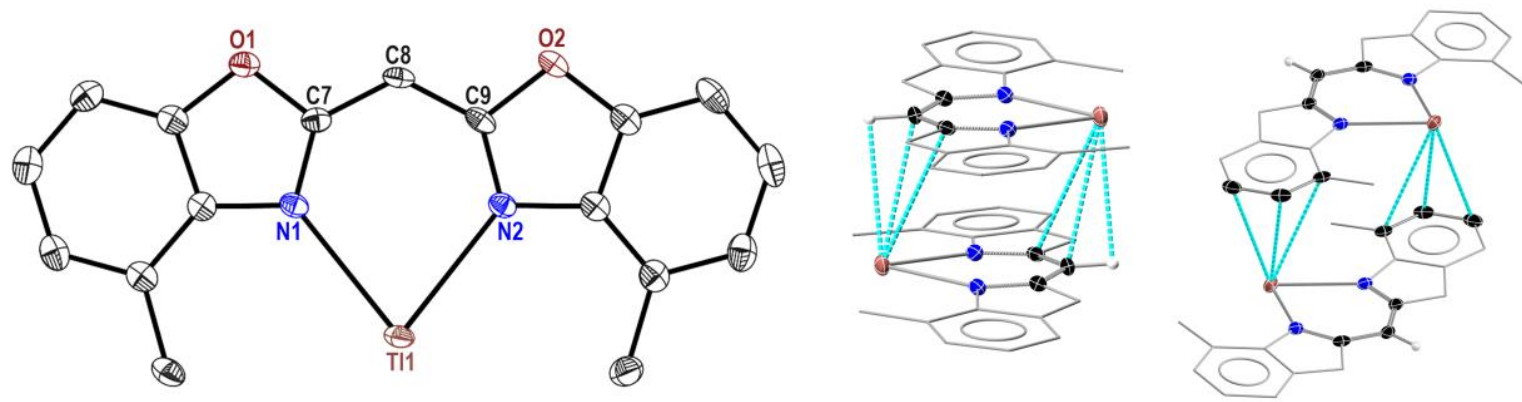

Figure 2-11. Molecular structure of $\left[\mathrm{Tl}^{\mathrm{l}}\left({ }^{(4-\mathrm{Me}} \mathrm{Box}_{2} \mathrm{CH}\right)\right]$ (7) (left). Noncovalent $\eta^{3}-\mathrm{Tl}^{\mathrm{I}} \cdots \mathrm{C}_{3} \mathrm{~N}_{2}$ plane (middle) and $\eta^{3}-\mathrm{Tl}^{\mathrm{L}} \ldots$ arene (right) intermolecular interactions are represented with blue dashed lines. Anisotropic displacement parameters are depicted at 50\% probability level. Hydrogen atoms except $8-\mathrm{H}$ (middle/right) and co-crystallised solvents are omitted for clarity. 
More specifically, one $\mathrm{Tl}^{\mathrm{I}}$ cation seems to engage in a $\eta^{3}$-intermolecular interaction with the backbone of a neighbouring complex's $\mathrm{C}_{3} \mathrm{~N}_{2}$ unit (H8-C8-C9) (Figure 2-11, middle) as well as in a $\eta^{3}$-Tl/arene (C2-C3-C4) interaction with another complex moiety (Figure 2-11, right) similar to $\left[\mathrm{Tl}^{\mathrm{I}}\left(\mathrm{PN}^{\mathrm{pyr}} \mathrm{P}\right)\right]^{[87 \mathrm{~b}]}$ ( $\mathrm{PN}^{\text {pyr }} \mathrm{P}=2,5$-bis((diisopropylphosphino)methyl)pyrrole). Apart from the $\mathrm{Tl}^{\mathrm{I}} \cdots \pi$-arene interactions, metal-metal contacts exist in some thallium complexes, e.g., $\left[\mathrm{Tl}^{\mathrm{I}}\left(\mathrm{C}_{5}\left\{\mathrm{CH}_{2} \mathrm{Ph}\right\}_{5}\right)\right]^{[138]}$ or dinuclear $\left[\left\{\mathrm{Tl}^{\mathrm{I}}\left({ }^{\text {Dipp }} \mathrm{NCMeCHCMeNCH}_{2}\right)\right\}_{2}\right]^{[78,86 a]}$ (Figure 1-12, Tl-V), whereas in latter complexes the cations are held in close proximity to one another owing to the ligand design. The closest Tl...Tl distance (ca. $4.661 \AA$ ) of $\left[\mathrm{Tl}^{\mathrm{I}}\left({ }^{4-\mathrm{Me}} \mathrm{Box}_{2} \mathrm{CH}\right)\right]$ (7) exceeds the limit for $\mathrm{Tl}-\mathrm{Tl}$ contacts by more than $0.5 \AA$ (Figure 2-12), which is twice the maximal van der Waals radii for $\mathrm{Tl}^{\mathrm{I}}(2.00 \AA)^{[138]}$.

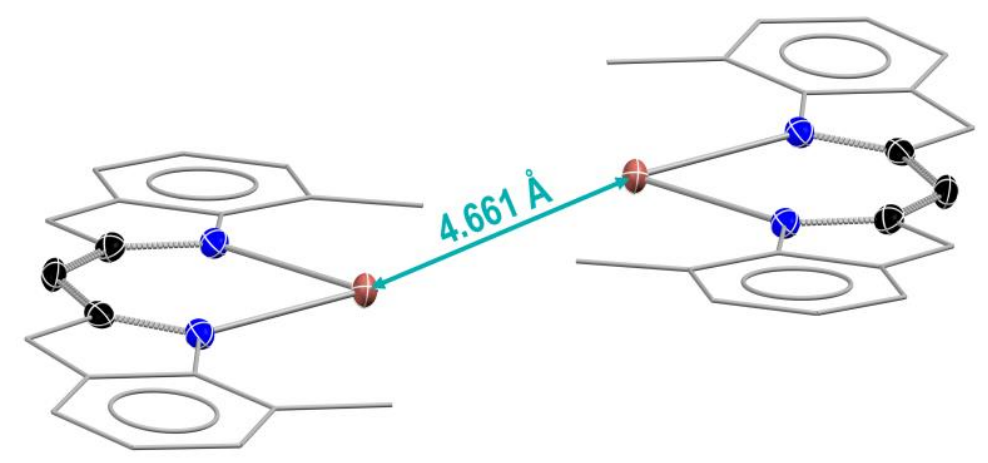

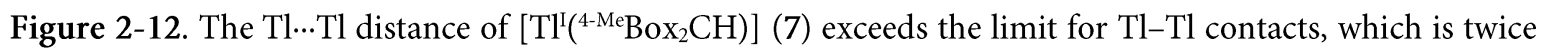
the maximal van der Waals radii for $\operatorname{Tl}^{\mathrm{I}}(2.00 \AA)$, and therefore no interactions between the two metal centres is assumed.

Thus, it is fair to assume that no interaction appears between the two cations. In general, NacNaclike complexes incorporate widely diversified distances between $\mathrm{C}_{3} \mathrm{~N}_{2}$ plane and thallium ion due to $\mathrm{Tl} \cdots \mathrm{Tl}$, intra- and intermolecular noncovalent interactions. In the thallacyle 7, bond lengths of Tl1$\mathrm{N} 12.528(2)$ and T11-N2 2.521(3) are observed. Accessorily, the distance of thallium cation and $\mathrm{C}_{3} \mathrm{~N}_{2}$ plane is $0.165(4) \AA$ while the two benzoxazolyl moieties form a folding angle of 6.6(1) ${ }^{\circ}$. The successful salt metathesis reaction of 6 to $\left[\mathrm{Tl}^{\mathrm{I}}\left({ }^{4-\mathrm{Me}} \mathrm{Box}_{2} \mathrm{CH}\right)\right]$ (7) was corroborated by NMR spectroscopy. The ${ }^{1} \mathrm{H}$ NMR spectrum of 7 exhibits a deshielding and simultaneous downfield shift of the methanide bridge to $\delta 4.93 \mathrm{ppm}$ and the methyl groups to $\delta 2.68 \mathrm{ppm}$, in relation to lithiated starting material 6 or the neutral ligand. Besides, the signals of the aryl protons are somewhat upfield shifted compared to ${ }^{4-\mathrm{Me}} \mathrm{Box}_{2} \mathrm{CH}_{2}$, but are quite similar to the chemical shift of 6 . Additionally, the synthesis of carbene analogous 7 was confirmed by mass spectrometry (ESI[+], toluene, $m / z 482.0(100)[M]^{+}$) and elemental analysis.

Although several synthesis routes were investigated, it was neither possible to isolate a monomeric $\mathrm{In}^{\mathrm{I}}$ analogue of complex 7 nor an oligomeric indium species. A first attempt was inspired by previous results from Hill and co-workers. ${ }^{[2,73,74]}$ The precursor 6 and $\mathrm{In}^{\mathrm{I} I}$ were separately dissolved in THF and cooled to $-70^{\circ} \mathrm{C}$ (Scheme 2-9). Thereafter, the solutions were mixed and stirred at $-70^{\circ} \mathrm{C}$ for $3 \mathrm{~h}$ under the exclusion of light to prevent the disproportionation of the $\operatorname{In}^{\mathrm{I}}$ cations. Afterwards, the obtained suspension was allowed to warm to ambient temperature and stirred for $2 \mathrm{~d}$. Instead of an indium diyl, crystals of $\left[\left({ }^{4-\mathrm{Me}} \mathrm{Box}_{2} \mathrm{CH}_{2}\right) \mathrm{Li}\left({ }^{4-\mathrm{Me}} \mathrm{Box}_{2} \mathrm{CH}\right)\right](6 \mathrm{a})$ suitable for single crystal XRD analysis 
(for details see 5.1.8) were grown out of a toluene solution $\left(2^{\circ} \mathrm{C}\right)$ after work-up procedures. This complex, consisting of a monoanionic as well as a neutral ligand, is reminiscent of the lithium complex $\left[\left(\{2-\mathrm{Py}\}_{2} \mathrm{CH}_{2}\right) \mathrm{Li}\left(\{2-\mathrm{Py}\}_{2} \mathrm{CH}\right)\right]$ published by Gornitzka and Stalke. ${ }^{[00]}$
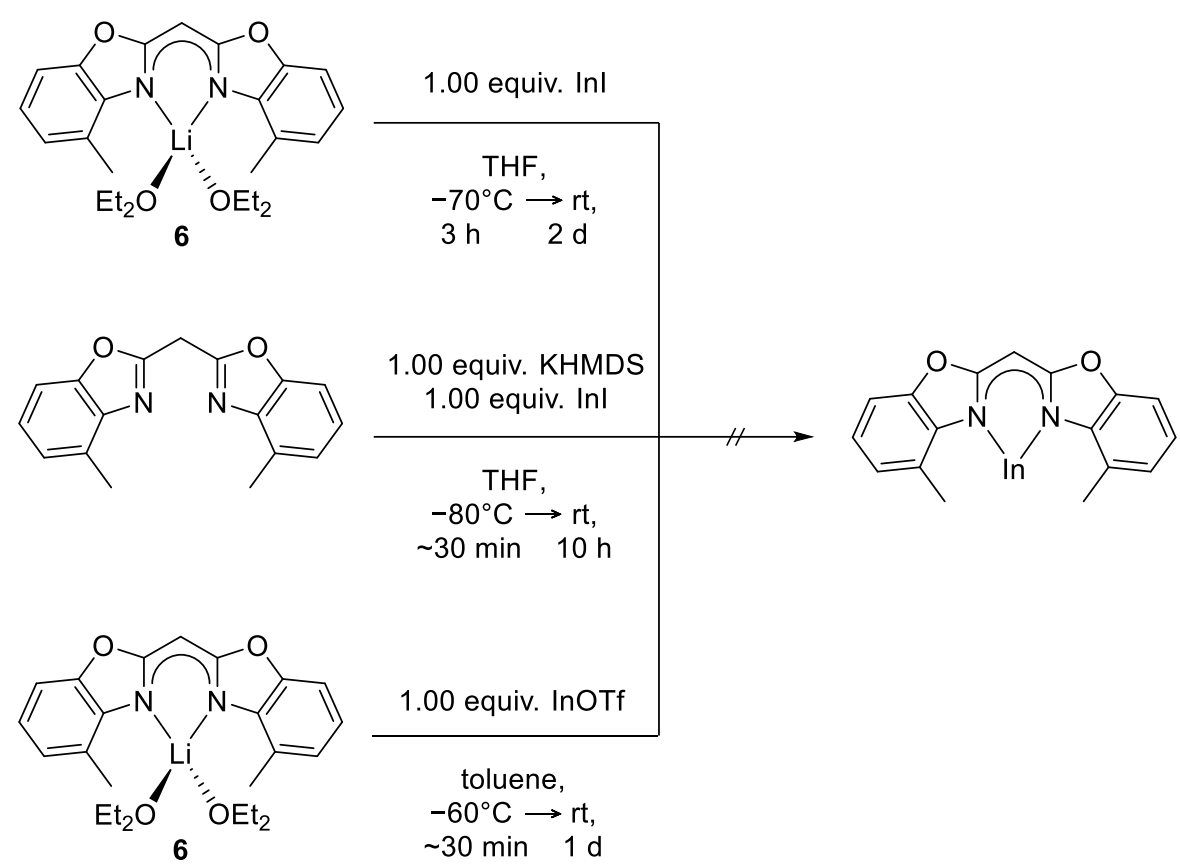

$\sim 30 \min 1 \mathrm{~d}$

Scheme 2-9. Different synthetic approaches for the synthesis of a monomeric $\operatorname{In}^{\mathrm{I}}$ analogue of complex 7 .

In another approach, ${ }^{4-\mathrm{Me}} \mathrm{Box}_{2} \mathrm{CH}_{2}$ was first deprotonated using $\mathrm{KHMDS}$ in THF at $0^{\circ} \mathrm{C}$ (Scheme 2-9). The subsequent salt metathesis reaction with $\operatorname{In}^{\mathrm{I} I}$ at $-80^{\circ} \mathrm{C}$ and ambient temperature $(10 \mathrm{~h})$ led to a dark-green precipitate. This precipitate was separated from the solution by filtration and dried under reduced pressure. After all volatiles of the filtrate had been removed in vacuo, only unreacted starting material ${ }^{4-\mathrm{Me}} \mathrm{Box}_{2} \mathrm{CH}_{2}$ could be isolated.

The formation of a dark-green precipitate was also achieved by reacting 6 and InOTf in toluene at $-60^{\circ} \mathrm{C}$ and ambient temperature $(1 \mathrm{~d})$ under the exclusion of light (Scheme 2-9). The dark-green compound is insoluble in common solvents (THF, toluene, MeCN, acetone, ethyl acetate), and immediately decomposes in DMF or DMSO. Perhaps a polymeric or oligomeric indium species was formed similar to hexameric $\left[\left(L^{6}\right) \operatorname{IIn}^{\mathrm{II}}\left\{\operatorname{In}^{\mathrm{I}}\left(L^{6}\right)\right\}_{4} \operatorname{In}^{\mathrm{II}} \mathrm{I}\left(L^{6}\right)\right]\left(L^{6}=\{3,5 \text {-xylyl-NCMe }\}_{2} \mathrm{CH}\right)^{[74]}$ (Figure 1-10, In-V) published by Hill and co-workers. This seems to be likely considering the planar alignment of the bis(4-methyl-benzoxazol-2-yl)methanide ligand and its weakly pronounced steric demand in both perpendicular positions. In order to analyse the dark-green precipitate, elemental analysis and ATR-IR spectroscopy were performed, however, the obtained data were inconclusive. Perhaps solidstate NMR spectroscopy or powder diffraction experiments could have given insights into the composition of the dark-green solid. 
The next attempts focused on the synthesis of a six-membered gallium(I) heterocycle. In 2000, Power et al. reported the first synthesis of monomeric $\left[\mathrm{Ga}^{\mathrm{I}}\left({ }^{\mathrm{Dipp}} \mathrm{NacNac}\right)\right]$ by salt metathesis reaction of the corresponding lithium species and "GaI"[50] in toluene at $-78^{\circ} \mathrm{C} \cdot{ }^{[55]}$ Additionally, the obtained reaction solution was treated with an excess of potassium to reduce any $\left[\mathrm{Ga}^{\mathrm{III} I} \mathrm{I}_{2}\left({ }^{\mathrm{Dipp}} \mathrm{NacNac}\right)\right]$ formed

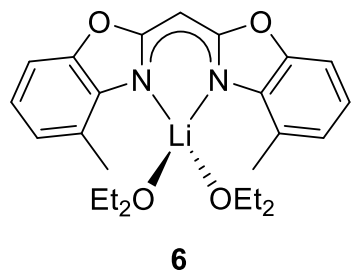

6

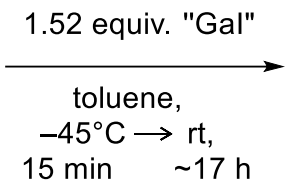

$15 \min \sim 17 \mathrm{~h}$

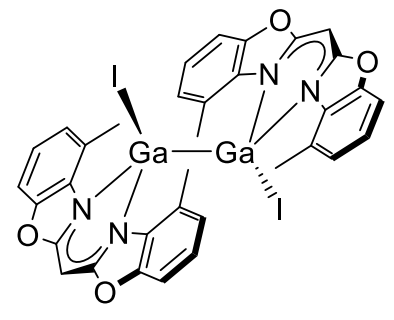

$8 \mathbf{a}$

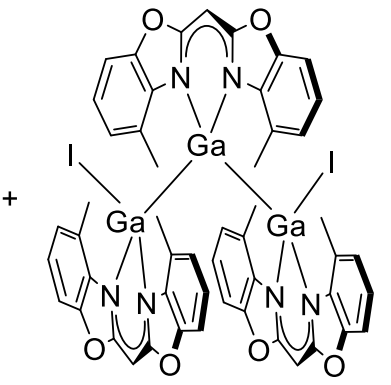

8b

Scheme 2-10. Salt metathesis reaction of 6 and "Gal" resulted in a product mixture of $\left[\mathrm{Ga}^{\mathrm{III}} \mathrm{I}\left({ }^{4-\mathrm{Me}} \mathrm{Box}_{2} \mathrm{CH}\right)\right]_{2}$ (8a) and trimeric $\left[\left({ }^{4-\mathrm{Me}} \mathrm{Box}_{2} \mathrm{CH}\right) \mathrm{Ga}^{\mathrm{I}} \mathrm{Ga}^{\mathrm{II}}{ }_{2} \mathrm{I}_{2}\left({ }^{4-\mathrm{Me}} \mathrm{Box}_{2} \mathrm{CH}\right)_{2}\right](\mathbf{8 b})$.

in the reaction. With this in mind, precooled toluene $\left(-45^{\circ} \mathrm{C}\right)$ was added to the lithium precursor 6 and $~ 1.5$ equiv. of "GaI" (Scheme 2-10). After the yellow-green suspension had been stirred at this temperature for $15 \mathrm{~min}$, it was allowed to warm to ambient temperature and stirred overnight. Volatiles were removed under reduced pressure, and the residue was extracted with toluene. Slow evaporation of toluene yielded yellow crystals of dimeric $\left[\mathrm{Ga}^{\mathrm{II}}{ }^{4}\left({ }^{4-\mathrm{Me}} \mathrm{Box}_{2} \mathrm{CH}\right)\right]_{2}(8 \mathrm{a})$ and trimeric $\left[\left({ }^{4-M e} \mathrm{Box}_{2} \mathrm{CH}\right) \mathrm{Ga}^{\mathrm{I}} \mathrm{Ga}^{\mathrm{II}} \mathrm{I}_{2}\left({ }^{4-\mathrm{Me}} \mathrm{Box}_{2} \mathrm{CH}\right)_{2}\right](\mathbf{8 b})$ suitable for single crystal XRD analyses. The dimeric species 8a (Figure 2-13) crystallised in monoclinic space group $C 2$ with two half molecules in the asymmetric unit.
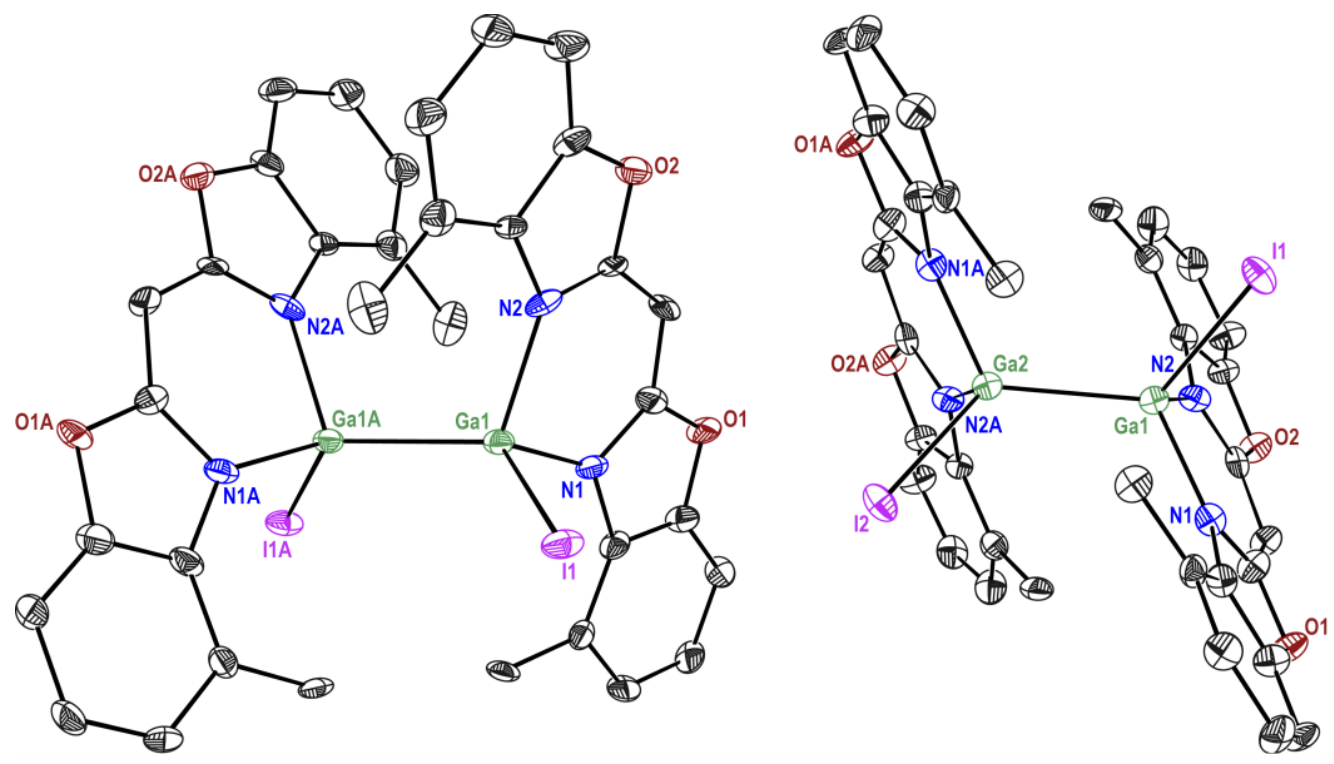

Figure 2-13. Solid-state structure of digallane 8a depicted from two different angles. Anisotropic displacement parameters are depicted at 50\% probability level. Hydrogen atoms are omitted for clarity.

The solid structure of digallane $8 \mathbf{a}$ displays a $\mathrm{Ga}^{\mathrm{II}} \mathrm{I}_{2}$ core unit that is $\kappa^{2}-N, N^{\prime}$-coordinated by two monoanionic ( $\left.{ }^{4-\mathrm{Me}} \mathrm{Box}_{2} \mathrm{CH}\right)$ ligands, respectively. These two ligands $\left(\mathrm{C}_{3} \mathrm{~N}_{2}\right.$ moieties) are slightly twisted to one another, enclosing an angle of about $25.1^{\circ}$ or $35.3^{\circ}$. The gallium atoms themselves are 
coordinated in a distorted tetrahedral fashion, while bond lengths of Ga-N 1.966(9) to 2.017(10) $\AA$, Ga-I 2.5839(14) to 2.5893(15) $\AA$ and Ga-Ga 2.470(2) to 2.464(2) $\AA$ are observed. These distances are in agreement with related four- and five-membered digallanes, for example, $\left[\mathrm{Ga}^{\mathrm{II}} \mathrm{I}\left((\mathrm{DippN})_{2} \mathrm{CR}\right)\right]_{2}{ }^{[53 \mathrm{a}, 139]}(\mathrm{R}=\mathrm{H}, \mathrm{Me}, t \mathrm{Bu})$ or $\left[\mathrm{Ga}^{\mathrm{II}} \mathrm{I}(\mathrm{RNCH})_{2}\right]_{2}{ }^{[140]}\left(\mathrm{R}=\mathrm{Dipp},{ }^{\mathrm{t}} \mathrm{Bu}\right)$. Additionally, complex 8a comprises bite angles $\mathrm{N}-\mathrm{Ga}-\mathrm{N}$ of $94.4(3)^{\circ} / 95.4(4)^{\circ}$, torsion angles $\mathrm{I}-\mathrm{Ga}-\mathrm{Ga}-\mathrm{I}$ of circa $110.83^{\circ} /-110.43^{\circ}$ as well as dislocations of $\mathrm{Ga} \cdots \mathrm{C}_{3} \mathrm{~N}_{2}$ moiety of $0.060(13) / 0.089(13) \AA$ (Table 2-3). These values are comparable to the related six-membered species $\left[\mathrm{Ga}{ }^{\mathrm{II}} \mathrm{I}\left({ }^{\mathrm{Dmp}} \mathrm{NacNac}\right)\right]_{2}^{[141]}(\mathrm{Dmp}=$ $\mathrm{C}_{6} \mathrm{H}_{3}-2,6-\mathrm{Me}_{2}$ ) published by Braun et al., which shows a similar bite angle $\mathrm{N}-\mathrm{Ga}-\mathrm{N}$ of $95.63(14)^{\circ}$ whereas the torsion angle I-Ga-Ga-I of $-82.02^{\circ}$ as well as the distance $\mathrm{Ga} \cdots \mathrm{C}_{3} \mathrm{~N}_{2}$ plane of $0.741 \AA$ significantly differ from $\mathbf{8 a}$. In addition, DFT calculations were performed on digallane $\mathbf{8 a}$ using the pbe0/def2-TZVP $\left(\mathrm{Ga}, \mathrm{I}, \mathrm{C}_{3} \mathrm{~N}_{2}\right)$ and def2-SVP $(\mathrm{O}, \mathrm{C}, \mathrm{H})$ level of theory (for details, see chapter 4.1.5). ${ }^{[142]}$ The optimised gas-phase structure is in good accordance $(\mathrm{RMS}=0.284$, RMSD $=0.275$ ) with the measured solid-state structure (Table 2-3). According to the Löwdin bond order of 0.9401, the GaGa bond $\left(2.457 \AA, \Delta_{\text {calc-exp }}=-1.00^{-20} \AA\right)$ is a non-polar single bond. Considering the NBO analysis, the gallium atoms are bond by two sp hybrid orbitals. ${ }^{[143]}$

Table 2-3. Experimental and calculated (pbe0/def2-TZVP $\left(\mathrm{Ga}, \mathrm{I}, \mathrm{C}_{3} \mathrm{~N}_{2}\right)$ and def2-SVP $(\mathrm{O}, \mathrm{C}, \mathrm{H})$ ) bond lengths ( $(\AA)$ and angles $\left(^{\circ}\right)$ of $8 \mathbf{a}$ and $\mathbf{8 b}$.

\begin{tabular}{|c|c|c|c|c|}
\hline & $\begin{array}{c}{\left[\mathrm{Ga}^{\mathrm{II}} \mathrm{I}\left(\mathrm{Box}_{2} \mathrm{CH}\right)\right]_{2}} \\
(8 \mathrm{a})\end{array}$ & $\begin{array}{l}\text { Calculated } \\
(8 a)\end{array}$ & $\begin{array}{c}{\left[\left({ }^{4-\mathrm{Me}} \mathrm{Box}_{2} \mathrm{CH}\right) \mathrm{Ga}^{\mathrm{I}}\right.} \\
\left.\mathrm{Ga}^{\mathrm{II}}{ }_{2} \mathrm{I}_{2}\left({ }^{4-\mathrm{Me}}{ }^{-} \mathrm{Box}_{2} \mathrm{CH}\right)_{2}\right] \\
(8 \mathbf{b})\end{array}$ & $\begin{array}{c}\text { Calculated } \\
(8 b)\end{array}$ \\
\hline $\mathrm{Ga}^{\mathrm{II}}-\mathrm{N}$ & $\begin{array}{c}1.968(10), \\
2.017(10) \\
1.966(9) \\
1.980(9)\end{array}$ & $\begin{array}{l}2.006 \\
2.018\end{array}$ & $\begin{array}{l}1.984(7), \\
2.002(7), \\
1.979(7), \\
1.996(6)\end{array}$ & $\begin{array}{l}2.017 \\
2.004 \\
2.014 \\
2.013\end{array}$ \\
\hline $\mathrm{Ga}^{\mathrm{I}}-\mathrm{N}$ & - & - & $\begin{array}{l}2.007(6) \\
2.018(6)\end{array}$ & $\begin{array}{l}2.028 \\
2.027\end{array}$ \\
\hline $\mathrm{Ga}^{\mathrm{II}}-\mathrm{I}$ & $\begin{array}{l}2.5893(15) \\
2.5839(14)\end{array}$ & 2.578 & $\begin{array}{l}2.5479(13), \\
2.5611(13)\end{array}$ & $\begin{array}{l}2.580 \\
2.588\end{array}$ \\
\hline Ga-Ga & $\begin{array}{l}2.470(2), \\
2.464(2)\end{array}$ & 2.457 & $\begin{array}{l}2.4855(14), \\
2.4901(14)\end{array}$ & $\begin{array}{l}2.499 \\
2.519\end{array}$ \\
\hline $\mathrm{Ga}^{\mathrm{II}}-\mathrm{Ga}^{\mathrm{I}}-\mathrm{Ga}^{\mathrm{II}}$ & - & - & $135.41(5)$ & 138.11 \\
\hline $\mathrm{N}-\mathrm{Ga}^{\mathrm{II}}-\mathrm{N}$ & $\begin{array}{l}95.4(4), \\
94.4(3)\end{array}$ & 93.80 & $\begin{array}{l}94.0(3), \\
93.9(3),\end{array}$ & $\begin{array}{l}93.30, \\
93.23,\end{array}$ \\
\hline $\mathrm{N}-\mathrm{Ga}^{\mathrm{I}}-\mathrm{N}$ & - & - & $93.2(2)$ & 92.00 \\
\hline $\mathrm{Ga}^{\mathrm{II}} \ldots \mathrm{C}_{3} \mathrm{~N}_{2}$ plane & $\begin{array}{l}0.060(13), \\
0.089(13)\end{array}$ & 0.071 & $\begin{array}{l}0.258(11), \\
0.196(10),\end{array}$ & $\begin{array}{l}0.176 \\
0.235\end{array}$ \\
\hline $\mathrm{Ga}^{\mathrm{I}} \cdots \mathrm{C}_{3} \mathrm{~N}_{2}$ plane & - & - & $0.047(10)$ & 0.013 \\
\hline $\begin{array}{l}\text { Folding angle } \\
\qquad \mathrm{Ga}^{\mathrm{II}}\end{array}$ & $\begin{array}{l}6.1(5), \\
5.9(4)\end{array}$ & $\begin{array}{l}19.97 \\
19.95\end{array}$ & $\begin{array}{l}\text { 17.4(3), } \\
13.4(3),\end{array}$ & $\begin{array}{l}8.47 \\
8.92\end{array}$ \\
\hline $\mathrm{Ga}^{\mathrm{I}}$ & - & - & $13.4(2)$ & 12.80 \\
\hline
\end{tabular}



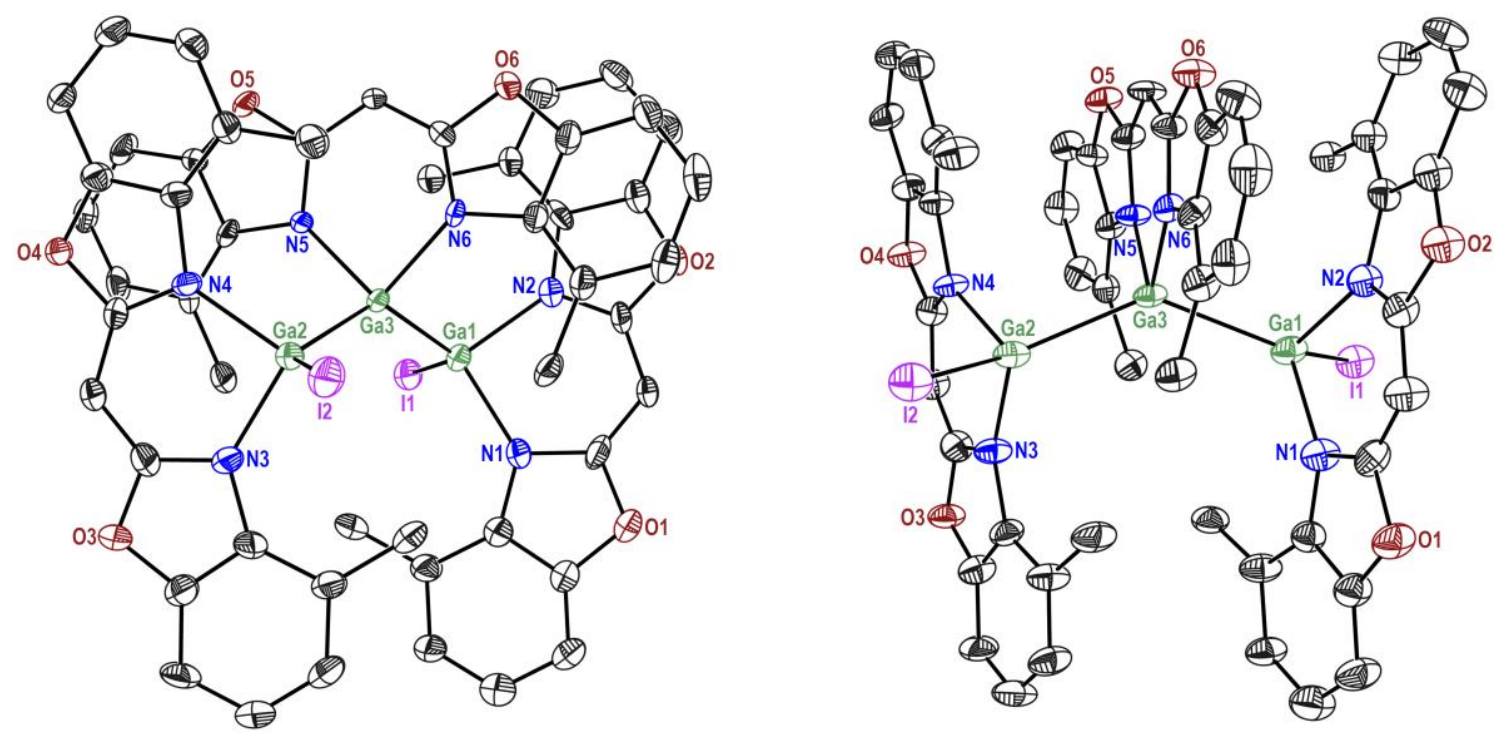

Figure 2-14. Solid-state structure of trigallane $\mathbf{8 b}$ depicted from two different angles. Anisotropic displacement parameters are depicted at 50\% probability level. Hydrogen atoms are omitted for clarity.

The trimeric $\left[\left({ }^{4-\mathrm{Me}} \mathrm{Box}_{2} \mathrm{CH}\right) \mathrm{Ga}^{\mathrm{I}} \mathrm{Ga}^{\mathrm{II}}{ }_{2} \mathrm{I}_{2}\left({ }^{4-\mathrm{Me}} \mathrm{Box}_{2} \mathrm{CH}\right)_{2}\right] \mathbf{8 b}$ crystallises in the triclinic space group $P \overline{1}$ with one complex molecule in the asymmetric unit (Figure 2-14). The trigallane consists of a central $\mathrm{Ga}^{\mathrm{I}}\left({ }^{4-\mathrm{Me}} \mathrm{Box}_{2} \mathrm{CH}\right)$ moiety that is coordinated by two $\mathrm{Ga}^{\mathrm{II}} \mathrm{I}\left({ }^{4-\mathrm{Me}} \mathrm{Box}_{2} \mathrm{CH}\right)$ fragments. Furthermore, angles calculated between $\mathrm{C}_{3} \mathrm{~N}_{2}$ planes of neighbouring ligands $\left(18.5(4)^{\circ}, 15.74(3)^{\circ}\right)$ display a less twisted or more parallel alignment between those compared to 8a. The two Ga-Ga bonds (Ga1-Ga3 2.4855(14) $\AA$, Ga2-Ga3 2.4901(14) $\AA$ ) are somewhat elongated compared to 8a but within the range of complexes containing a $\mathrm{Ga}_{3}$ chain, for instance, 2.541(1) $\AA$ and 2.460(1) $\AA$ in $\left[\left(\mathrm{Et}_{3} \mathrm{P}\right) \mathrm{Ga}^{\mathrm{II}} \mathrm{IGa}_{2} \mathrm{II}_{2}\left(\mathrm{Et}_{3} \mathrm{P}\right)_{2}\right]^{[144]}, 2.415(1) \AA$ to $2.438(2) \AA$ in $\left[\left({ }^{\mathrm{t}} \mathrm{BuC}\{\mathrm{N} R\}_{2}\right) \mathrm{Ga}^{\mathrm{I}} \mathrm{Ga}^{\mathrm{II}}{ }_{2} \mathrm{I}_{2}\left(\{R \mathrm{~N}\}_{2} \mathrm{C} \mathrm{Bu}\right)_{2}\right]^{[53]}(R$ $={ }^{i} \mathrm{Pr}$, cylco-hexyl $)$ or $2.4436(18) \AA$ to $2.5062(17) \AA$ in $\left[\mathrm{Ga}^{\mathrm{I}} \mathrm{XGa}_{2}{ }_{2}{ }_{2} \mathrm{X}_{2}\left({ }^{\mathrm{Dipp} N a c N a c}\right)_{2}\right]^{[145]}(X=\mathrm{Cl}, \mathrm{Me})$. In comparison to the amidinate based trigallanes ${ }^{[53]}$ reported by Linti et al., the Ga1-Ga3-Ga2 $135.41(5)^{\circ}$ angle (Table 2-3) is less acute while the $\mathrm{NacNac}^{[145]}$ containing complex by Fischer et al. shows a similar angle of $135.48(3)^{\circ}$. Moreover, the bite angle $\mathrm{N}-\mathrm{Ga}-\mathrm{N}$ of all fragments are almost equal (Table 2-3). Interestingly, the central gallium ion shows slightly longer $\mathrm{Ga}-\mathrm{N}$ bonds compared to the $\mathrm{Ga}^{\mathrm{II}}-\mathrm{N}$ bonds $\left(\Delta \mathrm{Ga}^{\mathrm{I} / \mathrm{II}}-\mathrm{N} \sim 0.022(7)\right.$ ) in the complex periphery. This might be explained by Bent's rule, meaning that the electronegative iodine atoms impose a p-character in Ga1-I1 and Ga2I2, whereas the s-character in the Ga-N bonds is increased. ${ }^{[146]}$ In addition, the central $\left.\mathrm{Ga}^{\mathrm{I}}{ }^{4-\mathrm{Me}} \mathrm{Box}_{2} \mathrm{CH}\right)$ fragment shows the smallest dislocation of metal ion $(\mathrm{Ga} 3)$ and $\mathrm{C}_{3} \mathrm{~N}_{2}$ plane $(0.047(10) \AA)$, which is most likely explained by its more symmetrical coordination environment. Moreover, the folding angles of the $\left({ }^{4-\mathrm{Me}} \mathrm{Box}_{2} \mathrm{CH}\right)$ ligands ranging between $13.4(3)^{\circ}$ and $17.4(3)^{\circ}$ do not seem to be affected by the oxidation state of the coordinating gallium centre. However, these angles are more distinctive than in digallane $\mathbf{8 a}$ (Table 2-3). DFT calculations on $\mathbf{8 b}$ using the pbe0/def2-TZVP $\left(\mathrm{Ga}, \mathrm{I}, \mathrm{C}_{3} \mathrm{~N}_{2}\right)$ and def2-SVP $(\mathrm{O}, \mathrm{C}, \mathrm{H})$ level of theory are in good agreement (RMS = $0.057, \mathrm{RMSD}=0.258$ ) with the parameters of the solid-state structure (Table 2-3).${ }^{[142]}$ According to the obtained Löwdin bond orders of 0.916 and 0.924 , the Ga-Ga bond (2.499 and 2.519 $\AA$ ) is a single bond. NBO analyses show that the gallium atoms are bond by three sp-hybrid orbitals. ${ }^{[143]}$ 
The signals in the NMR spectra could not be unequivocally assigned owing to the formation of a product mixture, including starting materials as well as decomposition products such as $\left[(\mu-\mathrm{O})\left\{\mathrm{Ga}^{\mathrm{III}} \mathrm{I}_{2}\left({ }^{4-\mathrm{Me}} \mathrm{Box}_{2} \mathrm{CH}\right)\right\}_{2}\right]$. However, the synthesis of dimeric $8 \mathbf{a}(\mathrm{m} / \mathrm{z}(\%) 946.8(100))$ and trimeric $8 \mathrm{~b}$ ( $\mathrm{m} / \mathrm{z}(\%) 1292.5$ (15)) was verified by mass spectrometry (LIFDI, toluene). So far, it was not possible to selectively synthesise compound $\mathbf{8 a}$ and $\mathbf{8 b}$ or to separate both complexes from each other. Because of that, and due to the higher abundancy ${ }^{[8]}$ of aluminium, the focus was shifted to the synthesis of lighter aluminium analogues.

Especially, the Al-I bond is prone to reduction ${ }^{[14 a, 37 a, 147]}$ with strong reducing agents for example potassium, sodium ${ }^{[15 d, 148]}$ or magnesium $(\mathrm{I})^{[42 b, 149]}$ compounds. Thus, different synthesis routes for $\left[\mathrm{All}_{2}\left({ }^{4-\mathrm{Me} B o x}{ }_{2} \mathrm{CH}\right)\right]$ (9) were investigated (Scheme 2-11). First of all, precursor 1 and freshly sublimated aluminium triiodide were reacted in toluene $(\operatorname{method} A)$. Starting at $0^{\circ} \mathrm{C}$, the solution was warmed to ambient temperature and stirred overnight. After workup, complex 9 was isolated in poor yields. This might be owed to the fact that compound 9 has a low solubility in toluene, which was used for extraction in the workup process, while ethers e.g., THF, were avoided on account of ether cleavage in the following reduction.

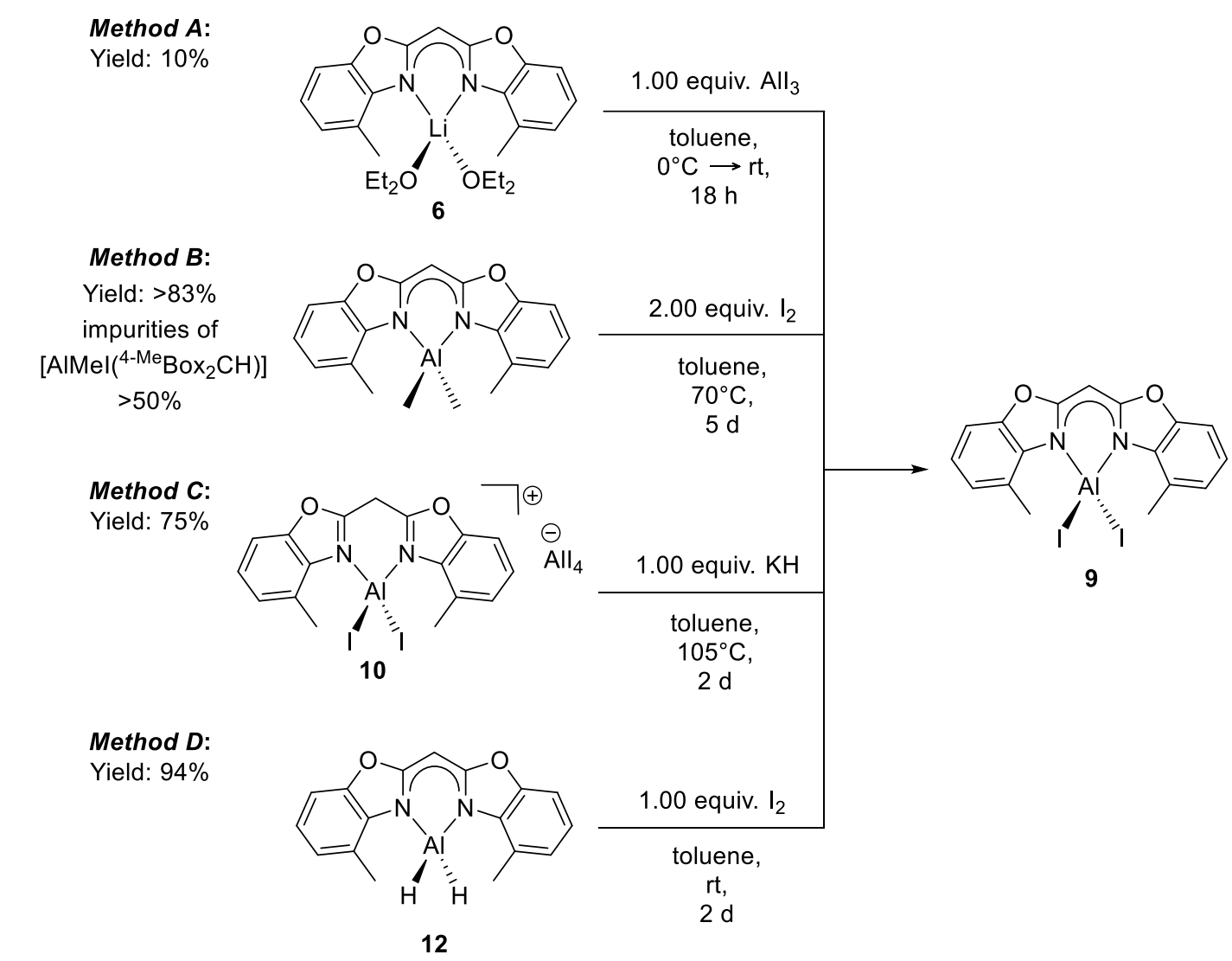

Scheme 2-11. Various synthesis routes of $\left[\mathrm{AlI}_{2}\left({ }^{4-\mathrm{Me}} \mathrm{Box}_{2} \mathrm{CH}\right)\right](9)$.

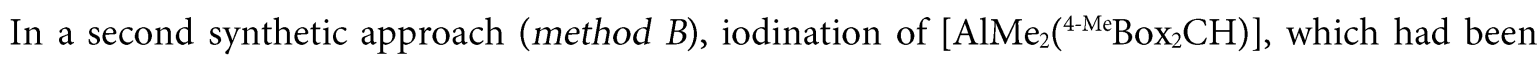
synthesised according to literature, ${ }^{[106]}$ was investigated. For this purpose, the dimethyl aluminium species was dissolved in toluene and first reacted with one equivalent of iodine at ambient temperature. After the purple solution had been stirred for $3 \mathrm{~h}$ at ambient temperature and $70^{\circ} \mathrm{C}$ 
overnight, a second equivalent of iodine was added to the orange-red solution. A white precipitate formed and the obtained suspension was heated $5 \mathrm{~d}$ at $70^{\circ} \mathrm{C}$, allowed to cool to ambient temperature and filtered. The obtained brownish solid was washed with hexane and dried under reduced pressure. Unfortunately, the reaction was incomplete, probably due to the poor solubility of

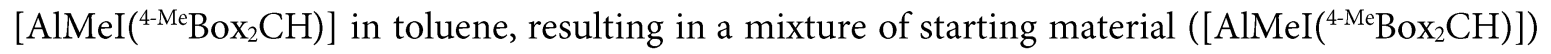
and 9.

A third synthetic approach was investigated (method $C$ ) because of the dissatisfying results of method $A$ to $B$. This synthesis route is inspired by the dipyridyl methane $\left(\left\{2-\mathrm{Py}_{2} \mathrm{CH}_{2}\right)\right.$ ligand, which was utilised by Tuononen et al. to synthesise complexes $\left[\mathrm{AlCl}_{2}\left(\left\{2-\mathrm{Py}_{2} \mathrm{CH}_{2}\right)_{2}\right]^{+}\left[\mathrm{AlCl}_{4}\right]^{-}\right.$or $\left[\mathrm{AlCl}_{2}(\{2-\right.$ $\left.\left.\mathrm{Py}_{2} \mathrm{CH}_{2}\right)\right]^{+} \mathrm{Cl}^{-} /\left[\mathrm{AlCl}_{4}\right]^{-}$depending on the ratio of starting materials and solvents (see Chapter 1.2,

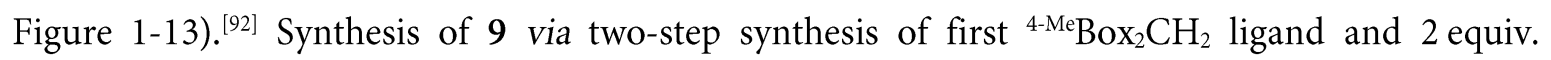
aluminium iodide and subsequent deprotonation were investigated. For this purpose, aluminium iodide and ${ }^{4-}{ }^{-}{ }^{-}{ }_{0 x} \mathrm{CH}_{2}$ were stirred in toluene at ambient temperature for $15 \mathrm{~min}$. After the suspension had been refluxed at $120^{\circ} \mathrm{C}$ for $3 \mathrm{~d}$, it was cooled to ambient temperature and the supernatant solution was separated by filtration.
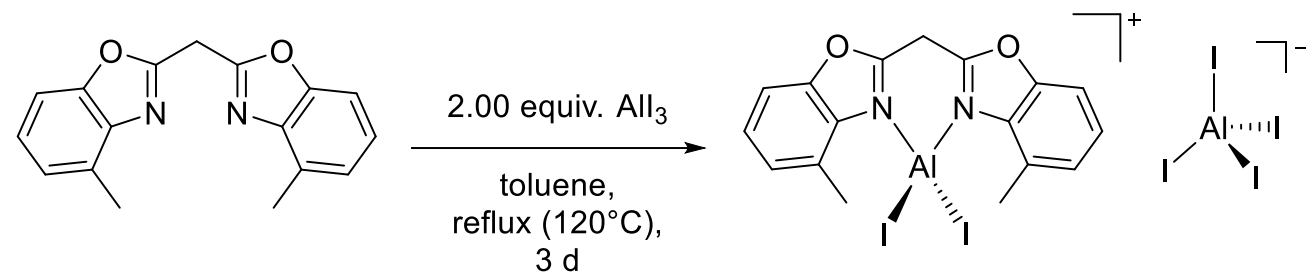

$$
\begin{gathered}
10 \\
94 \%
\end{gathered}
$$

Scheme 2-12. Synthesis of $\left[\mathrm{AlI}_{2}\left({ }^{4-\mathrm{Me}} \mathrm{Box}_{2} \mathrm{CH}_{2}\right)\right]^{+}\left[\mathrm{AlI}_{4}\right]^{-}(10)$ starting from neutral ${ }^{4-\mathrm{Me}} \mathrm{Box}_{2} \mathrm{CH}_{2}$.

To remove the unreacted ligand, the white filter cake was washed with pentane and dried under reduced pressure. Compound 10 was finally isolated as a white powder in excellent yield (YLD: 94\%). Crystals of $\left[\mathrm{AlI}_{2}\left({ }^{4-\mathrm{Me} B o{ }_{2}} \mathrm{CH}_{2}\right)\right]^{+}\left[\mathrm{AlI}_{4}\right]^{-}(10)$ suitable for single crystal XRD measurements were grown out of a saturated DCM solution by slow evaporation. The aluminium salt crystallises in the monoclinic space group $P 2_{1} / n$ with one complex molecule and its counterion in the asymmetric unit (Figure 2-15).
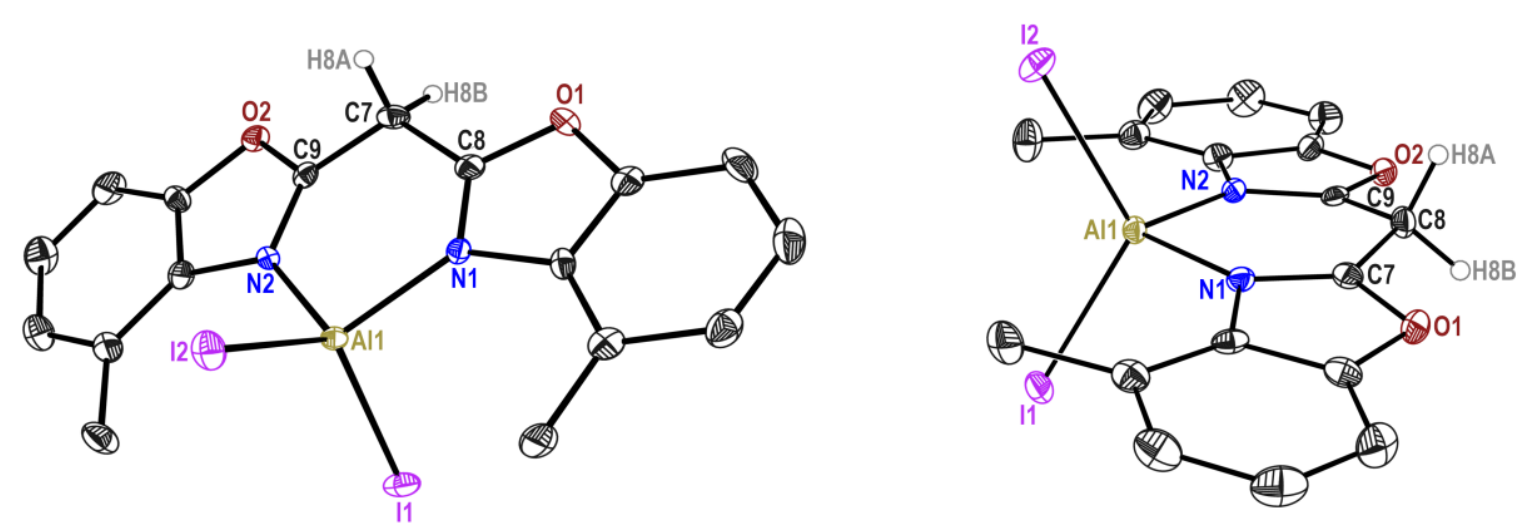

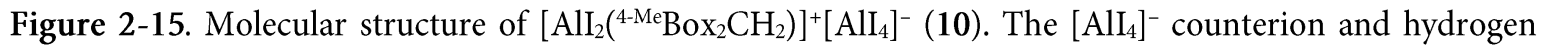
atoms except for $\mathrm{H} 8 \mathrm{~A}$ and $\mathrm{H} 8 \mathrm{~B}$ are omitted for clarity. Anisotropic displacement parameters are depicted at $50 \%$ probability level. 
The metal centre Al2 is almost perfectly tetrahedral coordinated (I-Al-I 106.31(4) ${ }^{\circ}$ to $\left.111.76(4)^{\circ}\right)$, caused by the unitary substituents in the tetraiodido anion, while the second aluminium ion Al1 features a distorted tetrahedral coordination. The two imine nitrogen aluminium bonds in $\mathbf{1 0}$ are elongated (Al1-N1 1.931(3) $\AA$, Al1-N2 $1.927(3) \AA)$ in comparison to $\left[\mathrm{AlI}_{2}\left(\mathrm{Box}_{2} \mathrm{CH}_{2}\right)\right](\mathrm{Al} 1-\mathrm{N} 1$ $1.8713(13) \AA, 1.8665(13) \AA)^{[2]}$, probably because of the less pronounced electron density at the nitrogen atoms correlating with the two protons at the ligand backbone. Thereby, the $\mathrm{C}_{3} \mathrm{~N}_{2}$ plane comprises bond lengths of C7-N1 1.312(4) $\AA$ and C9-N2 1.313(4) $\AA$ as well as C7-C8 1.477(5) $\AA$ and C8-C9 1.475(5) $\AA$ indicating a localised double bonds between $\mathrm{C}-\mathrm{N}\left(\mathrm{N}\left(\mathrm{sp}^{2}\right)=\mathrm{C}\left(\mathrm{sp}^{2}\right) 1.29 \AA\right.$; $\left(\mathrm{sp}^{2}\right)-$ $\left.\mathrm{C}\left(\mathrm{sp}^{2}\right) 1.40 \AA\right)$ and $\mathrm{C}-\mathrm{C}$ single bonds $\left(\mathrm{C}\left(\mathrm{sp}^{2}\right)=\mathrm{C}\left(\mathrm{sp}^{2}\right) 1.47 \AA ; \mathrm{C}\left(\mathrm{sp}^{2}\right)-\mathrm{C}\left(\mathrm{sp}^{3}\right) 1.51 \AA\right) .{ }^{[137]}$ The absence of a conjugated system within the $\mathrm{C}_{3} \mathrm{~N}_{2}$ unit causes an increased folding angle of $11.67(9)^{\circ}$ between the two benzoxazolyl fragments. This is accompanied by a dislocation $(0.123(4) \AA)$ of the aluminium ion from the NacNac mimicking unit. Compound 10 displays poor solubility in most common solvents except for DCM due to its salt-like character. The ${ }^{1} \mathrm{H}$ NMR spectrum of compound 10 shows a significant downfield shift of the methane bridge $\left(\Delta \delta\left(-\mathrm{CH}_{2}-\right) 1.49 \mathrm{ppm}\right)$, methyl groups $\left(\Delta \delta\left(-\mathrm{CH}_{3}\right)\right.$ $0.72 \mathrm{ppm}$ ) and aryl protons compared to the bare ligand, caused by the introduction of the cationic $\mathrm{AlI}_{2}^{+}$fragment.
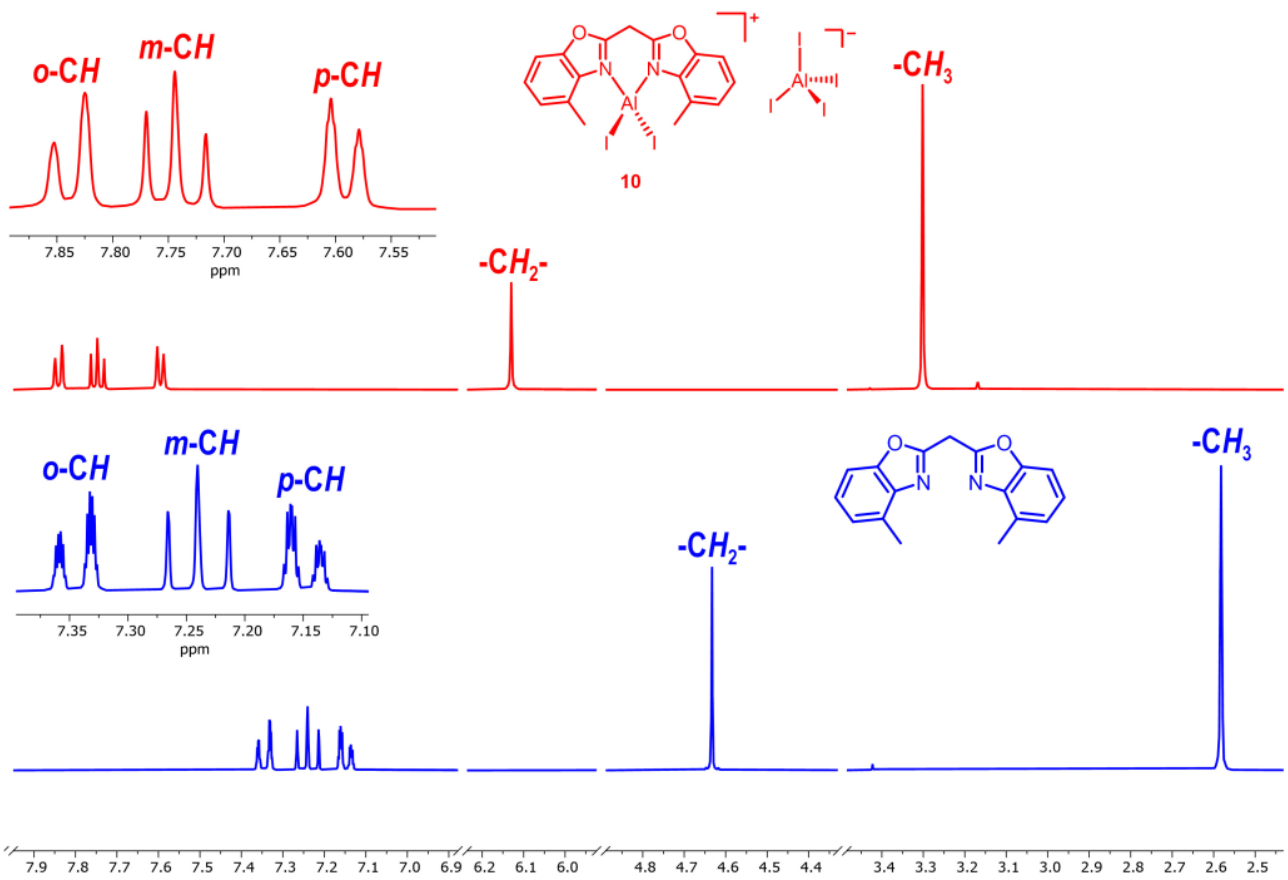

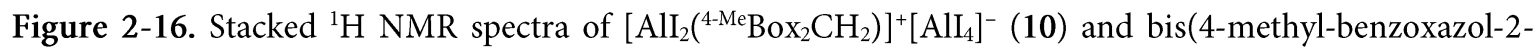
yl)methane in DCM- $d_{2}$.

Moreover, the ${ }^{27} \mathrm{Al}$ NMR spectrum revealed a broad resonance $\left(\omega_{1 / 2}=515 \mathrm{~Hz}\right)$ for

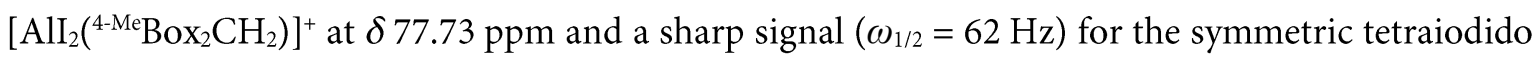
aluminiuminate at $\delta 25.74 \mathrm{ppm}$. These chemical shifts coincide with literature values of related aluminium compounds $\left(\left[\mathrm{AlI}_{4}\right]^{-}\left(\mathrm{MeCN}-d_{3}\right)^{[150]}: \delta 28 \mathrm{ppm}\right.$; [AlMe $\left.2\left({ }^{\text {Dipp NacNac}}\right)\right]$ (benzene- $\left.d_{6}\right)^{[14 a]}: \delta$

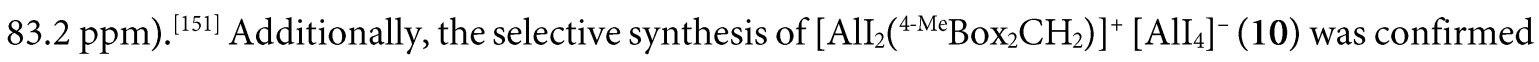
by elemental analysis. 
In further reaction, compound 10 was deprotonated with potassium hydride (method $C$ ). For this purpose, the two starting materials were mixed in toluene and reacted at $105^{\circ} \mathrm{C}$ for $2 \mathrm{~d}$ caused by their poor solubility. After that, the solution turned yellow, and a white precipitate appeared. This mixture was allowed to cool to ambient temperature and then filtered. Volatiles were removed in vacuo, and $\left[\mathrm{AlI}_{2}\left({ }^{4-\mathrm{Me}} \mathrm{Box}_{2} \mathrm{CH}\right)\right]$ (9) was isolated as an off-white solid in good yields (75\%). Disadvantages of method $C$ are the more elaborate reaction procedures and minor impurities of $\mathrm{K}\left[\mathrm{AlI}_{4}\right]$ salt, which can not be excluded entirely.

In another reaction (method $D$ ) compound 9 was synthesised by iodination of $\left[\mathrm{AlH}_{2}\left({ }^{4-\mathrm{Me}^{e} \mathrm{Box}} 2 \mathrm{CH}\right)\right]$ (12) (for synthesis vide infra) according to Stasch et al. or Jones et al. ${ }^{[56,139]}$ In the course of this, alane 12 was dissolved in toluene and reacted with one equivalent of iodine at ambient temperature. The reaction of the two starting materials was characterised by a quick change of colour from yellow to red back to yellow and the formation of hydrogen gas. After the reaction mixture had been stirred for $2 \mathrm{~d}$, a yellow solution and a white precipitate could be observed. Subsequently, volatiles were evaporated, and obtained precipitate was dried under reduced pressure. Compound 9 was isolated as a yellowish-white solid in excellent yields and used for synthesis without further purification. In summary, method $D$ is the most convenient synthesis route for 9 due to short reaction times and excellent yields. Crystals suitable for single crystal XRD measurements were grown out of a saturated toluene solution at $-20^{\circ} \mathrm{C}$ after a few days. $\left[\mathrm{AlI}_{2}\left({ }^{4-\mathrm{Me}} \mathrm{Box} 2 \mathrm{CH}\right)\right](9)$ crystallises in the triclinic space group $P \overline{1}$ with one complex molecule in the asymmetric unit (Figure 2-17). The aluminium ion is coordinated by nitrogen (Al1-N1 1.8873(16) $\AA$, Al1-N2 1.8840(16) $\AA$ ), and iodine (Al1-I1 2.5284(8) $\AA$, Al1-I2 2.5275(9) $\AA$ ) atoms in a distorted tetrahedral fashion. This distorted geometry is accompanied by bite angles of N1-Al1-N2 $99.35(7)^{\circ}$ and I1-Al1-I2 of $117.75(3)^{\circ}$. Furthermore, a dislocation between $\mathrm{Al}^{\mathrm{III}}$ ion and $\mathrm{C}_{3} \mathrm{~N}_{2}$ plane of $0.026(2) \AA$ as well as butterfly folding angle of $5.47(6)^{\circ}$ were detected. The latter parameters are slightly reduced in relation to unsubstituted $\left[\mathrm{AlI}_{2}\left(\mathrm{Box}_{2} \mathrm{CH}\right)\right]$ (5). However, relevant bond lengths (Al1-N1/2, Al1-I1/2, N1/2-C7/9, C7/9-C8) and angles (N1Al1-N2, I1-Al1-I2) (Table 2-4) are slightly elongated or expanded compared to 5.
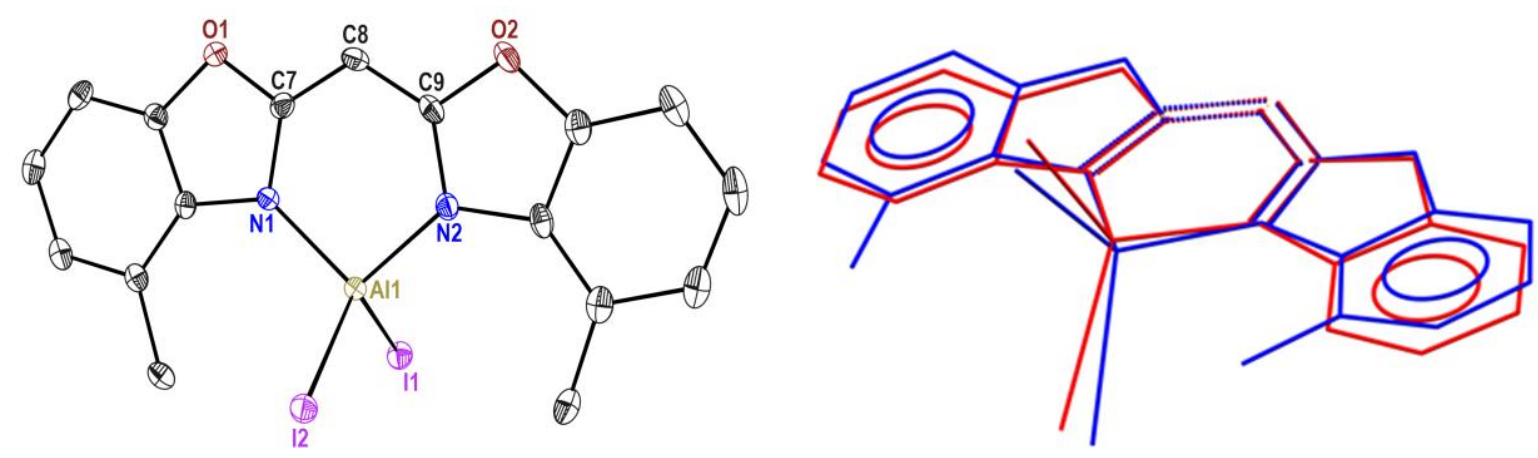

Figure 2-17. Molecular structure of $\left[\mathrm{AlI}_{2}\left({ }^{4-\mathrm{Me} B o x}{ }_{2} \mathrm{CH}\right)\right](9)$ (left). Anisotropic displacement parameters are depicted at $50 \%$ probability level. Hydrogen atoms are omitted for clarity. Superimposed structure of compound 9 and the unsubstituted complex $\left[\mathrm{AlI}_{2}\left(\mathrm{Box}_{2} \mathrm{CH}\right)\right](5)$ (right). 
The ${ }^{1} \mathrm{H}$ NMR spectrum of compound 9 (benzene- $d_{6}$ ) displays a downfield shift of the methyl residues

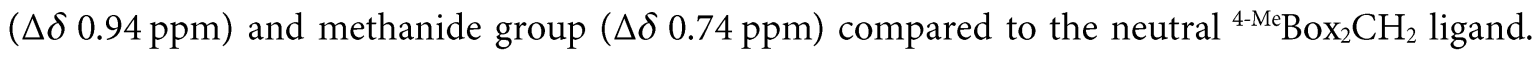
Moreover, the aromatic protons coincide in a multiplet at $\delta 6.68 \mathrm{ppm}$ (benzene- $d_{6}$ ), which

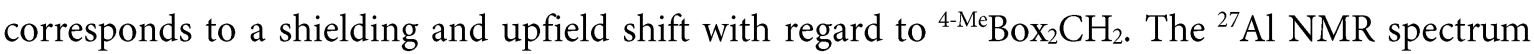
shows a broad singlet of $\delta 76.39\left(\omega_{1 / 2}=406 \mathrm{~Hz}\right) \mathrm{ppm}$. Accessorily, the synthesis of $\left[\mathrm{AlI}_{2}\left({ }^{4-\mathrm{Me}}{ }^{-\mathrm{Box}_{2} \mathrm{CH}}\right)\right]$ (9) was confirmed by LIFDI mass spectrometry ( $\mathrm{m} / z(\%) 702.0(100)[M+2 \mathrm{THF}]^{+}, 629.9$ (57) $[M+\mathrm{THF}]^{+}$.) and elemental analysis.

Table 2-4. Selected bond lengths $(\AA)$ and angles $\left(^{\circ}\right)$ of 9,10 and 11.

\begin{tabular}{|c|c|c|c|}
\hline & $\begin{array}{c}{\left[\mathrm{AlI}_{2}\left({ }^{4-\mathrm{Me}} \mathrm{Box}_{2} \mathrm{CH}\right)\right]} \\
(9)\end{array}$ & 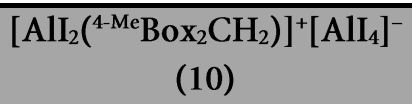 & $\begin{array}{c}{\left[\mathrm{AlI}\left({ }^{4-\mathrm{Me}} \mathrm{Box}_{2} \mathrm{CH}\right)\right]_{2}} \\
(11)\end{array}$ \\
\hline Al-N & $1.8840(16), 1.8873(16)$ & $1.930(3), 1.927(3)$ & $\begin{array}{l}1.929(6), 1.924(6), \\
1.934(8), 1.920(7)\end{array}$ \\
\hline Al-I & $2.5279(8), 2.5275(9)$ & $2.4828(11), 2.4736(11)$ & $2.583(2), 2.591(2)$ \\
\hline $\mathrm{N}-\mathrm{C}$ & $1.355(2), 1.356(2)$ & $1.312(4), 1.313(4)$ & $\begin{array}{c}1.339(9), 1.347(9), \\
1.306(10), 1.364(10)\end{array}$ \\
\hline $\mathrm{C}-\mathrm{C}$ & $1.377(3), 1.379(3)$ & $1.477(5), 1.475(5)$ & $\begin{array}{l}.376(11), 1.367(11), \\
1.413(11), 1.341(12)\end{array}$ \\
\hline $\mathrm{Al}-\mathrm{Al}$ & - & - & $2.584(4), 2.599(5)$ \\
\hline I-Al-I & $117.75(3)$ & $122.39(4)$ & - \\
\hline N-Al-N & $99.35(7)$ & $97.29(12)$ & $95.9(2), 96.0(3)$ \\
\hline Al $\ldots \mathrm{C}_{3} \mathrm{~N}_{2}$ plane & $0.026(2)$ & $0.123(4)$ & $0.087(8), 0.050(9)$ \\
\hline Folding angle & $5.47(6)$ & $11.67(9)$ & $5.8(3), 5.2(3)$ \\
\hline
\end{tabular}

Based on the diiodido aluminium complex (9), numerous reduction attempts were carried out varying the reduction agent, solvent, and reaction conditions. In general, all reaction mixtures showed a change of colour after being stirred for about one day. First, precursor 9 was reacted with potassium-based reducing agents such as finely divided $\mathrm{K}, \mathrm{KC} 8$, or $\mathrm{K} / \mathrm{KI}(5 \% \mathrm{w} / \mathrm{w})$ in the exact stoichiometric amount (1:1). In doing so, a large volume of a nonpolar aprotic solvent, e. g., toluene, had to be used because of the poor solubility of compound 9. Alas, all reaction attempts resulted in indefinable product mixtures or starting material 9. Thus, reactions were attempted with an excess of reducing agent and/or higher temperatures. However, the formation of a low-oxidation or -valent complex could not be observed either. Furthermore, reactions were carried out in diethyl ether or solvent mixtures of toluene/ether. Unfortunately, other reduction approaches of 9 with sodiumbased reducing agents $(\mathrm{Na}, \mathrm{Na} / \mathrm{NaCl}(5 \% \mathrm{w} / \mathrm{w}))$ and $\left[\mathrm{AlI}_{2}\left({ }^{4-\mathrm{Me}} \mathrm{Box}_{2} \mathrm{CH}\right)\right](9)$ also led to indefinable product mixtures. Thereafter, precursor 9 was reacted with half equiv. $\left[\mathrm{Mg}^{\mathrm{I}}\left(\mathrm{Mes}^{\mathrm{NacNac}}\right)\right]_{2},{ }^{[42 a, 152]}$ (Scheme 2-13) according to Stasch et al. and Jones et al. ${ }^{[149,153]}$ Therefore, both starting materials were mixed in small-scale NMR experiments ([ $\left.\mathrm{D}_{8}\right]$ toluene) at ambient temperature for one day. No reaction was observed (NMR), perhaps due to the poor solubility of the two reactants. Subsequently, the mixture was heated to $70^{\circ} \mathrm{C}$ in order to dissolve both starting materials. After the reaction mixture had been heated for $2 \mathrm{~d}$, the ${ }^{1} \mathrm{H}$ NMR spectrum unveiled a chemical shift of the protons, which were priorly assigned to $\left[\mathrm{Mg}^{\mathrm{I}}\left({ }^{\mathrm{Mes}} \mathrm{NacNac}\right)\right]_{2}$ and hint to the formation of by-product 
$\left[\mathrm{Mg}{ }^{\mathrm{II}}\left({ }^{\mathrm{Mes}} \mathrm{NacNac}\right)\right]_{2}^{[152 \mathrm{a}]}$. However, most of compound 9 seemed to be unreacted. Crystals grew out of the saturated yellow solution at ambient temperature after $\sim 1 \mathrm{~d}$. Light microscopic examinations and subsequent single crystal XRD analyses revealed the formation of $\left[\mathrm{Mg}^{\mathrm{II}} \mathrm{I}\left({ }^{\mathrm{Mes}} \mathrm{NacNac}\right)\right]_{2}^{[152 \mathrm{a}]}$ and $\left[\mathrm{Al}^{\mathrm{II}} \mathrm{I}\left({ }^{4-\mathrm{Me}} \mathrm{Box}_{2} \mathrm{CH}\right)\right]_{2}(11)$. In the course of this, the majority of the crystals appeared to be large, blocklike, and colourless crystals of $\left[\mathrm{Mg}^{\mathrm{III}}\left({ }^{\mathrm{Mes}} \mathrm{NacNac}\right)\right]_{2}$, whereas only a few thin trapezoidal crystals of species 11 were isolated. Traces of iodine-containing compounds might explain the formation of the magnesium diiodido by-product, e.g. $\mathrm{AlI}_{3}$ or $\mathrm{K}\left[\mathrm{All}_{4}\right]$, which would react with $\left[\mathrm{Mg}^{\mathrm{I}}(\mathrm{Mes} \mathrm{NacNac})\right]_{2}$ instead of reacting with 9 . To completely reduce precursor 9 , an excess ( 2 equiv.) of $\mathrm{Mg}^{\mathrm{I}}$ reducing agent was added. Unfortunately, this did not result in an increased amount of $\left[\mathrm{Al}^{\mathrm{II}} \mathrm{I}\left({ }^{4-\mathrm{Me}^{-} \mathrm{Box}} \mathrm{CH}\right)\right]_{2}$ (11). In further reactions, it was hitherto neither possible to separate both complexes nor increase the yield of dialane 11 .

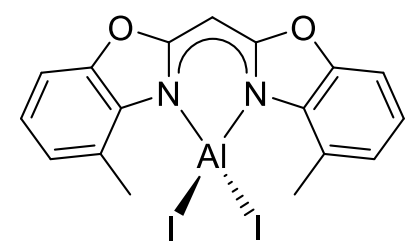

9
0.50 equiv. $\left[\mathrm{Mg}^{\mathrm{l}}\left({ }^{\mathrm{Mes}} \mathrm{NacNac}\right)\right]_{2}$

toluene, $70^{\circ} \mathrm{C}$, $2 \mathrm{~d}$

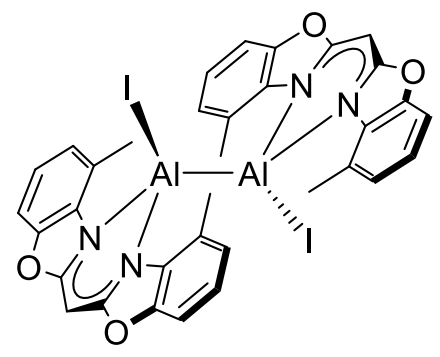

11

few crystals

Scheme 2-13. Reduction of complex (9) and $\left[\mathrm{Mg}^{\mathrm{I}\left({ }^{\mathrm{Mes}} \mathrm{NacNac}\right)}\right]_{2}$ to $\left[\mathrm{Al}^{\mathrm{II} I} \mathrm{I}\left({ }^{-\mathrm{Me}} \mathrm{Box}_{2} \mathrm{CH}\right)\right]_{2}(11)$.

Thus, dimeric aluminium(II) species 11 has only been characterised by single crystal XRD measurements. Compound 11 crystallises in the monoclinic space group $C 2$ with one molecule in the asymmetric unit. The dimeric $\left[\mathrm{Al}^{\mathrm{II}} \mathrm{I}\left({ }^{4-\mathrm{Me}} \mathrm{Box}_{2} \mathrm{CH}\right)\right]_{2}$ (11) complex is isostructural to $\left[\mathrm{Ga}^{\mathrm{II}} \mathrm{I}\left({ }^{4-\mathrm{Me}} \mathrm{Box}_{2} \mathrm{CH}\right)\right]_{2}(8 \mathrm{a})(\mathrm{RMS}=0.183, \mathrm{RMSD}=4.917)$ (Figure 2-18, right).
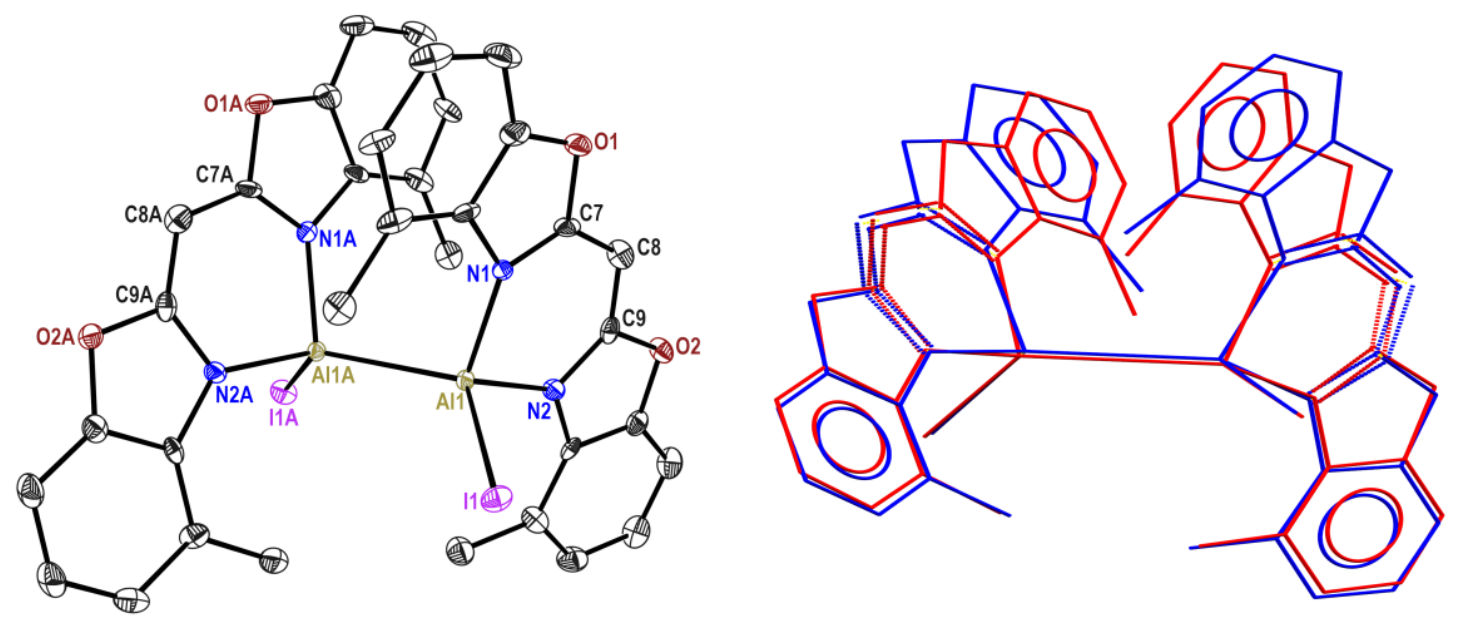

Figure 2-18. Molecular structure of $\left[\mathrm{Al}^{\mathrm{II}} \mathrm{I}\left({ }^{4-\mathrm{Me}} \mathrm{Box}_{2} \mathrm{CH}\right)\right]_{2}(11)$ (left). Anisotropic displacement parameters are depicted at $50 \%$ probability level. Hydrogen atoms are omitted for clarity. Superimposed structure of compound 11 and unsubstituted $\left[\mathrm{Ga}^{\mathrm{II}} \mathrm{I}\left({ }^{4-\mathrm{Me}} \mathrm{Box}_{2} \mathrm{CH}\right)\right]_{2}(\mathbf{8 a})$ (right). 
The $\mathrm{Al}^{\mathrm{II}}$ ions are $\kappa^{2}-N, N^{\prime}$-chelated by monoanionic ${ }^{4-\mathrm{Me}} \mathrm{Box}_{2} \mathrm{CH}$ ligands (Al-N 1.920(7) to 1.934(8) $\AA$ ) while bite angles N1-Al1-N2 of $95.9(2)^{\circ}$ and N3-Al2-N4 of $96.0(3)^{\circ}$ were detected (Table 2-4). Additionally, slightly more acute bite angles $\mathrm{N}-\mathrm{Al}-\mathrm{N}$ are observed in 11 compared to $\left[\mathrm{AlI}_{2}\left({ }^{4-\mathrm{Me}} \mathrm{Box}_{2} \mathrm{CH}\right)\right](9)$ and $\left[\mathrm{AlI}_{2}\left({ }^{4-\mathrm{Me}} \mathrm{Box}_{2} \mathrm{CH}_{2}\right)\right]^{+}\left[\mathrm{AlI}_{4}\right]^{-}(10)$. The $\mathrm{Al}-\mathrm{N}$ bond lengths of 11 are similar to those in the salt 10, whereas corresponding bonds in precursor 9 are shorter. These structural parameters show a high conformity to related [( $\left.{ }^{\mathrm{Dipp}} \mathrm{NacNac}\right) \mathrm{IAl}_{-}-\mathrm{AlI}_{2}-\mathrm{cAAC}$ ] (cAAC $=$ cyclic alkyl

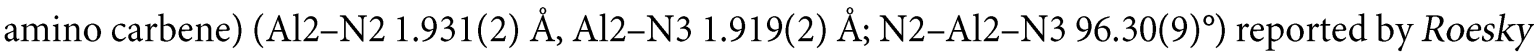
and co-workers. ${ }^{[35]}$ Moreover, the coordination sphere of aluminium consists of an iodide ion (Al1I1 2.583(2) $\AA$, Al2-I2 2.591(2) $\AA$ ) and a second aluminium fragment (Al1-Al1A 2.584(4) $\AA$, Al2Al2A 2.599(5) $\AA$ ). The $\mathrm{Al}^{\mathrm{II}}-\mathrm{Al}{ }^{\mathrm{II}}$ bond lengths of $\left[\left({ }^{\mathrm{Dipp}} \mathrm{NacNac}\right) \mathrm{IAl}-\mathrm{AlI}_{2}-\mathrm{cAAC}\right]^{[35]}$ (Al1-Al2 2.6327(11) $\AA),\left[\operatorname{AlI}\left(A r^{\prime}\right)\right]_{2}{ }^{[15 c]}\left(A r^{\prime}=\mathrm{C}_{6} \mathrm{H}_{3}-2,6-\mathrm{Dipp}\right)(\mathrm{All}-\mathrm{All} \mathrm{A} 2.609(2) \AA)$ and $\left[\mathrm{AlI}\left(\{\mathrm{DippN}\}_{2} \mathrm{NC}\right.\right.$ $\left.\left.{ }^{i} \mathrm{Pr}_{2}\right)\right]_{2}{ }^{[42 b]}$ (All-All' 2.6083(19) $\AA$ ) are slightly elongated, while in $\mathrm{LI}_{2} \mathrm{Al}-\mathrm{AlI}_{2} L$ complexes ${ }^{[154]}(L=$ $\mathrm{OEt}_{2}, \mathrm{THF}, \mathrm{PEt}_{3}$ ) (Al-Al 2.52(2) to 2.546(3) $\AA$ ) as well as [AlICp $\left.{ }^{*}\right]_{2}{ }^{[155]}$ (Al1-Al2 2.5321(10) $\AA$ ) are shortened. Besides this, dihedral angles of 11 (I1-Al1-Al1A-I1A ca. $-111.3^{\circ}$, I2-Al2-Al2A-I2A ca. $\left.110.9^{\circ}\right)$ are reduced in comparison to compounds comprising an I-Al-Al-I moiety $\left(\sim 180^{\circ}\right)^{[42 b, 154]}$, except for $\left[\mathrm{AlICp}^{*}\right]_{2}{ }^{[155]}$ (I1-Al1-Al2-I2 91.14(3) $\left.{ }^{\circ}\right)$. The two $\left\{\mathrm{Al}^{\mathrm{II}} \mathrm{I}\left({ }^{4-\mathrm{Me}} \mathrm{Box}_{2} \mathrm{CH}\right)\right\}$ fragments of 11 enclose angles of $35.5^{\circ}$ and $24.4^{\circ}$ between the two $\mathrm{C}_{3} \mathrm{~N}_{2}$ planes. Additionally, increased dislocations of the $\mathrm{Al}^{\mathrm{II}}$-ions from the $\mathrm{C}_{3} \mathrm{~N}_{2}$ planes $\left(\mathrm{Al}^{\mathrm{II}} \ldots \mathrm{C}_{3} \mathrm{~N}_{2}\right.$ plane $0.087(8)$ and $0.050(9) \AA$ ) concerning $\left[\mathrm{AlI}_{2}\left({ }^{4-\mathrm{Me}} \mathrm{Box} 2 \mathrm{CH}\right)\right]$ (9) are observed, while the butterfly folding angles are not affected by the reduction (Table 2-4). DFT calculations on 11 performed at pbe0/def2-TZVP(Al, I, $\left.\mathrm{C}_{3} \mathrm{~N}_{2}\right)$ and def2$\operatorname{SVP}(\mathrm{O}, \mathrm{C}, \mathrm{H})$ levels of theory are in good agreement $(\mathrm{RMS}=0.297$, RMSD $=0.630)$ with the solidstate structure. ${ }^{[142]}$ According to the obtained Löwdin bond order of 0.877 , the Al-Al bond (2.606 $\AA$, $\Delta_{\text {calc-exp }}=1.45^{-2} \AA$ ) is a single bond. The aluminium atoms are bond as reported for $8 \mathbf{a}$ by two sp hybrid orbitals. ${ }^{[143]}$ Compound 11 could not be further characterised, caused by its low yields (few crystals) and because it was not possible to separate it from its side product. The preorganisation, meaning a structurally caused proximity between the two aluminium centres within a precursor compound, as reported for dimeric $\left[\mathrm{AlH}_{2}\left(\mathrm{RC}\{\mathrm{NDipp}\}_{2}\right)\right]_{2}{ }^{[42 b]}\left(\mathrm{R}=\mathrm{Me}, p\right.$-tolyl, $\left.{ }^{\mathrm{t}} \mathrm{Bu}, \mathrm{N}^{\mathrm{i}} \mathrm{Pr}_{2}\right)$ or $\left[\left\{\left({ }^{\mathrm{Dep}} \mathrm{NacNac}\right) \mathrm{Mg}(\mu\right.\right.$ $\left.\left.\mathrm{H})_{3} \mathrm{AlH}\left(\mathrm{NMe}_{3}\right)\right\}_{2}\right]^{[156]}$ would most likely result in higher yields. The $\mathrm{Al}-\mathrm{H}$ bond is less ionic compared to the Al-I bond. ${ }^{[157]}$ In general, aluminium hydride compounds, e.g., $\mathrm{AlH}_{3}$ or $\mathrm{LiAlH}_{4}$, can be utilised as reducing and hydrogen storage agents. ${ }^{[158]}$ Accessorily, soluble aluminium hydride complexes such as $\left[\mathrm{AlH}_{2}(L)\right]$ ( $L={ }^{\text {Dipp } N a c N a c}$, pyrrole-based $\{\mathrm{N}, \mathrm{N}, \mathrm{N}\}$-pincer ligands) gained increasing interest caused by their potential as hydrogen catalysts in deprotonation, insertion, and activation reactions. ${ }^{[159]}$

Hence, bis(4-methyl-benzoxazol-2-yl)methane ligand was reacted with 1.12 eqiv. $\mathrm{AlH}_{3} \cdot \mathrm{NMe}_{3}$, which was priorly prepared according to Ruff and Hawthorne via reaction of $\mathrm{LiAlH}_{4}$ and $\mathrm{HNMe}_{3} \mathrm{Cl}^{[160]}$ in toluene at $-30^{\circ} \mathrm{C}$. Subsequently, the reaction mixture was slowly warmed to ambient temperature and stirred for $4 \mathrm{~h}$. About half of the solvent was removed in vacuo, and the formed precipitate was redissolved by carefully heating the mixture. Colourless crystals of N,N'-bis\{4-methyl-benzoxazol-2yl)methanide\} dihydrido aluminium (12) suitable for single crystal XRD experiments were obtained 
at $2^{\circ} \mathrm{C}$ overnight. A second crop of crystalline 12 was grown out of a concentrated mother liquor at $-30^{\circ} \mathrm{C}$ after a few days.
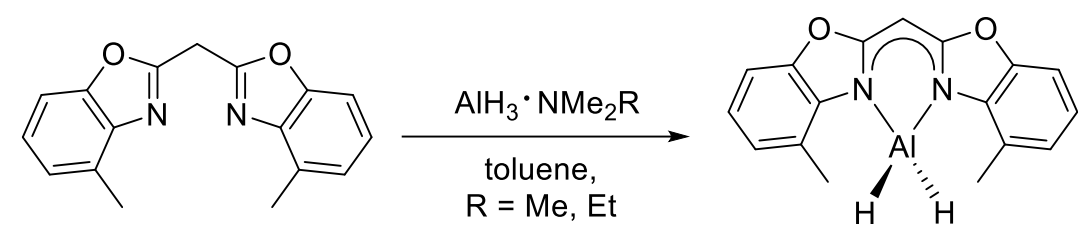

12

Scheme 2-14. Reaction of ${ }^{4-\mathrm{Me}} \mathrm{Box}_{2} \mathrm{CH}_{2}$ and $\mathrm{AlH}_{3} \cdot \mathrm{NMe}_{2} \mathrm{R}(\mathrm{R}=\mathrm{Me}, \mathrm{Et})$ in toluene.

The deprotonation was repeated due to the moderate overall yields (46\%) using a commercially available alane dimethylethylamine $\left(\mathrm{AlH}_{3} \cdot \mathrm{NEtMe}_{2}\right)$ solution in toluene. Therefore, neutral ${ }^{4-\mathrm{Me}} \mathrm{Box}_{2} \mathrm{CH}_{2}$ ligand was dissolved in toluene, cooled to $0^{\circ} \mathrm{C}$, and 1.06 equiv. $\mathrm{AlH}_{3} \cdot \mathrm{NEtMe}_{2}$ solution was added. The reaction solution was warmed to ambient temperature and stirred for $1 \mathrm{~d}$. A white precipitate of $\left[\mathrm{AlH}_{2}\left({ }^{4-\mathrm{Me}} \mathrm{Box}_{2} \mathrm{CH}\right)\right](12)$ was formed, separated by filtration, and dried under reduced pressure. Obtained white precipitate and crystals of 12 , which were grown out of saturated mother liquor at $-30^{\circ} \mathrm{C}$, led to higher yields (77\%). Single crystal XRD analyses demonstrated that alane 12 (Figure 2-19) crystallises in the monoclinic space group $P 2_{1} / c$ with two complex molecules in the asymmetric unit.
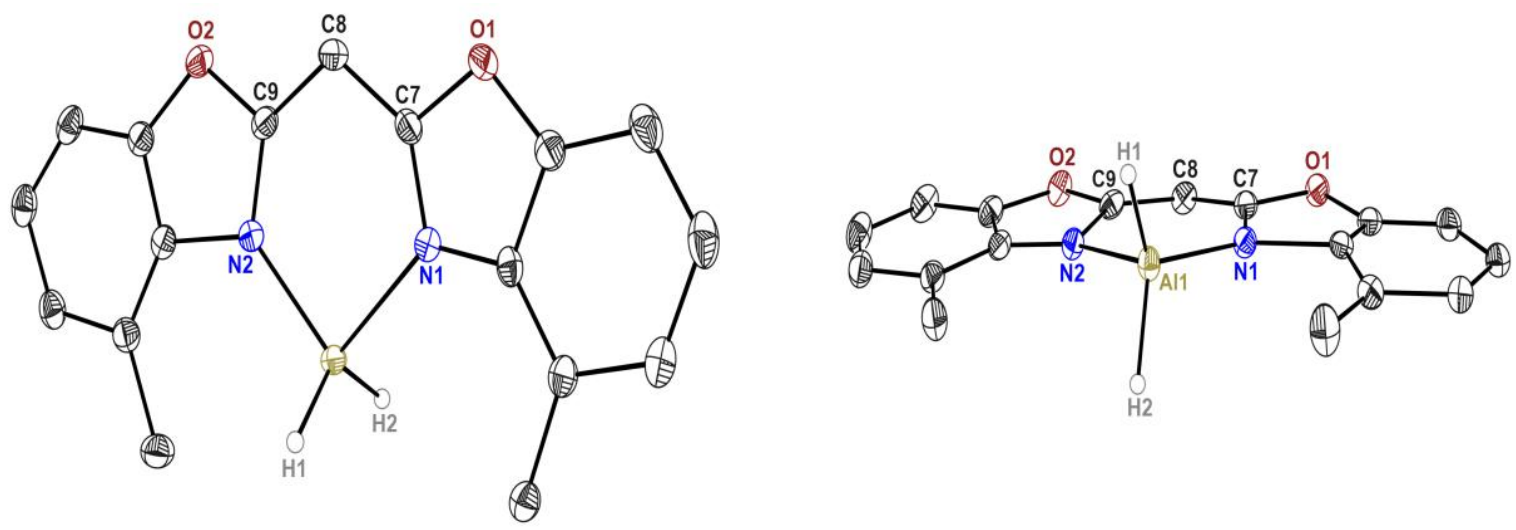

Figure 2-19. Solid-state structure of $\left[\mathrm{AlH}_{2}\left({ }^{4-\mathrm{Me}} \mathrm{Box}_{2} \mathrm{CH}\right)\right]$ (12). Anisotropic displacement parameters are depicted at 50\% probability level. Hydrogen atoms except metal-bound ones (H1, H2) are omitted for clarity.

Complex 12 consists of a aluminium(III) cation that is $\kappa^{2}-N, N^{\prime}$-chelated by the negatively charged ligand and freely refined hydride anions in a slightly distorted tetrahedral fashion (Table 2-5). Therefore, bite angles of $95.23(5)^{\circ}$ and $94.66(5)^{\circ}$ are more acute than the ideal tetrahedral angle, but within the range of related aluminium hydride complexes. ${ }^{[161]}$ The metal ion is almost equidistantly coordinated (1.9161(15) to 1.9240(15) $\AA$ ) to the two imine nitrogen atoms, while the H-Al-H angle is expanded $\left(115.2(10)^{\circ}\right.$ and $\left.115.8(9)^{\circ}\right)$. Additionally, rather small dislocations of cation from the planar $\mathrm{C}_{3} \mathrm{~N}_{2}$ moiety $\left(\mathrm{Al} \cdots \mathrm{C}_{3} \mathrm{~N}_{2} 0.1685(16)\right.$ to $0.1562(16) \AA$ ) were observed as well as a butterfly folding angle of $4.08(4)^{\circ}$ and $8.13(3)^{\circ}$. 
Table 2-5. Selected bond lengths $(\AA)$ and angles $\left({ }^{\circ}\right)$ of 12 to 17 . Different fragments of a complex are subdivided by dashed lines.

\begin{tabular}{|c|c|c|c|c|c|c|c|}
\hline No. & Compound & $\mathrm{Al}-\mathrm{N}$ & $\mathrm{Al}-\mathrm{H}$ & $\mathrm{Al}-\mathrm{Al}$ & $\mathbf{N}-\mathbf{A l}-\mathbf{N}$ & $\mathrm{Al} \cdots \mathrm{C}_{3} \mathrm{~N}_{2}$ & $\begin{array}{c}\text { Folding } \\
\text { angle }\end{array}$ \\
\hline 12 & {$\left[\mathrm{AlH}_{2}\left(4-\mathrm{Me} \mathrm{Box}_{2} \mathrm{CH}\right)\right]$} & $\begin{array}{l}1.9170(12), \\
1.9680(13) \\
1.9175(13), \\
1.9192(13)\end{array}$ & $\begin{array}{l}1.568(16), \\
1.456(19), \\
1.491(18), \\
1.572(17)\end{array}$ & - & $\begin{array}{l}95.23(5), \\
94.66(5)\end{array}$ & $\begin{array}{l}0.1685(16) \\
0.1562(16)\end{array}$ & $\begin{array}{l}4.08(4), \\
8.13(3)\end{array}$ \\
\hline 13 & {$\left[\left({ }^{4-\mathrm{Me}} \mathrm{Box}_{2} \mathrm{CH}\right) \mathrm{HAl}\right.$} & $\begin{array}{l}1.9637(18) \\
1.9543(17)\end{array}$ & $1.590(16)$ & $2.6188(13)$ & $92.88(7)$ & $0.495(2)$ & $9.89(6)$ \\
\hline & $\left.\mathrm{AlH}\left({ }^{\text {Dipp }} \mathrm{NacNac}\right)\right]$ & $\begin{array}{l}1.9246(16), \\
1.9255(16)\end{array}$ & $1.629(16)$ & & $94.35(7)$ & $0.7697(19)$ & \\
\hline 14 & {$\left[\left({ }^{4-\mathrm{Me}} \mathrm{Box}_{2} \mathrm{CH}\right) \mathrm{HAl}\right.$} & $\begin{array}{l}1.9088(12) \\
1.9025(13)\end{array}$ & $1.475(18)$ & $2.6487(11)$ & $95.08(6)$ & $0.6313(15)$ & $16.20(7)$ \\
\hline & $\begin{array}{c}\mathrm{Al}\left({ }^{(\mathrm{Dipp} N a c N a c)}\right] \\
\mathrm{BArF}_{20}\end{array}$ & $\begin{array}{l}1.8596(12) \\
1.8558(11)\end{array}$ & & & $96.99(6)$ & $0.1361(15)$ & \\
\hline $15 \mathrm{a}$ & {$\left[\mathrm{AlH}\left({ }^{4-\mathrm{Me}} \mathrm{Box}_{2} \mathrm{CH}\right)\right]_{2}$} & $\begin{array}{l}1.973(2), \\
1.946(2) \\
1.955(3), \\
1.946(3)\end{array}$ & $\begin{array}{l}1.63(3) \\
1.63(2)\end{array}$ & $2.583(4)$ & $\begin{array}{l}92.88(11), \\
93.36(14)\end{array}$ & $\begin{array}{l}0.391(2), \\
0.394(3)\end{array}$ & $\begin{array}{l}2.55(2), \\
4.34(2)\end{array}$ \\
\hline $15 b$ & 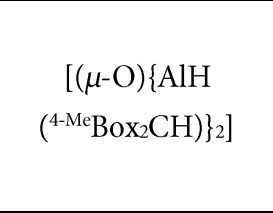 & $\begin{array}{l}1.898(5), \\
1.959(5) \\
1.928(7), \\
1.974(6)\end{array}$ & $\begin{array}{l}1.30(5) \\
1.30(4)\end{array}$ & - & $\begin{array}{l}94.8(2) \\
93.3(3)\end{array}$ & $\begin{array}{l}0.088(4) \\
0.142(5)\end{array}$ & $\begin{array}{l}2.55(2) \\
4.34(2)\end{array}$ \\
\hline 16 & 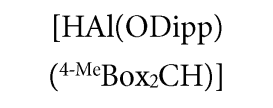 & $\begin{array}{l}1.9038(11) \\
1.9138(11)\end{array}$ & $1.500(14)$ & - & $95.33(4)$ & $0.1063(12)$ & $4.80(7)$ \\
\hline 17 & $\begin{array}{c}{[(\mu-\mathrm{O})\{\mathrm{Al}(\mathrm{ODipp})} \\
\left.\left.\left({ }^{4-\mathrm{Me}} \mathrm{Box}_{2} \mathrm{CH}\right)\right\}_{2}\right]\end{array}$ & $\begin{array}{l}1.9016(17), \\
1.9009(17)\end{array}$ & - & - & $96.22(7)$ & $0.143(2)$ & $2.48(4)$ \\
\hline
\end{tabular}

The ${ }^{1} \mathrm{H}$ NMR spectrum of $\left[\mathrm{AlH}_{2}\left({ }^{4-\mathrm{Me}} \mathrm{Box}_{2} \mathrm{CH}\right)\right]$ (12) in benzene- $\mathrm{d}_{6}$ shows a deshielding and simultaneous downfield shift of the methane or the methanide bridge occurs from $\delta\left(-\mathrm{H}_{2} \mathrm{C}-\right)$ $4.11 \mathrm{ppm}$ to $\delta(-\mathrm{CH}-) 5.08 \mathrm{ppm}$ in contrast to the uncharged ligand. Moreover, the two methyl groups experience a downfield shift $\left(\Delta \delta\left(-\mathrm{CH}_{3}\right) 0.30 \mathrm{ppm}\right)$, while aromatic protons are shifted to the upper field $(\Delta \delta(-\mathrm{CH}) \sim 0.20 \mathrm{ppm})$. A broad singlet at $\delta 5.43 \mathrm{ppm}$ is assigned to both hydride atoms that are also evidenced by the observation of IR stretching vibrations at $\tilde{v}_{\mathrm{H}-\mathrm{Al}}=1876(\mathrm{w})$ and $1867(\mathrm{~m}) \mathrm{cm}^{-1}$. Related complexes were reported to exhibit absorption bands at 1832 and $1795 \mathrm{~cm}^{-1}$ $\left[\mathrm{AlH}_{2}\left({ }^{\text {Dipp }} \mathrm{NacNac}\right)\right]^{[161 \mathrm{al}]}$ or 1840 and $1793 \mathrm{~cm}^{-1}\left[\mathrm{AlH}_{2}\left(\left\{\mathrm{DippNC}\left(\mathrm{NMe}_{2}\right)\right\}_{2} \mathrm{CH}\right)\right]^{[162]}$. In addition, the synthesis of alane 12 was verified by mass spectrometry (LIFDI[+], toluene), revealing a $\mathrm{m} / \mathrm{z}(\%)$ of 306.1 (100) based on $[M]^{+}$and $626.2(2)[2 \mathrm{M}-2 \mathrm{H}+\mathrm{O}]^{+}$. The latter species is most likely formed due to the reaction of 12 and traces of water. In regard to determine the temperature stability of $\left[\mathrm{AlH}_{2}\left({ }^{4-\mathrm{Me}} \mathrm{Box}_{2} \mathrm{CH}\right)\right](12)$, DSC $\left(25-130^{\circ} \mathrm{C}(10.0 \mathrm{~K} / \mathrm{min}), 130-250^{\circ} \mathrm{C}(0.5 \mathrm{~K} / \mathrm{min})\right)$ was performed (Chapter 5.4). The decomposition of 12 was detected at $\geq 158^{\circ} \mathrm{C}$ (Figure 5-57), whereby a decomposition enthalpy of about $\Delta H_{\mathrm{dec}}=-166 \mathrm{~kJ} / \mathrm{mol}$ (Figure 5-58) was calculated. Additionally, 12 
was found to emit fluorescence in the solid-state and solution (Figure 2-20). This is not surprising since benzoxazole-based compounds are known to develop luminescence. ${ }^{[163]}$

In toluene, an emission maximum was detected at $\lambda_{\max }=404 \mathrm{~nm}\left(0.01 \mathrm{mM}, \lambda_{\mathrm{ex}}=350 \mathrm{~nm}\right)$. Multiple solid-state fluorescence measurements of crystalline alane 12 were carried out under air, and ambient temperature showing a broad emission maximum at $\lambda_{\max }=445 \mathrm{~nm}\left(\lambda_{\mathrm{ex}}=350 \mathrm{~nm}\right)$ with a decrease in intensity overnight. This might be explained by the reaction of 12 with ambient oxygen or moisture.
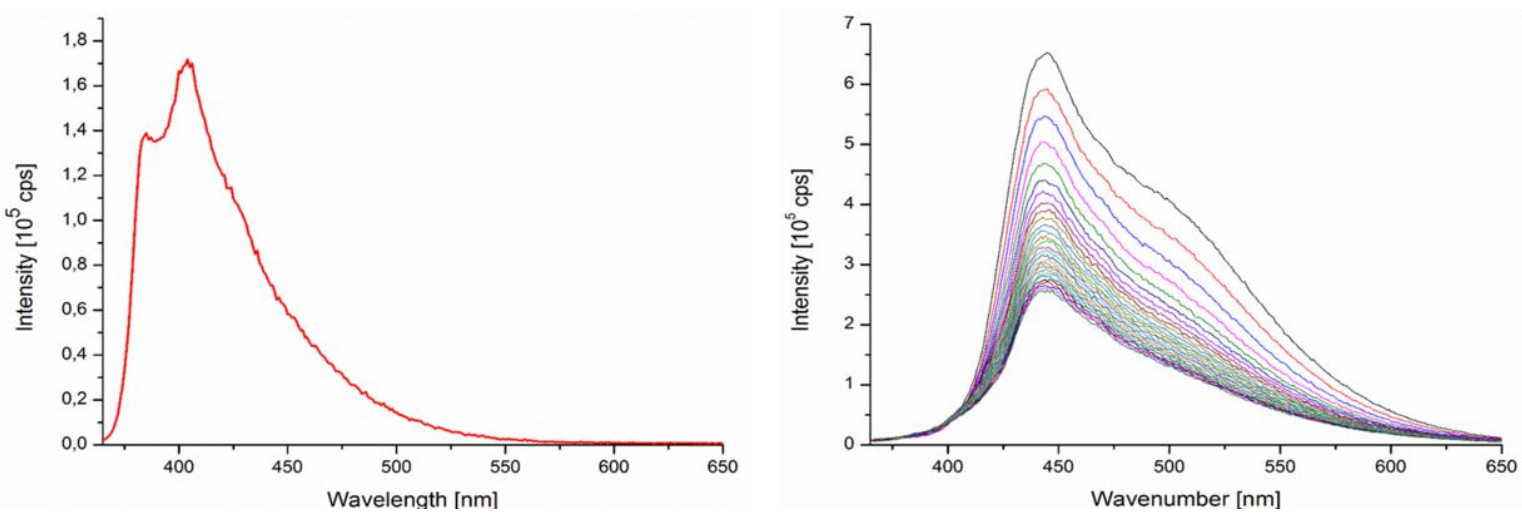

Figure 2-20. The fluorescence analysis of 12 in toluene $(0.01 \mathrm{mM})$ unveiled a emission maximum at $\lambda_{\max }=$ $404 \mathrm{~nm}\left(\lambda_{\mathrm{ex}}=350 \mathrm{~nm}\right)$ (left). Solid-state fluorescence measurements (right) of crystalline 12 that were performed in $30 \mathrm{~min}$ intervals for $14 \mathrm{~h}$ at room temperature under air showed a broad emission maximum at $\lambda_{\max }=445 \mathrm{~nm}\left(\lambda_{\mathrm{ex}}=350 \mathrm{~nm}\right)$ with a decrease in intensity.

In an alternative synthesis for 12 , bis\{4-methyl-benzoxazol-2-yl)methane and one equiv. lithium aluminium hydride were reacted in diethyl ether at low temperatures. Crystals of $\left[\left({ }^{4-\mathrm{Me}} \mathrm{Box}_{2} \mathrm{CH}\right)\left(\mathrm{Et}_{2} \mathrm{O}\right) \mathrm{Li}(\mu-\mathrm{H}) \mathrm{AlH}\left({ }^{4-\mathrm{Me}} \mathrm{Box}_{2} \mathrm{CH}\right)\right](12 \mathrm{a})$ grew out of a diethyl ether solution at $-30^{\circ} \mathrm{C}$ after several days (Table 2-5, for detail, see 5.1.15). Unfortunately, it was not possible to reproduce

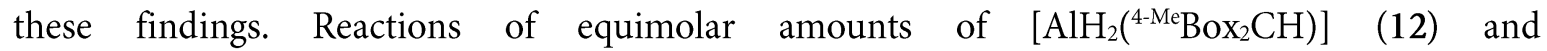

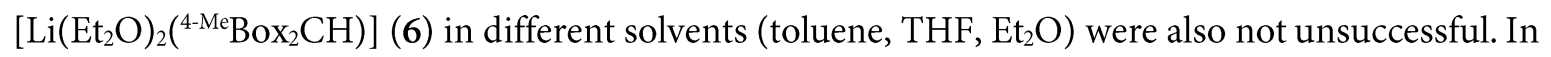
future research, the soluble $\left[\mathrm{AlH}_{2}\left({ }^{4-\mathrm{Me}} \mathrm{Box}_{2} \mathrm{CH}\right)\right](12)$ might be investigated as a hydrogen catalyst in deprotonation, insertion, and activation reactions. ${ }^{[159]}$ Thereby, the fluorescence of 12 in solution and the solid-state might be a useful feature to monitor or investigate reactions.

Previously, Nikonov et al. monitored the oxidative addition of the $\mathrm{Al}-\mathrm{H}$ bond in $\left[\mathrm{AlH}_{2}\left({ }^{\mathrm{Dipp}} \mathrm{NacNac}\right)\right]$ to $\left[\mathrm{Al}^{\mathrm{I}}\left({ }^{\text {Dipp }} \mathrm{NacNac}\right)\right]$ by ${ }^{1} \mathrm{H} \mathrm{NMR}$ experiments at variable temperatures. In doing so, an equilibrium mixture (Scheme 2-15) of starting materials and dimeric $\left[\mathrm{Al}^{\mathrm{II}} \mathrm{H}\left({ }^{\text {Dipp }} \mathrm{NacNac}\right)\right]_{2}$ species was observed. ${ }^{[164]}$<smiles>[2H][C@H]1N([PbH])C(C)=CC(C)N1[PbH]</smiles><smiles></smiles>
benzene- $d_{6}$

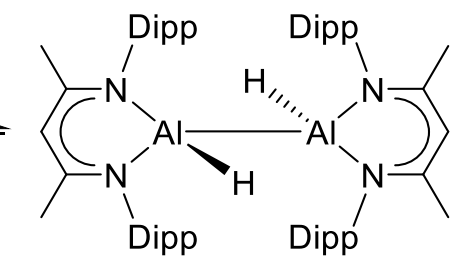

Scheme 2-15. Equilibrium of $\left[\mathrm{AlH}_{2}\left({ }^{\text {(ippp } N a c N a c}\right)\right],\left[\mathrm{Al}^{\mathrm{I}}\left({ }^{\text {Dipp }} \mathrm{NacNac}\right)\right]$ and dimeric $\left[\mathrm{Al}^{\mathrm{II}} \mathrm{H}\left({ }^{\mathrm{Dipp}} \mathrm{NacNac}\right)\right]_{2}{ }^{[164]}$ 
Inspired by these investigations, compound 12 and $\left[\mathrm{Al}^{\mathrm{I}}\left({ }^{\text {Dipp }} \mathrm{NacNac}\right)\right]$, which was synthesised according to Roesky and co-workers, ${ }^{[14 a]}$ were dissolved in toluene at ambient temperature (Scheme 2-16). The reaction solution, which turned yellow within minutes, was stirred for $1 \mathrm{~d}$. Thereafter,

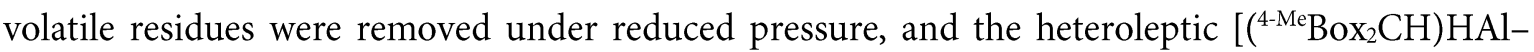
$\left.\mathrm{AlH}\left({ }^{\text {Dipp }} \mathrm{NacNac}\right)\right]$ (13) was isolated as a yellow powder in high yields (YLD: 96\%).

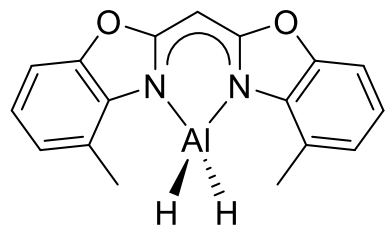

12

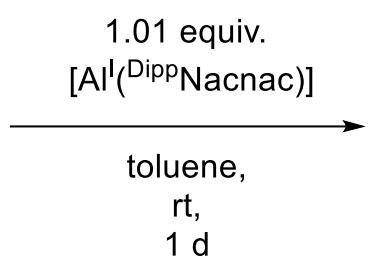

$1 \mathrm{~d}$

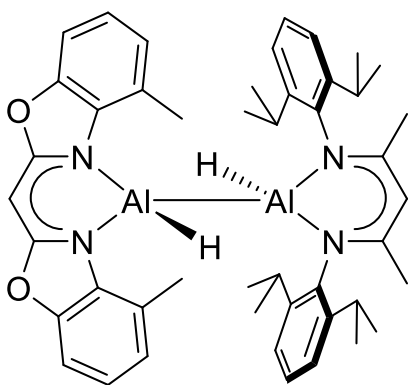

13

$96 \%$

Scheme 2-16. The reaction of alane 12 and $\left[\mathrm{Al}^{\mathrm{I}}\left({ }^{\mathrm{Dipp}} \mathrm{NacNac}\right)\right]$ resulted in dialane 13.

Single crystal XRD analyses were conducted on crystals grown from a saturated toluene solution at $-30^{\circ} \mathrm{C}$ after $3 \mathrm{~d}$. Dialane 13 crystallises in space group $P \overline{1}$ with one molecule in the asymmetric unit

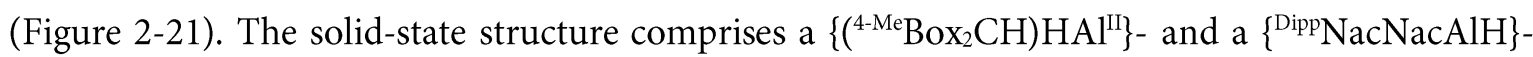
fragment linked by an $\mathrm{Al}^{\mathrm{II}}-\mathrm{Al}^{\mathrm{II}}$ bond. The $\mathrm{Al}-\mathrm{N}$ bonds of the benzoxazol-2-yl fragment (Al1-N1 1.9637(18) $\AA$, Al1-N2 1.9543(17) $\AA$ ) are elongated, whereas corresponding distances of the DippNacNac based moiety (Al2-N3 1.9246(16) $\AA$, Al2-N4 1.9255(16) $)$ ) are shortened, compared to the starting materials (Table 2-5). ${ }^{[164,165]}$
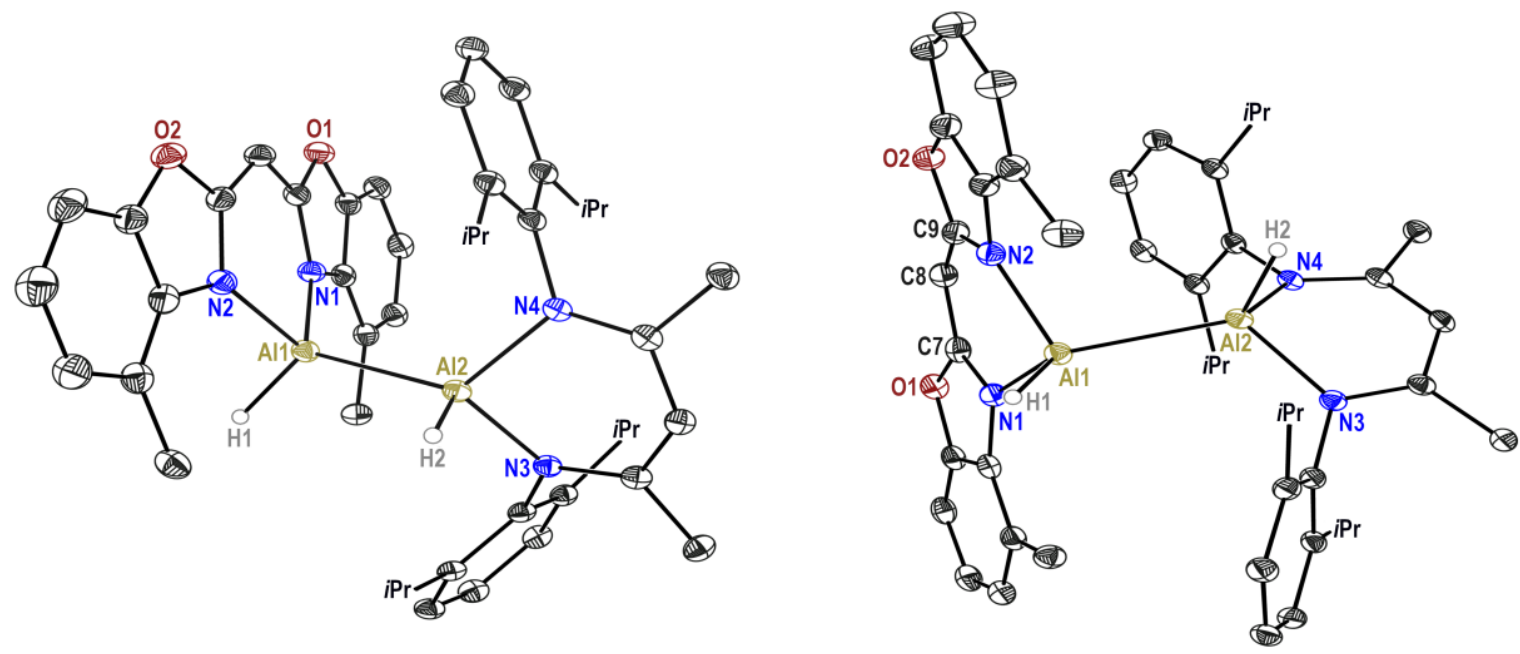

Figure 2-21. Solid-state structure of [ $\left.\left({ }^{4-\mathrm{Me}} \mathrm{Box}_{2} \mathrm{CH}\right) \mathrm{HAl}-\mathrm{AlH}\left({ }^{\text {Dipp }} \mathrm{NacNac}\right)\right](13)$. The anisotropic displacement parameters are depicted at 50\% probability level. Hydrogen atoms, except metal-bound ones (H1, H2), are omitted for clarity.

A metal-metal bond of 2.6188(13) $\AA$ is observed between the two $\mathrm{Al}^{\mathrm{II}}$-ions. This is in good agreement with related amidinato (2.5756(11) to 2.630(3) $\AA$ ) and guanidinato (2.675(1) $\AA$ ) dialanes Al-XXIII) or asymmetric [cAAC: $\left.\rightarrow X_{2} \mathrm{Al}^{\mathrm{II}}-\mathrm{Al}^{\mathrm{II}} X\left({ }^{\mathrm{Dipp}} \mathrm{NacNac}\right)\right](\mathrm{Al}-\mathrm{XXI})(X=\mathrm{Cl}, \mathrm{I})$ compounds $(2.595(2)$ to 
2.633(1) $\AA$ ). ${ }^{[35,42 b]}$ The dislocation of cation and $\mathrm{C}_{3} \mathrm{~N}_{2}$ plane $\left(\mathrm{Al} \cdots \mathrm{C}_{3} \mathrm{~N}_{2}\right)$ increases to $0.495(2) \AA$ for the benzoxazol-2-yl and 0.7697(19) $\AA$ for the NacNac fragment. Density functional theory calculations at the pbe0/def2-TZVP $\left(\mathrm{C}_{3} \mathrm{~N}_{2} \mathrm{AlH}-\mathrm{HAlC}_{3} \mathrm{~N}_{2}\right)$ and def2-SVP (all other atoms) levels were performed using the solid-state structure of 13 as starting point. ${ }^{[142]}$ The geometry of 13 is well reproduced by its calculated structure $(\mathrm{RMS}=0.147, \mathrm{RMSD}=0.521)$. The $\Delta E_{\mathrm{HOMO}-\mathrm{LUMO}}$ was determined to be $47.6 \mathrm{kcal} / \mathrm{mol}(2.07 \mathrm{eV})$. The obtained Löwdin bond order of $\mathrm{Al}^{\mathrm{II}}-\mathrm{Al}^{\mathrm{II}}\left(2.604 \AA, \Delta_{\text {calc-exp }}=-1.48 \cdot 10^{-2} \AA\right)$ is 0.967 , meaning that a single bond is observed between the two sp-hybridised aluminium atoms. Calculated natural population analysis (NPA) charges for aluminium (Al1 1.009, Al2 1.003) and hydride ( $\mathrm{H} 1-0.399, \mathrm{H} 2-0.411)$ show different values owing to the varying coordination geometries. ${ }^{[143]}$ Therefore, the two hydride atoms should develop differing reactivities, for example, in hydride abstraction reactions.

The ${ }^{1} \mathrm{H}$ NMR spectrum (benzene- $d_{6}$ ) of 13 displays an upfield shift of the methyl aryl groups and the methanide bridges of both complex fragments as compared to the starting materials. The aluminiumbound hydrides were detected at $\delta 5.81 \mathrm{ppm}$ (Figure 2-22) and at $\tilde{v}_{\mathrm{H}-\mathrm{Al}}=1840 \mathrm{~cm}^{-1}$ as well as $1814 \mathrm{~cm}^{-1}$ in the ATR-IR spectrum (Figure 2-23). Additionally, two septets $(\delta 3.39,3.12 \mathrm{ppm}$ ) were observed for the methine protons and four partly overlapping doublets ( $\delta 1.12$ to $0.96 \mathrm{ppm}$ ) were detected for the methyl groups of the ${ }^{i} \mathrm{Pr}$ groups, that are consistent with a $C_{s}$ symmetry in solution. ${ }^{1} \mathrm{H}$ NMR spectroscopic studies ( $\left[\mathrm{D}_{8}\right]$ toluene) at variable temperatures $\left(-80^{\circ} \mathrm{C}\right.$ to $\left.100^{\circ} \mathrm{C}\right)$ showed that, contrary to Nikonov's reaction (Scheme 2-16), ${ }^{[164]}$ there seems to be no equilibrium between the starting materials and dialane 13 (Figure 2-22).

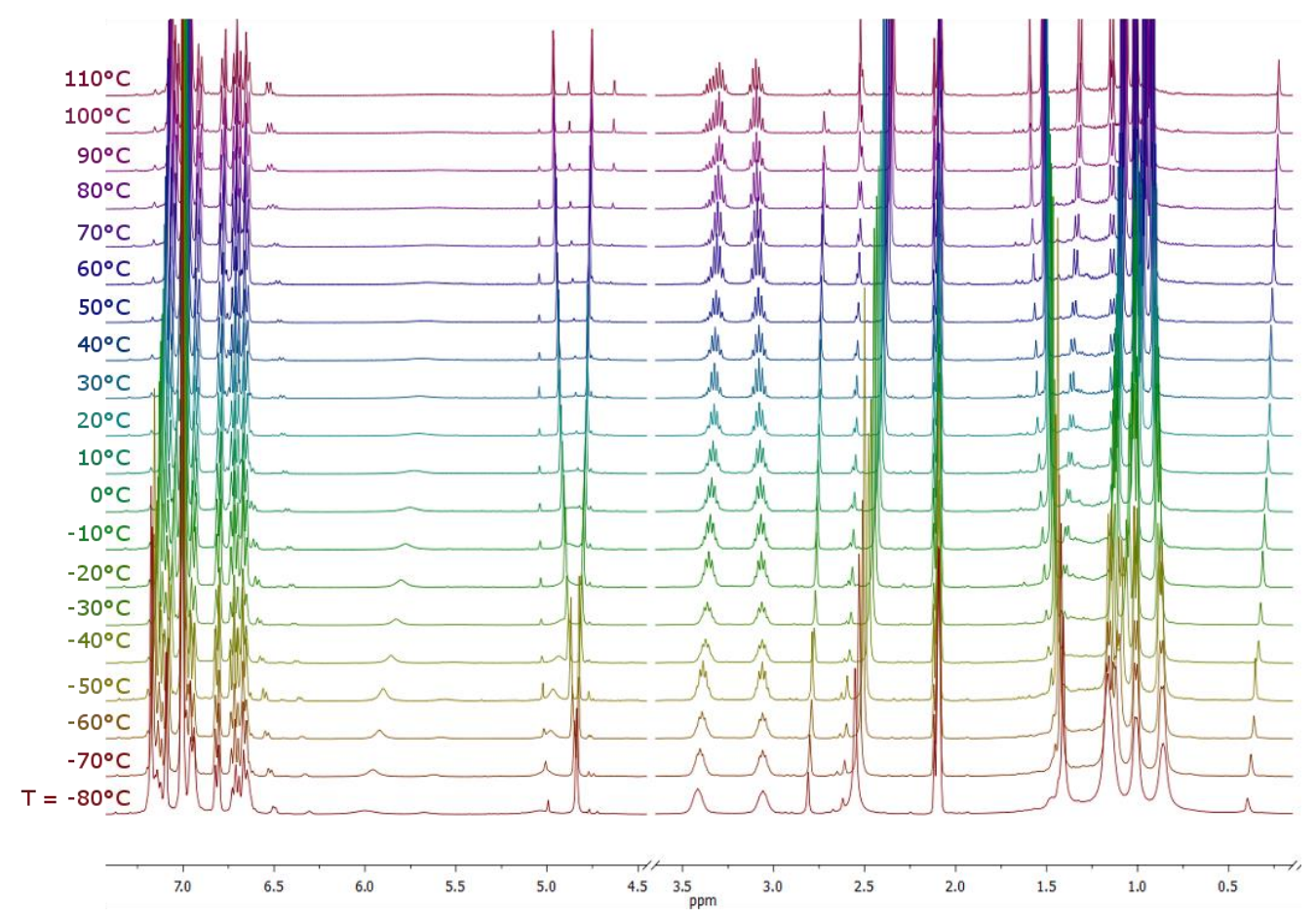

Figure 2-22. ${ }^{1} \mathrm{H}$ NMR studies of $\left[\left({ }^{4-\mathrm{Me}} \mathrm{Box}_{2} \mathrm{CH}\right) \mathrm{HAl}-\mathrm{AlH}\left({ }^{\mathrm{Dipp}} \mathrm{NacNac}\right)\right](13)$ in $\left[\mathrm{D}_{8}\right]$ toluene at variable temperatures $\left(-80^{\circ} \mathrm{C}\right.$ to $\left.100^{\circ} \mathrm{C}\right)$. 
Instead, a new species was confirmed at $\sim 80^{\circ} \mathrm{C}$. The ${ }^{1} \mathrm{H}$ DOSY measurements of 13 in $\left[\mathrm{D}_{8}\right]$ toluene (for detail see Chapter 5.3) resulted in a $M W_{\text {det }}=695 \mathrm{~g} / \mathrm{mol}\left(M W_{\text {diff }}=8 \%\right) .{ }^{[166]}$ This matches the dimeric species $\mathrm{m} / \mathrm{z} 750.4$ (100) detected by LIFDI[+] mass spectrometric analyses.
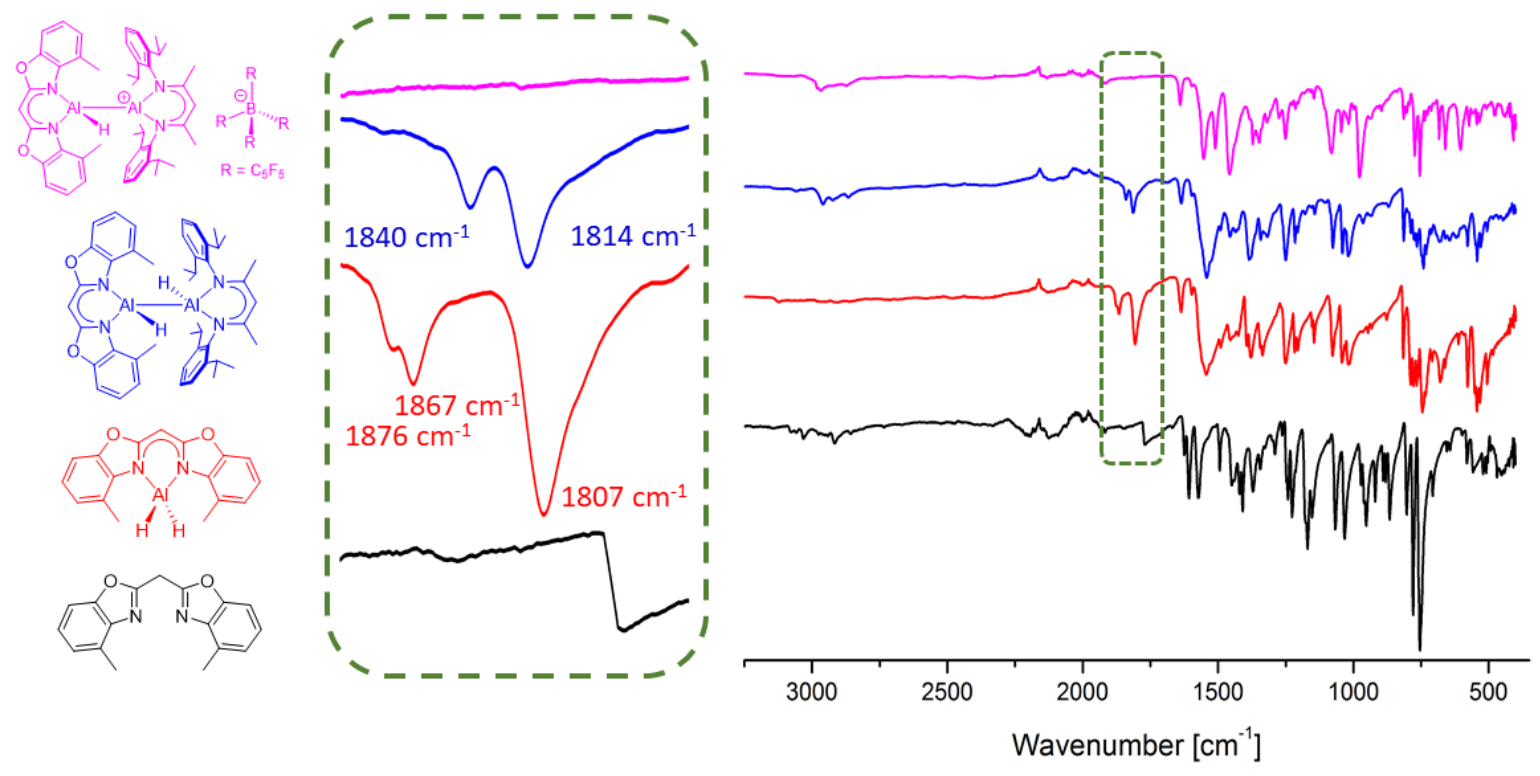

Figure 2-23. ATR-IR spectra and zoomed-in area (green-dotted line) of neutral ${ }^{4-\mathrm{Me}} \mathrm{Box}_{2} \mathrm{CH}_{2}$ (black), alane (12, red), dialane (13, blue), and cationic dialane (14, purple).

To test which hydride atom might have the higher hydricity, one equiv. of trityl tetrakis(pentafluorophenylborate) $\left(\left[\mathrm{Ph}_{3} \mathrm{C}\right]^{+}\left[\mathrm{B}\left(\mathrm{C}_{6} \mathrm{~F}_{5}\right)_{4}\right]^{-}\right)$was added under vigorous stirring to a toluene solution at ambient temperature (Scheme 2-17). The hydride abstraction and formation of $\mathrm{Ph}_{3} \mathrm{CH}$ proceeded within minutes. First, the reaction mixture turned bright red, and finally, two phases- a yellow upper toluene and a colourless oily lower phase - were noticed. After the twophased mixture had been rested for $1 \mathrm{~d}$ at ambient temperature, crystals suitable for single crystal XRD experiments grew out of the lower phase. The upper phase was decanted, and thereafter crystals of $\left.\left[{ }^{4-\mathrm{Me}} \mathrm{Box}_{2} \mathrm{CH}\right) \mathrm{HAl}-\mathrm{Al}\left({ }^{\mathrm{Dipp}} \mathrm{NacNac}\right)\right]^{+}\left[\mathrm{B}\left(\mathrm{C}_{6} \mathrm{~F}_{5}\right)_{4}\right]^{-}(\mathbf{1 4})$ were dried under reduced pressure (YLD: $81 \%)$.

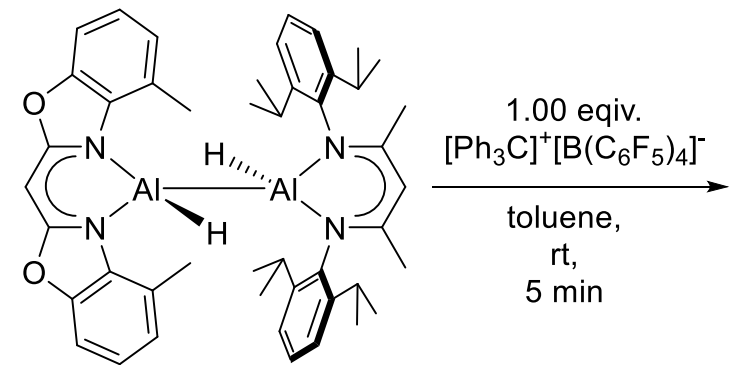

13

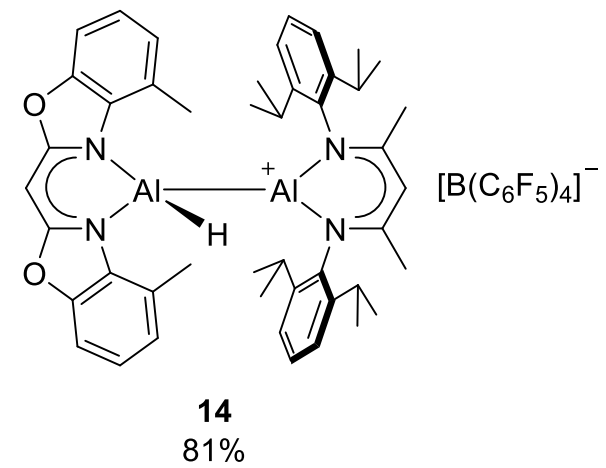

Scheme 2-17. Hydride abstraction of dialane 13 by trityl tetrakis(pentafluorophenylborate) in toluene.

The cationic dialane 14 crystallises in the triclinic space group $P \overline{1}$ with one ion pair and one and a half molecules of toluene in the asymmetric unit (Figure 2-24). The solid-state structure unveiled the selective hydride abstraction at the $\mathrm{NacNac}$ fragment rather than the $\mathrm{AlH}\left({ }^{4-\mathrm{Me}} \mathrm{Box}_{2} \mathrm{CH}\right)$ moiety. This 
is probably caused by the slightly more pronounced hydridic character of H2 (NPA charge -0.411) compared to H1 (NPA charge -0.399) in dialane 13. ${ }^{[143]}$
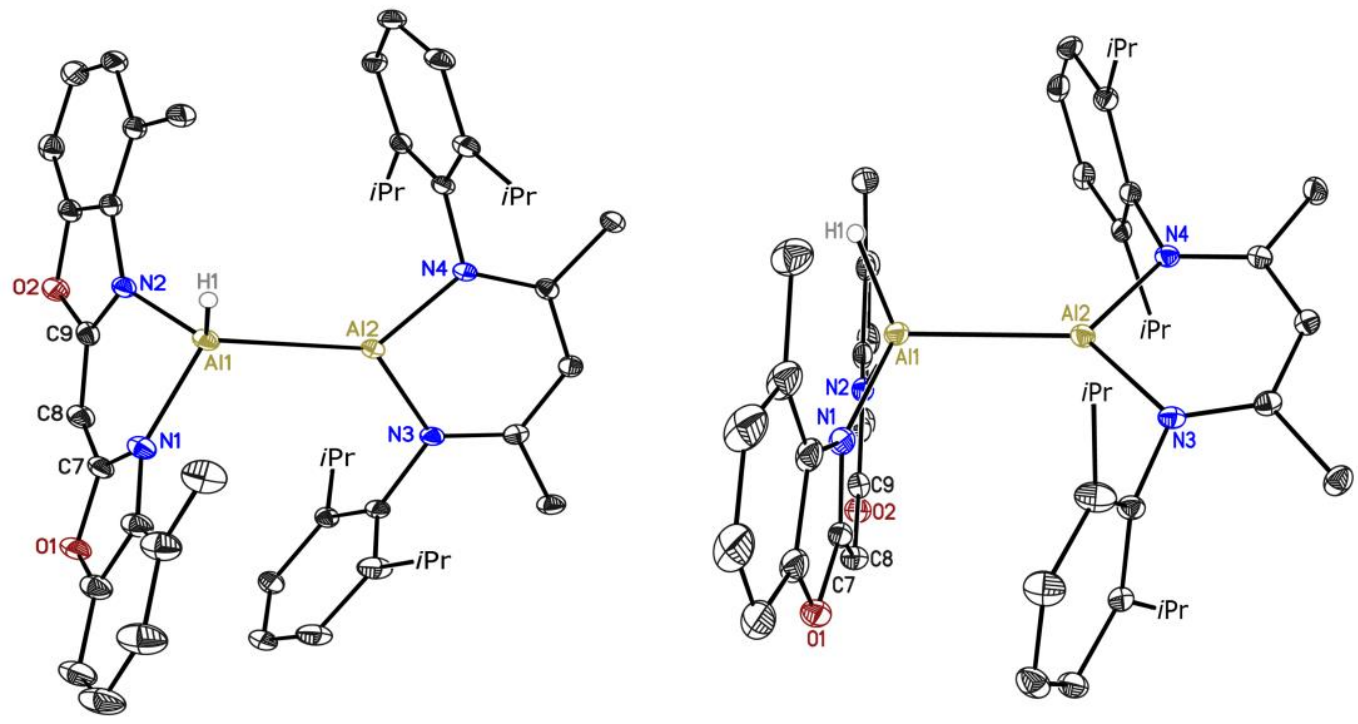

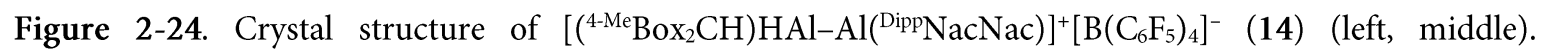
Anisotropic displacement parameters are depicted at $50 \%$ probability level. The $\left[\mathrm{B}\left(\mathrm{C}_{6} \mathrm{~F}_{5}\right)_{4}\right]^{-}$anion and all ligand-based hydrogen atoms are omitted for clarity. Superimposed structures (right) of compound 13 (blue) and 14 (red).

In comparison to complex 13 , the aluminium nitrogen bonds of $\mathrm{Al}\left({ }^{\mathrm{Dipp} N a c N a c}\right)$ are shortened $(\triangle(\mathrm{Al}-$ $\mathrm{N})$ ca. $0.07 \AA)$ while corresponding $\mathrm{Al}-\mathrm{N}$ of $\mathrm{AlH}\left({ }^{4-\mathrm{Me}} \mathrm{Box}_{2} \mathrm{CH}\right)$ fragment hardly change $(\Delta(\mathrm{Al}-\mathrm{N}) \mathrm{ca}$. $0.01 \AA)$. Furthermore, bite angles $\mathrm{N}-\mathrm{Al}-\mathrm{N}$ are slightly expanded $\left(\mathrm{AlH}\left({ }^{4-\mathrm{Me}} \mathrm{Box}{ }_{2} \mathrm{CH}\right): \Delta(\mathrm{N}-\mathrm{Al}-\mathrm{N})=\right.$ ca. $\left.2.2^{\circ} ; \mathrm{Al}\left({ }^{\text {(ipp }} \mathrm{NacNac}\right): \Delta(\mathrm{N}-\mathrm{Al}-\mathrm{N})=\mathrm{ca} .2 .6^{\circ}\right)$ with respect to neutral dialane 13 . Besides this, the aluminium hydride bond length Al1-H1 (Table 2-5) is slightly reduced, while the $\mathrm{Al}^{\mathrm{II}}-\mathrm{Al}^{\mathrm{II}}$ bond $\left(\Delta(\mathrm{Al} 1-\mathrm{Al} 2)\right.$ 0.0299(11) $\AA$ ) is extended. The dislocation between the aluminium ion and $\mathrm{C}_{3} \mathrm{~N}_{2}$ plane of $\mathrm{AlH}\left({ }^{4-\mathrm{Me}} \mathrm{Box}_{2} \mathrm{CH}\right)$ increases from $0.495(2)$ to $0.6313(15) \AA$ whereas $\mathrm{Al} \cdots \mathrm{C}_{3} \mathrm{~N}_{2}$ of $\mathrm{Al}\left({ }^{\text {Dipp }} \mathrm{NacNac}\right)$ significantly decreases from $0.7697(19)$ to $0.1363(15) \AA$. This nearly planar six-membered $\mathrm{AlC}_{3} \mathrm{~N}_{2}$ ring results in a higher $C_{2 v}$ molecular symmetry, which displays one septet $\left(\delta 2.36 \mathrm{ppm},-\mathrm{CH}\left(\mathrm{CH}_{3}\right)_{2}\right)$ and two doublets $\left(\delta 0.91 \mathrm{ppm}, \delta 0.71 \mathrm{ppm},-\mathrm{CH}\left(\mathrm{CH}_{3}\right)_{2}\right)$ for the isopropyl groups in the ${ }^{1} \mathrm{H} \mathrm{NMR}$ spectrum (bromobenzene- $d_{5}$ ). All NMR experiments were performed in dried bromobenzene- $d_{5}$ due to the low solubility of cationic aluminium complexes in common deuterated solvents. A marginal chemical shift was detected during temperature-dependent ${ }^{1} \mathrm{H}$ NMR experiments (Figure 2-25), as in the case of complex 13. A hydride interchange between both aluminium fragments or the

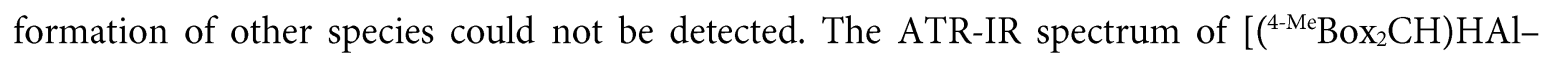
$\left.\mathrm{Al}\left({ }^{\text {Dipp }} \mathrm{NacNac}\right)\right]^{+}\left[\mathrm{B}\left(\mathrm{C}_{6} \mathrm{~F}_{5}\right)_{4}\right]^{-}(14)$ displayed no vibrational band in the typical range ${ }^{[167]}$ for $\mathrm{Al}-\mathrm{H}$ groups (Figure 2-23). 


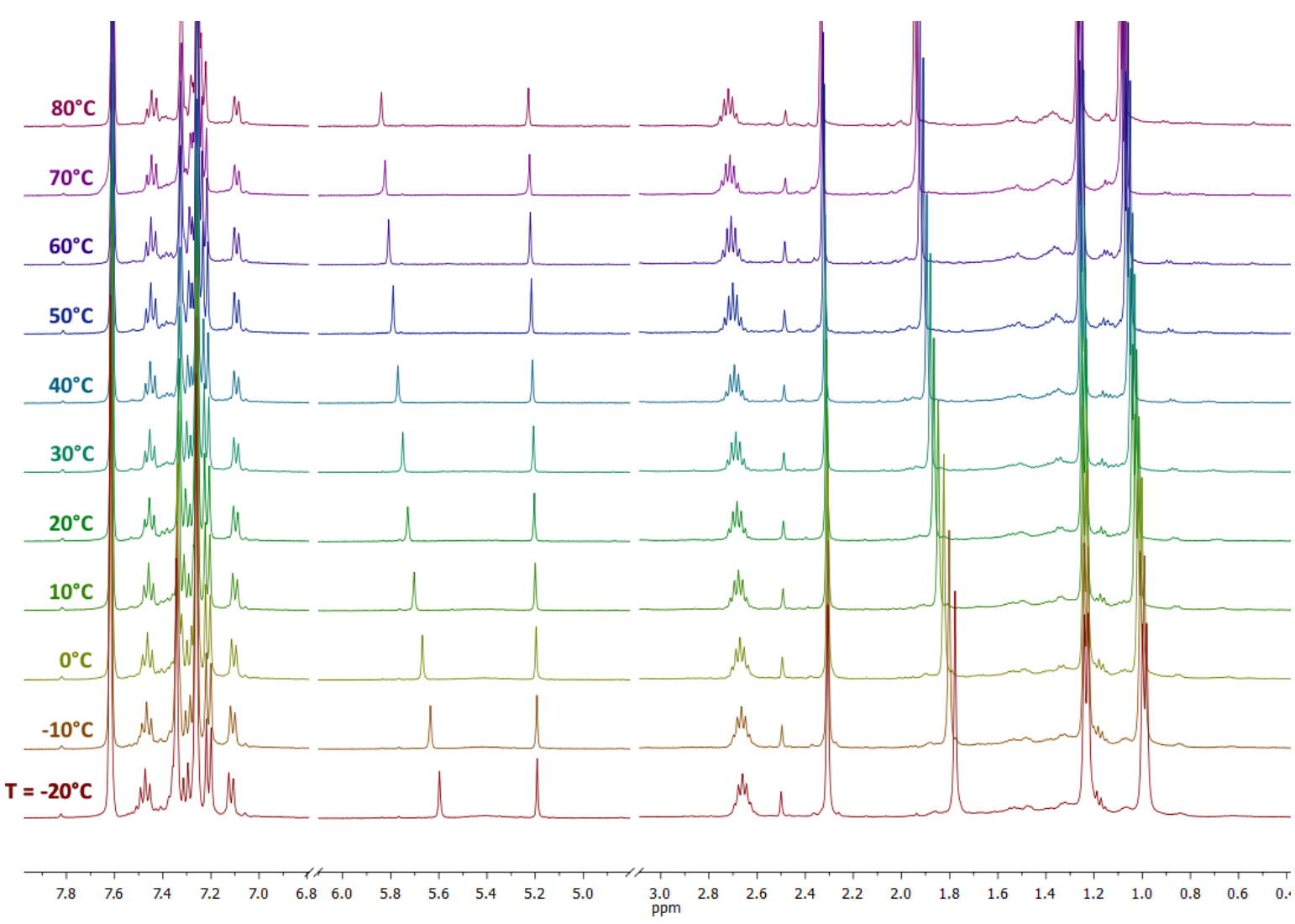

Figure 2-25. ${ }^{1} \mathrm{H}$ NMR studies $\left[\left({ }^{4-\mathrm{Me}} \mathrm{Box}_{2} \mathrm{CH}\right) \mathrm{HAl}-\mathrm{Al}\left({ }^{\text {Dipp }} \mathrm{NacNac}\right)\right]^{+}\left[\mathrm{B}\left(\mathrm{C}_{6} \mathrm{~F}_{5}\right)_{4}\right]^{-}$(14) in bromobenzene- $d_{5}$ at different temperatures $\left(-20^{\circ} \mathrm{C}\right.$ to $\left.80^{\circ} \mathrm{C}\right)$.

Besides, the synthesis of 14 could be proven by mass spectrometry (LIFDI[+], fluorobenzene, $\mathrm{m} / \mathrm{z}$ (\%) $749.4(3)[M]^{+}$) and elemental analysis. To gain more insights into the electronic structure of 14, DFT calculations were carried out at the pbe0/def2-TZVP $\left(\mathrm{C}_{3} \mathrm{~N}_{2} \mathrm{AlH}-\mathrm{AlC}_{3} \mathrm{~N}_{2}\right)$ and def2-SVP (all other atoms) level. ${ }^{[142]}$ The calculated and experimental structure are in good agreement (RMS =

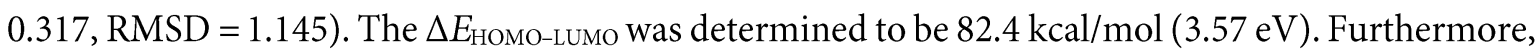
the $\mathrm{sp}^{2}$-hybridised $\mathrm{All}$ atom $(35.5 \% \mathrm{~s}, 64.5 \% \mathrm{p})$ of the $\mathrm{AlH}\left({ }^{4-\mathrm{Me}} \mathrm{Box}_{2} \mathrm{CH}\right)$ fragment and corresponding sp-hybridised $\mathrm{Al} 2$ centre $(78.3 \% \mathrm{~s}, 21.7 \% \mathrm{p})$ of $\left.\mathrm{Al}\left({ }^{\text {(ipp }} \mathrm{NacNac}\right)\right]$ form a single bond according to the obtained Löwdin bond order of $0.920\left(\mathrm{Al}-\mathrm{Al}_{\text {calc }} 2.633 \AA, \Delta_{\text {calc-exp }}=-1.57 \cdot 10^{-2} \AA\right) .{ }^{[143]}$ 
In 2010, Jones and Stasch et al. published the first examples of a thermally stable dialuminium(II) hydride complex, i.e., $\left[\mathrm{AlH}_{2}(\mathrm{IPr})\right]_{2}\left(\mathrm{IPr}=: \mathrm{C}\left[\left\{\left(\mathrm{C}_{6} \mathrm{H}_{3}-{ }^{i} \mathrm{Pr}_{2}-2,6\right) \mathrm{NCH}\right\}_{2}\right]\right)$, which was formed as a side product in the hydrogenation of $\left[\mathrm{Mg}\left({ }^{\mathrm{R} N a c N a c}\right)\right]_{2}$ ( $\left.\mathrm{R}=\mathrm{Dipp}, \mathrm{Mes}\right){ }^{[42 \mathrm{~b}]}$ With this in mind, $\left[\mathrm{AlH}_{2}\left({ }^{4-\mathrm{Me} B o x}{ }_{2} \mathrm{CH}\right)\right](12)$ was reacted with half an equivalent of $\left[\mathrm{Mg}^{\mathrm{I}}\left({ }^{\mathrm{Mes}} \mathrm{NacNac}\right)\right]_{2}$ in toluene (Scheme 2-18).

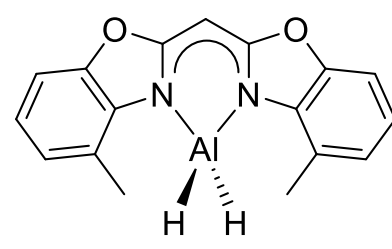

12

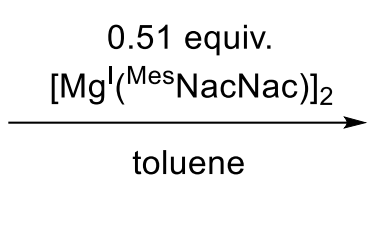

toluene

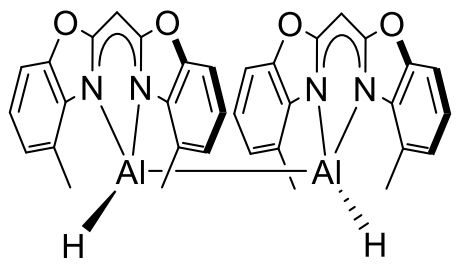

$15 a$

Scheme 2-18. Dehydrogenation of alane 12 to dialane $15 \mathrm{a}$.

First, both starting materials were mixed at $-30^{\circ} \mathrm{C}$, and the obtained suspension was warmed to ambient temperature. After stirring for roughly $3 \mathrm{~h}$, a clear orange solution was obtained, which turned darker overnight. Afterwards the reaction solution was filtered and cooled to $-30^{\circ} \mathrm{C}$. Thin yellow crystals suitable for single crystal XRD analyses were grown out of the saturated toluene solution after $2 \mathrm{~d}$. These plate-shaped crystals, which crystallised in the monoclinic space group $P 2_{1} / n$ with one complex molecule (Figure 2-26) and one toluene molecule in the asymmetric unit, show a disorder of $\left[\mathrm{AlH}\left({ }^{4-\mathrm{Me}} \mathrm{Box}_{2} \mathrm{CH}\right)\right]_{2}(15 \mathrm{a}$, s.o. $0.665(4))$ and $\left[(\mu-\mathrm{O})\left\{\mathrm{AlH}\left({ }^{4-\mathrm{Me}} \mathrm{Box}_{2} \mathrm{CH}\right)\right\}_{2}\right](15 \mathbf{b})$ with the minor site occupation factor (s. o.) of 0.335(4). Hence, all bond length and angles need to be discussed with care because they are influenced by the disorder. The Al-N bond lengths (1.946(3) to 1.973(3) $\AA$ ) and bite angles (N1-Al1A-N2 92.88(11) ${ }^{\circ}$, N3-Al2A-N4 93.36(14) ${ }^{\circ}$ ) of 15a (Table 2-5) seem to be close to the corresponding parameters of alane 12 , while the $\mathrm{Al}^{\mathrm{II}}-\mathrm{Al}^{\mathrm{II}}$ bond $(\mathrm{All} \mathrm{A}-\mathrm{Al} 2 \mathrm{~A}$
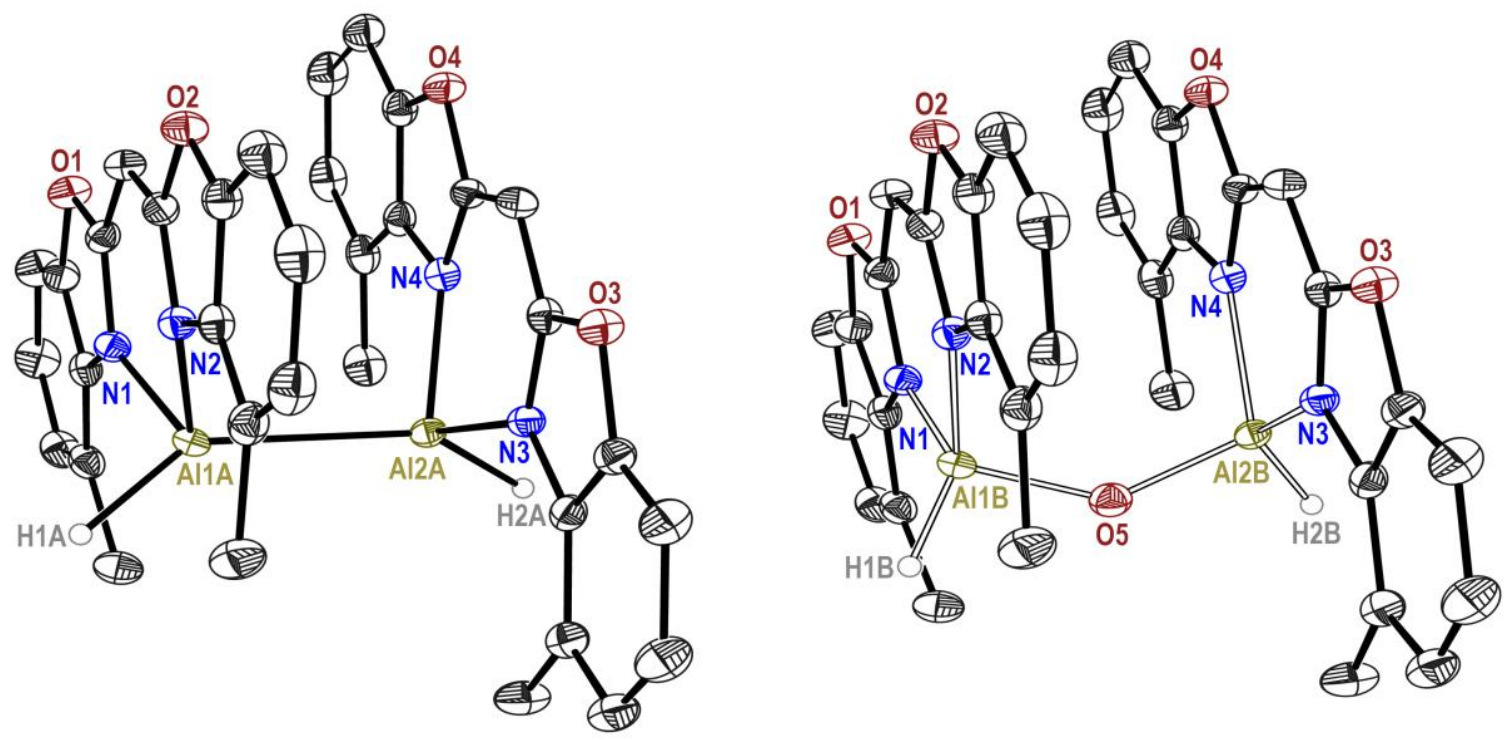

Figure 2-26. Co-crystallised $\left[\mathrm{AlH}\left({ }^{4-\mathrm{Me}}{ }^{-} \mathrm{Box}_{2} \mathrm{CH}\right)\right]_{2}(15 \mathrm{a}$, left $)$ and $\left.\left[(\mu-\mathrm{O})\left\{\mathrm{AlH}^{4-\mathrm{Me}} \mathrm{Box}_{2} \mathrm{CH}\right)\right\}_{2}\right]$ (15b, right). Dialane 15a is main the component with an occupancy of 0.665(4). Anisotropic displacement parameters are depicted at $50 \%$ probability level. All ligand-based hydrogen atoms are omitted for clarity. 
2.583(4) $\AA$ ) shortens compared to dialanes 13 and 14, but within range of related complexes ( $\mathrm{Al}-\mathrm{Al}$ 2.575 to $2.675 \AA) .{ }^{[15 h, 35,42 b]}$ Measured bond lengths of Al1B-O5 1.688(5) $\AA$ and Al2B-O5 1.691(6) $\AA$ along with the angle Al1B-O5-Al2B of $136.8(5)^{\circ}$ are in agreement with previously published dialuminoxanes, i. e., $\left.\left[(\mu-\mathrm{O})\{\mathrm{AlX}(L)\}_{2}\right]^{[161 \mathrm{~b}]}\left(L=\left\{\left(2,6-\mathrm{Me}_{2} \mathrm{C}_{6} \mathrm{H}_{3}\right) \mathrm{NCMe}\right\}_{2} \mathrm{CH}\right) ; X=\mathrm{H}, \mathrm{Me}, \mathrm{Cl}\right)$ or $\left.\left[(\mu-\mathrm{O})\left\{\mathrm{AlH}^{\mathrm{Ph}}{ }^{\mathrm{Ph}} \mathrm{HI}_{2} \mathrm{P}\right)\right\}_{2}\right]^{[168]}\left({ }^{\mathrm{Ph}} \mathrm{I}_{2} \mathrm{P}=2,6-\left(2,6-{ }^{\mathrm{i}} \mathrm{Pr}_{2}-\mathrm{C}_{6} \mathrm{H}_{3} \mathrm{~N}=\mathrm{CPh}\right)_{2}-\mathrm{C}_{5} \mathrm{H}_{3} \mathrm{~N}\right)$. Although this reaction was repeated several times while varying the reaction conditions with respect to the solvent, the concentration, the temperature, and reaction time, species $15 \mathrm{a}$ and $15 \mathrm{~b}$ were always found, sometimes in slightly differing amounts. Oxygenation by minute impurities of $\mathrm{O}_{2}$ might have led to dialuminoxane $15 \mathrm{~b}$ caused by the high reactivity of dialane $15 \mathrm{a}$ as reported for $\left[\left\{\left(\mu^{3}-\mathrm{O}\right) \mathrm{AlCp}^{*}\right\}_{4}\right]^{[169]}$ or $\left[(\mu-\mathrm{O})\left\{\mathrm{Al}\left({ }^{\mathrm{Dipp}} \mathrm{NacNac}\right)\right\}_{2}\right]^{[170]}$. Moreover, the formation of $15 \mathrm{~b}$ could be explained by the hydrolysis of alane 12, which was observed in the LIFDI mass spectrum.

When the reaction time was expanded over $1 \mathrm{~d}$, the formation of an aluminium mirror could be observed, possibly caused by the disproportionation of dialane 15a. In further reactions of 12 with $\left[\mathrm{Mg}^{\mathrm{I}}\left({ }^{\mathrm{Mes}} \mathrm{NacNac}\right)\right]_{2}$, a few crystals of $\left[\left(\left\{\left({ }^{\mathrm{Mes}} \mathrm{NacNac}\right) \mathrm{Mg}\right\}_{2}(\mu-\mathrm{H})\right)-\left\{\mathrm{H}_{3} \mathrm{Al}^{\mathrm{II}}-\mathrm{Al}^{\mathrm{II}} \mathrm{H}\left({ }^{4-\mathrm{Me}} \mathrm{Box}_{2} \mathrm{CH}\right)\right\}\right](15 \mathrm{c})$ (Figure 2-27) were isolated and characterised by single crystal XRD experiments (for details see Chapter 5.1.19). This asymmetrical species is reminiscent of symmetrical dialanate dianion $\left(\left[\mathrm{H}_{3} \mathrm{Al}^{\mathrm{II}}-\right.\right.$

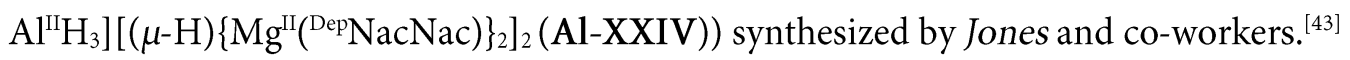
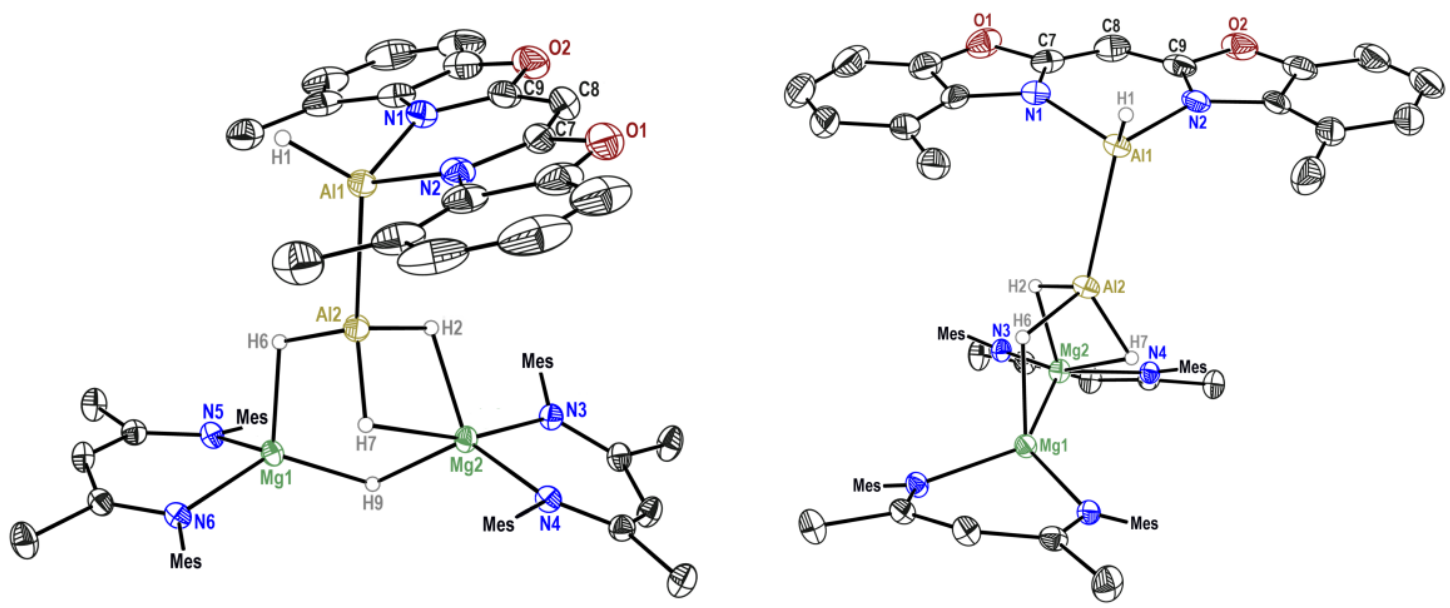

Figure 2-27. Crystal structure of $\left[\left(\left\{\left({ }^{\mathrm{Mes}} \mathrm{NacNac}\right) \mathrm{Mg}\right\}_{2}(\mu-\mathrm{H})\right)-\left\{\mathrm{H}_{3} \mathrm{Al}^{\mathrm{II}}-\mathrm{Al}^{\mathrm{II}} \mathrm{H}\left({ }^{4-\mathrm{Me}} \mathrm{Box}_{2} \mathrm{CH}\right)\right\}\right]$ (15c). Anisotropic displacement parameters are depicted at $50 \%$ probability level. The ligand-based hydrogen atoms are omitted for clarity.

No other analytical data for $15 \mathrm{c}$ were obtained because these findings could not be reliably repeated. The ${ }^{1} \mathrm{H}$ NMR spectra of crystalline $15 \mathbf{a} / \mathbf{1 5 b}$ show that the different by-products could not be separated. The methyl aryl groups $(\delta 2.60 \mathrm{ppm})$ and the methanide linker $(\delta 4.83 \mathrm{ppm})$ are more shielded and, therefore, upfield shifted compared to alane 12. Furthermore, the ATR-IR spectrum of $15 \mathrm{a} / 15 \mathrm{~b}$ exhibits two vibrational bands $\tilde{v}_{\mathrm{H}-\mathrm{Al}}=1876 \mathrm{~cm}^{-1}$ and $1783 \mathrm{~cm}^{-1}$. More importantly, mass spectrometry (LIFDI[+], toluene) corroborated the synthesis of dialane (15a) by $\mathrm{m} / z(\%)=610.1$ (34) $[M]^{+}$and dialuminoxane (15b) by $626.1(100)[M+O]^{+}$, respectively.

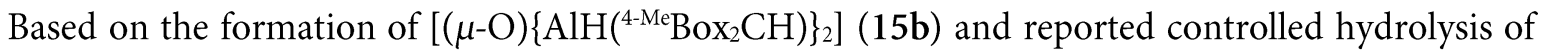
aluminium complexes, i. e., $\left[(\mu-\mathrm{O})\left\{\mathrm{AlH}\left({ }^{\mathrm{Mes}} \mathrm{NacNac}\right)\right\}_{2}\right]^{[171]}$, as well as the syntheses of molecular 
aluminoxanes ${ }^{[89,90,161 b, 168]}$, a half equiv. of water was added to a THF solution of $\left[\mathrm{AlH}_{2}\left({ }^{4-\mathrm{Me}^{e} \mathrm{Box}} 2 \mathrm{CH}\right)\right]$ (12) at ambient temperature. After dihydrogen gas evolution, an insoluble white powder precipitated. To increase the solubility and prevent the potential synthesis of insoluble oligomeric aluminoxanes ${ }^{[172]}$, compound 12 was first reacted with one equiv. of 2,6-diisopropylphenol (propofol) (Scheme 2-19).

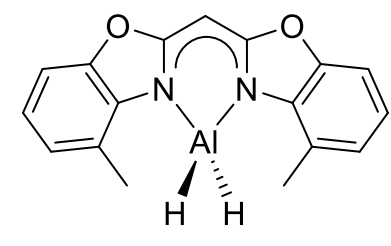

12

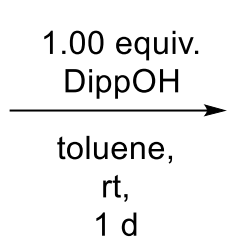

$1 \mathrm{rt}$

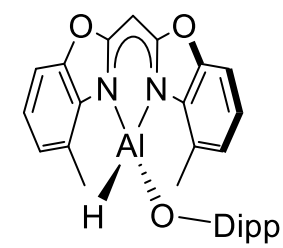

16

$88 \%$

Scheme 2-19. Synthesis of [AlH(ODipp) $\left.\left({ }^{4-\mathrm{Me}} \mathrm{Box}_{2} \mathrm{CH}\right)\right]$ (16) by deprotonation of propofol (DippOH).

Consequently, alane 12 was dissolved in toluene, and propofol (DippOH) was slowly added at ambient temperature. The solution was concentrated after it had been stirred for $1 \mathrm{~d}$. After that, twothirds of the volatiles were removed in vacuo, and product 16 partially precipitated as a white solid. The supernatant solution was decanted and cooled to $-30^{\circ} \mathrm{C}$. Crystals of $\left[\mathrm{AlH}(\mathrm{ODipp})\left({ }^{4-\mathrm{Me}} \mathrm{Box}_{2} \mathrm{CH}\right)\right]$ (16) suitable for single crystal XRD measurements could be obtained from this solution overnight (Figure 2-28). Species 16 crystallises in the triclinic space group $P \overline{1}$ with one complex molecule in the asymmetric unit.
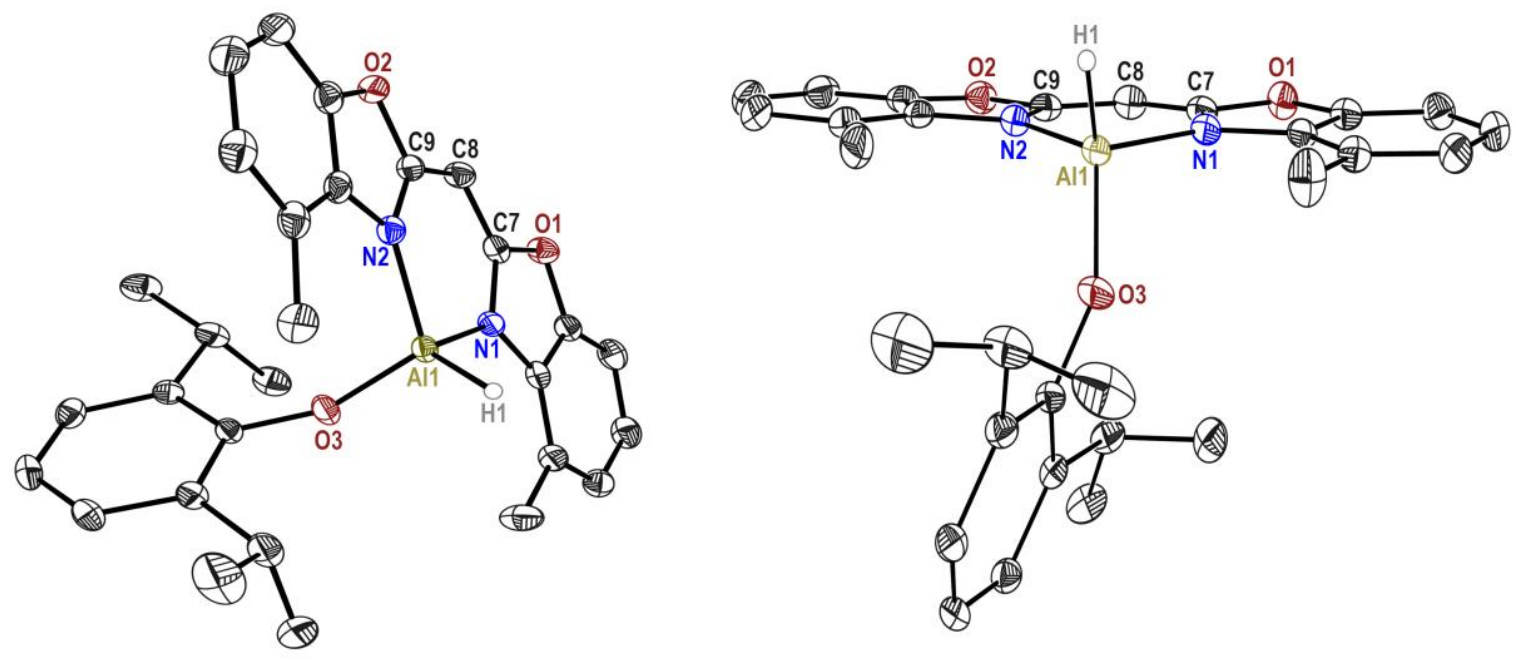

Figure 2-28. Crystal structure of $\left[\mathrm{AlH}(\mathrm{ODipp})\left({ }^{\left.4-\mathrm{Me} B \mathrm{Bx}_{2} \mathrm{CH}\right)}\right]\right.$ (16). Anisotropic displacement parameters are depicted at $50 \%$ probability level. All ligand-based hydrogen atoms are omitted for clarity.

The aluminium nitrogen bond lengths (Al1-N1 1.9038(11) $\AA$, Al1-N2 1.9138(11) $\AA$ ) are similar to those of 12 , and corresponding distances in the $\mathrm{AlH}\left({ }^{4-\mathrm{Me}} \mathrm{Box}{ }_{2} \mathrm{CH}\right)$ fragment of asymmetric dialane 13 (Table 2-5). Accessorily, the aluminium hydride bond Al1-H1 1.500(14) $\AA$ and the bite angle N1Al1-N2 of $95.33(4)^{\circ}$ are close to analogous parameters of alane 12. Relative to 12, the deviation of 
aluminium ion from the $\mathrm{C}_{3} \mathrm{~N}_{2}$ plane is slightly decreased ( $\mathrm{Al} \cdots \mathrm{C}_{3} \mathrm{~N}_{2} 0.1063(7) \AA$ ), while the butterfly folding angle of $4.80(7)^{\circ}$ between the two benzoxazol-2-yl moieties is increased. ${ }^{[89,90]}$ The related $\left[\mathrm{AlH}(\mathrm{OR})\left({ }^{\mathrm{Dipp}} \mathrm{NacNac}\right)\right](\mathrm{R}=\mathrm{Dipp}, \mathrm{Mes})$ complexes feature a more pronounced $\mathrm{Al} \cdots \mathrm{C}_{3} \mathrm{~N}_{2}$ deviation of 0.549(2) to 0.511(2) $\AA .{ }^{[173]}$ The bite angle N1-Al1-N2 of $95.33(4)^{\circ}$ and H1-Al1-O1 of $113.8(6)^{\circ}$ of complex 16 are more acute than corresponding angles in $\left[\mathrm{AlH}(\mathrm{ODipp})\left({ }^{\mathrm{Dipp}} \mathrm{NacNac}\right)\right]$, whereas Al-O length (16: 1.7053(12) $\AA$; [AlH(ODipp)( ${ }^{\text {Dipp NacNac) }]: ~ 1.712(1) ~} \AA$ ) and Al-O-C (16: 151.61(8) ; [AlH(ODipp) (Dipp NacNac)]: 151.28 $\left.(11)^{\circ}\right)$ are almost identical. These differences in the coordination sphere of the $\mathrm{Al}^{\mathrm{III}}$ ion might be elucidated by the lower steric hindrance of the bis(benzoxazole-2yl)methanide ligand in its third dimension orthogonal to the almost planar ligand. This means that the distortion of bulky ${ }^{\text {Dipp }} \mathrm{NacNac}$ is inevitable to accommodate the DippO group by reducing the interaction with the bulky residues. The ${ }^{1} \mathrm{H}$ NMR spectrum (benzene- $d_{6}$ ) of 16 (Figure 2-29) exhibits a significant deshielding and simultaneous downfield shift of the methanide bridge from $\delta 5.08 \mathrm{ppm}$ (12) to $\delta 5.43 \mathrm{ppm}$. In relation to alane 12 , the signal splitting of aromatic protons increases while the arylic methyl residues are slightly upfield shifted ( $\Delta \delta 0.09 \mathrm{ppm})$. Furthermore, the coordination of the DippO group to the aluminium ion causes a downfield shift of the characteristic iso-propyl septet $\left(-\mathrm{CH}\left(\mathrm{CH}_{3}\right)_{2}\right)$ to $\delta 3.50 \mathrm{ppm}$, as well as an upfield shift of the methyl doublet $\left(-\mathrm{CH}\left(\mathrm{CH}_{3}\right)_{2}\right)$ to $\delta 1.07 \mathrm{ppm}$.

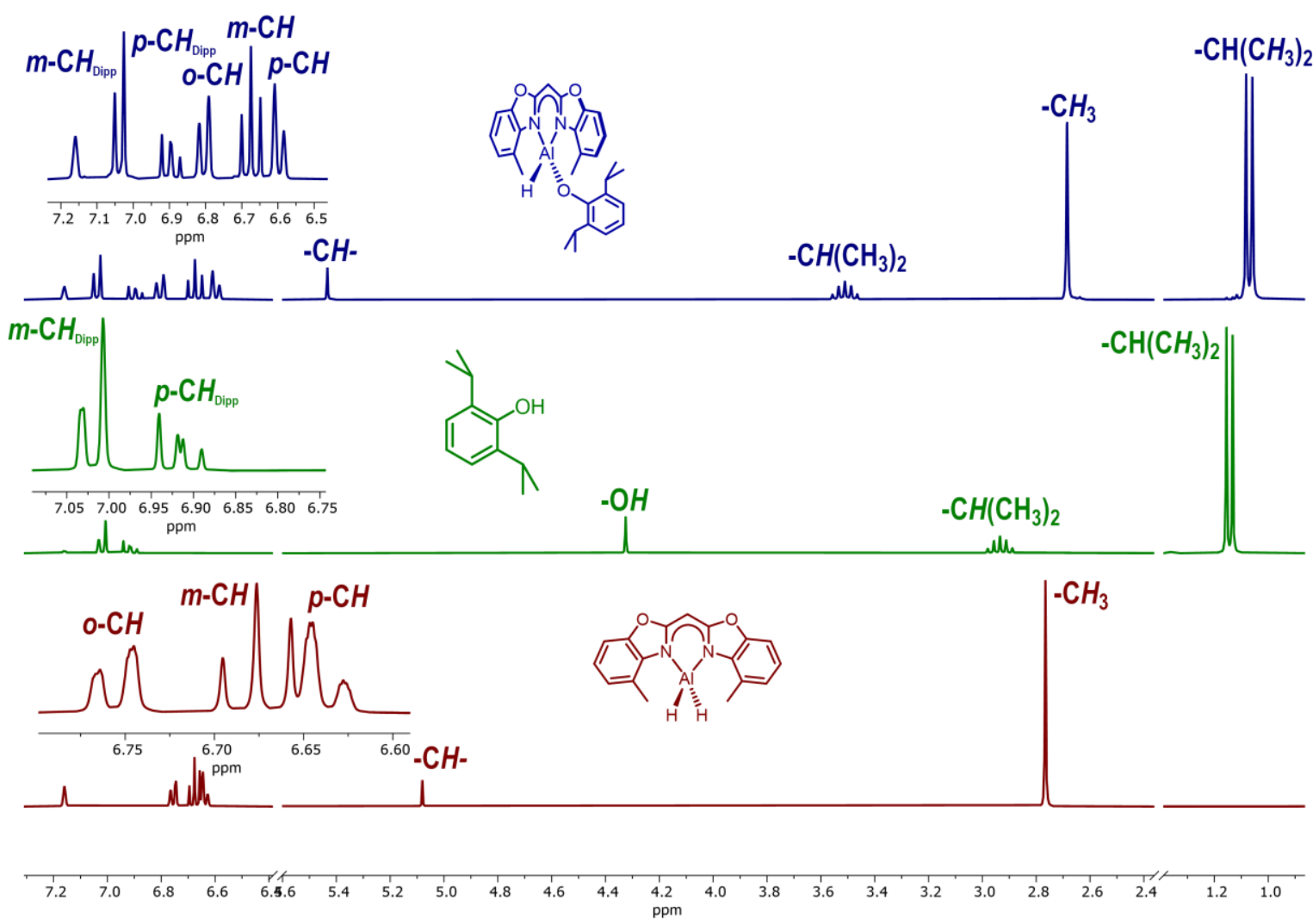

Figure 2-29. Stacked ${ }^{1} \mathrm{H}$ NMR spectra of $\left[\mathrm{AlH}(\mathrm{ODipp})\left({ }^{4-\mathrm{Me}} \mathrm{Box}_{2} \mathrm{CH}\right)\right](16)$, propofol and $\left[\mathrm{AlH}_{2}\left({ }^{4-\mathrm{Me}} \mathrm{Box}_{2} \mathrm{CH}\right)\right]$ (12) in benzene- $d_{6}$. 
The Al-H signal was not observed, presumably cause by peak broadening and a relatively low intensity. However, the presence of the hydride was confirmed by IR spectroscopy, which revealed a stretch peak at $1912 \mathrm{~cm}^{-1}$. Additionally, the successful synthesis of 16 was verified by mass spectrometry (LIFDI[+], toluene, $\mathrm{m} / \mathrm{z}(\%) 482.2(100)[M]^{+}$) and elemental analysis.

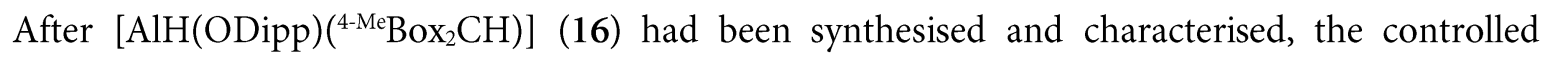
reaction hydrolysis was investigated with half equivalent of water. For this purpose, complex 16 was first dissolved in THF or toluene, and degassed water was added at ambient temperature (Scheme 2-20). Immediately after the addition of water, a dihydrogen gas evolution could be observed. The reaction mixture was stirred at ambient temperature for $1 \mathrm{~d}$, wherein a white solid precipitated after ca. 1 h. Volatiles were removed under reduced pressure, and a white powder, showing poor solubility in most solvents (toluene, THF, DCM, acetone, MeCN, fluoro- and bromobenzene), was obtained.

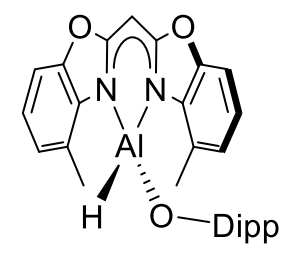

16

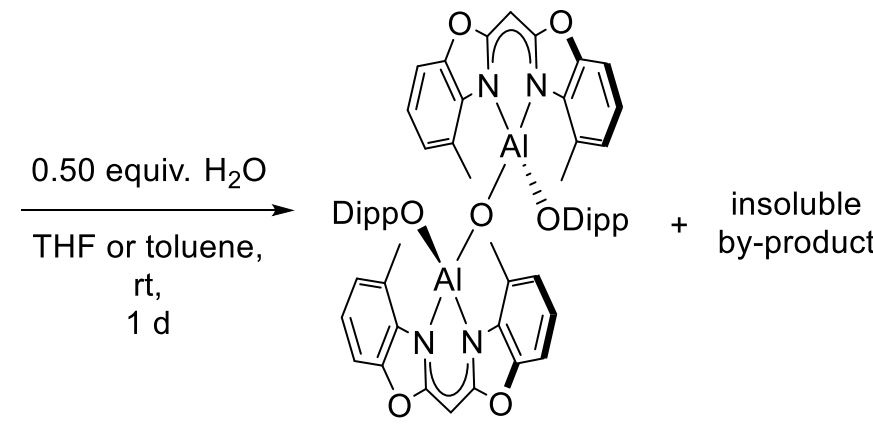

17

Scheme 2-20. The reaction of $\left[\mathrm{AlH}(\mathrm{ODipp})\left({ }^{4-\mathrm{Me}} \mathrm{Box}_{2} \mathrm{CH}\right)\right](16)$ and half an equivalent of water in THF or toluene.

${ }^{1} \mathrm{H}$ and ${ }^{13} \mathrm{C}$ NMR experiments of the soluble compounds in $\left[\mathrm{D}_{8}\right]$ toluene or $\left[\mathrm{D}_{8}\right] \mathrm{THF}$, respectively, revealed the synthesis of multiple species. One of these species is dialuminoxane $\left[(\mu-\mathrm{O})\left\{\mathrm{Al}(\mathrm{ODipp}){ }^{4-\mathrm{Me}} \mathrm{Box}_{2} \mathrm{CH}\right\}_{2}\right]$ (17), which was isolated from a saturated THF solution as colourless crystals. Complex 17 crystallises in space group $P 2_{1} / n$ with half a complex molecule in the asymmetric unit (Figure 2-30). 

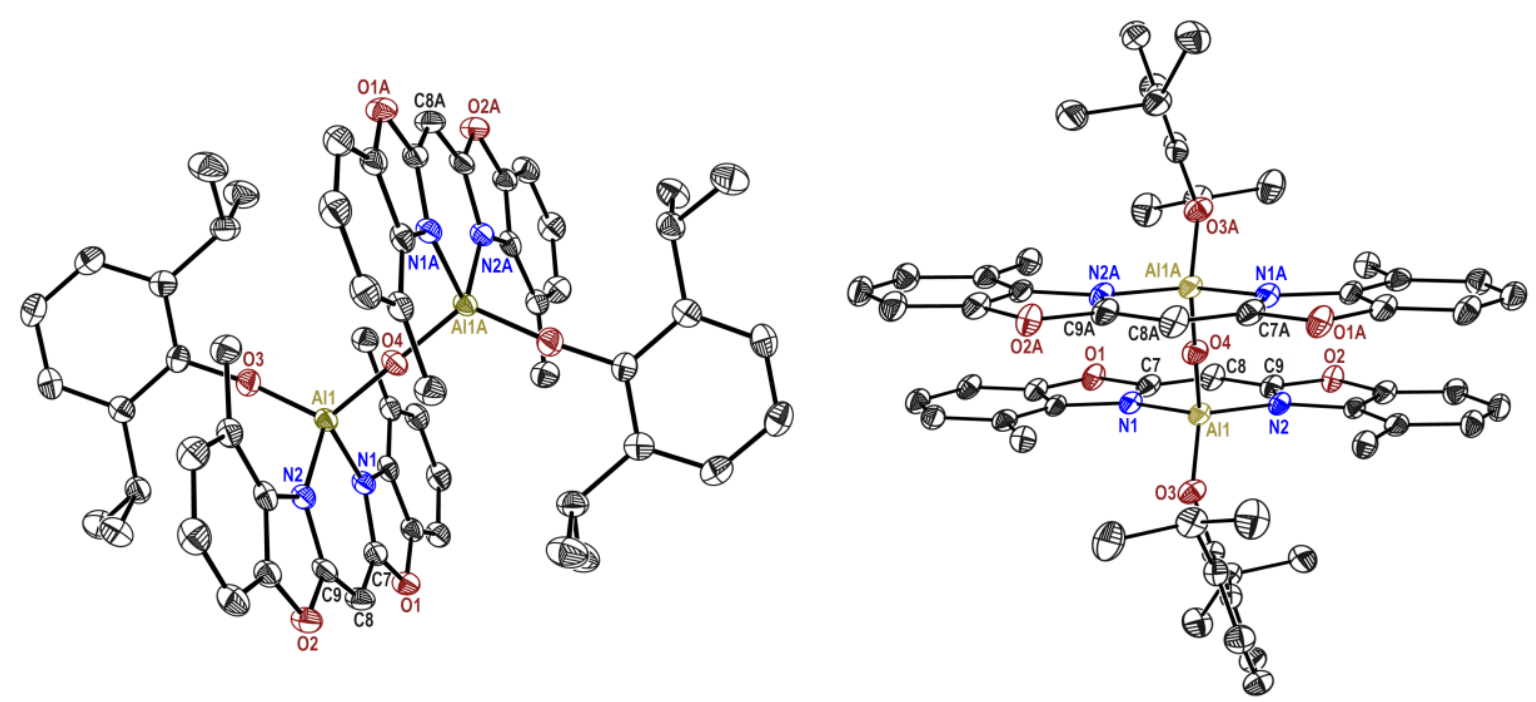

Figure 2-30. Crystal structure of $\left[(\mu-\mathrm{O})\left\{\mathrm{Al}(\mathrm{ODipp})\left({ }^{4-\mathrm{Me}} \mathrm{Box}_{2} \mathrm{CH}\right\}_{2}\right]\right.$ (17). Anisotropic displacement parameters are depicted at 50\% probability level. All hydrogen atoms are omitted for clarity.

The aluminium nitrogen bond lengths of Al1-N1 1.9016(17) $\AA$ and Al1-N2 1.9009(17) are slightly shorter than the values of those in the alanes 12 and 16 (Table 2-5). In addition, the bite angle N1Al1-N2 $96.22(7)^{\circ}$ is less acute, while the butterfly folding angle of $2.48(8)^{\circ}$ is reduced compared to precursor complexes 12 and 16. Interestingly, the bis(benzoxazol-2-yl)methanide ligands of complex

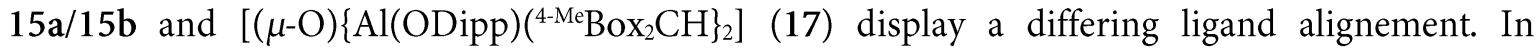
dialuminoxane 17 , the methyl groups of the ligands face one another while the bridging oxygen is located on the inversion centre (Figure 2-30). On the contrary, the disorder in $\mathbf{1 5 b}$ displays a partial overlay and a small angle of $40.49(9)^{\circ}$ between the planes of Al2B-Al1B-C8 and Al1B-Al2B-C25 of the almost parallel-aligned ligands (the angle between both moieties of $\mathrm{C}_{3} \mathrm{~N}_{2}$ is $\left.1.19(2)^{\circ}\right)$. The mass spectrum (LIFDI[+], THF) of the white solid displayed a signal at $m / z(\%) 978.3$ (100), which can be assigned to dialuminoxane 17. Additionally, the elemental analysis fitted the theoretical values of 17. The ATR IR spectrum of this solid detected no absorption in the typical range for aluminium

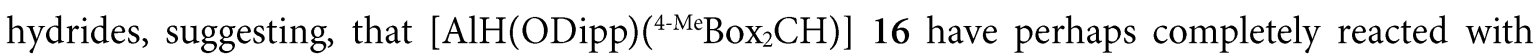
water. 


\subsection{Complexes based on Bis(4-benzhydryl-benzoxazol-2- yl)methane scaffold}

Major parts of this chapter have been published in:

[5] J. Kretsch, A. Kreyenschmidt, T. Schillmöller, M. Lõkov, R. Herbst-Irmer, I. Leito, D. Stalke, "Bis(4-benzhydryl-benzoxazol-2-yl)methane - from a Bulky NacNac Alternative to a Trianion in Alkali Metal Complexes", Chem. Eur. J. 2021, 27, 9858-9865. ${ }^{[5]}$

[6] J. Kretsch, A. Kreyenschmidt, T. Schillmöller, C. Sindlinger, R. Herbst-Irmer, D. Stalke, “Group 13 Heavier Carbene Analogs Stabilized by the Bulky Bis(4-benzhydryl-benzoxatol-2yl)methanide Ligand", Inorg. Chem. 2021, 60, 7389-7398. ${ }^{[6]}$

\subsubsection{Ligand Synthesis}

Despite the steric demand provided by ${ }^{i} \mathrm{Pr}$ - or ${ }^{t} \mathrm{Bu}$-residues close to the coordination pocket in ${ }^{4,6-R} \mathrm{Box}_{2} \mathrm{CH}_{2}\left(R={ }^{i} \mathrm{Pr},{ }^{\mathrm{B}} \mathrm{Bu}\right)$, which mimics the bulkiness provided by ${ }^{A} \mathrm{NacNac}$ ligands ( $\mathrm{Ar}=\mathrm{Dipp}$, Mes, Dep), low-oxidation or -valent group 2 or 13 compounds could so far not be synthesised. Hence, we decided to introduce even bulkier benzhydryl groups at the ligand scaffold. Here, we were inspired by compounds containing 2,6-dibenzhydrylphenyl residues such as [:MH( $L)]^{[174]}(M=\mathrm{Ge}$ or $\mathrm{Sn}, L=$ $\left.-\mathrm{N}(A r)\left(\mathrm{Si}^{\mathrm{i}} \mathrm{Pr}{ }_{3}\right), A r={ }^{-}{ }^{-} \mathrm{Pr}-\mathrm{C}_{6} \mathrm{H}_{2} \mathrm{Bzh}_{2}\right)$ or $\left[\mathrm{M}(A r \mathrm{~N})_{2} \mathrm{CN}=\mathrm{C}^{t} \mathrm{Bu}_{2}\right]^{[175]}\left(A r=4-{ }^{t} \mathrm{Bu}-\mathrm{C}_{6} \mathrm{H}_{2} \mathrm{Bzh}_{2}\right)$. In the present chapter, the six-step synthesis of bis(4-benzhydryl-benzoxazol-2-yl)methane $\left({ }^{4-\mathrm{BzhH}}{ }^{-} \mathrm{Box}_{2} \mathrm{CH}_{2}\right)$ will be discussed in detail.

For the synthesis of the sterically demanding ${ }^{4-} \mathrm{BzhH}^{2} \mathrm{Box}_{2} \mathrm{CH}_{2}$ (23) ligand, 2-amino-3benzhydrylphenol was first synthesised according to Renaud and co-workers. ${ }^{[176]}$ To further optimise the synthesis route, some reaction conditions and work-up procedures were modified (Scheme 2-21).
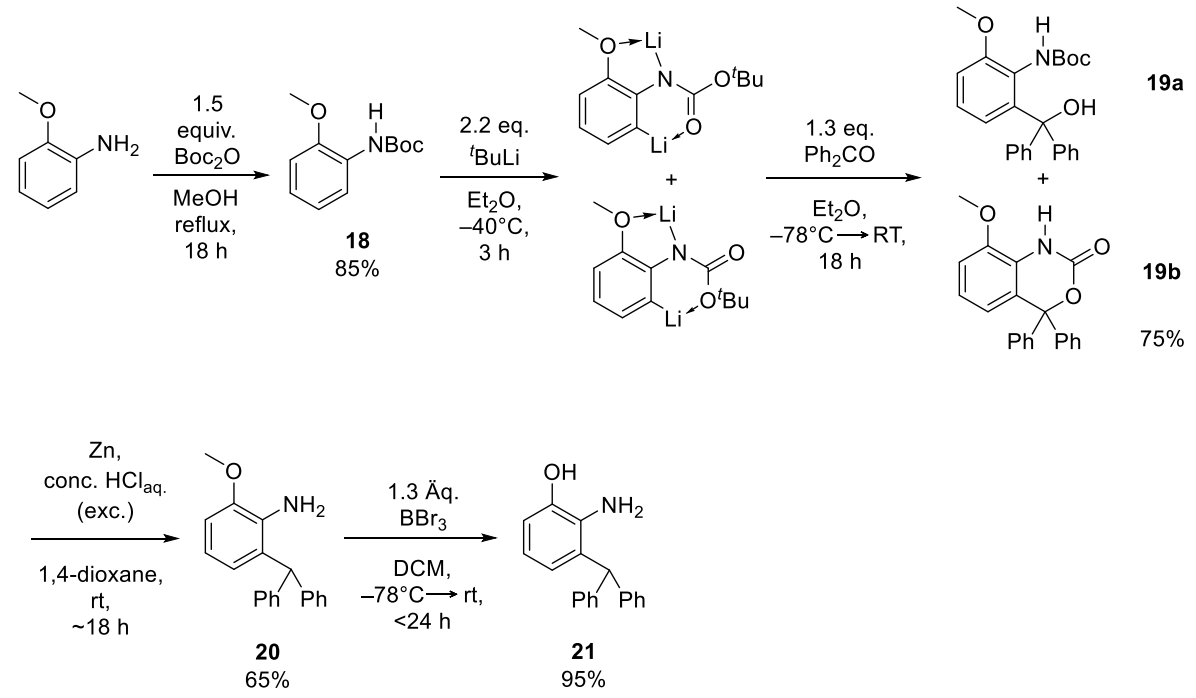

Scheme 2-21. Synthesis of bis(4-benzhydryl-benzoxazol-2-yl)methane $\left.{ }^{4-\mathrm{BrhH}^{2}} \mathrm{Box}_{2} \mathrm{CH}_{2}\right)$ (23) based on 2-anisidine. 
Starting from 2-anisidine, a tert-butyloxycarbonyl (Boc) protecting group was introduced via reaction with di-tert-butyl-dicarbamate $\left(\mathrm{Boc}_{2} \mathrm{O}\right)$ in methanol under reflux $\left(\sim 100^{\circ} \mathrm{C}\right)$ for $18 \mathrm{~h}^{[177]}$ After work-up procedures (for detail, see Chapter 4.1.9.1) and the subsequent distillation of the crude product at $130^{\circ} \mathrm{C}$ under fine vacuum, tert-butyl(2-methoxyphenyl) carbamate (18) was isolated as colourless oil in good yields (85\%). Afterwards, compound 18 was deprotonated both at the amine group and the $\mathrm{C} 3$-position (ortho imine position) by 2.20 equiv. ${ }^{\mathrm{B} u L i}$ solution, which was slowly added at $-45^{\circ} \mathrm{C}$. This dilithiated intermediate was directly reacted with a solution of benzophenone in $\mathrm{Et}_{2} \mathrm{O}$ at $-78^{\circ} \mathrm{C}$, and the obtained green mixture was carefully warmed to ambient temperature overnight. Demineralised water was subsequently added to quench unreacted ${ }^{\mathrm{B}} \mathrm{BuLi}$ or by-products. A white solid, a yellow ether phase, and a colourless water phase were observed. Work-up of the white solid and the liquid phases (for details, see Chapter 4.1.9.2) revealed a product mixture of carbamate 19a $(\sim 50 \%)$ and oxazin-2-one $19 \mathrm{~b}(\sim 50 \%)$ in a slightly varying ratio and an overall yield of $75 \%$. Interestingly, bicyclic oxazin-2-one $19 \mathrm{~b}$ that might be formed caused by the cleavage of tert-butyl group, was isolated instead of $\mathrm{N}$-(diphenylmethylene)- $\mathrm{N}$-(2-methoxyphenyl)amine reported by Renaud and co-workers. ${ }^{[176]}$ Purification or rather separation of compounds $19 \mathrm{a} / 19 \mathrm{~b}$ was not necessary, because both compounds could be transformed to 2-benzhydryl-6-methoxyaniline (20) by reduction and coupled deprotection. For this purpose, both compounds $19 \mathrm{a} / \mathbf{1 9 b}$ were reacted with an excess of zinc powder and concentrated hydrochloric acid in 1,4-dioxane (for details, see 4.1.9.3). ${ }^{[178]}$ After the dihydrogen gas formation had ceased, the suspension was neutralised by a sodium hydroxide solution. Further purification processes led to compound 20 in good yields (65\%). Deprotection of the methoxy group was accomplished in DCM by 1.3 equiv. of boron tribromide solution at $-78^{\circ} \mathrm{C}$. After that, the olive-green solution was slowly warmed to ambient temperature overnight. ${ }^{[179]}$ The reaction time should not exceed $1 \mathrm{~d}$ to avoid the formation of side products. A saturated solution of sodium hydrogen carbonate in water was added to decompose the excess of $\mathrm{BBr}_{3}$ and neutralise the reaction mixture $(\mathrm{pH}=8-9)$ under the release of carbon dioxide. The organic phase was separated via a separation funnel, and the aqueous phase was extracted with ethyl acetate. Thereafter, the organic phases were washed with demineralised water and dried using $\mathrm{MgSO}_{4}$. Solvents were removed under reduced pressure, and 2-amino-3-benzhydrylphenol (21) was isolated in excellent yields (95\%). In this context, it is worth mentioning that reported syntheses of precursors 18 to 21 can be easily upscaled for bigger quantities and simply be purified by washing and by ultrasonic treatments. Subsequently, one equivalent of aminophenol derivative 21 was reacted (Scheme 2-22) with an equivalent of ethyl cyanoacetimidate hydrochloride in $\mathrm{MeOH}$ under reflux $\left(85^{\circ} \mathrm{C}\right)$ for $3 \mathrm{~d}$.
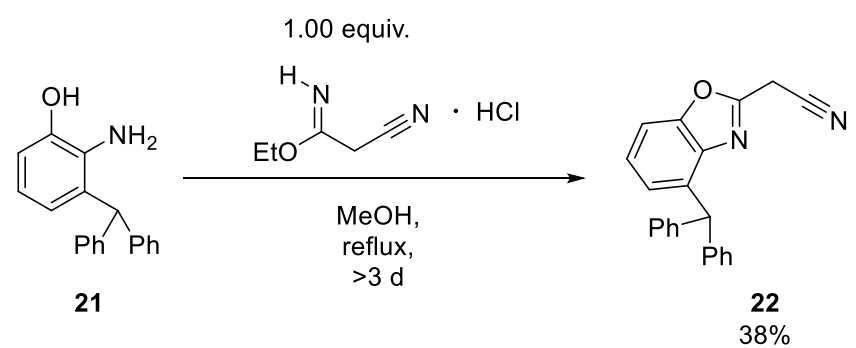

Scheme 2-22. Reaction of 2-amino-3-benzhydrylphenol (21) and one equiv. of ethyl cyanoacetimidate hydrochloride in $\mathrm{MeOH}$. 
The 2-(4-benzhydrylbenzoxazol-2-yl)acetonitrile (22) was isolated as a white solid in moderate yields after work-up (for details see Chapter 4.1.9.5). This product is a potent precursor for asymmetrically substituted bis(heterocylco)methane ligands with a sterically demanding 4-benzhydryl-benzoxazol2-yl group such as $\left(\mathrm{C}_{6} \mathrm{H}_{4} \mathrm{NCS}\right) \mathrm{CH}_{2}\left(1-\mathrm{MeNCNC}_{6} \mathrm{H}_{4}\right)$ reported by Stalke, Dauer, and Koehne. ${ }^{[105]}$

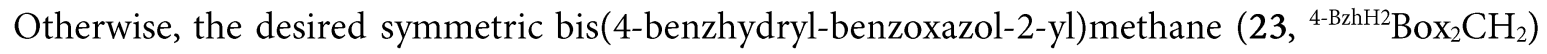
ligand was generated by cyclocondensation reaction of well-established ethylbisimidate dihydrochloride $\mathrm{C}_{3}$-linker and 2.0 equiv. of $21 .^{[106,108 \mathrm{a}, 108 \mathrm{~b}, 121]}$ For this purpose, starting materials were heated in $\mathrm{MeOH}$ under reflux $\left(85^{\circ} \mathrm{C}\right)$ for at least $3 \mathrm{~d}$. A white precipitate was formed overnight. Afterwards, the reaction mixture was cooled to ambient temperature and stored at $-30^{\circ} \mathrm{C}$.

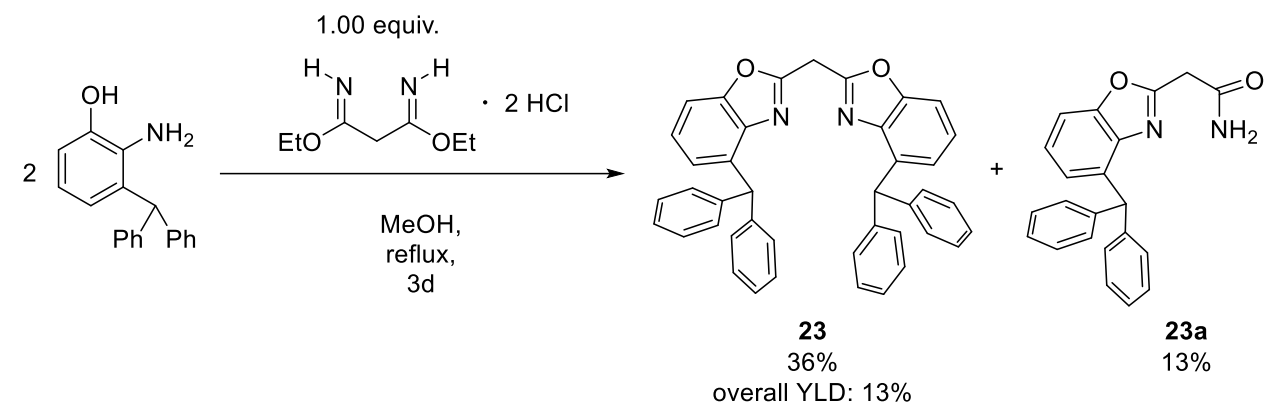

Scheme 2-23. Synthesis of bis(4-benzhydryl-benzoxazol-2-yl)methane (23) and 2-(4-benzhydrylbenzoxazol2-yl)acetamide (23a) by two equiv. 2-amino-3-benzhydrylphenol and ethylbisimidate dihydrochloride.

The white precipitate was subsequently filtered and washed with a saturated, aqueous sodium hydrogen carbonate solution and demineralised water. The isolated solid mainly consists of 23 , however, 2-(4-benzhydrylbenzoxazol-2-yl)acetamide (23a) occurred as a by-product. This might be due to minor impurities of moisture in $\mathrm{MeOH}$ that resulted in the hydrolysation of an imidate moiety on the semi-cyclised intermediate. To completely remove traces of unreacted aminophenol 21, the white solid was washed and sonicated with $\mathrm{MeOH}$, centrifuged, and the supernatant solution was finally decanted. This purification process was repeated twice and the obtained solid was dried under reduced pressure. Additionally, ${ }^{4-\mathrm{BzhH} 2} \mathrm{Box}_{2} \mathrm{CH}_{2}$ (23) and 2-(4-benzhydrylbenzoxazol-2-yl) acetamide (23a) were separated by column chromatography on silica gel (THF/hexane $3: 2 ; R_{\mathrm{f}}(23)=0.9$; $\left.R_{\mathrm{f}}(23 \mathrm{a})=0.48\right)$. After volatiles had been removed in vacuo, compound 23 and $23 \mathrm{a}$ were isolated in decent yields (YLD(23): 36\%, overall yield: 13\%; YLD(23a): 13\%). Crystals of bis(4-benzhydrylbenzoxazol-2-yl)methane (23) suitable for single crystal XRD measurements were grown out of a saturated solution of ethyl acetate by slow cooling or by vapour diffusion of pentane. The symmetric ligand crystallised in monoclinic space group $P 2_{1} / c$ with one ligand molecule in the asymmetric unit (Figure 2-31). 


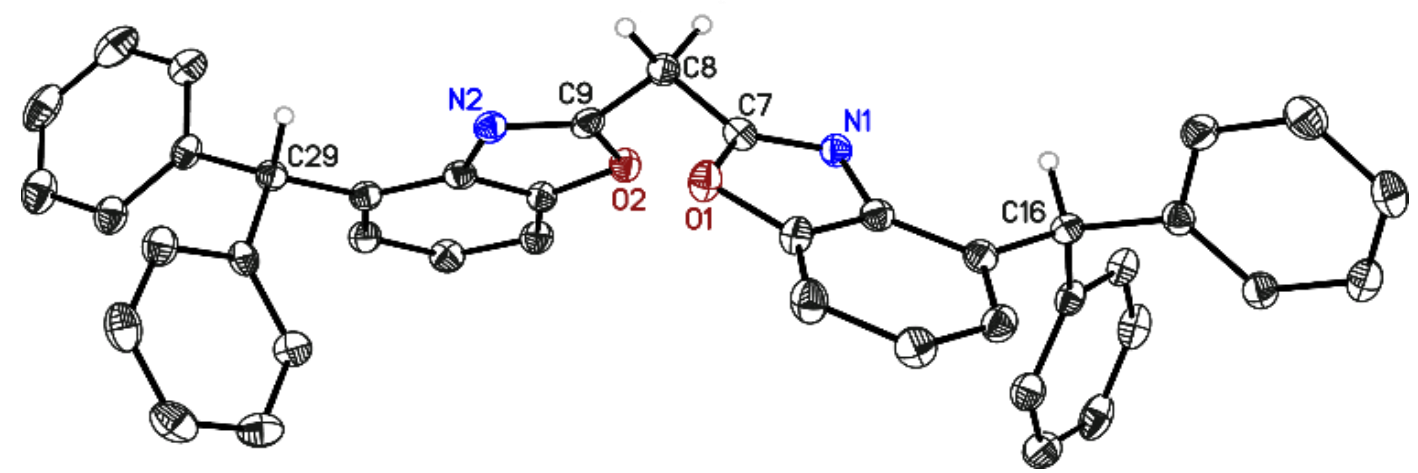

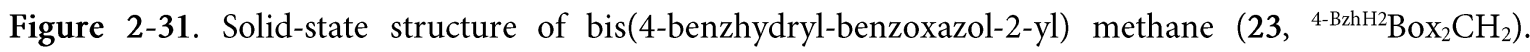
Anisotropic displacement parameters are depicted at the 50\% probability level. All hydrogen atoms are omitted for clarity except for the bridging (methylene) and benzylic ones. Selected bond lengths $[\AA]$ and bond angles $\left[^{\circ}\right]$ : N1-C7 1.289(2), N2-C9 1.291(2), C7-C8 1.491(2), C8-C9 1.497(2), C7-C8-C9 115.71(14), N1/2-C7-C8$\mathrm{C} 9=103.5(2)^{\circ} /-26.38(9)^{\circ} ; \mathrm{O} 1 / 2-\mathrm{C} 7-\mathrm{C} 8-\mathrm{C} 9=31.47(10)^{\circ} /-71.05(19)^{\circ}$.

The bridging carbon atom C8 is coordinated such as other symmetrically substituted bisheterocyclomethanes ${ }^{[89,90,104,106,128]}$ in a distorted tetrahedral fashion with a slightly expanded C7C8-C9 angle of $115.71(14)^{\circ}$ (related ligands: ${ }^{4-\mathrm{Me}} \mathrm{Box}_{2} \mathrm{CH}_{2}=110.79(12)^{\circ}$ to $\mathrm{Box}_{2} \mathrm{CH}_{2}=$ $\left.111.23(9)^{\circ}\right) .^{[104,106]}$ Furthermore, both benzoxazole moieties are less twisted $63.25(4)^{\circ}$ compared to

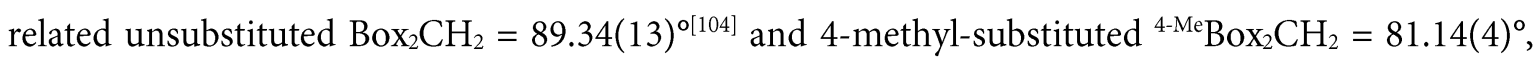
which display an almost orthogonal alignment of the heteroaromatic planes. ${ }^{[104,106]}$ This is most likely attributed to the bulkier benzhydryl groups. These cause wider dihedral angles between $\mathrm{C}_{3}$-linker moiety and nitrogen or oxygen atoms $\left(\mathrm{N} 1 / 2-\mathrm{C} 7-\mathrm{C} 8-\mathrm{C} 9=103.5(2)^{\circ} /-26.38(9)^{\circ}\right.$; O1/2-C7-C8-C9 $\left.=31.47(10)^{\circ} /-71.05(19)^{\circ}\right)$, somewhat akin to 4,6-butyl-substituted ${ }^{4,6-\mathrm{tBu}} \mathrm{Box}_{2} \mathrm{CH}_{2}$ (twist $=76.50(7)^{\circ}$, $\mathrm{N} 1 / \mathrm{N} 2-\mathrm{C} 17-\mathrm{C} 1-\mathrm{C} 2=-22.06(9)^{\circ} / 133.20(18)^{\circ}$, O1/O2-C17-C1-C2 $\left.=23.05(10)^{\circ} /-46.69(19)^{\circ}\right){ }^{[108 a]}$

Additionally, the solid-state structure of 23 displays intermolecular hydrogen bonds (Figure 2-32), where one of the acidic methylene hydrogen atoms interacts with the imine nitrogen atoms (N1…H8'A $2.49 \AA$ ) of an adjacent molecule and vice versa. In contrast, the molecular structures of related ligands ${ }^{4,6-\mathrm{Pr}} \mathrm{Box}_{2} \mathrm{CH}_{2}\left(\mathrm{~N} 1 \cdots \mathrm{H} 8 \text { 'A } 2.39 \AA, \mathrm{N} 1 \cdots \mathrm{H} 8^{\prime \prime} \mathrm{B} 2.63 \AA\right)^{[106]}$ and ${ }^{4,6-\mathrm{BBu}} \mathrm{Box}_{2} \mathrm{CH}_{2}(\mathrm{~N} 1 \cdots \mathrm{H} 8$ 'A $2.58 \AA, \mathrm{N} 1 \cdots \mathrm{H} 8$ ” $\mathrm{B} 2.64 \AA)^{[108 a]}$ show intermolecular $\mathrm{C}-\mathrm{H} \cdots \mathrm{N}$ hydrogen bonds of both methylene hydrogen atoms.

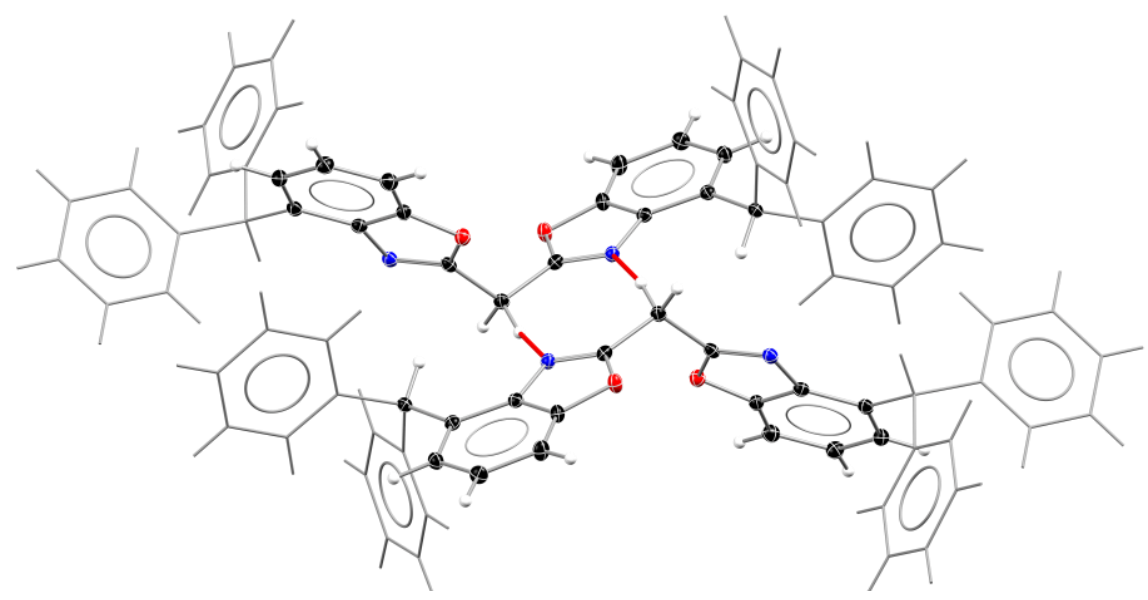

Figure 2-32. Intermolecular hydrogen bonds of the acidic methylene hydrogen atom and the imine nitrogen atom (N1‥H8'A $2.49 \AA)$ of an adjacent molecule and vice versa. Hydrogen bonds are shown as solid red lines. 


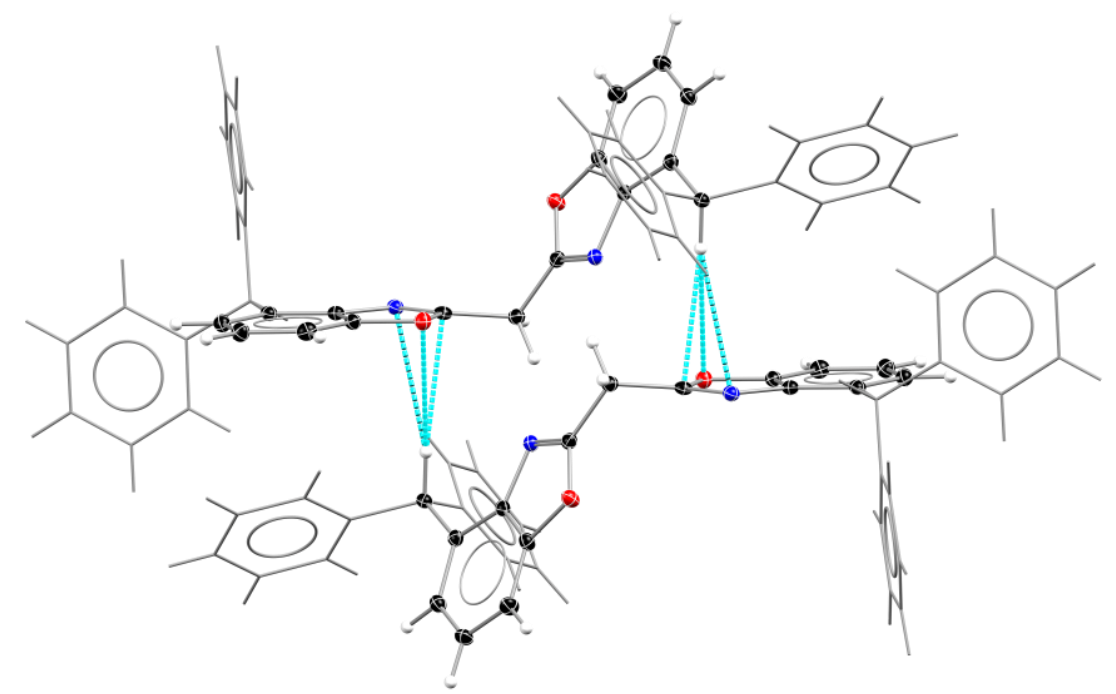

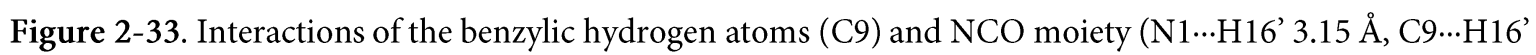
$2.81 \AA, \mathrm{O} 1 \cdots \mathrm{H} 16^{\prime} 2.83 \AA$ ) of a nearby molecule are depicted as dashed blue lines.

Furthermore, interactions are observed among the weakly acidic benzylic hydrogen atoms $\left(\mathrm{p} K_{\mathrm{a}}=33\right)^{[180]}$ and the NCO unit of a neighbouring molecule (Figure 2-33, N1‥H16 $3.15 \AA$, C9...H16' $2.81 \AA, \mathrm{O} 1 \cdots \mathrm{H} 16$ ' $2.83 \AA$ ). The acidity of methylene protons correlates with the attached groups or rather the electronic properties of benzoxazole moieties, respectively. ${ }^{[3]} \mathrm{UV} / \mathrm{Vis}$ spectrophotometric titration experiments ${ }^{[114]}$ performed by Leito and Lõkov ensued a $\mathrm{p} K_{\mathrm{a}}$ value of 26.59(6) in acetonitrile supporting that ${ }^{4-\mathrm{BrhH}^{2}} \mathrm{Box}_{2} \mathrm{CH}_{2}$ (23) is a stronger acid than $\mathrm{Box}_{2} \mathrm{CH}_{2}$

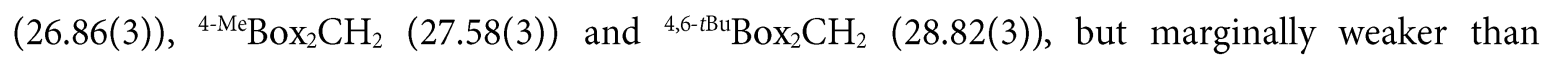
bis(benzothiazol-2-yl)methane $(26.14(3)) .^{[3]}$ 


\subsubsection{Group 1 Complexes}

Bis(4-benzhydryl-benzoxazol-2-yl)methane (23) was reacted with alkali metal-based deprotonation or reduction agents to gain insights into its properties and to establish it as an appropriate precursor for salt elimination reactions. All reactions were carried out in toluene at ambient temperature. The reaction conditions such as reaction time or equivalents of alkali metal (hydrides) were adjusted to the reaction requirements (Scheme 2-24).

In the case of bis(4-benzhydryl-benzoxazol-2-yl)methanide sodium $\left(\left[\mathrm{Na}\left({ }^{4-\mathrm{BzhH}^{2}} \mathrm{Box}_{2} \mathrm{CH}\right)\right]\right)(24)$, the starting material 23 and one equivalent of neat sodium metal were vigorously stirred until all metal was consumed ( $5 \mathrm{~d}$ ). After that, volatiles were removed under reduced pressure, and compound 24 was isolated as a white powder in excellent yields (98\%).

4-BzhH2 $\mathrm{Box}_{2} \mathrm{CH}_{2}$ a) to d)

(23)

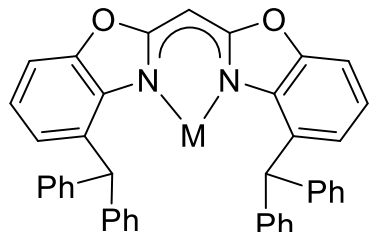

$M=N a(24), K\left(25_{1}\right)$

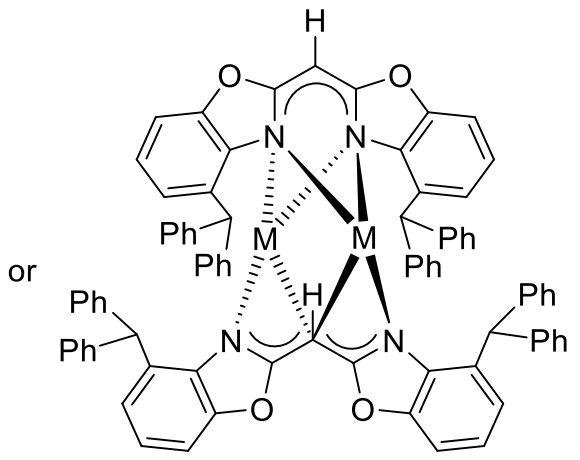

$\mathrm{M}=\mathrm{K}\left(25_{2}\right), \mathrm{Rb}(26), \mathrm{Cs}(27)$

Scheme 2-24. Syntheses of complex 24 to 27 were performed in toluene and ambient temperature under the following conditions: a) 1.04 equiv. Na, 5 d, YLD: 98\%, b) 1.15 equiv. KH, 1 d, YLD: 89\%, c) 1.10 equiv. Rb, 1 d, YLD: $76 \%$, d) 1.10 equiv. Cs, 6 h, YLD: 74\%.

Crystals suitable for single crystal XRD investigations were grown from a saturated toluene solution at $-28^{\circ} \mathrm{C}$. The sodium species 24 crystallised in the monoclinic space group $P 2_{1} / n$ with one complex molecule and one solvent molecule (toluene) in the asymmetric unit (Figure 2-34). The monomeric
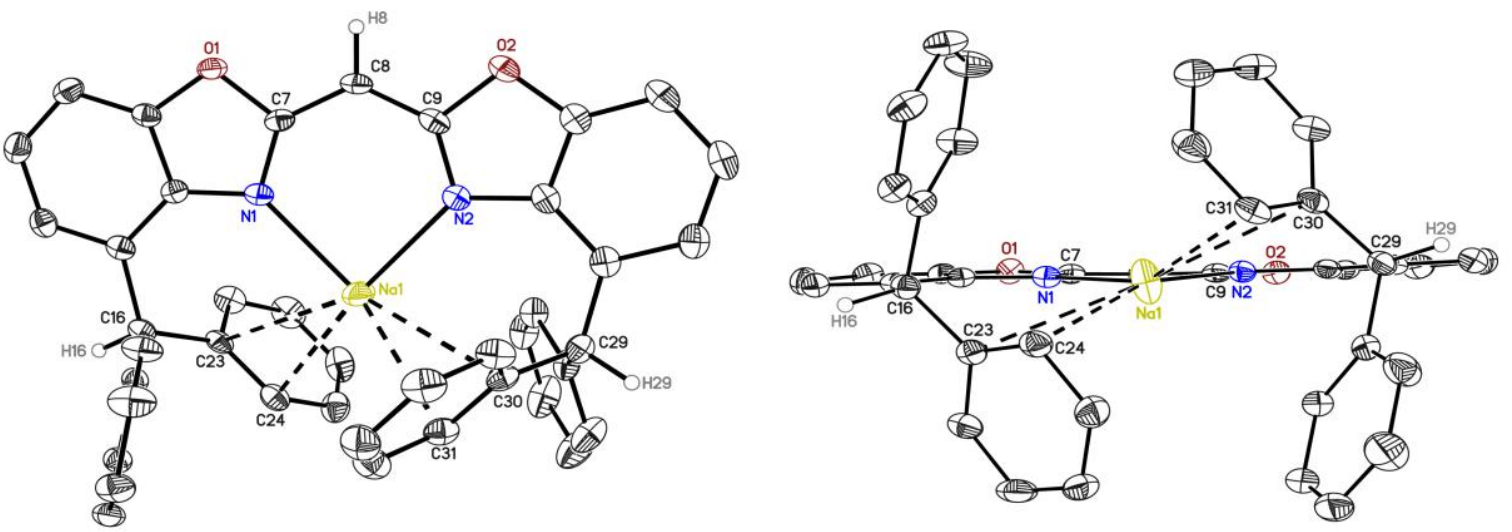

Figure 2-34. Molecular structure of bis(4-benzhydryl-benzoxazol-2-yl)methanide sodium (24, $\left.\left[\mathrm{Na}\left({ }^{4-\mathrm{BzhH}^{2}} \mathrm{Box}_{2} \mathrm{CH}\right)\right]\right)$. Anisotropic displacement parameters are depicted at the $50 \%$ probability level. All hydrogen atoms are omitted for clarity except for the bridging (methylene) and benzylic ones. 
$\left[\mathrm{Na}\left({ }^{4-\mathrm{BzhH} 2} \mathrm{Box}_{2} \mathrm{CH}\right)\right](24)$ comprises a sodium ion, which is $\kappa^{2}-\mathrm{N}, N^{\prime}$-coordinated $(\mathrm{N} 1-\mathrm{Na} 1-\mathrm{N} 2$ $\left.86.53(5)^{\circ}\right)$ by the imine nitrogen atoms. A negligible dislocation of the cation from the $\mathrm{C}_{3} \mathrm{~N}_{2}$ plane of $0.117(2) \AA$ and a minute butterfly folding angle of $4.82(6)^{\circ}$ are observed. Nitrogen sodium bond lengths of 24 (Na1-N1 2.3392(16) $\AA$; Na1-N2 2.3456(15) $\AA$ ) are similar to Na1-N1 2.358(6) $\AA$ bond of the six-membered sodium $\beta$-diketiminate complex $\left[(\mathrm{THF})_{2} \mathrm{NaL}\right]^{[84]}\left(L=\left\{\mathrm{N}(\mathrm{SiMe})_{3} \mathrm{C}(\mathrm{Ph})\right\}_{2} \mathrm{CH}\right)$ but slightly shorter than neutral five-membered TMEDA based [[\{Na $\left.\left.\left\{\mathrm{N}\left(\mathrm{SiMe}_{3}\right)(\mathrm{Dipp})\right\}(\mathrm{TMEDA})\right\}_{2}\right]$ (Na1-N2 2.4726(17) $\AA$; Na1-N3 2.461(2) $\AA)^{[181]}$ or four-membered guadinate complex $\left[\left[\mathrm{Na}\left\{\left({ }^{\mathrm{i} P N N C}(\mathrm{NAr})\left(\mathrm{HN}^{\mathrm{i} P r}\right)\right\}(\mathrm{THF})\right]_{2} \quad\left(A r=2,6-\mathrm{Me}_{2} \mathrm{C}_{6} \mathrm{H}_{3}\right) \quad(\mathrm{Na} 1-\mathrm{N} 1 \quad 2.453(1) \AA, \quad \mathrm{Na} 1-\mathrm{N} 2\right.\right.$ $2.558(2) \AA)^{[182]}$. Moreover, the coordination sphere of $\mathrm{Na}^{+}$ions is saturated by $\pi$-arene interactions to one phenyl residue of each benzhydryl group. This way, the benzhydryl hydrogen atoms are twisted away from the metal. The $\mathrm{Na} \cdots \mathrm{C}_{A r}$ distances range from 2.8305(18) $\left(\mathrm{C}_{\text {ortho }}\right)$ to $3.0414(18) \AA$ $\left(\mathrm{C}_{\text {ipso }}\right)$, indicating a dihaptic arene coordination. ${ }^{[183]}$ Comparable interactions similar to metallocenes were described in coordination monomers, for example $\left[\mathrm{Na}(\mathrm{py})_{3}\left(\mathrm{C}_{5} \mathrm{Me}_{5}\right)\right]^{[184]}\left(\mathrm{Na} \cdots \mathrm{C}_{A r}: 2.658(5)\right.$ to $2.701(5) \AA)$ and $\left[\mathrm{Na}(\mathrm{THF})_{3}\left(\mathrm{CpyPh}_{2}\right)\right]^{[185]}\left(\mathrm{Na} \cdots \mathrm{C}_{\text {ipso }}: 2.859(9), \mathrm{Na} \cdots \mathrm{C}_{\text {ortho }} 3.068(9) \AA\right)$, or polymers $\left[\mathrm{Na}\left\{\mu-\mathrm{N}\left(\mathrm{Si}_{-} \mathrm{Me}_{3}\right)\left(\mathrm{SiMe}_{2} \mathrm{Ph}\right)\right\}\right]_{n}^{[186]}\left(\mathrm{Na} \cdots \mathrm{C}_{\text {ipso }}: 2.686(1) \AA, \mathrm{Na} \cdots \mathrm{C}_{\text {ortho: }}\right.$ 2.884(2) $\AA$ ), [\{Na(THF)NC(Ph)-

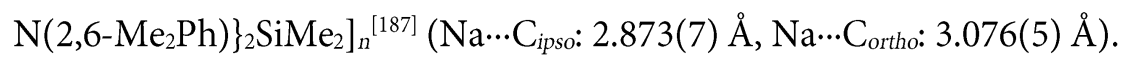

The ${ }^{1} \mathrm{H}$ NMR spectra of ${ }^{4-\mathrm{BzhH} 2} \mathrm{Box}_{2} \mathrm{CH}_{2}$ (23) and $\left[\mathrm{Na}\left({ }^{4-\mathrm{BzhH} 2} \mathrm{Box}_{2} \mathrm{CH}\right)\right]$ (24) in toluene (Figure 2-35) revealed a significant deshielding and simultaneous downfield shift of the methanide bridge from $\delta\left(-H_{2} \mathrm{C}-\right)=3.85 \mathrm{ppm}$ to $\delta(-H \mathrm{C}-)=5.38 \mathrm{ppm}$. Besides, benzylic protons experience a significant upfield shift from $\delta\left(-\mathrm{HCPh}_{2}\right)=6.41 \mathrm{ppm}$ to $5.27 \mathrm{ppm}$.
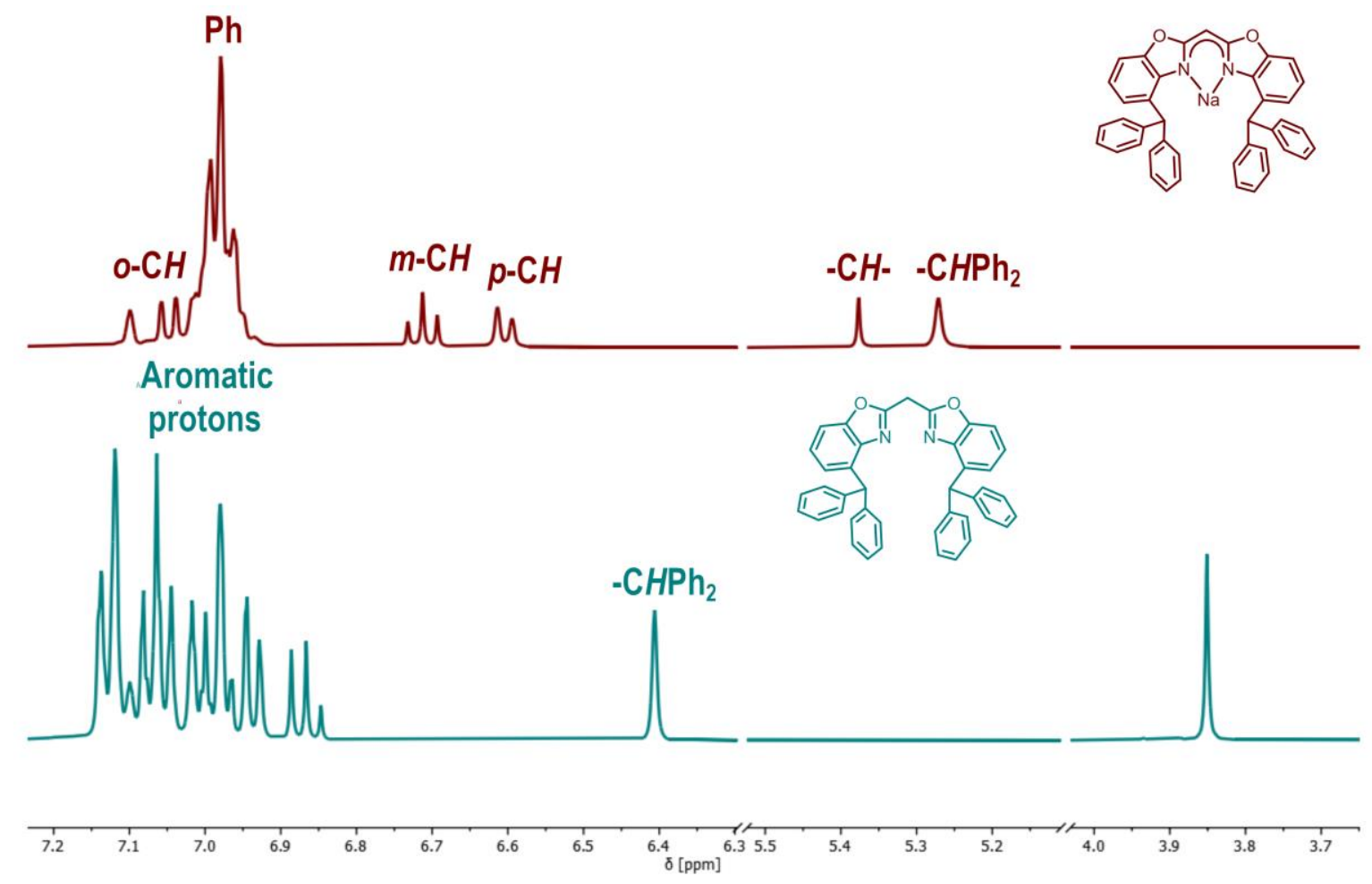

Figure 2-35. Stacked ${ }^{1} \mathrm{H}$ NMR spectra of ${ }^{4-\mathrm{BzhH} 2} \mathrm{Box}_{2} \mathrm{CH}_{2}(23)$ and $\left[\mathrm{Na}\left({ }^{4-\mathrm{BrhH} 2} \mathrm{Box}_{2} \mathrm{CH}\right)\right](24)$ in $\left[\mathrm{D}_{8}\right]$ toluene. 
The arene protons $\left(\mathrm{Ph}\right.$ an $\left.\mathrm{NCOC}_{6} \mathrm{H}_{3}\right)$ of sodium complex 24 are slightly shifted upfield in relation to ${ }^{4-\mathrm{BzhH} 2} \mathrm{Box}_{2} \mathrm{CH}_{2}$. The synthesis of $\left[\mathrm{Na}\left({ }^{4-\mathrm{BrhH} 2} \mathrm{Box}_{2} \mathrm{CH}\right)\right]$ (24) was additionally confirmed by mass spectrometry (LIFDI $[+]$, toluene $\mathrm{m} / \mathrm{z}(\%): 604.1(100)[M]^{+}$) and elemental analysis.

The reaction of ${ }^{4-\mathrm{BzhH}^{2}} \mathrm{Box}_{2} \mathrm{CH}_{2}$ (23) and potassium hydride in toluene at ambient temperature (Scheme 2-24 vide supra) led to a red reaction mixture. After the mixture had been stirred for $1 \mathrm{~d}$ at ambient temperature, volatiles were removed under reduced pressure and $\left[\mathrm{K}\left({ }^{4-\mathrm{BzhH} H}{ }^{\mathrm{Box}}{ }_{2} \mathrm{CH}\right)\right](25)$ was isolated as a reddish-white powder in excellent yields (89\%). Colourless crystals of the potassium complex 25 formed out of a saturated toluene solution at $-30^{\circ} \mathrm{C}$ after $1 \mathrm{~d}$. Single crystal XRD measurements unveiled the formation of a monomeric $\left[\mathrm{K}\right.$ (toluene) $\left.\left({ }^{4-\mathrm{BzhH} 2} \mathrm{Box}_{2} \mathrm{CH}\right)\right]\left(25_{1}\right)$ and a dimeric $\left[\mathrm{K}\left({ }^{4-\mathrm{BhhH}^{2}} \mathrm{Box}_{2} \mathrm{CH}\right)\right]_{2}\left(25_{2}\right)$ species. The monomeric species $25_{1}$ (Figure 2-36) crystallises in $P \overline{1}$ with one complex and a half toluene molecule in the asymmetric unit. Complex $25_{1}$ consists of a distorted $\kappa^{2}-N, N^{\prime}$-coordinated potassium cation, which features additional weak $K \cdots \pi$-arene interactions to one toluene molecule and one phenyl group of the benzhydryl moieties, respectively.
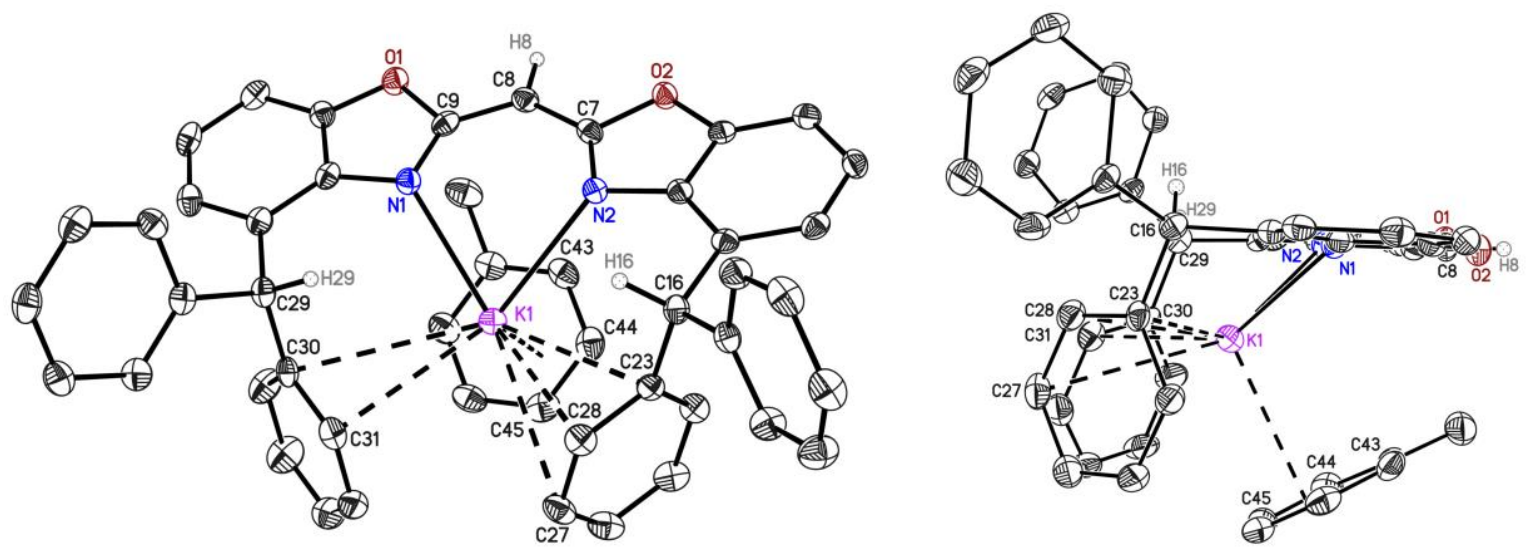

Figure 2-36. Molecular structure of monomeric \{bis(4-benzhydryl-benzoxazol-2-yl)methanide\}potassium $\left(25_{1},\left[\mathrm{~K}(\right.\right.$ toluene $\left.\left.)\left({ }^{4-\mathrm{BzhH}^{2}} \mathrm{Box}_{2} \mathrm{CH}\right)\right]\right)$. Anisotropic displacement parameters are depicted at the $50 \%$ probability level. All hydrogen atoms are omitted for clarity except for the bridging (methylene) and benzylic ones.

In comparison to $\left[\mathrm{Na}\left({ }^{4-\mathrm{BhhH} 2} \mathrm{Box}_{2} \mathrm{CH}\right)\right]$ (24), a fairly prominent deviation of the cation from the $\mathrm{C}_{3} \mathrm{~N}_{2}$ plane $(1.571(3) \AA)$ is present in $25_{1}$. Due to the larger ionic radius of potassium, ${ }^{[120]}$ longer $\mathrm{K}-\mathrm{N}$ distances (K1-N1 2.7768(18) Å; K1-N2 2.6982(18) $\AA$ ) and an acute bite angle N1-K1-N2 of $70.73(5)^{\circ}$ are observed. This is accompanied by an increasing butterfly folding angle of $5.54(8)^{\circ}$. Furthermore, potassium phenyl carbon distances suggest that the cation is $\eta^{2}$ - (K1-C30 3.467(2) $\AA$, K1-C31 3.224(2) $\AA$ ) and $\eta^{3}$-coordinated (K1-C23 3.314(2) $\AA$, K1-C27 3.503(2) $\AA$, K1-C28 3.236(2) $\AA$ ) (A search in the CSD version 5.41 (Aug. 2020) for structures with $\mathrm{K}$ and phenyl groups excluding $\eta^{6}$ coordinated ones provided a range of short contacts between $\mathrm{K}$ and $\mathrm{C}_{\text {ortho }}$ of 2.77 to $3.76 \AA)^{[188]}$ by one phenyl residue of each benzhydryl group. ${ }^{[185,189]}$ Additionally, one toluene molecule is capping the cation in a $\eta^{3}$-fashion (K1-C43 3.344(2) $\AA$, K1-C44 3.098(2) $\AA$, K1-C45 3.152(2) ), which prevents the formation of a coordination polymer, observed for potassium compounds of related ${ }^{R} \mathrm{Box}_{2} \mathrm{CH}_{2}\left(\mathrm{R}=4-\mathrm{Me}, 4,6^{-} \mathrm{Pr}, 4,6^{-} \mathrm{Bu}\right)^{[1,108 \mathrm{a}, 108 b]}$ or $\mathrm{H}^{\mathrm{Dipp}} \mathrm{NacNac}{ }^{[190]}$ ligands. 
The second donor-base free and dimeric species $25_{2}$ crystallises in the monoclinic space group $P 2_{1} / \mathcal{C}$ with one complex molecule and four toluene molecules in the asymmetric unit (Figure 2-37, left). However, these toluene molecules do not coordinate to the cation. Isostructural molecular structures were observed for the rubidium (YLD: 76\%) and caesium (YLD: 74\%) complexes. They were synthesised via facile deprotonation of 23 by neat rubidium (26, YLD: 76\%) or caesium (27, YLD: $74 \%$ ) in toluene at room temperature (Scheme 2-24 vide supra). The colourless crystals of the heavier alkali metal analogues suitable for single crystal XRD analyses were gained by liquid-liquid diffusion of pentane in a saturated toluene solution at $-30^{\circ} \mathrm{C}$ after $1 \mathrm{~d}$. All three compounds display a monoanionic (E,E)-bis(4-benzhydryl-benzoxazol-2-yl)methanide fragment coordinating two alkali ions in $\eta^{2}, \eta^{1}$-fashion (N1-N2-C9; N1-N2-C7) by the NacNac-like $\mathrm{C}_{3} \mathrm{~N}_{2}$, respectively (Figure 2-37, top right).
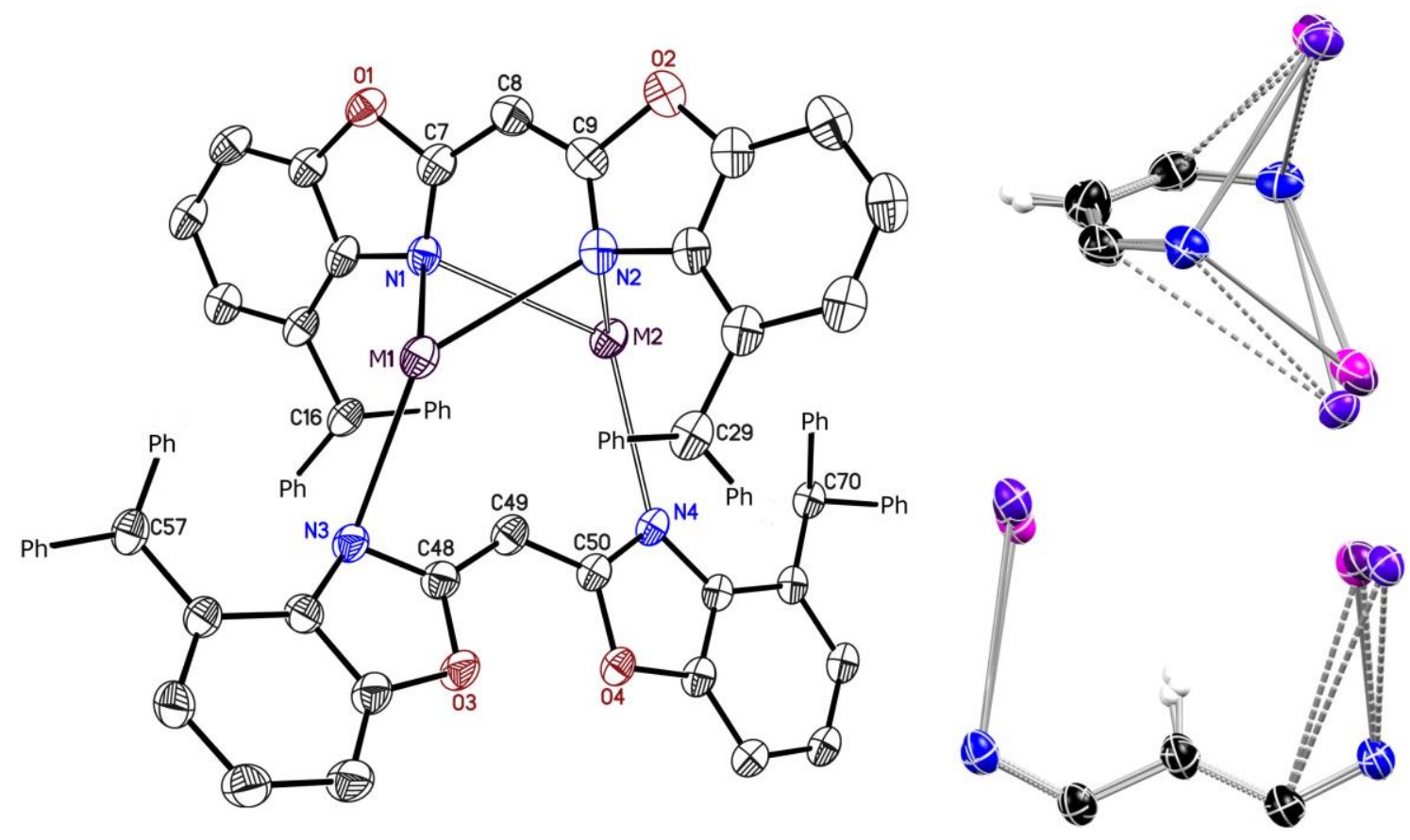

$\mathrm{K} \mathrm{Rb} \mathrm{Cs}$

Figure 2-37. Molecular structure of dimeric \{bis(4-benzhydryl-benzoxazol-2-yl)methanide\} alkali metal complexes $\left(\left[M\left({ }^{4-\mathrm{BzhH}^{2}} \mathrm{Box}_{2} \mathrm{CH}\right)\right]_{2}, M=\mathrm{K}\left(25_{2}\right)\right.$, $\mathrm{Rb}(26)$, Cs (27)) (left). Anisotropic displacement parameters are depicted at the $50 \%$ probability level. All hydrogen atoms are omitted for clarity. Superposition of $25_{2}-27$ showing NacNac-like $\mathrm{C}_{3} \mathrm{~N}_{2}$ unit of $(E, E)-\left({ }^{4-\mathrm{BzhH}^{2}} \mathrm{Box}_{2} \mathrm{CH}\right)$ (top right) as well as twisted $(Z, Z)-\left({ }^{4-\mathrm{BzhH}^{2}} \mathrm{Box}_{2} \mathrm{CH}\right)$ (bottom right) and their coordinating alkali metal ion, respectively.

In addition, a single phenyl group of each benzhydryl residue forms an additional $\eta^{6}$ - or $\eta^{2}$ coordination (Figure 2-38). A second deprotonated (Z,Z)-isomer of 23 bridges the two metal ions in a $\eta^{3}$-fashion (C49-C48-N3; N4-C50-C49) (Figure 2-37, bottom right). The coordination sphere of the cations is again satiated by $\pi$-arene interactions of the adjacent phenyl groups $\left(\eta^{4}\right.$ and $\left.\eta^{2}\right)$. Moreover, close interactions of the potassium ion and a suitable arranged methanide group in $25_{2}$ culminate in rather short potassium hydrogen distances (K1-H49 2.89(3), , K2-H49 2.77(3) ), and an elongated $\mathrm{C}-\mathrm{H}$ to $1.01(3) \AA .^{[191]}$ 

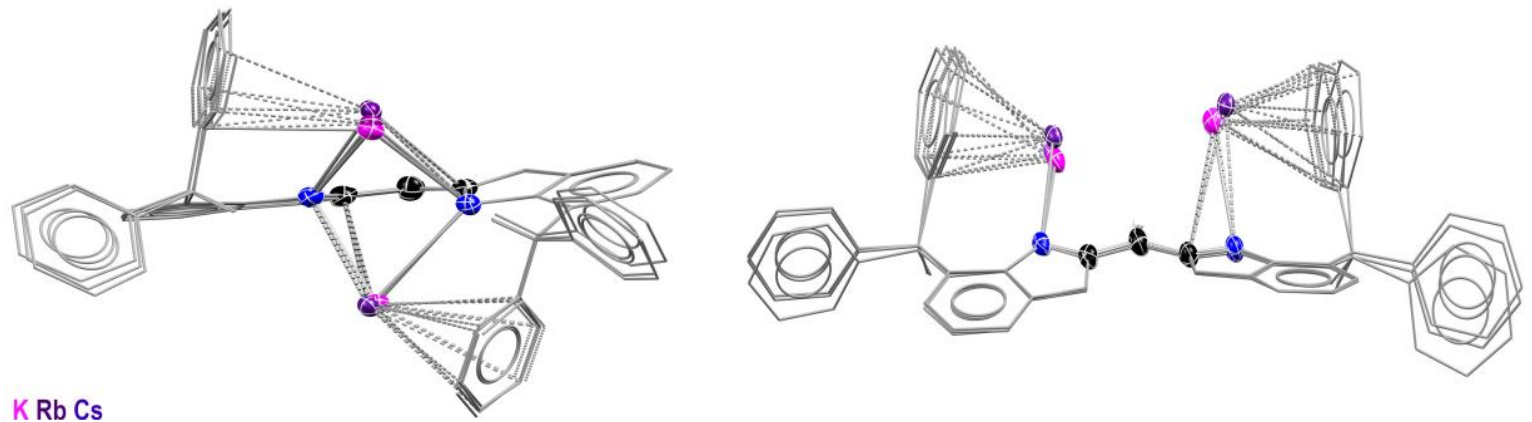

Figure 2-38. Alkali metal $\pi$-arene interactions of the $(E, E)-\left({ }^{4-\mathrm{BzhH}^{2}} \mathrm{Box}_{2} \mathrm{CH}\right)(\mathrm{left})$ and the $(Z, Z)-\left({ }^{4-\mathrm{BzhH}^{2}} \mathrm{Box}_{2} \mathrm{CH}\right)$ isomer (right).

The $\mathrm{K}-\mathrm{H} 49-\mathrm{C} 49$ angles of $102(2)^{\circ}$ for $\mathrm{K} 1$ and $127(2)^{\circ}$ for $\mathrm{K} 2$ also witness these interactions, because they are similar to $\left[\left\{\mathrm{K}(\mathrm{THF})_{4}\right\}_{2} \mathrm{Ln}\left\{(\mu-\mathrm{H})_{2} \mathrm{BC}_{8} \mathrm{H}_{14}\right\}_{4}\right](\mathrm{Ln}=\mathrm{Eu}, \mathrm{Yb})(\mathrm{K}-\mathrm{H} 2.64(4)$ to 3.37(3) $\AA, \mathrm{K}-\mathrm{H}-$ C 117.8 to $\left.120.7^{\circ}\right)^{[192]}$ or $\left[\mathrm{K}(\mathrm{Ar})_{2}\right]\left[\mathrm{M}\left\{\mathrm{N}\left(\mathrm{SiMe}_{3}\right)_{2}\right\}_{3}\right](M=\mathrm{Mg}, A r=$ benzene, toluene, $p$-xylene; $M=$ $\mathrm{Zn}, A r=o$-xylene) $\left(\mathrm{K}-\mathrm{H} 2.81(2) \text { to } 3.07 \AA \text {, } \mathrm{K}-\mathrm{H}-\mathrm{C} 85 \text { to } 145^{\circ}\right)^{[188 b, 193]}$. The solid-state structures of 26 and 27 also unveil interactions of metal ions and methanide bridges, however, due to the increased residual electron density, the determination of the position of freely refined hydrogen atoms is not reliable. Rising effective ionic radii, ${ }^{[108 a, 120]}$ increasing polarisability and softness of the cations are encountered moving down the alkali metal group on account of the shielding effect. ${ }^{[194]}$ These features (for details, see Table 2-6) cause a lengthening of the metal nitrogen bonds for monoanionic $(E, E)$ - and $(Z, Z)-\left({ }^{4-\mathrm{BzhH}^{2}} \mathrm{Box}_{2} \mathrm{CH}\right)$, more acute average $\mathrm{N}-\mathrm{M}-\mathrm{N}$ angles, and a larger dislocation of the metal from the $\mathrm{C}_{3} \mathrm{~N}_{2}$ plane as well as from the $\mathrm{HC}_{2} \mathrm{~N}$ unit. Interestingly, the detected butterfly folding angles in the two isomers $\left.(E, E)-\left({ }^{4-\mathrm{BzhH}^{2}} \mathrm{Box}_{2} \mathrm{CH}\right) \approx 23^{\circ} ;(Z, Z)-\left({ }^{4-\mathrm{BhhH}^{2}} \mathrm{Box}_{2} \mathrm{CH}\right) \approx 16^{\circ}\right)$ are negligibly affected while coordinating the alkali metal ions.

Table 2-6. Selected bond lengths $[\AA]$ and angles $\left[{ }^{\circ}\right]$ of $(E, E)-$ and $(Z, Z)-\left({ }^{4-B z h H} 2 \mathrm{Box}_{2} \mathrm{CH}\right)$ in the alkali metal complexes $\left(M=\mathrm{Na}(24), \mathrm{K}\left(25_{1} / 25_{2}\right), \mathrm{Rb}(26), \mathrm{Cs}(27)\right)$.

\begin{tabular}{|c|c|c|c|c|c|c|c|c|c|}
\hline & \multicolumn{5}{|c|}{$(E, E)-\left({ }^{4-\mathrm{BzhH} 2} \mathrm{Box}_{2} \mathrm{CH}\right)$} & & \multicolumn{3}{|c|}{$(Z, Z)-\left({ }^{4-\mathrm{BzhH}^{2}} \mathrm{Box}_{2} \mathrm{CH}\right)$} \\
\hline & 24 & 251 & $25_{2}$ & 26 & 27 & & $25_{2}$ & 26 & 27 \\
\hline $\begin{array}{c}M-\mathbf{N} \\
{[\AA ̊]} \\
\end{array}$ & $\begin{array}{l}2.3392(16), \\
2.3456(15)\end{array}$ & $\begin{array}{l}2.7768(18), \\
2.6982(18)\end{array}$ & $\begin{array}{l}2.812(2)- \\
3.015(2)\end{array}$ & $\begin{array}{l}2.924(5)- \\
3.063(4) \\
\end{array}$ & $\begin{array}{l}3.050(3)- \\
3.285(3)\end{array}$ & $M-\mathbf{N}[\AA]$ & $\begin{array}{l}2.775(2), \\
2.812(2)\end{array}$ & $\begin{array}{l}2.905(5) \\
2.948(5)\end{array}$ & $\begin{array}{l}3.033(3) \\
3.202(3)\end{array}$ \\
\hline $\begin{array}{c}\mathrm{N}-\mathrm{M}-\mathrm{N} \\
\left.{ }^{\circ}\right] \\
\end{array}$ & $86.53(5)$ & $70.73(5)$ & $\begin{array}{l}67.57(7) \\
64.07(6) \\
\end{array}$ & $\begin{array}{l}65.15(13), \\
63.34(12)\end{array}$ & $\begin{array}{l}63.76(8) \\
63.52(8)\end{array}$ & $\begin{array}{c}M \cdots \mathrm{C}_{3} \mathrm{~N}_{2} \\
{[\AA \AA]}\end{array}$ & $\begin{array}{r}3.170(3)- \\
3.493(3)\end{array}$ & $\begin{array}{l}3.297(6)- \\
3.633(6)\end{array}$ & $\begin{array}{l}2.603(10) \\
1.252(19)\end{array}$ \\
\hline $\begin{array}{c}M \cdots \mathrm{C}_{3} \mathrm{~N} \\
{[\AA ̊ \AA]}\end{array}$ & $0.117(2)$ & $1.571(3)$ & $\begin{array}{l}1.877(4) \\
2.282(3) \\
\end{array}$ & $\begin{array}{l}2.036(7) \\
2.303(7) \\
\end{array}$ & $\begin{array}{l}2.302(5) \\
2.430(5)\end{array}$ & $\begin{array}{c}M \cdots \mathrm{HC}_{2} \\
{[\AA ̊]}\end{array}$ & $\begin{array}{l}2.18(3), \\
0.85(5)\end{array}$ & $\begin{array}{l}2.196(9) \\
0.699(13)\end{array}$ & $\begin{array}{l}2.60(5), \\
1.16(8)\end{array}$ \\
\hline $\begin{array}{l}\text { Folding } \\
\text { angle }\left[^{\circ}\right]\end{array}$ & $4.82(6)$ & $5.54(8)$ & $23.22(9)$ & $23.63(19)$ & $\begin{array}{l}20.65(14) \\
25.24(13)\end{array}$ & $\begin{array}{l}\text { Folding } \\
\text { angle }\left[^{\circ}\right]\end{array}$ & $16.75(8)$ & $15.55(14)$ & $\begin{array}{l}17.85(11) \\
15.22(10)\end{array}$ \\
\hline
\end{tabular}

The dimeric alkali metal complexes $25-27$ were additionally studied by ${ }^{1} \mathrm{H}$ and ${ }^{13} \mathrm{C}\left\{{ }^{1} \mathrm{H}\right\} \mathrm{NMR}$ spectroscopy in $\left[D_{8}\right]$ THF. Recorded ${ }^{1} \mathrm{H}$ NMR spectra display a distinctive pattern of chemical shifts arising from the $C_{2 \mathrm{v}}$ symmetry of monoanionic bis(benzoxazol-2-yl)methanide scaffold and the benzylic protons, whereas protons of the benzhydryl groups could not be clearly assigned because of 
their signal overlap. Deprotonation of bis(4-benzhydryl-benzoxazol-2-yl)methane (23) results in an accumulation of electron density in the aromatic bezoxazol-2-yl periphery that again entails a general shielding of corresponding protons and an upfield shift. Concerning the ${ }^{1} \mathrm{H}$ NMR shifts of the methanide groups, a continuous but minor decline along $\mathrm{K}(\delta 4.66 \mathrm{ppm})>\mathrm{Rb}(\delta 4.65 \mathrm{ppm})>\mathrm{Cs}(\delta$ $4.64 \mathrm{ppm}$ ) compounds is noticed (Figure 2-39). The opposite is found for para-positioned protons of the benzoxazolyl moieties and benzylic protons. Those exhibit a small but noticeable downfield shift $\delta(3-, 13-\mathrm{H}) 6.33 \mathrm{ppm}$ to $6.43 \mathrm{ppm}$ and $\delta(16-, 29-\mathrm{H})=6.03 \mathrm{ppm}$ to $6.17 \mathrm{ppm}$, which is in agreement with the negative charge being restored in the phenylic benzhydryl groups yielding a growing metal arene interaction.

The remaining benzoxazol-2-yl protons in ortho- and meta-position (4-,12- and 5-, 11-H) do not seem to be influenced by varying the alkali cations. Although the ${ }^{1} \mathrm{H}$ NMR spectra of 25-27
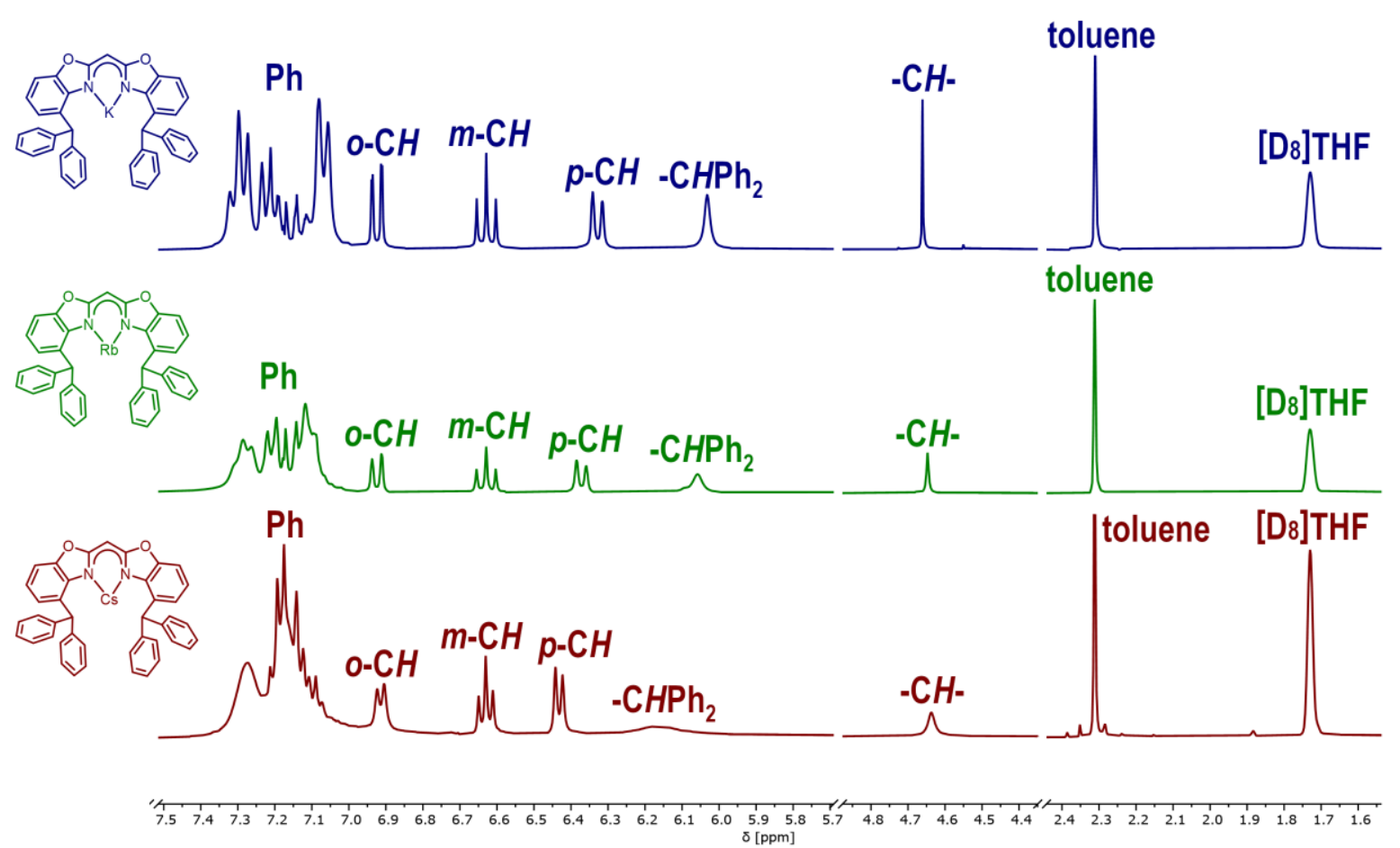

Figure 2-39. Stacked ${ }^{1} \mathrm{H}$ NMR spectra of alkali metal compounds $\left[\mathrm{M}\left({ }^{4-\mathrm{BhhH} 2} \mathrm{Box}_{2} \mathrm{CH}\right)\right]_{2}\left(\mathrm{M}=\mathrm{K}\left(\mathbf{2 5}_{2}\right), \mathrm{Rb}(\mathbf{2 6})\right.$, Cs (27)) in $\left[D_{8}\right]$ THF.

$\left(\left[\mathrm{D}_{8}\right] \mathrm{THF}\right)$ and the monomeric sodium species 24 ([ $\left.\mathrm{D}_{8}\right]$ toluene) were measured in different solvents, benzylic protons (16-, 29-H) exhibit a remarkable change in the average chemical shifts $(\Delta \delta=$ $0.82 \mathrm{ppm}$ ). Again, these deviations in their molecular structure are likely explained by enlarging metal radii and associate properties that result in a strengthening of the metal $\pi$-arene interactions. The ${ }^{87} \mathrm{Rb}$ NMR spectrum of complex 26 from a THF solution shows two broad singlets. Most likely $\left[\mathrm{Rb}\left({ }^{4-\mathrm{BzhH}^{2}} \mathrm{Box}_{2} \mathrm{CH}\right)\right]_{2}$ rearranges to give a THF-solvated rubidium cation $\left[\mathrm{Rb}(\mathrm{THF})_{n}\right](\delta-1.69 \mathrm{ppm})$ and a bis(4-benzhydryl-benzoxazol-2-yl)methanide $\}$ anion $\left[\mathrm{Rb}\left({ }^{4-\mathrm{BzhH}^{2}} \mathrm{Box}_{2} \mathrm{CH}\right)_{2}\right](\delta-254.69 \mathrm{ppm})$. The ${ }^{133} \mathrm{Cs}$ NMR spectrum ([D $]$ THF) of 27 exhibits only one signal at $\delta-31.12 \mathrm{ppm}$. Additionally, elemental analysis and mass spectrometry (LIFDI[+], THF) confirmed the synthesis of the heavier alkali metal compounds 25-27. 
Based on reported $(Z, Z)$ - and $(E, E)$-isomers of alkali metal complexes 25-27 and acquired knowledge of sterically less demanding bis(benzoxazol-2-yl)methanide potassium complexes ${ }^{[108 a, 108 b]}$ and their 18-crown- 6 derivatives, ${ }^{[1,112]}$ the curiosity arouse, whether the reaction of 25 with crown ether would prefer the formation of a $(Z, Z)-,(E, E)$ - or $(Z, E)$-isomeric species. Therefore, bis(4-benzhydrylbenzoxazol-2-yl)methane was first deprotonated with an excess of potassium hydride in THF at ambient temperature (Scheme 2-25). After the red reaction mixture had been stirred for $1 \mathrm{~d}$, unreacted potassium hydride was removed by filtration and 0.99 equiv. 18-crown- 6 was added.<smiles>C=Cc1ccccc1Cc1ccccc1</smiles>

$(Z, Z)-28$

$(Z, E / E, Z)-28$

$(E, E)-\mathbf{2 8}$

$\left[(\mathrm{THF})_{2} \mathrm{~K} @ 18-\text { crown-6] }\right]^{+}$

$95 \%$

Scheme 2-25. Reaction of complexes 25 and one equivalent of 18-crown-6 resulted in the solvent separated ion pair $\left[(\mathrm{THF})_{2} \mathrm{~K}(18 \text {-crown-6) }]^{+}{ }^{+4-\mathrm{BrhH} 2} \mathrm{Box}_{2} \mathrm{CH}\right]^{-}$(28). A permanent rearrangement of the $(Z, Z)-,(Z, E / E, Z)-$, and $(E, E)-\left({ }^{4-\mathrm{BhH}^{2}} \mathrm{Box}_{2} \mathrm{CH}\right)$ diastereomers is ubiquitous in solution.

Within seconds, a strong blue fluorescence $\left(\lambda_{\max }=454 \mathrm{~nm}, \lambda_{\text {ex }}=350 \mathrm{~nm}, 1 \mathrm{mM}\right.$; detail in chapter 5.4, Figure 5-51) of the red solution becomes entrenched. The reaction mixture was further stirred for $1 \mathrm{~d}$ at ambient temperature, volatiles were removed in vacuo, and the solvent separated ion pair $\left[(\mathrm{THF})_{2} \mathrm{~K}(18 \text {-crown-6) }]^{+}\left[{ }^{4-\mathrm{BzhH}^{2}} \mathrm{Box}_{2} \mathrm{CH}\right]^{-}\right.$(28) was isolated as a reddish solid in excellent yields (95\%). Colourless crystals suitable for single crystal XRD analyses were grown by slow vapour diffusion of pentane to a saturated THF solution of 28 at ambient temperature after $3 \mathrm{~d}$ (Figure 2-40).

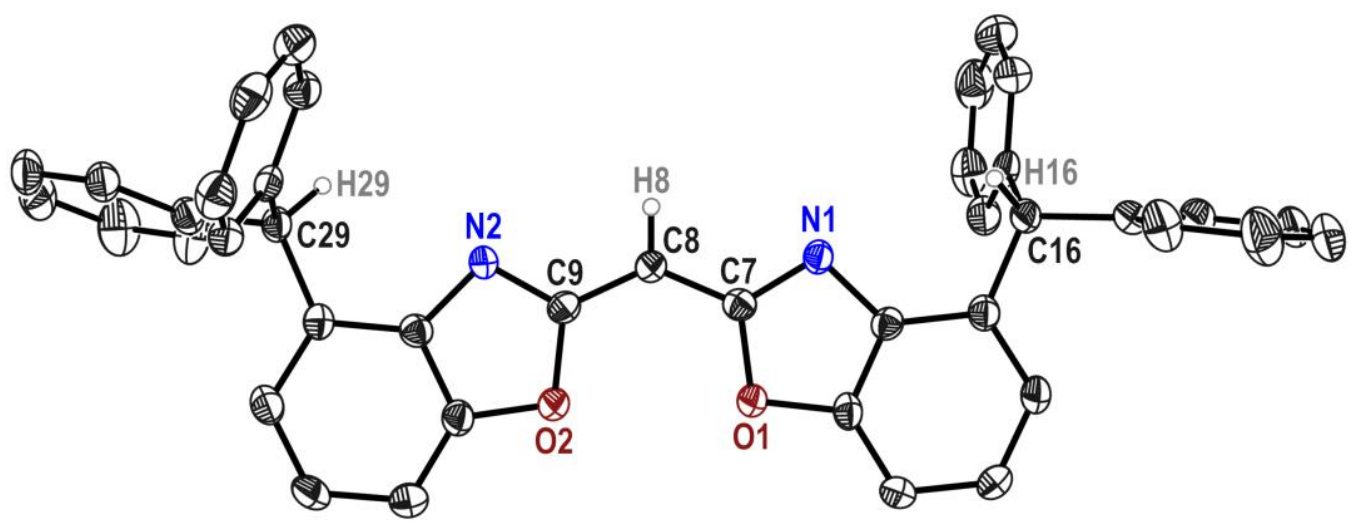

Figure 2-40. Molcular structure of $\left[{ }^{4-\mathrm{BzhH}^{2}} \mathrm{Box}_{2} \mathrm{CH}\right]^{-}$anion from 28, $\left[(\mathrm{THF})_{2} \mathrm{~K}(18-\mathrm{crown}-6)\right]^{+}\left[{ }^{4-\mathrm{BzhH}^{2}} \mathrm{Box}_{2} \mathrm{CH}\right]^{-}$. The counter ion $\left[(\mathrm{THF})_{2} \mathrm{~K}(18 \text {-crown-6) }]^{+}\right.$is omitted for clarity. Anisotropic displacement parameters are depicted at the 50\% probability level. All hydrogen atoms are omitted for clarity except for the bridging (methylene) and benzylic ones. Selected bond lengths $[\AA]$ and bond angles $\left[^{\circ}\right]$ : N1-C7 1.329(2), N2-C9 1.327(2), C7-C8 1.390(2), C8-C9 1.389(2), C9-C8-C7 131.34(15). 
The solvent separated ion pair of 28 crystallises in the triclinic space group $P \overline{1}$ containing one [bis(4benzhydryl-benzoxazol-2-yl)methanide $]^{-}$anion and two halves of the $\left[\left\{(\mathrm{THF})_{2} \mathrm{~K} @(18 \text {-crown-6) }\}\right]^{+}\right.$ cations in the asymmetric unit (Figure 2-40). In contrast to $\left[(L) \mathrm{K} @\left(18\right.\right.$-crown-6)] $\left(L=\mathrm{Box}_{2} \mathrm{CH}\right.$, $\left.{ }^{4,6-\mathrm{Pr}} \mathrm{Box}_{2} \mathrm{CH}\right)^{[1,112]}$ that both develop contact ion pairs in the solid, compound 28 was found to form a solvent separated ion pair. Expectedly, the $(Z, Z)-\left({ }^{4-\mathrm{BhhH}^{2}} \mathrm{Box}_{2} \mathrm{CH}\right)$ isomer seems to be preferred over

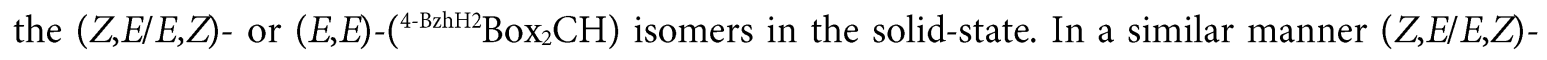
isomers are observed in the molecular structure of $\left[\mathrm{K}\left(18 \text {-crown-6) }\left(\mathrm{Box}_{2} \mathrm{CH}\right)\right]_{n}(3)(n \rightarrow \infty){ }^{[1]}\right.$ which displays disorders in the N/O positions (sof. $(\mathrm{N} 1)=0.39(3)$, sof. $(\mathrm{N} 2)=0.82(3)$ ) indicating a small energy difference between all isomers. The exclusive formation of a $(Z, Z)$-isomer accompanied by only an oxygen coordination at the metal is found in $\left[\mathrm{K}\left(18 \text {-crown-6) }\left({ }^{4,6-\mathrm{Pr}} \mathrm{Box}_{2} \mathrm{CH}\right) \cdot \mathrm{H}_{2} \mathrm{O}\right]_{n}\right.$ $(n \rightarrow \infty) .{ }^{[12]}$ Furthermore, the molecular structure of the $(Z, Z)$-isomer 28 unveils a butterfly folding angle of $5.03(9)^{\circ}$, which is almost consistent to the angles observed in monomeric species of $25_{1}$ $\left(5.54(8)^{\circ}\right)$ and $24\left(4.82(6)^{\circ}\right)$. This obtuse-angled benzoxazol-2-yl moieties and the bond length of C7C8 $1.390(2) \AA$ and C8-C9 $1.389(2) \AA$ that are between $1.54 \AA\left(\mathrm{C}\left(\mathrm{sp}^{3}\right)-\mathrm{C}\left(\mathrm{sp}^{3}\right)\right)$ and $1.34 \AA$ $\left(\mathrm{C}\left(\mathrm{sp}^{2}\right)=\mathrm{C}\left(\mathrm{sp}^{2}\right)\right)$ as well as N1-C7 1.329(2) $\AA$ and N2-C9 1.327(2) $\AA$ that are between $1.47 \AA\left(\mathrm{C}\left(\mathrm{sp}^{3}\right)\right.$ $\left.\mathrm{N}\left(\mathrm{sp}^{3}\right)\right)$ and $1.29 \AA\left(\mathrm{C}\left(\mathrm{sp}^{2}\right)=\mathrm{N}\left(\mathrm{sp}^{2}\right)\right)$ imply a fully conjugated system extended throughout the virtually planar ligand. ${ }^{[123]}$ Based on these findings, the Gibbs free energy differences $\Delta G$ of the monoanionic $(E, E)-,(Z, E / E, Z)$ - or $(E, E)-\left({ }^{4-B z h} \mathrm{Box}_{2} \mathrm{CH}\right)$ isomers were calculated by density functional theory at the BP86/def2-SVP level (for details, see Chapter 4.1.5 and Chapter 5.8). Calculated Gibbs free energy differences are $\Delta G<14 \mathrm{kcal} / \mathrm{mol}$ for all configurational isomers. Thus, most likely, in solution, the permanent rotation around the methanide bridge, accompanied by the rearrangement of the isomers (Scheme 2-25), is ubiquitous. Moreover, the synthesis of $\left[\left\{(\mathrm{THF})_{2} \mathrm{~K} @(18\right.\right.$-crown6) $\left.\}\left({ }^{4-\mathrm{BzhH} 2} \mathrm{Box}_{2} \mathrm{CH}\right)\right](28)$ was verified by mass spectrometry (ESI[-],THF $\mathrm{m} / \mathrm{z}(\%): 581.2$ (100) $\left.\left[\left({ }^{4-\mathrm{BzhH} 2} \mathrm{Box}_{2} \mathrm{CH}\right)\right]^{-}\right)$and elemental analysis.

Since Brown or Buncel and Menon ascertained that triphenyl methane is deprotonated in THF by potassium hydride when $\mathrm{DMF}^{[195]}$ or 18 -crown- $6^{[196]}$ is added, ${ }^{[197]}$ we wanted to examine whether deprotonation of one or both benzylic protons can be accomplished by the addition of one or two equivalents of crown ether and hydride, respectively, to a solution of compound 25. However, reactions of different amounts of potassium hydride and 18-crown-6 all yielded the polymeric $\left[\left\{(\mathrm{THF})_{2} \mathrm{~K} @(18 \text {-crown-6) }\}\left\{\mathrm{K}_{2}\left({ }^{4-\mathrm{Bzh}} \mathrm{Box}_{2} \mathrm{CH}\right)\right\}\right]_{n}(n \rightarrow \infty)(29)\right.$ as highly sensitive, dark-purple crystals by storing the THF solutions at $-30^{\circ} \mathrm{C}$. The mounting and collection of a single crystal XRD data set was challenging owing to the crystals sensitivity and their dark colour. The synthesis of 29 was improved by using ligand 23 and the exact stoichiometric quantities $\left({ }^{4-\mathrm{BrhH} 2} \mathrm{Box}_{2} \mathrm{CH}_{2}: \mathrm{KH}: 18\right.$-crown-6 $=1: 3: 2$ ) (Scheme 2-26), which are based on the solid-state structure. Immediately after the addition 


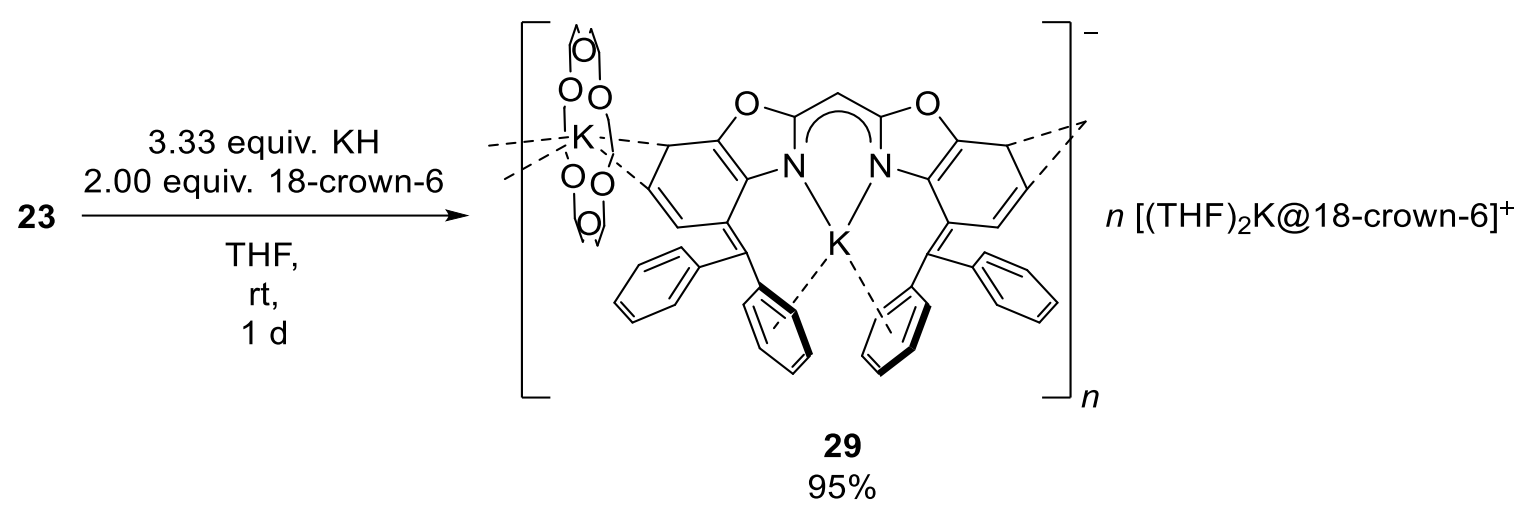

Scheme 2-26. Optimised synthesis of polymeric $\left[\left\{(\mathrm{THF})_{2} \mathrm{~K}(18\right.\right.$-crown-6) $\}\left\{\mathrm{K}\left(18 \text {-crown-6) } \mathrm{K}\left({ }^{4-\mathrm{Bzh}} \mathrm{Box}_{2} \mathrm{CH}\right)\right\}\right]_{n}$ $(n \rightarrow \infty)(29)$ by addition of 3.33 equiv. of $\mathrm{KH}$ and two equiv. of 18-crown-6.

of starting materials to a solution of 23 in THF, a strong blue fluorescence of the dark-red solution was observed. The reaction mixture was stirred for about $1 \mathrm{~d}$, whereas a red solid precipitated that was separated from the supernatant solution by decantation. This precipitate was washed three times with pentane, dried under reduced pressure, and stored at $-30^{\circ} \mathrm{C}$ for further syntheses or analyses (YLD: $95 \%$ ). The formerly separated solution was also cooled to $-30^{\circ} \mathrm{C}$ for crystallisation. The trianionic complex 29 crystallises in monoclinic space group $P 2 / n$ with half a formula unit in the asymmetric unit (Figure 2-42).

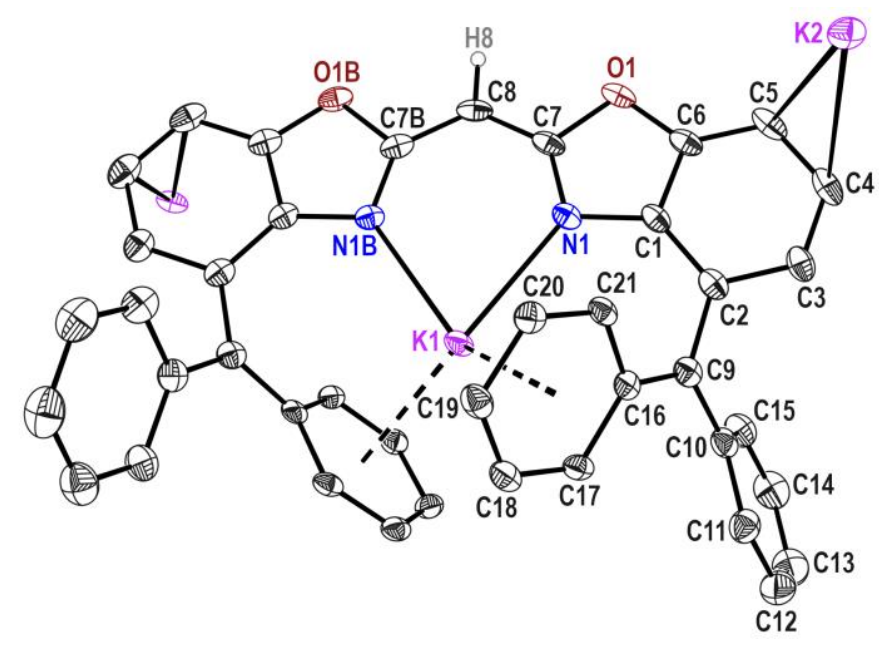

Figure 2-41. Molecular structure of polymeric $\left[\left\{(\mathrm{THF})_{2} \mathrm{~K} @(18-\text { crown-6) }\}\left\{\mathrm{K} @\left(18 \text {-crown-6)K(4-Bzh } \mathrm{Box}_{2} \mathrm{CH}\right)\right\}\right]_{n}\right.$ $(n \rightarrow \infty)(29)$. The cationic [(THF $)_{2} \mathrm{~K} @(18-\text { crown-6) }]^{+}$moiety was omitted for clarity. Anisotropic displacement parameters are depicted at the 50\% probability level. All hydrogen atoms are omitted for clarity except for the bridging (methylene) one.

The coordination polymer comprises a potassium ion (K3) solely coordinated by the oxygen atoms of 18-crown-6 and two THF molecules, which are omitted for clarity (Figure 2-42). A second potassium atom (K2) is coordinated in a $\eta^{2}$-fashion (C4-K2 3.329(3) $\AA$, C5-K2 3.245(8) $\AA$ ) by the aryl moieties of two adjacent $(E, E)$-trianions and a crown ether molecule resulting in a polymeric structure and eschew THF. A third potassium ion (K3) is surrounded by two nitrogen atoms in $\kappa^{2}$ fashion (N1-K1 2.686(3) $\AA$ ) and one phenyl ring of each benzhydryl moiety in a symmetrically $\eta^{6}$ fashion $\left(\mathrm{C}_{\mathrm{Ph}}-\mathrm{K} 1: 2.930(3) \AA\right.$ to 3.291(3) $\AA$ ), respectively. Determined nitrogen potassium distances 


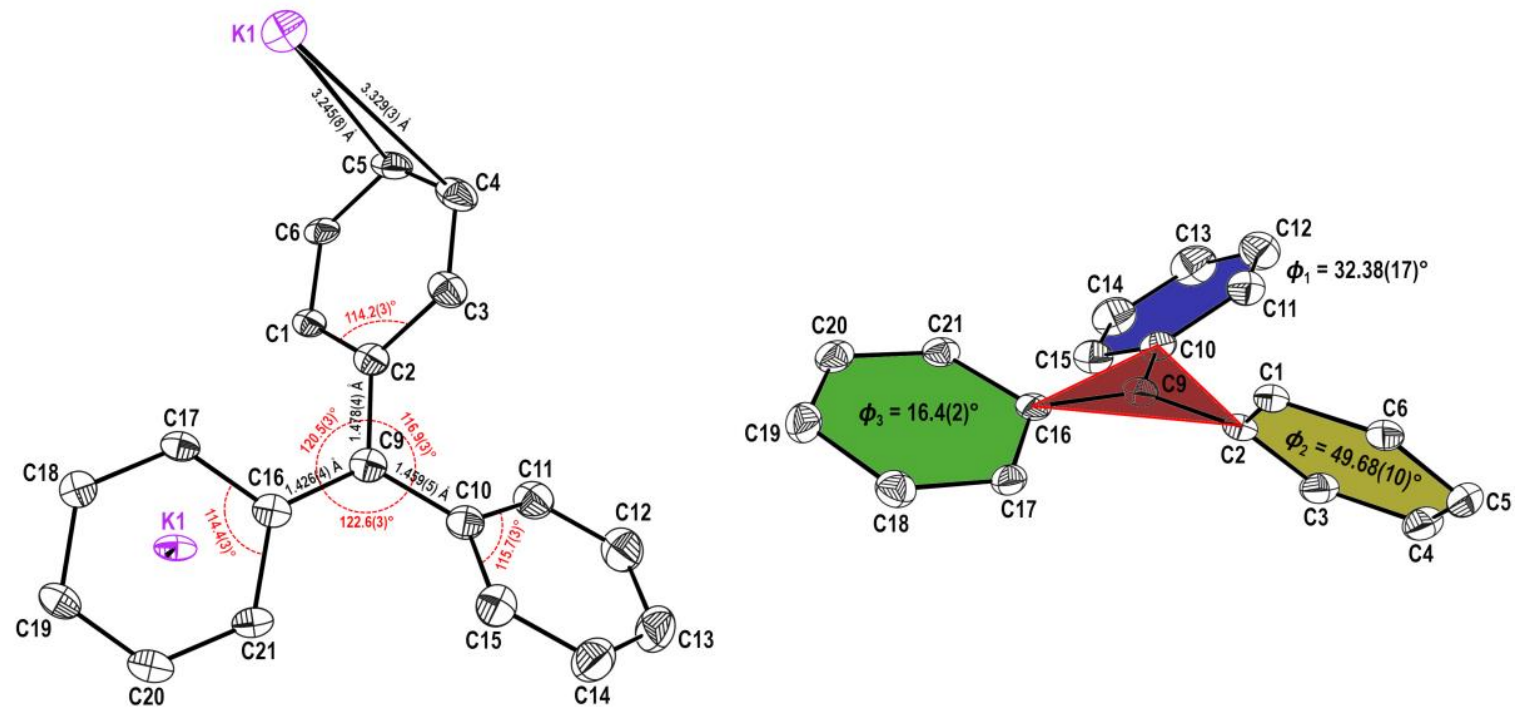

Figure 2-42. Benzhydryliden fragment of 29 coordinating the potassium ions with selected angles and bond lengths (left). Propeller-like arranged benzhydryl moiety and angles $(\phi)$ observed between C2-C10-C16 plane (red) and the aryl (blue) as well as phenyl (green, yellow) units (right).

and the perfect planarity of the ligand scaffold with the cation in plane are in good agreement to the unsolvated $\kappa^{2}-N_{,} N^{\prime}-\left[\mathrm{K}\left({ }^{\text {Dipp }} \mathrm{NacNac}\right)\right]^{[190]}$ complex (N1-K1 2.710(3) $\AA$, N2-K1 2.652(2) $\AA$ ). The two benzhydrilic positions $\left(\mathrm{C}_{\mathrm{bzh}}\right)$ show shortenend bond lengths to flanking $\mathrm{C}_{\mathrm{ipso}}$-atoms (C2-C9

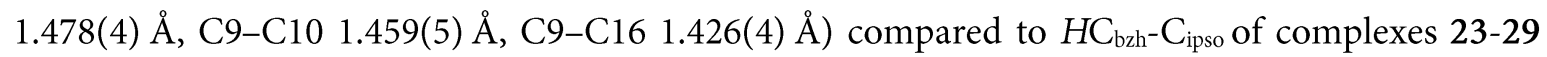
(1.508(8) $\AA$ to $1.538(6) \AA$ ) because of their deprotonation. The two anionic C9-atoms are essentially in-plane with pendant $\mathrm{C}_{\mathrm{ipso}}$-atoms $(\mathrm{C} 2, \mathrm{C} 10, \mathrm{C} 16)$ similar to previously studied potassium trityl complexes $\left.\left[\mathrm{KCPh}_{3}(\mathrm{THF})(\mathrm{PMDTA})\right]\right]^{[189]}\left[\mathrm{KCPh}_{3}(\mathrm{PMDTA}]^{[198]}\right.$ or $\left[\mathrm{KCPh}_{3}(L)\right]_{n}(L=$ diglyme,

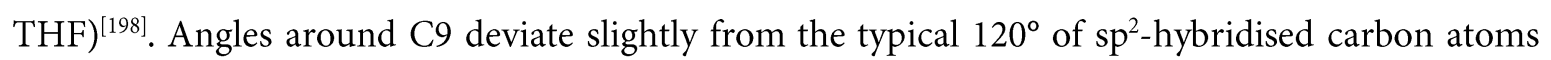
(Figure 2-42, left), while the steric constraints inhibit the phenyl rings from being coplanar, leading to a propeller-like arrangement. Within this arrangement, the angles $\phi$ (Figure 2-42, right) of the phenyl groups with respect to $\mathrm{C} 2-\mathrm{C} 10-\mathrm{C} 16$ plane $\left(\mathrm{C}_{3}\right.$-plane) are $\phi_{1}=32.38(17)^{\circ}(\mathrm{C} 10$ to $\mathrm{C} 15)$ and $\phi_{2}=49.68(10)^{\circ}$ (C1 to C6), whereas the smallest angle and shortest bond (C9-C16 1.426(4) $\AA$ ) involves the phenyl system to which the cation (K3) is coordinated. These angles correspond to an increased $\pi$-electron-delocalisation, which is dependent on the overlap of the $\mathrm{C}_{3}$-plane $(\mathrm{C} 2-\mathrm{C} 10-$ $\mathrm{C} 16)$ and coordinating phenyl ring (C16 to $\mathrm{C} 21)$ by a $\cos (\phi)^{2}$ function. ${ }^{[189,199]}$ Meaning that although the phenyl group is twisted $\left(\phi_{3}=16.4(2)^{\circ}\right)$ the overlap would amount to about $92 \%$, which is a greater overlap than observed for $\left[\mathrm{KCPh}_{3}(\mathrm{THF})(\mathrm{PMDTA})\right]^{[189]}\left(\phi=17.7^{\circ}, \cos (\phi)^{2} \approx 90 \%\right)$. Additionally, the observed angles of the C9-coordinating phenyl ring (C16) and benzoxazol-2-yl moieties (C2) exhibit a considerable angle contraction $\left(\mathrm{C} 17-\mathrm{C} 16-\mathrm{C} 21114.4(3)^{\circ}, \mathrm{C} 1-\mathrm{C} 2-\mathrm{C} 3114.2(3)^{\circ}\right)$ while the noncoordinating phenyl ring seems to be less affected $\left(\mathrm{C} 15-\mathrm{C} 10-\mathrm{C} 11115.7(3)^{\circ}\right)$. This quinoid distortion that is reported for $\mathrm{Ph} X$ compounds when $X$ is an electropositive element $\left(\mathrm{Li}^{[200]}, \mathrm{Na}^{[201]}\right)$ or an electron-donating group $\left(\mathrm{CH}_{2}^{-}\right)^{[202]}$ results in a generally less pronounced angle contraction at the para positions that is strongest expressed at the $\mathrm{K} 2$ coordinating $\mathrm{C} 4-$ and $\mathrm{C} 5-$ atoms (C6-C5-C4 $\left.115.1(4)^{\circ}\right)$. 
Further analyses of 29 were challenging owing to its low solubility in most common solvents (toluene, benzene, or THF). To find further evidence for the synthesis of the trifold deprotonated anion (4-Bzh ${ }^{4} x_{2} \mathrm{CH}$ ), suspensions of the dark red precipitate (29) were once again protonated (excess $\approx 20$ equiv. $\mathrm{H}_{2} \mathrm{O}$ or $\mathrm{D}_{2} \mathrm{O}$ ) in small scale (NMR experiment) with a) $\mathrm{H}_{2} \mathrm{O}+\left[\mathrm{D}_{8}\right] \mathrm{THF}$, b) $\mathrm{D}_{2} \mathrm{O}+$ $\left[\mathrm{D}_{8}\right] \mathrm{THF}$ and c) $\mathrm{D}_{2} \mathrm{O}+\mathrm{THF}$. Measured ${ }^{1} \mathrm{H}$ NMR (Figure 2-43a) $+b$ )) and ${ }^{2} \mathrm{H}$ NMR spectra (Figure 2-43 c)) were compared to ${ }^{1} \mathrm{H}$ NMR spectra of 28 in d) $\left.\left[\mathrm{D}_{8}\right] \mathrm{THF}, e\right) \mathrm{H}_{2} \mathrm{O}+\left[\mathrm{D}_{8}\right]$ THF and $\left.f\right) \mathrm{D}_{2} \mathrm{O}+$ $\left[\mathrm{D}_{8}\right]$ THF. The successful reprotonation of the benzylic position (C9) was observed in a) as a singlet of $6.24 \mathrm{ppm}$, while in $b$ ) the deuteration led to a significantly reduced signal. The benzylic positions

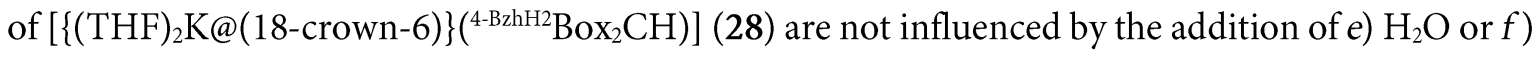
$\mathrm{D}_{2} \mathrm{O}$ due to its $\mathrm{p} K_{\mathrm{a}}$ value ${ }^{[180]}$ of about 33 . Furthermore, the deuteration of 29 by $\mathrm{D}_{2} \mathrm{O}$ and consequent deprotonation was confirmed via ${ }^{2} \mathrm{H}$ NMR spectroscopy showing a broad singlet at $6.20 \mathrm{ppm}$. The singlet of the backbone (-CH-) was detected at $4.73 \mathrm{ppm}$ in a) and e) but vanished in $b$ ) and $f$ ) as soon as $\mathrm{D}_{2} \mathrm{O}$ was added. These observations in combination with the distinctive singlet in ${ }^{2} \mathrm{H}$ NMR spectrum of $c$ ) at $4.73 \mathrm{ppm}$, hint at an equilibrium between water and the linking methylene or methanide unit. The same behaviour could be observed for $\left[\mathrm{K}\left(18 \text {-crown-6) }\left({ }^{4,6-\mathrm{Pr}} \mathrm{Box}_{2} \mathrm{CH}\right) \cdot \mathrm{H}_{2} \mathrm{O}\right]_{n}\right.$ $(n \rightarrow \infty)^{[112]}$ or $\left[\mathrm{K}\left(18 \text {-crown-6) }\left(\mathrm{Box}_{2} \mathrm{CH}\right)\right]_{n}(3)(n \rightarrow \infty)^{[1]}\right.$.

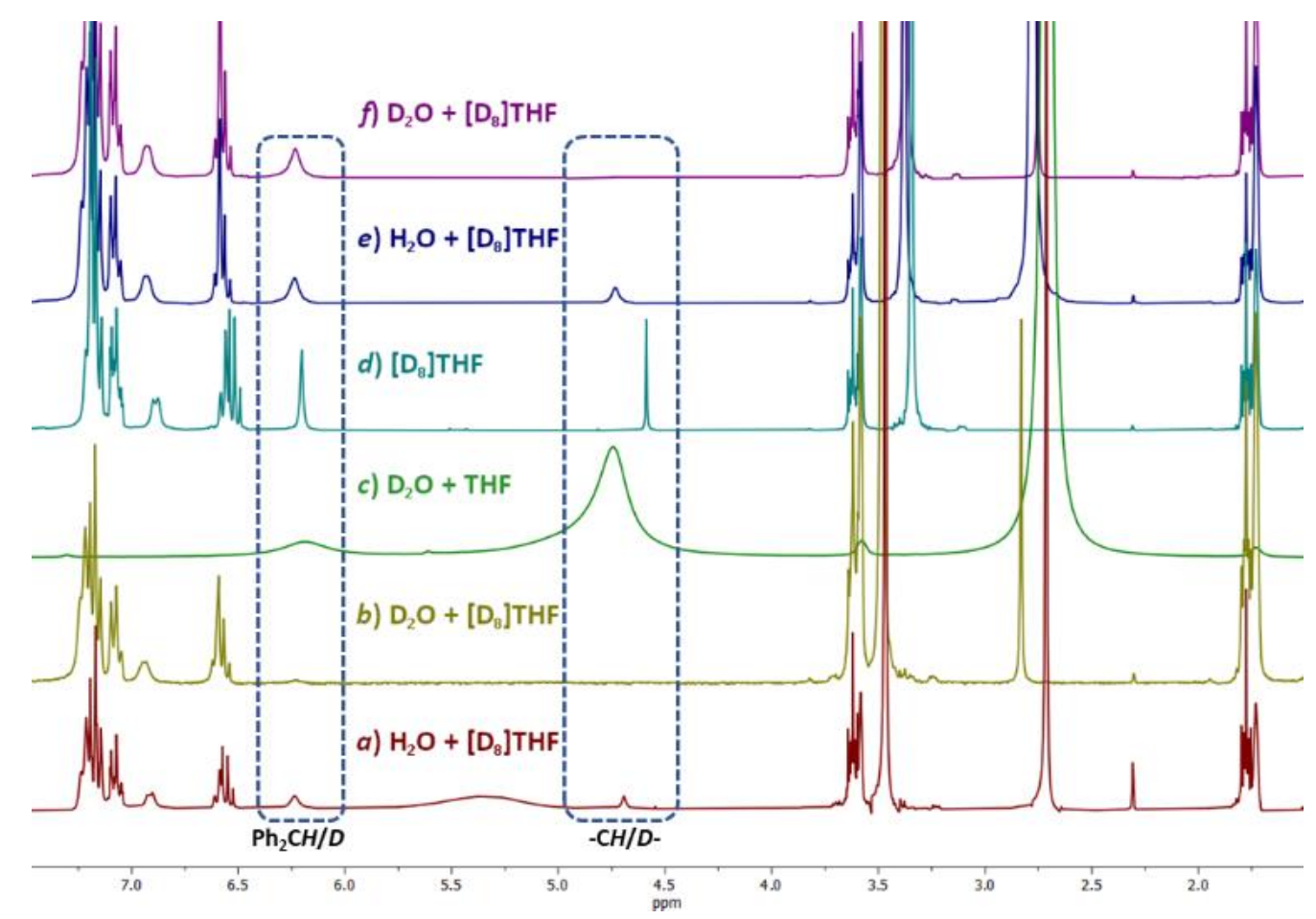

Figure 2-43. ${ }^{1} \mathrm{H}$ NMR spectra of 29 and a) $\left.\mathrm{H}_{2} \mathrm{O}+\left[\mathrm{D}_{8}\right] \mathrm{THF}, b\right) \mathrm{D}_{2} \mathrm{O}+\left[\mathrm{D}_{8}\right] \mathrm{THF}$ and ${ }^{2} \mathrm{H}$ NMR spectra c) $\mathrm{D}_{2} \mathrm{O}$ + THF. ${ }^{1} \mathrm{H}$ NMR spectra of complex 28 and $d$ ) $\left[\mathrm{D}_{8}\right]$ THF , e) $\mathrm{H}_{2} \mathrm{O}+\left[\mathrm{D}_{8}\right] \mathrm{THF}$ and $\left.f\right) \mathrm{D}_{2} \mathrm{O}+\left[\mathrm{D}_{8}\right] \mathrm{THF}$.

Additionally, mass spectrometry (ESI[-], THF) of 29, which was previously reacted with deuterated water revealed ion peaks based on mono-, di- and tri-deuterated species (m/z (\%): 582.2 (19)

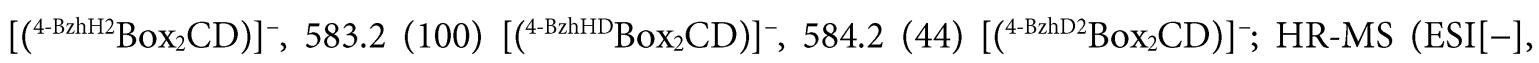
THF m/z: 582.2274 (cal. 582.2282 for, $\mathrm{C}_{41} \mathrm{H}_{28} \mathrm{DN}_{2} \mathrm{O}_{2}$ ), 583.2335 (cal. 583.2380 for [( ${ }^{4-\mathrm{BzhHD}}{ }^{\mathrm{Box}}{ }_{2} \mathrm{CD}$ )] $]^{-}$, 
$\mathrm{C}_{41} \mathrm{H}_{27} \mathrm{D}_{2} \mathrm{~N}_{2} \mathrm{O}_{2}$, 584.2380 (cal. 584.2417 for $\left[\left({ }^{4-\mathrm{BrhD} 2} \mathrm{Box}_{2} \mathrm{CD} \text { ) }\right]^{-}, \mathrm{C}_{41} \mathrm{H}_{26} \mathrm{D}_{3} \mathrm{~N}_{2} \mathrm{O}_{2}\right.$ ). The addition of deuterated water to a solution of $\mathbf{2 8}$ in THF caused the formation of non- or monodeuterated ligand (HR-MS (ESI[-], THF) m/z: 581.2240 (cal. 581.2235 for [( $\left.\left.{ }^{4-\mathrm{BzhH}^{2}} \mathrm{Box}_{2} \mathrm{CH}\right)\right]^{-}, \mathrm{C}_{41} \mathrm{H}_{29} \mathrm{~N}_{2} \mathrm{O}_{2}$ ), 582.296 (cal. 582.2297 for $\left.\left[\left({ }^{4-\mathrm{BzhH}^{2}} \mathrm{Box}_{2} \mathrm{CD}\right)\right]^{-}, \mathrm{C}_{41} \mathrm{H}_{28} \mathrm{DN}_{2} \mathrm{O}_{2}\right)$ ), which supports the thesis of an equilibrium between water and methylene or methanide linker. 


\subsubsection{Excursus: Salt metathesis reaction of $\left[\left\{(T H F){ }_{2} K @(18-c r o w n-6)\right\}^{+}\{K @(18-\right.$ crown-6)K( $\left.\left.\left.{ }^{4-B z h} \mathrm{Box}_{2} \mathrm{CH}\right)\right\}^{-}\right]_{n}(n \rightarrow \infty)(29)$.}

Subsequently, salt metathesis reactions of potassium species 29 and metal(III) salts such as aluminium or indium chloride were performed in THF and PhF. Here, the reactivity of potassium salt 29 is limited due to its poor solubility. The reaction of 29 and indium(III) chloride is until now the only one of which a novel complex $\left[\mathrm{K} @\left(18 \text {-crown-6) }(\mu-\mathrm{Cl}) \operatorname{In}\left({ }^{4-\mathrm{Bzh}} \mathrm{Box}_{2} \mathrm{CH}\right)\right]_{2}(30)\right.$ was isolated. In doing so, first fluorobenzene and thereafter indium(III) chloride were added to compound 29 under vigorous stirring at ambient temperature (Scheme 2-27). The dark-red solid suspension turned orange-red while most of the red solid was dissolved. After the reaction mixture had been stirred for $1 \mathrm{~d}$, the colourless precipitate $(\mathrm{KCl})$ and orange solution were separated by filtration. Colourless

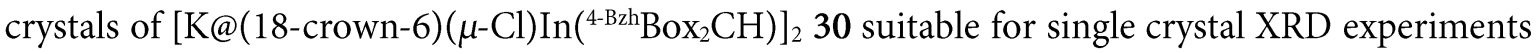
were grown out of the saturated filtrate at $-30^{\circ} \mathrm{C}$ after $\sim 3 \mathrm{~d}$ (YLD: $27 \%$ ). The yields of compound 30 could not be increased in further work-up of the decanted solution.
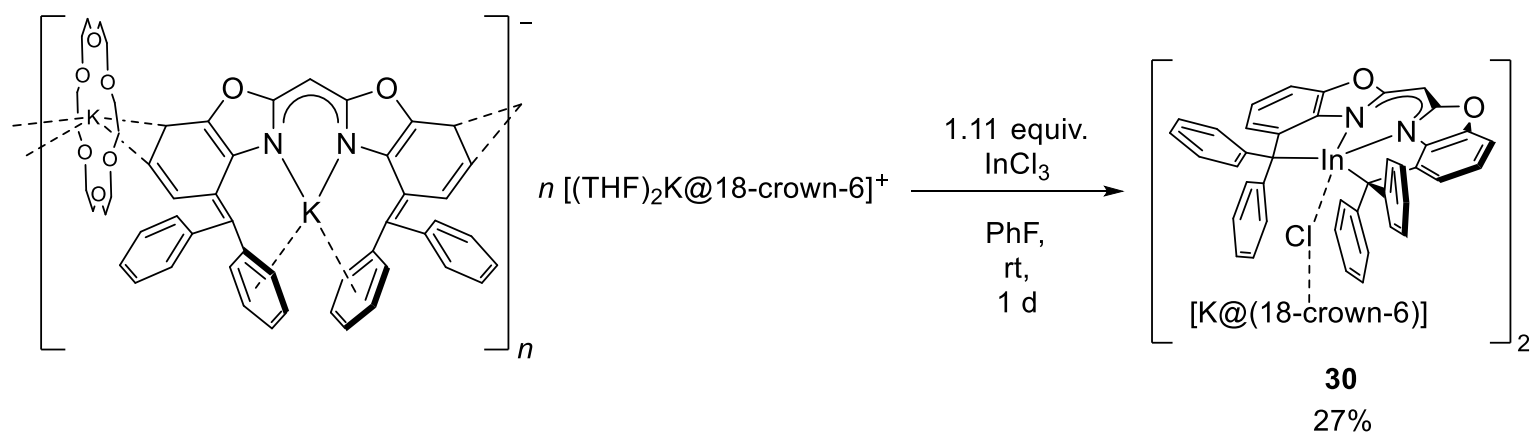

Scheme 2-27. Reaction of compound 29 and $\mathrm{InCl}_{3}$ resulting in $\left[\mathrm{K} @\left(18 \text {-crown-6)( } \mu \text {-Cl) } \operatorname{In}\left({ }^{4-\mathrm{Brh}} \mathrm{Box}_{2} \mathrm{CH}\right)\right]_{2}(30)\right.$.

Compound 30 crystallises in the triclinic space group $P \overline{1}$ with a dimeric complex molecule and two fluorobenzene molecules in the asymmetric unit (Figure 2-44). Complex 30, which might be described as an ate complex, consisting of two crown-ether-complexed potassium chloride moieties bonding the indium atoms via $\mathrm{In}-\mathrm{Cl}-\mathrm{K}$ bridging interactions. The two moieties are bound to one another by the interaction of a potassium ion K1 and the oxygen atom O3' (2.7064(18) $\AA$ ) of the second 18-crown-6 molecule. Here, the four-membered In1-Cl1-K1-O3' unit is almost perfectly linearly aligned, containing In1-Cl1-K1 of $168.71(3)^{\circ}$ and $\mathrm{Cl} 1-\mathrm{K} 1-\mathrm{O} 33^{\prime}$ of $171.91(4)^{\circ}$, respectively. A similar structural motive was observed in $\left[\mathrm{K} @(18 \text {-crown- } 6)(\mu-\mathrm{Cl}) \mathrm{Be}\left(L_{a}\right)\right]_{2}\left(L_{\mathrm{a} / b}=\{\mathrm{DippNCMe}\}=\mathrm{CH}-\right.$ $\left.\left\{\mathrm{C}(\mathrm{HMe})_{a} /(=\mathrm{Me})_{b} \mathrm{NDipp}\right\}\right),{ }^{[203]}$ compared to the latter complex, the indium species 30 comprises a nearly perpendicular alignment $\left(83.67(5)^{\circ}\right)$ of the tetradentate ${ }^{4-\mathrm{Bzh}} \mathrm{Box}_{2} \mathrm{CH}$ scaffolds and the $\mathrm{M}-\mathrm{Cl}-$

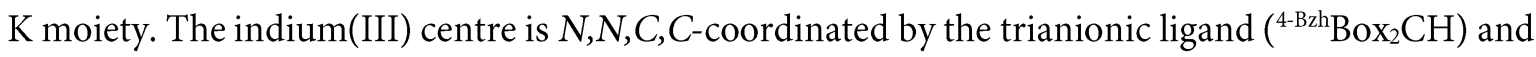
an apical chloride atom in a distorted square pyramidal (SPy) fashion (Figure 2-44, bottom left). The

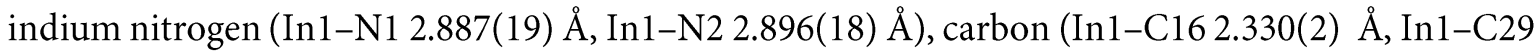
2.351(2) $\AA$ ) and chloride (In1-Cl1 2.4766(9) $\AA$ ) bond lengths are in the range of complexes such as $\left[\operatorname{InCl}_{2 / 0}(L)_{1 / 2}\right]^{[204]}\left(L_{2}=\mathrm{Me}_{2} \mathrm{NCH}_{2} \mathrm{Ph},\left\{\mathrm{Me}_{3} \mathrm{Si}\right\}_{2} \mathrm{CPy} ; L_{1}=\mathrm{TMEDA}, R_{2}=\mathrm{Me}\right)$ or $\left[\mathrm{InClPy} \mathrm{Naph}_{2}\right]_{2}^{[205]}$ containing a pentacoordinated $\mathrm{In}^{\mathrm{III}}$ cation. The formation of a SPy coordination geometry at the indium centre is evidenced by a slight dislocation of In 1 from the coordinating N1, N2, C16, C29 
moiety $(0.3784(12) \AA)$ compared to a trigonal bipyramidal coordination. The six-membered bite angle of the $\mathrm{C}_{3} \mathrm{~N}_{2}$ moiety N1-In1-N2 of $68.82(6)^{\circ}$ is more acute than the two five-membered angles N1-In1-C16 77.64(7) ${ }^{\circ}$ and N2-In1-C29 77.48(7) ${ }^{\circ}$. However, the most expanded angle is observed between the benzhydrilic positions and the metal ion (C16-In1-C29 129.13(8) $)^{\circ}$. Additionally, the bond lengths between benzhydrilic carbon atoms and bound aryl moieties are in the range $(1.509(3)$ to $1.534(3) \AA$ ) of typical single bonds $\left(\mathrm{C}\left(\mathrm{sp}^{3}\right)-\mathrm{C}\left(\mathrm{sp}^{2}\right) 1.54 \AA, \mathrm{C}\left(\mathrm{sp}^{2}\right)-\mathrm{C}\left(\mathrm{sp}^{2}\right) 1.51 \AA\right)$, indicating that the lone pairs are located at C16 and C29 whereas no delocalisation appears. ${ }^{[123]}$ Beside this, the coordination of the $\mathrm{In}^{\mathrm{III}}$ cation is enabled by the well-expressed ligand folding of $30.06(6)^{\circ}$ between the two benzoxazolyl residues.
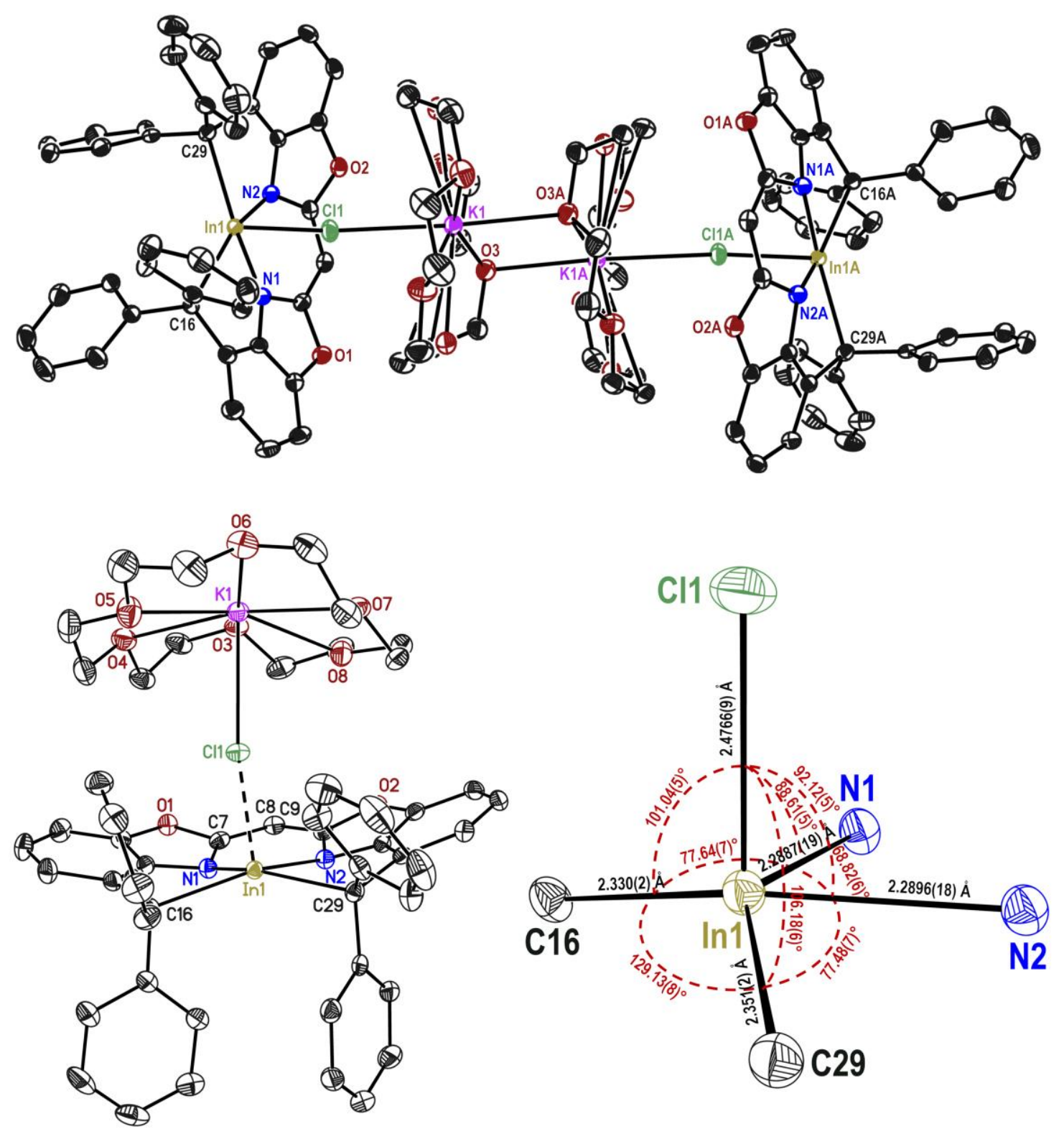

Figure 2-44. Crystal structure of dimeric $\left[\mathrm{K} @(18-c r o w n-6)(\mu-\mathrm{Cl}) \operatorname{In}\left({ }^{4-\mathrm{Bzh}} \mathrm{Box}_{2} \mathrm{CH}\right)\right]_{2}$ (30) (top). Asymmetric unit of 30 (bottom left) and coordination geometry (bottom right) at the In $^{\mathrm{III}}$ centre showing bond lengths and angles. Anisotropic displacement parameters are depicted at the $50 \%$ probability level. All hydrogen atoms are omitted for clarity except for the bridging (methylene) and benzylic ones. 
The ${ }^{1} \mathrm{H}$ NMR spectrum of 30 (Figure 2-45, top) in $\left[\mathrm{D}_{8}\right]$ THF confirms the successful salt metathesis reaction of $\mathrm{InCl}_{3}$ and 29. The methylene backbone exhibits a significant deshielding and downfield shift to $\delta(-H \mathrm{C}-) 4.80 \mathrm{ppm}$ compared to potassium species 25 ( $\delta(-H \mathrm{C}-) 4.66 \mathrm{ppm})$ or $28(\delta(-H \mathrm{C}-)$ $4.59 \mathrm{ppm})$. As expected, no signals of the former benzhydrilic protons could be observed owing to the former deprotonation. Furthermore, the phenylic positions are not magnetically equivalent, which is why two sets of signals are observed in ${ }^{1} \mathrm{H}$ and ${ }^{13} \mathrm{C}$ NMR spectrum, and resulting in a signal overlay, especially in the aromatic region of the ${ }^{1} \mathrm{H}$ NMR spectrum.

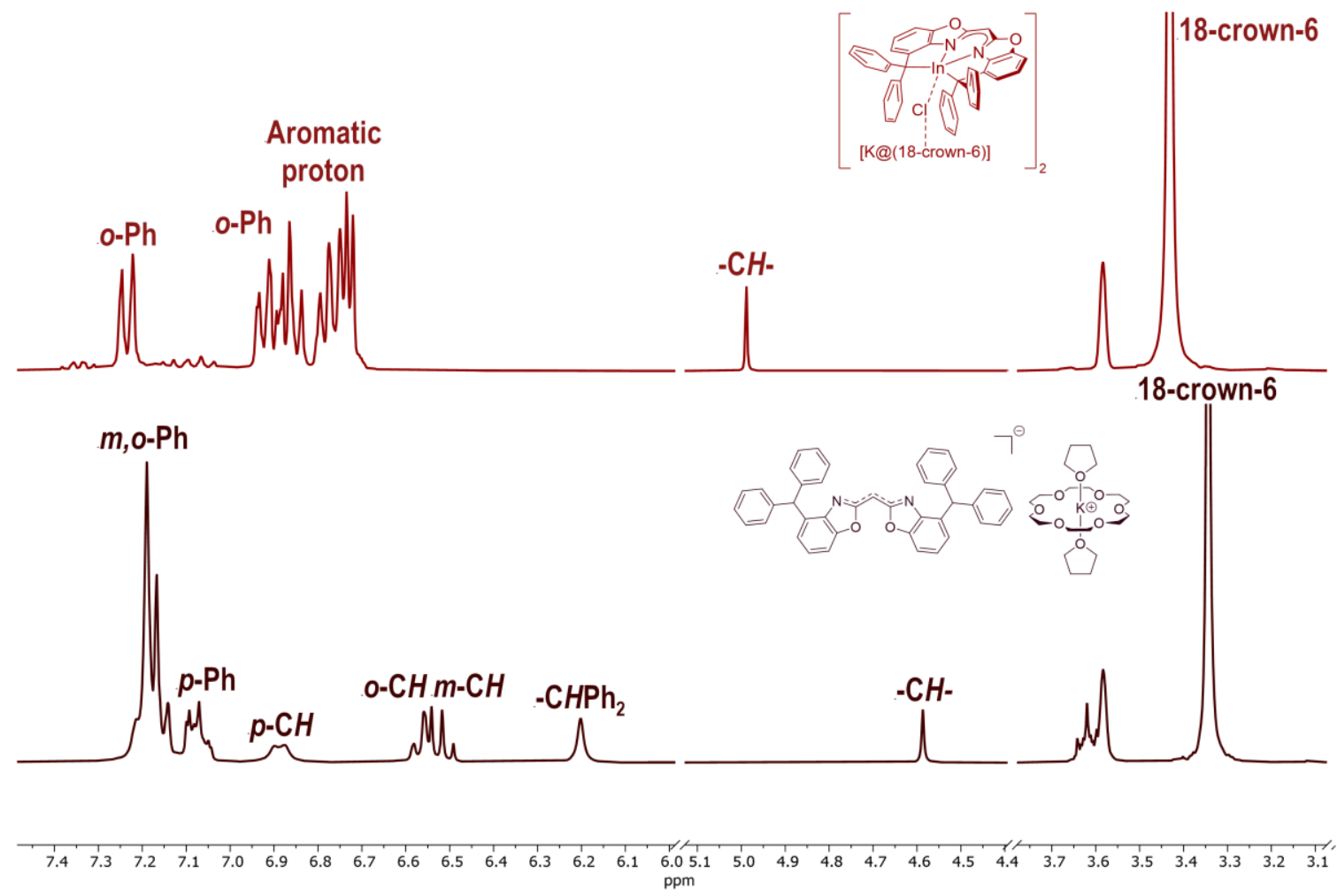

Figure 2-45. Stacked ${ }^{1} \mathrm{H}$ NMR spectra of 30 (top) and 28 (bottom) in $\left[\mathrm{D}_{8}\right] \mathrm{THF}$.

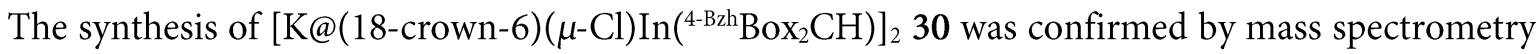
(LIFDI[+],THF: m/z(\%)694.1 (1) [M-Cl-(K@18-crown-6) $]^{+}$) and elemental analysis. 
As already mentioned, a disadvantage of the trianionic potassium compound (29) is its poor solubility in most common solvents. Moreover, the former reaction showed that it might be challenging to separate it from the potassium coordinated by the 18-crown- 6 ether. To generate a soluble and crown ether free trianionic species for salt metathesis reactions, ${ }^{4-\mathrm{BrhH} 2}{ }^{-} \mathrm{Box}_{2} \mathrm{CH}_{2}$ (23) ligand was reacted with a Lochmann-Schlosser base. ${ }^{[206]}$ Hence, the neutral bis(4-benzhydrylbenzoxazol-2-yl)methane was dissolved in THF and cooled to $-30^{\circ} \mathrm{C}$. After that, three equiv. of potassium tert-butoxide were added, and the reaction solution turned yellow-orange. A solution of ${ }^{n} \mathrm{BuLi}$ in hexane (3.30 equiv.) was added under vigorous stirring of the reaction solution at $-30^{\circ} \mathrm{C}$. The solution turned red during the addition of ${ }^{n} \mathrm{BuLi}$, but immediately decoloured until more than one equiv. was added. Then, the reaction solution was allowed to warm to ambient temperature and stirred for $1 \mathrm{~d}$. Subsequently, the deep red solution was layered with hexane and stored at $-30^{\circ} \mathrm{C}$. After about $1 \mathrm{~d}$, red crystals suitable for single crystal XRD experiments grew out of the profoundly

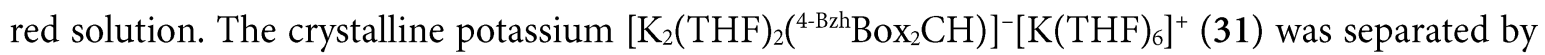
decantation of the solution via syringe and thereafter dried under reduced pressure. The isolated crystals (YLD: 70\%) were analytically pure and could be used for further syntheses. The decanted solution was concentrated, and a second crop of crystals (YLD: 5\%) was obtained from the saturated solution, after repeating the previous crystallisation procedures. The drying process of the crystals lead to a partial removal of circa 4 equiv. THF, which fits the elemental analysis. Therefore, the effective yields should be higher.
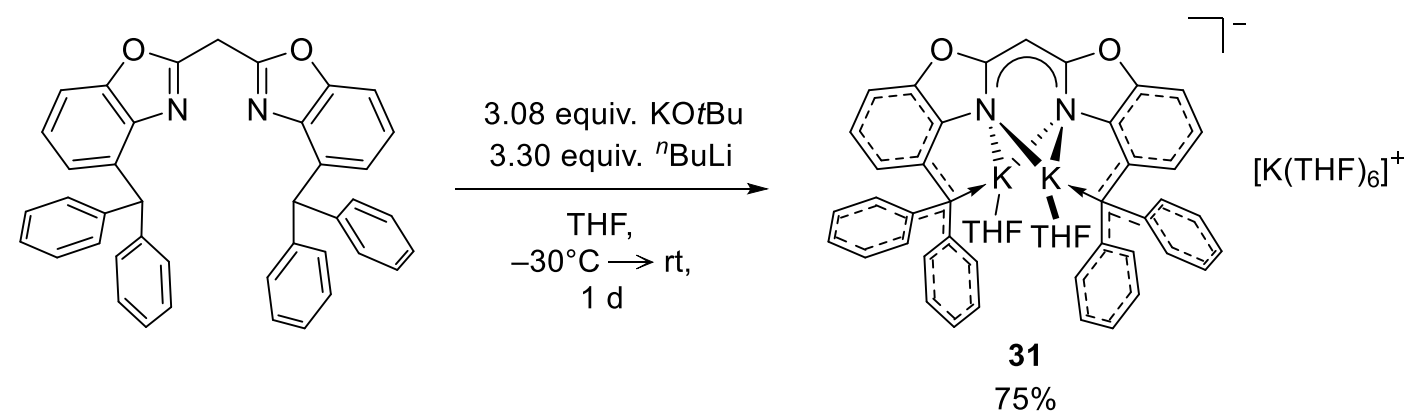

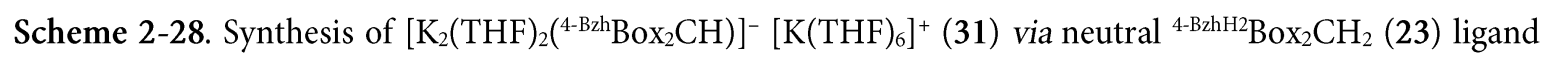
and a Schlosser base.

Compound 31 crystallises in the monoclinic space group $C 2 / c$ with one and a half complex molecules in the asymmetric unit (Figure 2-47). The potassium species 31 consists of a solvent separated ion pair, more precisely, a potassium cation $\left[\mathrm{K}(\mathrm{THF})_{6}\right]^{+}$octahedrally-coordinated by THF and the

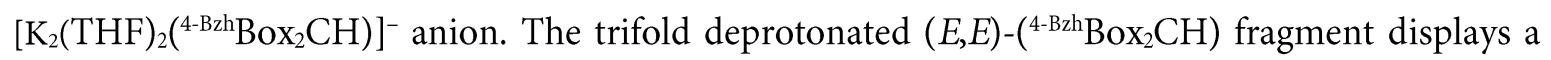
$\eta^{2}, \eta^{1}$-coordination of the two potassium atoms by the $\mathrm{C}_{3} \mathrm{~N}_{2}$ moiety (N1-N2-C9; N1-N2-C7), according to dimeric complex $\left[\mathrm{K}\left({ }^{4-\mathrm{BhhH}^{2}} \mathrm{Box}_{2} \mathrm{CH}\right)\right]_{2}\left(25_{2}\right)$. In comparison to compound $25_{2}$, the range of potassium nitrogen distances from K1-N1 2.705(2) to K1-N2 3.075(2) $\AA$ is broader, indicating a more expressed slipped or twisted position of the cations. This also leads to a more acute $\mathrm{N}-\mathrm{K}-\mathrm{N}$ angles of $61.28(8)^{\circ}$ to $61.60(6)^{\circ}$ and shorter $\mathrm{K} \cdots \mathrm{C}_{3} \mathrm{~N}_{2}$ distances of 1.612(4) to 1.774(4) $\AA$ compared to $25_{2}$ or heavier homologues 26 and 27 . The folding angles between the two benzoxazole fragments is $4.93(6)^{\circ}$ and therefore smaller than the angle in $25_{2}$ closer to the monomeric sodium 24 or potassium 


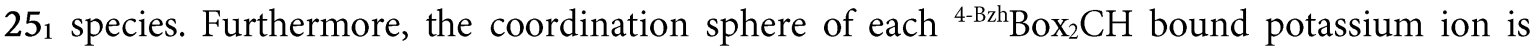
satiated by one THF molecule and $\pi$-arene interactions of the adjacent benzhydryliden residues.
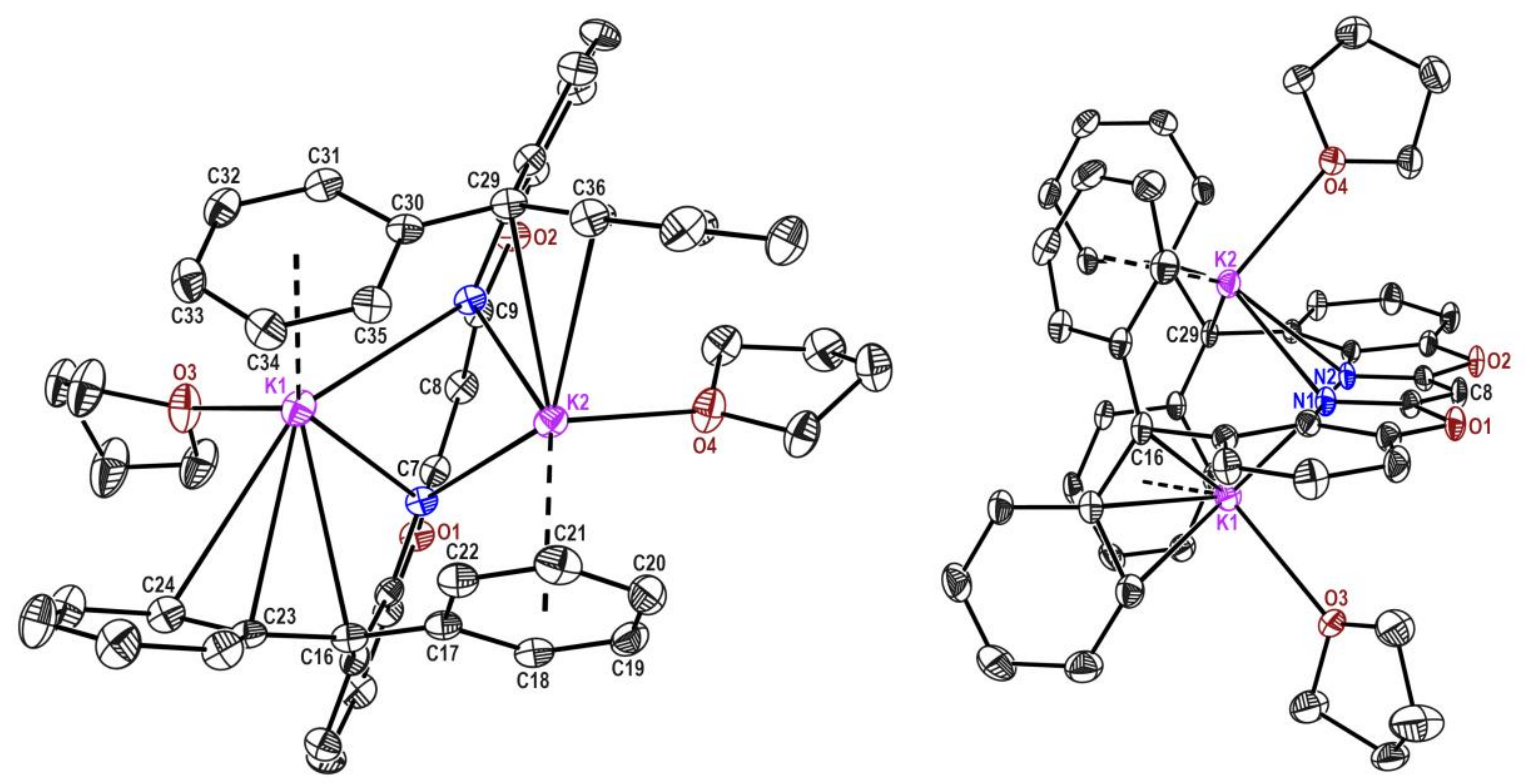

Figure 2-47. Molecular structure of $\left.\mathrm{K}_{2}(\mathrm{THF})_{2}\left({ }^{4-\mathrm{Bzh}} \mathrm{Box}_{2} \mathrm{CH}\right)\right]^{-}\left[\mathrm{K}(\mathrm{THF})_{6}\right]^{+}(31)$ depicted from two different perspectives (right, left). The cationic $\left[\mathrm{K}(\mathrm{THF})_{6}\right]^{+}$counterion as well as the hydrogen atoms are omitted for clarity. Asymmetric displacement parameters are depicted at 50\% probability level.

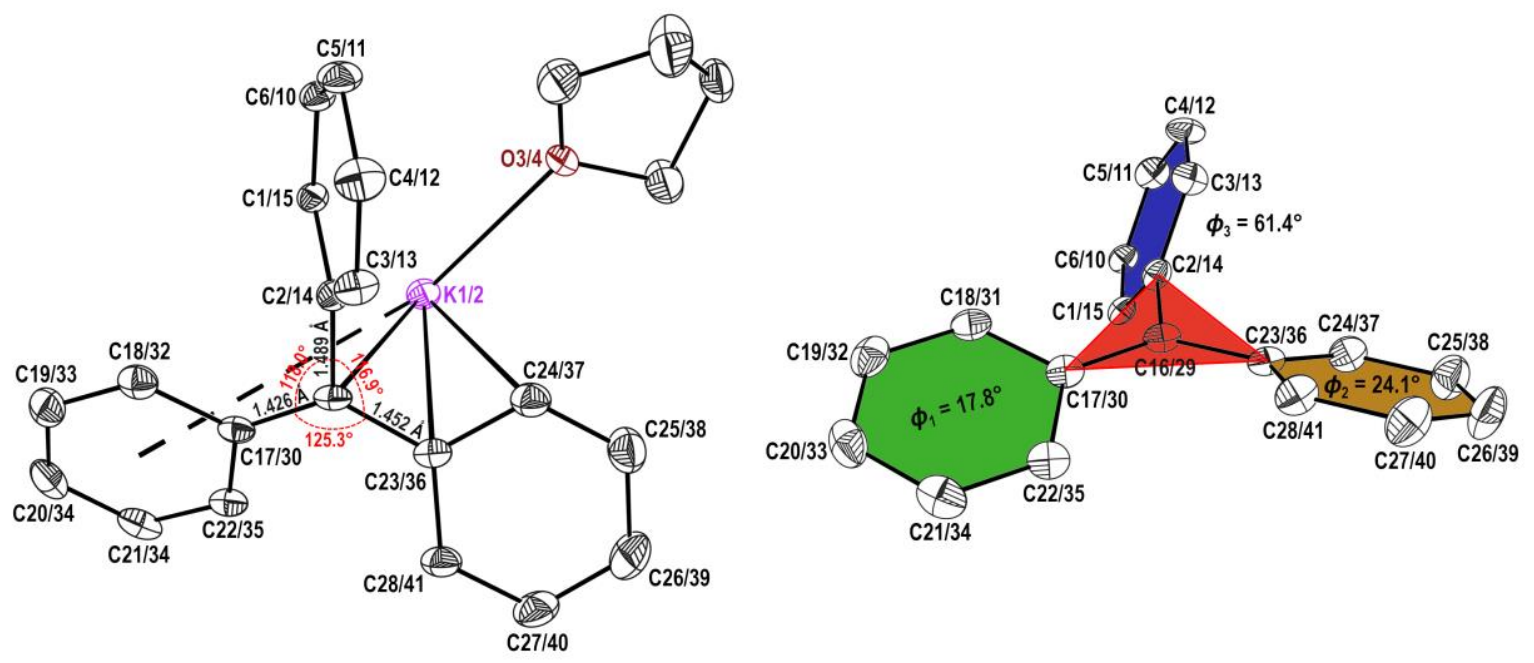

Figure 2-46. Benzhydryliden fragment of 31 coordinating the potassium ion with angles and bond lengths at C16/29 (left). Propeller-like arranged benzhydryl moiety and angles $(\phi)$ observed between C2/14-C17/39$\mathrm{C} 23 / 36$ plane (red) and the aryl (blue) as well as phenyl (green, yellow) units (right).

Here, one phenyl residue and the methanide atom of each deprotonated benzhydryl groups coordinates in a $\eta^{3}$ - or $\eta^{2}$-fashion (K1-C16 3.232(6) $\AA$, K1-C23 3.299(3) $\AA$, K1-C24 3.327(3) $\AA$; K2C29 3.092(3) $\AA$, K2-C36 3.294(2) $\AA$ ), whereas the second phenyl rest exhibits $\eta^{6}$-coordination (C17 to C22 3.111(3) to 3.143(3) $\AA$, C30 to C35 3.114(3) to 3.360(2) $\AA$ ), respectively. The steric constraints of the phenyl residues once more thwart the formation of their coplanar alignment at methanide atoms C16 and C29. Moreover, a propeller-like arrangement is observed as described for 


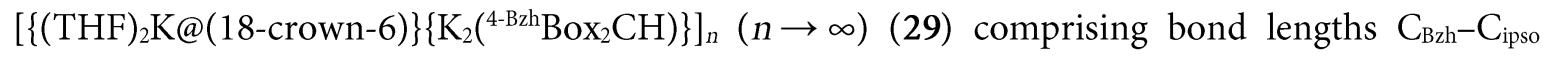
(Average: $\mathrm{C}_{\mathrm{Bzh}}-\mathrm{C} 2 / 141.489 \AA, \mathrm{C}_{\mathrm{Bzh}}-\mathrm{C} 17 / 301.426 \AA, \mathrm{C}_{\mathrm{Bzh}}-\mathrm{C} 23 / 361.452 \AA$ ) and $\mathrm{C}_{\mathrm{ipso}}-\mathrm{C}_{\mathrm{Bzh}}-\mathrm{C}_{\mathrm{ipso}}$ angles (Average: $\mathrm{C} 23 / 36-\mathrm{C}_{\mathrm{Bzh}}-\mathrm{C} 2 / 14116.9^{\circ}, \mathrm{C} 2 / 14-\mathrm{C}_{\mathrm{Bzh}}-\mathrm{C} 17 / 30118.0^{\circ}, \mathrm{C} 17 / 30-\mathrm{C}_{\mathrm{Bzh}}-\mathrm{C} 23 / 36125.3^{\circ}$ ) These parameters as well as the angles between the plane of the three $\mathrm{C}_{\mathrm{ipso}}(\mathrm{C} 2 / 14-\mathrm{C} 17 / 30-\mathrm{C} 23 / 36)$ atoms and corresponding phenyl or aryl fragment $\left(\phi_{1}(\mathrm{C} 17 / \mathrm{C} 30\right.$ to $\mathrm{C} 22 / \mathrm{C} 35)=17.8^{\circ}, \phi_{2}(\mathrm{C} 23 / \mathrm{C} 36$ to $\mathrm{C} 28 / \mathrm{C} 41)=24.1^{\circ}, \phi_{3}(\mathrm{C} 1 / \mathrm{C} 10$ to $\left.\mathrm{C} 6 / \mathrm{C} 15)=61.4^{\circ}\right)$ imply a increased $\pi$-electron-delocalisation $\left(\cos (\phi)^{2}=90.1 \%\right.$ (C17/C30 to C22/C35), 83.3\% (C23/C36 to C28/C41), 22.9\% (C1/C10 to C6/C15)) among them while the most density seems to be accumulated on the $\eta^{6}$-coordinating phenyl ring (C17 to C22 and C30 to C35).

The ${ }^{1} \mathrm{H}$ and ${ }^{13} \mathrm{C}$ NMR spectra of 31 (Figure 2-48) in $\left[\mathrm{D}_{8}\right] \mathrm{THF}$ confirm the synthesis of $\left[\mathrm{K}_{2}(\mathrm{THF})_{2}\left({ }^{4-\mathrm{Bzh}} \mathrm{Box}_{2} \mathrm{CH}\right)\right]^{-}\left[\mathrm{K}(\mathrm{THF})_{6}\right]^{+}(31)$ by trifold deprotonation. The former methylene group shows a minor upfield shift to $\delta(-H C-) 4.48 \mathrm{ppm}$ regarding potassium complexes $25(\delta(-H \mathrm{C}-)$ $4.66 \mathrm{ppm})$ or $28(\delta(-H C-) 4.59 \mathrm{ppm})$. A significant shielding accompanied by a chemical shift of $5.67 \mathrm{ppm}(\Delta \delta(25) \sim 1.4 \mathrm{ppm})$ is detected for the p-phenyl bound protons $(20-\mathrm{H}, 26-\mathrm{H}, 33-\mathrm{H}, 39-\mathrm{H})$, due to the increased negative charge within the ligand scaffold, which seems to accumulate at the phenyl residues. Furthermore, the partially overlapping signals of the benzoxazolyl and $o, m$-phenyl protons also experience an upfield shift. The integration of the non-deuterated THF molecules shows that drying of the red crystals leads to a loss of about four THF molecules. This is in agreement with the elemental analysis of the dried crystals $\left[\mathrm{K}_{2}(\mathrm{THF})_{2}\left({ }^{4-\mathrm{Bzh}} \mathrm{Box}_{2} \mathrm{CH}\right)\right]^{-}\left[\mathrm{K}(\mathrm{THF})_{6}\right]^{+}(31)$.
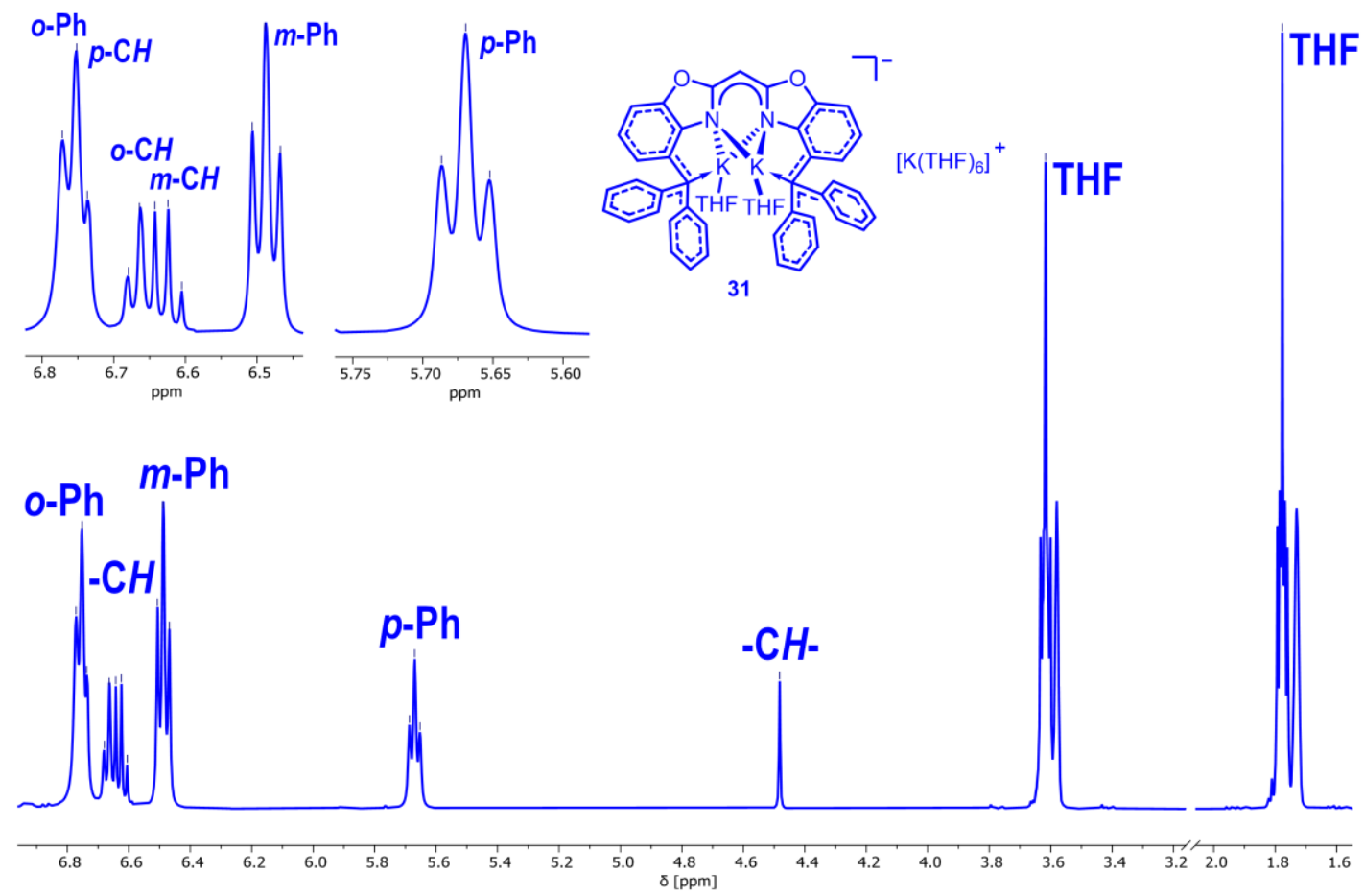

Figure 2-48. ${ }^{1} \mathrm{H}$ spectrum of $\left[\mathrm{K}_{2}(\mathrm{THF})_{2}\left({ }^{4-\mathrm{Bzh} \mathrm{Box}} \mathrm{CH}_{2}\right)\right]^{-}\left[\mathrm{K}(\mathrm{THF})_{6}\right]^{+}(31)$ in $\left[\mathrm{D}_{8}\right] \mathrm{THF}$.

The ${ }^{13} \mathrm{C}$ NMR spectrum of 31 in $\left[\mathrm{D}_{8}\right]$ THF displays a chemical shift of $\delta 84.34 \mathrm{ppm}$ for $C_{\mathrm{Bzh}}$ (16-C, 29C) that is more similar to the chemical shift of methanide carbon atoms in related $[\mathrm{K}(\mathrm{PMDTA})(\mathrm{THF})(L)]^{[185,189]}\left(L=C \mathrm{Ph}_{2} \mathrm{py}: \delta 97.0 \mathrm{ppm}, L=C \mathrm{Ph}_{3}: \delta 88.7 \mathrm{ppm}\right)$ complexes than the 
range of alkali species 24 to 28 ( $\mathrm{HC}_{\mathrm{Bzh}}(16-\mathrm{C}, 29-\mathrm{C}): \delta 51.68$ to $\left.53.63 \mathrm{ppm}\right)$. The obtained trifold deprotonated species might be a promising precursor for further salt elimination reactions, mainly due to its straightforward synthesis and its solubility in THF. 


\subsubsection{Group 13 Complexes}

After isolation and characterisation of alkali metal complexes 24-27 (Chapter 2.4.2), this chapter shall focus on the syntheses of group 13 complexes derived from the bis(4-benzhydryl-benzoxazol2-yl)methane ( $\left.{ }^{4-\mathrm{BrhH}^{2}} \mathrm{Box}_{2} \mathrm{CH}_{2}\right)$ ligand. Those alkali metal compounds, and in particular $\left[\mathrm{K}\left({ }^{4-\mathrm{BzhH} 2} \mathrm{Box}_{2} \mathrm{CH}\right)\right](25)$ and $\left[\mathrm{Na}\left({ }^{4-\mathrm{BzhH}^{2}} \mathrm{Box}_{2} \mathrm{CH}\right)\right](24)$, are ideal precursors for salt metathesis reactions due to their facile synthesis and their solubility in toluene or THF. The reaction of the corresponding precursor and group 13 metal(I) reagents (Scheme 2-29) such as TlOTf, InOTf ${ }^{\text {f1a] }}$ and "GaI"[50,51] in toluene afforded monomeric complex $\left[M_{13}\left({ }^{4-\mathrm{BzhH}^{2}} \mathrm{Box}_{2} \mathrm{CH}\right)\right]\left(M_{13}=\mathrm{Tl}(32), \mathrm{In}(33)\right.$ and $\mathrm{Ga}(34)$ ) in moderate yields.
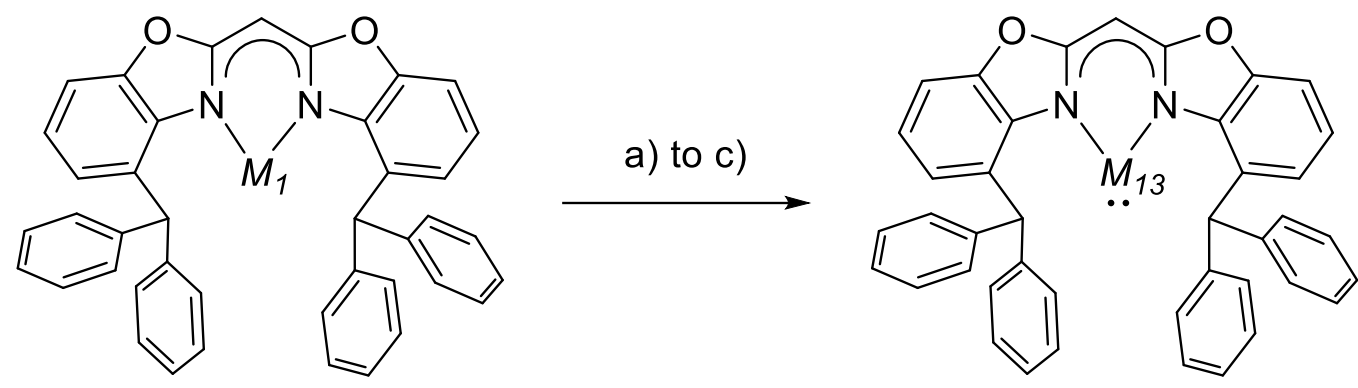

Scheme 2-29. Synthesis of monomeric group 13 metallacycles 32 to 34 were carried out in toluene under following reaction conditions: a) $M_{1}=\mathrm{Na}, 1.02$ equiv. TlOTf, $-30^{\circ} \mathrm{C}$ to rt (2 d), YLD: $55 \%$; b) $M_{1}=\mathrm{K}$, 1.00 equiv. InOTf, rt, $24 \mathrm{~h}$, YLD: $57 \%$; c) $M_{1}=\mathrm{K}, 1.65$ equiv. "GaI", $-30^{\circ} \mathrm{C}(5 \mathrm{~d})$ to rt ( $2 \mathrm{~d}$ ), YLD: $33 \%$.

Here, the salt metathesis reaction of 25 and TlOTf was incomplete, thus the sodium species 24 was used for the synthesis of the thallium heterocycle 32 . The reaction conditions were slightly adjusted owing to the properties of metal salts used (see 4.1.10.8 to 4.1.10.11 for details). Especially, the salt metathesis reaction of 25 and "GaI" at higher temperatures or rapid heating from $-30^{\circ} \mathrm{C}$ to ambient temperature resulted in disproportionation indicated by the formation of a gallium mirror. Additionally, the gallium diiodide complex $\left[\mathrm{GaI}_{2}\left({ }^{4-\mathrm{BzhH}^{2}} \mathrm{Box} 2 \mathrm{CH}\right)\right](34 \mathrm{a})$ was isolated as colourless crystals and analysed by single crystal XRD experiments (for details see chapter 5.1.35). Crystals of the carbene analogues 32 to 34 were grown out of saturated toluene solutions at $-30^{\circ} \mathrm{C}$ after several days. The metallacycles isostructurally crystallise in the triclinic space group $P \overline{1}$ with one complex molecule and two toluene molecules in the asymmetric unit (Figure 2-49). The solid-state structures of 32 to 34 consist of a mono-cation that is $\kappa^{2}-N, N^{\prime}$-chelated by the two nitrogen atoms of a NacNaclike $\mathrm{C}_{3} \mathrm{~N}_{2}$ fragment (Table 2-7). Ascending group 13 from the thallium species 32 to the molecular structures of lighter indium 33 and gallium 34 congeners (Table 2-7, Figure 2-49), a shortening of the average metal nitrogen bonds $\left(M_{13}-\mathrm{N}_{\text {avg. }}\right.$ 32: $\left.2.507 \AA ; 33: 2.375 \AA ; 34: 2.1508 \AA\right)$ and a widening of the $\mathrm{N}-\mathrm{M}_{13}-\mathrm{N}$ angles $\left(32: 77.73(10)^{\circ} ; 33: 81.21(8)^{\circ} ; 34: 86.27(5)^{\circ}\right)$ is observed. The dislocations of the $\mathrm{Tl}^{\mathrm{I}}$ and $\mathrm{In}^{\mathrm{I}}$ cations from the $\mathrm{C}_{3} \mathrm{~N}_{2}$ plane are equal within estimated standard deviations, whereas the distance $M_{13} \cdots C_{3} \mathrm{~N}_{2}$ of 34 (Table 2-7) is noticeably reduced. The butterfly folding angle between both benzoxazolyl moieties declines from 32 to 34 (Table 2-7). 


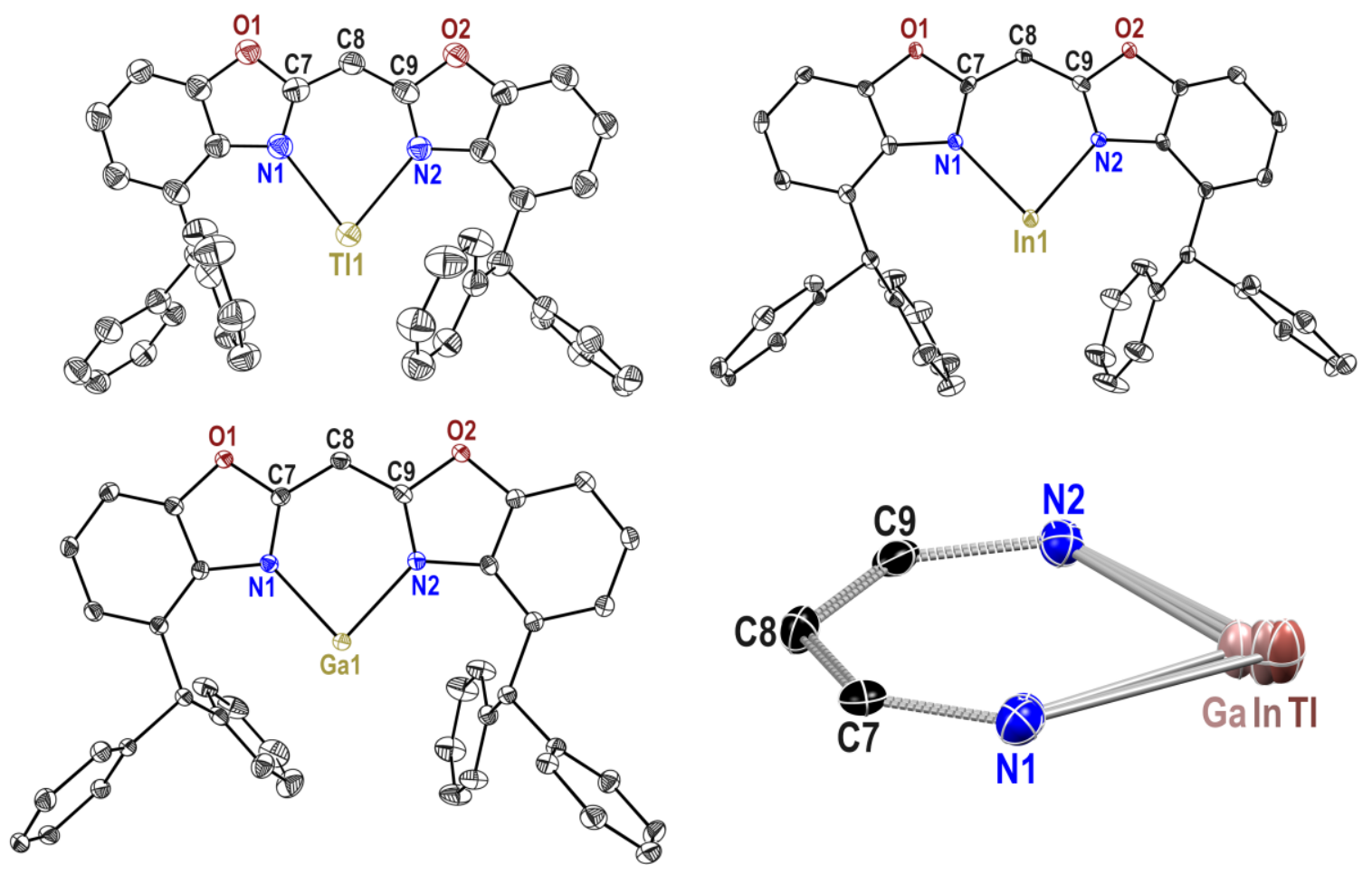

Figure 2-49. Solid-state structures of Group 13 metallylenes 32-34 (Top and bottom left). Anisotropic displacement parameters are depicted at the 50\% probability level. Hydrogen atoms are omitted for clarity. Superimposed $M_{13} \mathrm{C}_{3} \mathrm{~N}_{2}$ moieties of compound 32-34 (bottom right).

Table 2-7. Selected bond length $[\AA]$ and angles $\left[{ }^{\circ}\right]$ of complexes 32 to 34 .

\begin{tabular}{lccc}
\hline & $\left.\left[\mathrm{Tl}^{4-\mathrm{BzhH} 2} \mathrm{Box}_{2} \mathrm{CH}\right)\right]$ & {$\left[\mathbf{I n}\left(\begin{array}{c}\left.\left.4-\mathrm{BzhH}_{2} \mathrm{Box}_{2} \mathrm{CH}\right)\right] \\
(32)\end{array}\right.\right.$} & $\begin{array}{c}{\left[\mathrm{Ga}\left({ }^{4-\mathrm{BzhH}_{2}} \mathrm{Box}_{2} \mathrm{CH}\right)\right]} \\
(34)\end{array}$ \\
\hline$M_{13}-\mathrm{N}[\AA]$ & $2.494(3), 2.519(3)$ & $2.367(2), 2.383(2)$ & $2.1417(13), 2.1598(12)$ \\
\hline $\mathrm{N}-M_{13}-\mathrm{N}\left[^{\circ}\right]$ & $77.73(10)$ & $81.21(8)$ & $86.27(5)$ \\
\hline$M_{13} \cdots \mathrm{C}_{3} \mathrm{~N}_{2}[\AA]$ & $0.182(5)$ & $0.187(4)$ & $0.1617(16)$ \\
\hline Folding angle $\left[{ }^{\circ}\right]$ & $7.29(7)$ & $6.69(6)$ & $6.01(4)$ \\
\hline
\end{tabular}

These findings are in good agreement with reported monomeric six-membered NacNac-based $\left(L^{6}\right)$ thallium, indium and gallium heterocycles such as $\left[M_{13} L^{6}\right]\left(M_{13}=\mathrm{Tl},{ }^{[17 c, 72,84]} \operatorname{In}^{[17 c, 72,73 a]}\right.$ and $\left.\mathrm{Ga}^{[54,55,207]}\right)$ or bis(NacNac) complexes as $\left[\left(M_{13} L\right)_{2} R\right]^{[68,78,86 a]}\left(M_{13}=\mathrm{Tl}\right.$, In, Ga; $L=\{$ DippNCMe $\} \mathrm{HC}\{\mathrm{MeCN}\} ; R=$ 1,2-alkylene, 1,3-xlylene, or (hetero)arylene bridge).

The ${ }^{1} \mathrm{H}$ NMR spectra of 32-34 ([ $\left.\mathrm{D}_{8}\right]$ toluene) show that the chemical shift of the methanide bridge (32: $\delta(-\mathrm{CH}-) 5.40 \mathrm{ppm} ; 33: \delta(-\mathrm{CH}-) 5.43 \mathrm{ppm} ; 34: \delta(-\mathrm{CH}-) 5.40 \mathrm{ppm})$ is only marginally affected by the metal switch. In contrast, the benzhydrylic protons $(16-\mathrm{H}, 29-\mathrm{H})$ of $\left[\mathrm{Ga}\left({ }^{4-\mathrm{BzhH}^{2}} \mathrm{Box}_{2} \mathrm{CH}\right)\right](34)$ are significantly low-field shifted to $\delta\left(\mathrm{HCPh}_{2}\right) 6.85 \mathrm{ppm}$ compared to the heavier indium (33: $\left.\delta\left(\mathrm{HCPh}_{2}\right) 6.22 \mathrm{ppm}\right)$ or thallium complexes $\left(32: \delta\left(H C \mathrm{Ph}_{2}\right) 5.77 \mathrm{ppm}\right)$. This upfield shift might be due to a decrease of electronegativity from $\mathrm{Ga}$ to $\mathrm{Tl}$. The arene-bound protons are slightly influenced by the metal exchange. 
Additionally, the successful syntheses of thallium (32), indium (33) and gallium (34) metallacylces were confirmed by mass spectrometry (LIFDI[+], toluene: $32: \mathrm{m} / \mathrm{z}(\%)=786.1(100)[M]^{+}, 991.0(10)$ $[M+\mathrm{Tl}]^{+}$. 33: $\left.\mathrm{m} / \mathrm{z}(\%) 582.5(3)[M+\mathrm{H}-\mathrm{In}]^{+}, 696.1(100)[M]^{+} ; 34: \mathrm{m} / \mathrm{z}(\%) 650.0(100)[M]^{+}\right)$as well as elemental analysis.

To access $\left[\mathrm{AlI}_{2}\left({ }^{4-\mathrm{BzhH}^{2}} \mathrm{Box}_{2} \mathrm{CH}\right)\right](37)$, which is a potential precursor for an aluminium(I) complex, bis(4-benzhydryl-benzoxazol-2-yl)methane ligand (Scheme 2-30, method $A$ ) was reacted with a solution of $\mathrm{AlMe}_{3}$ in $n$-hexane at ambient temperature. ${ }^{[14 a, 56]}$ After the reaction solution had been stirred for $18 \mathrm{~h}$, volatiles were removed under reduced pressure, and yellowish powder was obtained and washed with $n$-hexane. Dimethyl aluminium bis(4-benzhydryl-benzoxazol-2-yl)methanide complex (35) was finally obtained as a white powder in moderate yields (62\%).

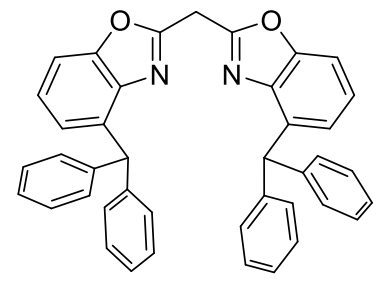

\begin{tabular}{c|c} 
Method $B:$ & toluene, \\
1.10 equiv. & rt, \\
$\mathrm{H}_{3} \mathrm{Al}\left(\mathrm{NMe}_{2} \mathrm{Et}\right)$ & $1 \mathrm{~d}$
\end{tabular}

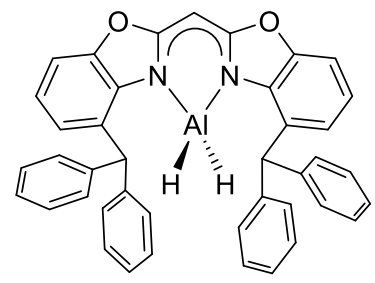

38: $59 \%$

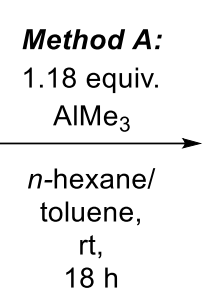

$8 \mathrm{~h}$

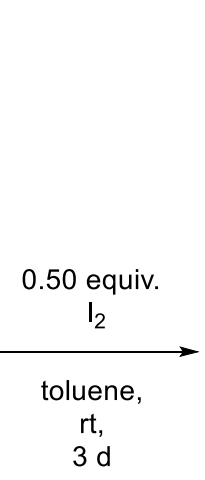

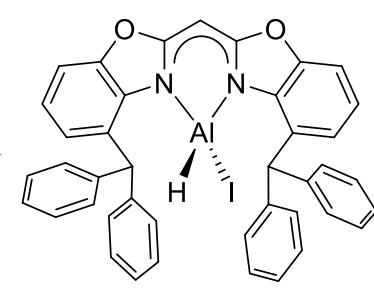

39: $78 \%$

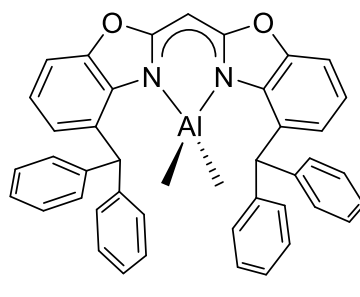

35: $62 \%$

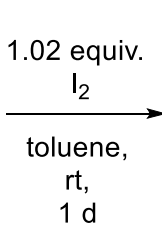

d

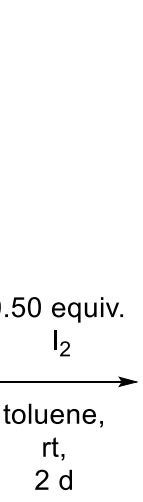

d

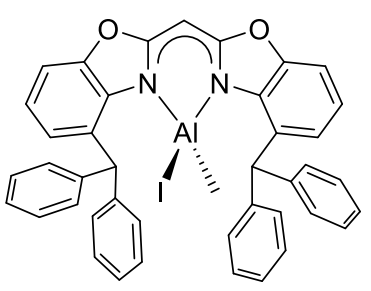

36: $82 \%$
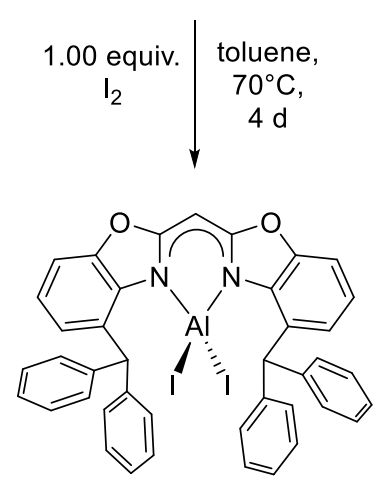

37:

Method A: $76 \%$

Method B: $65 \%$

Scheme 2-30. Synthetic routes for $\left[\mathrm{AlI}_{2}\left({ }^{4-\mathrm{BrhH}}{ }^{-} \mathrm{Box} 2 \mathrm{CH}\right)\right]$ (37) via iodination of dimethyl aluminium species 35 $(\operatorname{method} A)$ or aluminium dihydride species $38(\operatorname{method} B)$.

Crystals of [ $\left.\mathrm{AlMe}_{2}\left({ }^{4-\mathrm{BzhH} 2} \mathrm{Box}_{2} \mathrm{CH}\right)\right](35)$ suitable for single crystal XRD experiments were grown from a saturated solution of toluene at $-30^{\circ} \mathrm{C}$. Complex 35 crystallises in the triclinic space group $P \overline{1}$ with one complex molecule in its asymmetric unit (Figure 2-50). The aluminium ion is coordinated in a distorted tetrahedral fashion by the two methyl groups and the nitrogen atoms of ${ }^{4-\mathrm{BzhH} 2} \mathrm{Box}_{2} \mathrm{CH}$, while the oxygen atoms are pointing away from the metal ion. As expected, the bite angle N1-Al1-N2 = $96.39(5)^{\circ}$ is more acute than the other tetrahedral angles. This is accompanied by nitrogen aluminium bond lengths of Al1-N1 1.9509(11) $\AA$ and Al1-N2 1.9536(11) $\AA$ and carbon aluminium distances Al1-C42 1.9659(13) $\AA$ and Al1-C43 1.9729(14) $\AA$. In addition, the metal ion is almost perfectly located in the $\mathrm{C}_{3} \mathrm{~N}_{2}$ plane $\left(0.0022(14) \AA\right.$ ), while a butterfly folding angle of $5.47^{\circ}$ is observed (Table 2-7). Based on the molecular structures, the average aluminium nitrogen bonds

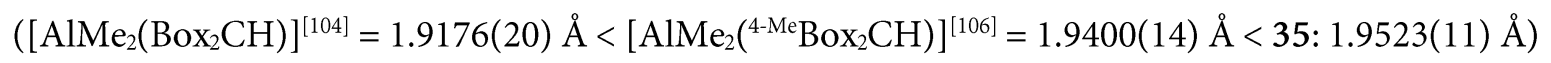



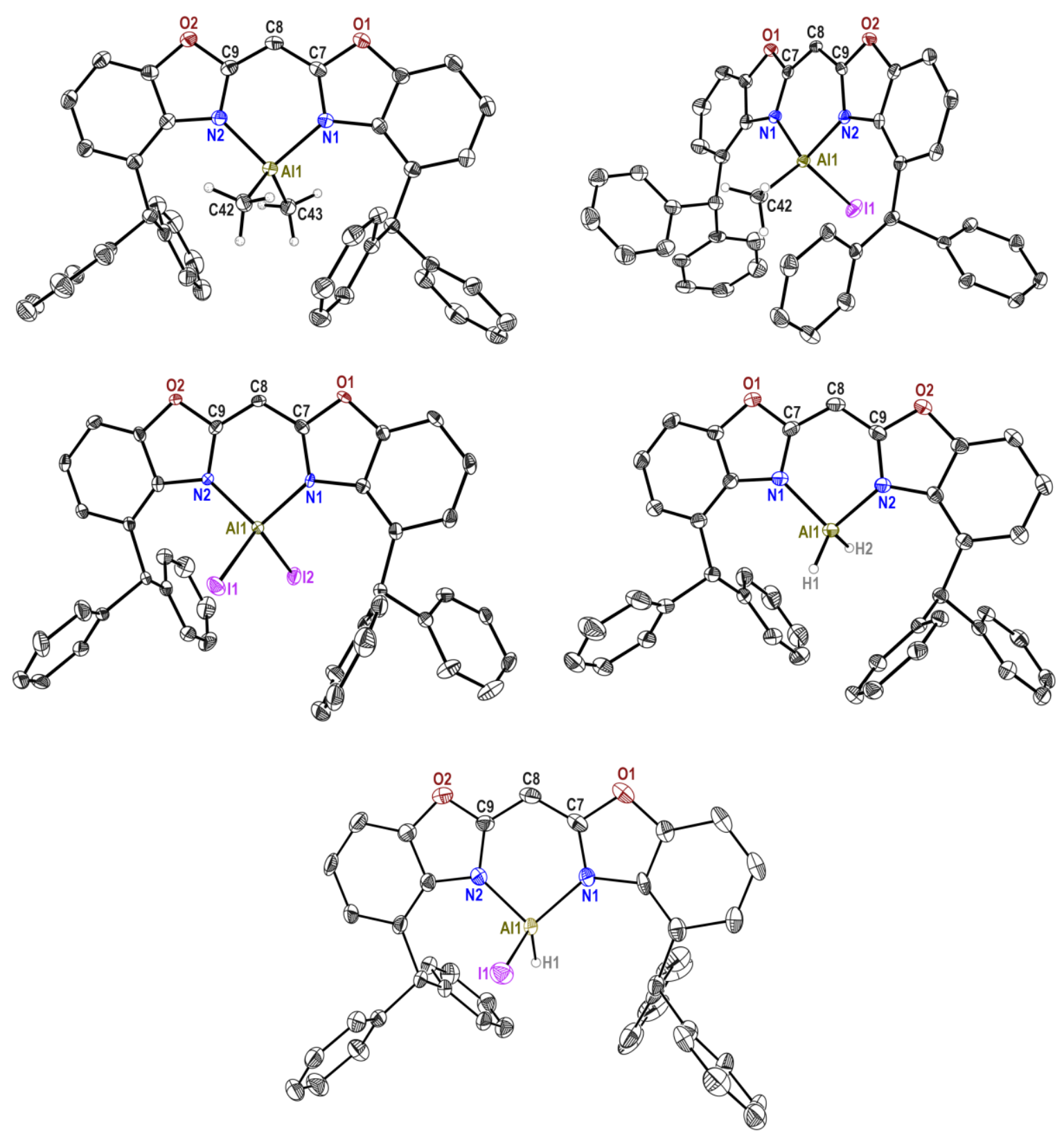

Figure 2-50. Solid-state structure of aluminium complexes 35 to 39. Anisotropic displacement parameters are depicted at 50\% probability level. Hydrogen atoms with exception of the $\mathrm{AlMe}_{2}$ and $\mathrm{AlH}_{2}$ are omitted for clarity.

and bite angles $\left(\left[\mathrm{AlMe}_{2}\left(\mathrm{Box}_{2} \mathrm{CH}\right)\right]^{[104]}=91.67(9)^{\circ}<\left[\mathrm{AlMe}_{2}\left({ }^{4-\mathrm{Me}} \mathrm{Box}_{2} \mathrm{CH}\right)\right]^{[106]}=94.68(6)^{\circ}<35\right.$ : $\left.96.39(5)^{\circ}\right)$ seem to increase when bulkier groups are attached next to the nitrogen binding pocket (C4-position). On the contrary, the deviation of metal ion and $\mathrm{C}_{3} \mathrm{~N}_{2}$ plane decreases from $0.2957(26) \AA$ to $0.0054(22) \AA$ and previously mentioned value of $\left[\mathrm{AlMe}_{2}\left({ }^{4-\mathrm{BrhH}^{2}} \mathrm{Box}_{2} \mathrm{CH}\right)\right]$ (35: $0.0022(14))$. The ${ }^{1} \mathrm{H}$ NMR spectrum of 35 in $\left[\mathrm{D}_{8}\right]$ toluene shows a singlet at $\delta-0.45 \mathrm{ppm}$ that was assigned to the aluminium bound methyl groups. Moreover, the singlet of $-\mathrm{CH}$ - backbone is significantly downfield shifted to $\delta 5.22 \mathrm{ppm}$ in comparison to the methylene ( $\delta 3.85 \mathrm{ppm}$ ) group of the ${ }^{4-\mathrm{BzhH}^{2}} \mathrm{Box}_{2} \mathrm{CH}_{2}$ ligand while the benzylic and benzoxazolyl bound protons are almost unaffected by the deprotonation. The ${ }^{13} \mathrm{C}$ NMR spectroscopic, mass spectrometric (LIFDI[+], toluene: $\mathrm{m} / \mathrm{z}(\%)$ $\left.638.3(100)[M]^{+}, 623.3(4)[M-\mathrm{Me}]^{+}, 582.3(4)\left[M-\mathrm{AlMe}_{2}\right]^{+}\right)$and elemental analyses approved the 


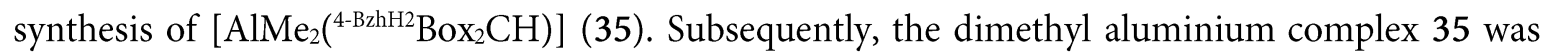
reacted with one equivalent of iodine at ambient temperature in toluene. After the solution had been stirred for $1 \mathrm{~d}$, a clear orange solution was observed, volatiles were removed under reduced pressure

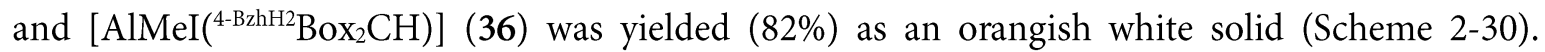
Crystals of the mono-iodinated compound 36 were grown by liquid-liquid diffusion of pentane in toluene at $-30^{\circ} \mathrm{C}$. Species 36 crystallises in the triclinic space group $P \overline{1}$ with one complex molecule in the asymmetric unit (Figure 2-50). In relation to 35, the tetrahedrally coordinated aluminium ion of 36 exhibits shorter bond lengths to the nitrogen atoms (Al1-N1 1.919(2) $\AA$, Al1-N2 1.917(2) $\AA$ ) and an expansion of the bite angle to $98.05(11)^{\circ}$ (Table 2-8). The distance of metal ion and $\mathrm{C}_{3} \mathrm{~N}_{2}$ plane (0.029(3) $\AA$ ) rises and the butterfly folding angle of $12.74(9)^{\circ}$ is substantially pronounced.

Table 2-8. Selected bond length $[\AA]$ and angles $\left[{ }^{\circ}\right]$ of aluminium complexes 35 to 39 .

\begin{tabular}{|c|c|c|c|c|c|}
\hline$L=\left({ }^{4-\mathrm{BzhH} 2} \mathrm{Box}_{2} \mathrm{CH}\right)$ & {$\left[\operatorname{AlMe}_{2}(L)\right]$} & {$[\operatorname{AlMeI}(L)]$} & {$\left[\mathrm{AlI}_{2}(L)\right]$} & {$\left[\mathrm{AlH}_{2}(L)\right]$} & {$[\operatorname{AlHI}(L)]$} \\
\hline & 35 & 36 & 37 & 38 & 39 \\
\hline $\mathrm{Al}-\mathrm{N}[\AA]$ & $\begin{array}{l}1.9509(11) \\
1.9536(11)\end{array}$ & $\begin{array}{l}1.919(2) \\
1.917(2)\end{array}$ & $\begin{array}{l}1.892(3) \\
1.896(3)\end{array}$ & $\begin{array}{l}1.9233(19) \\
1.9222(19)\end{array}$ & $\begin{array}{l}1.896(6) \\
1.891(6)\end{array}$ \\
\hline $\mathrm{Al}-\mathrm{X}$ & $\begin{array}{l}1.9659(13) \\
1.9729(14)\end{array}$ & $\begin{array}{c}2.5583(13) \\
1.952(3)\end{array}$ & $\begin{array}{l}2.4970(12) \\
2.5078(13)\end{array}$ & $\begin{array}{l}1.505(15) \\
1.484(15)\end{array}$ & $\begin{array}{c}2.562(2) \\
1.40(8)\end{array}$ \\
\hline $\mathrm{N}-\mathrm{Al}-\mathrm{N}\left[{ }^{\circ}\right]$ & $96.39(5)$ & $98.05(11)$ & $99.76(11)$ & $95.27(6)$ & $97.6(3)$ \\
\hline $\mathrm{Al} \cdots \mathrm{C}_{3} \mathrm{~N}_{2}[\AA]$ & $0.0022(14)$ & $0.029(3)$ & $0.021(3)$ & $0.2556(17)$ & $0.236(7)$ \\
\hline Folding angle $\left[{ }^{\circ}\right]$ & $5.47(7)$ & $12.74(9)$ & $6.36(8)$ & $4.09(5)$ & $3.1(3)$ \\
\hline
\end{tabular}

The ${ }^{1} \mathrm{H}$ NMR spectrum of $\left[\mathrm{AlMeI}\left({ }^{4-\mathrm{BzhH} 2} \mathrm{Box}_{2} \mathrm{CH}\right)\right]$ (36) evinces a singlet of the methyl group at $\delta-0.65 \mathrm{ppm}$, slightly upfield shifted compared to dimethyl aluminium complex 35 . The proton of the bridging group - $\mathrm{CH}-(8-\mathrm{H})$ is marginally shifted to $\delta 5.17 \mathrm{ppm}$, whereas the two benzylic protons and the benzoxazole protons in ortho position to the oxygen atom $(5-\mathrm{H}, 11-\mathrm{H})$ are deshielded and accordingly downfield shifted. In addition, the successful synthesis of 36 was confirmed by ${ }^{13} \mathrm{C} \mathrm{NMR}$ spectroscopy, mass spectrometry (LIFDI[+], toluene: $\mathrm{m} / \mathrm{z}(\%) 750.0(100)[M]^{+}, 623.3(4)[M-\mathrm{I}]^{+}$, $\left.582.2(7)[M-A l M e I+H]^{+}\right)$and elemental analysis. Reactions of 35 and two equivalents of iodine in toluene at ambient temperature led to 36 and small amounts of diiodine aluminium species 37. Finally, the synthesis of $\left[\mathrm{AlI}_{2}\left({ }^{4-\mathrm{BzhH}^{2}} \mathrm{Box}_{2} \mathrm{CH}\right)\right]$ (37) was accomplished via reaction of 35 and two equivalents of iodine, or 36 and one equivalent of iodine at $70^{\circ} \mathrm{C}$ in toluene. To determine the necessary reaction time, a sample of $\left[\mathrm{AlMe}_{2}\left({ }^{4-\mathrm{BrhH}^{2}} \mathrm{Box}_{2} \mathrm{CH}\right)\right]$ (35) was monitored by ${ }^{1} \mathrm{H}$ NMR spectroscopy (Figure 2-51) for one week. After the sample had been heated for $4 \mathrm{~d}$, species 37 could be isolated as the main product in solution alongside to mono-methylated species 36 and ${ }^{4-\mathrm{BzhH} 2} \mathrm{Box}_{2} \mathrm{CH}_{2}$ (23). Apart from the solvated species, a white precipitate was observed in the NMR sample. This white solid appeared to be the target product 37 . Therefore the reaction was upscaled by reacting the starting materials for $>4 \mathrm{~d}$ at $70^{\circ} \mathrm{C}$. After the reaction mixture had been cooled to 


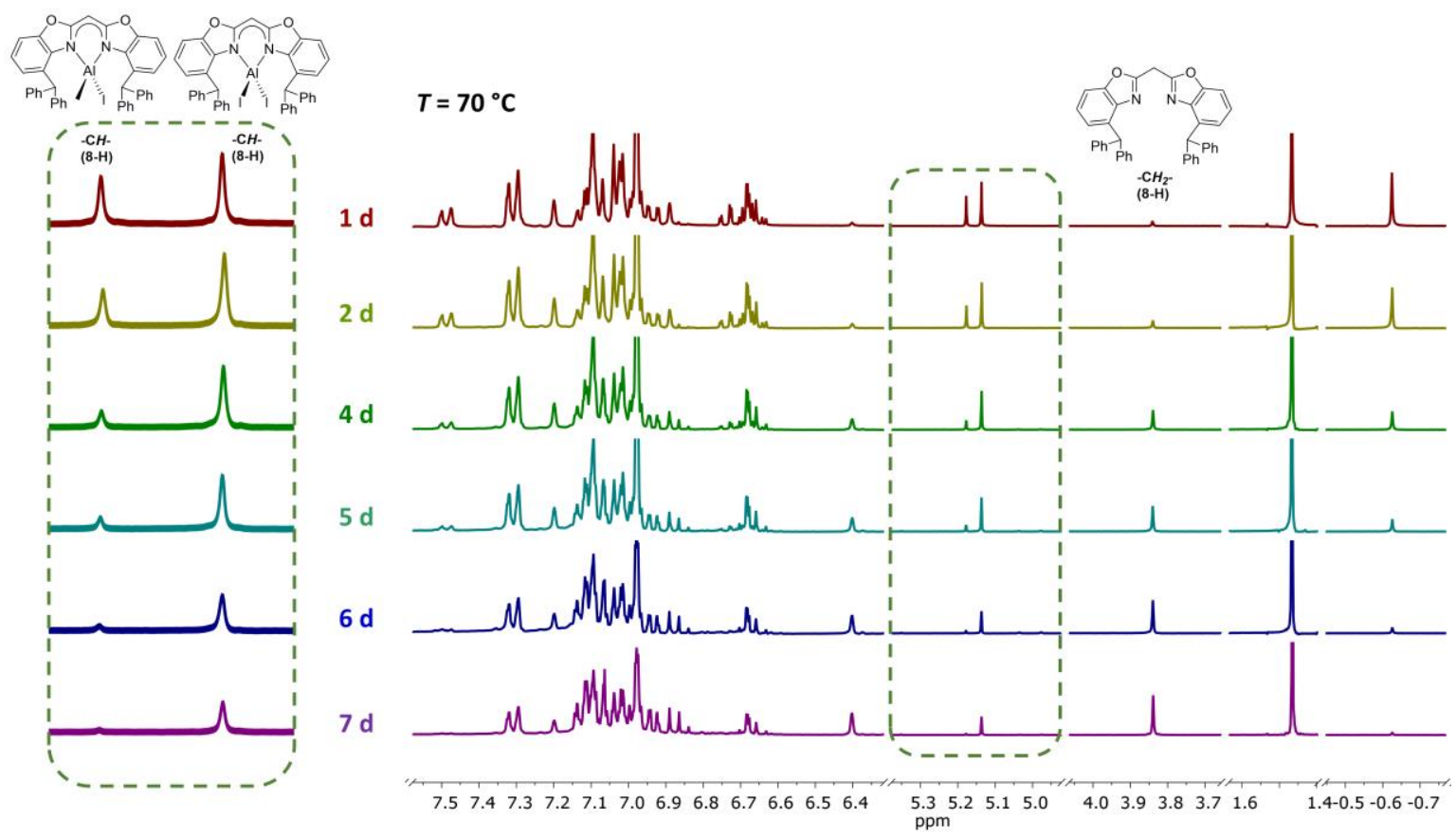

Figure 2-51. Stacked ${ }^{1} \mathrm{H}$ NMR spectra showing the reaction of 36 and two equiv. of iodine at $70^{\circ} \mathrm{C}$ for one week.

ambient temperature, $\left[\mathrm{AlI}_{2}\left({ }^{4-\mathrm{BhhH}^{2}} \mathrm{Box}_{2} \mathrm{CH}\right)\right]$ (37) precipitated. Subsequently, the brownish solution mainly consisting of mono-iodinated compound 36 and ${ }^{4-\mathrm{BzhH} 2} \mathrm{Box}_{2} \mathrm{CH}_{2}$ was separated by filtration. Afterwards, compound 37 was washed with toluene and dried under reduced pressure. Finally, $\left[\mathrm{AlI}_{2}\left({ }^{4-\mathrm{BrhH} 2} \mathrm{Box} 2 \mathrm{CH}\right)\right](37)$ was isolated as yellowish white powder (method $A$ ) in good yields (76\%).

Alternatively, the synthesis of diiodide aluminium complexes, e.g., $\left[\operatorname{AlI}_{2}(L)\right]\left(L=\{\mathrm{DippN}\}_{2} \mathrm{CR}, R=\right.$ ${ }^{t} \mathrm{Bu}^{[139]}, \mathrm{Cy}_{2} \mathrm{~N}^{[42 b]},{ }^{i} \mathrm{Pr}_{2} \mathrm{~N}^{[42 b]}$; $\{\text { DippNPPh}\}_{2} \mathrm{CH}^{[56]}$ ), could be accomplished via iodination of the corresponding alane precursors. Accordingly, ${ }^{4-\mathrm{BzhH} 2} \mathrm{Box}_{2} \mathrm{CH}_{2}$ (23) was reacted in toluene with a solution of $\mathrm{AlH}_{3} \cdot \mathrm{NMe}_{2} \mathrm{Et}$ (0.5 M toluene) at ambient temperature (Scheme 2-30, method B). After stirring at ambient temperature overnight, analytically pure aluminium hydride complex $\left[\mathrm{AlH}_{2}\left({ }^{4-\mathrm{BzhH}^{2}} \mathrm{Box}_{2} \mathrm{CH}\right)\right]$ (38) precipitated as a colourless powder (49\%). The supernatant was decanted and a second crop of micro-crystalline alane $38(10 \%)$ was isolated by reducing the solvent volume in vacuo and storing at $-30^{\circ} \mathrm{C}$ for $1 \mathrm{~d}$. Crystals of alane 38 suitable for single crystal XRD analysis were grown from a saturated fluorobenzene or toluene solution at $-30^{\circ} \mathrm{C}$ after several days. Compound 38 crystallises in the space group $P \overline{1}$ with one complex molecule and half a molecule of fluorobenzene in its asymmetric unit (Figure 2-50). The aluminium ion is $\kappa^{2}-N, N$-coordinated by the ligand and two hydride ions leading to a distorted tetrahedral coordination geometry, which was also observed in compound 36-38. The aluminium nitrogen bond lengths (Al1-N1 1.9233(14) $\AA$, Al1$\mathrm{N} 21.9222(14) \AA$ ), the bite angle $\left(95.27(6)^{\circ}\right)$, and the folding angle (4.09(5) $\AA$ ) of complex 38 (Table 2-8) are similar to $\left[\mathrm{AlH}_{2}\left({ }^{4-\mathrm{Me}} \mathrm{Box}_{2} \mathrm{CH}\right)\right](12),{ }^{[4]}$ whereas the distance from $\mathrm{Al}$ to $\mathrm{C}_{3} \mathrm{~N}_{2}$ plane is increased

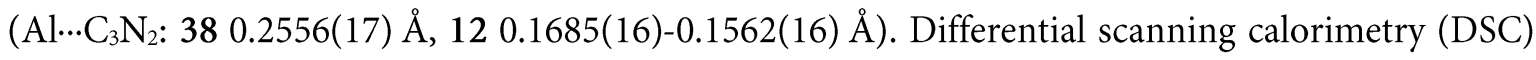
of complex $38\left(25-130^{\circ} \mathrm{C}(10.0 \mathrm{~K} / \mathrm{min}) ; 130-250^{\circ} \mathrm{C}(0.5 \mathrm{~K} / \mathrm{min})\right)$ displays the evaporation of cocrystallised fluorobenzene at about $\geq 76^{\circ} \mathrm{C}$, while the decomposition of the alane 38 was detected at 
$\geq 210^{\circ} \mathrm{C}$. This means the temperature stability of $\left[\mathrm{AlH}_{2}\left({ }^{4-\mathrm{BzhH}^{2}} \mathrm{Box}_{2} \mathrm{CH}\right)\right]$ (38) is raised in comparison

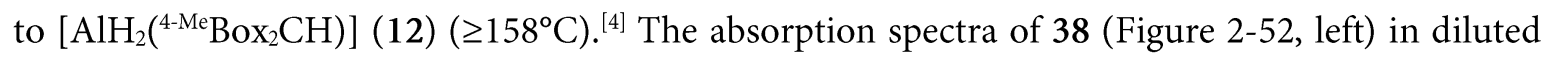
toluene solution $\left(10^{-5} \mathrm{M}\right.$ ) exhibits a maximum at $\lambda_{\max }=369 \mathrm{~nm}$ and a shoulder at $\lambda=357 \mathrm{~nm}$ (for further details, see chapter 5.4 and 5.4). The fluorescence spectra of 38 (Figure 2-52, right) displayed a emission maximum at $\lambda_{\max }=400 \mathrm{~nm}\left(\lambda_{\mathrm{ex}}=350 \mathrm{~nm}, 10^{-5} \mathrm{M}\right)$ with a redshift of $\Delta \lambda \approx 31 \mathrm{~nm}$.
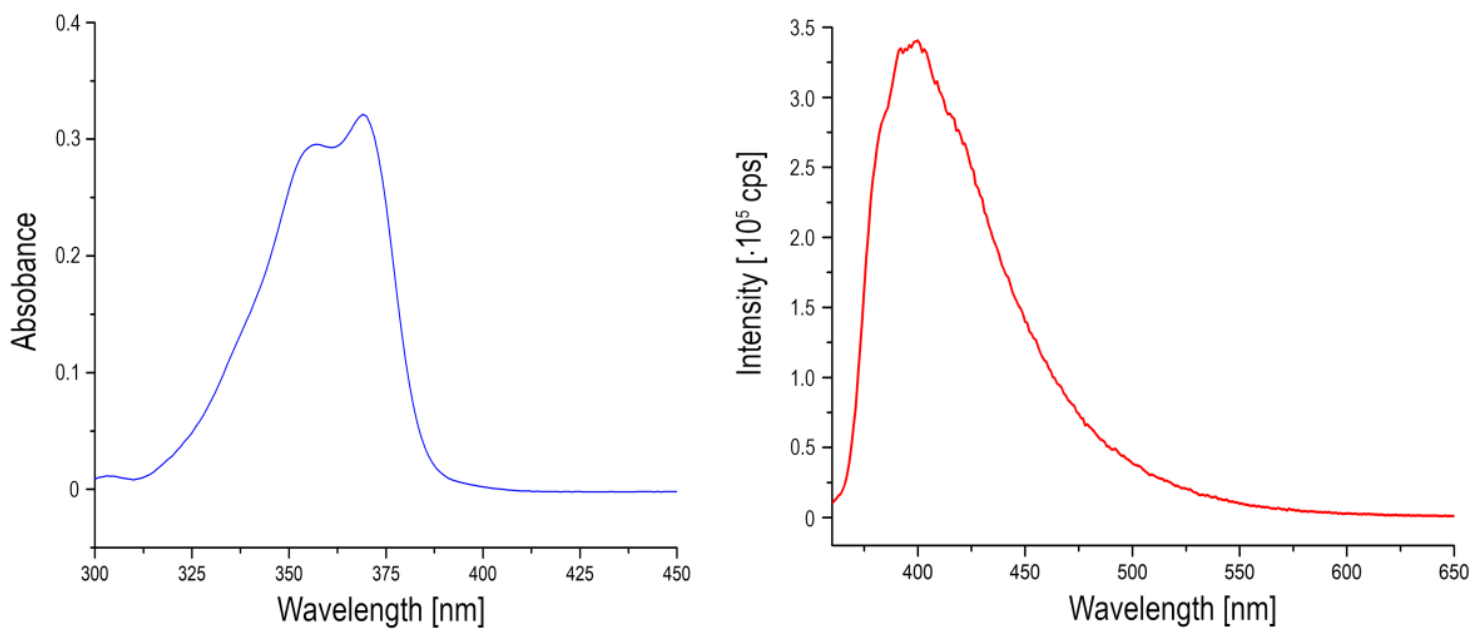

Figure 2-52. UV/Vis spectrum of $\left[\mathrm{AlH}_{2}\left({ }^{4-\mathrm{Bzh} \mathrm{Box}}{ }_{2} \mathrm{CH}\right)\right] 38$ in diluted toluene solution $(0.01 \mathrm{mM})$ (left). The figure shows an excerpt of the region around $320-475 \mathrm{~nm}$. The absorption spectra of 38 in diluted toluene solution $\left(10^{-5} \mathrm{M}\right)$ displays a maximum at $\lambda_{\max }=369 \mathrm{~nm}$ and a shoulder at $\lambda=357 \mathrm{~nm}$. Fluorescence spectrum of 38 in diluted toluene solution $(0.01 \mathrm{mM})$ exhibits a emission maximum at $\lambda_{\max }=400 \mathrm{~nm}\left(\lambda_{\mathrm{ex}}=350 \mathrm{~nm}\right)$ (right).

Solid-state fluorescence measurements of 38 (Figure 2-52, right), were carried out at ambient temperature under air. The obtained spectra displayed a broad emission maximum at $\lambda_{\max }=442 \mathrm{~nm}$ $\left(\lambda_{\mathrm{ex}}=350 \mathrm{~nm}\right)$, almost identical to $\left[\mathrm{AlH}_{2}\left({ }^{4-\mathrm{Me}} \mathrm{Box}_{2} \mathrm{CH}\right)\right]\left(\lambda_{\max }=445 \mathrm{~nm}\right) \cdot{ }^{[4]}$ The quantum yield was determined to $\phi_{\mathrm{F}}=30.6 \%$, and the obtained lifetime is in the typical range of a few nanoseconds ( $\tau=2.4 \mathrm{~ns}$ ). A decrease of intensity was detected overnight that is most likely caused by the reaction of 38 with moisture or oxygen (Figure 2-53).
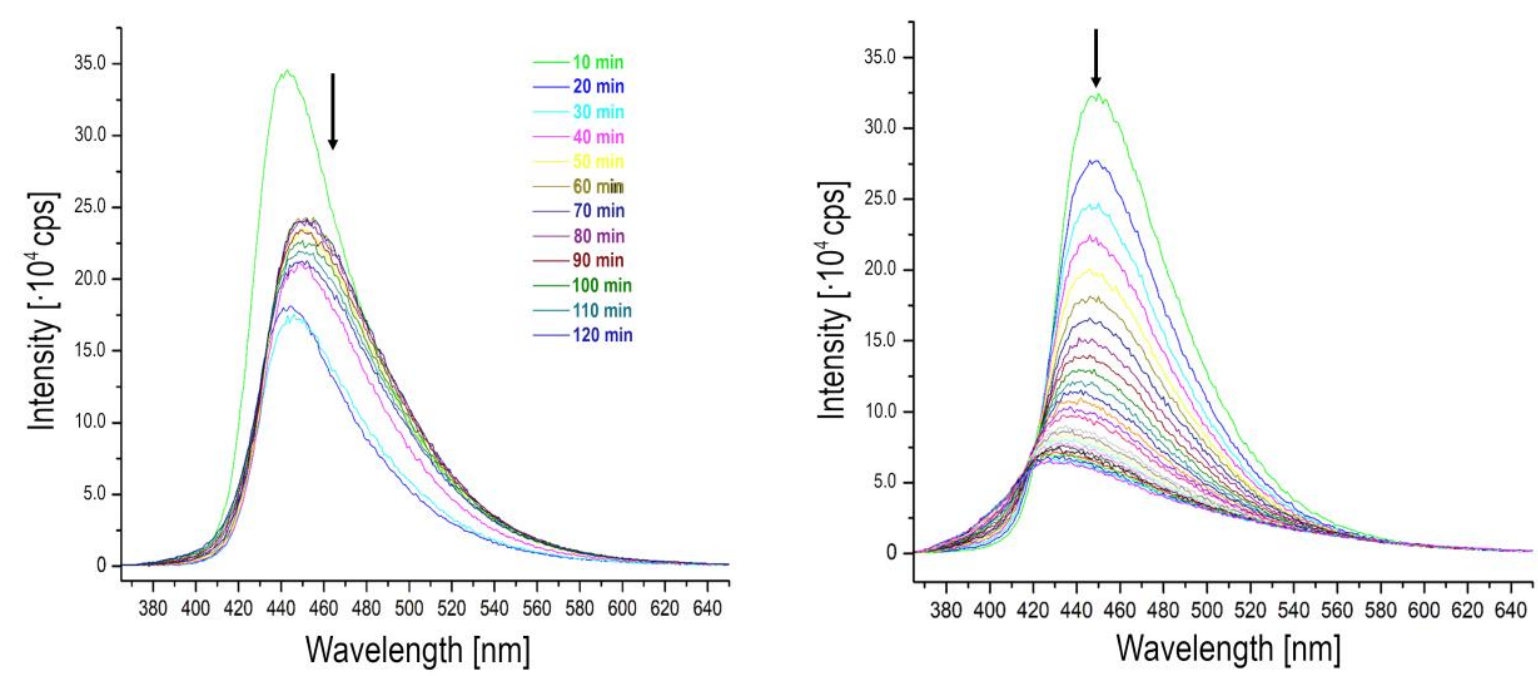

Figure 2-53. Stacked fluorescence spectra detecting the decompostion of dialane 38 over $2 \mathrm{~h}$ (measurement rate $10 \mathrm{~min}$ ) (left) and overnight (measurement rate $30 \mathrm{~min}$ ). The decrease of intensity is most likely due to the reaction of 38 with moisture or oxygen. 
The ${ }^{1} \mathrm{H}$ NMR spectrum of dialane 38 (benzene- $d_{6}$, [ $\left.\mathrm{D}_{8}\right]$ toluene) verified the deprotonation of the ligand. The signal of the former methylene group ( $\mathrm{H}-8)$ is downfield shifted to $\delta 5.03 \mathrm{ppm}$ compared

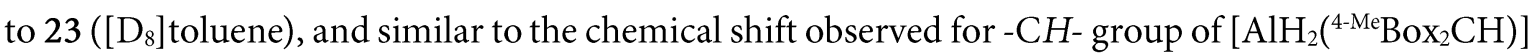
$(\delta 5.04 \mathrm{ppm})^{[4]}$. The hydride atoms $\left(\mathrm{AlH}_{2}\right)$ are detected at $\delta 4.86 \mathrm{ppm}$ as a broad singlet, while benzylic $(\delta 6.70 \mathrm{ppm})$ and benzoxazolylic protons are overlapping. The synthesis of $\left[\mathrm{AlH}_{2}\left({ }^{4-\mathrm{BzhH} 2} \mathrm{Box}_{2} \mathrm{CH}\right)\right]$ (38) could be confirmed by mass spectrometry (LIFDI[+], toluene: 610.1 (100) $\left.[M]^{+}, 608.1(35)[M-2 \mathrm{H}]^{+}, 532.1(10)\left[M-\mathrm{AlH}_{2}+\mathrm{H}\right]^{+}\right)$and elemental analysis. Subsequently, dialane 38 and 0.5 equiv. of molecular iodine were reacted in toluene at ambient temperature (Scheme 2-30). The mixture was stirred for three days, and the formed white solid of [AlHI $\left.\left({ }^{4-\mathrm{BzhH}^{2}} \mathrm{Box}_{2} \mathrm{CH}\right)\right]$ (39) was separated by filtration from the yellow solution and dried in vacuo. The solution was concentrated and stored at $-30^{\circ} \mathrm{C}$. After one night, a second crop of crystalline 39 was isolated

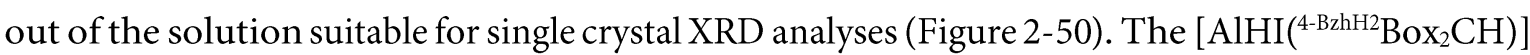
(39) was finally obtained in good yields (78\%). The mono-iodinated species crystallises in the space group Pna2 $2_{1}$ with one complex molecule and two toluene in the asymmetric unit. As reported for 3538 , the aluminium centre is coordinated in a distorted tetrahedral fashion by two nitrogen atoms as well as a hydride and an iodide ion. The aluminium nitrogen distances (Al1-N1 1.9247(19) $\AA$, Al1N2 1.9242(19) $\AA$ ) are slightly contracted compared to 38, however, similar to 36 and 37 (Table 2-8). Besides, the bite angle (N-Al-N 97.6(3) $)^{\circ}$ is somewhat widened with respect to 37 while folding angle $\left(3.1(3)^{\circ}\right)$ and $\mathrm{Al} \cdots \mathrm{C}_{3} \mathrm{~N}_{2}(0.236(7) \AA)$ are reduced. Moreover, mass spectrometry (LIFDI[+], toluene: $\left.\mathrm{m} / \mathrm{z}(\%) 736.0(100)[M]^{+}\right)$, NMR spectroscopy and elemental analysis (for detail see 4.1.10.16) approved the synthesis of $\left[\mathrm{AlHI}\left({ }^{4-\mathrm{BzhH}}{ }^{-} \mathrm{Box}_{2} \mathrm{CH}\right)\right]$ (39). Apart from that, the diiodinated aluminium complex 37 could be obtained directly via reaction of one equiv. iodine and alane 38 in toluene at ambient temperature (Scheme 2-30). It was isolated as a white precipitate (37) after the reaction mixture had been stirred for $2 \mathrm{~d}$, filtered, and dried under reduced pressure. The filtrate was concentrated, and a second crop of 37 was yielded by subsequent work-up processes (for details see 4.1.10.14). In conclusion, compound 37 can be afforded via the two synthetic routes (method $A$ and $B$ ) in moderate yields (Scheme 2-30). Crystals of $\left[\mathrm{AlI}_{2}\left({ }^{4-\mathrm{BzhH}^{2}} \mathrm{Box}_{2} \mathrm{CH}\right)\right]$ (37) suitable for single crystal XRD experiments were grown from a saturated hot toluene solution. The diiodinated species 37 crystallises in the space group $P \overline{1}$ with one complex molecule and two half molecules of toluene in its asymmetric unit. In relation to the monoiodinated species 36 or 39 slightly shorter aluminium nitrogen bonds (Al1-N1 1.892(3) A, Al1-N2 1.896(3) $\AA$ ) and an extended bite angle N1-Al-N2 $\left(99.76(11)^{\circ}\right)$ are observed. Moreover, the aluminium iodine bonds (Al-I1 2.4970(11) $\AA$, Al-I2 2.5078(13) $\AA$ ) are marginally contracted compared to mono-iodinated complexes 36 and 39, similar to the bond lengths observed in diiodinated aluminium bis(benzoxazolyl)methanide species $\left[\mathrm{AlI}_{2}\left(\mathrm{Box}_{2} \mathrm{CH}\right)\right](5)$ (Al1-I1 2.5035(9) $\AA$, Al1-I2 2.4994(9) $\left.\AA\right)^{[2]}$ or $\left[\mathrm{AlI}_{2}\left({ }^{4-\mathrm{Me}} \mathrm{Box}_{2} \mathrm{CH}\right)\right]$ (9) (Al1-I1 2.5035(9) $\AA$, Al1-I2 2.4994(9) $\AA$ ). The distance of metal ion and NacNac-like moiety (0.021(3) $\AA$ ) is not influenced by the second iodination, while the folding angle is increased to $6.36(8)^{\circ}$. Further characterisation like mass spectrometry (LIFDI[+], toluene: $\mathrm{m} / \mathrm{z}(\%) 862.1(100)[M]^{+}$), elemental analysis, and NMR spectroscopy confirmed the successful syntheses of 37 via methods $A$ and $B$. After successful syntheses and characterisation of $\left[\mathrm{AlI}_{2}\left({ }^{4-\mathrm{BzhH}^{2}} \mathrm{Box}_{2} \mathrm{CH}\right)\right](37)$, reduction experiments were 
carried out under various reaction conditions (Scheme 2-31). For this purpose, 37 was reacted with two equivalents of well-established reducing agents like $\mathrm{K}^{[14 a]}, \mathrm{Na}^{[15 c, 15 \mathrm{~d}]}$ or $\left[\mathrm{Mg}^{\mathrm{I}}\left({ }^{\mathrm{Mes}} \mathrm{NacNac}\right)\right]_{2}{ }^{[42 \mathrm{a}, 149]}$ in toluene, THF or diethyl ether at ambient temperatures. Further reactions were performed at elevated temperatures due to the poor solubility of diiodido species 37 in those solvents or using an excess of reducing agents (e.g., $\mathrm{K}, \mathrm{KC}_{8}$ ). Unfortunately, all experiments have hitherto led to inconclusive product mixtures or unreacted starting material (37).

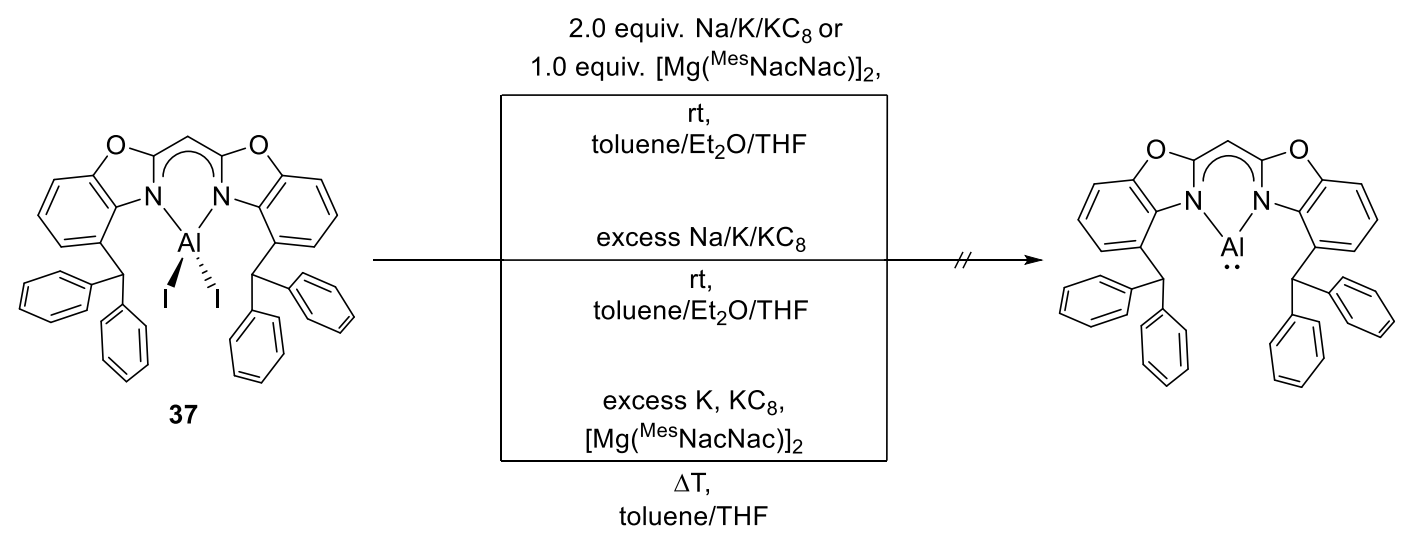

Scheme 2-31. Reduction attempts carried out for the synthesis of alanediyl based on bis(benzoxazolyl)methane ligand.

Density functional theory calculations at the pbe0/def2-TZVP $\left(M_{13}, \mathrm{C}_{3} \mathrm{~N}_{2}\right)$ and def2-SVP (all other atoms) levels of theory were carried out to optimise the full complexes $\left[M_{13}\left({ }^{4-\mathrm{BzhHH}^{2}} \mathrm{Box}_{2} \mathrm{CH}\right)\right]\left(M_{13}=\right.$ $\mathrm{Tl}$ (32), In (33), Ga (34), Al) in their singlet ground state (Table 2-9, for further detail, see Chapter 4.1.5). The reported solid-state structures ( 32 to 34 ) were used as starting points for calculations except for $M_{13}=\mathrm{Al}$, which was calculated based on the complex geometry of 34 as well as 38 . The experimental geometries of complexes 32 to 34 are reproduced well with good to excellent agreement of key bond distances (Table 2-9). Relevant orbitals for $\left[M_{13}\left({ }^{4-\mathrm{BzhH}^{2}} \mathrm{Box}_{2} \mathrm{CH}\right)\right]\left(M_{13}=\mathrm{Tl}\right.$ to $\left.\mathrm{Al}\right)$ are shown in Figure 2-54. The HOMOs of the NHC-analogues exhibit hybrid orbitals with a directional lone pair contribution that are high in s-character with some p-contribution (Table 2-9) for the lighter metals. For the heavier elements like In and Tl, the lone pair contribution is found in lowerlying occupied orbitals (Tl: HOMO-4, In: HOMO-1). Furthermore, an unoccupied metal-based porbital perpendicular to the metallaheterocylce (Tl and In: LUMO, Ga+Al: LUMO+1) coincides with already reported NacNac compounds. Considering these findings, HOMO-X to LUMO+Y energy gaps from $135 \mathrm{kcal} / \mathrm{mol}(5.86 \mathrm{eV})$ to $93.0 \mathrm{kcal} / \mathrm{mol}(4.03 \mathrm{eV})$ were calculated (Figure 2-54, Table 2-9), which show increasing values down group 13. Calculated natural population analysis (NPA) ${ }^{[208]}$ charges of $M_{13}$ cations $\left(M_{13}=\mathrm{Tl}\right.$ to $\left.\mathrm{Al}\right)$ are in line with reported values of $\left[M_{13}\left(\{\mathrm{DippNPPh}\}_{2} \mathrm{CH}\right)\right]^{[56]}$ or $\left[M_{13}\left(\{\mathrm{DippN}\}_{2} \mathrm{PPh}_{2}\right)\right]^{[52 c]}$. As expected, the two coordinating nitrogen atoms and the carbon atom of the bridging moiety (- $\mathrm{CH}-$ ) are assigned with significant negative charges similar to related lithium complexes $\left[\mathrm{Li}(\mathrm{THF})_{2}\left({ }^{4-R} \mathrm{Box}_{2} \mathrm{CH}\right)\right]^{[108 b]}\left(R={ }^{i} \mathrm{Pr},{ }^{t} \mathrm{Bu}\right)$. Although, the $M_{13}-\mathrm{N}$ bond distances in $\mathrm{Tl}$ and In species differ, a symmetric charge distributions indicate a pronounced delocalised iminoamide description within the ligands' $\mathrm{C}_{3} \mathrm{~N}_{2}$ moieties. Those observations are consistent with the values of related six-membered group $13 \mathrm{NHC}$ analogues. 

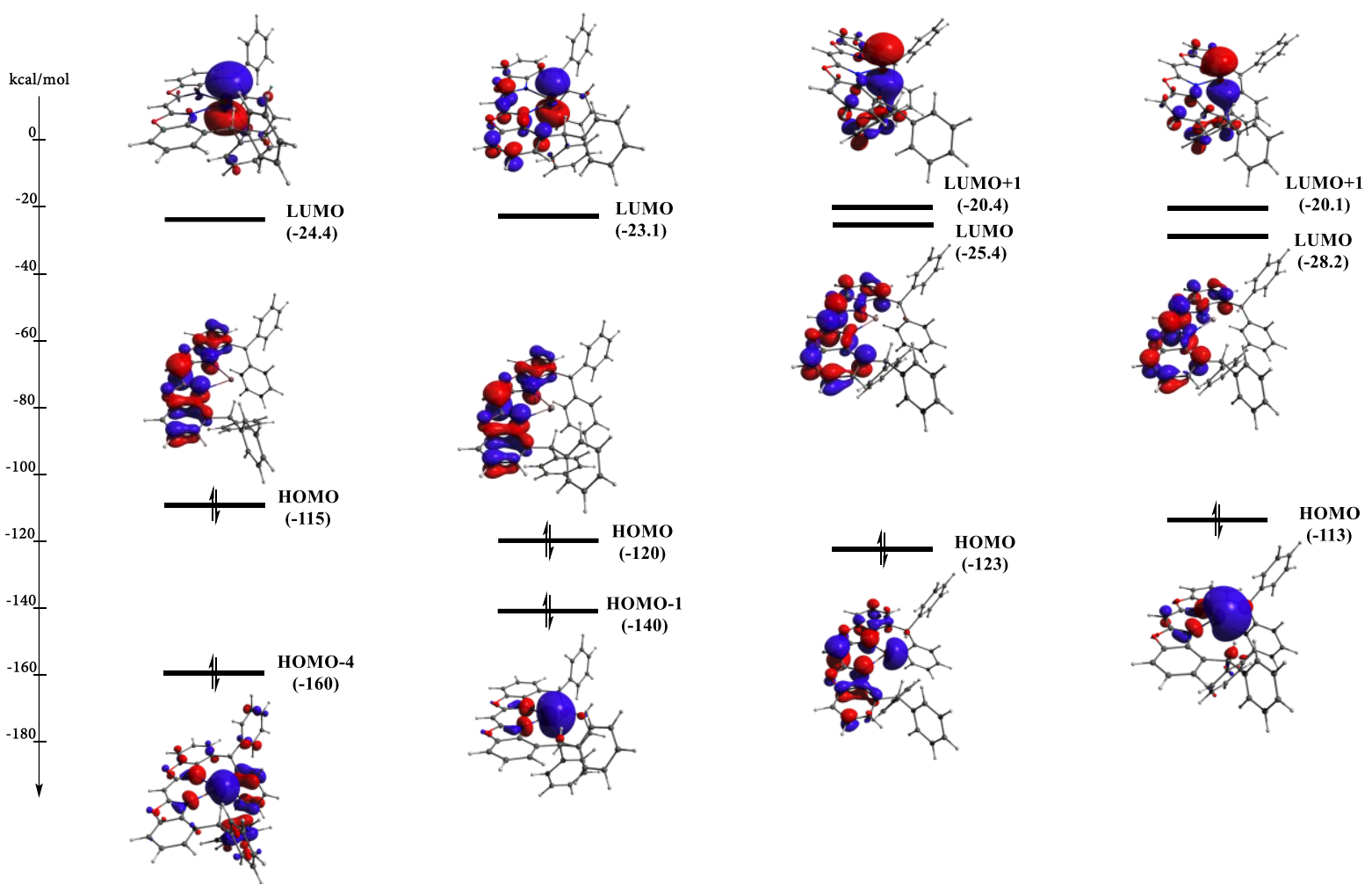

Figure 2-54. Calculated frontier molecular orbitals (isovalue $\left.0.04 \mathrm{e}^{-3}\right)$ of $\left[M_{13}\left({ }^{4-\mathrm{BzhH}} 2 \mathrm{Box}_{2} \mathrm{CH}\right)\right]\left(M_{13}=\mathrm{Tl}(32)\right.$, In (33), $\mathrm{Ga}$ (34), Al) in their singlet ground state (Table 2-9, for further detail, see Chapter 4.1.5).

Table 2-9. Selected computational (DFT) results (for further detail, see Chapter 4.1.5) for the optimised monomers $\left.\left[M_{13}{ }^{(4-B z h H 2} \mathrm{Box}_{2} \mathrm{CH}\right)\right]\left(M_{13}=\mathrm{Tl}(32)\right.$, In (33), $\left.\mathrm{Ga}(34), \mathrm{Al}\right)$.

\begin{tabular}{|c|c|c|c|c|}
\hline$L=\left({ }^{4-\mathrm{BhhH}^{2}} \mathrm{Box}_{2} \mathrm{CH}\right)$ & {$[\mathrm{Tl}(L)]$} & $\begin{array}{c}{[\operatorname{In}(L)]} \\
33\end{array}$ & $\begin{array}{c}{[\mathrm{Ga}(L)]} \\
34\end{array}$ & {$[\mathrm{Al}(L)]$} \\
\hline$M_{13-\mathrm{N}}[\AA]$ & $2.542(4.8)$ & $2.371(0.4)$ & $2.112(-3.0)$ & 2.022 \\
\hline$\left(\Delta_{\text {calc-exp }}\left[\cdot 10^{2} \AA\right]\right)$ & $2.514(-0.5)$ & $2.394(1.1)$ & $2.120(-4.0)$ & 2.019 \\
\hline $\begin{array}{l}\mathrm{N}-\mathrm{C}[\AA] \\
\left(\Delta_{\text {calc-exp }}\left[\cdot 10^{2} \AA\right]\right)\end{array}$ & $\begin{array}{l}1.332(0.3), \\
1.332(-0.1)\end{array}$ & $\begin{array}{l}1.337(0.7) \\
1.333(0.3)\end{array}$ & $\begin{array}{c}1.338(-0.1), \\
1.336(0.1)\end{array}$ & $\begin{array}{l}1.344, \\
1.341\end{array}$ \\
\hline $\begin{array}{l}\mathrm{C}-\mathrm{C}[\AA] \\
\left(\Delta_{\text {calc-exp }}\left[\cdot 10^{2} \AA\right]\right)\end{array}$ & $\begin{array}{l}1.385(-1.4), \\
1.385(-0.3)\end{array}$ & $\begin{array}{l}1.384(-1.0), \\
1.835(-1.1)\end{array}$ & $\begin{array}{l}1.383(-0.8), \\
1.382(-0.9)\end{array}$ & $\begin{array}{l}1.380 \\
1.380\end{array}$ \\
\hline $\begin{array}{l}\Delta E_{\text {номо-цимо }} \\
{[\mathrm{kcal} / \mathrm{mol}](\mathrm{eV})}\end{array}$ & $\begin{array}{l}90.2 \\
(3.91)\end{array}$ & $\begin{array}{c}96.9 \\
(4.20)\end{array}$ & $\begin{array}{c}98.0 \\
(4.25)\end{array}$ & $\begin{array}{c}84.9 \\
(3.68)\end{array}$ \\
\hline $\begin{array}{l}\Delta E_{M_{13} \mathrm{~s}-M_{13} \mathrm{p}} \\
{[\mathrm{kcal} / \mathrm{mol}](\mathrm{eV})}\end{array}$ & $\begin{array}{c}151 \\
(6.56) \\
\text { HOMO-4 to LUMO }\end{array}$ & $\begin{array}{c}117 \\
(5.08) \\
\text { HOMO-1 to LUMO }\end{array}$ & $\begin{array}{c}103 \\
(4.47) \\
\text { HOMO to LUMO+1 }\end{array}$ & $\begin{array}{c}93.0 \\
(4.03) \\
\text { HOMO to LUMO+1 }\end{array}$ \\
\hline $\begin{array}{l}\text { LP hybridization on } \\
M_{13}\end{array}$ & $\begin{array}{l}99.5 \% \mathrm{~s}, \\
0.5 \% \mathrm{p}\end{array}$ & $\begin{array}{l}97.6 \% \mathrm{~s}, \\
2.4 \% \mathrm{p}\end{array}$ & $\begin{array}{l}92.7 \% \mathrm{~s} \\
7.3 \% \mathrm{p}\end{array}$ & $\begin{array}{l}88.7 \% \mathrm{~s}, \\
11.3 \% \mathrm{p}\end{array}$ \\
\hline Charges (nat.), $M_{13}$ & 0.856 & 0.883 & 0.745 & 0.795 \\
\hline Charges (nat.), $\mathrm{N}$ & $-0.687,-0.687$ & $-0.751,-0.762$ & $-0.744,-0.741$ & $-0.790,-0.796$ \\
\hline Charges (nat.), C & $0.509,0.509$ & $0.517,0.518$ & $0.531,0.532$ & $0.539,0.539$ \\
\hline Charges (nat.), C & -0.519 & -0.514 & -0.512 & -0.508 \\
\hline
\end{tabular}




\section{SUMMARY \& OUTLOOK}

This thesis's overall objective was to investigate bis(benzoxazol-2-yl)methane derivatives (Figure 3-1) in the light of low-oxidation or low-valent group 13 complexes. Therefore, metal precursors for salt metathesis reactions were first synthesised by facile deprotonation of the ligands (Figure 3-1) with the appropriate neat alkali metals, alkali metal organics, or hydrides. First, these group 1 metal complexes were extensively studied. Subsequently, salt metathesis reaction of suitable complexes and heavier group 13 metal(I) salts resulted in different coordination species, mainly depending on the sterically demand of the corresponding ligand scaffolds. In addition, a particular focus was on the preparation of aluminium halides and hydrides, which could be converted to $\mathrm{Al}^{\mathrm{II}}$ or $\mathrm{Al}^{\mathrm{I}}$ compounds by reduction to some extent.

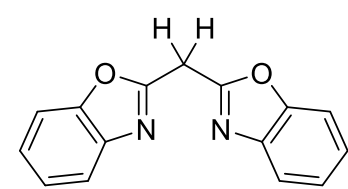

Bis(benzoxazol-2-yl)methan $\mathrm{Box}_{2} \mathrm{CH}_{2}$

$\mathrm{p} K_{\mathrm{a}}=26.89(3)$

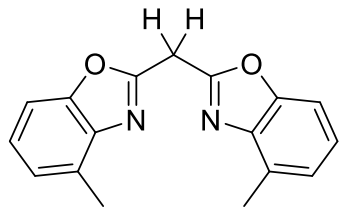

Bis(4-methyl-benzoxazol-2-yl)methan

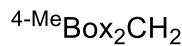

$\mathrm{p} K_{\mathrm{a}}=27.59(3)$

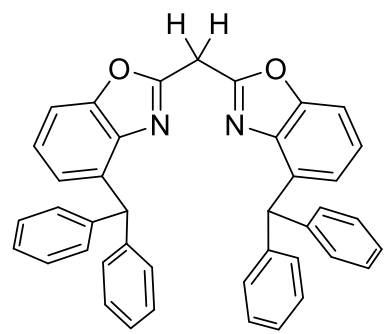

Bis(4-benzhydryl-benzoxazol-2-yl)methan

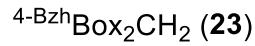

$\mathrm{p} K_{\mathrm{a}}=26.61(6)$

Figure 3-1. Bis(benzoxazol-2-yl)methane ligand scaffolds used in this work and their $\mathrm{p} K_{\mathrm{a}}$ values determined by UV/Vis spectrophotometric titration experiments in acetonitrile.

The first chapters were concerned with the unsubstituted bis(benzoxazol-yl)methane $\left(\mathrm{Box}_{2} \mathrm{CH}_{2}\right)$ ligand, priorly introduced to group 1 and 13 coordination chemistry by Dauer in our group. Nevertheless, it had not yet been possible to synthesise a dihalide aluminium species that would be a promising starting material for an $\mathrm{Al}^{\mathrm{I}}$ species. Considering this, salt metathesis reaction, which had hitherto not been investigated, was identified as a potential synthetic route for dihalide aluminium compounds. In general, THF was avoided in all salt metathesis and deprotonation/metallation reactions due to possible ether cleavage in subsequent reductions. Hence, the $\left(\mathrm{Box}_{2} \mathrm{CH}_{2}\right)$ ligand was converted to lithium precursor $\left[\mathrm{Li}\left(\mathrm{Et}_{2} \mathrm{O}\right)_{2}\left(\mathrm{Box}_{2} \mathrm{CH}_{2}\right)\right] 1$ via concerted deprotonation and lithiation via a ${ }^{n} \mathrm{BuLi}$ solution in diethyl ether. As an alternative starting material for the salt metathesis, potassium complexes 2 and 3 were prepared by deprotonation with $\mathrm{KH}$. However, these compounds are poorly soluble in toluene or diethyl ether, and therefore were not used in salt metathesis reactions with $\mathrm{Al}^{\mathrm{III}}$ halides. Akin to the study of the water-stability of $\left[\mathrm{K}\left(18\right.\right.$-crown-6) $\left.\left.{ }^{4,6-\mathrm{BBu}} \mathrm{Box}_{2} \mathrm{CH}\right) \cdot\left(\mathrm{H}_{2} \mathrm{O}\right)_{0.35}\right]$, reported by Koehne, ${ }^{[112]}$ the hydrolysis of potassium species 2 and 3 was investigated by ${ }^{1} \mathrm{H}$ NMR water titration experiments in THF. Here, an equilibrium could be observed between the deprotonated species 2 or 3 and the protonated $\mathrm{Box}_{2} \mathrm{CH}_{2}$ ligand. This, at first, seems to contradict the $\mathrm{p} K_{\mathrm{a}}$ value of unsubstituted $\mathrm{Box}_{2} \mathrm{CH}_{2}$ in acetonitrile, attained through $\mathrm{UV} / \mathrm{V}$ is spectrophotometric titration (Figure 3-1) experiments by Lõkov in Leito's group. ${ }^{[3,113]}$ An explanation of these findings might be the formation of ion pairs (contact and solvent-shared ion pairs) or larger aggregates in 
lower polarity solvents such as THF or DME ${ }^{[118]}$ Thereby, an ion pair acidity/basicity is observed that deviates from the $\mathrm{p} K_{\mathrm{a}}$ value of $\left(\mathrm{Box}_{2} \mathrm{CH}_{2}\right)$ determined by titration with organic bases. Comparable studies of Olmstead and Bordwell on 1,3-dicarbonyl (acac) compounds show that apart from the cation type, the $\mathrm{p} K_{\mathrm{a}}$ values are directly coupled to multiple parameters such as the structural or conformational properties of the ligands. ${ }^{[134]}$

Starting with the lithium precursor 1 , the two dihalide aluminium species 4 and 5 were synthesised and characterised by NMR spectroscopy, mass spectrometry (LIFDI), single crystal XRD, and elemental analysis. Considering the inadequate yields and poor solubility of $\mathbf{4}$ and $\mathbf{5}$ in solvents necessary for low-valent or -oxidation compounds, e.g., aromatic hydrocarbons or diethyl ether, the focus of this work shifted towards the somewhat bulkier methyl-substituted $\left({ }^{4-\mathrm{Me}} \mathrm{Box}_{2} \mathrm{CH}_{2}\right)$ ligand.

In the second part of this work, the lithium etherate complex $\mathbf{6}$ was initially synthesised according to the preparation of 1 . Starting from precursor 6 , the thallium species 7 was gained by facile salt metathesis with thallium triflate ( $\mathrm{Tl}^{\mathrm{I} O T f}$ ). The solid-state structure of 7 showed intermolecular $\mathrm{Tl}^{\mathrm{I}} \cdots \pi$-arene interactions, whereas metal-metal contacts could be excluded, because the limit for Tl$\mathrm{Tl}$ contacts was exceeded. The isolation of the corresponding $\operatorname{In}^{\mathrm{I}}$ analogue of 7 was hitherto not possible. However, some salt metathesis reactions with indium(I) salts led to a dark-green precipitate, which was insoluble in common solvents (THF, toluene, MeCN, acetone, ethyl acetate), and immediately decomposed in polar aprotic solvents, i.e., DMF or DMSO. Perhaps a polymeric or oligomeric indium species similar to hexameric $\left[(L) \operatorname{In} n^{\mathrm{II}}\left\{\operatorname{In}^{\mathrm{I}}(L)\right\}_{4} \operatorname{In}{ }^{\mathrm{II}} \mathrm{I}(L)\right]^{[74]}(L=(\{3,5$-xylyl$\mathrm{NCMe}\}_{2} \mathrm{CH}$ ) was formed due to the planar alignment of the bis(4-methyl-benzoxazol-2yl)methanide and its weakly pronounced steric demand perpendicular to the ligand plane. Elemental analysis and ATR-IR spectroscopy were performed in order to analyse the dark-green precipitate. However, the obtained data were inconclusive. Solid-state NMR spectroscopy or powder diffraction experiments could probably give further insights.

The salt metathesis reaction of lithium precursor 6 and "GaI" yielded a product mixture of the digallane $\mathbf{8 a}$ and the trigallane $\mathbf{8 b}$. Both species were characterised by single crystal XRD experiments and by mass spectrometry (LIFDI). Unfortunately, the two species $8 \mathbf{a}$ and $\mathbf{8 b}$ could not be selectively synthesised or separated yet. Driven by the higher abundancy and lower price of aluminium compared to the heavier group 13 elements, the emphasis shifted on low-valent aluminium compounds.

Hence, various synthetic routes were examined for bis(4-methyl-benzoxazol-2-yl)methanide diiodido aluminium (9). Since salt metathesis reaction of 6 and $\mathrm{AlI}_{3}$ accessed 9 in unsatisfactory yields, and the transformation of dimethyl aluminium complex and iodine resulted in a product mixture of mono- and diiodinated species, eventually, the most suitable method to synthesise 9 was found to be the iodination of alane 12. Moreover, compound 9 was prepared via deprotonation of

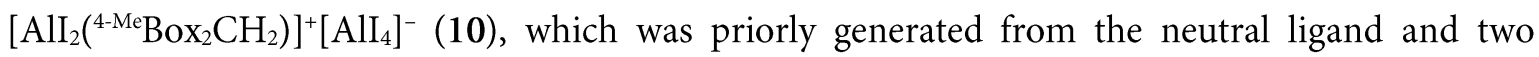
equivalents aluminium triiodide. Numerous reduction attempts were performed based on 9 by varying solvent, reducing agent, and reaction conditions. Nevertheless, only a few crystals of complex 
9 could be isolated after reduction with half equivalent of $\left[\mathrm{Mg}^{\mathrm{I}}\left({ }^{\mathrm{Mes}} \mathrm{NacNac}\right)\right]_{2}$ in toluene. In further reactions using different solvents or amounts of $\mathrm{Mg}^{\mathrm{I}}$ reducing agent, it was neither possible to increase the yields of dialuminium species 11 nor to separate the by-product, i.e., $\left[\mathrm{Mg}{ }^{\mathrm{II}}\left({ }^{\mathrm{Mes}} \mathrm{NacNac}\right)\right]_{2}$.

Furthermore, the aluminium hydride bis(4-methyl-benzoxazyl-2-yl)methanide complex (12), which exhibits solid-state fluorescence, was studied in detail by spectroscopic methods (NMR, ATR-IR, and fluorescence), DSC (differential scanning calorimetry), mass spectrometry (LIFDI), and single crystal $\mathrm{X}$-ray diffraction. Propelled by previous research on low-valent and -oxidation aluminium hydride compounds, the oxidative addition of 12 to $\left[\mathrm{Al}^{\mathrm{I}}\left({ }^{\mathrm{Dipp}} \mathrm{NacNac}\right)\right]$ resulted in, as far as we know, the first structurally characterised asymmetric dialane $\left[\left({ }^{4-\mathrm{Me}}{ }^{\mathrm{Box}}{ }_{2} \mathrm{CH}\right) \mathrm{HAl}^{\mathrm{II}}-\mathrm{Al}^{\mathrm{II}} \mathrm{H}\left({ }^{\text {Dipp }} \mathrm{NacNac}\right)\right]$ (13) (Scheme 3-1). Temperature-dependent ${ }^{1} \mathrm{H}$ NMR spectroscopy $\left(-80^{\circ} \mathrm{C}\right.$ to $\left.110^{\circ} \mathrm{C}\right)$ of 13 showed no equilibrium between the starting materials and the latter product. In order to determine which $\mathrm{H}^{-}$ion of 13 might have the higher hydricity, one equivalent of hydride abstraction agent trityl tetrakis(pentafluorophenylborate) $\left(\left[\mathrm{CPh}_{3}\right]^{+}\left[\mathrm{B}\left(\mathrm{C}_{6} \mathrm{~F}_{5}\right)\right]^{-}\right)$was added to a solution of 13 . Here, the selective abstraction of the bis(4-methyl-benzoxazol-2-yl)methanide-fragment bound hydride was observed, resulting in 14 . Interestingly, temperature-dependent ${ }^{1} \mathrm{H}$ NMR spectroscopy $\left(-20^{\circ} \mathrm{C}\right.$ to $80^{\circ} \mathrm{C}$ ) of 14 in bromobenzene- $d_{5}$ displayed no exchange of the hydride ion between the two aluminium centres. The second hydride could not be abstracted by the addition of two equivalents

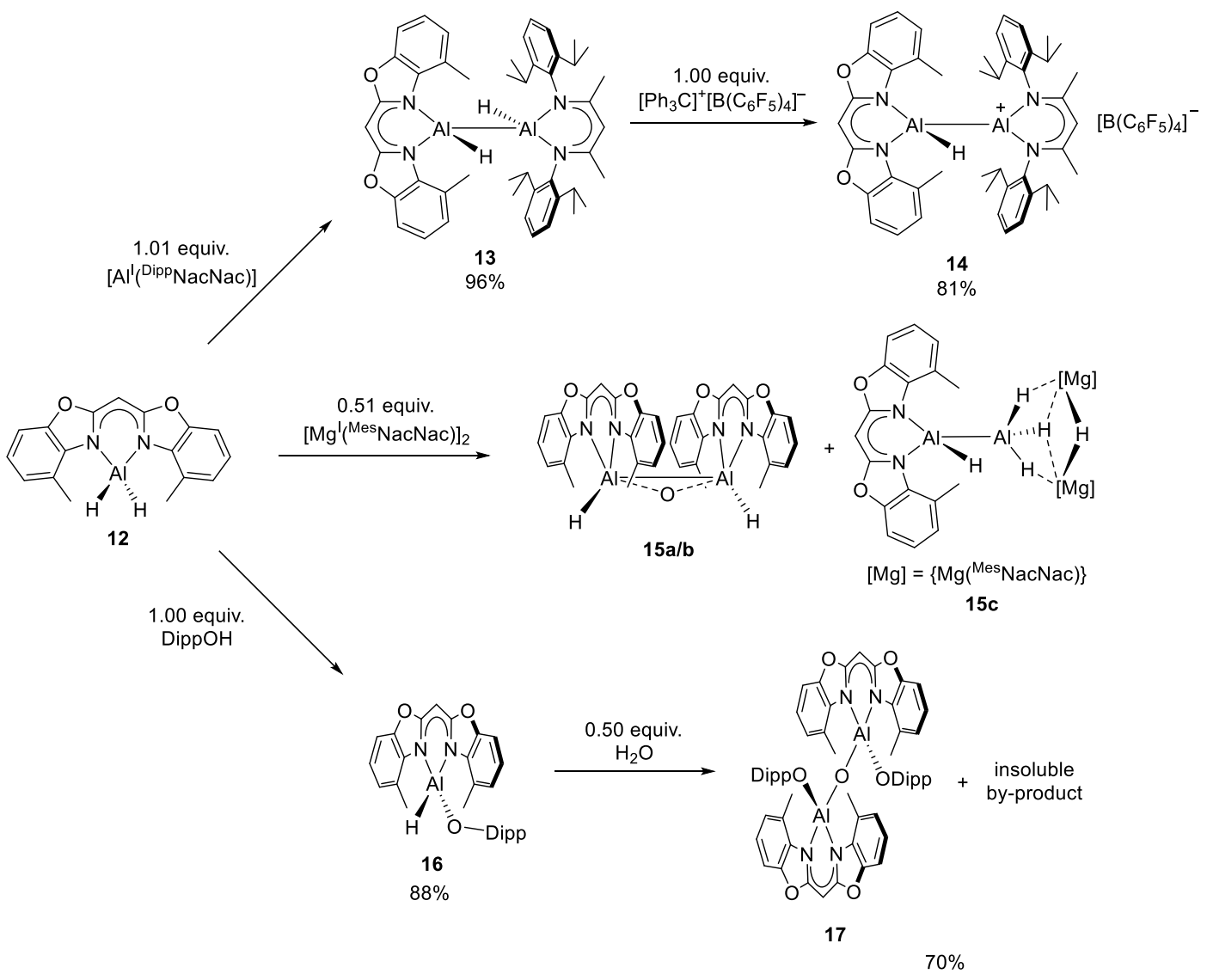

Scheme 3-1. Reactivity of the aluminium dihydrido species 12 with different substrates. 
of $\left[\mathrm{CPh}_{3}\right]^{+}\left[\mathrm{B}\left(\mathrm{C}_{6} \mathrm{~F}_{5}\right)\right]^{-}$. Accessorily, dialane 12 was reduced by half equivalent $\left[\mathrm{Mg}\left({ }^{\mathrm{Mes}} \mathrm{NacNac}\right)\right]_{2}$ in toluene (Scheme 3-1). Co-crystals suitable for single crystal XRD measurements demonstrated the formation of symmetric dialane $15 \mathrm{a}(66.5 \%)$ and dialuminoxane $15 \mathrm{~b}(33.5 \%)$, which was also confirmed by mass spectroscopy (LIFDI). Although this reaction was repeated, varying the reaction conditions in respect to solvent, concentration, temperature, and reaction time, we always found species $15 \mathrm{a}$ and $15 \mathrm{~b}$ in slightly various amounts. Oxygenation with minor impurities of $\mathrm{O}_{2}$ could lead most likely to the dialumoxane $15 \mathrm{~b}$, because of the high reactivity of $15 \mathrm{a}$. Another explanation for the formation of $15 \mathrm{~b}$ might be the hydrolysis of 12 . Moreover, the formation of an aluminium mirror was observed, caused by the disproportionation of dialane $15 \mathrm{a}$ when the reaction time was expanded over $1 \mathrm{~d}$. In a further reaction of 12 and $\left[\mathrm{Mg}^{\left.\mathrm{I}\left({ }^{\mathrm{Mes}} \mathrm{NacNac}\right)\right]_{2}}\right.$ a few crystals of $\left[\left(\left\{\left({ }^{\mathrm{Mes}} \mathrm{NacNac}\right) \mathrm{Mg}\right\}_{2}(\mu-\mathrm{H})\right)\left\{\mathrm{H}_{3} \mathrm{Al}^{\mathrm{II}}-\mathrm{Al}^{\mathrm{II}} \mathrm{H}\left({ }^{4-\mathrm{Me}} \mathrm{Box}_{2} \mathrm{CH}\right)\right\}\right]$ (15c) were isolated and characterised by single crystal X-ray analyses. Regarding the formation of dialuminoxane $15 \mathrm{~b}$, dialane 12 and half an equivalent of water were reacted to examine the complex further. However, the reaction carried out in various solvents yielded an insoluble oligomeric aluminoxane. To prevent this oligomerisation and support the formation of a molecular dialuminoxane, aluminium dihydride 12 was initially

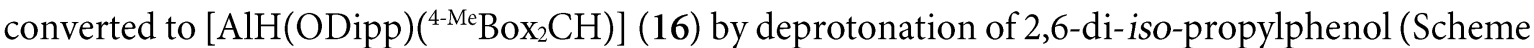
3-1). This sterically encumbered compound 16 was then reacted with half an equivalent of water resulting in various reaction products. Among them, dialuminoxane 17 could be isolated and characterised. In future research, the soluble aluminium hydride compounds 12 and 13 might be studied as hydrogen catalysts in deprotonation, insertion, and activation reactions. Thereby, the fluorescence properties of 12 in solution and the solid-state might be a valuable feature in order to monitor or investigate these reactions.

Despite the steric demand provided by ${ }^{i} \mathrm{Pr}$ - or ${ }^{t} \mathrm{Bu}$-residues at the $\mathrm{C} 4$-position in proximity to the coordination pocket of the corresponding bis(benzoxazol-2-yl)methane derivatives, mimicking the bulkiness provided by NacNac ligands, low-oxidation or low-valent group 2 or group 13 compounds could so far not be synthesised. Thus, even bulkier benzhydryl groups should be introduced at the C4-position of the bis(benzoxazol-2-yl)methane ligand scaffold.

Therefore, the third chapter focused on the synthesis and characterisation of the novel bis(4benzhydryl-benzoxazol-2-yl)methane $\left(23,{ }^{4-}{ }^{-}{ }^{-}{ }^{2} \mathrm{Box}_{2} \mathrm{CH}_{2}\right)$ ligand as well as its group 1 and 13 complexes. Ligand 23 was accessed by a six-step synthesis (18-22) starting from $o$-anisidine. Furthermore, 2-(4-benzhydrylbenzoxazol-2-yl)acetamide (23a) could be isolated as a hydrolysis side product by purification on column chromatography. To get a better knowledge of its properties and find an appropriate precursor complex for subsequent salt elimination reactions, 23 was deprotonated with alkali metal bases. The otained products were analysed by NMR spectroscopy, mass spectrometry, and single crystal XRD experiments. Crystals grown from toluene solutions 

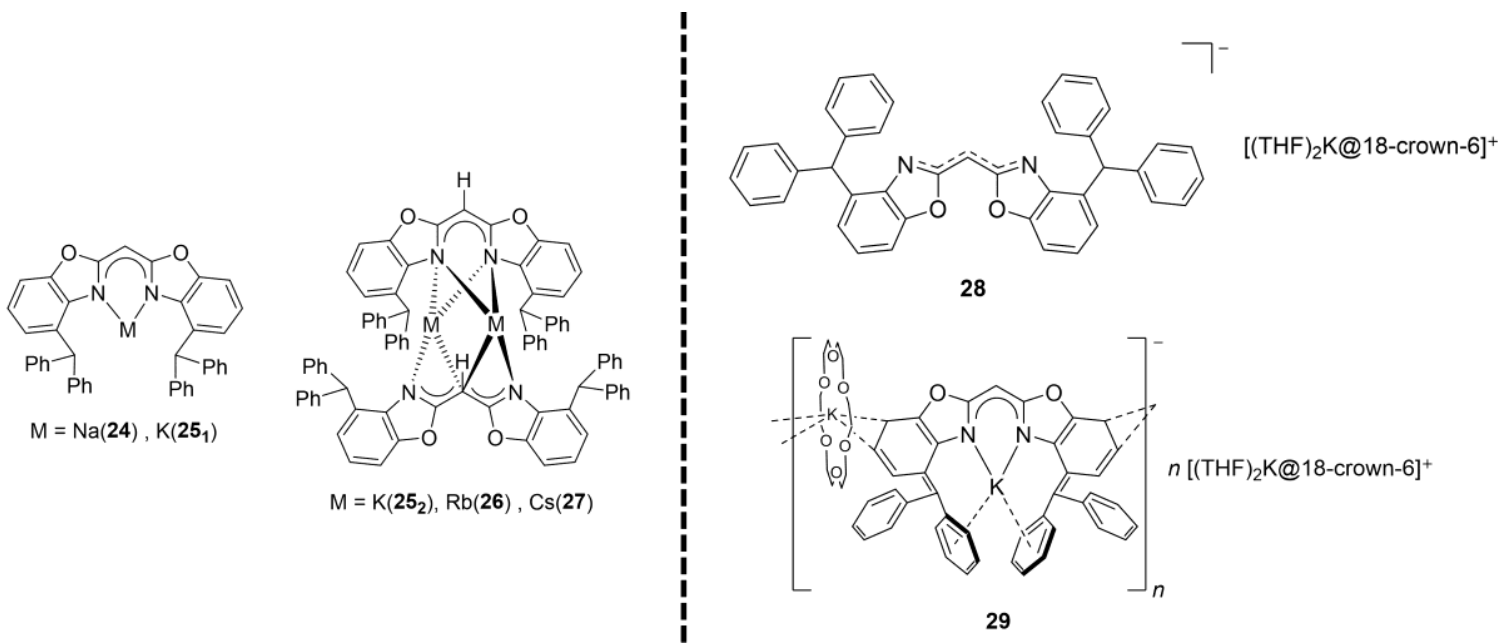

Figure 3-2. Monoanionic (24-28) and trianionic (29) alkali metal complexes on the basis of bis(4-benzhydrylbenzoxazol-2-yl)methane (23).

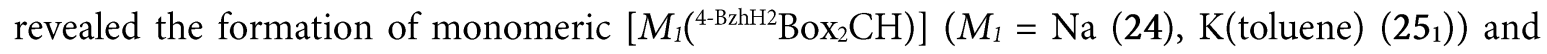
dimeric $\left.\left[M_{1}{ }^{4-{ }^{-B z h} B x_{2}} \mathrm{CH}\right)\right]\left(M_{1}=\mathrm{K}\left(25_{2}\right), \mathrm{Rb}(26), \mathrm{Cs}(27)\right)$ species in the solid-state (Figure 3-2, left). The latter alkali metal compounds showed a distorted $\kappa^{2}-N, N^{\prime}$-coordinatinated $(Z, Z)$ as well as a $(E, E)$-configurational isomers, which exhibited various polyhaptic metal arene interactions. Potassium ion sequestration of 25 via 18 -crown- 6 led to a solvent-separated ion pair 28 comprising energetically favoured monoanionic $(Z, Z)$-bis(4-benzhydryl-benzoxazol-2-yl)methanide ligand and $\left[(\mathrm{THF})_{2} \mathrm{~K}(18 \text {-crown-6) }]^{+}\right.$(Figure 3-2, right top). In addition, trifold deprotonation of 23 with three equivalents of potassium hydride and two equivalents 18-crown-6 produced polymeric

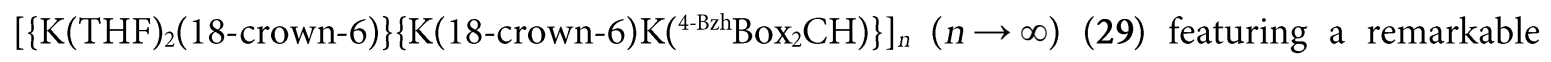
trianionic ligand. Single crystal XRD measurements of 29 showed one potassium ion to be $\eta^{2}$ coordinated by the benzoxazol-2-yl scaffolds of two adjacent trianionic ligands and a crown ether molecule (Figure 3-2, right bottom). A second potassium cation is surrounded by two nitrogen atoms in a $\kappa^{2}$-fashion and one phenyl ring of each benzhydryl moiety in a symmetrically $\eta^{6}$-fashion. Further reactions and analyses of $\mathbf{2 9}$ were challenging caused by its low solubility in most common solvents, e.g., toluene or THF. Subsequently, salt metathesis reactions of 29 and metal(III) salts such as aluminium or indium chloride were performed in THF and $\mathrm{PhF}$. The reaction of 29 and indium(III) chloride resulted in a dimeric complex 30 comprising two indium(III) centres, which are $N, N, C, C$ coordinated by the trianionic ligand $\left({ }^{4-\mathrm{Bzh}} \mathrm{Box}_{2} \mathrm{CH}\right)$ and an apical chloride atom in a distorted square pyramidal (SPy) fashion. Moreover, a THF soluble and crown ether free trianionic bis(4benzhydryliden-benzoxazol-2-yl)methanide species 31 was generated by reacting ligand 23 and a potassium tert-butoxide Lochmann-Schlosser base. Dark red crystals of 31 that were isolated in good yields (YLD: 75\%) and comprised a trifold deprotonated (E,E)-(-Bzh $\left.\mathrm{Box}_{2} \mathrm{CH}\right)$ moiety exhibiting $\eta^{3}-$ coordinations of the $\mathrm{C}_{3} \mathrm{~N}_{2}$ moiety and the two potassium ions. In future research, this compound might be utilised as a precursor for salt metathesis reactions. The tetradentate coordination pocket, somewhat similar to salen or porphyrin ligand scaffolds, could probably cause complexes containing square-planar coordinated metal centres (Figure 3-3, left). Especially, the synthesis of square-planar coordinated aluminium(III) complexes incorporating a non-innocent ligand, reported by Berben et 
al. or Greb et al., show interesting reactivities in bond activation. ${ }^{[209]}$ Alternatively, the coordination of two metal ions is conceivable, resulting, for example, in two five-membered metalla heterocycles (Figure 3-3, right).
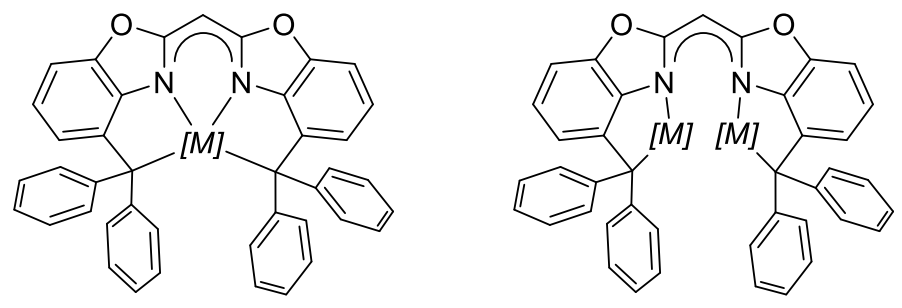

$[M]=$ fragments of main or transition metals

Figure 3-3. Coordination motifs, e.g., square planar, likely achieved with the trianionic ligand scaffold.

The two benzhydryl groups attached to the benzoxazol-2-yl scaffold might be seen as a chelate ligand incorporating two triphenylmethyl moieties, which are also known to stabilise carbonium ions or radicals (Scheme 3-2). Thus, future compounds based on bis(4-benzhydryl-benzoxazol-2yl)methane (23) might be investigated, for instance, by cyclic voltammetry.
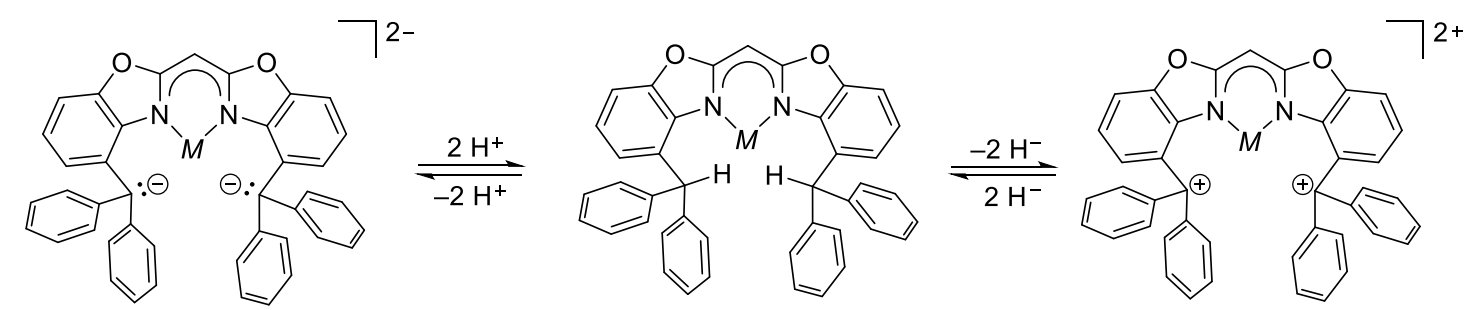

Scheme 3-2. Conceivable deprotonation and hydride abstraction reactions of bis(4-benzhydryl-benzoxazol-2yl)methane (23) based compounds.

Starting from the alkali metal species, the class of monomeric group $13 \mathrm{NHC}$ analogues 32 (Tl), 33 (In), and $34(\mathrm{Ga})$ was extended by facile salt metathesis reactions with the corresponding metal salts (Figure 3-4, left). Additionally, the gallium diiodido complex (34a) and a gallium mirror formed when the reaction with "GaI" was performed at higher temperatures or rapid heating from $-30^{\circ} \mathrm{C}$ to ambient temperature. The metallacycles were successfully characterised and additionally investigated by DFT calculations. These calculations unveiled that compound 32 to 34 comprise a largely unhybridised metal centre with a metal-based lone pair high in s character and an energetically higher-lying virtual orbital featuring significant contributions from the metal-based p-orbitals. Apart from this, two synthetic routes to aluminium diiodido species 37 were elaborated (Figure 3-4, right). In the first route, ligand 23 was converted with trimethylaluminium to species 35 , which was subsequently monoiodinated to compound 36 (Figure 3-4, right). The diiodinationed compound 37 was finally obtained by heating a mixture of 35 and two equivalents of molecular iodine at $70^{\circ} \mathrm{C}$ for 4 days. In a second synthetic approach, the alane species 38 was initially synthesised according to 12 . 

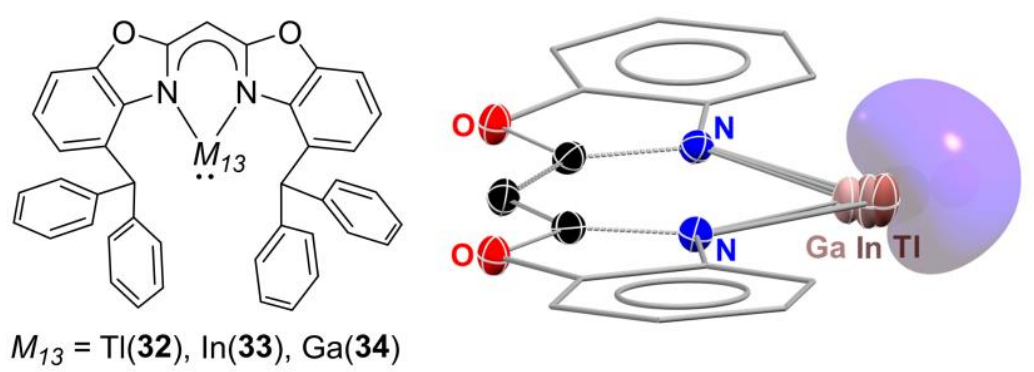

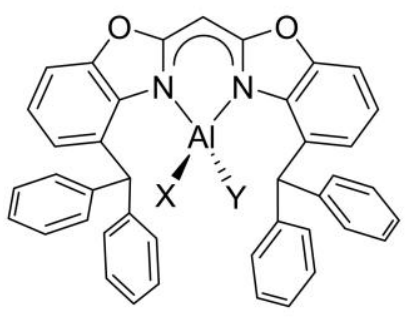

35: $X=M e, Y=M e$;

36: $X=M e, Y=I$;

37: $X=I, Y=I$;

38: $X=H, Y=H$;

39: $X=H, Y=I$;

Figure 3-4. Monomeric group 13 NHC analogues 32 (Tl), 33 (In) and 34 (Ga) (left) and aluminium complexes 35 to 39 (right) based on bis(4-benzhydryl-benzoxazol-2-yl)methane (23) ligand.

In comparison to the latter alane 12 , the temperature stability of 38 is increased from $158^{\circ} \mathrm{C}$ to $210^{\circ} \mathrm{C}$, whereas solid-state fluorescence measurements of the two aluminium dihydride compounds are almost identical. The di- and monoiodination of complexes 37 and 39 were thereafter accessed in high yields via iodiation of 38 with a half or one equivalent of molecular iodine in toluene at ambient temperature. Until now, the synthesis of a carbenoid $\mathrm{Al}^{\mathrm{I}}$ complex could not be accomplished via conventional reducing agents. Thus, future work might investigate the preparation of alanediyl based on 23 via salt metathesis reaction (Scheme 3-3) of alkali metal compounds (24-27) and accessible $\mathrm{Al}^{\mathrm{I}}$ species such as $\left[\mathrm{Al}^{\mathrm{I} C \mathrm{Cp}^{*}}\right]_{4}$. In this way, the known $\left[\mathrm{Al}^{\mathrm{I}}\left({ }^{\text {Dipp }} \mathrm{NacNac}\right)\right]$ could already be prepared in good yields by Kretschmer and co-workers. ${ }^{[68]}$ However, it is also possible that an alanediyl species based on 23 is not accessible due to the insertion of such a species into the $\mathrm{C}-\mathrm{O}$ bond (for details, see Chapter 1.1.1) as it was observed for benzofuran or $R_{2} \mathrm{BPh}(R=$ oxazol-2-ylidene). Moreover, the reactivity or acidity of benzhydrilic protons might prevent the formation of an alanediyl complex. On the other hand, the gallanediyl 34 might be further investigated towards its reactivity to substrates or as a ligand in (transition)metal complexes.
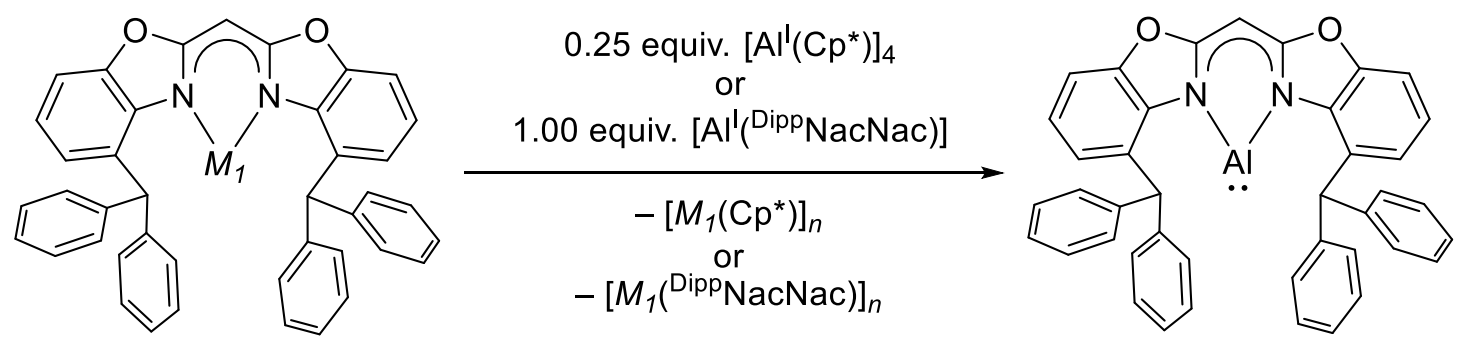

Scheme 3-3. Possible approaches for bis(benzoxazol-2-yl)methane based alanediyl complex inspired by salt metathesis reactions reported by Kretschmer and coworkers.

Althogether, within this work, the first aluminium(II) complexes were isolated based on bis(4methyl-benzoxazol-2-yl)methane ligand. Furthermore, a sterically demanding bis(4-benzhydrylbenzoxazol-2-yl)methane ligand was synthesised and introduced to coordination chemistry by group 1 and group 13 metals. Additional binding sites, which can be obtained by removal of the benzhydrilic protons might be applied to stabilise cations in the oxidation state +III. Apart from that, 
the synthesis of NHC analogues 32 to 34 revealed that 23 is a promising ligand for future low-valent metal complexes. Furthermore, present and future research deals with bis(benzoxazol-2-yl)methane derivates used in transition metal and lanthanide complexes. These compounds are already used, for instance, as benchmark systems for single molecular magnets. Additionally, the ligand platform is currently extended by BoxNac derivates, which will hopefully unite the fluorescence properties of the benzoxazol-2-yl-systems and the steric demand of the NacNac ligands. 


\section{EXPERIMENTAL PART}

Major parts of this Ph.D. thesis have been published in:

[1] J. Kretsch, Anne Kreyenschmidt, R. Herbst-Irmer, D. Stalke, “Alkali metal complexes based on bisheterocyclomethanide ligands", Dalton Trans. 2018, 36, 12606-12612. [1]

[2] J. Kretsch, R. Herbst-Irmer, D. Stalke, "Aluminum(III) Halide Complexes based on a Bis(benzoxazol-2-yl)methane Ligand", Z. Anorg. Allg. Chem. 2018, 14, 657-660. ${ }^{[2]}$

[3] J. Kretsch, I Koehne, Märt Lõkov, Ivo Leito, D. Stalke, "Bis(benzoxazol-2-yl)methanes Hounding NacNac: Varieties and Applications in Main Group Metal Coordination”, Eur. J. Inorg. Chem. 2019, 28, 3258-3264. ${ }^{[3]}$

[4] J. Kretsch, Anne Kreyenschmidt, Timo Schillmöller, R. Herbst-Irmer, D. Stalke, "Mixed LowValent Alanes from the Bis(4-methyl-benzoxazol-2-yl)methanide Ligand", Inorg. Chem. 2020, 59, 13690-13699. ${ }^{[4]}$

[5] J. Kretsch, Anne Kreyenschmidt, Timo Schillmöller, Märt Lõkov, R. Herbst-Irmer, D. Stalke, "Bis(4-benzhydryl-benzoxazol-2-yl)methane - from a Bulky NacNac Alternative to a Trianion in Alkali Metal Complexes", Chem. Eur. J. 2021, 27, 9858-9865. ${ }^{[5]}$

[6] J. Kretsch, A. Kreyenschmidt, T. Schillmöller, C. Sindlinger, R. Herbst-Irmer, D. Stalke, "Group 13 Heavier Carbene Analogs Stabilized by the Bulky Bis(4-benzhydryl-benzoxatol-2yl)methanide Ligand", Inorg. Chem. 2021, 60, 7389-7398. ${ }^{[6]}$

\subsection{Work Techniques and Experimental Setups}

\subsubsection{Handling of Air- and Moisture-Sensitive Compounds}

All manipulations involving air- and moisture sensitive compounds were carried out under an argon atmosphere using Schlenk techniques ${ }^{[210]}$ or handled in an argon glove box. All solvents used for metalation reactions and subsequent manipulations were distilled from sodium or potassium, or sodium-potassium alloy before use. Filtering of moisture sensitive compounds was carried out with the aid of self-made filter-cannulas assembled from WHATMAN fiberglass filters ( $\mathrm{GF} / \mathrm{B}, 25 \mathrm{~mm})$, which were applied with TEFLON $^{\oplus}$ tape to TEFLON $^{\oplus}$ cannulas. 


\subsubsection{Preparation and Workup of Starting Materials}

Starting materials were purchased commercially and were used as received if not stated otherwise. The unsubstituted bis(benzoxazol-2-yl)methane $\left(\mathrm{Box}_{2} \mathrm{CH}_{2}\right)$ and bis(4-methyl-benzoxazol-2-

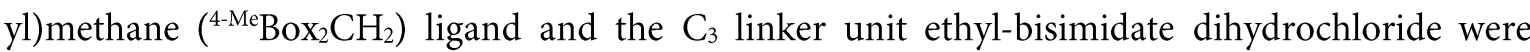
prepared according to procedures by Ben Ammar ${ }^{[121]}$, Forlani ${ }^{[103 c]}$, and Dauer ${ }^{[104,106]}$. Potassium graphite $\left(\mathrm{KC}_{8}\right)$ was prepared following a procedure by Uhlig. ${ }^{[211]}$ Low-valent NacNac based compounds $\left[\mathrm{Mg}^{\mathrm{I}}\left({ }^{\mathrm{Mes}} \mathrm{NacNac}\right)\right]_{2}^{[152]}$ and $\left[\mathrm{Al}^{\mathrm{I}}\left({ }^{\text {Dipp }} \mathrm{NacNac}\right)\right]^{[14 a]}$ were synthesised according to literature procedures. The precursor In ${ }^{\mathrm{I} O T f}$ was prepared following the procedures by Macdonald ${ }^{[71 \mathrm{a}]}$, while "GaI" $\left([\mathrm{Ga}]_{2}\left[\mathrm{Ga}_{2} \mathrm{I}_{6}\right]\right)$ was synthesised following the procedures by Green ${ }^{[50,51]}$. The organometallic reagents ${ }^{n} \mathrm{BuLi}$, as well as $t \mathrm{BuLi}$ were percolated through $\mathrm{CELITE}^{\circ}$ (frit, $\mathrm{P} 4$ ) before use to separate formed lithium hydroxide, followed by the determination of the concentration according to a procedure by Burchat. ${ }^{[212]}$ Deuterated benzene and toluene were dried over potassium $\left(65^{\circ} \mathrm{C}\right)$, THF was dried over $\mathrm{LiAlH}_{4}$, and solvents were additionally stored over molecular sieves ( $3 \AA$ ) in an argonfilled glovebox.

\subsubsection{Elemental Analyses}

Elemental analyses $(\mathrm{C}, \mathrm{H}, \mathrm{N})$ were performed on an ELEMENTAR Vario EL3 machine at the Micro-analytics Laboratory, Department of Inorganic Chemistry, University of Göttingen. Deviations between the calculated and measured mass fractions are due to the loss of lattice solvent molecules or minor impurities.

\subsubsection{IR Spectroscopy (ATR)}

IR-Spectra were measured by a AGILENT Cary 630 FTIR spectroscometer equipped with Dial Path Technology and analyzed by FTIR Microlab software. The samples were prepared in a Glovebox on the sample table and brought to contact with a the spectormeter's diamond-ATR probe head. The reported Al-H peaks ( $\tilde{v})$ were labeled according to their relative intensity: vs (very strong), s (strong), m (medium), w (weak), vw (very weak).

\subsubsection{Mass Spectrometry}

The mass spectra were recorded at the Central Analytics Department, Department of Organic Chemistry, University of Göttingen. EI-MS ${ }^{[213]}$ spectra $(70 \mathrm{eV})$ were recorded with a THERMO FINNIGAN DSQ, ESI-MS ${ }^{[214]}$ spectra with a BRUKER MicrOTOF and LIFDI-MS ${ }^{[215]}$ spectra with a Jeol AccuTOF spectrometer. The isotopic pattern of molecule ion and fragment ion peaks are correlated to their isotopes with the highest natural abundancies (e.g. ${ }^{1} \mathrm{H},{ }^{7} \mathrm{Li},{ }^{13} \mathrm{C},{ }^{14} \mathrm{~N},{ }^{16} \mathrm{O},{ }^{19} \mathrm{~F},{ }^{23} \mathrm{Na},{ }^{27} \mathrm{Al}$, $\left.{ }^{35} \mathrm{Cl} /{ }^{37} \mathrm{Cl},{ }^{39} \mathrm{~K},{ }^{69} \mathrm{Ga} /{ }^{71} \mathrm{Ga},{ }^{85} \mathrm{Rb} /{ }^{87} \mathrm{Rb},{ }^{113} \mathrm{In} /{ }^{115} \mathrm{In},{ }^{127} \mathrm{I},{ }^{133} \mathrm{Cs},{ }^{203} \mathrm{Tl} /{ }^{205} \mathrm{Tl}\right)$. 


\subsubsection{NMR Techniques and Experiments}

The NMR spectroscopic data were recorded with either a BRUKER Avance III $300 \mathrm{MHz}$ or BRUKER Ascend $400 \mathrm{MHz}$ spectrometer. All measurements were conducted at ambient temperature with samples prepared in $1-10 \%$ solutions of deuterated solvents. All spectra were processed with MESTRENOVA 6.02. The chemical shifts $(\delta)$ are given in ppm relative to TMS, using the residual solvent signals as internal standards. ${ }^{[216]}$ Coupling constants $(J)$ are reported in $\mathrm{Hz}$ and standard abbreviations indicating multiplicity are used as follows: $\mathrm{s}=\operatorname{singlet}, \mathrm{d}=$ doublet, $\mathrm{t}=$ triplet, $\mathrm{m}=$ multiplet, $\mathrm{br}=$ broad. Combined abbreviations are derived from their components (e.g. $\mathrm{dd}=$ doublet of doublets). A correct signal assignment was ascertained by applying $2 \mathrm{D}{ }^{1} \mathrm{H},{ }^{13} \mathrm{C}$ HSQC ${ }^{[217]}$ and ${ }^{1} \mathrm{H},{ }^{13} \mathrm{C}-\mathrm{HMBC}{ }^{[218]} \mathrm{NMR}$ techniques. ${ }^{1} \mathrm{H},{ }^{15} \mathrm{~N}-\mathrm{HMBC}$ spectra were recorded using a relaxation delay of 2 s. $2048 \times 256$ data points were sampled over a spectral width of $12 \mathrm{ppm}$ in $\mathrm{F} 2$ and $200 \mathrm{ppm}$ in F1. The number of scans was 2. The DOSY experiments were recorded on two spectrometers. A BRUKER Ascend 400 spectrometer equipped with an observe broadband probe with $\mathrm{z}$-axis gradient coil with a maximum gradient strength of $57 \mathrm{G} \mathrm{cm}^{-1}$ and a BRUKER Ascend III HD 400 spectrometer equipped with an inverse broadband probe with z-axis gradient coil with a maximum gradient strength of $51 \mathrm{G} \mathrm{cm}^{-1}$.

\subsubsection{1 ${ }^{1} \mathrm{H}$-DOSY-ECC-MW Estimation: Sample Preparation and Measuring Parameters}

${ }^{1} \mathrm{H}$-DOSY-ECC- $M W$ measurements and calculations were carried out in collaboration with AnneKathrin Kreyenschmidt from the group of Prof. Dr. Dietmar Stalke. All samples for a ${ }^{1} \mathrm{H}$-DOSYECC- $M W^{[166,219]}$ estimation were prepared by the addition of an equimolar amount of adamantane $(A D A M)$ as an internal reference to a solution of the analyte in $\left[\mathrm{D}_{8}\right]$ toluene. The ECC-parameters for DOSY measurements in these solvents are given in Chapter 5.3. It was shown in previous studies that for most organometallic compounds, the DSE calibration curve is the most suitable for an accurate estimation. ${ }^{[220]}$ Thus, only resulting values from the DSE and for comparison from the merge calibration curve are considered in the discussion of the DOSY results in Chapter 5.3. For measurements, sample spinning was deactivated, and the temperature was set and kept at $298 \mathrm{~K}$. The experiments were performed using the dstebpgp3s pulse sequence. ${ }^{[221]}$ The diffusion time was $\Delta=0.1 \mathrm{~s}$. The duration of the magnetic field pulse gradients $\delta / 2$ was adjusted for every compound in a range of 400-3500 $\mu$ s. After Fourier transformation, processing with a line broadening of $2 \mathrm{~Hz}$ and baseline correction, the diffusion dimension was processed with the TOPSPIN 4.0.7 software. Diffusion coefficients were calculated by GAUSSIAN fits with the T1/T2 software in TOPSPIN. For $M W$ calculation details, see Table 5-41. 


\subsubsection{2 ${ }^{1} \mathrm{H}$ NMR Water Titration Experiments}

The samples were prepared in Young NMR tubes using $22.2 \mathrm{mg}$ (2) or $20.6 \mathrm{mg}$ (3) analyte dissolved in $0.5 \mathrm{~mL}$ of $\left[\mathrm{D}_{8}\right]$ THF. Well-defined amounts of water $(0.2 \mu \mathrm{L}$ per step, range 0.2 to $2.0 \mu \mathrm{L} ; 0.4 \mu \mathrm{L}$ per step, range 2.0 to $4.0 \mu \mathrm{L} ; 0.8 \mu \mathrm{L}$ per step, range 4.0 to $8.0 \mu \mathrm{L}$ per step) were added to the NMR sample with an GILSON pipetman micropipette ( $\max =2 \mu \mathrm{L})$, and the effect of the successively increasing water content was monitored by ${ }^{1} \mathrm{H}$ NMR spectroscopy. Measurements were carried out with a Bruker Ascend $400 \mathrm{MHz}$ spectrometer.

\subsubsection{Computational Details of Electronic Structure Analyses}

Computations using density functional theory were performed using ORCA (version 4.1.). ${ }^{[142 \mathrm{~h}, 142 \mathrm{i}]} \mathrm{All}$ structures were initially optimized on RI-BP86-D3B $J^{[142 g]}$-def2SVP/J model chemistry ${ }^{[142 a, 142 b, 142 c, 142 d, 142 f]}$ in the gas phase followed by a frequency calculation on the same level of theory and thermochemical corrections were taken from these frequency calculations.

All calculations were performed on the entire molecules $(8 \mathrm{a}, 8 \mathrm{~b}, 11,13,14,32,33,34)$ with their solid-state structures as starting points except for alanediyl $\left[\mathrm{Al}^{\mathrm{I}}\left({ }^{4-\mathrm{BzhH}^{2}} \mathrm{Box}_{2} \mathrm{CH}\right)\right]$ that was calculated based on the complex geometry of $\mathbf{3 4}$ and 38. Both starting points resulted in optimised structures with a neglectable geometrical deviation. Thus only 34 based structure was used for further investigations. The complexes were optimised in their singlet states. All structures were then reoptimized using RIJCOSX-pbe $0^{[142]}-\mathrm{D} 3 \mathrm{~B}-\operatorname{def} 2 \mathrm{TZVP}\left([\mathrm{M}] \mathrm{C}_{3} \mathrm{~N}_{2}\right)+\operatorname{def} 2 \mathrm{SVP} / \mathrm{f}^{[142 \mathrm{f}]}$ (all other atoms) model chemistry, and all energies and spectroscopic properties were subsequently calculated based on these data. ECP were applied where defined as default in ORCA4.1 (In: ECP28, Tl: ECP46). Natural bond order analyses were carried out using NBO 7.0. ${ }^{[143]}$ Graphical depictions were obtained using CHEMCRAFT. ${ }^{[222]}$

The influence of the solvent on the anions of 28 was completed by single-point calculations using the $\mathrm{CPCM}_{\text {formalism }}{ }^{[7]}$ with THF as solvent. All anionic structural isomers were preoptimized in Avogardo: an open-source molecular builder and visualization tool Version 1.2.0 $0^{[8]}$ by UFF ${ }^{[9]}$ except $\left[(Z, Z)-\left({ }^{4-\mathrm{BzhH}^{2}} \mathrm{Box}_{2} \mathrm{CH}\right)\right]^{-}(\mathbf{2 8 h})$, which was obtained from single crystal XRD experiments. All structures were verified as true minima on the potential energy surface by the absence of imaginary frequency. Molecular images of 28a to $28 \mathbf{i}$ were created with IBOVIEW v20150427. ${ }^{[10]}$

\subsubsection{Single Crystal X-ray Diffraction Experiments}

\subsubsection{Crystal Selection and Handling}

The selection of air- and moisture-sensitive crystals was carried out under an argon inert gas followed by the quick transfer of the crystal to a microscope slide covered in perfluorinated polyether oil. The crystals were immediately shock cooled using the X-TEMP2 device. ${ }^{[223]}$ A suitable single crystal was selected with the help of a microscope equipped with a polarising filter. The crystal was then mounted 
either on a MITEGEN ${ }^{\odot}$ MicroMount loop or on the tip of a glass fiber, and fixed to a goniometer head where it was shock-cooled to 100(2) K by the crystal cooling device.

\subsubsection{Data Collection and Processing}

Data collection was performed either on a BRUKER SMART APEX diffractometer with an INCOATEC I $\mu$ S-Mo-Microsource $(\lambda=0.71073 \AA)$, a BRUKER TXS rotating-Mo-ande $(\lambda=0.71073 \AA)$, or a BRUKER SMART APEX with an INCOATEC I $\mu$ S-Mo-Microsource $(\lambda=0.56086 \AA) .{ }^{[224]}$ All diffractometers were equipped with an OXFORD CRYOSYSTEMS crystal cooling device, an APEX II CCD detector, and either INCOATEC Quazar or Helios mirror optics mounted on a D8-goniometer. The diffractometers were controlled by the $A P E X 2^{[225]}$ program suite. Prior to each experiment a test run (matrix-scan) was recorded to check the crystal quality, cell paramters and to determine the exposure time. Measurements were conducted in a $\omega$-scan mode with a step width of $0.5^{\circ}$ per frame and fixed $\Phi$ angles at a temperature of $100(2) \mathrm{K}$ if not stated otherwise. Determination and refinement of the unit cell was done with the $A P E X 2^{[225]}$ or $A P E X 3^{[226]}$ program suite. All data were integrated with $S A I N T^{[227]}$, and a semi-empirical absorption correction with $S A D A B S^{[228]}$ was applied. In the case of non-merohedral twinning the TWINABS ${ }^{[229]}$ programs were used. If necessary, an additional $3 \lambda$ correction of the data was carried out. ${ }^{[230]}$ Data statistics and preliminary space group determination as well as file setup for strcuture solution and refinement was performed with the program XPREP. ${ }^{[231]}$

\subsubsection{Structure Solution and Refinement}

All structures have been solved by direct methods using SHELXT within SHELTXL. ${ }^{[232]}$ Structure solution was performed on $F_{0}^{2}$, which are directly proportional the measured integrities, via SHELXL within SHELXTL using the shelXle GUI. ${ }^{[233]}$ If not stated otherwise, all C-bonded hydrogen atoms were refined isotropically on calculated positions using a riding model. The positions were geomtrically optimised and the $U_{\text {iso }}$ were constrained to 1.2. $U_{\text {eq }}$ of the pivot atom or $1.5 \mathrm{Ueg}$ of the methyl carbon atom. All refinements were carried out to minimise the function $M\left(p_{i}, k\right)$ shown in Eq. 4-1 using the weights defined in Eq. 4-2.

Eq. 4-1

$$
\begin{gathered}
M\left(p_{i}, k\right)=\sum_{H} w_{H}\left[k\left|F_{o b s}(H)\right|^{2}-\left|F_{c a l c}(H)\right|^{2}\right]^{2}=\min \\
\left(p_{i} \text { : structural parameters, } k \text { : scale factor }\right)
\end{gathered}
$$

Eq. 4-2

$$
w_{H}^{-1}=\sigma_{H}^{2} F_{o b s}^{2}+(g 1 \cdot P)^{2}+g 2 \cdot P \quad \text { with } \quad P=\frac{F_{o b s t}^{2} 0+2 F_{c a l c}^{2}}{3}
$$


The results of the refinements were verified by comparison of the calculated and the observed structure factors. Commonly used criteria are the residual $R 1$ (Eq. 4-3) and $w R 2$ (Eq. 4-4).

Eq. 4-3

$$
R 1=\frac{\sum|| F_{o b s}|-| F_{c a l c}||}{\sum\left|F_{o b s}\right|}
$$

Eq. 4-4

$$
w R 2=\sqrt{\frac{\sum w\left(F_{o b s}^{2}-F_{c a l c}^{2}\right)^{2}}{\sum w\left(F_{o b s}^{2}\right)^{2}}}
$$

Additionally, the goodness of fit $(G o F, S)$, a figure of merit showing the relation between deviation of $F_{c a l c}$ from $F_{o b s}$, and the over-determination of refined parameters is calculated with Eq. 4-5.

Eq. 4-5

$$
S=\sqrt{\frac{\sum w\left(F_{o b s}^{2}-F_{c a l c}^{2}\right)^{2}}{n-p}}
$$

( $n$ : number of reflections, $p$ : number of parameters)

The residual densities from difference Fourier analysis should be small. The residuals are generally found in the bonding regions due to the model restrictions. Higher residuals for heavy scatterers are acceptable as they arise mainly from absorption effects and Fourier truncation errors owing to the limited recorded resolution range. The highest peak and deepest hole from difference Fourier analysis are listed in the crystallographic tables. The quality of the model is depicted by the size, ellipticity and orientation of the ADPs. These ADPs should be equal in size with little ellipticity and oriented perpendicular to the bonds. All graphics were generated and plotted with the $X P^{[234]}$ program with the anisotropic displacement parameters at the 50\% probability level unless stated otherwise.

\subsubsection{Treatment of Disorder}

Structures containing disordered fragments were refined using constraints and restraints. Constraints used within this work are, for instance, the site occupation factor and the AFIX instruction that defines and constrains rigid groups.

Mathematically, restraints are treated as additional experimental observations, thus increasing the number of data to refine against. In the presence of restraints the minimisation function changes as follows:

Eq. 4-6

$$
M=\sum w\left(F_{o b s}^{2}-F_{c a l c}^{2}\right)^{2}+w_{r}\left(R_{\text {target }}-R_{\text {calc }}\right)^{2}
$$

The geometries of chemically equivalent but crystallographically independent fragments can be fitted to each other by distance restraints. Especially, the 1,2 distances (bond lengths) and 1,3 distances 
(bond angles) are set to be equal within their effective standard deviations. This is helpful for refining disordered positions as the averaging of equivalent fragments implements chemical information and distance restraints (SADI and SAME) and anisotropic displacement parameter restraints (SIMU, $D E L U$, and RIGU $)^{[137]}$ 


\subsubsection{Complex based on bis(benzoxazol-2-yl)methanide}

\subsubsection{1 \{Bis(benzoxazol-2-yl)methanide\}bis\{ethoxyethane\} lithium (1)}

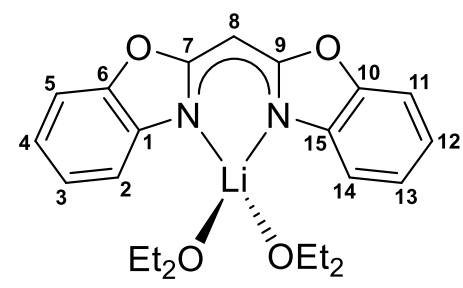

Bis(benzoxazol-2-yl)methane (530 mg, $2.12 \mathrm{mmol}, 1.00$ equiv.) was dissolved in $\mathrm{Et}_{2} \mathrm{O}(8 \mathrm{~mL})$ and cooled to $0^{\circ} \mathrm{C}$. At this temperature, a solution of ${ }^{n} \mathrm{BuLi}$ (921 $\mu \mathrm{L}, 136 \mathrm{mg}, 2.12 \mathrm{mmol}, 1.00$ equiv.) in hexane was slowly added. After the reaction mixture was stirred for $2 \mathrm{~h}$ at room temperature, volatiles were removed under reduced pressure, and a yellowish-white powder (1) was obtained. Crystals suitable for single crystal X-ray diffraction experiments were grown out of a saturated $\mathrm{Et}_{2} \mathrm{O}$ solution at $2^{\circ} \mathrm{C}$.

Chemical Formula:

Molecular weight:

Yield:

${ }^{1} \mathrm{H}$ NMR

(300 MHz, [D $\left.\left.\mathrm{D}_{8}\right] \mathrm{THF}\right)$ :

$\delta=7.13-7.10(\mathrm{~m}, 2 \mathrm{H}, 2-\mathrm{H}, 14-\mathrm{H}), 7.09-7.06(\mathrm{~m}, 2 \mathrm{H}, 5-\mathrm{H}$, 11-H), 7.01-6.95 (m, $2 \mathrm{H}, 3-\mathrm{H}, 13-\mathrm{H}), 6.84-6.79$ (m, $2 \mathrm{H}, 4-\mathrm{H}$, $14-\mathrm{H}), \quad 4.80(\mathrm{~s}, \quad 1 \mathrm{H}, 8-\mathrm{H}), \quad 3.39\left(\mathrm{q},{ }^{3} J_{\mathrm{HH}}=7.0 \mathrm{~Hz}, 8 \mathrm{H}\right.$, $\left.\mathrm{CH}_{2}\left(\mathrm{Et}_{2} \mathrm{O}\right)\right), 1.12\left(\mathrm{t},{ }^{3} J_{\mathrm{HH}}=7.0 \mathrm{~Hz}, 12 \mathrm{H}, \mathrm{CH}_{3}\left(\mathrm{Et}_{2} \mathrm{O}\right)\right)$ ppm.

${ }^{13} \mathrm{C}\left\{{ }^{1} \mathrm{H}\right\}$ NMR

(75 MHz, [D $\left.\left.\mathrm{D}_{8}\right] \mathrm{THF}\right)$ :

$\delta=171.14(\mathrm{C}-7, \mathrm{C}-9), 150.33$ (C-6, C-10), 145.46 (C-1, C-15), 123.52 (C-3, C-13), 119.67 (C-4, C-12), 113.36 (C-5, C-11), 108.54 (C-2, C-14), $66.38\left(\mathrm{O}-\mathrm{CH}_{2}\left(\mathrm{Et}_{2} \mathrm{O}\right)\right), 57.38$ (C-8), 15.74 $\left(\mathrm{CH}_{3}\left(\mathrm{Et}_{2} \mathrm{O}\right)\right)$ ppm.

${ }^{7} \mathrm{Li} \mathrm{NMR}$

$\left(116 \mathrm{MHz},\left[\mathrm{D}_{8}\right] \mathrm{THF}\right): \quad \delta=2.19 \mathrm{ppm}$.

MS (LIFDI[+], toluene)

$\mathrm{m} / \mathrm{z}(\%)$ :

$256.08(100)\left[M-2 \mathrm{Et}_{2} \mathrm{O}\right]^{+}, 506.1(4)\left[M+\left(\mathrm{Box}_{2} \mathrm{CH}\right)\right]^{+}$.

Elemental analysis

in $\%$ (calculated)

$\mathrm{C}_{23} \mathrm{H}_{29} \mathrm{LiN}_{2} \mathrm{O}_{4}$

$404.44 \mathrm{~g} / \mathrm{mol}$

$771 \mathrm{mg}, 1.91 \mathrm{mmol}, 90 \%$

$\mathrm{C}_{23} \mathrm{H}_{29} \mathrm{LiN}_{2} \mathrm{O}_{4}(404.44 \mathrm{~g} / \mathrm{mol}):$ C 68.20 (66.31), H 6.68 (7.23), N 7.58 (6.93). 


\subsubsection{2 \{Bis(benzoxazol-2-yl)methanide\}tetrahydrofuran potassium (2)}

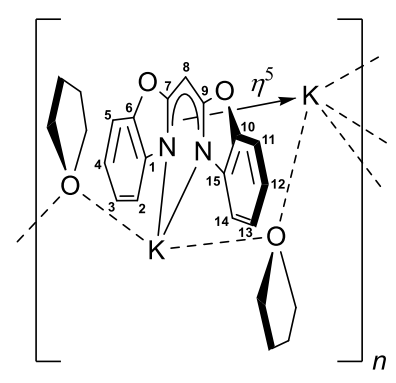

Bis(benzoxazol-2-yl)methane ( $49.3 \mathrm{mg}, 197 \mu \mathrm{mol}, 1.00$ equiv.) was dissolved in THF (4 mL) and cooled to $-30^{\circ} \mathrm{C}$. At this temperature, potassium hydride ( $15 \mathrm{mg}, 374 \mu \mathrm{mol}, 1.90$ equiv.) was added. While stirring, the reaction mixture was allowed to warm to room temperature. After $18 \mathrm{~h}$ the solution was filtered, and volatiles were removed under reduced pressure. Crystals from the yellowish solid were obtained from a concentrated solution of 2 in THF by slow evaporation.

Chemical Formula: $\quad \mathrm{C}_{19} \mathrm{H}_{17} \mathrm{KN}_{2} \mathrm{O}_{2}$

Molecular weight: $\quad 360.45 \mathrm{~g} / \mathrm{mol}$

Yield:

$55 \mathrm{mg}, 191 \mu \mathrm{mol}, 97 \%$

${ }^{1} \mathrm{H}$ NMR

$\left(300 \mathrm{MHz},\left[\mathrm{D}_{8}\right] \mathrm{THF}\right): \quad \delta=7.03-7.01(\mathrm{~m}, 2 \mathrm{H}, 2-\mathrm{H}, 14-\mathrm{H}), 7.00-6.97(\mathrm{~m}, 2 \mathrm{H}, 5-\mathrm{H}$, 11-H), 6.86-6.83 (m, $2 \mathrm{H}, 3-\mathrm{H}, 13-\mathrm{H}), 6.71-6.65(\mathrm{~m}, 2 \mathrm{H}, 4-\mathrm{H}$, 12- $\mathrm{H}), 4.64$ (s, $1 \mathrm{H}, 8-\mathrm{H}), 3.62\left(\mathrm{~m}, 4 \mathrm{H}, \mathrm{O}-\mathrm{CH}_{2}(\mathrm{THF})\right), 1.77$ (m, $\left.4 \mathrm{H}, \mathrm{CH}_{2}(\mathrm{THF})\right) \mathrm{ppm}$.

${ }^{13} \mathrm{C}\left\{{ }^{1} \mathrm{H}\right\}$ NMR

(75 MHz, [D $\left.\left.\mathrm{D}_{8}\right] \mathrm{THF}\right)$ :

$\delta=170.94$ (C-7, C-9), 150.53 (C-6, C-10), 147.86 (C-1, C-15),

122.69 (C-3, C-13), 118.61 (C-4, C-12), 113.29 (C-2, C-14),

107.76 (C-5, C-11), $68.40\left(\mathrm{O}-\mathrm{CH}_{2}(\mathrm{THF})\right), 56.98$ (C-8), 26.55

$\left(\mathrm{CH}_{2}(\mathrm{THF})\right) \mathrm{ppm}$.

MS (LIFDI[+], toluene)

$m / z(\%)$ :

249.0 (11) $[M-\mathrm{K}-\mathrm{THF}]^{+}, 288.0(100)[M-\mathrm{THF}]^{+}, \quad 327.0$ (28)

$[\mathrm{M}+\mathrm{K}-\mathrm{THF}]^{+}$.

Elemental analysis

in \% (calculated)

$\mathrm{C}_{19} \mathrm{H}_{17} \mathrm{KN}_{2} \mathrm{O}_{2}$ (360.45 g/mol): C 55.41 (63.31), H 3.31 (4.75), N 8.83

(7.77). (The deviation is due to the loss of lattice THF molecules in the drying process.) 


\subsubsection{3 \{Bis(benzoxazol-2-yl)methanide\}(18-crown-6) potassium (3)}

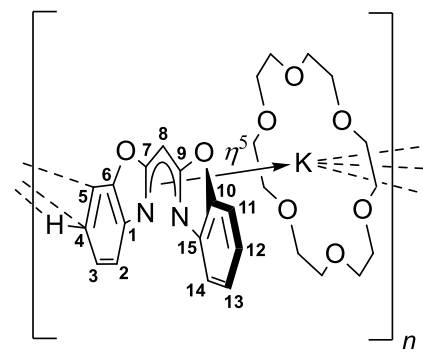

Bis(benzoxazol-2-yl)methane (100 mg, $400 \mu \mathrm{mol}, 1.00$ equiv.) was dissolved in toluene ( $5 \mathrm{~mL}$ ) and cooled to $-30^{\circ} \mathrm{C}$. At this temperature, potassium hydride $(24 \mathrm{mg}, 600 \mu \mathrm{mol}, 1.50$ equiv.) and 18 crown-6 (106 mg, $401 \mu \mathrm{mol}, 1.00$ equiv.) were added. While stirring, the reaction mixture was allowed to warm to room temperature. After $24 \mathrm{~h}$, the solution was filtered, and solvents were removed under reduced pressure. Crystals suitable for single crystal X-ray diffraction were grown out of a concentrated solution of 3 in toluene.

Chemical Formula:

Molecular weight:

Yield:

${ }^{1} \mathrm{H}$ NMR

(300 MHz, [D $\left.\left.\mathrm{D}_{8}\right] \mathrm{THF}\right)$ :
$\mathrm{C}_{27} \mathrm{H}_{33} \mathrm{KN}_{2} \mathrm{O}_{8}$

$$
552.67 \mathrm{~g} / \mathrm{mol}
$$

$181 \mathrm{mg}, 328 \mu \mathrm{mol}, 82 \%$

$\delta=7.06-7.03(\mathrm{~m}, 2 \mathrm{H}, 2-\mathrm{H}, 14-\mathrm{H}), 6.98-6.96(\mathrm{~m}, 2 \mathrm{H}, 5-\mathrm{H}$, 11-H), 6.80-6.75 (m, $2 \mathrm{H}, 5-\mathrm{H}, 11-\mathrm{H}), 6.62-6.57$ (m, $2 \mathrm{H}, 4-\mathrm{H}$, 12-H), 4.64 (s, $1 \mathrm{H}, 8-\mathrm{H}), 3.46$ (m, $24 \mathrm{H}, 18$-crown-6) ppm.

${ }^{13} \mathrm{C}\left\{{ }^{1} \mathrm{H}\right\}$ NMR

(75 MHz, $\left.\left[\mathrm{D}_{8}\right] \mathrm{THF}\right)$ :

$\delta=170.74(\mathrm{C}-7, \mathrm{C}-9), 151.06$ (C-6, C-10), 148.35 (C-1, C-15), 122.41 (C-3, C-13), 117.41 (C-4, C-12), 114.06 (C-2, C-14), 107.12 (C-5, C-11), 70.91 (18-crown-6), 57.34 (C-8) ppm.

MS (LIFDI[+], toluene)

$\mathrm{m} / \mathrm{z}(\%)$ :

$303.1(100)\left[M-\left(\mathrm{Box}_{2} \mathrm{CH}\right)\right]^{+}$.

MS (ESI[+], THF)

$\mathrm{m} / \mathrm{z}(\%)$ :

$303.1(100)\left[M-\left(\mathrm{Box}_{2} \mathrm{CH}\right)\right]^{+}$.

MS (ESI[-], THF)

$\mathrm{m} / \mathrm{z}(\%)$ :

249.1 (100) [M-K@18-crown-6 $]^{-}, 513.2$ (12) $[M-\mathrm{K}]^{-}, 521.2$ (21)

$[M]^{-}$.

Elemental analysis

in $\%$ (calculated)

$\mathrm{C}_{27} \mathrm{H}_{33} \mathrm{KN}_{2} \mathrm{O}_{8}(552.67 \mathrm{~g} / \mathrm{mol})$ : C 56.96 (56.68), H 5.65 (6.02), N 5.70 (5.07). 


\subsubsection{4 $\{$ Bis(benzoxazol-2-yl)methanide\}dichlorido aluminium (4)}<smiles></smiles>

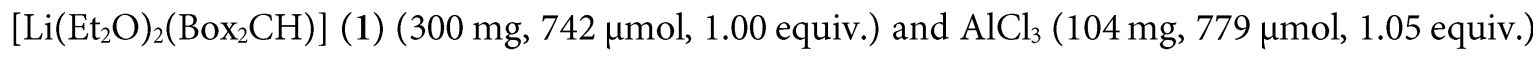
were given to a Schlenk flask in a glovebox. Toluene $(15 \mathrm{~mL})$ was added at $0^{\circ} \mathrm{C}$ and stirred for $10 \mathrm{~min}$. While stirring, the mixture was allowed to warm to ambient temperature. After it had been stirred for $48 \mathrm{~h}$ at ambient temperature, volatiles were removed under reduced pressure, and the solid was extracted with toluene $(3 \times 6 \mathrm{~mL})$. The remaining solvent was evaporated in vacuo to yield 4 as a white powder. Single crystals suitable for X-ray diffraction experiments grew from a saturated toluene solution stored at $-20^{\circ} \mathrm{C}$ in a freezer.

\section{Chemical Formula:}

Molecular weight:

Yield:

${ }^{1} \mathrm{H}$ NMR

(300 MHz, $\left[\mathrm{D}_{8}\right]$ toluene):

$\left.\delta=7.50\left(\mathrm{ddd}, 2 \mathrm{H},{ }^{3}\right)_{\mathrm{H}, \mathrm{H}}=7.8 \mathrm{~Hz},{ }^{4} J_{\mathrm{H}, \mathrm{H}}=1.1 \mathrm{~Hz},{ }^{5}\right)_{\mathrm{H}, \mathrm{H}}=0.7 \mathrm{~Hz}, 2-\mathrm{H}$, 14-H), 6.85-6.69 (m, 6 H, 3-H, 4-H, 5-H, 11-H, 12-H, 13-H), 5.05 (s, $1 \mathrm{H}, 8-\mathrm{H}) \mathrm{ppm}$.

\section{${ }^{13} \mathrm{C}\left\{{ }^{1} \mathrm{H}\right\}$ NMR}

(75 MHz, $\left[\mathrm{D}_{8}\right]$ toluene):

\section{MS (LIFDI[+], toluene)}

$m / z(\%)$ :
$\mathrm{C}_{15} \mathrm{H}_{12} \mathrm{AlCl}_{2} \mathrm{~N}_{2} \mathrm{O}_{2}$

$350.15 \mathrm{~g} / \mathrm{mol}$

$43.8 \mathrm{mg}, 125 \mu \mathrm{mol}, 17 \%$, not optimised

\section{1}

$\delta=125.61$ (C-3, C-13), 124.03 (C-4, C-12), 114.04 (C-2, C-14), 110.10 (C-5, C-11), 62.39 (C-8) ppm. Because of the low solubility of these complexes in $\left[\mathrm{D}_{8}\right]$ toluene quaternary carbon atoms were not observed in the ${ }^{13} \mathrm{C}-\mathrm{NMR}$ spectrum.

\author{
$346.0(100)[M]^{+}, 250.1\left[M-\mathrm{AlCl}_{2}+\mathrm{H}\right]^{+}(16)$.
}

\section{Elemental analysis}

in \% (calculated)

$\mathrm{C}_{15} \mathrm{H}_{12} \mathrm{AlCl}_{2} \mathrm{~N}_{2} \mathrm{O}_{2}$ (350.15 g/mol): C 51.98 (51.90), H 2.81 (2.61), N 7.65 (8.07). 


\subsubsection{5 $\{$ Bis(benzoxazol-2-yl)methanide\}diiodido aluminium (5)}

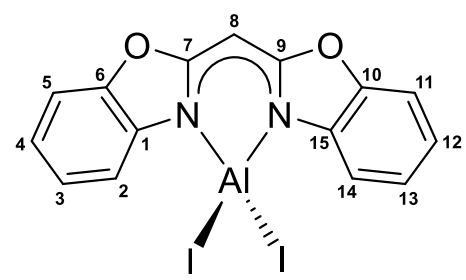

Complex 5 was prepared according to $\left[\mathrm{AlCl}_{2}\left(\mathrm{Box}_{2} \mathrm{CH}\right)\right]$ (4). Toluene $(15 \mathrm{~mL})$ was added to [ $\left.\mathrm{Li}\left(\mathrm{Et}_{2} \mathrm{O}\right)_{2}\left(\mathrm{Box}_{2} \mathrm{CH}\right)\right](1)\left(300 \mathrm{mg}, 742 \mu \mathrm{mol}, 1.00\right.$ equiv.) and $\mathrm{AlI}_{3}(318 \mathrm{mg}, 779 \mu \mathrm{mol}, 1.05$ equiv.) at $0^{\circ} \mathrm{C}$. After volatiles were removed under reduced pressure, $\left[\mathrm{AlI}_{2}\left(\mathrm{Box}_{2} \mathrm{CH}\right)\right](5)$ was obtained by extraction with toluene $(3 \times 6 \mathrm{~mL})$. Single crystals of 5 suitable for X-ray diffraction analysis were grown out of a saturated toluene solution at $-20^{\circ} \mathrm{C}$ after a few days.

Chemical Formula:

Molecular weight:

Yield:

${ }^{1} \mathrm{H}$ NMR

(300 MHz, $\left[\mathrm{D}_{8}\right]$ toluene):

$\delta=7.74\left(\mathrm{ddd}, 2 \mathrm{H},{ }^{3} J_{\mathrm{H}, \mathrm{H}}=7.8 \mathrm{~Hz},{ }^{4} J_{\mathrm{H}, \mathrm{H}}=0.7 \mathrm{~Hz},{ }^{5} J_{\mathrm{H}, \mathrm{H}}=0.7 \mathrm{~Hz}, 2-\mathrm{H}\right.$, 14-H), 6.87-6.70 (m, 6 H, 3-H, 4-H, 5-H, 11-H, 12-H, 13-H), 5.05 (s, $1 \mathrm{H}, 8-\mathrm{H}) \mathrm{ppm}$.

${ }^{13} \mathrm{C}\left\{{ }^{1} \mathrm{H}\right\}$ NMR

(75 MHz, $\left[\mathrm{D}_{8}\right]$ toluene):

$\delta=125.62(\mathrm{C}-3, \mathrm{C}-13), 124.09$ (C-4, C-12), 114.29 (C-2, C-14), 110.24(C-5, C-11), 62.84 (C-8) ppm. Because of the low solubility of these complexes in $\left[\mathrm{D}_{8}\right]$ toluene quaternary carbon atoms were not observed in the ${ }^{13} \mathrm{C}-\mathrm{NMR}$ spectrum.

MS (LIFDI[+], toluene)

$\mathrm{m} / \mathrm{z}(\%)$ :

$529.8(100)[M]^{+}, 250.1\left[M-\mathrm{AlI}_{2}+\mathrm{H}\right]^{+}$.

Elemental analysis

in $\%$ (calculated)
$\mathrm{C}_{15} \mathrm{H}_{12} \mathrm{AlI}_{2} \mathrm{~N}_{2} \mathrm{O}_{2}$

$533.06 \mathrm{~g} / \mathrm{mol}$

$35 \mathrm{mg}$, 9\%, not optimised 


\subsubsection{Complex based on bis(4-methyl-benzoxazol-2-yl)methanide}

\subsubsection{1 \{Bis(4-methyl-benzoxazol-2-yl)methanide\}bis\{ethoxyethane\}lithium (6)}

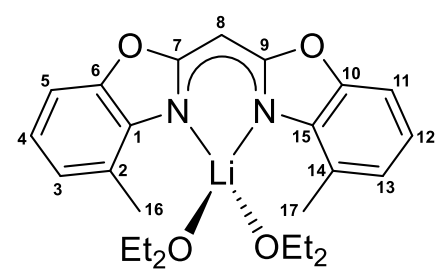

Bis(4-methyl-benzoxazol-2-yl)methane (518 mg, $1.86 \mathrm{mmol}$, 1.00 equiv.) was dissolved in $\mathrm{Et}_{2} \mathrm{O}$ $(20 \mathrm{~mL})$ and cooled to $0^{\circ} \mathrm{C}$. At this temperature, a solution of ${ }^{n} \mathrm{BuLi}(1.10 \mathrm{~mL}, 124 \mathrm{mg}, 1.93 \mathrm{mmol}$, 1.04 equiv.) in hexane was slowly added. Afterwards, the reaction mixture was stirred at $0^{\circ} \mathrm{C}$ for $15 \mathrm{~min}$ and room temperature for $2 \mathrm{~h}$. The solvent was removed under reduced pressure, and a yellowish-white powder (6) was obtained. Crystals suitable for single crystal X-ray diffraction were grown out of a saturated $\mathrm{Et}_{2} \mathrm{O}$ solution at $2^{\circ} \mathrm{C}$.

Chemical Formula:

$\mathrm{C}_{25} \mathrm{H}_{33} \mathrm{LiN}_{2} \mathrm{O}_{4}$

Molecular weight:

$432.49 \mathrm{~g} / \mathrm{mol}$

Yield:

$692 \mathrm{mg}, 1.60 \mathrm{mmol}, 86 \%$

${ }^{1} \mathrm{H}$ NMR

(300 MHz, $\left.\left[\mathrm{D}_{8}\right] \mathrm{THF}\right)$ :

$\delta=6.94\left(\mathrm{dd}, 2 \mathrm{H},{ }^{3} \mathrm{~J}_{\mathrm{HH}}=7.6 \mathrm{~Hz},{ }^{4} \mathrm{~J}_{\mathrm{HH}}=1.3 \mathrm{~Hz}, 5-\mathrm{H}, 11-\mathrm{H}\right), 6.80$ $\left(\mathrm{dd}, 2 \mathrm{H},{ }^{3} \mathrm{~J}_{\mathrm{HH}}=7.6 \mathrm{~Hz},{ }^{4} J_{\mathrm{HH}}=1.3 \mathrm{~Hz}, 3-\mathrm{H}, 13-\mathrm{H}\right), 6.72(\mathrm{dd}, 2 \mathrm{H}$, $\left.{ }^{3} J_{\mathrm{HH}}=7.6 \mathrm{~Hz}, 4-\mathrm{H}, 12-\mathrm{H}\right), 4.80(\mathrm{~s}, 1 \mathrm{H}, 8-\mathrm{H}), 3.39\left(\mathrm{q},{ }^{3} J_{\mathrm{HH}}=\right.$ $\left.7.0 \mathrm{~Hz}, 8 \mathrm{H}, \mathrm{CH}_{2}\left(\mathrm{Et}_{2} \mathrm{O}\right)\right), 2.45\left(\mathrm{~s}, 6 \mathrm{H},-\mathrm{CH}_{3}\right), 1.12\left(\mathrm{t},{ }^{3} J_{\mathrm{HH}}=\right.$ $\left.7.0 \mathrm{~Hz}, 12 \mathrm{H}, \mathrm{CH}_{3}\left(\mathrm{Et}_{2} \mathrm{O}\right)\right)$ ppm.

${ }^{13} \mathrm{C}\left\{{ }^{1} \mathrm{H}\right\}$ NMR

(75 MHz, [D $\left.\left.\mathrm{D}_{8}\right] \mathrm{THF}\right)$ :

$\delta=171.5(\mathrm{C}-7, \mathrm{C}-9), 149.9$ (C-6, C-10), 144.3 (C-1, C-15), 124.6

(C-3, C-13), 123.2 (C-2, C-14), 119.5 (C-4, C-12), 106.0 (C-5,

$\mathrm{C}-11), 66.38\left(\mathrm{O}-\mathrm{CH}_{2}\left(\mathrm{Et}_{2} \mathrm{O}\right)\right), 57.2(\mathrm{C}-8), 15.74\left(\mathrm{CH}_{3}\right), 15.74$ $\left(\mathrm{CH}_{3}\left(\mathrm{Et}_{2} \mathrm{O}\right)\right)$ ppm.

\section{${ }^{7} \mathrm{Li}$ NMR}

$\left(116 \mathrm{MHz},\left[\mathrm{D}_{8}\right] \mathrm{THF}\right): \quad \delta=2.13 \mathrm{ppm}$.

MS (LIFDI[+], THF)

$\mathrm{m} / z(\%)$ :

$284.0(100)\left[M-2 \mathrm{Et}_{2} \mathrm{O}\right]^{+}$.

Elemental analysis

in \% (calculated)

$\mathrm{C}_{21} \mathrm{H}_{23} \mathrm{LiN}_{2} \mathrm{O}_{3}(358.37 \mathrm{~g} / \mathrm{mol}): \mathrm{C} 69.23$ (70.38), H 6.54 (6.47), N 7.98 (7.82). 


\subsubsection{2 \{Bis(4-methyl-benzoxazol-2-yl)methanide\}thallium(I) (7)}

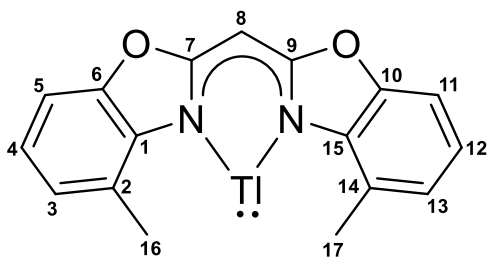

Thallium triflate ( $127 \mathrm{mg}, 359 \mu \mathrm{mol}, 1.00$ equiv.) and 6 ( $155 \mathrm{mg}, 359 \mu \mathrm{mol}, 1.00$ equiv.) were dissolved in $\mathrm{Et}_{2} \mathrm{O}(2 \times 4 \mathrm{~mL})$ and cooled to $-30^{\circ} \mathrm{C}$. After the precooled solutions were mixed under vigorous stirring at $-30^{\circ} \mathrm{C}$, the obtained reaction mixture turned dark immediately. The mixture was stirred at this temperature for $\sim 30 \mathrm{~min}$, allowed to warm to ambient temperature, and stirred for $2 \mathrm{~h}$.Volatiles were removed under reduced pressure, and a black-greyish solid was obtained. After that, toluene $(5 \mathrm{~mL})$ was added, and the suspension was ultrasonicated for $5 \mathrm{~min}$. Subsequently, the suspension was filtered by a transfer cannula equipped with a glass fiber filter, and the filter cake was extracted with toluene $(2 \times 2 \mathrm{~mL})$. The yellow-orange solution was concentrated $(\sim 5 \mathrm{~mL})$ and stored at $-30^{\circ} \mathrm{C}$. Crystals suitable for single crystal X-ray diffraction were obtained after $1 \mathrm{~d}$.

Chemical Formula:

Molecular weight:

Yield:

${ }^{1} \mathrm{H}$ NMR

(300 MHz, $\left.\left[\mathrm{D}_{8}\right] \mathrm{THF}\right)$ :

$\delta=7.03\left(\mathrm{~d}, 2 \mathrm{H},{ }^{3} J_{\mathrm{HH}}=7.2 \mathrm{~Hz}, 5-\mathrm{H}, 11-\mathrm{H}\right), 6.87\left(\mathrm{~d}, 2 \mathrm{H},{ }^{3} J_{\mathrm{HH}}=7.2 \mathrm{~Hz}\right.$, $3-\mathrm{H}, 13-\mathrm{H}), 6.80\left(\mathrm{~d}, 2 \mathrm{H},{ }^{3} J_{\mathrm{HH}}=7.6 \mathrm{~Hz}, 4-\mathrm{H}, 12-\mathrm{H}\right), 4.93(\mathrm{~s}, 1 \mathrm{H}, 8-$ $\mathrm{H}), 2.68\left(\mathrm{~s}, 6 \mathrm{H},-\mathrm{CH}_{3}\right) \mathrm{ppm}$.

${ }^{13} \mathrm{C}\left\{{ }^{1} \mathrm{H}\right\}$ NMR

(101 MHz, [D $\left.\left.\mathrm{D}_{8}\right] \mathrm{THF}\right)$ :

$\delta=168.93$ (7-C, 9-C), 149.71 (6-C, 10-C), 143.57 (1-C, 15-C), 125.61 (C-3, 11-C), 123.48 (2-C, 14-C), 120.85 (4-C, 12-C), 106.58 (5-C, 11 C), $59.57(8-\mathrm{C}), 21.33\left(-\mathrm{C}\left(\mathrm{CH}_{3}\right)_{3}\right) \mathrm{ppm}$.

MS (ESI $[+]$, toluene)

$\mathrm{m} / \mathrm{z}(\%)$ :

$482.0(100)[M]^{+}$

Elemental analysis

in \% (calculated)
$\mathrm{C}_{17} \mathrm{H}_{13} \mathrm{~N}_{2} \mathrm{O}_{2} \mathrm{Tl}$

$481.68 \mathrm{~g} / \mathrm{mol}$

$56.5 \mathrm{~g}, 117 \mu \mathrm{mol}, 33 \%$
$\mathrm{C}_{17} \mathrm{H}_{13} \mathrm{~N}_{2} \mathrm{O}_{2} \mathrm{Tl}$ (481.68 g/mol): C 44.00 (42.39), H 2.87 (2.72), N 6.08 (5.82). 
4.1.8.3 Bis(\{bis(4-methyl-benzoxazol-2-yl)methanide\}iodido gallium(II)) (8a) and bis(\{bis(4-methyl-benzoxazol-2-yl)methanide\}iodido-gallium(II))\{ bis(4-methyl-benzoxazol-2-yl)methanide\}gallium(I) (8b)
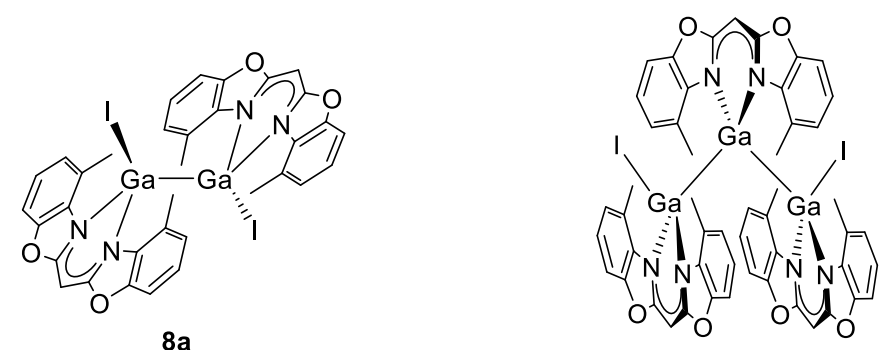

$8 \mathbf{b}$

Precursor complex 6 (256 mg, $614 \mu \mathrm{mol}, 1.00$ equiv.) and "GaI" (184 mg, $933 \mu \mathrm{mol}, 1.52$ equiv.) were weighed in a Schlenk flask. Toluene $(4 \mathrm{~mL})$ was added at $-45^{\circ} \mathrm{C}$ and stirred at this temperature for $15 \mathrm{~min}$. Then the yellow-green suspension was allowed to warm to ambient temperature and stirred overnight. The volatiles were removed under reduced pressure, and the residue was extracted with toluene $(\sim 5 \mathrm{~mL})$. Crystals suitable for single crystal XRD experiment of dimeric $\left[\mathrm{Ga}^{\mathrm{II}} \mathrm{I}\left({ }^{4-\mathrm{Me}} \mathrm{Box} 2 \mathrm{CH}\right)\right]_{2}$ (8a) and trimeric $\left.\left[\left({ }^{4-\mathrm{Me}} \mathrm{Box}_{2} \mathrm{CH}\right) \mathrm{Ga}^{\mathrm{I}} \mathrm{Ga}^{\mathrm{II}} \mathrm{I}_{2}{ }^{4-{ }^{4}} \mathrm{Box}_{2} \mathrm{CH}\right)_{2}\right](\mathbf{8 b})$ were obtained by slow evaporation of toluene from a concentrated solution. Until now, it was not possible to selectively synthesise compounds $\mathbf{8} \mathbf{a}$ and $\mathbf{8 b}$ or separate the two complexes from each other.

Chemical Formula 8a:

$\mathrm{C}_{34} \mathrm{H}_{26} \mathrm{~N}_{4} \mathrm{O}_{4} \mathrm{Ga}_{2} \mathrm{I}_{2}$

Molecular weight:

$947.86 \mathrm{~g} / \mathrm{mol}$

Chemical Formula 8b:

$\mathrm{C}_{51} \mathrm{H}_{39} \mathrm{~N}_{6} \mathrm{O}_{6} \mathrm{Ga}_{3} \mathrm{I}_{2}$

Molecular weight:

$1294.89 \mathrm{~g} / \mathrm{mol}$

MS (LIFDI[+], toluene)

$\mathrm{m} / \mathrm{z}(\%)$ :

1292.5 (15) $\left[\left({ }^{4-\mathrm{Me}} \mathrm{Box}_{2} \mathrm{CH}\right) \mathrm{Ga}^{\mathrm{I}} \mathrm{Ga}^{\mathrm{II}}{ }_{2} \mathrm{I}_{2}\left({ }^{4-\mathrm{Me}} \mathrm{Box}_{2} \mathrm{CH}\right)_{2}\right]^{+}, 946.8$ (100) $\left[\mathrm{Ga}^{\mathrm{II}} \mathrm{I}\left({ }^{4-\mathrm{Me}} \mathrm{Box}_{2} \mathrm{CH}\right)\right]_{2}^{+}$. 


\subsubsection{Bis(4-methyl-benzoxazol-2-yl)methane\}diiodido aluminium tetraiodidoaluminate (10)}

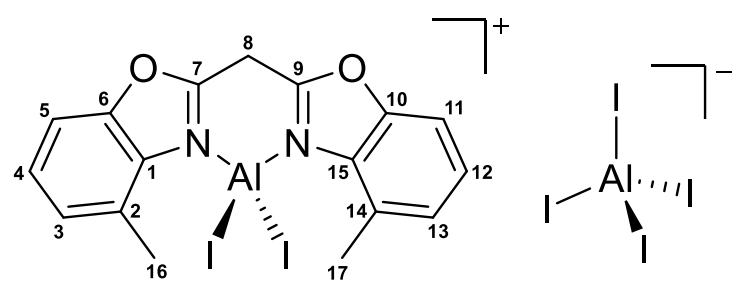

Bis(4-methyl-benzoxazol-2-yl)methane (300.0 mg, $1.08 \mathrm{mmol}, 1.00$ equiv.), as well as aluminium triiodide ( $878.9 \mathrm{mg}, 2.16 \mathrm{mmol}, 2.00$ equiv.), were filled into a Schlenk finger. Thereafter, toluene $(10 \mathrm{~mL})$ was added, and the obtained suspension was stirred at ambient temperature for $15 \mathrm{~min}$, and additionally, at $80^{\circ} \mathrm{C}$ for $3 \mathrm{~d}$. After the suspension was allowed to cool to ambient temperature, the yellow solution was filtered with a transfer cannula equipped with a glass fiber filter, and the obtained filter cake was washed with pentane $(3 \times 3 \mathrm{~mL})$. The white compound 10 was used without further purification. Crystals suitable for single crystal XRD experiments were grown out of a saturated solution of DCM by slow evaporation of the solvent.

Chemical Formula:

Molecular weight:

Yield:

${ }^{1} \mathrm{H}$ NMR

(300 MHz, $\mathrm{CD}_{2} \mathrm{Cl}_{2}$ ): $\delta=7.84\left(\mathrm{~d}, 2 \mathrm{H},{ }^{3} J_{\mathrm{HH}}=8.1 \mathrm{~Hz}, 5-\mathrm{H}, 11-\mathrm{H}\right), 7.75\left(\mathrm{dd}, 2 \mathrm{H},{ }^{3} J_{\mathrm{HH}}=\right.$ $8.1 \mathrm{~Hz}, 4-\mathrm{H}, 12-\mathrm{H}), 7.60\left(\mathrm{~d}, 2 \mathrm{H},{ }^{3} J_{\mathrm{HH}}=8.1 \mathrm{~Hz}, 4-\mathrm{H}, 12-\mathrm{H}\right), 6.13$ (s, $1 \mathrm{H}, 8-\mathrm{H}), 3.30\left(\mathrm{~s}, 6 \mathrm{H},-\mathrm{CH}_{3}\right) \mathrm{ppm}$.

${ }^{13} \mathrm{C}\left\{{ }^{1} \mathrm{H}\right\}$ NMR

(75 MHz, $\mathrm{CD}_{2} \mathrm{Cl}_{2}$ ):

$$
\begin{aligned}
& \delta=161.31(\mathrm{C}-7, \mathrm{C}-9), 150.47 \text { (C-6, C-10), } 132.31 \text { (C-1, C-15), } \\
& 131.75(\mathrm{C}-3, \mathrm{C}-13), 130.80(\mathrm{C}-4, \mathrm{C}-12), 129.45(\mathrm{C}-2, \mathrm{C}-14), \\
& 111.21(\mathrm{C}-5, \mathrm{C}-11), 31.14(\mathrm{C}-8), 24.13\left(-\mathrm{CH}_{3}\right) \mathrm{ppm} .
\end{aligned}
$$

${ }^{1} \mathrm{H},{ }^{15} \mathrm{~N}$ HMBC

$\left(41 \mathrm{MHz}, \mathrm{CD}_{2} \mathrm{Cl}_{2}\right.$ ):

$\delta=-185.68 \mathrm{ppm}$.

${ }^{27} \mathrm{Al} \mathrm{NMR}$

$\left(130 \mathrm{MHz}, \mathrm{CD}_{2} \mathrm{Cl}_{2}\right)$ :

$\delta=77.73\left(\omega_{1 / 2}=515 \mathrm{~Hz}, \mathrm{~N}_{2} \mathrm{AlI}_{2}\right),-25.74\left(\omega_{1 / 2}=62 \mathrm{~Hz},\left[\mathrm{AlI}_{4}\right]^{-}\right) \mathrm{ppm}$.

Elemental analysis

in \% (calculated)
$\mathrm{C}_{17} \mathrm{H}_{14} \mathrm{Al}_{2} \mathrm{I}_{6} \mathrm{~N}_{2} \mathrm{O}_{2}$ (1093.70 g/mol): C 18.78 (18.67), H 1.34 (1.29), $\mathrm{N}$ 2.74 (2.56). 


\subsubsection{5 \{Bis(4-methyl-benzoxazol-2-yl)methanide\}diiodido aluminium (9)}

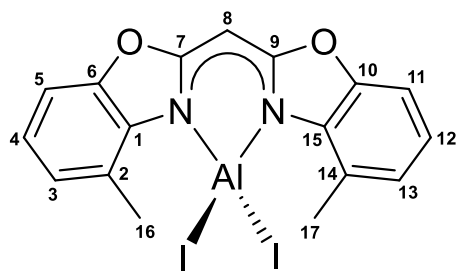

Method A: Complex 1 ( $248 \mathrm{mg}, 573 \mu \mathrm{mmol}, 1.00$ equiv.) was dissolved in toluene ( $5 \mathrm{~mL}$ ) and cooled to $0^{\circ} \mathrm{C}$. Afterwards, freshly sublimated aluminium iodide $(245 \mathrm{mg}, 602 \mu \mathrm{mmol}, 1.05$ equiv.) was added under the counter flow of inert gas and stirred for $\sim 30 \mathrm{~min}$. While stirring, the mixture was allowed to warm to ambient temperature. After $18 \mathrm{~h}$, volatile residues were removed under reduced pressure, and the obtained solid was extracted with toluene $(3 \times 5 \mathrm{~mL})$. Once again, volatiles were evaporated, and white-yellowish powder of complex 9 was dried under fine vacuum ( $31 \mathrm{mg}, 55 \mu \mathrm{mol}$, $10 \%)$. Crystals of aluminium diiodido complex 9 suitable for single crystal XRD experiments were grown out of a saturated solution of toluene at $-20^{\circ} \mathrm{C}$.

Method B: [AlMe $\left.{ }_{2}{ }^{\left.4-\mathrm{Me} B o x_{2} \mathrm{CH}\right)}\right)(306.0 \mathrm{mg}, 917.0 \mu \mathrm{mmol}, 1.00$ equiv. $)$ was dissolved in toluene $(6 \mathrm{~mL})$. Iodine $(232.6 \mathrm{mg}, 916.4 \mu \mathrm{mol}, 1.00$ equiv.) was added at ambient temperature under argon counter flow. The purple solution was stirred at ambient temperature for $3 \mathrm{~h}$ and overnight at $70^{\circ} \mathrm{C}$. Thereafter, a second equivalent of iodine ( $232.6 \mathrm{mg}, 916.4 \mu \mathrm{mol}, 1.00$ equiv.) was added to the slightly orange-red suspension with a white precipitate. The suspension was heated $5 \mathrm{~d}$ at $70^{\circ} \mathrm{C}$, allowed to cool to ambient temperature, and filtered by a transfer cannula equipped with a glass fiber filter. The obtained brownish solid was washed with hexane $(4 \mathrm{~mL}, 3 \times 2 \mathrm{~mL})$ and dried under fine vacuum. Compound 9 was isolated with impurities up to $50 \%$ of $\left[\mathrm{AlMeI}\left({ }^{4-\mathrm{Me}} \mathrm{Box}_{2} \mathrm{CH}\right)\right]$ according to ${ }^{1} \mathrm{H}$ NMR experiments (9+[AlMeI $\left.\left.\left({ }^{4-\mathrm{Me}} \mathrm{Box}_{2} \mathrm{CH}\right)\right]: 338 \mathrm{mg}, 278 \mu \mathrm{mol}, 83 \%\right)$.

Method C: Compound 10 (406.0 mg, $371 \mu \mathrm{mmol}, 1.00$ equiv.) as well as potassium hydride ( $16.0 \mathrm{mg}$, $408 \mu \mathrm{mmol}, 1.10$ equiv.) were weighed in a Schlenk flask. Toluene $(15 \mathrm{~mL})$ was added, and the mixture was stirred $2 \mathrm{~d}$ at $105^{\circ} \mathrm{C}$. Subsequently, the suspension, containing a white precipitate and yellow solution, was allowed to cool to ambient temperature and filtered by a transfer cannula equipped with a glass fiber filter. Volatiles were removed in vacuo, and obtained off-white solid 9 (155 mg, $278 \mu \mathrm{mol}$, 75\%) was dried under medium vacuum.

Method D: $\left[\mathrm{AlH}_{2}\left({ }^{4-\mathrm{Me}} \mathrm{Box}_{2} \mathrm{CH}\right)\right](12)(191.1 \mathrm{mg}, 632.9 \mu \mathrm{mol}, 1.00$ equiv.) was dissolved in toluene (6 mL), iodine ( $158.4 \mathrm{mg}, 624.1 \mu \mathrm{mol}, 1.00$ equiv.) was added, and the mixture was stirred at ambient temperature for $2 \mathrm{~d}$. Dissolving iodine immediately reacted with alane 12 while dihydrogen gas formation was observed. The formation of a yellow solution and a white precipitate was observed. Volatile residues were evaporated, and the yellowish-white solid was dried under reduced pressure (326 mg, $584 \mu \mathrm{mol}, 94 \%$ ).
Chemical Formula:
$\mathrm{C}_{17} \mathrm{H}_{13} \mathrm{AlI}_{2} \mathrm{~N}_{2} \mathrm{O}_{2}$
Molecular weight:
$558.09 \mathrm{~g} / \mathrm{mol}$ 
Method A Yield:

Method B Yield:

Method C Yield:

Method D Yield:

${ }^{1} \mathrm{H}$ NMR

(300 MHz, $\left[\mathrm{D}_{8}\right]$ toluene):
$31 \mathrm{mg}, 55 \mu \mathrm{mol}, 10 \%$

$155 \mathrm{mg}, 278 \mu \mathrm{mol}, 75 \%$

9+[AlMeI $\left.\left({ }^{4-\mathrm{Me}} \mathrm{Box}_{2} \mathrm{CH}\right)\right]: 338 \mathrm{mg}, 278 \mu \mathrm{mol}, 83 \%$

$326 \mathrm{mg}, 584 \mu \mathrm{mol}, 94 \%$

$\delta=6.74-6.66(\mathrm{~m}, 6 \mathrm{H}, 3-\mathrm{H}, 4-\mathrm{H}, 5-\mathrm{H}, 12-\mathrm{H}, 13-\mathrm{H}, 14-\mathrm{H}), 5.07$ (s, $1 \mathrm{H}, 8-\mathrm{H}), 3.19$ (s, $\left.6 \mathrm{H},-\mathrm{CH}_{3}\right) \mathrm{ppm}$.

${ }^{1} \mathrm{H}$ NMR

(400 MHz, [D $\mathrm{D}_{6}$ benzene):

$\delta=6.73-6.64(\mathrm{~m}, 6 \mathrm{H}, 3-\mathrm{H}, 4-\mathrm{H}, 5-\mathrm{H}, 12-\mathrm{H}, 13-\mathrm{H}, 14-\mathrm{H}), 5.05$ (s, $1 \mathrm{H}, 8-\mathrm{H}), 3.22\left(\mathrm{~s}, 6 \mathrm{H},-\mathrm{CH}_{3}\right) \mathrm{ppm}$

\section{${ }^{13} \mathrm{C}\left\{{ }^{1} \mathrm{H}\right\}$ NMR}

(101 MHz, [D 6 benzene): $\delta=166.25$ (C-7, C-9), 148.16 (C-6, C-10), 134.17 (C-1, C-15), 128.19 (C-4, C-12), 125.17 (C-2, C-14), 124.39 (C-3, C-13), $107.65(\mathrm{C}-5, \mathrm{C}-11), 62.47(\mathrm{C}-8), 23.86\left(-\mathrm{CH}_{3}\right) \mathrm{ppm}$.

${ }^{1} \mathrm{H},{ }^{15} \mathrm{~N}$ HMBC

(51 MHz, [D 6 benzene):

$\delta=-229.8 \mathrm{ppm}$.

${ }^{27} \mathrm{Al} \mathrm{NMR}$

(130 MHz, [D $\left.\mathrm{D}_{6}\right]$ benzene): $\quad \delta=76.39\left(\omega_{1 / 2}=406 \mathrm{~Hz}\right) \mathrm{ppm}$.

MS (LIFDI[+], THF)

$\mathrm{m} / \mathrm{z}(\%)$ :

$702.0(100)[M+2 \mathrm{THF}]^{+}, 629.9(57)[M+\mathrm{THF}]^{+}$.

Elemental analysis

in \% (calculated)
$\mathrm{C}_{17} \mathrm{H}_{13} \mathrm{All}_{2} \mathrm{~N}_{2} \mathrm{O}_{2}$ (558.09 g/mol): C 36.59 (37.30), H 2.35 (2.51), N $5.02(5.07)$. 


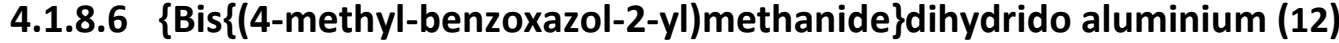

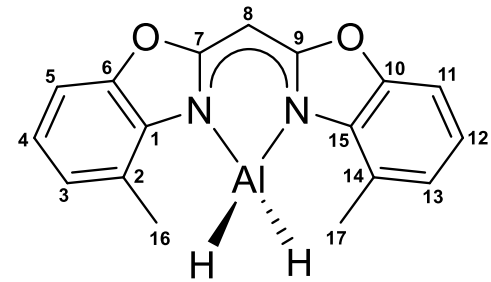

Method A: Bis(4-methyl-benzoxazol-2-yl)methane (254 mg, $913 \mathrm{mmol}, 1.00$ equiv.) was dissolved in toluene $(5 \mathrm{~mL})$ and cooled to $-30^{\circ} \mathrm{C}$. A freshly prepared solution of trimethylamine alane $(367 \mathrm{mg}$, $4.12 \mathrm{mmol}, 1.12$ equiv. $)$ in toluene $(10 \mathrm{~mL})$ was also cooled to $-30^{\circ} \mathrm{C}$ and added to the precooled ligand solution. The reaction solution was slowly allowed to warm to ambient temperature and stirred for $4 \mathrm{~h}$ at ambient temperature. About half of the solvent was removed under reduced pressure, and the observed white precipitate was carefully redissolved by heating the mixture. Storage of this clear yellow solution at $2^{\circ} \mathrm{C}$ lead to the formation of crystals suitable for single crystal diffraction experiments. A second crop of crystals was grown from the concentrated mother liquor at $-30^{\circ} \mathrm{C}$.

Method B: Bis(4-methyl-benzoxazol-2-yl)methane ( $1.57 \mathrm{~g}, 5.64 \mathrm{mmol}, 1.00$ equiv.) was dissolved in toluene $(15 \mathrm{~mL})$ and cooled to $0^{\circ} \mathrm{C}$. A solution of dimethyethyllamine alane $(12.0 \mathrm{~mL}, 619 \mathrm{mg}, 6.00 \mathrm{mmol}$, 1.06 equiv.) in toluene was added to the solution. After the yellow reaction solution was stirred for $15 \mathrm{~min}$ at $0^{\circ} \mathrm{C}$, it was allowed to warm to ambient temperature and stirred for $24 \mathrm{~h}$. The obtained white precipitate was separated by filtration with a transfer canula equipped with a glass fiber filter and dried under reduced pressure. A second crop of colourless crystals was grown from the concentrated mother liquor at $-30^{\circ} \mathrm{C}$.

Chemical Formula:

Molecular weight:

Yield (method $A)$ :

Yield $(\operatorname{method} B)$ :

${ }^{1} \mathrm{H}$ NMR

(300 MHz, [D $\mathrm{D}_{8}$ toluene):

\author{
$\mathrm{C}_{17} \mathrm{H}_{15} \mathrm{AlN}_{2} \mathrm{O}_{2}$ \\ $306.30 \mathrm{~g} / \mathrm{mol}$ \\ $128.6 \mathrm{mg}, 420 \mu \mathrm{mol}, 46 \%$ \\ $1.33 \mathrm{~g}, 4.34 \mathrm{mmol}, 77 \%$
}

$\delta=6.75\left(\mathrm{dd}, 2 \mathrm{H},{ }^{3} J_{\mathrm{HH}}=7.6 \mathrm{~Hz},{ }^{4} \mathrm{~J}_{\mathrm{HH}}=1.5 \mathrm{~Hz}, 5-\mathrm{H}, 11-\mathrm{H}\right), 6.68$

$\left(\mathrm{dd}, 2 \mathrm{H},{ }^{3} J_{\mathrm{HH}}=7.6 \mathrm{~Hz}, 4-\mathrm{H}, 12-\mathrm{H}\right), 6.62\left(\mathrm{dd}, 2 \mathrm{H},{ }^{3} J_{\mathrm{HH}}=7.6 \mathrm{~Hz}\right.$

$\left.{ }^{4} \mathrm{~J}_{\mathrm{HH}}=1.5 \mathrm{~Hz}, 3-\mathrm{H}, 13-\mathrm{H}\right), 5.34(\mathrm{sbr}, 2 \mathrm{H}, \mathrm{Al}-\mathrm{H}), 5.04(\mathrm{~s}, 1 \mathrm{H}, 8-$

$\mathrm{H}), 2.74\left(\mathrm{~s}, 6 \mathrm{H},-\mathrm{CH}_{3}\right)$.

\section{${ }^{1} \mathrm{H}$ NMR}

(400 MHz, [D 6 benzene): $\quad \delta=6.75\left(\mathrm{dd}, 2 \mathrm{H},{ }^{3} J_{\mathrm{HH}}=7.6 \mathrm{~Hz},{ }^{4} J_{\mathrm{HH}}=1.5 \mathrm{~Hz}, 5-\mathrm{H}, 11-\mathrm{H}\right), 6.67$

$\left(\mathrm{dd}, 2 \mathrm{H},{ }^{3} \mathrm{~J}_{\mathrm{HH}}=7.6 \mathrm{~Hz}, 4-\mathrm{H}, 12-\mathrm{H}\right), 6.63\left(\mathrm{dd}, 2 \mathrm{H},{ }^{3} J_{\mathrm{HH}}=7.6 \mathrm{~Hz}\right.$

$\left.{ }^{4} J_{\mathrm{HH}}=1.5 \mathrm{~Hz}, 3-\mathrm{H}, 13-\mathrm{H}\right), 5.43(\mathrm{sbr}, 2 \mathrm{H}, \mathrm{Al}-\mathrm{H}), 5.08(\mathrm{~s}, 1 \mathrm{H}, 8-$

$\mathrm{H}), 2.77\left(\mathrm{~s}, 6 \mathrm{H},-\mathrm{CH}_{3}\right)$. 
${ }^{13} \mathrm{C}\left\{{ }^{1} \mathrm{H}\right\}$ NMR

(101 MHz, [D $\mathrm{D}_{6}$ benzene): $\quad \delta=168.26(\mathrm{C}-7, \mathrm{C}-9), 148.32(\mathrm{C}-6, \mathrm{C}-10), 136.25(\mathrm{C}-1, \mathrm{C}-15)$, 126.61 (C-3, C-13), 124.58 (C-2, C-14), 123.13 (C-4, C-12), 107.43 (C-5, C-11), 60.28 (C-8), $18.14\left(-\mathrm{CH}_{3}\right)$.

${ }^{27} \mathrm{Al} \mathrm{NMR}$

(130 MHz, $\left[\mathrm{D}_{6}\right]$ benzene): could not be observed.

MS (LIFDI[+], toluene)

$\mathrm{m} / \mathrm{z}(\%)$ :

$306.1(100)[\mathrm{M}]^{+}, 626.2(2)[2 \mathrm{M}-2 \mathrm{H}+\mathrm{O}]^{+}$.

IR

(ATR):

$\tilde{v}_{\mathrm{H}-\mathrm{Al}}=1886(\mathrm{w}), 1806(\mathrm{~m})$.

Elemental analysis

in \% (calculated)

$\mathrm{C}_{17} \mathrm{H}_{15} \mathrm{AlN}_{2} \mathrm{O}_{2}(306.30 \mathrm{~g} / \mathrm{mol}): \mathrm{C} 66.66$ (65.99), H 4.94 (4.89), N 9.15 (9.15).

\subsubsection{7 \{Bis\{(4-methyl-benzoxazol-2-yl)methanide\}hydrido aluminium \{bis(2,6- diisopropylphenyl)-2,4-pentanediiminato\}hydrido aluminium (13)}

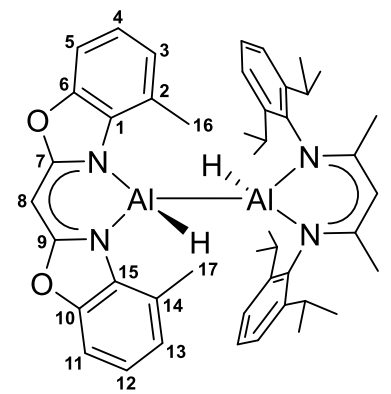

$\left\{N, N^{\prime}\right.$-bis $\{(4$-methyl-benzoxazol-2-yl)methanide $\}$ dihydrido aluminium $\quad(51.5 \mathrm{mg}, \quad 168 \mu \mathrm{mol}$, 1.00 equiv.) (12) as well as $\left\{N, N^{\prime}\right.$-bis(2,6-diisopropylphenyl)-2,4-pentanediiminato $\}$ aluminium (75.2 $\mathrm{mg}, 169 \mu \mathrm{mol}, 1.01$ equiv.) were dissolved in toluene $(6 \mathrm{~mL})$. The reaction mixture, which turned yellow after a few minutes, was stirred for $24 \mathrm{~h}$. The solvent was removed under reduced pressure, and a yellow solid was obtained. Crystals suitable for single crystal diffraction experiments were grown from a saturated toluene solution at $-30^{\circ} \mathrm{C}$ after $3 \mathrm{~d}$.

Chemical Formula: $\quad \mathrm{C}_{46} \mathrm{H}_{56} \mathrm{Al}_{2} \mathrm{~N}_{4} \mathrm{O}_{2}$

Molecular weight: $\quad 750.94 \mathrm{~g} / \mathrm{mol}$

Yield:

$121 \mathrm{mg}, 161 \mu \mathrm{mol}, 96 \%$

${ }^{1} \mathrm{H}$ NMR

(300 MHz, [D $\left.\mathrm{D}_{6}\right]$ benzene): $\quad \delta=7.10\left(\mathrm{dd}, 2 \mathrm{H},{ }^{3} J_{\mathrm{HH}}=7.8 \mathrm{~Hz}, p-\mathrm{CH}_{\mathrm{dipp}}\right), 7.05\left(\mathrm{dd}, 2 \mathrm{H},{ }^{3} J_{\mathrm{HH}}=\right.$ $\left.7.8 \mathrm{~Hz},{ }^{4} J_{\mathrm{HH}}=1.7 \mathrm{~Hz}, o-\mathrm{CH}_{\text {dipp }}\right), 6.96\left(\mathrm{dd}, 2 \mathrm{H},{ }^{3} J_{\mathrm{HH}}=7.8 \mathrm{~Hz}\right.$, $\left.{ }^{4} J_{\mathrm{HH}}=1.7 \mathrm{~Hz}, o-\mathrm{CH}_{\text {dipp }}\right), 6.81\left(\mathrm{dd}, 2 \mathrm{H},{ }^{3} J_{\mathrm{HH}}=7.5 \mathrm{~Hz},{ }^{4} J_{\mathrm{HH}}=\right.$ $1.5 \mathrm{~Hz}, 5-\mathrm{H}, 11-\mathrm{H}), 6.74\left(\mathrm{dd}, 2 \mathrm{H},{ }^{3} J_{\mathrm{HH}}=7.5 \mathrm{~Hz}, 4-\mathrm{H}, 12-\mathrm{H}\right)$, 
$6.65\left(\mathrm{dd}, 2 \mathrm{H},{ }^{3} J_{\mathrm{HH}}=7.5 \mathrm{~Hz}^{4} J_{\mathrm{HH}}=1.5 \mathrm{~Hz}, 2-\mathrm{H}, 14-\mathrm{H}\right), 4.97(\mathrm{~s}$, $1 \mathrm{H},-\mathrm{CH}-$ ), 4.87 (s, $1 \mathrm{H}, \mathrm{C}-8$ ), 3.39 (hept, $2 \mathrm{H},{ }^{3} \mathrm{~J}_{\mathrm{HH}}=6.8 \mathrm{~Hz}$, $\left.\mathrm{CH}\left(\mathrm{CH}_{3}\right)_{2}\right), 3.12$ (hept, $\left.2 \mathrm{H},{ }^{3} J_{\mathrm{HH}}=6.8 \mathrm{~Hz},-\mathrm{CH}\left(\mathrm{CH}_{3}\right)_{2}\right), 2.45(\mathrm{~s}$, $\left.6 \mathrm{H},-\mathrm{CH}_{3}\right), 1.50\left(\mathrm{~s}, 6 \mathrm{H},-\mathrm{NCCH}_{3}\right), 1.12\left(\mathrm{~d}, 6 \mathrm{H},{ }^{3} J_{\mathrm{HH}}=6.8 \mathrm{~Hz}\right.$, $\left.\mathrm{CH}\left(\mathrm{CH}_{3}\right)_{2}\right), 1.04\left(\mathrm{dd}, 12 \mathrm{H},{ }^{3} \mathrm{~J}_{\mathrm{HH}}=6.8 \mathrm{~Hz},-\mathrm{CH}\left(\mathrm{CH}_{3}\right)_{2}\right), 0.96(\mathrm{~d}$, $\left.6 \mathrm{H},{ }^{3} \mathrm{~J}_{\mathrm{HH}}=6.8 \mathrm{~Hz},-\mathrm{CH}\left(\mathrm{CH}_{3}\right)_{2}\right) \mathrm{ppm}$.

\section{${ }^{13} \mathrm{C}\left\{{ }^{1} \mathrm{H}\right\} \mathrm{NMR}$}

(75 MHz, [D $\mathrm{D}_{6}$ benzene): $\quad \delta=170.21\left(-\mathrm{NCCH}_{3}\right), 168.15(\mathrm{C}-7, \mathrm{C}-9), 148.77$ (C-6, C-10), 145.52 (o- $C_{\text {dipp }}$ ), 142.74 (ipso- $C_{\text {dipp }}$ ), 142.33 (ipso- $C_{\text {dipp }}$ ), 136.52 (C-1, C-15), 126.86 ( $\left.p-\mathrm{CH}_{\text {dipp }}\right), 126.53$ (C-3, C-13), 125.97 (C-2, $\mathrm{C}-14), 124.50$ (o- $\left.C \mathrm{H}_{\text {dipp }}\right), 124.16$ (o- $\left.\mathrm{CH}_{\text {dipp }}\right), 122.31$ (C-4, C-12), 106.60 (C-5, C-11), 98.13 (-CH-),), 61.23 (C-8), 28.93 ($\left.\mathrm{CH}\left(\mathrm{CH}_{3}\right)_{2}\right), 28.27\left(-\mathrm{CH}\left(\mathrm{CH}_{3}\right)_{2}\right), 25.22\left(-\mathrm{CH}\left(\mathrm{CH}_{3}\right)_{2}\right), 24.49$ $\left.\mathrm{CH}\left(\mathrm{CH}_{3}\right)_{2}\right), 24.39\left(-\mathrm{CH}\left(\mathrm{CH}_{3}\right)_{2}\right), 24.06\left(-\mathrm{CH}\left(\mathrm{CH}_{3}\right)_{2}\right), 23.44$ $\left(-\mathrm{NCCH}_{3}\right), 18.14\left(-\mathrm{CH}_{3}\right)$ ppm.

\section{${ }^{27} \mathrm{Al} \mathrm{NMR}$}

(130 MHz, $\left[D_{6}\right]$ benzene): could not be observed.

MS (LIFDI[+], toluene)

$\mathrm{m} / \mathrm{z}(\%)$ :

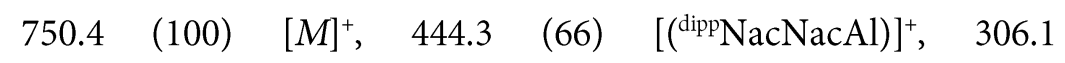
$\left[M-\left({ }^{\mathrm{dipp}} \mathrm{NacNacAl}\right)+\mathrm{H}\right]^{+}$.

IR

(ATR): $\quad \tilde{v}_{\mathrm{H}-\mathrm{Al}}=1840(\mathrm{~m}), 1814(\mathrm{w})$.

\section{Elemental analysis}

in \% (calculated)

$\mathrm{C}_{46} \mathrm{H}_{56} \mathrm{Al}_{2} \mathrm{~N}_{4} \mathrm{O}_{2}$ (750.94 g/mol): C 73.49 (73.57), H 7.23 (7.57), N 7.24 (7.46). 
4.1.8.8 \{Bis\{(4-methyl-benzoxazol-2-yl)methanide\}hydrido aluminium $\{$ bis(2,6diisopropylphenyl)-2,4-pentanediiminato\}aluminium tetrakis(pentafluorophenyl)borate (14)

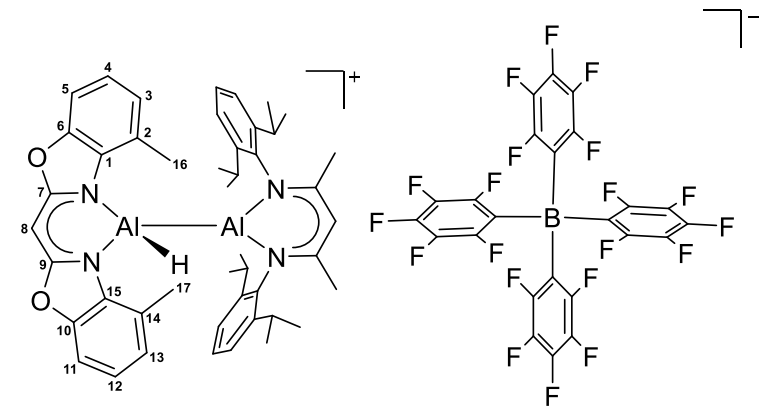

A solution of $\left\{N, N^{\prime}\right.$-bis $\{(4-m e t h y l-b e n z o x a z o l-2-y l) m e t h a n i d o\} h y d r i d o$ aluminium $\left\{N, N^{\prime}-(2,6-\right.$ diisopro-pylphenyl)-2,4-pentanediimine\}hydridoaluminium (13) (67.7 mg, $90.18 \mu \mathrm{mol}, 1.00$ equiv.) in toluene $(2 \mathrm{~mL}$ ) was added under vigorously stirring to trityl tetrakis(pentafluorophenyl)borate (83.4 mg, $90.32 \mu \mathrm{mol}, 1.00$ equiv.). First, the mixture turned bright red, and after it was stirred for 5 minutes, a slightly yellow upper phase and a colourless oily lower phase were observed. After this mixture rested for $1 \mathrm{~d}$ at ambient temperature, crystals suitable for single crystal diffraction experiments grew from the lower phase. The upper phase was decanted, and the crystals dried under vacuum.

Chemical Formula:

Molecular weight:

Yield:

${ }^{1} \mathrm{H}$ NMR

(400 MHz, $\left.\mathrm{C}_{6} \mathrm{D}_{5} \mathrm{Br}\right)$ :

\author{
$\mathrm{C}_{70} \mathrm{H}_{55} \mathrm{Al}_{2} \mathrm{BF}_{20} \mathrm{~N}_{4} \mathrm{O}_{2}$ \\ $1428.98 \mathrm{~g} / \mathrm{mol}$ \\ $104.9 \mathrm{mg}, 73.4 \mu \mathrm{mol}, 81 \%$
}

$\delta=6.94-6.88\left(\mathrm{~m}, 8 \mathrm{H}, p-\mathrm{CH}_{\mathrm{dipp}}, o-\mathrm{CH}_{\mathrm{dipp}}, 4-\mathrm{H}, 12-\mathrm{H}\right), 6.77(\mathrm{~d}$, $\left.2 \mathrm{H},{ }^{3} J_{\mathrm{HH}}=7.1 \mathrm{~Hz}, 3-\mathrm{H}, 13-\mathrm{H}\right), 5.41(\mathrm{~s}, 1 \mathrm{H},-\mathrm{CH}-), 4.88(\mathrm{~s}, 1 \mathrm{H}$, C-8), 2.36 (hept, $\left.2 \mathrm{H},{ }^{3} \mathrm{~J}_{\mathrm{HH}}=6.8 \mathrm{~Hz},-\mathrm{CH}\left(\mathrm{CH}_{3}\right)_{2}\right), 1.98(\mathrm{~s}, 6 \mathrm{H}$, $\left.\mathrm{CH}_{3}\right), 1.54\left(\mathrm{~s}, 6 \mathrm{H},-\mathrm{NCCH}_{3}\right), 0.91\left(\mathrm{~d}, 12 \mathrm{H},{ }^{3} J_{\mathrm{HH}}=6.8 \mathrm{~Hz},-\right.$ $\left.\mathrm{CH}\left(\mathrm{CH}_{3}\right)_{2}\right), 0.71\left(\mathrm{~d}, 12 \mathrm{H},{ }^{3} \mathrm{~J}_{\mathrm{HH}}=6.8 \mathrm{~Hz},-\mathrm{CH}\left(\mathrm{CH}_{3}\right)_{2}\right) .6 .94-6.88$ $\left(\mathrm{m}, 8 \mathrm{H}, p-\mathrm{CH}_{\text {dipp, }}, o-\mathrm{CH}_{\text {dipp }}, 4-\mathrm{H}, 12-\mathrm{H}\right), 6.77\left(\mathrm{~d}, 2 \mathrm{H},{ }^{3} \mathrm{~J}_{\mathrm{HH}}=\right.$ 7.1 Hz, 3-H, 13-H), 5.41 (s, $1 \mathrm{H},-\mathrm{CH}-), 4.88$ (s, $1 \mathrm{H}, \mathrm{C}-8), 2.36$ (hept, $\left.2 \mathrm{H},{ }^{3} J_{\mathrm{HH}}=6.8 \mathrm{~Hz},-\mathrm{CH}\left(\mathrm{CH}_{3}\right)_{2}\right), 1.98\left(\mathrm{~s}, 6 \mathrm{H},-\mathrm{CH}_{3}\right), 1.54$ $\left(\mathrm{s}, 6 \mathrm{H},-\mathrm{NCCH}_{3}\right), 0.91\left(\mathrm{~d}, 12 \mathrm{H},{ }^{3} \mathrm{~J}_{\mathrm{HH}}=6.8 \mathrm{~Hz},-\mathrm{CH}\left(\mathrm{CH}_{3}\right)_{2}\right), 0.71$ $\left(\mathrm{d}, 12 \mathrm{H},{ }^{3} J_{\mathrm{HH}}=6.8 \mathrm{~Hz},-\mathrm{CH}\left(\mathrm{CH}_{3}\right)_{2}\right)$.

${ }^{13} \mathrm{C}\left\{{ }^{1} \mathrm{H}\right\}$ NMR

(101 MHz, $\left.\mathrm{C}_{6} \mathrm{D}_{5} \mathrm{Br}\right)$ :

$\delta=173.76\left(-\mathrm{NCCH}_{3}\right), 167.56(\mathrm{C}-7, \mathrm{C}-9), 147.82(\mathrm{C}-6, \mathrm{C}-10)$, 136.00 (o- $C_{\text {dipp }}$ ), 142.22 (ipso- $C_{\text {dipp }}$ ), 133.52 (C-1, C-15), 128.43 ( $p-\mathrm{CH}_{\text {dipp }}$ ), 127.14 (C-3, C-13), 124.28 (C-2, C-14), 124.98 (o$\left.\mathrm{CH}_{\text {dipp }}\right), 124.44$ (C-4, C-12), 107.68 (C-5, C-11), 104.28 (-CH-), 
$61.18(\mathrm{C}-8), 24.43\left(-\mathrm{CH}\left(\mathrm{CH}_{3}\right)_{2}\right), 22.88\left(-\mathrm{CH}\left(\mathrm{CH}_{3}\right)_{2}\right), 23.17$ $\left(-\mathrm{NCCH}_{3}\right), 19.39\left(-\mathrm{CH}_{3}\right) \mathrm{ppm}$.

\section{${ }^{19} \mathrm{~F}$ NMR}

$\left(282 \mathrm{MHz}, \mathrm{C}_{6} \mathrm{D}_{5} \mathrm{Br}\right)$ :

\section{${ }^{11} \mathrm{~B}$ NMR}

(96 MHz, $\left.\mathrm{C}_{6} \mathrm{D}_{5} \mathrm{Br}\right)$ :

${ }^{27} \mathrm{Al}$ NMR

$\left(130 \mathrm{MHz}, \mathrm{C}_{6} \mathrm{D}_{5} \mathrm{Br}\right)$ :

MS (LIFDI[+], toluene)

$\mathrm{m} / \mathrm{z}(\%)$ :

IR

(ATR):

\section{Elemental analysis}

in \% (calculated) $\delta=-131.75\left(\mathrm{~d}_{\mathrm{br}}, 16 \mathrm{H},{ }^{3} J_{\mathrm{FF}}=9.2 \mathrm{~Hz}, o-\mathrm{C}_{6} \mathrm{~F}_{5}\right),-162.13\left(\mathrm{t}, 8 \mathrm{~F},{ }^{3} J_{\mathrm{FF}}=\right.$ $\left.21.1 \mathrm{~Hz}, p-\mathrm{C}_{6} \mathrm{~F}_{5}\right),-165.97\left(\mathrm{t}_{\mathrm{br}}, 16 \mathrm{~F},{ }^{3} \mathrm{~J}_{\mathrm{FF}}=18.4 \mathrm{~Hz}, m-\mathrm{C}_{6} \mathrm{~F}_{5}\right) \mathrm{ppm}$.

$\delta=-16.24(\mathrm{~s}) \mathrm{ppm}$.

could not be observed.

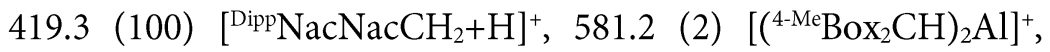
$749.4(3)[M]^{+}$.

$\tilde{v}_{\mathrm{H}-\mathrm{Al}}=$ could not be observed.

$\mathrm{C}_{70} \mathrm{H}_{55} \mathrm{Al}_{2} \mathrm{BF}_{20} \mathrm{~N}_{4} \mathrm{O}_{2}$ (1428.37 g/mol): C 59.41 (58.84), H 3.94 (3.88), N 4.15 (3.92). 
4.1.8.9 Bis(\{bis\{(4-methyl-benzoxazol-2-yl)methanide\}hydrido aluminium) (15a) and $\quad(\mu$-oxo)-Bis(\{bis\{(4-methyl-benzoxazol-2-yl)methanide\}hydrido aluminium) (15b)
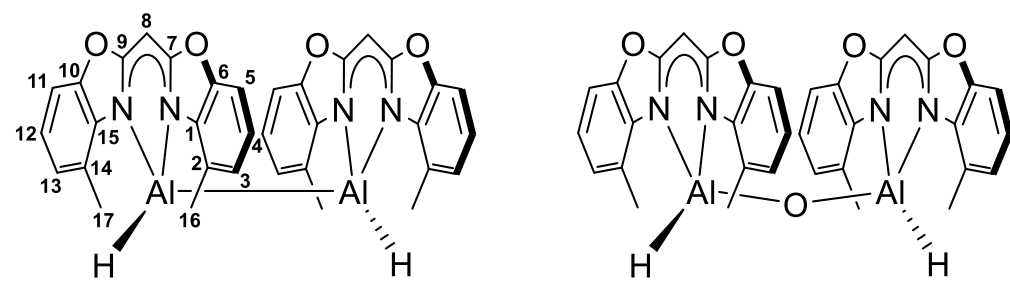

Alane 12 (46.5 mg, $151.8 \mu \mathrm{mol}, 1.00$ equiv.) was dissolved in toluene $(2 \mathrm{~mL})$ and $\left[\mathrm{Mg}\left({ }^{\mathrm{Mes}} \mathrm{NacNac}\right)\right]_{2}$ (55.1 mg, $77.1 \mu \mathrm{mol}, 0.51$ equiv.) was added at $-30^{\circ} \mathrm{C}$. Afterwards, the reaction mixture was allowed to warm to ambient temperature and stirred overnight. After stirring about $3 \mathrm{~h}$, a clear orange solution was obtained that became dark orange overnight. The solution was filtered by a pipette equipped with a glass fiber filter and cooled to $-30^{\circ} \mathrm{C}$ for crystallisation. Among other by-products that could not be separated, crystals of $15 \mathrm{a} / 15 \mathrm{~b}$ grew out of a saturated toluene solution after $2 \mathrm{~d}$ as thin yellow plates. These crystals were suitable for single crystal XRD measurement. The yield of this reaction could not be reliably determined due to the formation of side products such as $\left[(\mu-\mathrm{H}) \mathrm{Mg}\left({ }^{\mathrm{Mes}} \mathrm{NacNac}\right)\right]_{2}$ or $15 \mathrm{c}$. Therefore, NMR analyses revealed different side products among $15 a / 15 b:$

\section{${ }^{1} \mathrm{H}$ NMR}

(400 MHz, [D 6 benzene): $\quad \delta=6.74\left(\mathrm{~d}, 2 \mathrm{H},{ }^{3} J_{\mathrm{HH}}=7.5 \mathrm{~Hz}, 5-\mathrm{H}, 11-\mathrm{H}\right), 6.68\left(\mathrm{dd}, 2 \mathrm{H},{ }^{3} J_{\mathrm{HH}}=\right.$ $7.7 \mathrm{~Hz}, 4-\mathrm{H}, 12-\mathrm{H}), 6.46\left(\mathrm{~d}, 2 \mathrm{H},{ }^{3} J_{\mathrm{HH}}=7.3 \mathrm{~Hz}, 2-\mathrm{H}, 14-\mathrm{H}\right), 4.83$ (s, $1 \mathrm{H}, \mathrm{C}-8), 2.60\left(\mathrm{~s}, 6 \mathrm{H},-\mathrm{CH}_{3}\right)$.

${ }^{13} \mathrm{C}\left\{{ }^{1} \mathrm{H}\right\}$ NMR

(101 MHz, [D $\mathrm{D}_{6}$ ]benzene): $\quad \delta=167.53$ (C-7, C-9), 148.09 (C-6, C-10), 136.07 (C-1, C-15), 126.69 (C-3, C-13), 124.52 (C-2, C-14), 122.71 (C-4, C-12), $107.11(\mathrm{C}-5, \mathrm{C}-11), 60.10(\mathrm{C}-8), 19.32\left(-\mathrm{CH}_{3}\right) \mathrm{ppm}$.

MS (LIFDI[+], toluene)

$\mathrm{m} / \mathrm{z}(\%)$ :

$610.1(34)[M]^{+}, 626.1(100)[M+\mathrm{O}]^{+}$.

IR

(ATR):

$\tilde{v}_{\mathrm{H}-\mathrm{Al}}=1876(\mathrm{~m}), 1783(\mathrm{w})$. 


\subsubsection{0 \{Bis(4-methyl-benzoxazol-2-yl)methanide\}(2,6- diisopropylphenolate)hydrido aluminium (16)}

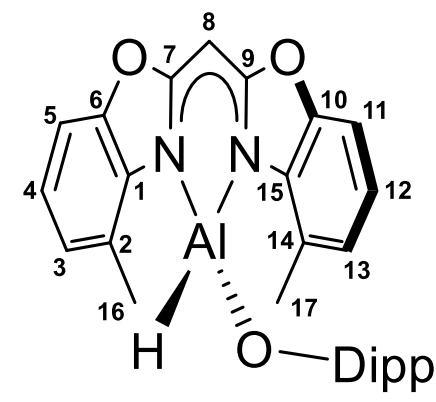

$\left\{N, N^{\prime}\right.$-bis $\{(4-m e t h y l-b e n z o x a z o l-2-y l)-m e t h a n i d o\}$ dihydrido $\quad$ aluminium $\quad(193 \mathrm{mg}, \quad 630 \mu \mathrm{mol}$, 1.00 equiv.) (12) was dissolved in toluene ( $8 \mathrm{~mL}$ ), and 2,6-diisopropylphenol (propofol) (112 mg, $117 \mu \mathrm{L}, 630 \mu \mathrm{mol}, 1.00$ equiv.) was slowly added under ambient temperature while stirring continuously. After $1 \mathrm{~d}$, about two-thirds of the solvent were evaporated, whereby a white solid precipitated. The supernatant solution was removed by a syringe, filtered through a glass pipette equipped with a glass fiber filter, and stored at $-30^{\circ} \mathrm{C}$ for crystallization. After one night, crystals suitable for single crystal diffraction experiment were obtained. The previously isolated white solid was dried under reduced pressure. This solid was also used for further syntheses.

Chemical Formula:

Molecular weight:

Yield:

${ }^{1} \mathrm{H}$ NMR

(400 MHz, [D $\left.\mathrm{D}_{6}\right]$ benzene):
$\mathrm{C}_{29} \mathrm{H}_{31} \mathrm{AlN}_{2} \mathrm{O}_{3}$

$482.56 \mathrm{~g} / \mathrm{mol}$

$268.0 \mathrm{mg}, 73.4 \mu \mathrm{mol}, 88 \%$

$\delta=7.04\left(\mathrm{~d}, 2 \mathrm{H},{ }^{3} J_{\mathrm{HH}}=7.6 \mathrm{~Hz}, m-\mathrm{CH}\right), 6.90\left(\mathrm{dd}, 1 \mathrm{H},{ }^{3} J_{\mathrm{HH}}=\right.$ $8.0 \mathrm{~Hz}, 7.1 \mathrm{~Hz}, p-\mathrm{CH}), 6.80\left(\mathrm{~d}, 2 \mathrm{H},{ }^{3} \mathrm{~J}_{\mathrm{HH}}=7.9 \mathrm{~Hz}, 5-\mathrm{H}, 11-\mathrm{H}\right)$, $6.68\left(\mathrm{dd}, 2 \mathrm{H},{ }^{3} J_{\mathrm{HH}}=7.7 \mathrm{~Hz}, 4-\mathrm{H}, 12-\mathrm{H}\right), 6.59\left(\mathrm{~d}, 2 \mathrm{H},{ }^{3} J_{\mathrm{HH}}=\right.$ $7.6 \mathrm{~Hz} 3-\mathrm{H}, 13-\mathrm{H}), 5.43(\mathrm{~s}, 1 \mathrm{H}, 8-\mathrm{H}), 3.50$ (sept, $2 \mathrm{H},{ }^{3} \mathrm{~J}_{\mathrm{HH}}=$ $\left.6.9 \mathrm{~Hz},-\mathrm{CH}\left(\mathrm{CH}_{3}\right)_{2}\right), 2.68\left(\mathrm{~s}, 6 \mathrm{H},-\mathrm{CH}_{3}\right), 1.07\left(\mathrm{~d}, 6 \mathrm{H},{ }^{3} \mathrm{~J}_{\mathrm{HH}}=\right.$ $\left.6.9 \mathrm{~Hz},-\mathrm{CH}\left(\mathrm{CH}_{3}\right)_{2}\right)$ ppm.

\section{${ }^{13} \mathrm{C}\left\{{ }^{1} \mathrm{H}\right\}$ NMR}

(101 MHz, [D $\left.\mathrm{D}_{6}\right]$ benzene): $\quad \delta=168.31(\mathrm{C}-7, \mathrm{C}-9), 151.53(\mathrm{C}-\mathrm{O}), 148.10(\mathrm{C}-6, \mathrm{C}-10)$, $137.55\left(\mathrm{C}-\mathrm{CH}\left(\mathrm{CH}_{3}\right)_{2}\right), 135.81(\mathrm{C}-1, \mathrm{C}-15), 126.96$ (C-3, C-13), 124.78 (C-2, C-14), 123.64 (o-CH), 123.54 (C-4, $\mathrm{C}-12), 120.04(\mathrm{~m}-\mathrm{CH}), 107.44$ (C-5, C-11), 61.27 (C-8), $27.19 \quad\left(-\mathrm{CH}\left(\mathrm{CH}_{3}\right)_{2}\right), \quad 23.79 \quad\left(-\mathrm{CH}\left(\mathrm{CH}_{3}\right)_{2}\right), \quad 19.13$ $\left(-\mathrm{CH}_{3}\right) \mathrm{ppm}$.

\footnotetext{
${ }^{27} \mathrm{Al} \mathrm{NMR}$

(130 MHz, $\left.\mathrm{C}_{6} \mathrm{D}_{5} \mathrm{Br}\right)$ :

could not be observed.
} 
MS (LIFDI[+], toluene)

$\mathrm{m} / \mathrm{z}(\%)$ :

$482.2(100)[M]^{+}$.

IR

(ATR):

$\tilde{v}_{\mathrm{H}-\mathrm{Al}}=1912(\mathrm{w})$.

Elemental analysis

in \% (calculated) $\quad \mathrm{C}_{29} \mathrm{H}_{31} \mathrm{AlN}_{2} \mathrm{O}_{3}(482.56 \mathrm{~g} / \mathrm{mol}): \mathrm{C} 71.65(72.18), \mathrm{H} 6.35$ (6.48), N 6.30

\subsubsection{1 ( $\mu$-oxo)Bis(\{Bis(4-methyl-benzoxazol-2-yl)methanide\}\{2,6- diisopropylphenolate\}aluminium) (17)}

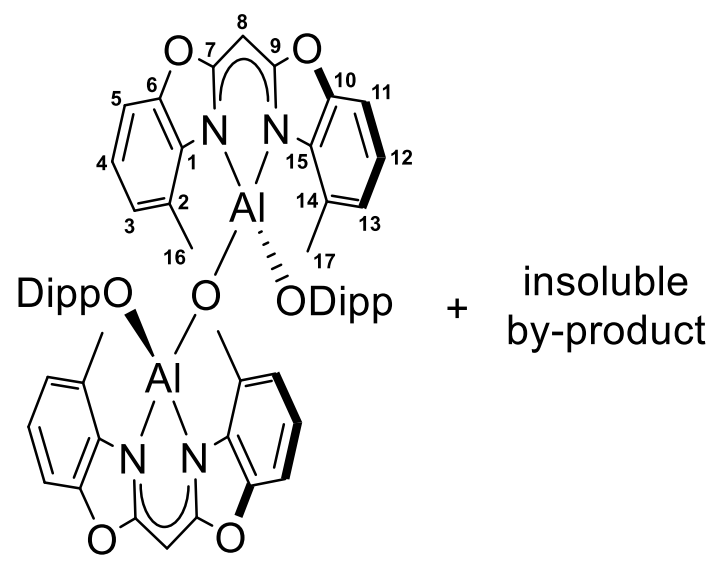

Complex 16 (44.3 mg, $91.8 \mu \mathrm{mol}, 1.00$ equiv.) was dissolved in THF or toluene( $0.5 \mathrm{~mL})$. Immediately after water $(0.83 \mu \mathrm{L}, 45.9 \mu \mathrm{mol}, 0.50$ equiv.) was added to the yellow solution at ambient temperature, a gas formation (dihydrogen) was observed. The mixture was stirred $1 \mathrm{~d}$, while a white solid precipitated after $1 \mathrm{~h}$. Afterwards, volatiles were removed under reduced pressure, and the obtained powder was used for further analyses. The white powder exhibited a poor solubility in most solvents (toluene, thf, DCM, acetone, MeCN, fluoro- and bromobenzene). The ${ }^{1} \mathrm{H}$ and ${ }^{13} \mathrm{C}$ NMR spectra $\left(\left[D_{8}\right]\right.$ toluene or $\left.\left[D_{8}\right] \mathrm{THF}\right)$ of the soluble components showed the synthesis of multiple species. Crystals suitable for single crystal XRD experiment grew out of a saturated THF solution in an NMR tube.

Chemical Formula: $\quad \mathrm{C}_{58} \mathrm{H}_{60} \mathrm{Al}_{2} \mathrm{~N}_{4} \mathrm{O}_{7}$

Molecular weight: $\quad 979.10 \mathrm{~g} / \mathrm{mol}$

Yield:

$31.5 \mathrm{mg}, 32.2 \mu \mathrm{mol}, 70 \%$

MS (LIFDI[+], THF)

$m / z(\%)$ :

$978.3(100)[M]^{+}$.

IR

(ATR): $\quad \tilde{v}_{\mathrm{H}-\mathrm{Al}}=$ No signal was detected. 
Elemental analysis

in \% (calculated)

$\mathrm{C}_{29} \mathrm{H}_{31} \mathrm{AlN}_{2} \mathrm{O}_{3}$ (482.56 g/mol): C 71.65 (72.18), H 6.35 (6.48), N 6.30

(5.81).

\subsubsection{Synthesis of bis(4-benzhydryl-benzoxazol-2-yl)methane}

\subsubsection{1 tert-butyl(2-methoxyphenyl)carbamate (18)}<smiles>COc1ccccc1NC(=O)OC(C)(C)C</smiles>

2-Anisidine (20.93 g, $19.20 \mathrm{~mL}(1.09 \mathrm{~g} / \mathrm{mL}), 169.9 \mathrm{mmol}, 1.00$ equiv.), di-tert-butyl-dicarbamate (55.63 g, $54.54 \mathrm{~mL}(1.02 \mathrm{~g} / \mathrm{mL}), 254.9 \mathrm{mmol}, 1.50$ equiv.) were dissolved in methanol $(300 \mathrm{~mL})$. The slightly brown reaction solution was heated under reflux $\left(\sim 100^{\circ} \mathrm{C}\right)$ for $18 \mathrm{~h}$. The mixture was allowed to cool to room temperature, the solvent was removed under vacuum, and demineralised water $(100 \mathrm{~mL})$ was added. The aqueous phase was separated and extracted with DCM $(3 \times 30 \mathrm{~mL})$. Subsequently, the organic phase was washed with a saturated sodium chloride solution $(1 \times 40 \mathrm{~mL})$ and dried over $\mathrm{MgSO}_{4}$. After the organic solvents had been removed under reduced pressure, a brownish, oily substance was obtained. This substance was distilled under vacuum (fine vacuum) at $130^{\circ} \mathrm{C}$, and the colourless oil could be used without further purification.

Chemical Formula:

Molecular weight:

Yield:

${ }^{1} \mathrm{H}$ NMR

(300 MHz, $\left.\mathrm{CDCl}_{3}\right)$ :

\section{${ }^{13} \mathrm{C}\left\{{ }^{1} \mathrm{H}\right\}$ NMR \\ (75 $\left.\mathrm{MHz}, \mathrm{CDCl}_{3}\right)$ :}

$\mathrm{C}_{12} \mathrm{H}_{17} \mathrm{NO}_{3}$

$$
223.27 \mathrm{~g} / \mathrm{mol}
$$

$$
32.25 \mathrm{~g}, 144.4 \mathrm{mmol}, 85 \%
$$

$\delta=8.10(\mathrm{~m}, 1 \mathrm{H}, 2-\mathrm{H}), 7.12(\mathrm{~s} \mathrm{r}, 1 \mathrm{H}, \mathrm{NH}), 7.00-6.91(\mathrm{~m}, 2 \mathrm{H}, 3-\mathrm{H}$, 4-H), 6.88-6.81 (m, $1 \mathrm{H}, 5-\mathrm{H}), 3.84\left(\mathrm{~s}, 3 \mathrm{H}, \mathrm{OCH}_{3}\right), 1.54(\mathrm{~s}, 9 \mathrm{H}$, $\left.\mathrm{C}\left(\mathrm{CH}_{3}\right)_{3}\right) \mathrm{ppm}$.

$\delta=152.7(-\mathrm{COOtBu}), 147.5$ (6-C), 128.1 (C-3), 122.3 (4-C), 121.0 (3-C), 118.0 (2-C), $110.0(5-\mathrm{C}), 80.2\left(-\mathrm{C}\left(\mathrm{CH}_{3}\right)_{3}\right), 55.5\left(-\mathrm{OCH}_{3}\right), 28.3$ $\left(-\mathrm{C}\left(\mathrm{CH}_{3}\right)_{3}\right) \mathrm{ppm}$.

MS (ESI[+], THF)

$\mathrm{m} / \mathrm{z}(\%)$ :

$246.1(53)[M+\mathrm{Na}]^{+}, 224.1(11)[M+\mathrm{H}]^{+}, 168.1(55)[M-t \mathrm{Bu}+\mathrm{H}]^{+}$, $124.1(100)\left[M-t \mathrm{Bu}-\mathrm{CO}_{2}+\mathrm{H}\right]^{+}$. 
HR-MS (ESI[+], THF)

$m / z:$

Elemental analysis

in $\%$ (calculated)
224.1280 (cal. 224.1280 for $[M+\mathrm{H}]^{+}, \mathrm{C}_{12} \mathrm{H}_{18} \mathrm{NO}_{3}$ ), 226.1103 (cal. 226.1101 for $\left.[M+\mathrm{Na}]^{+}, \mathrm{C}_{12} \mathrm{H}_{18} \mathrm{NNaO}_{3}\right)$.

$\mathrm{C}_{14} \mathrm{H}_{21} \mathrm{NO}_{3}(223.27 \mathrm{~g} / \mathrm{mol}): \mathrm{C} 64.71$ (64.55), H 7.67 (7.67), N 6.31 (6.27).

\subsubsection{2 tert-butyl(2-(hydroxydiphenylmethyl)-6-methoxyphenyl)carbamateol (19a) and 8-methoxy-4,4-diphenyl-1,4-dihydro-2H-benzo[d][1,3]oxazin-2- one (19b)}<smiles>COc1cccc(NC(=O)OCc2ccccc2)c1C(O)(c1ccccc1)c1ccccc1</smiles><smiles>COc1cccc2c1NC(=O)OC2(c1ccccc1)c1ccccc1</smiles>

tert-butyl(2-methoxyphenyl)carbamate $(10.19 \mathrm{~g}, 45.64 \mathrm{mmol}, 1.00$ equiv.) was introduced in a Schlenk flask $(500 \mathrm{~mL})$, and dry $\mathrm{Et}_{2} \mathrm{O}(70 \mathrm{~mL})$ was added. The solution was cooled to $-45^{\circ} \mathrm{C}$ $\left(\mathrm{MeCN} / \mathrm{CO}_{2(\mathrm{~s})}\right)$, and a solution of tert-Butyllithium in pentane $(53.98 \mathrm{~mL}(1.9 \mathrm{~mol} / \mathrm{L}), 100.4 \mathrm{mmol}$, $2.20 \mathrm{eq})$ was slowly added to the reaction solution. After the reaction mixture was stirred between $40^{\circ} \mathrm{C}$ to $-20^{\circ} \mathrm{C}$ for $3 \mathrm{~h}$, the mixture was cooled to $-78^{\circ} \mathrm{C}\left(\mathrm{EtOH} / \mathrm{CO}_{2(\mathrm{~s})}\right)$, and a solution of benzophenone $\left(10.91 \mathrm{~g}, 59.33 \mathrm{mmol}, 1.30\right.$ equiv.) in $\mathrm{Et}_{2} \mathrm{O}(40 \mathrm{~mL})$ was added. The dark green solution was stirred overnight $(\sim 18 \mathrm{~h})$ while it was slowly allowed to warm to ambient temperature. Subsequently, demineralised water $(100 \mathrm{~mL})$ was carefully added to the solution after which a white solid, a yellow ether, and a colourless water phase were observed. The white solid was separated by filtration, and the liquid phases were filled in a separating funnel. After this separated white solid had been washed with hexane $(200 \mathrm{~mL})$ in an ultrasonic bath $(10-15 \mathrm{~min})$, it was again filtered and dried in vacuo. The organic phase was removed from the aqueous phase via a separation funnel, and the aqueous phase was extracted with $\mathrm{Et}_{2} \mathrm{O}(3 \times 20 \mathrm{~mL})$. United organic phases $\left(\mathrm{Et}_{2} \mathrm{O}\right)$ were dried with $\mathrm{MgSO}_{4}$. Volatiles were removed under reduced pressure, and the obtained oily, white solid was ultrasonicated with hexane $(50 \mathrm{~mL})$, filtered, and dried under fine vacuum (overall yield $75 \%$ ).

\section{Compound 19a:}

Chemical Formula:

$\mathrm{C}_{21} \mathrm{H}_{27} \mathrm{NO}_{4}$

Molecular weight:

$405.19 \mathrm{~g} / \mathrm{mol}$

Yield:

$6.56 \mathrm{~g}, 14.56 \mathrm{mmol}, 32 \%$

\section{Compound 19b:}

Chemical Formula:

$\mathrm{C}_{21} \mathrm{H}_{17} \mathrm{NO}_{3}$

Molecular weight:

$331.37 \mathrm{~g} / \mathrm{mol}$

Yield: 


\section{Compound 19a ${ }^{1} \mathrm{H}$ NMR}

(300 MHz, $\mathrm{CDCl}_{3}$ ):

Compound $19 \mathrm{~b}{ }^{1} \mathrm{H}$ NMR

(300 $\mathrm{MHz}, \mathrm{CDCl}_{3}$ ): $\delta=7.32-7.20(\mathrm{~m}, 10 \mathrm{H}, \mathrm{Ph}), 7.04\left(\mathrm{dd}, 1 \mathrm{H},{ }^{3} J_{\mathrm{HH}}=8.1 \mathrm{~Hz}, 4-\mathrm{H}\right), 6.91$

$\left(\mathrm{dd}, 1 \mathrm{H},{ }^{3} J_{\mathrm{HH}}=8.3 \mathrm{~Hz},{ }^{4} J_{\mathrm{HH}}=1.2 \mathrm{~Hz}, 3-\mathrm{H}\right), 6.31\left(\mathrm{dd}, 1 \mathrm{H},{ }^{3} J_{\mathrm{HH}}=\right.$

$\left.7.9 \mathrm{~Hz},{ }^{4} J_{\mathrm{HH}}=1.2 \mathrm{~Hz}, 5-\mathrm{H}\right), 6.14\left(\mathrm{~s}_{\mathrm{br}}, 1 \mathrm{H}, \mathrm{NH}\right), 4.38\left(\mathrm{~s}_{\mathrm{br}}, 1 \mathrm{H}, \mathrm{OH}\right)$,

$3.82\left(\mathrm{~s}, 3 \mathrm{H},-\mathrm{OCH}_{3}\right), 1.26\left(\mathrm{~s}, 9 \mathrm{H},-\mathrm{C}\left(\mathrm{CH}_{3}\right)_{3}\right) \mathrm{ppm}$.

$\left.\delta=7.32-7.20(\mathrm{~m}, 10 \mathrm{H}, \mathrm{Ph}), 7.04\left(\mathrm{dd}, 1 \mathrm{H},{ }^{3}\right)_{\mathrm{HH}}=8.1 \mathrm{~Hz}, 4-\mathrm{H}\right), 6.91$

$\left(\mathrm{dd}, 1 \mathrm{H},{ }^{3} J_{\mathrm{HH}}=8.3 \mathrm{~Hz},{ }^{4} J_{\mathrm{HH}}=1.2 \mathrm{~Hz}, 3-\mathrm{H}\right), 6.31\left(\mathrm{dd}, 1 \mathrm{H},{ }^{3} J_{\mathrm{HH}}=\right.$ $\left.7.9 \mathrm{~Hz},{ }^{4} J_{\mathrm{HH}}=1.2 \mathrm{~Hz}, 5-\mathrm{H}\right), 6.14\left(\mathrm{~s}_{\mathrm{br}}, 1 \mathrm{H}, \mathrm{NH}\right), 4.38\left(\mathrm{~s}_{\mathrm{br}}, 1 \mathrm{H}, \mathrm{OH}\right)$, $3.82\left(\mathrm{~s}, 3 \mathrm{H},-\mathrm{OCH}_{3}\right), 1.26\left(\mathrm{~s}, 9 \mathrm{H},-\mathrm{C}\left(\mathrm{CH}_{3}\right)_{3}\right) \mathrm{ppm}$.

$685.3(88)[2 \times(19 b)+\mathrm{Na}]^{+}, 663.3(12)[2 \times(19 b)+\mathrm{H}]^{+}, 354.1(46)$ $[(19 b)+\mathrm{Na}]^{+}, 332.1(100)[(19 b)]^{+}, 290.2(94)[(19 a)-B o c-O H+H]^{+}$.

MS (ESI[+], THF)

$m / z(\%)$ :

HR-MS (ESI[+], THF)

$\mathrm{m} / \mathrm{z}$ :
354.1100 (cal. 354.1101 for $\left.[(19 b)+\mathrm{Na}]^{+}, \mathrm{C}_{21} \mathrm{H}_{17} \mathrm{NNaO}_{3}\right), 332.1282$

(cal. 332.1281 for $[(19 b)+\mathrm{H}]^{+}, \mathrm{C}_{21} \mathrm{H}_{18} \mathrm{NO}_{3}$ ), 290.1538 (cal. 290.1539 for $\left.[(19 a)-B o c-O H+H]^{+}, \mathrm{C}_{12} \mathrm{H}_{20} \mathrm{NO}\right)$.

\subsubsection{2-Benzhydryl-6-methoxyaniline (20)}

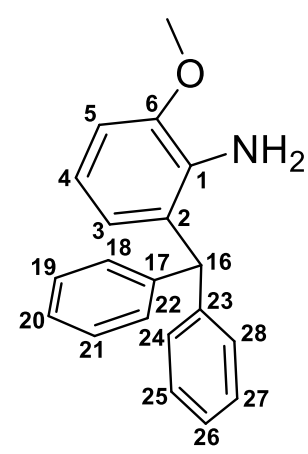

A mixture of 19a (10.65 g, $26.26 \mathrm{mmol}, 1.00$ equiv.) and $19 \mathrm{~b}$ ( $16.67 \mathrm{~g}, 50.31 \mathrm{mmol}, 1.92$ equiv.) were dissolved in 1,4-dioxane $(300 \mathrm{~mL})$. Zinc powder ( $150 \mathrm{~g}, 2.30 \mathrm{~mol}, 30.0$ equiv.) was added to the yellow solution. Afterwards, a concentrated hydrochloric acid $(260 \mathrm{~mL})$ was slowly added dropwise to the vigorously stirred suspension by a dropping funnel. The mixture was stirred overnight $(\sim 18 \mathrm{~h})$ until gas evolution has ceased. The reaction mixture was adjusted to $\mathrm{pH}>7$ by an aqueous sodium hydroxide solution. The obtained white suspension was filled in a separation funnel and extracted with $\mathrm{Et}_{2} \mathrm{O}(4 \times 200 \mathrm{~mL})$. The organic phase was dried over $\mathrm{MgSO}_{4}$, solvents were removed under reduced pressure, and the obtained yellow oil was dried under fine vacuum $(>3 \mathrm{~h})$. Thereafter, $n$-hexane $(300 \mathrm{~mL})$ was added to the oil, and the mixture was ultrasonicated for $30 \mathrm{~min}$. The white precipitate was filtered out by a Büchner funnel, washed with pentane $(4 \times 200 \mathrm{~mL})$, and dried in vacuo. Compound 20 was isolated as a white powder. 
$\begin{array}{ll}\text { Chemical Formula: } & \mathrm{C}_{20} \mathrm{H}_{19} \mathrm{NO} \\ \text { Molecular weight: } & 289.38 \mathrm{~g} / \mathrm{mol} \\ \text { Yield: } & 14.37 \mathrm{~g}, 49.8 \mathrm{mmol}, 65 \%\end{array}$

${ }^{1} \mathrm{H}$ NMR

(300 MHz, $\left.\mathrm{CDCl}_{3}\right)$ :

$\delta=7.39-7.32(\mathrm{~m}, 4 \mathrm{H}, 19-\mathrm{H}, 21-\mathrm{H}, 25-\mathrm{H}, 27-\mathrm{H}), 7.31-7.26(\mathrm{~m}, 2 \mathrm{H}$, 20-H, 26-H), 7.21-7.18 (m, 4 H, 18-H, 22-H, 24-H, 28-H), 6.80 (dd, $\left.1 \mathrm{H},{ }^{3} J_{\mathrm{HH}}=8.1 \mathrm{~Hz},{ }^{4} J_{\mathrm{HH}}=1.4 \mathrm{~Hz}, 5-\mathrm{H}\right), 6.72\left(\mathrm{dd}, 1 \mathrm{H},{ }^{3} \mathrm{~J}_{\mathrm{HH}}=8.1 \mathrm{~Hz}\right.$, $4-\mathrm{H}), 6.38\left(\mathrm{ddd}, 1 \mathrm{H},{ }^{3} J_{\mathrm{HH}}=8.1 \mathrm{~Hz},{ }^{4} J_{\mathrm{HH}}=1.4 \mathrm{~Hz},{ }^{4} J_{\mathrm{HH}}=0.5 \mathrm{~Hz}, 3-\mathrm{H}\right)$, $5.58(\mathrm{~s}, 1 \mathrm{H}, 16-\mathrm{H}), 3.90\left(\mathrm{~s}, 3 \mathrm{H},-\mathrm{OCH}_{3}\right), 3.74\left(\mathrm{~s}_{\mathrm{br}}, 2 \mathrm{H},-\mathrm{NH}_{2}\right) \mathrm{ppm}$.

${ }^{13} \mathrm{C}\left\{{ }^{1} \mathrm{H}\right\} \mathrm{NMR}$

(75 $\mathrm{MHz}, \mathrm{CDCl}_{3}$ ):

$\delta=147.6$ (6-C), 134.2 (1-C), 129.6 (18-C, 22-C, 24-C, 28-C), 129.5 (2-C), 128.6 (19-C, 21-C, 25-C, 27-C), 126.7 (20-C, 26-C), 122.3 (3-

C), 117.6 (4-C), 108.6 (5-C), $55.7\left(-\mathrm{OCH}_{3}\right), 52.3(16-\mathrm{C}) \mathrm{ppm}$.

MS (ESI[+], THF)

$\mathrm{m} / \mathrm{z}(\%)$ :

$290.2(100)[M+\mathrm{H}]^{+}, 312.1(11)[M+\mathrm{Na}]^{+}$.

HR-MS (ESI[+], THF)

$\mathrm{m} / \mathrm{z}$ :

290.1542 (cal. 290.1539 for $[M+\mathrm{H}]^{+}, \mathrm{C}_{20} \mathrm{H}_{19} \mathrm{NO}$ ).

Elemental analysis

in \% (calculated) $\quad \mathrm{C}_{20} \mathrm{H}_{19} \mathrm{NO}(289.38 \mathrm{~g} / \mathrm{mol}): \mathrm{C} 82.77$ (83.01), H 6.37 (6.62), N 4.67 (4.84).

\subsubsection{2-Amino-3-benzhydrylphenol (21)}

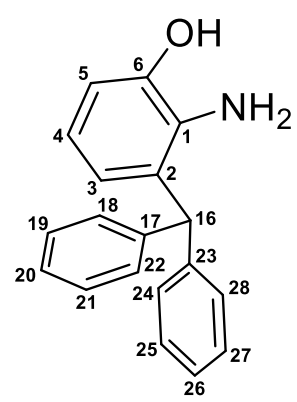

2-Benzhydryl-6-methoxyaniline (20) (8.32 g, $28.4 \mathrm{mmol}$, 1.00 equiv.) was dissolved in DCM $(450 \mathrm{~mL})$. A solution of boron tribromide $(9.27 \mathrm{~g}, 3.51 \mathrm{~mL}(2.64 \mathrm{~g} / \mathrm{mL}), 37.0 \mathrm{mmol}, 1.30$ equiv.) in DCM $(37 \mathrm{~mL})$, which was freshly prepared in a dropping funnel, was carefully added at $-78^{\circ} \mathrm{C}$ $\left(\mathrm{EtOH} / \mathrm{CO}_{2(\mathrm{~s})}\right)$. The olive-green solution was slowly allowed to warm to ambient temperature overnight ( $18 \mathrm{~h}$ ) while stirring. To avoid the formation of by-products, the reaction time should not exceed $1 \mathrm{~d}$. After that a saturated solution of sodium hydrogen carbonate in water $(240 \mathrm{~mL})$ was 
added dropwise to the reaction solution. At first, the reaction mixture turned yellow, and a white precipitate was formed while gas formation (dihydrogen) was observed, and the precipitate slowly dissolved. After stirring $\sim 3 \mathrm{~h}$, the precipitate was completely dissolved $(\mathrm{pH}=8-9$ ), and two phasesan aqueous clear and a yellow organic phase- were observed. The organic phase was separated by a separation funnel, and the aqueous phase was extracted with ethyl acetate $(3 \times 80 \mathrm{~mL})$. Thereafter, the organic phases were washed with demineralised water $(3 \times 50 \mathrm{~mL})$ and dried with $\mathrm{MgSO}_{4}$. Solvents were removed under reduced pressure, and beige solid was obtained. After drying overnight, the solid was used without further purification.

$\begin{array}{ll}\text { Chemical Formula: } & \mathrm{C}_{19} \mathrm{H}_{17} \mathrm{NO} \\ \text { Molecular weight: } & 275.13 \mathrm{~g} / \mathrm{mol} \\ \text { Yield: } & 7.49 \mathrm{~g}, 27.5 \mathrm{mmol}, 95 \%\end{array}$

${ }^{1} \mathrm{H}$ NMR

(300 MHz, $\left.\mathrm{CDCl}_{3}\right): \quad \delta=7.31-7.19(\mathrm{~m}, 6 \mathrm{H}, 19-\mathrm{H}, 20-\mathrm{H}, 21-\mathrm{H}, 25-\mathrm{H}, 26-\mathrm{H}, 27-\mathrm{H}), 7.13-$ 7.09 (m, 4 H, 18-H, 22-H, 24-H, 28-H), $6.64\left(\mathrm{dd}, 1 \mathrm{H},{ }^{3} J_{\mathrm{HH}}=7.8 \mathrm{~Hz}\right.$, $\left.{ }^{4} J_{\mathrm{HH}}=1.4 \mathrm{~Hz}, 5-\mathrm{H}\right), 6.56\left(\mathrm{dd}, 1 \mathrm{H},{ }^{3} J_{\mathrm{HH}}=7.8 \mathrm{~Hz}, 4-\mathrm{H}\right), 6.27(\mathrm{dd}, 1 \mathrm{H}$, $\left.{ }^{3} J_{\mathrm{HH}}=7.6 \mathrm{~Hz},{ }^{4} J_{\mathrm{HH}}=1.0 \mathrm{~Hz}, 3-\mathrm{H}\right), 5.51(\mathrm{~s}, 1 \mathrm{H}, 16-\mathrm{H}), 3.99\left(\mathrm{sbr}_{\mathrm{br}}\right.$, $\left.3 \mathrm{H},-\mathrm{NH}_{2},-\mathrm{OH}\right) \mathrm{ppm}$.

${ }^{13} \mathrm{C}\left\{{ }^{1} \mathrm{H}\right\}$ NMR

$\left(75 \mathrm{MHz}, \mathrm{CDCl}_{3}\right)$ :

$\delta=144.5$ (6-C), 142.6 (17-C, 23-C), 132.5 (1-C), 131.7 (2-C), 129.6 (18-C, 22-C, 24-C, 28-C), 128.7 (19-C, 21-C, 25-C, 27-C), 126.8 (20C, 26-C), 122.6 (3-C), 118.8 (4-C), 113.5 (5-C), 52.4 (16-C) ppm.

MS (ESI[+], THF)

$\mathrm{m} / \mathrm{z}(\%)$ :

$276.1(100)[M+\mathrm{H}]^{+}, 298.1(3)[M+\mathrm{Na}]^{+}$.

HR-MS (ESI[+], THF)

$\mathrm{m} / \mathrm{z}$ :

276.1382 (cal. 276.1383 for $[M+\mathrm{H}]^{+}, \mathrm{C}_{19} \mathrm{H}_{18} \mathrm{NO}$ ), 298.1200 (cal. 298.1202 for $\left.[M+N a]^{+}, \mathrm{C}_{19} \mathrm{H}_{17} \mathrm{NNaO}\right)$.

\section{Elemental analysis}

in $\%$ (calculated)

$\mathrm{C}_{19} \mathrm{H}_{17} \mathrm{NO}(275.13 \mathrm{~g} / \mathrm{mol}): \mathrm{C} 82.87$ (82.88), H 5.98 (6.22), N 4.90 (5.09). 


\subsubsection{2-(4-benzhydrylbenzo[d]oxazol-2-yl)acetonitrile (22)}

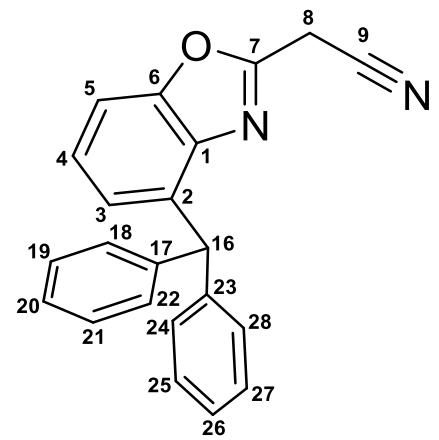

2-Amino-3-benzhydrylphenol (21) (6.29 g, $22.8 \mathrm{mmol}, 1.00$ equiv.) and ethyl cyanoacetimidate hydrochloride $(3.39 \mathrm{~g}, 22.8 \mathrm{mmol}, 1.00$ equiv.) were weighed into a Schlenk flask (50 mL). Subsequently, anhydrous $\mathrm{MeOH}(32 \mathrm{~mL})$ was added, and the obtained white suspension -Ethyl cyanoacetimidate hydrochloride was dissolved at $\sim 60^{\circ} \mathrm{C}$ - was heated at $85^{\circ} \mathrm{C}$ for $3 \mathrm{~d}$. A white precipitate formed in the reaction mixture overnight. After the mixture had been refluxed for two additional days, the flask was allowed to cool to ambient temperature and stored for one night at $30^{\circ} \mathrm{C}$. The precipitate was filtered by a Buchner funnel and washed with a saturated aqueous solution of sodium hydrogen carbonate. $(3 \times 12 \mathrm{~mL})$ and demineralised water $(3 \times 12 \mathrm{~mL})$. After that, the white compound was filled in an even number of centrifuge tubes, $\mathrm{MeOH}(\sim 8 \mathrm{~mL})$ was added until the tubes were balanced, and obtained suspensions were ultrasonicated for at least $15 \mathrm{~min}$. Afterwards, the tubes were placed in a centrifuge, rotated at $2000 \mathrm{rpm}$ for $4 \mathrm{~min}$, whereupon solvents were decanted. This procedure was repeated two times. The white solid was dried under reduced pressure overnight and was used for analysis without further purification.

$\begin{array}{ll}\text { Chemical Formula: } & \mathrm{C}_{22} \mathrm{H}_{16} \mathrm{~N}_{2} \mathrm{O} \\ \text { Molecular weight: } & 324.38 \mathrm{~g} / \mathrm{mol} \\ \text { Yield: } & 2.82 \mathrm{~g}, 8.69 \mathrm{mmol}, 38 \%\end{array}$

${ }^{1} \mathrm{H}$ NMR

$\left(300 \mathrm{MHz}, \mathrm{CDCl}_{3}\right): \quad \delta=7.38\left(\mathrm{dd}, 1 \mathrm{H},{ }^{3} \mathrm{~J}_{\mathrm{HH}}=8.2 \mathrm{~Hz},{ }^{4} J_{\mathrm{HH}}=0.9 \mathrm{~Hz}, 5-\mathrm{H}\right), 7.29-7.24(\mathrm{dd}$, $\left.1 \mathrm{H},{ }^{3} \mathrm{H}_{\mathrm{HH}}=7.9 \mathrm{~Hz},{ }^{4} J_{\mathrm{HH}}=0.9 \mathrm{~Hz}, 4-\mathrm{H}\right), 7.24-7.18(\mathrm{~m}, 4 \mathrm{H}, 19-\mathrm{H}, 21-$ H, 25-H, 27-H), 7.18 (m, 2 H, 20-H, 26-H), 7.13-7.09 (m, 4 H, 18-H, $22-\mathrm{H}, 24-\mathrm{H}, 28-\mathrm{H}), 6.97\left(\mathrm{dd}, 1 \mathrm{H},{ }^{3} \mathrm{H}_{\mathrm{HH}}=7.6 \mathrm{~Hz},{ }^{4} \mathrm{JH}_{\mathrm{HH}}=0.8 \mathrm{~Hz}, 3-\mathrm{H}\right)$, 6.21 (s, $1 \mathrm{H}, 16-\mathrm{H}), 3.96$ (s, $2 \mathrm{H}, 8-\mathrm{H}) \mathrm{ppm}$.

${ }^{13} \mathrm{C}\left\{{ }^{1} \mathrm{H}\right\}$ NMR

$\left(75 \mathrm{MHz}, \mathrm{CDCl}_{3}\right)$ :

$\delta=154.7$ (7-C), $151.2(6-\mathrm{C}), 142.9$ (17-C, 23-C), 139.9 (1-C), 129.4 (18-C, 22-C, 24-C, 28-C), 128.5 (19-C, 21-C, 25-C, 27-C), 126.6 (20C, 26-C), 125.9 (4-C), 125.5 (3-C), 113.2 (9-C), 109.1 (5-C), 51.3 (16-C), 18.9 (8-C) ppm. 
MS (ESI[+], THF)

$\mathrm{m} / \mathrm{z}(\%)$ :

$325.1(47)[M+\mathrm{H}]^{+}, 347.1(100)[M+\mathrm{Na}]^{+}$.

HR-MS (ESI[+], THF)

$\mathrm{m} / \mathrm{z}$ :

325.1333 (cal. 325.1335 for $[M+\mathrm{H}]^{+}, \mathrm{C}_{22} \mathrm{H}_{17} \mathrm{~N}_{2} \mathrm{O}$ ), 347.1155 (cal. 347.1155 for $\left.[M+N a]^{+}, \mathrm{C}_{22} \mathrm{H}_{16} \mathrm{~N}_{2} \mathrm{NaO}\right)$.

Elemental analysis

in \% (calculated)

$\mathrm{C}_{19} \mathrm{H}_{17} \mathrm{NO}$ (324.38 g/mol): C 81.38 (81.46), H 4.95 (4.97), N 8.64

(8.64).

\subsubsection{Bis(4-benzhydrylbenzoxazol-2-yl)methane (23)}
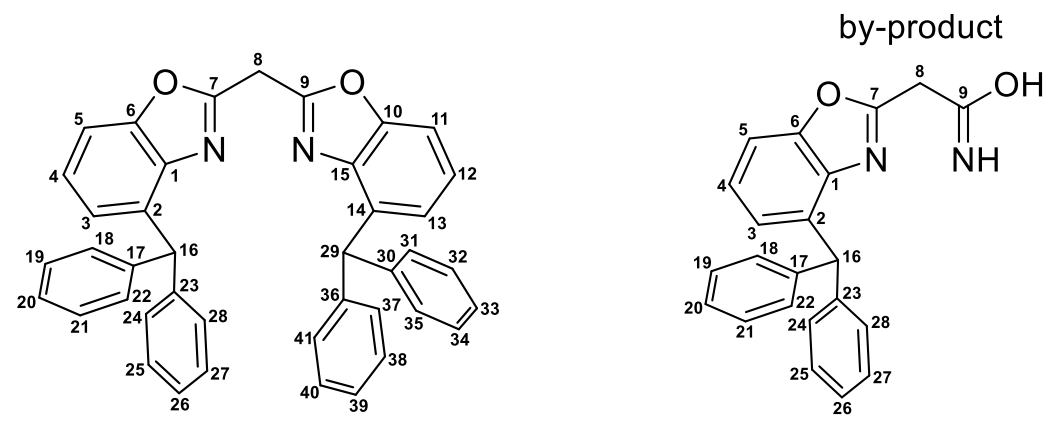

2-Amino-3-benzhydrylphenol (22) (15.0 g, $54.5 \mathrm{mmol}, 2.00$ equiv.) and ethyl cyanoacetimidate hydrochloride ( $6.30 \mathrm{~g}, 27.2 \mathrm{mmol}, 1.00$ equiv.) were weighed into a Schlenk flask $(250 \mathrm{~mL})$. Subsequently, anhydrous $\mathrm{MeOH}(75 \mathrm{~mL})$ was added, and the obtained white suspension -Ethyl cyanoacetimidate hydrochloride was dissolved at $\sim 60^{\circ} \mathrm{C}$ - was heated at $85^{\circ} \mathrm{C}$ for $3 \mathrm{~d}$. A white precipitate formed in the reaction mixture overnight. After the mixture had been refluxed for two more days, the flask was allowed to cool to ambeint temperature and stored for one night at $-30^{\circ} \mathrm{C}$. The precipitate was filtered by a Buchner funnel and washed with a saturated, aqueous solution of sodium hydrogen carbonate $(3 \times 30 \mathrm{~mL})$ and demineralised water $(3 \times 30 \mathrm{~mL})$. Thereafter, the white compound was filled in an even number of centrifuge tubes, $\mathrm{MeOH}(\sim 10 \mathrm{~mL})$ was added until the tubes were balanced, and obtained suspensions were ultrasonicated for at least $15 \mathrm{~min}$. Afterwards, the tubes were placed in a centrifuge, rotated at $2000 \mathrm{rpm}$ for $4 \mathrm{~min}$, whereupon solvents were decanted. This procedure was repeated two times. The white solid was dried under reduced pressure and purified by column chromatography on silica gel (THF/hexane 3:2).

Chemical Formula: $\quad \mathrm{C}_{41} \mathrm{H}_{30} \mathrm{~N}_{2} \mathrm{O}_{2}$

Molecular weight: $\quad 582.70 \mathrm{~g} / \mathrm{mol}$

$\boldsymbol{R}_{\mathrm{f}}(\mathrm{THF} /$ hexane $3: 2): \quad 0.90$

Yield: $\quad 5.72 \mathrm{~g}, 9.82 \mathrm{mmol}, 36 \%$ 
${ }^{1} \mathrm{H}$ NMR

(400 MHz, $\left.\mathrm{CDCl}_{3}\right)$ :

\section{${ }^{1} \mathrm{H}$ NMR}

(400 MHz, [D $\left.\left.\mathrm{D}_{8}\right] \mathrm{THF}\right)$ : $\delta=7.40\left(\mathrm{~d}, 2 \mathrm{H},{ }^{3} \mathrm{JHH}_{\mathrm{HH}}=8.1 \mathrm{~Hz}, 5-\mathrm{H}, 11-\mathrm{H}\right), 7.34-7.21(\mathrm{~m}, 22 \mathrm{H}, 4-\mathrm{H}$, $12-\mathrm{H}, 18-\mathrm{H}, 19-\mathrm{H}, 20-\mathrm{H}, 21-\mathrm{H}, 22-\mathrm{H}, 24-\mathrm{H}, 25-\mathrm{H}, 26-\mathrm{H}, 27-\mathrm{H}, 28-$ $\mathrm{H}, 31-\mathrm{H}, 32-\mathrm{H}, 33-\mathrm{H}, 34-\mathrm{H}, 35-\mathrm{H}, 37-\mathrm{H}, 38-\mathrm{H}, 39-\mathrm{H}, 40-\mathrm{H}, 41-\mathrm{H})$, $7.04\left(\mathrm{~d}, 2 \mathrm{H},{ }^{3} J_{\mathrm{HH}}=7.6 \mathrm{~Hz}, 3-\mathrm{H}, 13-\mathrm{H}\right), 6.36(\mathrm{~s}, 2 \mathrm{H}, 16-\mathrm{H}, 29-\mathrm{H})$, $4.61(\mathrm{~s}, 2 \mathrm{H}, 8-\mathrm{H}) \mathrm{ppm}$.

$7.35\left(\mathrm{dd}, 2 \mathrm{H},{ }^{3} \mathrm{~J}_{\mathrm{HH}}=8.3 \mathrm{~Hz},{ }^{4} \mathrm{~J}_{\mathrm{HH}}=0.8 \mathrm{~Hz}, 5-\mathrm{H}, 11-\mathrm{H}\right), 7.22-7.16(\mathrm{~m}$, $10 \mathrm{H},{ }^{3} J_{\mathrm{HH}}=8.1 \mathrm{~Hz}, 4-\mathrm{H}, 12-\mathrm{H}, 19-\mathrm{H}, 21-\mathrm{H}, 25-\mathrm{H}, 27-\mathrm{H}, 32-\mathrm{H}, 34-\mathrm{H}$, $38-\mathrm{H}, 40-\mathrm{H}), 7.12-7.10$ (m, 12 H, 18-H, 20-H, 22-H, 24-H, 26-H, 28$\mathrm{H}, 31-\mathrm{H}, 33-\mathrm{H}, 35-\mathrm{H}, 37-\mathrm{H}, 39-\mathrm{H}, 41-\mathrm{H}), 6.95\left(\mathrm{~d}, 2 \mathrm{H},{ }^{3} J_{\mathrm{HH}}=7.6 \mathrm{~Hz}\right.$, $\left.{ }^{4} J_{\mathrm{HH}}=0.8 \mathrm{~Hz}, 3-\mathrm{H}, 13-\mathrm{H}\right), 6.25(\mathrm{~s}, 2 \mathrm{H}, 16-\mathrm{H}, 29-\mathrm{H}), 4.58(\mathrm{~s}, 2 \mathrm{H}, 8-$ H) ppm.

\section{${ }^{1} \mathrm{H}$ NMR}

(400 MHz, [D $\left.\mathrm{D}_{8}\right]$ toluene):

7.14-7.10 (m, 8 H, 18-H, 20-H, 22-H, 24-H, 26-H, 28-H, 31-H, 33H, 35-H, 37-H, 39-H, 41-H), 7.08-7.04 (m, 8 H, 19-H, 21-H, 25-H, 27-H, 32-H, 34-H, 38-H, 40-H), 7.02-7.00 (m, 4 H, 20-H, 26-H, 33H, 39-H), 6.97-6.93 (m, 4 H, 3-H, 5-H, 11-H, 13-H), 6.89-6.85 (dd, $\left.2 \mathrm{H},{ }^{3} J_{\mathrm{HH}}=7.8 \mathrm{~Hz}, 4-\mathrm{H}, 12-\mathrm{H}\right), 6.41(\mathrm{~s}, 2 \mathrm{H}, 16-\mathrm{H}, 29-\mathrm{H}), 3.85(\mathrm{~s}, 2 \mathrm{H}$, 8-H) ppm.

\section{${ }^{1} \mathrm{H}$ NMR}

(400 MHz, [D 6 benzene):

7.18-7.15 (m, 8 H, 18-H, 20-H, 22-H, 24-H, 26-H, 28-H, 31-H, 33$\mathrm{H}, 35-\mathrm{H}, 37-\mathrm{H}, 39-\mathrm{H}, 41-\mathrm{H}), 7.10-7.06$ (m, 8 H, 19-H, 21-H, 25-H, 27-H, 32-H, 34-H, 38-H, 40-H), 7.03-7.00 (m, 4 H, 20-H, 26-H, 33$\mathrm{H}, 39-\mathrm{H}), 6.97-6.94(\mathrm{~m}, 4 \mathrm{H}, 3-\mathrm{H}, 5-\mathrm{H}, 11-\mathrm{H}, 13-\mathrm{H}), 6.87-6.83$ (dd, $\left.2 \mathrm{H},{ }^{3} J_{\mathrm{HH}}=7.8 \mathrm{~Hz}, 4-\mathrm{H}, 12-\mathrm{H}\right), 6.48(\mathrm{~s}, 2 \mathrm{H}, 16-\mathrm{H}, 29-\mathrm{H}), 3.87(\mathrm{~s}, 2 \mathrm{H}$, 8-H) ppm.

\section{${ }^{13} \mathrm{C}\left\{{ }^{1} \mathrm{H}\right\}$ NMR}

$\left(101 \mathrm{MHz}, \mathrm{CDCl}_{3}\right)$ : $\delta=159.35$ (7-C, 9-C), 151.16 (6-C, 10-C), 143.28 (17-C, 23-C, 30-C, 36-C), 140.30 (1-C, 15-C), 136.41 (2-C, 14-C), 129.52 (18-C, 22-C, 24-C, 28-C, 31-C, 35-C, 37-C, 41-C), 128.41 (19-C, 21-C, 25-C, 27C, 32-C, 34-C, 38-C, 40-C), 126.49 (20-C, 26-C, 33-C, 39-C), 125.11 (4-C, 12-C), 125.04 (3-C, 13-C), 108.90 (5-C, 11-C), 51.13 (16-C, 29C), $29.73(8-\mathrm{C}) \mathrm{ppm}$. 


\section{${ }^{13} \mathrm{C}\left\{{ }^{1} \mathrm{H}\right\}$ NMR}

$\left(101 \mathrm{MHz},\left[\mathrm{D}_{8}\right] \mathrm{THF}\right)$ : $\delta=160.89$ (7-C, 9-C), 152.13 (6-C, 10-C), 144.39 (17-C, 23-C, 30-C, 36-C), 141.45 (1-C, 15-C), 137.39 (2-C, 14-C), 130.24 (18-C, 22-C, 24-C, 28-C, 31-C, 35-C, 37-C, 41-C), 128.97 (19-C, 21-C, 25-C, 27C, 32-C, 34-C, 38-C, 40-C), 127.01 (20-C, 26-C, 33-C, 39-C), 125.64 (4-C, 12-C), 125.57 (3-C, 13-C), 109.35 (5-C, 11-C), 52.16 (16-C, 29 C), 29.74 (8-C) ppm.

\section{${ }^{13} \mathrm{C}\left\{{ }^{1} \mathrm{H}\right\}$ NMR}

(101 MHz, [D $\mathrm{D}_{8}$ toluene): $\delta=159.67$ (7-C, 9-C), 151.39 (6-C, 10-C), 143.69 (17-C, 23-C, 30-C, 36-C), 140.94 (1-C, 15-C), 137.12 (2-C, 14-C), 129.81 (18-C, 22-C, 24-C, 28-C, 31-C, 35-C, 37-C, 41-C), 128.49 (18-C, 22-C, 24-C, 28C, 31-C, 35-C, 37-C, 41-C), 126.50 (20-C, 26-C, 33-C, 39-C), 125.05 (4-C, 12-C), 125.01 (3-C, 13-C), 108.71 (5-C, 11-C), 51.72 (16-C, 29C), $28.91(8-C)$ ppm.

\section{${ }^{13} \mathrm{C}\left\{{ }^{1} \mathrm{H}\right\}$ NMR}

(101 MHz, [D $]$ benzene):

$\delta=159.71$ (7-C, 9-C), 151.42 (6-C, 10-C), 143.73 (17-C, 23-C, 30-C, 36-C), 140.96 (1-C, 15-C), 137.12 (2-C, 14-C), 129.89 (18-C, 22-C, 24-C, 28-C, 31-C, 35-C, 37-C, 41-C), 128.62 (18-C, 22-C, 24-C, 28C, 31-C, 35-C, 37-C, 41-C), 126.61 (20-C, 26-C, 33-C, 39-C), 125.16 (4-C, 5-C, 11-C, 12-C), 108.84 (5-C, 11-C), 51.80 (16-C, 29-C), 29.07 (8-C) ppm.

\section{MS (ESI[+], THF)}

$\mathrm{m} / \mathrm{z}(\%)$ :

$605.2(14)[M+\mathrm{Na}]^{+}, 583.2(100)[M+\mathrm{H}]^{+}$.

HR-MS (ESI[+], THF)

$\mathrm{m} / \mathrm{z}$ :

605.2196 (cal. 605.2199 for $[M+\mathrm{Na}]^{+}, \mathrm{C}_{41} \mathrm{H}_{30} \mathrm{~N}_{2} \mathrm{NaO}_{2}$ ), 583.2381 (cal. 583.2380 for $\left.[M+\mathrm{H}]^{+}, \mathrm{C}_{22} \mathrm{H}_{17} \mathrm{~N}_{2} \mathrm{O}_{2}\right)$.

Elemental analysis

in \% (calculated)

$\mathrm{C}_{41} \mathrm{H}_{30} \mathrm{~N}_{2} \mathrm{O}_{2}$ (582.70 g/mol): C 84.70 (84.51), H 5.07 (5.19), N 4.65 (4.81).

$\begin{array}{ll}\text { Chemical Formula: } & \mathrm{C}_{22} \mathrm{H}_{18} \mathrm{~N}_{2} \mathrm{O}_{2} \\ \text { Molecular weight: } & 324.40 \mathrm{~g} / \mathrm{mol} \\ \boldsymbol{R}_{\mathrm{f}} \text { (THF/hexane 3:2): } & 0.48 \\ \text { Yield: } & 0.69 \mathrm{~g}, 8.69 \mathrm{mmol}, 13 \%\end{array}$


${ }^{1} \mathrm{H}$ NMR

(300 MHz, [D $]$ DMSO):

$\delta=7.75\left(\mathrm{~s}_{\mathrm{br}}, 1 \mathrm{H},-\mathrm{NH}\right), 7.29(\mathrm{~m}, 4 \mathrm{H}, 19-\mathrm{H}, 21-\mathrm{H}, 25-\mathrm{H}, 27-\mathrm{H}), 7.27$ $\left(\mathrm{d}, 1 \mathrm{H},{ }^{3} \mathrm{JHH}_{\mathrm{HH}}=7.2 \mathrm{~Hz}, 4-\mathrm{H}\right), 6.18\left(\mathrm{~d}, 1 \mathrm{H},{ }^{3} J_{\mathrm{HH}}=8.1 \mathrm{~Hz}, 5-\mathrm{H}\right), 7.21(\mathrm{~m}$, $2 \mathrm{H}, 20-\mathrm{H}, 26-\mathrm{H}), 7.13$ (m, $4 \mathrm{H}, 18-\mathrm{H}, 22-\mathrm{H}, 24-\mathrm{H}, 28-\mathrm{H}), 6.94$ (d, $\left.1 \mathrm{H},{ }^{3} J_{\mathrm{HH}}=7.6 \mathrm{~Hz}, 3-\mathrm{H}\right), 6.18(\mathrm{~s}, 1 \mathrm{H}, 16-\mathrm{H}), 3.85(\mathrm{~s}, 2 \mathrm{H}, 4-\mathrm{H}) \mathrm{ppm}$.

${ }^{13} \mathrm{C}\left\{{ }^{1} \mathrm{H}\right\}$ NMR

(75 MHz, [D $]$ DMSO):

$$
\begin{aligned}
& \delta=167.73 \text { (9-C), } 161.52 \text { (7-C), } 150.36 \text { (6-C), } 142.98 \text { (17-C, 23-C), } \\
& \text { 139.64 (1-C), 135.12 (1-C), } 129.00 \text { (18-C, 22-C, 24-C, 28-C), } 128.42 \\
& \text { (19-C, 21-C, 25-C, 27-C), } 126.42 \text { (20-C, 26-C), } 124.76 \text { (4-C), } 124.26 \\
& \text { (3-C), } 108.78 \text { (5-C), } 50.69 \text { (16-C), } 35.93 \text { (8-C) ppm. }
\end{aligned}
$$

MS (ESI[+], THF)

$\mathrm{m} / \mathrm{z}(\%)$ :

$343.2(73)[M+\mathrm{H}]^{+}, 365.1(100)[M+\mathrm{Na}]^{+}$.

HR-MS (ESI[+], THF)

$\mathrm{m} / \mathrm{z}$ :

343.1438 (cal. 343.1441 for $[M+\mathrm{H}]^{+}, \mathrm{C}_{22} \mathrm{H}_{18} \mathrm{~N}_{2} \mathrm{O}_{2}$ ), 365.1253 (cal. 365.1253 for $\left.[M+N a]^{+}, \mathrm{C}_{22} \mathrm{H}_{16} \mathrm{~N}_{2} \mathrm{NaO}_{2}\right)$.

Elemental analysis

in \% (calculated)

$\mathrm{C}_{41} \mathrm{H}_{30} \mathrm{~N}_{2} \mathrm{O}_{2}$ (324.40 g/mol): C 76.80 (77.17), H 5.45 (5.30), N 7.85 (8.18).

\subsubsection{Complex based on bis(4-benzhydryl-benzoxazol-2-yl)methanide}

\subsubsection{1 \{Bis(4-benzhydryl-benzoxazol-2-yl)methanide\}sodium (24)}

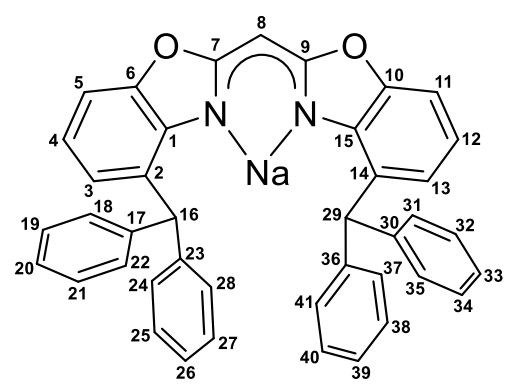

Sodium ( $4.00 \mathrm{mg}, 174 \mu \mathrm{mol}$, 1.04 equiv.) as well as bis(4-benzhydryl-benzoxazol-2-yl)methane (97.4 mg, $167 \mu \mathrm{mol}, 1.00$ equiv.) were weighed in and dissolved in toluene $(6 \mathrm{~mL})$. The reaction mixture was vigorously stirred for $5 \mathrm{~d}$ at room temperature. While stirring, the formation of a white precipitate was observed $(\sim 1 \mathrm{~d})$. After $5 \mathrm{~d}$, the sodium was completely consumed, the solvent was removed under reduced pressure. The obtained white solid was used for analyses without further purification. Crystals suitable for single crystal X-ray diffraction experiments were grown from a saturated solution of 24 in toluene at $-28^{\circ} \mathrm{C}$.

Chemical Formula: $\quad \mathrm{C}_{41} \mathrm{H}_{29} \mathrm{~N}_{2} \mathrm{NaO}_{2}$ 
Molecular weight:

Yield:

\section{${ }^{1} \mathrm{H}$ NMR}

(300 MHz, [D $\left.\mathrm{D}_{8}\right]$ toluene):

$\delta=7.05\left(\mathrm{~d}, 2 \mathrm{H},{ }^{3} J_{\mathrm{HH}}=7.1 \mathrm{~Hz}, 5-\mathrm{H}, 15-\mathrm{H}\right), 7.01-6.95(\mathrm{~m}, 20 \mathrm{H}, 17-\mathrm{H}$, $18-\mathrm{H}, 19-\mathrm{H}, 20-\mathrm{H}, 21-\mathrm{H}, 22-\mathrm{H}, 23-\mathrm{H}, 24-\mathrm{H}, 25-\mathrm{H}, 26-\mathrm{H}, 27-\mathrm{H}, 28-$ $\mathrm{H}, 30-\mathrm{H}, 31-\mathrm{H}, 32-\mathrm{H}, 33-\mathrm{H}, 34-\mathrm{H}, 35-\mathrm{H}, 36-\mathrm{H}, 37-\mathrm{H}, 38-\mathrm{H}, 39-\mathrm{H}$, $40-\mathrm{H}, 41-\mathrm{H}), 6.71\left(\mathrm{dd}, 2 \mathrm{H},{ }^{3} \mathrm{HH}_{\mathrm{HH}}=7.8 \mathrm{~Hz}, 4-\mathrm{H}, 12-\mathrm{H}\right), 6.60(\mathrm{~d}, 2 \mathrm{H}$, $\left.{ }^{3} J_{\mathrm{HH}}=7.7 \mathrm{~Hz}, 3-\mathrm{H}, 13-\mathrm{H}\right), 5.38$ (s, $\left.1 \mathrm{H}, 8-\mathrm{H}\right), 5.27$ (s, $2 \mathrm{H}, 16-\mathrm{H}, 29-$ H) ppm.

${ }^{13} \mathrm{C}\left\{{ }^{1} \mathrm{H}\right\}$ NMR

(75 MHz, [D $\left.\mathrm{D}_{8}\right]$ toluene):

$\delta=169.77$ (7-C, 9-C), 149.77 (6-C, 10-C), 143.78 (1-C, 15-C), 129.44 (18-C, 22-C, 24-C, 28-C, 31-C, 35-C, 37-C, 41-C), 129.15 (17-C, $23-$ C, 30-C, 36-C), 129.07 (19-C, 21-C, 25-C, 27-C, 32-C, 34-C, 38-C, 40-C), 126.91 (20-C, 26-C, 33-C, 39-C), 126.83 (2-C, 14-C), 124.36 (3-C, 13-C), 58.51 (8-C), 53.63 (16-C, 29-C) ppm.

MS (LIFDI[+], toluene)

$\mathrm{m} / \mathrm{z}(\%)$ :

$604.1(100)[\mathrm{M}]^{+}$.

Elemental analysis

in \% (calculated)
$\mathrm{C}_{41} \mathrm{H}_{29} \mathrm{~N}_{2} \mathrm{NaO}_{2}(604.68 \mathrm{~g} / \mathrm{mol}):$ C 79.38 (81.44), $\mathrm{H} 4.97$ (4.83), N 4.61 (4.63).

\subsubsection{2 \{Bis(4-benzhydryl-benzoxazol-2-yl)methanide\}potassium (25)}

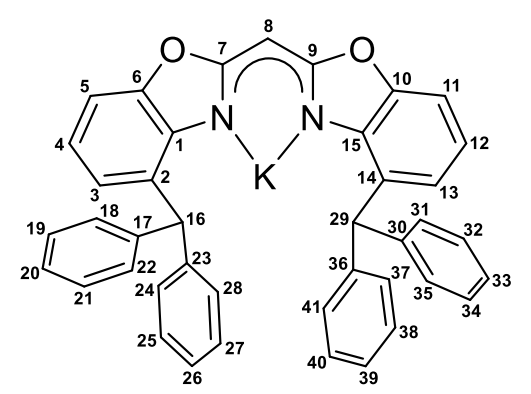

Bis(4-benzhydryl-benzoxazol-2-yl)methane ( $180 \mathrm{mg}, 309 \mu \mathrm{mol}, 1.00$ equiv.) was dissolved in toluene $(8 \mathrm{~mL})$. After potassium hydride $(14.2 \mathrm{mg}, 354 \mu \mathrm{mol}, 1.15$ equiv.) was added to the solution at ambient temperature, hydrogen formation was observed, and the mixture turned immediately red. The reaction mixture was vigorously stirred for $1 \mathrm{~d}$. Afterwards, the solvent was removed under reduced pressure. The reddish-white powder was used for further syntheses without further purification. Crystals of 25 suitable for single crystal XRD measurements were obtained from a saturated toluene solution at $-30^{\circ} \mathrm{C}$ after $1 \mathrm{~d}$.

Chemical Formula: $\quad \mathrm{C}_{41} \mathrm{H}_{29} \mathrm{KN}_{2} \mathrm{O}_{2}$ 
Molecular weight:

Yield:

${ }^{1} \mathrm{H}$ NMR

(300 MHz, $\left.\left[\mathrm{D}_{8}\right] \mathrm{THF}\right)$ :
$620.79 \mathrm{~g} / \mathrm{mol}$

$196.1 \mathrm{mg}, 275 \mu \mathrm{mol}, 89 \%$

$\delta=7.32-7.17(\mathrm{~m}, 12 \mathrm{H}, 19-\mathrm{H}, 20-\mathrm{H}, 21-\mathrm{H}, 25-\mathrm{H}, 26-\mathrm{H}, 27-\mathrm{H}, 32-\mathrm{H}$, 33-H, 34-H, 38-H, 39-H, 40-H), 7.08-7.06 (m, 8 H, 18-H, 22-H, 24$\mathrm{H}, 28-\mathrm{H}, 31-\mathrm{H}, 35-\mathrm{H}, 37-\mathrm{H}, 41-\mathrm{H}), 6.93\left(\mathrm{dd}, 2 \mathrm{H},{ }^{3} J_{\mathrm{HH}}=7.8 \mathrm{~Hz},{ }^{4} J_{\mathrm{HH}}\right.$ $=1.0 \mathrm{~Hz}, 5-\mathrm{H}, 11-\mathrm{H}), 6.63\left(\mathrm{dd}, 2 \mathrm{H},{ }^{3} \mathrm{JHH}_{\mathrm{HH}}=7.8 \mathrm{~Hz}, 4-\mathrm{H}, 12-\mathrm{H}\right), 6.33$ $\left(\mathrm{dd}, 2 \mathrm{H},{ }^{3} J_{\mathrm{HH}}=7.8 \mathrm{~Hz},{ }^{4} J_{\mathrm{HH}}=1.0 \mathrm{~Hz}, 3-\mathrm{H}, 13-\mathrm{H}\right), 6.03(\mathrm{~s}, 2 \mathrm{H}, 16-\mathrm{H}$, 29-H), 4.66 (s, $1 \mathrm{H}, 8-\mathrm{H}) \mathrm{ppm}$.

${ }^{13} \mathrm{C}\left\{{ }^{1} \mathrm{H}\right\}$ NMR

(75 MHz, [D $]$ THF):

$\delta=169.98$ (7-C, 9-C), 149.88 (6-C, 10-C), 145.82 (1-C, 15-C), 145.44 (17-C, 23-C, 30-C, 36-C), 130.52 (18-C, 22-C, 24-C, 28-C, 31-C, 35C, 37-C, 41-C), 129.33 (19-C, 21-C, 25-C, 27-C, 32-C, 34-C, 38-C, 40-C), 128.21 (2-C, 14-C), 127.14, (20-C, 26-C, 33-C, 39-C), 123.68 (3-C, 13-C), 118.70 (4-C, 12-C), 106.22 (5-C, 11-C), 57.52 (8-C), $51.92(16-\mathrm{C}, 29-\mathrm{C}) \mathrm{ppm}$.

MS (LIFDI, THF)

$\mathrm{m} / \mathrm{z}(\%)$ :

$659.3(4)[M+\mathrm{K}]^{+}, 620.3(100)[M]^{+}, 582.3(4)[M-\mathrm{K}+\mathrm{H}]^{+}$.

Elemental analysis

in \% (calculated)

$\mathrm{C}_{41} \mathrm{H}_{29} \mathrm{KN}_{2} \mathrm{O}_{2}(620.79 \mathrm{~g} / \mathrm{mol}):$ C 75.10 (79.33), H 4.71 (4.71), N 4.50 (4.51).

\subsubsection{3 $\{$ Bis(4-benzhydryl-benzoxazol-2-yl)methanide\}rubidium (26)}

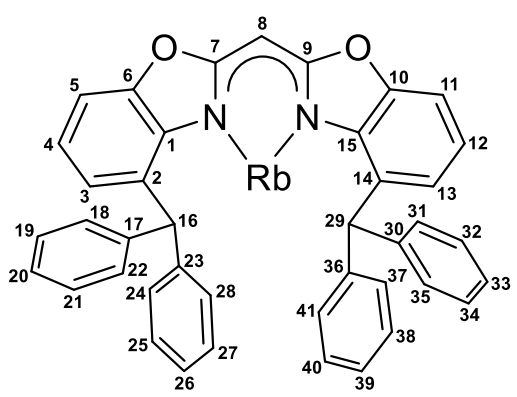

A solution of bis(4-benzhydryl-benzoxazol-2-yl)methane ( $97.7 \mathrm{mg}, 168 \mu \mathrm{mol}, 1.00$ equiv.) in toluene $(6 \mathrm{~mL})$ was added to rubidium $(15.8 \mathrm{mg}, 185 \mu \mathrm{mol}, 1.10$ equiv.). The solution turned red immediately, and dihydrogen gas formation was observed. The reaction mixture was vigorously stirred at ambient temperature until all rubidium $(1 \mathrm{~d})$ was consumed. Afterwards, the solvent was removed under reduced pressure. The reddish-white powder was used for further analysis without additional workup. Crystals suitable for single crystal XRD were obtained by liquid-liquid diffusion of pentane in a saturated toluene solution at $-30^{\circ} \mathrm{C}$ after $3 \mathrm{~d}$.

Chemical Formula: $\quad \mathrm{C}_{41} \mathrm{H}_{29} \mathrm{~N}_{2} \mathrm{O}_{2} \mathrm{Rb}$ 
Molecular weight:

Yield:

${ }^{1} \mathrm{H}$ NMR

(300 MHz, $\left.\left[\mathrm{D}_{8}\right] \mathrm{THF}\right)$ :
$667.16 \mathrm{~g} / \mathrm{mol}$

$85.4 \mathrm{mg}, 128.0 \mu \mathrm{mol}, 76 \%$

$\delta=7.30-7.22(\mathrm{~m}, 12 \mathrm{H}, 19-\mathrm{H}, 20-\mathrm{H}, 21-\mathrm{H}, 25-\mathrm{H}, 26-\mathrm{H}, 27-\mathrm{H}, 32-\mathrm{H}$, 33-H, 34-H, 38-H, 39-H, 40-H), 7.12-7.09 (m, 8 H, 18-H, 22-H, 24$\mathrm{H}, 28-\mathrm{H}, 31-\mathrm{H}, 35-\mathrm{H}, 37-\mathrm{H}, 41-\mathrm{H}), 6.92\left(\mathrm{dd}, 2 \mathrm{H},{ }^{3} J_{\mathrm{HH}}=7.8 \mathrm{~Hz},{ }^{4} J_{\mathrm{HH}}\right.$ $=1.0 \mathrm{~Hz}, 5-\mathrm{H}, 11-\mathrm{H}), 6.63\left(\mathrm{dd}, 2 \mathrm{H},{ }^{3} J_{\mathrm{HH}}=7.8 \mathrm{~Hz}, 4-\mathrm{H}, 12-\mathrm{H}\right), 6.37$ $\left(\mathrm{dd}, 2 \mathrm{H},{ }^{3} J_{\mathrm{HH}}=7.8 \mathrm{~Hz},{ }^{4} \mathrm{JHH}_{\mathrm{HH}}=1.0 \mathrm{~Hz}, 3-\mathrm{H}, 13-\mathrm{H}\right), 6.06(\mathrm{~s}, 2 \mathrm{H}, 16-\mathrm{H}$, 29-H), 4.65 (s, $1 \mathrm{H}, 8-\mathrm{H})$ ppm.

${ }^{13} \mathrm{C}\left\{{ }^{1} \mathrm{H}\right\}$ NMR

(75 MHz, [D $\left.\left.\mathrm{D}_{8}\right] \mathrm{THF}\right)$ :

$\delta=169.83$ (7-C, 9-C), 150.01 (6-C, 10-C), 145.85 (1-C, 15-C), 138.47 (17-C, 23-C, 30-C, 36-C), 130.73 (18-C, 22-C, 24-C, 28-C, 31-C, 35C, 37-C, 41-C), 129.27 (19-C, 21-C, 25-C, 27-C, 32-C, 34-C, 38-C, 40-C), 128.38 (2-C, 14-C), 126.99 (20-C, 26-C, 33-C, 39-C), 123.87 (3-C, 13-C), 118.61 (4-C, 12-C), 106.13 (5-C, 11-C), 57.17 (8-C), 52.14 (16-C, 29-C) ppm.

${ }^{87} \mathrm{Rb}\left\{{ }^{1} \mathrm{H}\right\}$ NMR

$\left(176 \mathrm{MHz},\left[\mathrm{D}_{8}\right] \mathrm{THF}\right)$ : $\delta=-1.69\left(\left[\mathrm{Rb}(\mathrm{THF})_{6}\right]\right),-254.69\left(\left[\mathrm{Rb}\left({ }^{4-\mathrm{BzhH}^{2}} \mathrm{Box}_{2} \mathrm{CH}\right)_{2}\right]\right) \mathrm{ppm}$.

MS (LIFDI, THF)

$m / z(\%):$

$751.1(95)[M+\mathrm{Rb}]^{+}, 667.1(100)[M+\mathrm{H}]^{+}, 666.1(50)[M]^{+}, 582.3(7)$ $[M-\mathrm{Rb}+\mathrm{H}]^{+}$.

Elemental analysis

in \% (calculated)
$\mathrm{C}_{41} \mathrm{H}_{29} \mathrm{~N}_{2} \mathrm{O}_{2} \mathrm{Rb}(667.16 \mathrm{~g} / \mathrm{mol}): \mathrm{C} 71.65$ (73.81), $\mathrm{H} 4.69$ (4.38), N 4.73 (4.20).

\subsubsection{4 \{Bis(4-benzhydryl-benzoxazol-2-yl)methanide\}caesium (27)}

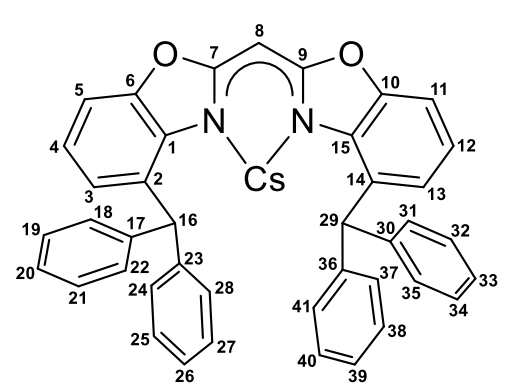

A solution of bis(4-benzhydryl-benzoxazol-2-yl)methane (102.5 mg, $175.9 \mu \mathrm{mol}, 1.00$ equiv.) in toluene $(6 \mathrm{~mL})$ was added to cesium $(25.7 \mathrm{mg}, 193 . \mu \mathrm{mol}, 1.10$ equiv.). The solution turned red immediately, and dihydrogen gas formation was observed. The reaction mixture was vigorously stirred at ambient temperature until all cesium $(\sim 6 \mathrm{~h})$ was consumed. After that, the solvent was 
removed under reduced pressure. The reddish-white powder was used for further analysis without additional workup. Crystals suitable for single crystal XRD experiments were obtained by liquidliquid diffusion of pentane in a saturated toluene solution at $-30^{\circ} \mathrm{C}$ after $1 \mathrm{~d}$.

Chemical Formula:

Molecular weight:

Yield:

${ }^{1} \mathrm{H}$ NMR

(300 MHz, $\left.\left[\mathrm{D}_{8}\right] \mathrm{THF}\right)$ :
$\mathrm{C}_{41} \mathrm{H}_{29} \mathrm{~N}_{2} \mathrm{O}_{2} \mathrm{Cs}$

$714.60 \mathrm{~g} / \mathrm{mol}$

$93.3 \mathrm{mg}, 130.6 \mu \mathrm{mol}, 74 \%$

$\delta=7.28-7.16(\mathrm{~m}, 12 \mathrm{H}, 19-\mathrm{H}, 20-\mathrm{H}, 21-\mathrm{H}, 25-\mathrm{H}, 26-\mathrm{H}, 27-\mathrm{H}, 32-\mathrm{H}$, 33-H, 34-H, 38-H, 39-H, 40-H), 7.14-7.08 (m, 8 H, 18-H, 22-H, 24$\mathrm{H}, 28-\mathrm{H}, 31-\mathrm{H}, 35-\mathrm{H}, 37-\mathrm{H}, 41-\mathrm{H}), 6.92\left(\mathrm{dd}, 2 \mathrm{H},{ }^{3} J_{\mathrm{HH}}=7.7 \mathrm{~Hz},{ }^{4} \mathrm{JHH}_{\mathrm{HH}}\right.$ $=1.0 \mathrm{~Hz}, 5-\mathrm{H}, 11-\mathrm{H}), 6.63\left(\mathrm{dd}, 2 \mathrm{H},{ }^{3} \mathrm{~J}_{\mathrm{HH}}=7.7 \mathrm{~Hz}, 4-\mathrm{H}, 12-\mathrm{H}\right), 6.43$ $\left(\mathrm{dd}, 2 \mathrm{H},{ }^{3} J_{\mathrm{HH}}=7.7 \mathrm{~Hz},{ }^{4} J_{\mathrm{HH}}=1.0 \mathrm{~Hz}, 3-\mathrm{H}, 13-\mathrm{H}\right), 6.17(\mathrm{~s}, 2 \mathrm{H}, 16-\mathrm{H}$, 29-H), 4.64 (s, $1 \mathrm{H}, 8-\mathrm{H}) \mathrm{ppm}$.

${ }^{13} \mathrm{C}\left\{{ }^{1} \mathrm{H}\right\}$ NMR

(75 $\left.\mathrm{MHz},\left[\mathrm{D}_{8}\right] \mathrm{THF}\right)$

$\delta=169.58$ (7-C, 9-C), 150.25 (6-C, 10-C), 146.32 (1-C, 15-C), 145.78

(17-C, 23-C, 30-C, 36-C), 130.77 (18-C, 22-C, 24-C, 28-C, 31-C, 35C, 37-C, 41-C), 129.31 (19-C, 21-C, 25-C, 27-C, 32-C, 34-C, 38-C, 40-C), 129.06 (2-C, 14-C), 126.90 (20-C, 26-C, 33-C, 39-C), 123.81 (3-C, 13-C), 118.38 (4-C, 12-C), 105.98 (5-C, 11-C), 56.64 (8-C), 52.23 (16-C, 29-C) ppm.

${ }^{133} \mathrm{Cs}\left\{{ }^{1} \mathrm{H}\right\}$ NMR

(53 MHz, [D $\left.\left.\mathrm{D}_{8}\right] \mathrm{THF}\right): \quad \delta=-31.12 \mathrm{ppm}$.

MS (LIFDI, THF)

$\mathrm{m} / \mathrm{z}(\%)$ :

$714.0(7)[\mathrm{M}]^{+}, 132.9(100)[\mathrm{Cs}]^{+}$.

Elemental analysis

in \% (calculated)

$\mathrm{C}_{41} \mathrm{H}_{29} \mathrm{~N}_{2} \mathrm{O}_{2} \mathrm{Cs}$ (714.60 g/mol): C 69.80 (68.91), H 4.48 (4.09), N 4.52 (3.92). 


\subsubsection{5 \{(THF) $\left.{ }_{2} \mathrm{~K} @(18-c r o w n-6)\right\}\{B i s(4-b e n z h y d r y l-b e n z o x a z o l-2-y l) m e t h a n i d e\}$}

(28)

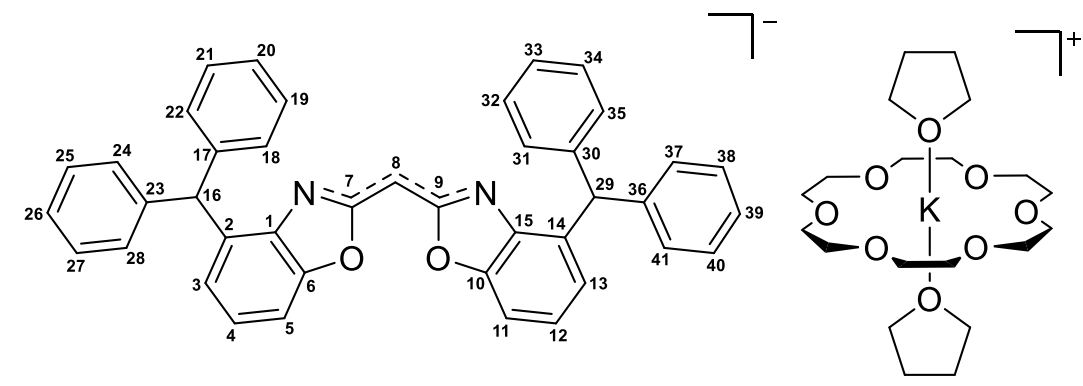

Bis(4-benzhydryl-benzoxazol-2-yl)methane ( $146 \mathrm{mg}, 251 \mu \mathrm{mol}, 1.00$ equiv.) was dissolved in THF (6 mL). Potassium hydride ( $18.3 \mathrm{mg}, 456 \mu \mathrm{mol}, 1.82$ equiv.) was added to the slightly yellow solution at ambient temperature. The reaction mixture turned immediately red while the formation of dihydrogen gas was observed. After the mixture was stirred for $1 \mathrm{~d}$, it was filtered by a syringe equipped with a glass fiber filter, and 18-crown-6 (65.6 mg, $248 \mu \mathrm{mol}, 0.99$ equiv.) was added to the obtained dark-red solution. Within seconds after addition, a strong blue fluorescence was noticed. The solution was stirred at ambient temperature for another day, volatiles were removed under reduced pressure, and 28 was isolated as a dark-red solid. Crystals $(\sim 20 \mathrm{mg})$ suitable for single crystal $\mathrm{X}$-ray diffraction experiments were grown by vapour diffusion of pentane $(1.2 \mathrm{~mL})$ into a THF $(0.8 \mathrm{~mL})$ solution.

Chemical Formula:

Molecular weight:

Yield:

${ }^{1} \mathrm{H}$ NMR

(300 MHz, $\left.\left[\mathrm{D}_{8}\right] \mathrm{THF}\right)$ :

\author{
$\mathrm{C}_{61} \mathrm{H}_{69} \mathrm{~N}_{2} \mathrm{O}_{10} \mathrm{~K}$ \\ $1029.33 \mathrm{~g} / \mathrm{mol}$ \\ $245.3 \mathrm{mg}, 238.3 \mu \mathrm{mol}, 95 \%$
}

\section{${ }^{1} \mathrm{H}$ NMR}

(400 MHz, [D $\left.\mathrm{D}_{6}\right]$ benzene): $\quad \delta=7.42(\mathrm{~m}, 8 \mathrm{H}, 18-\mathrm{H}, 22-\mathrm{H}, 24-\mathrm{H}, 28-\mathrm{H}, 31-\mathrm{H}, 35-\mathrm{H}, 37-\mathrm{H}, 41-\mathrm{H})$, 7.14-7.12 (m, 10 H, 3-H, 13-H, 19-H, 21-H, 25-H, 27-H, 32-H, 34$\mathrm{H}, 38-\mathrm{H}, 40-\mathrm{H}), 7.05\left(\mathrm{~d}, 2 \mathrm{H},{ }^{3} J_{\mathrm{HH}}=7.0 \mathrm{~Hz}, 20-\mathrm{H}, 26-\mathrm{H}, 33-\mathrm{H}, 39-\right.$ $\mathrm{H}), 7.01\left(\mathrm{~d}, 2 \mathrm{H},{ }^{3} \mathrm{JHH}_{\mathrm{HH}}=6.6 \mathrm{~Hz}, 5-\mathrm{H}, 11-\mathrm{H}\right), 6.76\left(\mathrm{dd}, 2 \mathrm{H},{ }^{3} J_{\mathrm{HH}}=\right.$ 7.7 Hz, 4-H, 12-H), 6.66 (s, 2 H, 16-H, 29-H), 5.29 (s, 1 H, 8-H), 3.57 (m, $8 \mathrm{H}, \mathrm{O}-\mathrm{CH}_{2}$ (THF), 2.95 (m, $24 \mathrm{H}, 18$-crown-6), 1.42 (m, $8 \mathrm{H}$, $\mathrm{CH}_{2}$ (THF)) ppm. 
${ }^{13} \mathrm{C}\left\{{ }^{1} \mathrm{H}\right\}$ NMR

(75 MHz, [D 8 THF):

${ }^{13} \mathrm{C}\left\{{ }^{1} \mathrm{H}\right\}$ NMR

(101 MHz, [D 6 benzene): $\delta=170.44$ (7-C, 9-C), 146.51 (17-C, 23-C, 30-C, 36-C), 130.51 (18C, 22- C, 24- C, 28-C, 31-C, 35-C, 37-C, 41-C), 128.52 (19-C, 21-C, 25-C, 27-C, 32-C, 34-C, 38-C, 40-C), 126.17 (20-C, 26-C, 33-C, 39C), 123.08 (3-C, 13-C), 116.38 (4-C, 12-C), 105.22 (5-C, 11-C), 70.97 (18-crown-6), 68.27 (O- $\mathrm{CH}_{2}$ (THF), 51.68 (16-C, 29-C), 26.43 $\left(\mathrm{CH}_{2}\right.$ (THF)) ppm. Quaternary carbon atoms (1-C, 2-C, 6-C, 10-C, 14-C, 15-C) as well as bridging 8-C could not be observed.

$\delta=169.82$ (7-C, 9-C), 151.11 (6-C, 10-C), 145.87 (17-C, C, 23-C, C, 30-C, C, 36-CC), 130.18 (18-C, C, 22-C, C, 24-C, C, 28-C, C, 31-C, C, 35-C, C, 37-C,C, 41-C C), 128.35 (19-C, 21-C, 25-C, 27-C, 32-C, 34-C, 38-C, 40-C), 129.17 (2-C, 14-C), 126.00 (20-C, 26-C, 33-C, 39C), 123.59 (3-C, 13-C), 117.48 (4-C, 12-C), 105.84 (5-C, 11-C), 69.86 (18-crown-6), 68.84 (O- $\mathrm{CH}_{2}$ (THF), 52.89 (8-C), 51.17 (16-C, 29C), $25.84\left(\mathrm{CH}_{2}\right.$ (THF) $)$ ppm. Quaternary carbon atoms (1-C, 15C)could not be observed.

MS (ESI[-], THF)

$\mathrm{m} / \mathrm{z}(\%)$ :

$581.2(100)\left[\left(^{4-\mathrm{BzhH}^{2}} \mathrm{Box}_{2} \mathrm{CH}\right)\right]^{-}$.

HR-MS (ESI[-], THF)

$m / z:$

\section{Elemental analysis}

in $\%$ (calculated)

$\mathrm{C}_{61} \mathrm{H}_{69} \mathrm{KN}_{2} \mathrm{O}_{10}(1029.33 \mathrm{~g} / \mathrm{mol}): \mathrm{C} 69.44$ (71.18), H 6.28 (6.76), N 2.83 (2.72).

Mass spectra of $28+\mathrm{D}_{2} \mathrm{O}$ :

MS (ESI[-], THF)

$\mathrm{m} / \mathrm{z}(\%)$ :

$581.2(100)\left[\left({ }^{4-\mathrm{BzhH}^{2}} \mathrm{Box}_{2} \mathrm{CH}\right)\right]^{-}$.

HR-MS (ESI[-], THF)

$\mathrm{m} / \mathrm{z}$ :
581.2213 (cal. 581.2235 for $\left.\left[\left(^{4-\mathrm{BzhH} 2} \mathrm{Box}_{2} \mathrm{CH}\right)\right]^{-}, \mathrm{C}_{41} \mathrm{H}_{29} \mathrm{~N}_{2} \mathrm{O}_{2}\right)$.
581.2240 (cal. 581.2235 for $\left.\left[\left({ }^{4-\mathrm{BzhH}^{2}} \mathrm{Box}_{2} \mathrm{CH}\right)\right]^{-}, \quad \mathrm{C}_{41} \mathrm{H}_{29} \mathrm{~N}_{2} \mathrm{O}_{2}\right)$, 582.2296 (cal. 582.2297 for $\left.\left[\left({ }^{4-\mathrm{BzhH} 2} \mathrm{Box}_{2} \mathrm{CD}\right)\right]^{-}, \mathrm{C}_{41} \mathrm{H}_{28} \mathrm{DN}_{2} \mathrm{O}_{2}\right)$ ). 


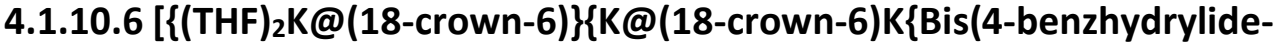 benzoxazol-2-yl)methanide\}] $]_{n}(29)$}

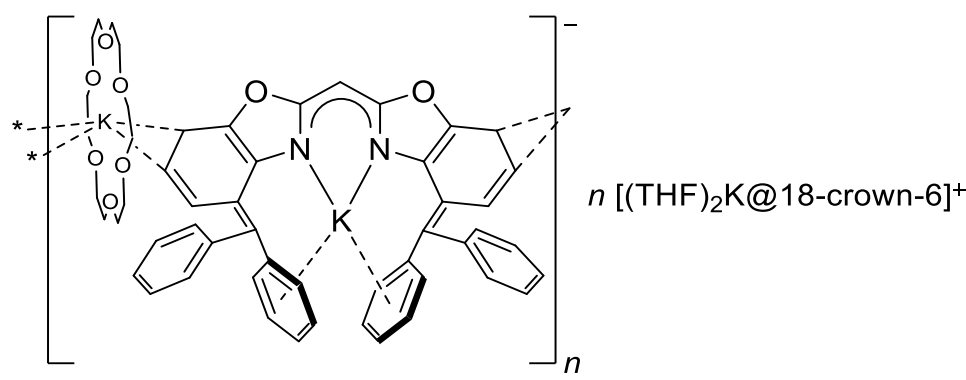

Bis(4-benzhydryl-benzoxazol-2-yl)methane ( $220.6 \mathrm{mg}, 379 \mu \mathrm{mol}, 1.00$ equiv.) was dissolved in THF ( $2 \mathrm{~mL}$ ). Potassium hydride (50.6 mg, $1.26 \mathrm{mmol}, 3.33$ equiv.) and 18-crown-6 (200.0 mg, $757 \mu \mathrm{mol}$, 2.00 equiv.) were added to the slightly yellow solution at ambient temperature. The reaction mixture turned immediately red, while the formation of dihydrogen gas was noticed. After the mixture had been stirred for at least $24 \mathrm{~h}$, a red solution with a strong blue fluorescence and dark-red solid was observed. The solution was removed via syringe, and the dark-red solid was washed with pentane $(3 \times 3 \mathrm{~mL})$. Afterwards, the obtained solid was dried under reduced pressure. Dark purple crystals suitable for single crystal XRD experiments were grown out of a saturated THF solution at $-30^{\circ} \mathrm{C}$ after $5 \mathrm{~d}$.

$\begin{array}{ll}\text { Chemical Formula: } & \mathrm{C}_{73} \mathrm{H}_{91} \mathrm{~K}_{3} \mathrm{~N}_{2} \mathrm{O}_{16} \\ \text { Molecular weight: } & 1369.82 \mathrm{~g} / \mathrm{mol} \\ \text { Yield: } & 245.3 \mathrm{mg}, 238.3 \mu \mathrm{mol}, 95 \%\end{array}$

Elemental analysis

in \% (calculated)

$\mathrm{C}_{73} \mathrm{H}_{91} \mathrm{~K}_{3} \mathrm{~N}_{2} \mathrm{O}_{16}(1369.82 \mathrm{~g} / \mathrm{mol}): \mathrm{C} 62.34$ (64.01), H 6.67 (6.70), N 2.17 (2.05).

Mass spectra $29+\mathrm{D}_{2} \mathrm{O}$ :

MS (ESI[-], THF)

$m / z(\%)$ :

$\left.582.2(19)\left[{ }^{4-\mathrm{BhhH}^{2}} \mathrm{Box}_{2} \mathrm{CD}\right)\right]^{-}, 583.2(100)\left[\left({ }^{4-\mathrm{BhHH}^{-}} \mathrm{Box}_{2} \mathrm{CD}\right)\right]^{-}, 584.2(44)$

HR-MS (ESI[-], THF)

$\mathrm{m} / \mathrm{z}$ :

582.2274 (cal. 582.2282 for, $\mathrm{C}_{41} \mathrm{H}_{28} \mathrm{DN}_{2} \mathrm{O}_{2}$ ), 583.2335 (cal. 583.2380

for [( ${ }^{4-\mathrm{BzhHD}} \mathrm{Box}_{2} \mathrm{CD}$ ) ] $]^{-}, \mathrm{C}_{41} \mathrm{H}_{27} \mathrm{D}_{2} \mathrm{~N}_{2} \mathrm{O}_{2}, 584.2380$ (cal. 584.2417 for $\left.\left[\left({ }^{4-\mathrm{BzhD}^{2}} \mathrm{Box}_{2} \mathrm{CD}\right)\right]^{-}, \mathrm{C}_{41} \mathrm{H}_{26} \mathrm{D}_{3} \mathrm{~N}_{2} \mathrm{O}_{2}\right)$. 


\subsubsection{7 [\{K@(18-crown-6) $(\mu-\mathrm{Cl}) \operatorname{In}\{\mathrm{Bis}(4-\mathrm{benzhydrylide-benzoxazol-2-}$ yl)methanide $]_{2}(30)$}

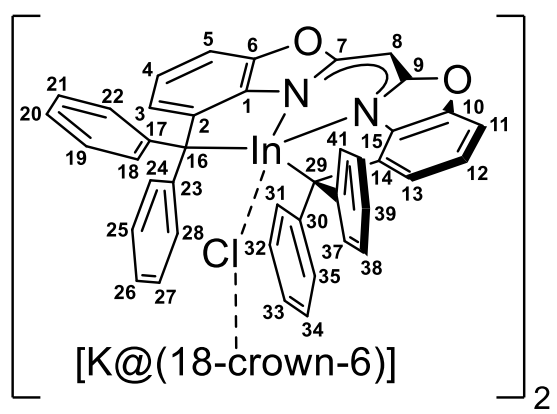

Fluorobenzene ( $3 \mathrm{~mL})$ was added to complex 29 ( $253.0 \mathrm{mg}, 379 \mu \mathrm{mol}, 1.00$ equiv.). Thereafter, indium chloride ( $45.3 \mathrm{mg}, 205 \mu \mathrm{mol}, 1.11$ equiv.) was added under vigorous stirring at ambient temperature. The suspension turned orange-red and clear after roughly $30 \mathrm{~min}$. After the reaction mixture had been stirred for $1 \mathrm{~d}$, the colourless precipitate and orange solution were separated by filtration using a glass pipette equipped with a glass fibre filter. Crystals of [K@(18-crown-6)( $\mu$ $\left.\mathrm{Cl}) \mathrm{In}\left({ }^{4-\mathrm{Bzh}} \mathrm{Box}_{2} \mathrm{CH}\right)\right]_{2} 30$ were grown out of a saturated fluorobenzene solution at $-30^{\circ} \mathrm{C}$ after $\sim 3 \mathrm{~d}$.

Chemical Formula:

Molecular weight:

Yield:

${ }^{1} \mathrm{H}$ NMR

(400 MHz, [D 8 THF):
$\mathrm{C}_{53} \mathrm{H}_{51} \mathrm{ClInKN}_{2} \mathrm{O}_{8}$

$1033.36 \mathrm{~g} / \mathrm{mol}$

$50.6 \mathrm{mg}, 49.0 \mu \mathrm{mol}, 27 \%$

$\delta=7.23\left(\mathrm{~d}, 4 \mathrm{H},{ }^{3} J_{\mathrm{HH}}=7.3 \mathrm{~Hz}, 18-\mathrm{H}, 22-\mathrm{H}, 31-\mathrm{H}, 35-\mathrm{H}\right), 6.93(\mathrm{~d}, 4 \mathrm{H}$, $\left.{ }^{3} J_{\mathrm{HH}}=7.4 \mathrm{~Hz}, 24-\mathrm{H}, 28-\mathrm{H}, 37-\mathrm{H}, 41-\mathrm{H}\right), 6.89$ (m, $\left.2 \mathrm{H}, 5-\mathrm{H}, 11-\mathrm{H}\right)$, $6.85\left(\mathrm{~d}, 4 \mathrm{H},{ }^{3} \mathrm{~J}_{\mathrm{HH}}=8.3 \mathrm{~Hz}, 19-\mathrm{H}, 21-\mathrm{H}, 32-\mathrm{H}, 34-\mathrm{H}\right), 6.79-6.75(\mathrm{~m}$, $\left.6 \mathrm{H},{ }^{3} J_{\mathrm{HH}}=5.9 \mathrm{~Hz}, 20-\mathrm{H}, 25-\mathrm{H}, 27-\mathrm{H}, 33-\mathrm{H}, 39-\mathrm{H}, 40-\mathrm{H}\right), 6.79-6.75$ (m, 6 H, 3-H, 4-H, 12-H, 13-H, 26-H, 40-H), 4.99 (s, 1 H, 8-H), 3.43 (m, $24 \mathrm{H}, 18$-crown-6) ppm.

\section{${ }^{13} \mathrm{C}\left\{{ }^{1} \mathrm{H}\right\}$ NMR}

(101 MHz, [D $]$ THF):

$\delta=170.68$ (7-C, 9-C), 152.01 (17-C, 30-C), 149.61 (23-C, 36-C), 148.99 (6-C, 10-C), 143.40 (2-C, 14-C), 136.84 (1-C, 15-C), 130.55 (18-C, 22-C, 31-C, 35-C), 130.28 (24-C, 28-C, 37-C, 41-C), 128.54 (19-C, 21-C, 32-C, 34-C), 127.68 (25-C, 27-C, 38-C, 40-C), 124.70 (3-C, 13-C), 123.24 (20-C, 33-C), 122.94 (26-C, 33-C), 119.83 (3-C, 13-C), 105.29 (5-C, 11-C), 71.13 (18-crown-6), 68.25 (C-16, C29), 59.57 (C-8) ppm.

MS (LIFDI[+], THF)

$\mathrm{m} / \mathrm{z}(\%)$ :

694.1(1) [M-Cl-(K@18-crown-6) $]^{+}$. 


\section{Elemental analysis}

in \% (calculated)

\subsubsection{8 $\left[\mathrm{K}_{2}(\mathrm{THF})_{2}\{\mathrm{Bis}(4-\text { benzhydrylide-benzoxazol-2-yl)methanide }\})\right]^{-}\left[\mathrm{K}(\mathrm{THF})_{6}\right]^{+}$} (31)

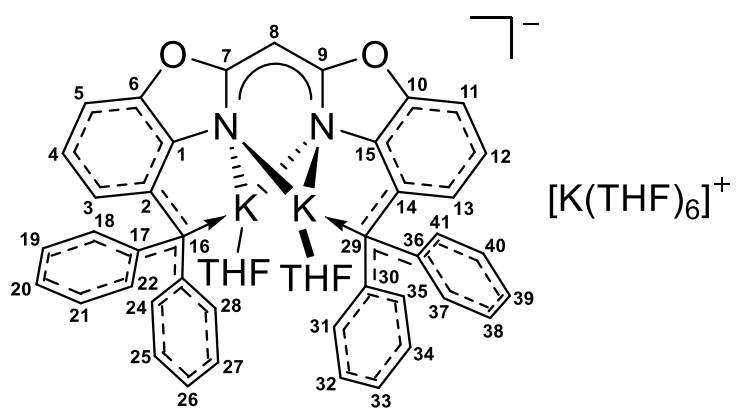

Bis(4-benzhydryl-benzoxazol-2-yl)methane ( $503.1 \mathrm{mg}, 863.4 \mu \mathrm{mol}, 1.00$ equiv.) was dissolved in THF $(8 \mathrm{~mL})$ and cooled to $-30^{\circ} \mathrm{C}$. Thereafter, potassium tert-butoxide $(298.5 \mathrm{mg}, 2.66 \mu \mathrm{mol}$, 3.08 equiv.) was added, and the reaction solution turned yellow-orange. A solution of ${ }^{n} \mathrm{BuLi}$ in hexane $(1.24 \mathrm{~mL}, 2.30 \mathrm{M}, 2.85 \mathrm{mmol}, 3.30$ equiv.) was slowly added under vigorous stirring of the reaction solution at $-30^{\circ} \mathrm{C}$. The solution turned red during the addition of ${ }^{n} \mathrm{BuLi}$, but immediately decoloured until more than one equiv. were added. The reaction solution was allowed to warm to ambient temperature and stirred for $1 \mathrm{~d}$. Subsequently, the deep red solution was layered with hexane $(\sim 1 \mathrm{~mL})$ and stored at $-30^{\circ} \mathrm{C}$. After about $1 \mathrm{~d}$, red crystals suitable for single crystal XRD experiments grew

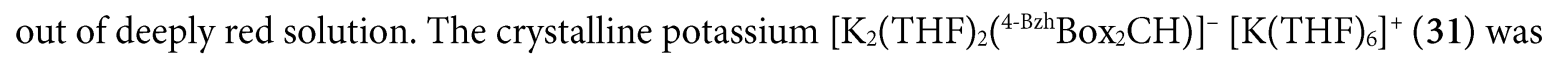
separated by decantation of the solution via syringe and thereafter dried under reduced pressure. The isolated crystals $(772.4 \mathrm{mg}, 606.4 \mu \mathrm{mol}, 70 \%)$ were analytically pure and could be used for further syntheses. The decanted solution was concentrated $(\sim 3 \mathrm{~mL})$, and a second crop of crystals $(51.2 \mathrm{mg}$, $40.2 \mu \mathrm{mol}, 5 \%)$ was obtained from the saturated solution after repeating the previous crystallisation procedures. The drying process of the crystals lead to a partial loss of circa 4 equiv. THF, which fits the elemental analysis, due to that the effective yields should be higher.

Chemical Formula:

Molecular weight:

Yield:

\section{${ }^{1} \mathrm{H}$ NMR}

(400 MHz, [D $\left.\left.\mathrm{D}_{8}\right] \mathrm{THF}\right)$ :
$\mathrm{C}_{73} \mathrm{H}_{91} \mathrm{~N}_{2} \mathrm{O}_{10} \mathrm{~K}_{3}$

$1273.83 \mathrm{~g} / \mathrm{mol}$

$823.6 \mathrm{mg}, 646.6 \mu \mathrm{mol}, 75 \%$

$\delta=6.76\left(\mathrm{~d}, 8 \mathrm{H},{ }^{3}\right)_{\mathrm{HH}}=7.8 \mathrm{~Hz}, 18-\mathrm{H}, 22-\mathrm{H}, 24-\mathrm{H}, 28-\mathrm{H}, 31-\mathrm{H}, 35-\mathrm{H}$, $37-\mathrm{H}, 41-\mathrm{H}), 6.75(\mathrm{~m}, 2 \mathrm{H}, 3-\mathrm{H}, 13-\mathrm{H}), 6.67\left(\mathrm{dd}, 2 \mathrm{H},{ }^{3} J_{\mathrm{HH}}=6.2 \mathrm{~Hz}\right.$, $5-\mathrm{H}, 11-\mathrm{H}), 6.62\left(\mathrm{dd}, 2 \mathrm{H},{ }^{3} J_{\mathrm{HH}}=7.5 \mathrm{~Hz}, 4-\mathrm{H}, 12-\mathrm{H}\right), 6.49(\mathrm{dd}, 8 \mathrm{H}$, $\left.{ }^{3} J_{\mathrm{HH}}=7.8 \mathrm{~Hz}, 19-\mathrm{H}, 21-\mathrm{H}, 25-\mathrm{H}, 27-\mathrm{H}, 32-\mathrm{H}, 34-\mathrm{H}, 38-\mathrm{H}, 40-\mathrm{H}\right)$, $5.67\left(\mathrm{dd}, 4 \mathrm{H},{ }^{3} J_{\mathrm{HH}}=6.9 \mathrm{~Hz}, 20-\mathrm{H}, 26-\mathrm{H}, 33-\mathrm{H}, 39-\mathrm{H}\right), 4.48(\mathrm{~s}, 1 \mathrm{H}$, 8-H) ppm. 
${ }^{13} \mathrm{C}\left\{{ }^{1} \mathrm{H}\right\}$ NMR

(101 MHz, [D $\mathrm{D}_{8}$ ] THF): $\quad \delta=170.36(7-\mathrm{C}, 9-\mathrm{C}), 151.36$ (6-C, 10-C), $146.95(1-\mathrm{C}, 15-\mathrm{C}), 146.57$

(17-C, 23-C, 30-C, 36-C), 136.31 (2-C, 14-C), 129.29 (19-C, 21-C,

25-C, 27-C, 32-C, 34-C, 38-C, 40-C), 128.70 (3-C, 13-C), 120.36 (4-

C, 12-C), 118.30 (18-C, 22-C, 24-C, 28-C, 31-C, 35-C, 37-C, 41-C),

109.45 (20-C, 26-C, 33-C, 39-C), 102.94 (5-C, 11-C), 84.34 (16-C,

29-C), $55.70(8-\mathrm{C}) \mathrm{ppm}$.

Elemental analysis

in \% (calculated) $\quad \mathrm{C}_{73} \mathrm{H}_{91} \mathrm{~N}_{2} \mathrm{O}_{10} \mathrm{~K}_{3}-4 \mathrm{THF}(985.40 \mathrm{~g} / \mathrm{mol}): C 69.27$ (69.48), H 5.95 (6.04), N 2.93 (2.84).

\subsubsection{9 \{Bis(4-benzhydryl-benzoxazol-2-yl)methanide\}thallium (32)}

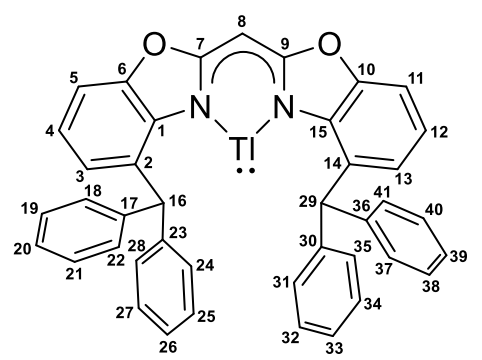

Bis(4-benzhydryl-benzoxazol-2-yl)methane $(81.2 \mathrm{mg}, 139.4 \mu \mathrm{mol}, 1.00$ equiv.) was dissolved in toluene $(5 \mathrm{~mL})$. Sodium tert-butoxide $(15.6 \mathrm{mg}, 162.3 \mu \mathrm{mol}, 1.16$ equiv.) was added at ambient temperature. After that, the yellow reaction mixture was stirred at ambient temperature for $1 \mathrm{~d}$. Subsequently, thallium triflate $(51.3 \mathrm{mg}, 145.1 \mu \mathrm{mol}, 1.10$ equiv.) was added, and the reaction mixture was again stirred at ambient temperature for $2 \mathrm{~d}$. A white precipitate could be observed while the solution became deep yellow. The precipitate was separated from the solution by filtration. A first crop of crystalline compound 1 was obtained after the solution had been stored at $-30^{\circ} \mathrm{C}$ for $1 \mathrm{~d}$. After $2 \mathrm{~d}$, a second crop of crystals (1) was grown out of the concentrated solution $(\sim 2 \mathrm{~mL})$ at $-30^{\circ} \mathrm{C}$.

Chemical Formula:

Molecular weight:

Yield:

${ }^{1} \mathrm{H}$ NMR

(300 MHz, [D $\left.\mathrm{D}_{8}\right]$ toluene):
$\mathrm{C}_{41} \mathrm{H}_{29} \mathrm{~N}_{2} \mathrm{O}_{2} \mathrm{Tl}$

$786.08 \mathrm{~g} / \mathrm{mol}$

$60.2 \mathrm{mg}, 47.6 \mu \mathrm{mol}, 55 \%$

$\delta=7.13-6.96(\mathrm{~m}, 22 \mathrm{H}, 5-\mathrm{H}, 11-\mathrm{H}, 18-\mathrm{H}, 19-\mathrm{H}, 20-\mathrm{H}, 21-\mathrm{H}, 22-\mathrm{H}$, 24-H, 25-H, 26-H, 27-H, 28-H, 31-H, 32-H, 33-H, 34-H, 35-H, 37$\mathrm{H}, 38-\mathrm{H}, 39-\mathrm{H}, 40-\mathrm{H}, 41-\mathrm{H}), 6.69$ (dd, $2 \mathrm{H},{ }^{3} J_{\mathrm{HH}}=7.8 \mathrm{~Hz}, 4-\mathrm{H}, 12-$ $\mathrm{H}), 6.62\left(\mathrm{~d}, 2 \mathrm{H},{ }^{3} \mathrm{H}_{\mathrm{HH}}=8.0 \mathrm{~Hz}, 3-\mathrm{H}, 13-\mathrm{H}\right), 5.77\left(\mathrm{~s}_{\mathrm{br}}, 2 \mathrm{H}, 16-\mathrm{H}, 19-\right.$ $\mathrm{H}), 5.40\left(\mathrm{~s}_{\mathrm{br}}, 1 \mathrm{H}, 8-\mathrm{H}\right) \mathrm{ppm}$. 


\section{${ }^{1} \mathrm{H}$ NMR}

(400 MHz, [D $\mathrm{D}_{6}$ benzene): $\quad \delta=7.09(\mathrm{~d}, 2 \mathrm{H}, 5-\mathrm{H}, 11-\mathrm{H}), 7.03-6.99(\mathrm{~m}, 18-\mathrm{H}, 19-\mathrm{H}, 20-\mathrm{H}, 21-\mathrm{H}$, 22-H, 24-H, 25-H, 26-H, 27-H, 28-H, 31-H, 32-H, 33-H, 34-H, 35$\mathrm{H}, 37-\mathrm{H}, 38-\mathrm{H}, 39-\mathrm{H}, 40-\mathrm{H}, 41-\mathrm{H}), 6.71\left(\mathrm{dd}, 2 \mathrm{H},{ }^{3} \mathrm{~J}_{\mathrm{HH}}=7.8 \mathrm{~Hz}, 4-\mathrm{H}\right.$, $12-\mathrm{H}), 6.67\left(\mathrm{~d}, 2 \mathrm{H},{ }^{3} \mathrm{H}_{\mathrm{HH}}=6.9 \mathrm{~Hz}, 3-\mathrm{H}, 13-\mathrm{H}\right), 5.78\left(\mathrm{~s}_{\mathrm{br}}, 2 \mathrm{H}, 16-\mathrm{H}\right.$, $19-\mathrm{H}), 5.53\left(\mathrm{~s}_{\mathrm{br}}, 1 \mathrm{H}, 8-\mathrm{H}\right) \mathrm{ppm}$.

\section{${ }^{13} \mathrm{C}\left\{{ }^{1} \mathrm{H}\right\} \mathrm{NMR}$}

(101 MHz, [D $\mathrm{D}_{8}$ toluene):

$\delta=168.96$ (7-C, 9-C), 149.51 (6-C, 10-C), 143.78 (17-C, 23-C, 30-C, 36-C), 142.32 (1-C, 15-C), 129.98 (18-C, 22-C, 24-C, 28-C, 31-C, 35C, 37-C, 41-C), 128.81 (19-C, 21-C, 25-C, 27-C, 32-C, 34-C, 38-C, 40-C), 126.57 (20-C, 26-C, 33-C, 39-C), 124.24 (3-C, 13-C), 120.37 (4-C, 12-C), 106.62 (5-C, 11-C), 60.34 (8-C), 52.17 (16-C, 29C) ppm. Quaternary atoms 2-C and 14-C could not be observed.

${ }^{13} \mathrm{C}\left\{{ }^{1} \mathrm{H}\right\} \mathrm{NMR}$

(101 MHz, [D $\mathrm{D}_{6}$ benzene): $\quad \delta=169.39$ (7-C, 9-C), 150.08 (6-C, 10-C), 144.15 (17-C, 23-C, 30-C, 36-C), 142.59 (1-C, 15-C), 130.54 (18-C, 22-C, 24-C, 28-C, 31-C, 35C, 37-C, 41-C), 129.13 (19-C, 21-C, 25-C, 27-C, 32-C, 34-C, 38-C, 40-C), 127.10 (20-C, 26-C, 33-C, 39-C), 124.72 (3-C, 13-C), 120.89 (4-C, 12-C), 107.09(5-C, 11-C), 60.74 (8-C), 53.35 (16-C, 29C) ppm. Quaternary atoms 2-C and 14-C could not be observed.

MS (LIFDI[+], toluene)

$\mathrm{m} / \mathrm{z}(\%)$ : $786.1(100)[M]^{+}, 991.0(10)[M+\mathrm{Tl}]^{+}$.

\section{Elemental analysis}

in \% (calculated)

\subsubsection{0 \{Bis(4-benzhydryl-benzoxazol-2-yl)methanide\}indium (33)}

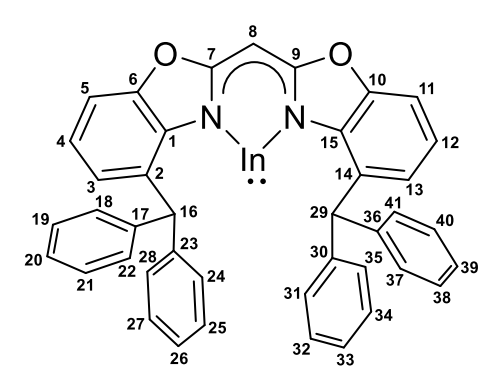

Bis(4-benzhydryl-benzoxazol-2-yl)methane ( $142.9 \mathrm{mg}, 245.2 \mu \mathrm{mol}, 1.00$ equiv.) was dissolved in toluene $(8 \mathrm{~mL})$, and potassium hydride ( $15.7 \mathrm{mg}, 391.5 \mu \mathrm{mol}, 1.60$ equiv.) was added at ambient temperature. Immediately after addition, dihydrogen gas formation was observed, and the reaction mixture turned red. After the reaction mixture was stirred at ambient temperature for $18 \mathrm{~h}$, it was filtered by a syringe equipped with a glass fiber filter, and indium triflate $(65.0 \mathrm{mg}, 246.3 \mu \mathrm{mol}$, 
1.00 equiv.) was added. The suspension was stirred for $24 \mathrm{~h}$ at ambient temperature. The yellow solution was separated from the white precipitate by filtration and stored at $-30^{\circ} \mathrm{C}$ overnight. About $2 \mathrm{~mL}$ of solvent was removed under vacuum, whereby a precipitate was formed that could not be redissolved at ambient temperature. Crystals suitable for single crystal XRD were grown out of the prementioned yellow filtrate at $-30^{\circ} \mathrm{C}$ after $2 \mathrm{~d}$.

$\begin{array}{ll}\text { Chemical Formula: } & \mathrm{C}_{41} \mathrm{H}_{29} \mathrm{~N}_{2} \mathrm{O}_{2} \mathrm{In} \\ \text { Molecular weight: } & 696.51 \mathrm{~g} / \mathrm{mol} \\ \text { Yield: } & 65.5 \mathrm{mg}, 94.0 \mu \mathrm{mol}, 57 \%\end{array}$

${ }^{1} \mathrm{H}$ NMR

(300 MHz, [D $\mathrm{D}_{8}$ ]toluene): $\quad \delta=7.11-7.02(\mathrm{~m}, 20 \mathrm{H}, 18-\mathrm{H}, 19-\mathrm{H}, 20-\mathrm{H}, 21-\mathrm{H}, 22-\mathrm{H}, 24-\mathrm{H}, 25-\mathrm{H}$, 26-H, 27-H, 28-H, 31-H, 32-H, 33-H, 34-H, 35-H, 37-H, 38-H, 39H,40-H, 41-H), 7.01-6.99 (m, 2 H, 5-H, 11-H), 6.74-6.72 (m, 3-H, 4H, 12-H, 13-H), 6.22 (s, 2 H, 16-H, 29-H), 5.43 (s, 1 H, 8-H) ppm.

\section{${ }^{1} \mathrm{H}$ NMR}

(400 MHz, [D $\mathrm{D}_{6}$ benzene): $\quad \delta=7.11-7.08(\mathrm{~m}, 16 \mathrm{H}, 18-\mathrm{H}, 19-\mathrm{H}, 21-\mathrm{H}, 22-\mathrm{H}, 24-\mathrm{H}, 25-\mathrm{H}, 27-\mathrm{H}$, 28-H, 31-H, 32-H, 34-H, 35-H, 37-H, 38-H, 40-H, 41-H), 7.07-7.02 (m, $4 \mathrm{H}, 20-\mathrm{H}, 26-\mathrm{H}, 33-\mathrm{H}, 39-\mathrm{H}), 7.01\left(\mathrm{~d}, 2 \mathrm{H},{ }^{3} J_{\mathrm{HH}}=7.6 \mathrm{~Hz},{ }^{4}\right)_{\mathrm{HH}}=$ $1.5 \mathrm{~Hz}, 5-\mathrm{H}, 11-\mathrm{H}), 6.77\left(\mathrm{dd}, 2 \mathrm{H},{ }^{3} J_{\mathrm{HH}}=7.8 \mathrm{~Hz},{ }^{4} J_{\mathrm{HH}}=1.3 \mathrm{~Hz}, 3-\mathrm{H}\right.$, $13-\mathrm{H}), 6.75\left(\mathrm{dd}, 2 \mathrm{H},{ }^{3} J_{\mathrm{HH}}=7.5 \mathrm{~Hz}, 4-\mathrm{H}, 12-\mathrm{H}\right), 6.23(\mathrm{~s}, 2 \mathrm{H}, 16-\mathrm{H}$, 29-H), 5.52 (s, $1 \mathrm{H}, 8-\mathrm{H}) \mathrm{ppm}$.

\section{${ }^{13} \mathrm{C}\left\{{ }^{1} \mathrm{H}\right\}$ NMR}

(101 MHz, [D $\mathrm{D}_{8}$ toluene): $\quad \delta=167.97$ (7-C, 9-C), 148.61 (6-C, 10-C), 142.93 (17-C, 23-C, 30-C, 36-C), 140.97 (1-C, 15-C), 130.56 (18-C, 22-C, 24-C, 28-C, 31-C, 35C, 37-C, 41-C), 129.82 (2-C, 14-C), 128.67 (19-C, 21-C, 25-C, 27-C, 32-C, 34-C, 38-C, 40-C), 126.99 (20-C, 26-C, 33-C, 39-C), 125.39 (3C, 13-C), 121.50 (4-C, 12-C), 107.26 (5-C, 11-C), 61.26 (8-C), 54.64 (16-C, 29-C) ppm.

\section{${ }^{13} \mathrm{C}\left\{{ }^{1} \mathrm{H}\right\}$ NMR}

(101 MHz, [D ${ }_{6}$ ]benzene): $\quad \delta=167.99$ (7-C, 9-C), 148.66 (6-C, 10-C), 142.98 (17-C, 23-C, 30-C, 36-C), 140.98 (1-C, 15-C), 130.62 (18-C, 22-C, 24-C, 28-C, 31-C, 35C, 37-C, 41-C), 129.11 (2-C, 14-C), 128.57 (19-C, 21-C, 25-C, 27-C, 32-C, 34-C, 38-C, 40-C), 127.05 (20-C, 26-C, 33-C, 39-C), 125.50 (3C, 13-C), 121.65 (4-C, 12-C), 107.35 (5-C, 11-C), 61.33 (8-C), 54.65 (16-C, 29-C) ppm.

MS (LIFDI[+], THF)

$\mathrm{m} / \mathrm{z}(\%)$ :

$582.5(3)[M+\mathrm{H}-\mathrm{In}]^{+}, 696.1(100)[M]^{+}$. 


\section{Elemental analysis}

in \% (calculated)

\subsubsection{1 \{Bis(4-benzhydryl-benzoxazol-2-yl)methanide\}gallium (34)}

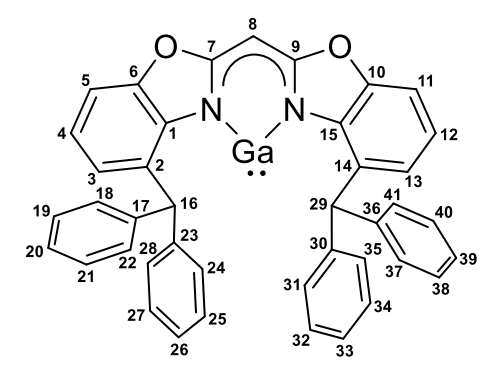

Bis(4-benzhydryl-benzoxazol-2-yl)methane ( $109.3 \mathrm{mg}, 187.6 \mu \mathrm{mol}, 1.00$ equiv.) was dissolved in toluene $(8 \mathrm{~mL})$. Potassium hydride $(8.3 \mathrm{mg}, 206.3 \mu \mathrm{mol}, 1.10$ equiv.) was added at ambient temperature, and the obtained mixture was stirred overnight. The raspberry red solution was cooled to $-30^{\circ} \mathrm{C}$. After the addition of "GaI" ( $60.7 \mathrm{mg}, 308.7 \mu \mathrm{mol}, 1.65$ equiv.), the reaction mixture was stirred at $-30^{\circ} \mathrm{C}$ for $5 \mathrm{~d}$ and at ambient temperature for one day. The white precipitate was separated by filtration from the yellow solution. Colourless crystals of $\mathbf{3 4}$ were obtained after the concentrated solution was stored at $-30^{\circ} \mathrm{C}$ for $2 \mathrm{~d}$. After separation of the mother liquor, evaporation of half of the solvent a second crop of crystals of colourless crystals was obtained.

$\begin{array}{ll}\text { Chemical Formula: } & \mathrm{C}_{41} \mathrm{H}_{29} \mathrm{~N}_{2} \mathrm{O}_{2} \mathrm{Ga} \\ \text { Molecular weight: } & 651.42 \mathrm{~g} / \mathrm{mol} \\ \text { Yield: } & 40.2 \mathrm{mg}, 61.7 \mu \mathrm{mol}, 33 \%\end{array}$

${ }^{1} \mathrm{H}$ NMR

(300 MHz, [D $\left.\mathrm{D}_{8}\right]$ toluene): $\quad \delta=7.18-7.09(\mathrm{~m}, 16 \mathrm{H}, 18-\mathrm{H}, 19-\mathrm{H}, 21-\mathrm{H}, 22-\mathrm{H}, 24-\mathrm{H}, 25-\mathrm{H}, 27-\mathrm{H}$, 28-H, 31-H, 32-H, 34-H, 35-H, 37-H, 38-H, 40-H, 41-H), 7.08-7.04 (m, 4 H, 20-H, 26-H, 33-H, 39-H), $6.94\left(\mathrm{~d}, 2 \mathrm{H},{ }^{3} J_{\mathrm{HH}}=7.7 \mathrm{~Hz}, 5-\mathrm{H}, 11-\right.$ $\mathrm{H}), 6.84\left(\mathrm{~d}, 2 \mathrm{H},{ }^{3} J_{\mathrm{HH}}=7.8 \mathrm{~Hz}, 3-\mathrm{H}, 13-\mathrm{H}\right), 6.75\left(\mathrm{dd}, 2 \mathrm{H},{ }^{3} J_{\mathrm{HH}}=7.8 \mathrm{~Hz}\right.$, 4-H, 12-H), 6.81 (s, 2 H, 16-H, 29-H), 5.40 (s, 1 H, 8-H) ppm.

\section{${ }^{1} \mathrm{H}$ NMR}

(400 MHz, [D $\left.\mathrm{D}_{6}\right]$ benzene): $\quad \delta=7.21-7.18(\mathrm{~m}, 8 \mathrm{H}, 18-\mathrm{H}, 22-\mathrm{H}, 24-\mathrm{H}, 28-\mathrm{H}, 31-\mathrm{H}, 35-\mathrm{H}, 37-\mathrm{H}$, 41-H), 7.13-7.12 (m, 8 H, 19-H, 21-H, 25-H, 27-H, 32-H, 34-H, 38H, 40-H), 7.08-7.07(m, 4 H, 20-H, 26-H, 33-H, 39-H), 6.96 (d, $2 \mathrm{H}$, $\left.{ }^{3} J_{\mathrm{HH}}=7.9 \mathrm{~Hz}, 5-\mathrm{H}, 11-\mathrm{H}\right), 6.88\left(\mathrm{~d}, 2 \mathrm{H},{ }^{3} \mathrm{~J}_{\mathrm{HH}}=7.3 \mathrm{~Hz}, 3-\mathrm{H}, 13-\mathrm{H}\right), 6.85$ (s, 2 H, 16-H, 29-H), $6.76\left(\mathrm{dd}, 2 \mathrm{H},{ }^{3} \mathrm{~J}_{\mathrm{HH}}=7.9 \mathrm{~Hz}, 4-\mathrm{H}, 12-\mathrm{H}\right), 5.47(\mathrm{~s}$, $1 \mathrm{H}, 8-\mathrm{H}) \mathrm{ppm}$. 
${ }^{13} \mathrm{C}\left\{{ }^{1} \mathrm{H}\right\}$ NMR

(101 MHz, [D $\mathrm{D}_{8}$ toluene): $\quad \delta=166.96$ (7-C, 9-C), 148.41 (6-C, 10-C), 143.09 (17-C, 23-C, 30-C, 36-C), 139.47 (1-C, 15-C), 130.76 (18-C, 22-C, 24-C, 28-C, 31-C, 35C, 37-C, 41-C), 130.69 (2-C, 14-C), 128.77 (19-C, 21-C, 25-C, 27-C, 32-C, 34-C, 38-C, 40-C), 126.25 (20-C, 26-C, 33-C, 39-C), 122.45 (4C, 12-C), 107.64 (5-C, 11-C), 62.96 (8-C), 54.97 (16-C, 29-C).

${ }^{13} \mathrm{C}\left\{{ }^{1} \mathrm{H}\right\}$ NMR

(101 MHz, [D $\mathrm{D}_{6}$ benzene): $\quad \delta=166.89$ (7-C, 9-C), 148.27 (6-C, 10-C), 142.95 (17-C, 23-C, 30-C, 36-C), 139.17 (1-C, 15-C), 130.52 (18-C, 22-C, 24-C, 28-C, 31-C, 5C, 37-C,41-C), 126.17 (2-C, 14-C), 128.67 (19-C, 21-C, 25-C, 27-C, 32-C, 34-C, 38-C, 40-C), 126.95 (20-C, 26-C, 33-C, 39-C), 122.40 (4C, 12-C), 107.53 (5-C, 11-C), 62.96 (8-C), 54.80 (16-C, 29-C).

MS (LIFDI[+], toluene)

$\mathrm{m} / \mathrm{z}(\%)$ : $650.0(100)[M]^{+}$.

Elemental analysis

in $\%$ (calculated) (4.30).

\subsubsection{2 \{Bis(4-benzhydryl-benzoxazol-2-yl)methanide\}dimethanido aluminium (35)}

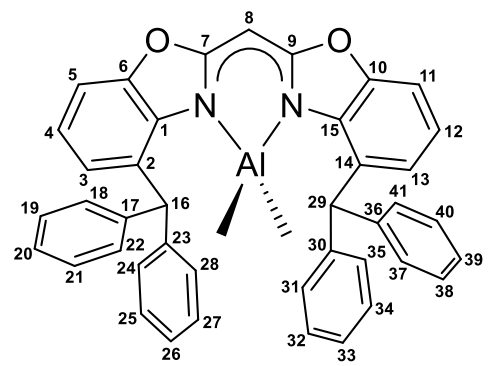

Bis(4-benzhydryl-benzoxazol-2-yl)methane ( $346.1 \mathrm{mg}, 594.0 \mu \mathrm{mol}, 1.00$ equiv.) was dissolved in toluene (12 mL). A solution of $\mathrm{AlMe}_{3}(50.46 \mathrm{mg}, 700.0 \mu \mathrm{mol}, 350 \mu \mathrm{L}(2 \mathrm{M}), 1.18$ equiv.) in $n$-hexane was slowly added at room temperature while stirring. After the lemon-coloured reaction solution was stirred for $18 \mathrm{~h}$, volatiles were removed in fine vacuum, and a yellowish powder was obtained. This powder was washed with $n$-hexane $(3 \times 3 \mathrm{~mL})$ and dried under vacuum. Crystals of 35 suitable for single crystal XRD experiments were obtained from a saturated solution of toluene at $-30^{\circ} \mathrm{C}$.

Chemical Formula:

Molecular weight:

Yield:
$\mathrm{C}_{43} \mathrm{H}_{35} \mathrm{AlN}_{2} \mathrm{O}_{2}$

$638.75 \mathrm{~g} / \mathrm{mol}$

$235.6 \mathrm{mg}, 593.9 \mathrm{mmol}, 62 \%$. 


\section{${ }^{1} \mathrm{H}$ NMR}

(300 MHz, [D $\left.\mathrm{D}_{8}\right]$ toluene): $\quad \delta=7.16-7.13(\mathrm{~m}, 8 \mathrm{H}, 18-\mathrm{H}, 22-\mathrm{H}, 24-\mathrm{H}, 28-\mathrm{H}, 31-\mathrm{H}, 35-\mathrm{H}, 37-\mathrm{H}$, 41-H), 7.08-7.03 (m, 8 H, 19-H, 21-H, 25-H, 27-H, 32-H, 34-H, 38H, 40-H), 7.00-6.98 (m, 4 H, 20-H, 26-H, 33-H, 39-H), 6.90 (dd, 2 H, $\left.{ }^{3} J_{\mathrm{HH}}=7.9 \mathrm{~Hz},{ }^{4} J_{\mathrm{HH}}=1.3 \mathrm{~Hz}, 3-\mathrm{H}, 13-\mathrm{H}\right), 6.79\left(\mathrm{dd}, 2 \mathrm{H},{ }^{3} J_{\mathrm{HH}}=7.9 \mathrm{~Hz}\right.$, $\left.{ }^{4} J_{\mathrm{HH}}=1.2 \mathrm{~Hz}, 5-\mathrm{H}, 11-\mathrm{H}\right), 6.68\left(\mathrm{dd}, 2 \mathrm{H},{ }^{3} \mathrm{JHH}_{\mathrm{HH}}=7.9 \mathrm{~Hz}, 4-\mathrm{H}, 12-\mathrm{H}\right)$, 6.43 (s, $2 \mathrm{H}, 16-\mathrm{H}, 29-\mathrm{H}), 5.22(\mathrm{~s}, 1 \mathrm{H}, 8-\mathrm{H}),-0.45$ (s, $6 \mathrm{H}$, $\left.\mathrm{Al}\left(\mathrm{CH}_{3}\right)_{2}\right) \mathrm{ppm}$.

\section{${ }^{13} \mathrm{C}\left\{{ }^{1} \mathrm{H}\right\}$ NMR}

(101 MHz, [D $\left.\mathrm{D}_{8}\right]$ toluene): $\quad \delta=167.95$ (7-C, 9-C), 148.90 (6-C, 10-C), 143.86 (17-C, 23-C, 30-C, 36-C), 136.48 (1-C, 15-C), 130.09 (18-C, 22-C, 24-C, 28-C, 31-C, 35C, 37-C, 41-C), 129.60 (2-C, 14-C), 128.45 (19-C, 21-C, 25-C, 27-C, 32-C, 34-C, 38-C, 40-C), 128.19 (3-C, 13-C), 126.77 (20-C. 26-C, 33C, 39-C), 122.98 (4-C, 12-C), 107.68 (5-C, 11-C), 60.16 (8-C), 51.62 (16-C, 29-C), $-4.93\left(\mathrm{Al}\left(\mathrm{CH}_{3}\right)_{2}\right) \mathrm{ppm}$.

MS (LIFDI[+], toluene)

$\mathrm{m} / \mathrm{z}(\%)$ : $638.3(100)[M]^{+}, 623.3(4)[M-\mathrm{Me}]^{+}, 582.3(4)\left[M-\mathrm{AlMe}_{2}\right]^{+}$.

Elemental analysis in \% (calculated) (4.39).

\subsubsection{3 \{Bis(4-benzhydryl-benzoxazol-2-yl)methanide\}iodidomethanido aluminium (36)}

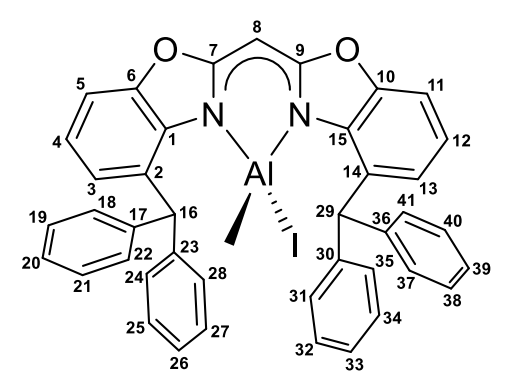

Compound 35 (123.9 mg, $194.0 \mu \mathrm{mol}, 1.00$ equiv.) was dissolved in toluene ( $3 \mathrm{~mL}$ ). Iodine (50.0 mg, $197.0 \mu \mathrm{mol}, 1.02$ equiv.) was added to a slightly yellow solution. The profound red reaction solution was stirred for $1 \mathrm{~d}$ at ambient temperature. Thereafter, the solution turned clear orange. The solvent was removed under reduced pressure, and 36 was obtained as an orangish white solid. Crystals suitable for single crystal X-ray diffraction analysis were grown by liquid-liquid diffusion of pentane in toluene.

Chemical Formula:

Molecular weight:
$\mathrm{C}_{42} \mathrm{H}_{32} \mathrm{AlIN}_{2} \mathrm{O}_{2}$

$750.62 \mathrm{~g} / \mathrm{mol}$ 
Yield:

${ }^{1} \mathrm{H}$ NMR

(400 MHz, [D $\mathrm{D}_{8}$ toluene):
$118.9 \mathrm{mg}, 158.4 \mu \mathrm{mol}, 82 \%$.

$\delta=7.49\left(\mathrm{~d}, 4 \mathrm{H},{ }^{3} \mathrm{JHH}_{\mathrm{HH}}=7.5 \mathrm{~Hz}, 18-\mathrm{H}, 22-\mathrm{H}, 31-\mathrm{H}, 35-\mathrm{H}\right), 7.13-7.09$ (m, 4 H, 19-H, 21-H, 32-H, 34-H), 7.04-7.02 (m, 12 H, 24-H, 25-C, 26-H, 27-C, 28-H, 37-H, 38-H, 39-H, 40-C, 41-H), 6.98-6.95 (m, $2 \mathrm{H}, 20-\mathrm{H}, 39-\mathrm{H}), 6.94\left(\mathrm{dd}, 2 \mathrm{H},{ }^{3} J_{\mathrm{HH}}=7.8 \mathrm{~Hz},{ }^{4} J_{\mathrm{HH}}=1.1 \mathrm{~Hz}, 3-\mathrm{H}, 13-\right.$ $\mathrm{H}), 6.90(\mathrm{~s}, 2 \mathrm{H}, 16-\mathrm{H}, 29-\mathrm{H}), 6.74\left(\mathrm{dd}, 2 \mathrm{H},{ }^{3} J_{\mathrm{HH}}=7.9 \mathrm{~Hz},{ }^{4} J_{\mathrm{HH}}=\right.$ $1.2 \mathrm{~Hz}, 5-\mathrm{H}, 11-\mathrm{H}), 6.67\left(\mathrm{dd}, 2 \mathrm{H},{ }^{3} J_{\mathrm{HH}}=7.9 \mathrm{~Hz}, 4-\mathrm{H}, 12-\mathrm{H}\right), 5.17(\mathrm{~s}$, $1 \mathrm{H}, 8-\mathrm{H}),-0.62\left(\mathrm{Al}\left(\mathrm{CH}_{3}\right)\right) \mathrm{ppm}$.

\section{${ }^{1} \mathrm{H}$ NMR}

(400 MHz, [D $\left.\mathrm{D}_{6}\right]$ benzene): $\quad \delta=7.53\left(\mathrm{~d}, 4 \mathrm{H},{ }^{3} \mathrm{H}_{\mathrm{HH}}=7.6 \mathrm{~Hz}, 18-\mathrm{H}, 22-\mathrm{H}, 31-\mathrm{H}, 35-\mathrm{H}\right), 7.16-7.12$ (m, 4 H, 19-H, 21-H, 32-H, 34-H), 7.10-7.02 (m, 12 H, 24-H, 25-C, 26-H, 27-C, 28-H, 37-H, 38-H, 39-H, 40-C, 41-H), 6.99-6.97 (m, $2 \mathrm{H}, 20-\mathrm{H}, 39-\mathrm{H}), 6.98(\mathrm{~s}, 2 \mathrm{H}, 16-\mathrm{H}, 29-\mathrm{H}), 6.96\left(\mathrm{dd}, 2 \mathrm{H},{ }^{3} J_{\mathrm{HH}}=\right.$ $\left.6.4 \mathrm{~Hz},{ }^{4} J_{\mathrm{HH}}=1.1 \mathrm{~Hz}, 3-\mathrm{H}, 13-\mathrm{H}\right), 6.72\left(\mathrm{dd}, 2 \mathrm{H},{ }^{3} J_{\mathrm{HH}}=7.9 \mathrm{~Hz},{ }^{4} J_{\mathrm{HH}}=\right.$ $1.1 \mathrm{~Hz}, 5-\mathrm{H}, 11-\mathrm{H}), 6.64\left(\mathrm{dd}, 2 \mathrm{H},{ }^{3} \mathrm{~J}_{\mathrm{HH}}=7.9 \mathrm{~Hz}, 4-\mathrm{H}, 12-\mathrm{H}\right), 5.18$ (s, $1 \mathrm{H}, 8-\mathrm{H}),-0.49\left(\mathrm{Al}\left(\mathrm{CH}_{3}\right)_{2}\right) \mathrm{ppm}$.

\section{${ }^{13} \mathrm{C}\left\{{ }^{1} \mathrm{H}\right\}$ NMR}

(101 MHz, [D $\left.\mathrm{D}_{8}\right]$ toluene):

$\delta=167.11$ (7-C, 9-C), 148.63 (6-C, 10-C), 145.18 (17-C, 30-C), 142.77 (23-C, 36-C), 135.10 (1-C, 15-C), 130.67 (18-C, 22-C, 31-C, 35-C), 130.41 (2-C, 14-C), 130.19 (24-C, 28-C, 37-C, 41-C), 128.99 (3-C, 13-C), 128.35 (19-C, 21-C, 32-C, 34-C), 128.30 (25-C, 27-C, 38-C, 40-C), 126.84 (20-C, 33-C), 126.78 (26-C, 39-C), 123.82 (4-C, 12-C), 107.90 (5-C, 11-C), 61.62 (8-C), 51.62 (16-C, 29-C), -2.61 $\left(\mathrm{Al}\left(\mathrm{CH}_{3}\right)\right)$ ppm.

\section{${ }^{13} \mathrm{C}\left\{{ }^{1} \mathrm{H}\right\}$ NMR}

(101 MHz, [D $\mathrm{D}_{6}$ benzene): $\quad \delta=167.11$ (7-C, 9-C), 148.64 (6-C, 10-C), 145.19 (17-C, 30-C), 142.86 (23-C, 36-C), 135.11 (1-C, 15-C), 130.72 (18-C, 22-C, 31-C, 35-C), 130.41 (2-C, 14-C), 130.25 (24-C, 28-C, 37-C, 41-C), 129.11 (3-C, 13-C), 128.47 (19-C, 21-C, 32-C, 34-C), 128.43 (25-C, 27-C, 38-C, 40-C), 126.95 (20-C, 33-C), 126.89 (26-C, 39-C), 123.97 (4-C, 12-C), 107.99 (5-C, 11-C), 61.73 (8-C), 51.69 (16-C, 29-C), -2.48 $\left(\mathrm{Al}\left(\mathrm{CH}_{3}\right)\right)$ ppm.

MS (LIFDI[+], toluene)

$m / z(\%):$
$750.0(100)[M]^{+}, 623.3(4)[M-\mathrm{I}]^{+}, 582.2(7)[M-\mathrm{AlMeI}+\mathrm{H}]^{+}$. 


\section{Elemental analysis}

in \% (calculated)

\subsubsection{4 \{Bis(4-benzhydryl-benzoxazol-2-yl)methanide\}diiodido aluminium (37)}

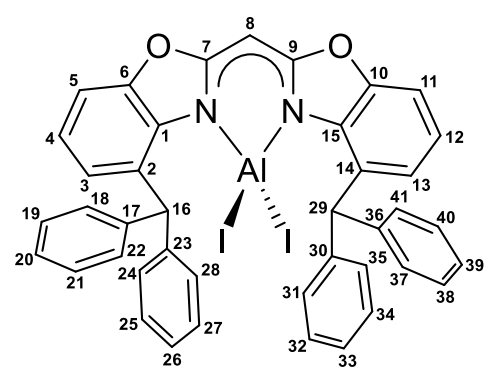

Method A: Complex 35 (214.8 mg, $336.3 \mu \mathrm{mol}, 1.00$ equiv.) was dissolved in toluene ( $4 \mathrm{~mL})$. Iodine ( $85.5 \mathrm{mg}, 336.3 \mu \mathrm{mol}, 1.00$ equiv.) was added to a slightly yellow solution. The deep red reaction solution was stirred for $1 \mathrm{~d}$ at ambient temperature. Subsequently, the solution became clear brown. After that, a second equivalent of iodine ( $85.5 \mathrm{mg}, 336.3 \mu \mathrm{mol}, 1.00$ equiv.) was added, and the solution was stirred for $1 \mathrm{~d}$ at ambient temperature and $4 \mathrm{~d}$ at $70^{\circ} \mathrm{C}$. A white precipitate was formed which was separated from the brown solution by a transfer canula equipped with a glass fiber filter. The precipitate was washed with toluene $(1 \mathrm{~mL})$ and dried under fine vacuum. Crystals of the obtained white powder 37 were grown out of hot saturated toluene solution. The powder was used without any further purification for synthesis.

Method B: Toluene (12 mL) was added to alane 38 (332.7 mg, $473.4 \mu \mathrm{mol}, 1.00$ equiv.). Subsequently, iodine ( $120.5 \mathrm{mg}, 474.8 \mu \mathrm{mol}, 1.00$ equiv.) was added in an argon counterflow to the white suspension. The iodine immediately reacted with solvated 38 while the reaction mixture became clear and yellow. A white solid precipitated after the reaction solution had been stirred for $1 \mathrm{~d}$ at ambient temperature. The mixture was stirred for another day, filtered by a Teflon tube equipped with a glass fiber filter, and obtained white solid was washed with toluene ( $3 \mathrm{~mL}$ ) and dried under reduced pressure (143.4 mg, $166.2 \mu \mathrm{mol}, 35 \%)$. The solution was concentrated to ca. $4 \mathrm{~mL}$ and stored at $-30^{\circ} \mathrm{C}$. A second crop of crystalline $37(121.8 \mathrm{mg}$, $166.2 \mu \mathrm{mol}, 30 \%)$ grew out of the solution after one night.

Chemical Formula:

Molecular weight:

Method A Yield:

Method B Yield:

${ }^{1} \mathrm{H}$ NMR

(300 MHz, [D $\mathrm{D}_{8}$ ]toluene):
$\mathrm{C}_{41} \mathrm{H}_{29} \mathrm{AlI}_{2} \mathrm{~N}_{2} \mathrm{O}_{2}$

$862.49 \mathrm{~g} / \mathrm{mol}$

$220.6 \mathrm{mg}, 255.8 \mathrm{mmol}, 76 \%$

$265.2 \mathrm{mg}, 307.5 \mu \mathrm{mol}, 65 \%$

$\delta=7.31\left(\mathrm{~d},{ }^{3} J_{\mathrm{HH}}=7.5 \mathrm{~Hz}, 8 \mathrm{H}, 18-\mathrm{H}, 22-\mathrm{H}, 24-\mathrm{H}, 28-\mathrm{H}, 31-\mathrm{H}, 35-\mathrm{H}\right.$, $37-\mathrm{H}, 41-\mathrm{H}$ ), 7.20 (s, $2 \mathrm{H}, 16-\mathrm{H}, 29-\mathrm{H}), 7.12-7.07$ (m, 8 H, 19-H, 21$\mathrm{H}, 25-\mathrm{H}, 27-\mathrm{H}, 32-\mathrm{H}, 34-\mathrm{H}, 38-\mathrm{H}, 40-\mathrm{H})$, 7.04-6.99(m, 4 H, 20-H, 
26-H, 33-H, 39-H), 6.70-6.63 (m, $6 \mathrm{H}, 3-\mathrm{H}, 4-\mathrm{H}, 5-\mathrm{H}, 11-\mathrm{H}, 12-\mathrm{H}$, 13-H), 5.13 (s, $1 \mathrm{H}, 8-\mathrm{H}) \mathrm{ppm}$.

${ }^{13} \mathrm{C}\left\{{ }^{1} \mathrm{H}\right\}$ NMR

(101 MHz, [D $\mathrm{D}_{8}$ ] toluene): $\quad \delta=166.21(7-\mathrm{C}, 9-\mathrm{C}), 148.44$ (6-C, 10-C), 144.23 (17-C, 23-C, 30-C, 36-C), 134.24 (1-C, 15-C), 130.91 (18-C, 22-C, 24-C, 28-C, 31-C, 35C, 37-C, 41-C), 128.45 (2-C, 14-C), 128.23 (19-C, 21-C, 25-C, 27-C, 32-C, 34-C, 38-C, 40-C), 126.73 (20-C, 26-C, 33-C, 39-C), 125.60 (3C, 13-C), 124.34 (4-C, 12-C), 107.96 (5-C, 11-C), 62.34 (8-C), 51.98 (16-C, 29-C) ppm.

MS (LIFDI[+], toluene)

$\mathrm{m} / \mathrm{z}(\%)$ :

$862.1(100)[M]^{+}$.

Elemental analysis

in \% (calculated)

$\mathrm{C}_{48} \mathrm{H}_{37} \mathrm{AlI}_{2} \mathrm{~N}_{2} \mathrm{O}_{2}(862.49 \mathrm{~g} / \mathrm{mol})$ : C 59.62 (60.39), H 3.81 (3.91), N $3.15(2.93)$.

\subsubsection{5 \{Bis(4-benzhydryl-benzoxazol-2-yl)methanide\}dihydrido aluminium (38)}

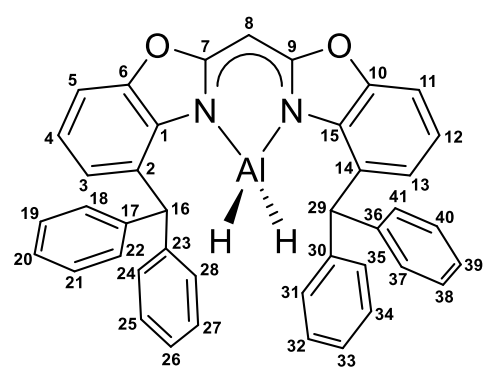

To a suspension of bis(4-benzhydryl-benzoxazol-2-yl)methane ( $967.7 \mathrm{mg}, 1.66 \mathrm{mmol}, 1.00$ equiv.) in toluene $(10 \mathrm{~mL})$ a $0.5 \mathrm{M}$ solution of $\mathrm{AlH}_{3} \cdot \mathrm{NMe}_{2} \mathrm{Et}(188.4 \mathrm{mg}, 3.65 \mathrm{~mL}, 1.83 \mathrm{mmol}, 1.10$ equiv.) in toluene was slowly added under vigorous stirring at ambient temperature. The reaction mixture turned bright yellow and during the addition of the aluminium hydride precursor. After the reaction solution had been stirred at ambient temperature overnight, a colourless powder precipitated out of the solution. The yellow solution was decanted by syringe, and obtained solid was dried under reduced pressure. This solid was found to consist of analytically pure complex 38 (569.0 mg). A second crop of crystalline alane 38 was yielded by crystallisation from the previously decanted solution (121.8 mg). Crystals suitable for single crystal X-ray diffraction analysis were grown from a saturated fluorobenzene or toluene solution.

Chemical Formula:

Molecular weight:

Yield:
$\mathrm{C}_{41} \mathrm{H}_{31} \mathrm{AlN}_{2} \mathrm{O}_{2} \cdot$ (toluene)

$702.83 \mathrm{~g} / \mathrm{mol}$

$690.8 \mathrm{mg}, 983.9 \mathrm{mmol}$, 59\%. 


\section{${ }^{1} \mathrm{H}$ NMR}

(400 MHz, [D 8 toluene):

$\delta=7.24-7.23(\mathrm{~m}, 8 \mathrm{H}, 18-\mathrm{H}, 22-\mathrm{H}, 24-\mathrm{H}, 28-\mathrm{H}, 31-\mathrm{H}, 35-\mathrm{H}, 37-\mathrm{H}$, 41-H), 7.13-7.09 (m, 8 H, 19-H, 21-H, 25-H, 27-H, 32-H, 34-H, 38$\mathrm{H}, 40-\mathrm{H}), 7.06-7.04(\mathrm{~m}, 4 \mathrm{H}, 20-\mathrm{H}, 26-\mathrm{H}, 33-\mathrm{H}, 39-\mathrm{H}), 6.90\left(\mathrm{dd},{ }^{3} \mathrm{~J}_{\mathrm{HH}}\right.$ $\left.=7.7 \mathrm{~Hz},{ }^{4} J_{\mathrm{HH}}=1.1 \mathrm{~Hz}, 2 \mathrm{H}, 3-\mathrm{H}, 13-\mathrm{H}\right), 6.77\left(\mathrm{dd},{ }^{3} J_{\mathrm{HH}}=8.0 \mathrm{~Hz}, 2 \mathrm{H}\right.$, 5-H, 11-H), 6.70 (s, 16-H, 29-H), $6.67\left(\mathrm{dd},{ }^{3} J_{\mathrm{HH}}=7.9 \mathrm{~Hz}, 2 \mathrm{H}, 4-\mathrm{H}\right.$, 12-H), 5.03 (s, $1 \mathrm{H}, 8-\mathrm{H}), 4.86$ (s $\mathrm{s}_{\mathrm{b}}, 2 \mathrm{H}, \mathrm{AlH}_{2}$ ) ppm.

\section{${ }^{1} \mathrm{H}$ NMR}

(300 MHz, [D $\left.\mathrm{D}_{6}\right]$ benzene):

$\delta=7.33-7.31(\mathrm{~m}, 8 \mathrm{H}, 18-\mathrm{H}, 22-\mathrm{H}, 24-\mathrm{H}, 28-\mathrm{H}, 31-\mathrm{H}, 35-\mathrm{H}, 37-\mathrm{H}$, 41-H), 7.19-7.13 (m, 8 H, 19-H, 21-H, 25-H, 27-H, 32-H, 34-H, 38$\mathrm{H}, 40-\mathrm{H}), 7.11-7.08(\mathrm{~m}, 4 \mathrm{H}, 20-\mathrm{H}, 26-\mathrm{H}, 33-\mathrm{H}, 39-\mathrm{H}), 6.96\left(\mathrm{dd},{ }^{3} \mathrm{~J}_{\mathrm{HH}}\right.$ $\left.=7.7 \mathrm{~Hz},{ }^{4} J_{\mathrm{HH}}=1.1 \mathrm{~Hz}, 2 \mathrm{H}, 3-\mathrm{H}, 13-\mathrm{H}\right), 6.82(\mathrm{~s}, 1 \mathrm{H}, 8-\mathrm{H}), 6.78(\mathrm{dd}$, ${ }^{3} J_{\mathrm{HH}}=8.0 \mathrm{~Hz},{ }^{4} J_{\mathrm{HH}}=1.2 \mathrm{~Hz}, 2 \mathrm{H}, 5-\mathrm{H}, 11-\mathrm{H} 6.70\left(\mathrm{dd},{ }^{3} J_{\mathrm{HH}}=7.9 \mathrm{~Hz}\right.$, $2 \mathrm{H}, 4-\mathrm{H}, 12-\mathrm{H}), 5.09$ (s, $1 \mathrm{H}, 8-\mathrm{H}), 5.00$ ( $\mathrm{s}_{\mathrm{br}}, 2 \mathrm{H}, \mathrm{AlH}_{2}$ ) ppm.

\section{${ }^{13} \mathrm{C}\left\{{ }^{1} \mathrm{H}\right\}$ NMR}

(101 MHz, [D $\mathrm{D}_{8}$ toluene):

$\delta=168.32$ (7-C, 9-C), 148.65 (6-C, 10-C), 143.52 (17-C, 23-C, 30-C, 36-C), 135.98 (1-C, 15-C), 130.48 (2-C, 14-C), 130.21 (18-C, 22-C, 24-C, 28-C, 31-C, 35-C, 37-C, 41-C), 128.59 (19-C, 21-C, 25-C, 27C, 32-C, 34-C, 38-C, 40-C), 127.22 (3-C, 13-C), 126.85 (20-C, 26-C, 33-C, 39-C), 123.06 (4-C, 12-C), 107.73 (5-C, 11-C), 60.75 (8-C), 52.40 (16-C, 29-C) ppm.

\section{${ }^{13} \mathrm{C}\left\{{ }^{1} \mathrm{H}\right\}$ NMR}

(101 MHz, $\left[\mathrm{D}_{6}\right]$ benzene):

$\delta=168.33$ (7-C, 9-C), 148.67 (6-C, 10-C), 143.57 (17-C, 23-C, 30-C, 36-C), 135.97 (1-C, 15-C), 130.48 (2-C, 14-C), 130.28 (18-C, 22-C, 24-C, 28-C, 31-C, 35-C, 37-C, 41-C), 128.70 (19-C, 21-C, 25-C, 27C, 32-C, 34-C, 38-C, 40-C), 127.31 (3-C, 13-C), 126.96 (20-C, 26-C, 33-C, 39-C), 123.19 (4-C, 12-C), 107.84 (5-C, 11-C), 60.88 (8-C), 52.49 (16-C, 29-C) ppm.

\section{MS (LIFDI[+], toluene)}

$\mathrm{m} / \mathrm{z}(\%)$ :

$610.1(100)[M]^{+}, 608.1(35)[M-2 \mathrm{H}]^{+}, 532.1(10)\left[M-\mathrm{AlH}_{2}+\mathrm{H}\right]^{+}$.

\section{Elemental analysis}

in \% (calculated)

$\mathrm{C}_{50} \mathrm{H}_{38.5} \mathrm{AlF}_{1.5} \mathrm{~N}_{2} \mathrm{O}_{2}$ (754.85 g/mol): C 79.59 (79.56), H 5.04 (5.14), N 3.83 (3.71). 
4.1.10.16 \{Bis(4-benzhydryl-benzoxazol-2-yl)methanide\}hydridoiodido aluminium (39)

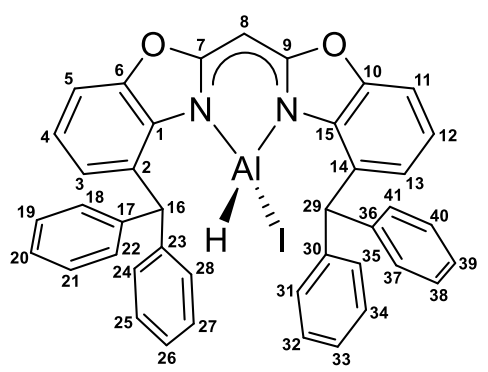

Toluene $(12 \mathrm{~mL})$ was added to alane 38 (330.1 mg, $469.7 \mu \mathrm{mol}, 1.00$ equiv.). Subsequently, iodine $(60.6 \mathrm{mg}, 238.8 \mu \mathrm{mol}, 0.51$ equiv.) was added in an argon counterflow to the white suspension. The iodine immediately reacted with solvated 38 while the reaction mixture became clear and yellow. A white solid precipitated after the reaction solution had been stirred at ambient temperature for $2 \mathrm{~d}$. The mixture was stirred for another day, filtered by a Teflon tube equipped with a glass fiber filter, and obtained white solid was dried under reduced pressure $(227.0 \mathrm{mg}, 246.5 \mu \mathrm{mol}, 52 \%)$. The solution was concentrated to ca. $5 \mathrm{~mL}$ and stored at $-30^{\circ} \mathrm{C}$. A second crop of crystalline $38(113.4 \mathrm{mg}, 123.1 \mu \mathrm{mol}, 26 \%)$ grew out of the solution after one night.

Chemical Formula:

Molecular weight:

Yield:

${ }^{1} \mathrm{H}$ NMR

(300 MHz, [D $\mathrm{D}_{8}$ toluene):
$\mathrm{C}_{41} \mathrm{H}_{30} \mathrm{AlIN}_{2} \mathrm{O}_{2} \cdot$ (toluene) $)_{2}$

$920.87 \mathrm{~g} / \mathrm{mol}$

$340.4 \mathrm{mg}, 369.7 \mu \mathrm{mol}, 78 \%$

$\delta=7.45\left(\mathrm{~d}, 4 \mathrm{H},{ }^{3} J_{\mathrm{HH}}=7.4 \mathrm{~Hz}, 18-\mathrm{H}, 22-\mathrm{H}, 31-\mathrm{H}, 35-\mathrm{H}\right), 7.17-7.07$ (m, 12 H, 19-H, 21-H, 24-H, 25-H, 27-H, 28-H, 32-H, 34-H, 37-H, 38-H, 40-H, 41-H), 7.00-6.98 (m, 4 H, 20-H, 26-H, 33-H, 39-H), 6.93 $\left(\mathrm{dd}, 2 \mathrm{H},{ }^{3} J_{\mathrm{HH}}=7.1 \mathrm{~Hz},{ }^{4} J_{\mathrm{HH}}=2.1 \mathrm{~Hz}, 3-\mathrm{H}, 13-\mathrm{H}\right), 6.80(\mathrm{~s}, 1 \mathrm{H}, 16-\mathrm{H}$, $29-\mathrm{H}), 6.73\left(\mathrm{dd}, 2 \mathrm{H},{ }^{3} J_{\mathrm{HH}}=8.6 \mathrm{~Hz},{ }^{4} J_{\mathrm{HH}}=2.1 \mathrm{~Hz}, 5-\mathrm{H}, 11-\mathrm{H}\right), 6.69$ $\left(\mathrm{dd}, 2 \mathrm{H},{ }^{3} \mathrm{H}_{\mathrm{HH}}=8.2 \mathrm{~Hz}, 4-\mathrm{H}, 12-\mathrm{H}\right), 5.04(\mathrm{~s}, 1 \mathrm{H}, 8-\mathrm{H}) \mathrm{ppm}$.

${ }^{13} \mathrm{C}\left\{{ }^{1} \mathrm{H}\right\}$ NMR

(101 MHz, [D $\mathrm{D}_{8}$ ]toluene): $\quad \delta=167.26$ (7-C, 9-C), 148.53 (6-C, 10-C), 144.49 (17-C, 30-C,), 144.49 (23-C, 36-C), 134.41 (1-C, 15-C), 130.91 (2-C, 14-C), 130.43 (18-C, 22-C, 31-C, 35-C), 130.34 (24-C, 28-C, 37-C, 41-C), 128.50 (19-C, 21-C, 25-C, 27-C, 32-C, 34-C, 38-C, 40-C), 127.88 (3-C, 13C), 126.96 (20-C, 26-C) 126.81 (33-C, 39-C), 123.74 (4-C, 12-C), 108.02 (5-C, 11-C), 62.49 (8-C), 52.39 (16-C, 29-C) ppm.

MS (LIFDI[+], toluene)

$\mathrm{m} / \mathrm{z}(\%)$ :

$736.0(100)[M]^{+}$ 


\section{Elemental analysis}

in \% (calculated)

$\mathrm{C}_{55} \mathrm{H}_{46} \mathrm{AlIN}_{2} \mathrm{O}_{2}$ (920.87 g/mol): C 71.59 (71.74), H 4.92 (5.04), N 3.03 (3.04). 


\section{APPENDIX}

Major parts of this chapter have been published in:

[1] J. Kretsch, Anne Kreyenschmidt, R. Herbst-Irmer, D. Stalke, "Alkali metal complexes based on bisheterocyclomethanide ligands", Dalton Trans. 2018, 36, 12606-12612. ${ }^{[1]}$

[2] J. Kretsch, R. Herbst-Irmer, D. Stalke, "Aluminum(III) Halide Complexes based on a Bis(benzoxazol-2-yl)methane Ligand", Z. Anorg. Allg. Chem. 2018, 14, 657-660. ${ }^{[2]}$

[3] J. Kretsch, I Koehne, Märt Lõkov, Ivo Leito, D. Stalke, "Bis(benzoxazol-2-yl)methanes Hounding NacNac: Varieties and Applications in Main Group Metal Coordination", Eur. J. Inorg. Chem. 2019, 28, 3258-3264. ${ }^{[3]}$

[4] J. Kretsch, Anne Kreyenschmidt, Timo Schillmöller, R. Herbst-Irmer, D. Stalke, "Mixed LowValent Alanes from the Bis(4-methyl-benzoxazol-2-yl)methanide Ligand”, Inorg. Chem. 2020, $59,13690-13699 .{ }^{[4]}$

[5] J. Kretsch, Anne Kreyenschmidt, Timo Schillmöller, Märt Lõkov, R. Herbst-Irmer, D. Stalke, "Bis(4-benzhydryl-benzoxazol-2-yl)methane - from a Bulky NacNac Alternative to a Trianion in Alkali Metal Complexes", Chem. Eur. J. 2021, 27, 9858-9865. ${ }^{\left[{ }^{[3}\right.}$

[6] J. Kretsch, A. Kreyenschmidt, T. Schillmöller, C. Sindlinger, R. Herbst-Irmer, D. Stalke, “Group 13 Heavier Carbene Analogs Stabilized by the Bulky Bis(4-benzhydryl-benzoxatol-2yl)methanide Ligand", Inorg. Chem. 2021, 60, 7389-7398. ${ }^{[6]}$ 


\subsection{Crystallographic Data}

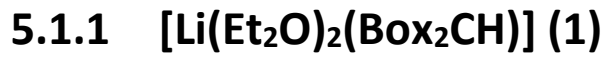

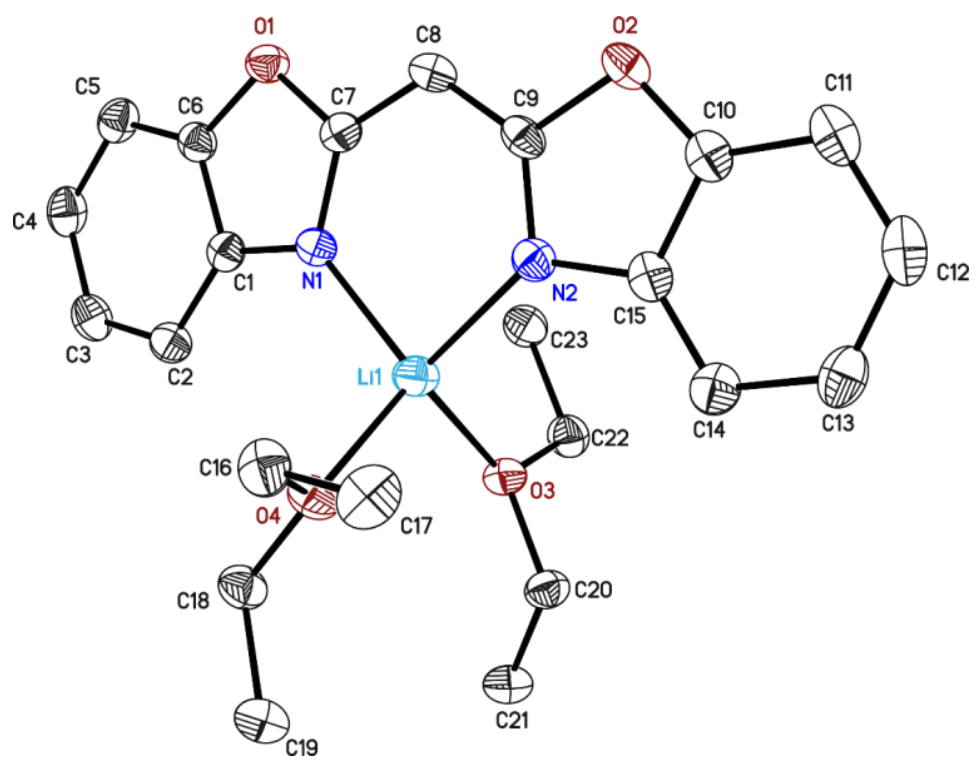

Figure 5-1. Asymmetric unit of 1 with thermal ellipsoids at 50\% probability level. The hydrogen atoms are omitted for clarity. Reprinted with permission from reference [1]. Copyright 2018, Royal Society of Chemistry.

Table 5-1. Crystallographic data of 1.

\begin{tabular}{|c|c|c|c|}
\hline Structure code & Compound 1 & $\rho_{\text {calcd. }}\left[\mathrm{Mg} \cdot \mathrm{m}^{-3}\right]$ & 1.217 \\
\hline CCDC no. & 1839909 & $\mu\left[\mathrm{mm}^{-1}\right]$ & 0.082 \\
\hline Empirical formula & $\mathrm{C}_{23} \mathrm{H}_{29} \mathrm{LiN}_{2} \mathrm{O}_{4}$ & $F(000)$ & 864 \\
\hline Formula weight $\left[\mathrm{g} \mathrm{mol}^{-1}\right]$ & 404.42 & Crystal size $\left[\mathrm{mm}^{3}\right]$ & $0.467 \times 0.352 \times 0.265$ \\
\hline Temperature $[\mathrm{K}]$ & $100(2)$ & $\theta$ range $\left[^{\circ}\right]$ & 2.375 to 25.547 \\
\hline Wavelength $[\AA]$ & 0.71073 & Reflections collected & 24547 \\
\hline Crystal system & Monoclinic & Unique Reflections & 4129 \\
\hline Space group & $P 2_{1} / c$ & $R_{\text {int }}$ & 0.0271 \\
\hline \multirow[t]{6}{*}{ Unit cell parameters } & $a=17.284(3) \AA$ & Completeness to $\theta_{\max }[\%]$ & 100.0 \\
\hline & $b=9.272(2) \AA$ & Restraints / parameters & $1 / 279$ \\
\hline & $c=13.883(3) \AA$ & Goodness-of-fit on $\mathrm{F}^{2}$ & 1.044 \\
\hline & $\alpha=90^{\circ}$ & $R 1[\mathrm{I}>2 \sigma(\mathrm{I})]$ & 0.0334 \\
\hline & $\beta=90.03(2)^{\circ}$ & $\mathrm{w} R 2$ (all data) & 0.0816 \\
\hline & $\gamma=90^{\circ}$ & Max. diff. peak / hole $\left[\mathrm{e} \AA^{-3}\right]$ & $0.210 /-0.155$ \\
\hline Volume $\left[\AA^{3}\right]$ & $2208.1(8)$ & $\begin{array}{l}\text { Absolute structure } \\
\text { parameter }^{[235]}\end{array}$ & - \\
\hline$Z$ & 4 & Extinction coefficient & - \\
\hline
\end{tabular}




\subsection{2 $\left[\mathrm{K}(\mathrm{THF})\left(\mathrm{Box}_{2} \mathrm{CH}\right)\right]_{n}(2)$}

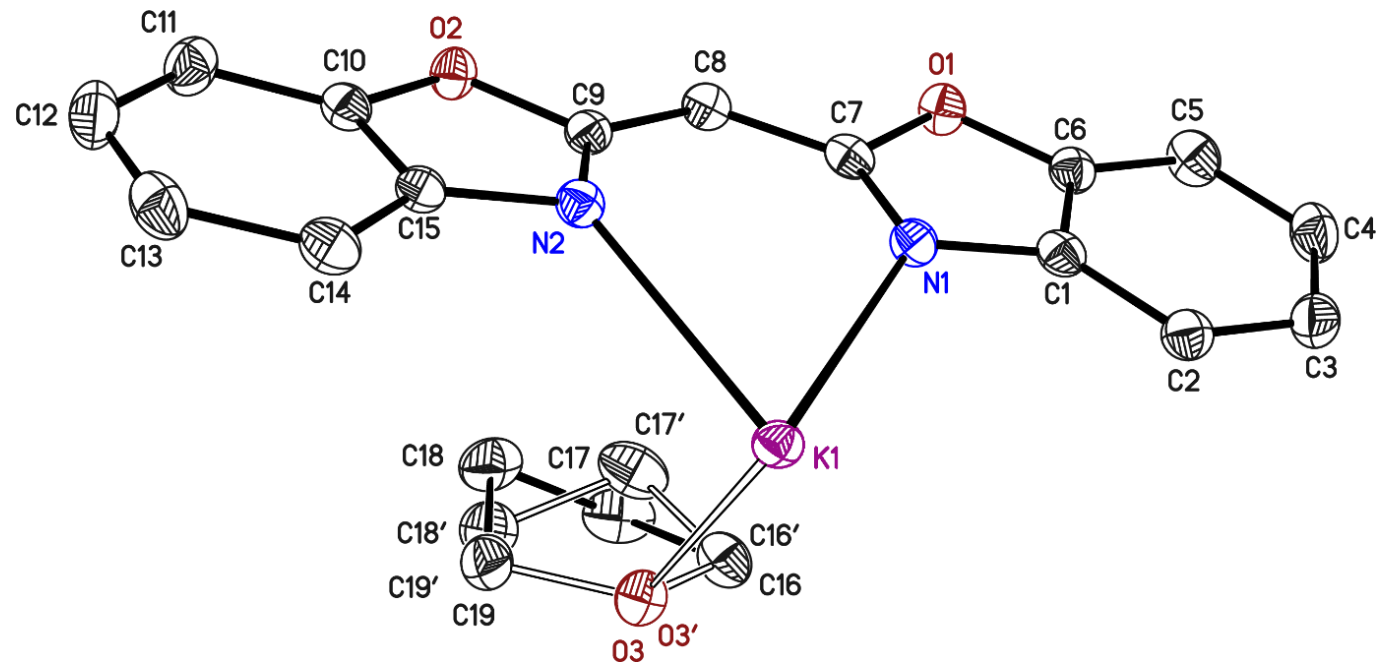

Figure 5-2. Molecular structure of 2 with thermal ellipsoids at 50\% probability level. The hydrogen atoms are omitted for clarity. The disordered thf was refined on one position. The occupancy of the main position refined to 0.75(2) for O3-C19. Reprinted with permission from reference [1]. Copyright 2018, Royal Society of Chemistry.

Table 5-2. Crystallographic data of 2.

\begin{tabular}{ll|ll}
\hline Structure code & Compound 2 & $\rho_{\text {calcd. }\left[\mathrm{Mg} \cdot \mathrm{m}^{-3}\right]}$ & 1.387 \\
CCDC no. & 1839910 & $\mu\left[\mathrm{mm}^{-1}\right]$ & 0.328 \\
Empirical formula & $\mathrm{C}_{19} \mathrm{H}_{17} \mathrm{KN}_{2} \mathrm{O}_{3}$ & $F(000)$ & 752 \\
Formula weight $\left[\mathrm{g} \mathrm{mol}^{-1}\right]$ & 360.44 & Crystal size $\left[\mathrm{mm}^{3}\right]$ & $0.364 \times 0.177 \times 0.126$ \\
Temperature $[\mathrm{K}]$ & $100(2)$ & $\theta$ range $\left.{ }^{\circ}\right]$ & 2.047 to 26.111 \\
Wavelength $[\AA]$ & 0.71073 & Reflections collected & 26470 \\
Crystal system & Orthorhombic & Unique Reflections & 3432 \\
Space group & $P$ na2 ${ }_{1}$ & $R_{\text {int }}$ & 0.0238 \\
Unit cell parameters & $a=11.200(2) \AA$ & Completeness to $\theta_{\max }[\%]$ & 100.0 \\
& $b=19.897(3) \AA$ & Restraints / parameters & $238 / 249$ \\
& $c=7.745(2) \AA$ & Goodness-of-fit on $\mathrm{F}^{2}$ & 1.028 \\
& $\alpha=90^{\circ}$ & $R 1$ [I>2 $\sigma(\mathrm{I})]$ & 0.0210 \\
& $\beta=90^{\circ}$ & wR2 (all data) & 0.0566 \\
Volume $\left[\AA^{3}\right]$ & $\gamma=90^{\circ}$ & Max. diff. peak / hole $[\mathrm{e} \AA$ & $0.184 /-0.250$ \\
& $1725.9(6)$ & Absolute structure & $0.008(15)$ \\
$Z$ & & parameter ${ }^{[235]}$ & \\
\hline
\end{tabular}




\subsection{3 $\left[\mathrm{K}(18-\mathrm{crown}-6)\left(\mathrm{Box}_{2} \mathrm{CH}\right)\right]_{n}(3)$}

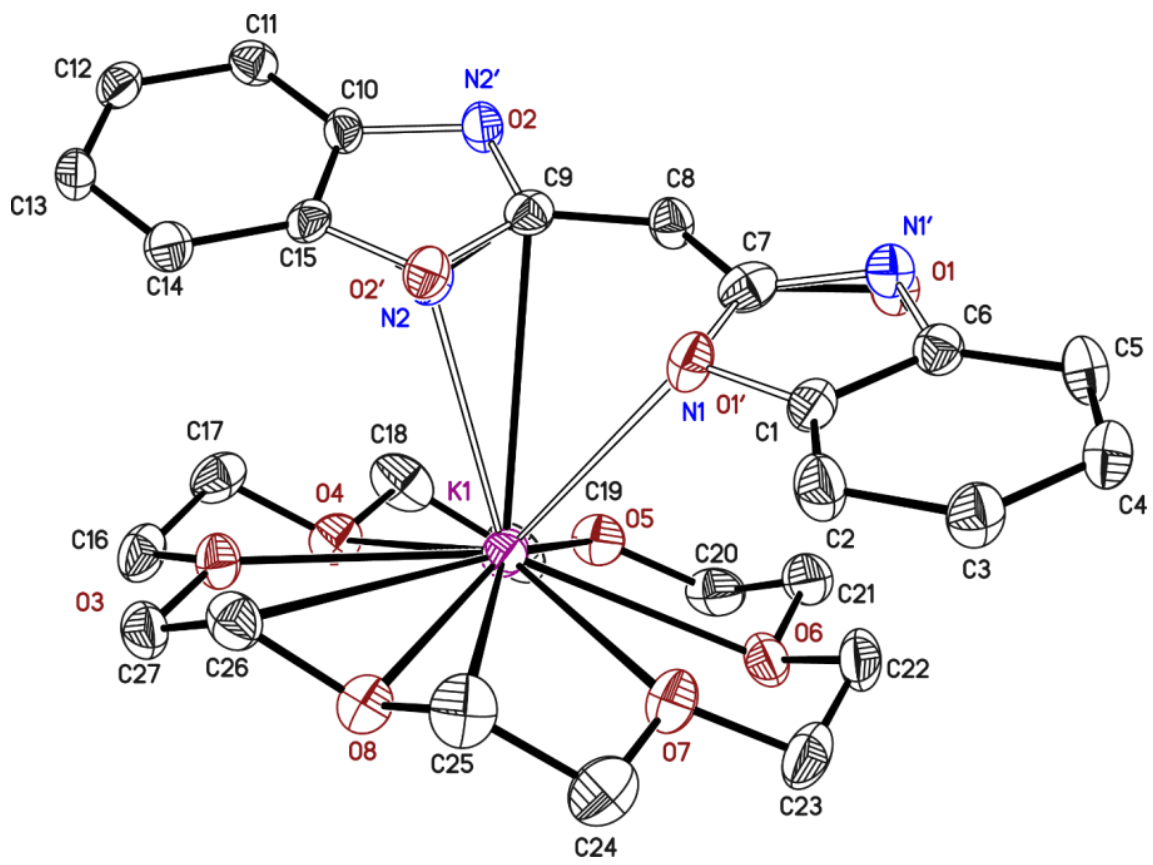

Figure 5-3. Molecular structure of 3 with thermal ellipsoids at 50\% probability level. The hydrogen atoms are omitted for clarity. The disordered ligand was refined on two positions. The occupancy of the main position is refined to 0.61 (3) for $\mathrm{O}^{\prime}$ '-C7'-N1' and 0.82(3) for O2-C9-N2. Reprinted with permission from reference [1]. Copyright 2018, Royal Society of Chemistry.

Table 5-3. Crystallographic data of 3.

\begin{tabular}{ll|ll}
\hline Structure code & Compound 3 & $\rho_{\text {calcd. }\left[\mathrm{Mg} \cdot \mathrm{m}^{-3}\right]}$ & 1.372 \\
CCDC no. & 1839911 & $\mu\left[\mathrm{mm}^{-1}\right]$ & 0.251 \\
Empirical formula & $\mathrm{C}_{27} \mathrm{H}_{33} \mathrm{KN}_{2} \mathrm{O}_{8}$ & $F(000)$ & 1168 \\
Formula weight $\left[\mathrm{g} \mathrm{mol}^{-1}\right]$ & 552.65 & Crystal size $\left[\mathrm{mm}^{3}\right]$ & $0.226 \times 0.172 \times 0.098$ \\
Temperature $[\mathrm{K}]$ & $100(2)$ & $\theta$ range $\left[{ }^{\circ}\right]$ & 1.855 to 26.427 \\
Wavelength $[\AA]$ & 0.71073 & Reflections collected & 33321 \\
Crystal system & Orthorhombic & Unique Reflections & 5489 \\
Space group & $P c a 2_{1}$ & $R_{\text {int }}$ & 0.0478 \\
Unit cell parameters & $a=15.913(7) \AA$ & Completeness to $\theta_{\max }[\%]$ & 100.0 \\
& $b=10.981(10) \AA$ & Restraints / parameters & $88 / 361$ \\
& $c=15.309(11) \AA$ & Goodness-of-fit on $\mathrm{F}^{2}$ & 1.074 \\
& $\alpha=90^{\circ}$ & $R 1[\mathrm{I}>2 \sigma(\mathrm{I})]$ & 0.0343 \\
& $\beta=90^{\circ}$ & wR2 (all data) & 0.0727 \\
Volume $\left[\AA^{3}\right]$ & $\gamma=90^{\circ}$ & Max. diff. peak / hole $\left[\mathrm{e} \AA^{-3}\right]$ & $0.288 /-0.268$ \\
& $2675(3)$ & Absolute structure & $0.035(11)$ \\
$Z$ & & parameter & \\
\hline
\end{tabular}




\subsection{4 $\left[\mathrm{AlCl}_{2}\left(\mathrm{Box}_{2} \mathrm{CH}\right)\right](4)$}

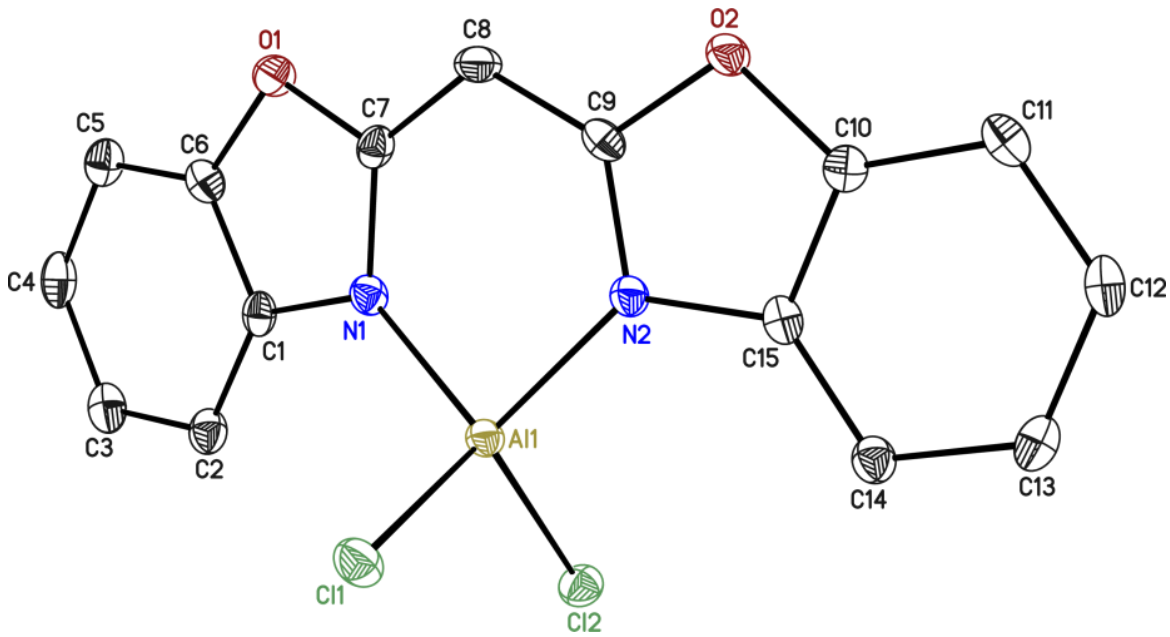

Figure 5-4. Molecular structure of 4. Anisotropic displacement parameters are depicted at the 50\% probability level. Hydrogen atoms are omitted for clarity. Reprinted with permission from reference [2]. Copyright 2018, John Wiley and Sons.

Table 5-4. Crystallographic data of 4.

\begin{tabular}{ll|ll}
\hline Structure code & JKBoxAlCl & $\rho_{\text {calcd. }\left[\mathrm{Mg} \cdot \mathrm{m}^{-3}\right]}$ & 1.600 \\
CCDC no. & 1829494 & $\mu\left[\mathrm{mm}^{-1}\right]$ & 0.271 \\
Empirical formula & $\mathrm{C}_{15} \mathrm{H}_{9} \mathrm{AlCl}_{2} \mathrm{~N}_{2} \mathrm{O}_{2}$ & $F(000)$ & 704 \\
Formula weight $\left[\mathrm{g} \mathrm{mol}^{-1}\right]$ & 347.12 & Crystal size $\left[\mathrm{mm}^{3}\right]$ & $0.42 \times 0.41 \times 0.20$ \\
Temperature $[\mathrm{K}]$ & $100(2)$ & $\theta$ range $\left[^{\circ}\right]$ & 1.793 to 20.274 \\
Wavelength $[\AA]$ & 0.5608 & Reflections collected & 21797 \\
Crystal system & Monoclinic & Unique Reflections & 2847 \\
Space group & $P 2_{1} / n$ & $R_{\text {int }}$ & 0.0263 \\
Unit cell parameters & $a=8.315(3) \AA$ & Completeness to $\theta_{\max }[\%]$ & 100.0 \\
& $b=16.035(5) \AA$ & Restraints / parameters & $88 / 199$ \\
& $c=10.812(4) \AA$ & Goodness-of-fit on $\mathrm{F}^{2}$ & 1.065 \\
& $\alpha=90^{\circ}$ & $R 1[\mathrm{I}>2 \sigma(\mathrm{I})]$ & 0.0245 \\
& $\beta=92.020(10)^{\circ}$ & wR2 (all data) & 0.0714 \\
Volume $\left[\AA^{3}\right]$ & $\gamma=90^{\circ}$ & Max. diff. peak / hole $\left[\mathrm{e} \AA^{-3}\right]$ & $0.263 /-0.250$ \\
& $1440.7(9)$ & Absolute structure & - \\
$Z$ & & parameter & \\
\hline
\end{tabular}




\subsection{5 [All $\left.{ }_{2}\left(\mathrm{Box}_{2} \mathrm{CH}\right)\right](5)$}

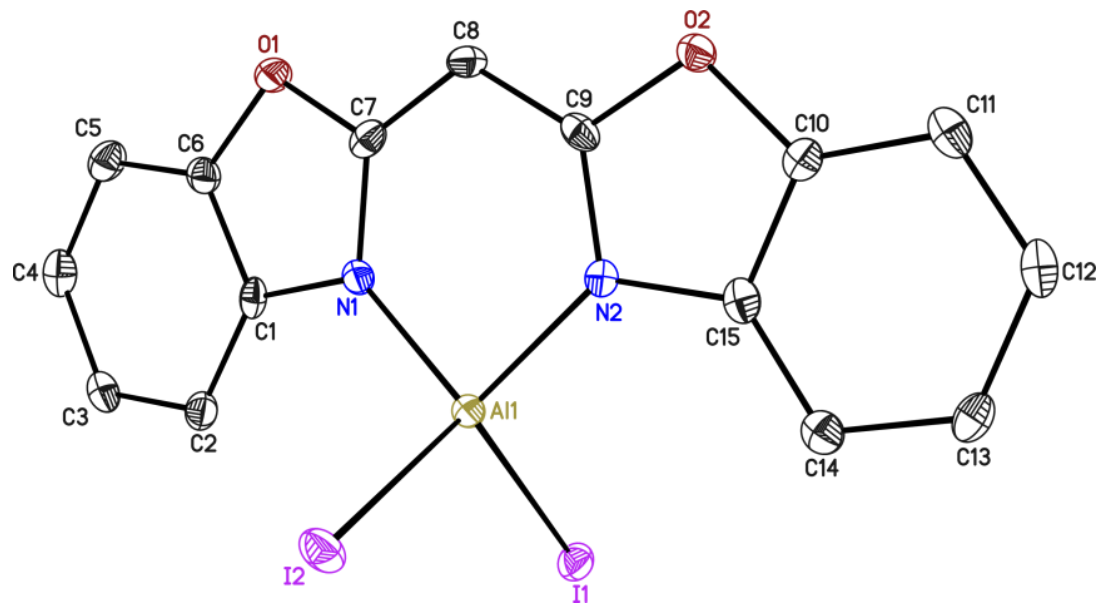

Figure 5-5. Molecular structure of 5. Anisotropic displacement parameters are depicted at the 50\% probability level. Hydrogen atoms are omitted for clarity. Reprinted with permission from reference [2]. Copyright 2018, John Wiley and Sons.

Table 5-5. Crystallographic data of 5.

\begin{tabular}{ll|ll}
\hline Structure code & JK_AlI_1 & $\rho_{\text {calcd. }\left[\mathrm{Mg} \cdot \mathrm{m}^{-3}\right]}$ & 2.191 \\
CCDC no. & 1829495 & $\mu\left[\mathrm{mm}^{-1}\right]$ & 2.109 \\
Empirical formula & $\mathrm{C}_{15} \mathrm{H}_{9} \mathrm{AlI}_{2} \mathrm{~N}_{2} \mathrm{O}_{2}$ & $F(000)$ & 496 \\
Formula weight $\left[\mathrm{g} \mathrm{mol}^{-1}\right]$ & 530.02 & Crystal size $\left[\mathrm{mm}^{3}\right]$ & $0.18 \times 0.13 \times 0.08$ \\
Temperature $[\mathrm{K}]$ & $100(2)$ & $\theta$ range $\left[{ }^{\circ}\right]$ & 2.326 to 19.766 \\
Wavelength $[\AA]$ & 0.5608 & Reflections collected & 25079 \\
Crystal system & Triclinic & Unique Reflections & 2949 \\
Space group & $P \overline{1}$ & $R_{\text {int }}$ & 0.0296 \\
Unit cell parameters & $\mathrm{a}=7.770(2) \AA$ & Completeness to $\theta_{\max }[\%]$ & 100.0 \\
& $b=8.229(2) \AA$ & Restraints / parameters & $0 / 199$ \\
& $c=14.500(3) \AA$ & Goodness-of-fit on $\mathrm{F}^{2}$ & 1.076 \\
& $\alpha=94.39(2)^{\circ}$ & $R 1[\mathrm{I}>2 \sigma(\mathrm{I})]$ & 0.0162 \\
& $\beta=103.31(2)^{\circ}$ & wR2 (all data) & 0.0393 \\
& $\gamma=114.76(2)^{\circ}$ & Max. diff. peak / hole $\left[\mathrm{e} \AA^{-3}\right]$ & $0.699 /-0.441$ \\
Volume $\left[\AA^{3}\right]$ & $803.4(4)$ & Absolute structure & - \\
& & parameter & \\
$Z$ & 2 & Extinction coefficient & - \\
\hline
\end{tabular}




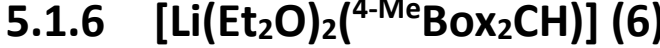

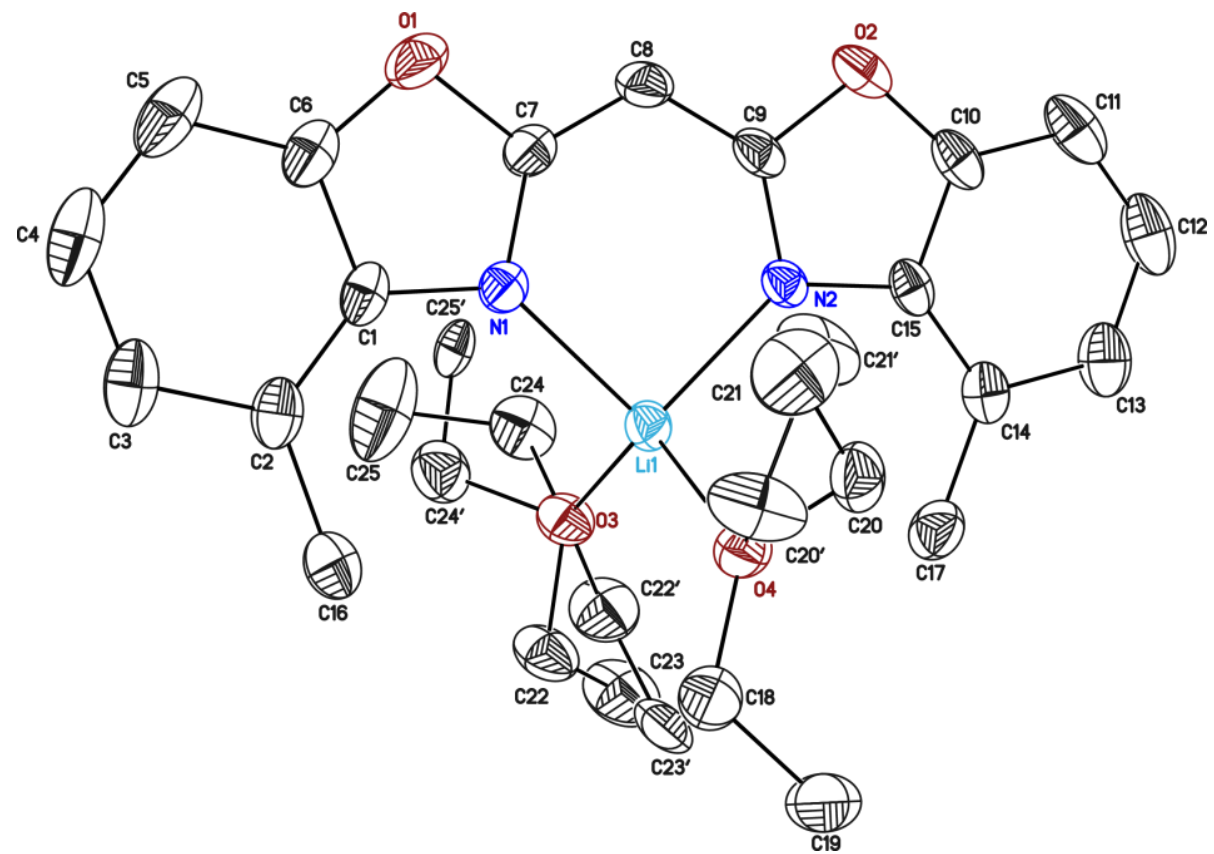

Figure 5-6. Molecular structure of 6 measured at $200 \mathrm{~K}$. Anisotropic displacement parameters are depicted at the 30\% probability level. Hydrogen atoms are omitted for clarity. The two diethyl ether molecules are disordered about two positions, while the occupancies of the minor refine to 0.177(11) and 0.102(6). The disordered parts are refined with distance restraints and restraints for the anisotropic displacement parameters.

Table 5-6. Crystallographic data of 6.

\begin{tabular}{ll|ll}
\hline Structure code & $\mathrm{JK} 175$ & $\rho_{\text {calcd. }}\left[\mathrm{Mg} \cdot \mathrm{m}^{-3}\right]$ & 1.156 \\
CCDC no. & - & $\mu\left[\mathrm{mm}^{-1}\right]$ & 0.077 \\
Empirical formula & $\mathrm{C}_{25} \mathrm{H}_{33} \mathrm{Li}_{2} \mathrm{~N}_{2} \mathrm{O}_{4}$ & $F(000)$ & 928 \\
Formula weight $\left[\mathrm{g} \mathrm{mol}^{-1}\right]$ & 432.47 & Crystal size $\left[\mathrm{mm}^{3}\right]$ & $0.222 \times 0.151 \times 0.150$ \\
Temperature $[\mathrm{K}]$ & $100(2)$ & $\theta$ range $\left[^{\circ}\right]$ & 1.163 to 25.358 \\
Wavelength $[\AA]$ & 0.71073 & Reflections collected & 59856 \\
Crystal system & Triclinic & Unique Reflections & 4504 \\
Space group & $P 2_{1} / c$ & $R_{\text {int }}$ & 0.0855 \\
Unit cell parameters & $a=18.1470(6) \AA$ & Completeness to $\theta_{\max }[\%]$ & 99.3 \\
& $b=8.9160(3) \AA$ & Restraints / parameters & $209 / 353$ \\
& $c=15.9160(3) \AA$ & Goodness-of-fit on $\mathrm{F}^{2}$ & 1.411 \\
& $\alpha=90^{\circ}$ & $R 1[\mathrm{I}>2 \sigma(\mathrm{I})]$ & 0.108 \\
& $\beta=105.21(10)^{\circ}$ & wR2 (all data) & 0.1676 \\
Volume $\left[\AA^{3}\right]$ & $\gamma=90^{\circ}$ & Max. diff. peak / hole $\left[\mathrm{e} \AA^{-3}\right]$ & $0.242 /-0.219$ \\
$Z$ & $2484.98(14)$ & Absolute structure & - \\
\hline
\end{tabular}




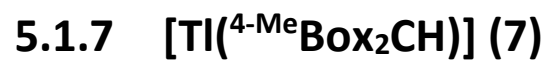

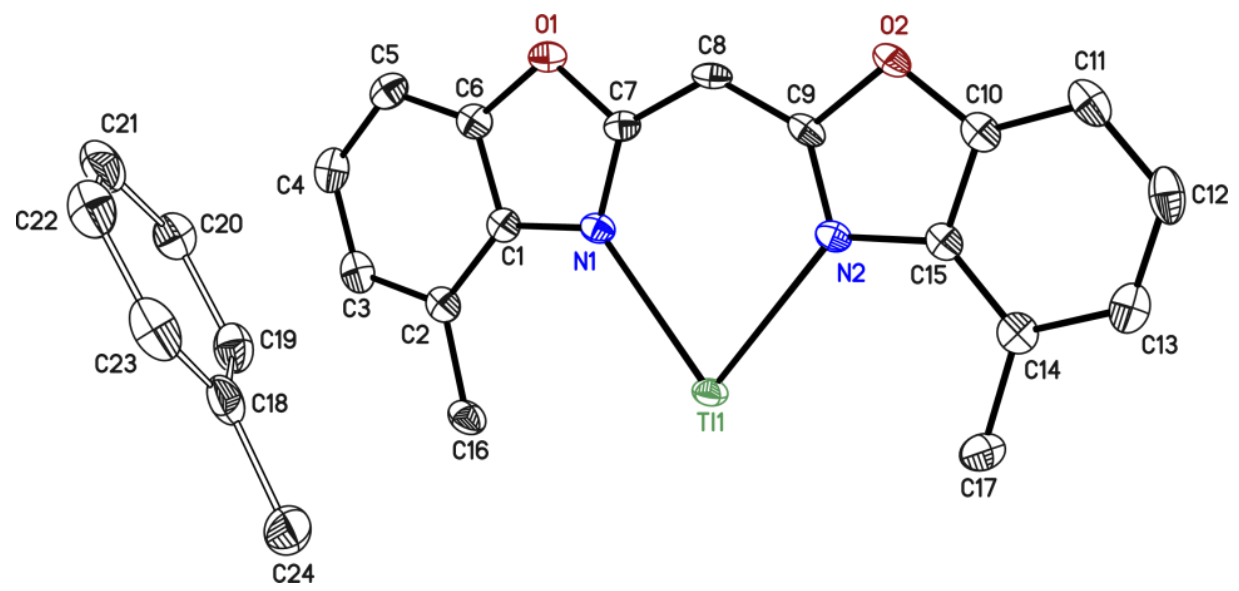

Figure 5-7. Molecular structure of 7. Anisotropic displacement parameters are depicted at the $50 \%$ probability level. Hydrogen atoms are omitted for clarity. The toluene molecule C18 to C24 is disordered about an inversion center.

Table 5-7. Crystallographic data of 7.

\begin{tabular}{ll|ll}
\hline Structure code & $\mathrm{JK} 179$ & $\rho_{\text {calcd. }}\left[\mathrm{Mg} \cdot \mathrm{m}^{-3}\right]$ & 2.039 \\
CCDC no. & - & $\mu\left[\mathrm{mm}^{-1}\right]$ & 9.411 \\
Empirical formula & $\mathrm{C}_{20.5} \mathrm{H}_{17} \mathrm{~N}_{2} \mathrm{O}_{2} \mathrm{Tl}$ & $F(000)$ & 502 \\
Formula weight $\left[\mathrm{g} \mathrm{mol}^{-1}\right]$ & 527.73 & Crystal size $\left[\mathrm{mm}^{3}\right]$ & $0.159 \times 0.102 \times 0.098$ \\
Temperature $[\mathrm{K}]$ & $100(2)$ & $\theta$ range $\left[^{\circ}\right]$ & 1.668 to 25.431 \\
Wavelength $[\AA]$ & 0.71073 & Reflections collected & 36050 \\
Crystal system & Triclinic & Unique Reflections & 3178 \\
Space group & $P \overline{1}$ & $R_{\text {int }}$ & 0.0324 \\
Unit cell parameters & $a=8.115(2) \AA$ & Completeness to $\theta_{\max }[\%]$ & 100.0 \\
& $b=8.968(2) \AA$ & Restraints / parameters & $31 / 265$ \\
& $c=12.730(3) \AA$ & Goodness-of-fit on $\mathrm{F}^{2}$ & 1.092 \\
& $\alpha=75.16(2)^{\circ}$ & $R 1[\mathrm{I}>2 \sigma(\mathrm{I})]$ & 0.0136 \\
& $\beta=79.53(2)^{\circ}$ & wR2 (all data) & 0.0345 \\
& $\gamma=75.37(2)^{\circ}$ & Max. diff. peak / hole $\left[\mathrm{e} \AA^{-3}\right]$ & $1.389 /-0.523$ \\
Volume $\left[\AA^{3}\right]$ & $859.7(4)$ & Absolute structure & - \\
& & parameter & \\
$Z$ & 2 & Extinction coefficient & - \\
\hline
\end{tabular}




\subsection{8 $\left[\mathrm{Li}\left({ }^{4-\mathrm{Me}} \mathrm{Box}_{2} \mathrm{CH}_{2}\right)\left({ }^{4-\mathrm{Me}} \mathrm{Box}_{2} \mathrm{CH}\right)\right](6 \mathrm{a})$}

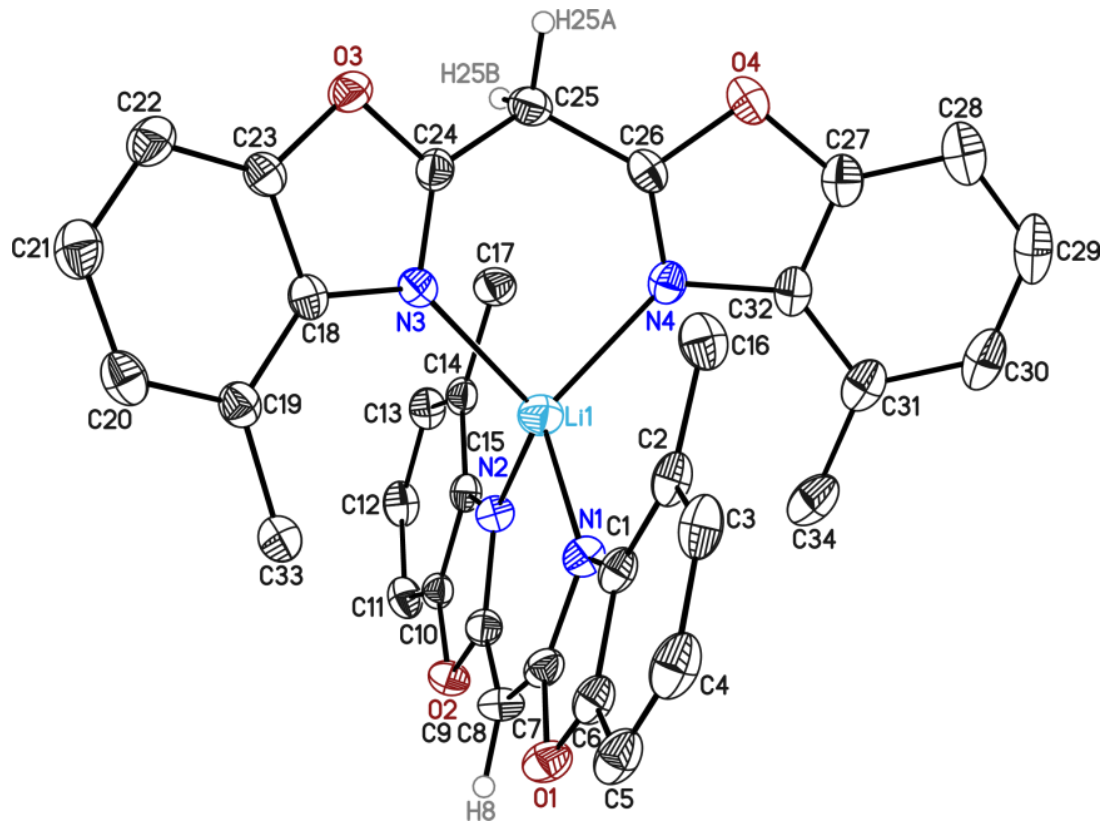

Figure 5-8. Molecular structure of 6a.Anisotropic displacement parameters are depicted at the 50\% probability level. Hydrogen atoms except H8, H25A and H25B are omitted for clarity.

Table 5-8. Crystallographic data of 6 a.

\begin{tabular}{ll|ll}
\hline Structure code & JK_TP11 & $\rho_{\text {calc. }}\left[\mathrm{Mg} \cdot \mathrm{m}^{-3}\right]$ & 1.342 \\
CCDC no. & - & $\mu\left[\mathrm{mm}^{-1}\right]$ & 0.089 \\
Empirical formula & $\mathrm{C}_{34} \mathrm{H}_{27} \mathrm{LiN}_{4} \mathrm{O}_{4}$ & $F(000)$ & 2352 \\
Formula weight $\left[\mathrm{g} \mathrm{mol}^{-1}\right]$ & 562.53 & Crystal size $\left[\mathrm{mm}^{3}\right]$ & $0.116 \times 0.079 \times 0.076$ \\
Temperature $[\mathrm{K}]$ & $100(2)$ & $\theta$ range $\left[{ }^{\circ}\right]$ & 1.494 to 25.353 \\
Wavelength $[\AA]$ & 0.71073 & Reflections collected & 107493 \\
Crystal system & Monoclinic & Unique Reflections & 10180 \\
Space group & $P 2_{1} / n$ & $R_{\text {int }}$ & 0.1099 \\
Unit cell parameters & $\mathrm{a}=18.180(2) \AA$ & Completeness to $\theta_{\max }[\%]$ & 100.0 \\
& $b=15.863(2) \AA$ & Restraints / parameters & $0 / 783$ \\
& $c=19.337(3) \AA$ & Goodness-of-fit on $\mathrm{F}^{2}$ & 1.028 \\
& $\alpha=90^{\circ}$ & $R 1[\mathrm{I}>2 \sigma(\mathrm{I})]$ & 0.0450 \\
& $\beta=93.35(2)^{\circ}$ & wR2 (all data) & 0.1015 \\
Volume $\left[\AA^{3}\right]$ & $\gamma=90^{\circ}$ & Max. diff. peak / hole $\left[\mathrm{e} \AA^{-3}\right]$ & $0.180 /-0.283$ \\
& $5567.1(13)$ & Absolute structure & - \\
$Z$ & & parameter & \\
\hline
\end{tabular}




\subsection{9 [Gal( $\left.\left.{ }^{4-M e} \mathrm{Box}_{2} \mathrm{CH}\right)\right]_{2}(8 \mathrm{a})$}

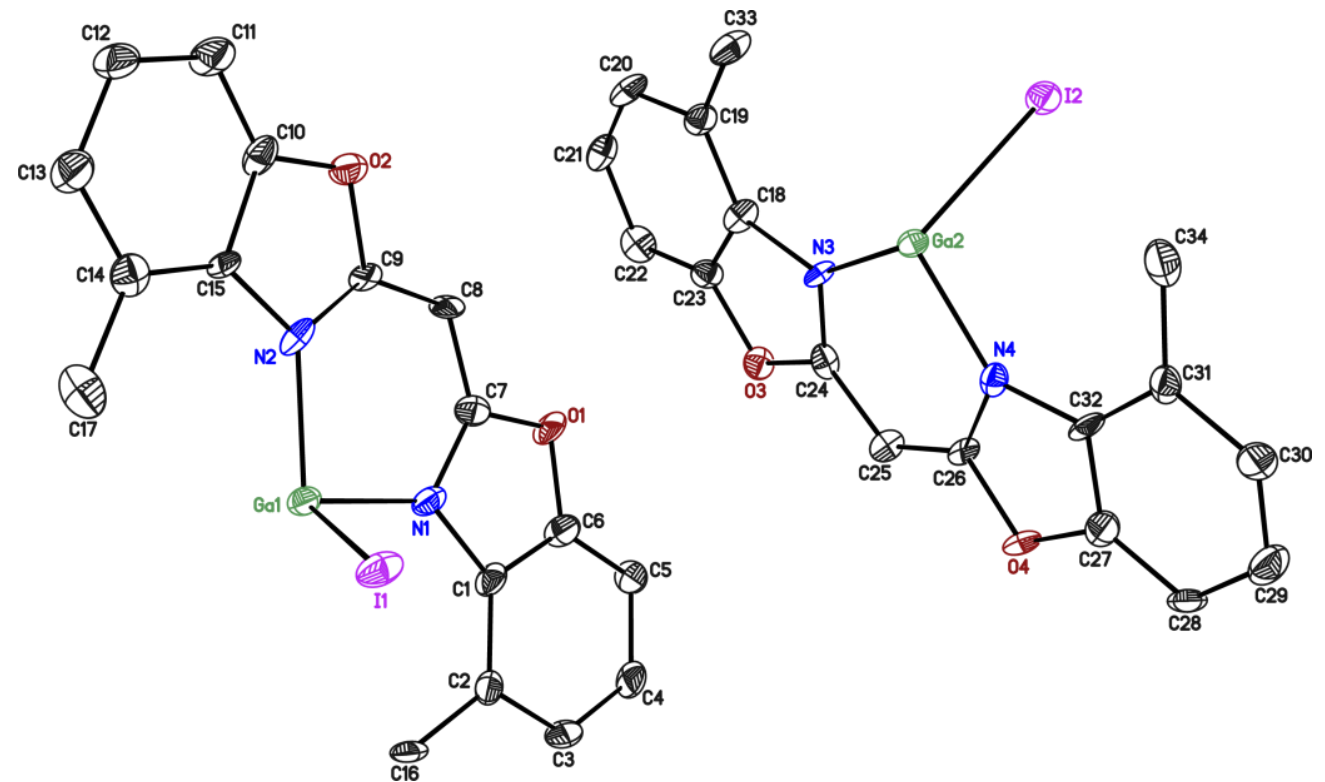

Figure 5-9. Molecular structure of 8a. Anisotropic displacement parameters are depicted at the 50\% probability level. Hydrogen atoms are omitted for clarity. The remaining parts of the molecules are generated by symmetry.

Table 5-9. Crystallographic data of $8 \mathrm{a}$.

\begin{tabular}{ll|ll}
\hline Structure code & $\mathrm{JK} \_190 \mathrm{~B}$ & $\rho_{\text {calcd. }}\left[\mathrm{Mg} \cdot \mathrm{m}^{-3}\right]$ & 1.940 \\
CCDC no. & - & $\mu\left[\mathrm{mm}^{-1}\right]$ & 1.909 \\
Empirical formula & $\mathrm{C}_{34} \mathrm{H}_{26} \mathrm{Ga}_{2} \mathrm{I}_{2} \mathrm{~N}_{4} \mathrm{O}_{4}$ & $F(000)$ & 1832 \\
Formula weight $\left[\mathrm{g} \mathrm{mol}^{-1}\right]$ & 947.83 & Crystal size $\left[\mathrm{mm}^{3}\right]$ & $0.075 \times 0.048 \times 0.045$ \\
Temperature $[\mathrm{K}]$ & $100(2)$ & $\theta$ range $\left[^{\circ}\right]$ & 1.789 to 19.860 \\
Wavelength $[\AA]$ & 0.56086 & Reflections collected & 34563 \\
Crystal system & Monoclinic & Unique Reflections & 6038 \\
Space group & $C 2$ & $R_{\text {int }}$ & 0.0672 \\
Unit cell parameters & $\mathrm{a}=17.505(4) \AA$ & Completeness to $\theta_{\max }[\%]$ & 100.0 \\
& $b=10.464(2) \AA$ & Restraints / parameters & $1 / 419$ \\
& $c=17.717(4) \AA$ & Goodness-of-fit on $\mathrm{F}^{2}$ & 1.063 \\
& $\alpha=90^{\circ}$ & $R 1[\mathrm{I}>2 \sigma(\mathrm{I})]$ & 0.0405 \\
& $\beta=90.33(2)^{\circ}$ & wR2 (all data) & 0.1007 \\
Volume $\left[\AA^{3}\right]$ & $\gamma=90^{\circ}$ & Max. diff. peak / hole $\left[\mathrm{e} \AA^{-3}\right]$ & $3.331 /-0.649$ \\
& $3245.1(12)$ & Absolute structure & $0.008(15)$ \\
$Z$ & & parameter & \\
\hline
\end{tabular}




\subsubsection{0 [( $\left.\left.{ }^{4-\mathrm{Me}} \mathrm{Box}_{2} \mathrm{CH}\right) \mathrm{Ga}^{\prime} \mathrm{Ga}_{2}{ }_{2} \mathrm{I}_{2}\left({ }^{4-\mathrm{Me}} \mathrm{Box}_{2} \mathrm{CH}\right)_{2}\right](8 \mathrm{~b})$}

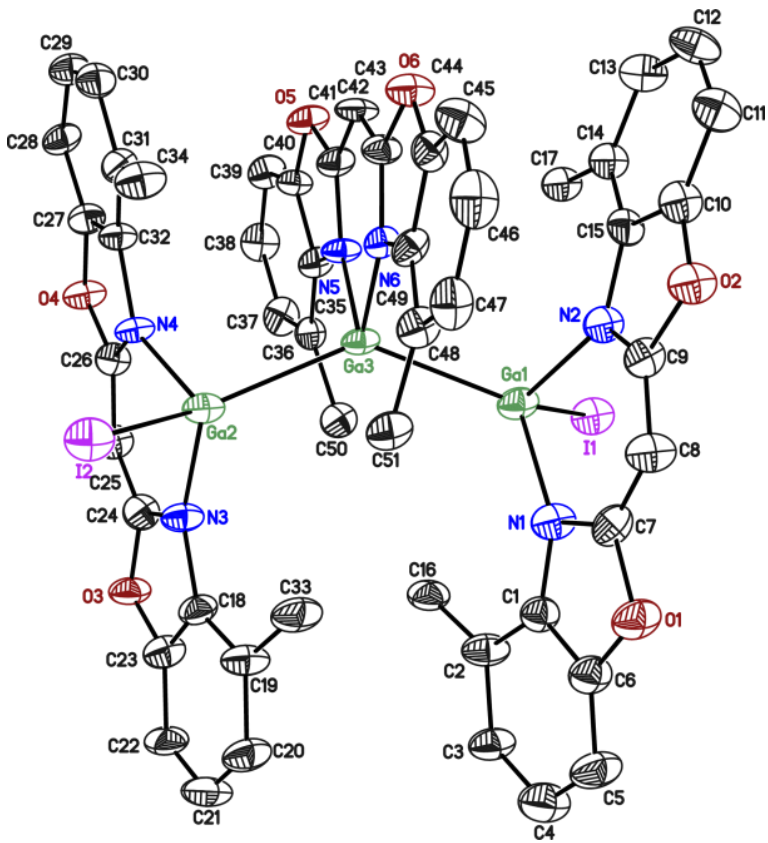

Figure 5-10. Molecular structure of $\mathbf{8 b}$. Anisotropic displacement parameters are depicted at the 50\% probability level. Hydrogen atoms are omitted for clarity.

Table 5-10. Crystallographic data of $8 b$.

\begin{tabular}{ll|ll}
\hline Structure code & $\mathrm{JK} 190$ & $\rho_{\text {calcd. }\left[\mathrm{Mg} \cdot \mathrm{m}^{-3}\right]}$ & 1.890 \\
CCDC no. & 1829495 & $\mu\left[\mathrm{mm}^{-1}\right]$ & 3.180 \\
Empirical formula & $\mathrm{C}_{51} \mathrm{H}_{39} \mathrm{Ga}_{3} \mathrm{I}_{2} \mathrm{~N}_{6} \mathrm{O}_{6}$ & $F(000)$ & 1268 \\
Formula weight $\left[\mathrm{g} \mathrm{mol}^{-1}\right]$ & 1294.84 & Crystal size $\left[\mathrm{mm}^{3}\right]$ & $0.127 \times 0.100 \times 0.084$ \\
Temperature $[\mathrm{K}]$ & $100(2)$ & $\theta$ range $\left[{ }^{\circ}\right]$ & 0.977 to 25.463 \\
Wavelength $[\AA]$ & 0.5608 & Reflections collected & 89467 \\
Crystal system & Triclinic & Unique Reflections & 8396 \\
Space group & $P \overline{1}$ & $R_{\text {int }}$ & 0.1121 \\
Unit cell parameters & $\mathrm{a}=10.564(2) \AA$ & Completeness to $\theta_{\max }[\%]$ & 100.0 \\
& $b=10.663(2) \AA$ & Restraints / parameters & $0 / 619$ \\
& $c=20.865(3) \AA$ & Goodness-of-fit on $\mathrm{F}^{2}$ & 1.255 \\
& $\alpha=86.80(2)^{\circ}$ & $R 1[\mathrm{I}>2 \sigma(\mathrm{I})]$ & 0.0591 \\
& $\beta=88.61(2)^{\circ}$ & wR2 (all data) & 0.1840 \\
Volume $\left[\AA^{3}\right]$ & $\gamma=76.30(2)^{\circ}$ & Max. diff. peak / hole $\left[\mathrm{e} \AA^{-3}\right]$ & $2.962 /-1.584$ \\
& $2275.9(7)$ & Absolute structure & - \\
$Z$ & & parameter & \\
\hline
\end{tabular}




\subsubsection{1 $\left[\mathrm{All}_{2}\left({ }^{4-\mathrm{Me}} \mathrm{Box}_{2} \mathrm{CH}\right)\right](10)$}

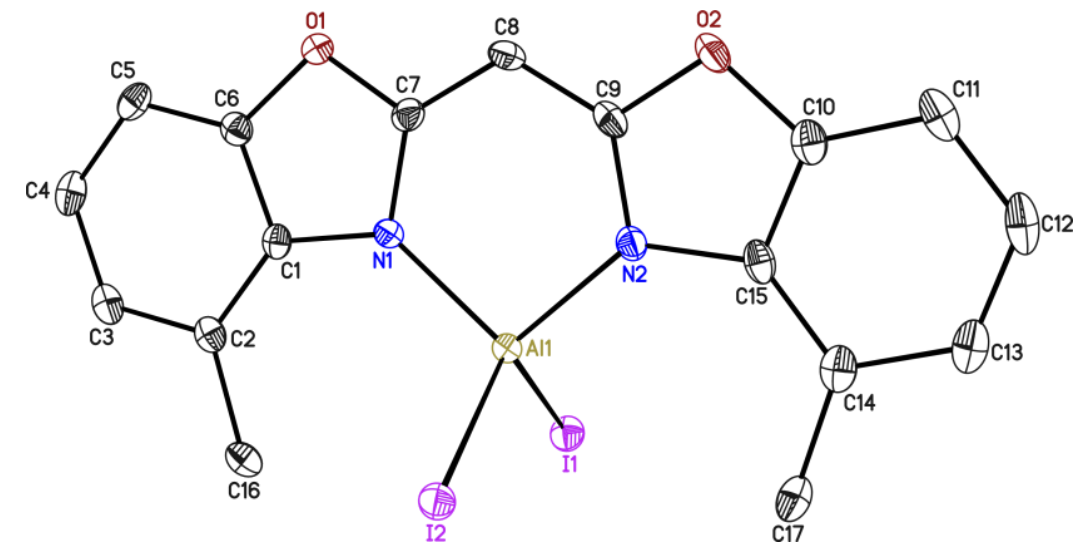

Figure 5-11. Molecular structure of 10. Anisotropic displacement parameters are depicted at the 50\% probability level. Hydrogen atoms are omitted for clarity.

Table 5-11. Crystallographic data of 10.

\begin{tabular}{ll|ll}
\hline Structure code & $\mathrm{JK} 190 \mathrm{~A}$ & $\rho_{\text {calc. }}\left[\mathrm{Mg} \cdot \mathrm{m}^{-3}\right]$ & 2.093 \\
CCDC no. & - & $\mu\left[\mathrm{mm}^{-1}\right]$ & 1.918 \\
Empirical formula & $\mathrm{C}_{17} \mathrm{H}_{13} \mathrm{AlI}_{2} \mathrm{~N}_{2} \mathrm{O}_{2}$ & $F(000)$ & 528 \\
Formula weight $\left[\mathrm{g} \mathrm{mol}^{-1}\right]$ & 558.07 & Crystal size $\left[\mathrm{mm}^{3}\right]$ & $0.220 \times 0.209 \times 0.147$ \\
Temperature $[\mathrm{K}]$ & $100(2)$ & $\theta$ range $\left[{ }^{\circ}\right]$ & 0.966 to 19.867 \\
Wavelength $[\AA]$ & 0.5608 & Reflections collected & 45721 \\
Crystal system & Triclinic & Unique Reflections & 3291 \\
Space group & $P \overline{1}$ & $R_{\text {int }}$ & 0.0195 \\
Unit cell parameters & $\mathrm{a}=7.494(2) \AA$ & Completeness to $\theta_{\max }[\%]$ & 100.0 \\
& $b=8.017(2) \AA$ & Restraints / parameters & $0 / 219$ \\
& $c=16.718(3) \AA$ & Goodness-of-fit on $\mathrm{F}^{2}$ & 1.101 \\
& $\alpha=84.64(2)^{\circ}$ & $R 1[\mathrm{I}>2 \sigma(\mathrm{I})]$ & 0.0118 \\
& $\beta=85.48(2)^{\circ}$ & wR2 (all data) & 0.0284 \\
Volume $\left[\AA^{3}\right]$ & $\gamma=62.40(2)^{\circ}$ & Max. diff. peak / hole $\left[\mathrm{e} \AA^{-3}\right]$ & $0.311 /-0.343$ \\
& $885.5(4)$ & Absolute structure & - \\
$Z$ & & parameter ${ }^{[235]}$ & \\
\hline
\end{tabular}




\subsubsection{2 $\left[\mathrm{All}_{2}\left({ }^{\left.\left.4-\mathrm{Me} \mathrm{Box}_{2} \mathrm{CH}_{2}\right)\right]^{+}[\mathrm{All}} 4\right]^{-}(10)\right.$}

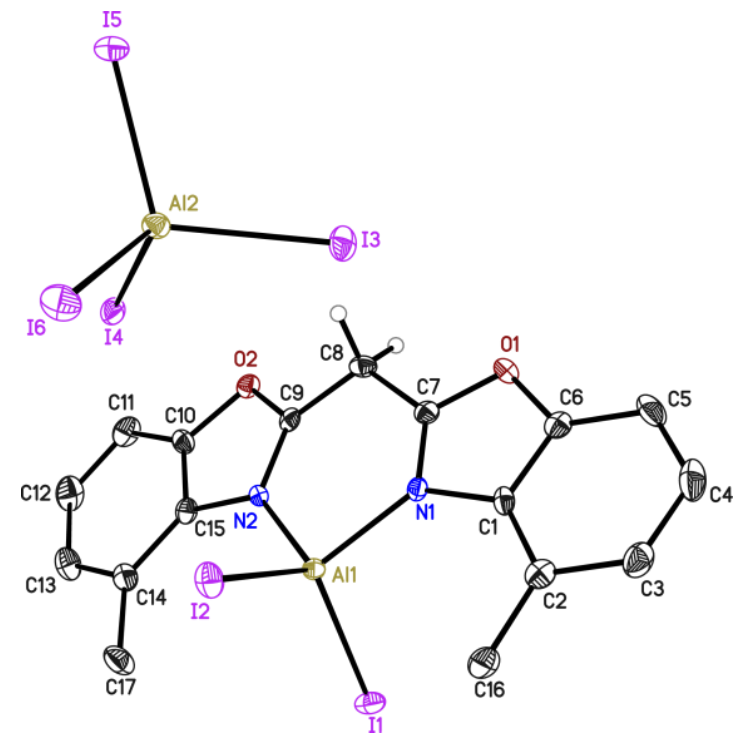

Figure 5-12. Molecular structure of 10. Anisotropic displacement parameters are depicted at the 50\% probability level. Hydrogen atoms are omitted for clarity.

Table 5-12. Crystallographic data of 10.

\begin{tabular}{|c|c|c|c|}
\hline Structure code & JK194 & $\rho_{\text {calcd. }}\left[\mathrm{Mg} \cdot \mathrm{m}^{-3}\right]$ & 2.597 \\
\hline CCDC no. & - & $\mu\left[\mathrm{mm}^{-1}\right]$ & 3.570 \\
\hline Empirical formula & $\mathrm{C}_{17} \mathrm{H}_{14} \mathrm{Al}_{2} \mathrm{I}_{6} \mathrm{~N}_{2} \mathrm{O}_{2}$ & $F(000)$ & 1960 \\
\hline Formula weight $\left[\mathrm{g} \mathrm{mol}^{-1}\right]$ & 1093.66 & Crystal size $\left[\mathrm{mm}^{3}\right]$ & $0.320 \times 0.190 \times 0.147$ \\
\hline Temperature $[\mathrm{K}]$ & $100(2)$ & $\theta$ range $\left[^{\circ}\right]$ & 1.756 to 19.839 \\
\hline Wavelength $[\AA]$ & 0.5608 & Reflections collected & 59510 \\
\hline Crystal system & Monoclinic & Unique Reflections & 5187 \\
\hline Space group & $P 2_{1} / n$ & $R_{\text {int }}$ & 0.0481 \\
\hline \multirow[t]{6}{*}{ Unit cell parameters } & $a=8.137(2) \AA$ & Completeness to $\theta_{\max }[\%]$ & 100.0 \\
\hline & $b=14.689(3) \AA$ & Restraints / parameters & $0 / 264$ \\
\hline & $c=23.592(2) \AA$ & Goodness-of-fit on $\mathrm{F}^{2}$ & 1.090 \\
\hline & $\alpha=90^{\circ}$ & $R 1[\mathrm{I}>2 \sigma(\mathrm{I})]$ & 0.0195 \\
\hline & $\beta=97.24(2)^{\circ}$ & wR2 (all data) & 0.0390 \\
\hline & $\gamma=90^{\circ}$ & Max. diff. peak / hole $\left[\mathrm{e}^{-3}\right]$ & $0.519 /-0.491$ \\
\hline Volume $\left[\AA^{3}\right]$ & $2797.3(9)$ & $\begin{array}{l}\text { Absolute structure } \\
\text { parameter }^{[235]}\end{array}$ & - \\
\hline$Z$ & 4 & Extinction coefficient & - \\
\hline
\end{tabular}




\subsubsection{3 [All( $\left.\left.{ }^{4-M e} \mathrm{Box}_{2} \mathrm{CH}\right)\right]_{2}(10)$}

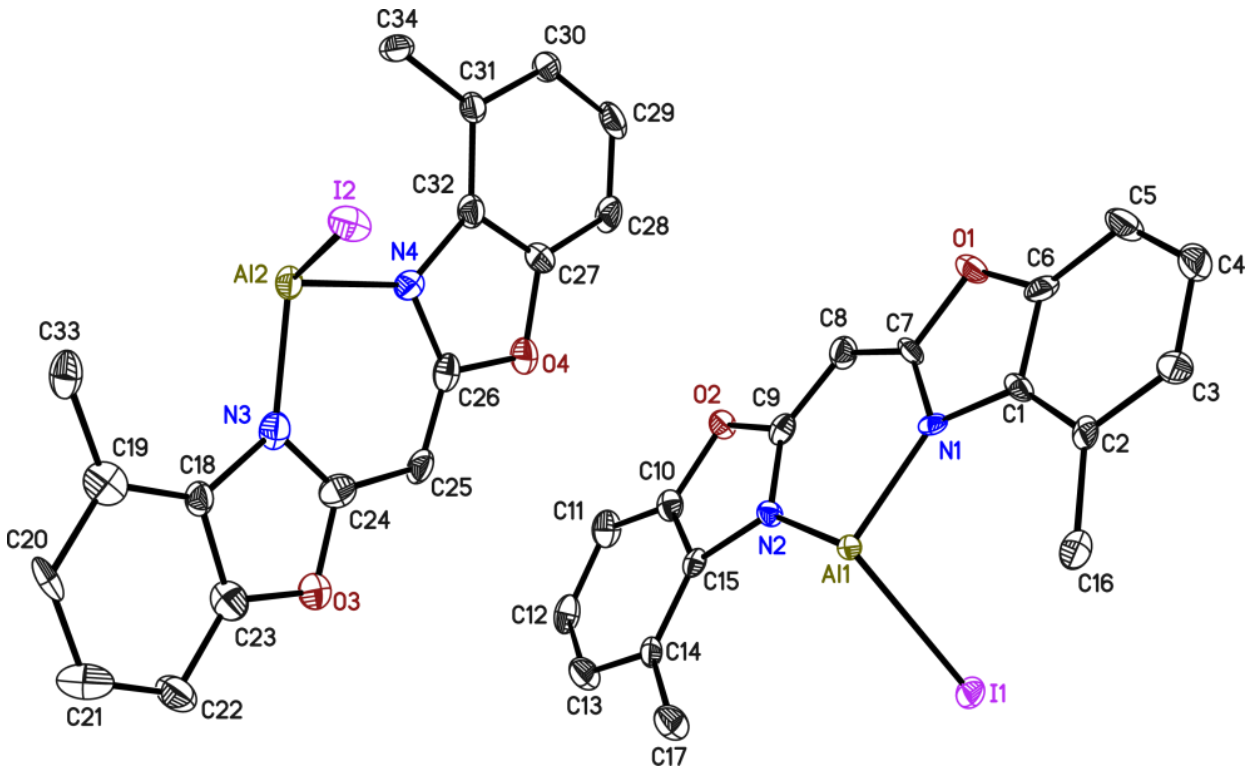

Figure 5-13. Molecular structure of 10. Anisotropic displacement parameters are depicted at the 50\% probability level. Hydrogen atoms are omitted for clarity. The remaining parts of the molecules are generated by symmetry.

Table 5-13. Crystallographic data of 10.

\begin{tabular}{ll|ll}
\hline Structure code & $\mathrm{JK} 511$ & $\rho_{\text {calcd. }}\left[\mathrm{Mg} \cdot \mathrm{m}^{-3}\right]$ & 1.780 \\
CCDC no. & - & $\mu\left[\mathrm{mm}^{-1}\right]$ & 1.094 \\
Empirical formula & $\mathrm{C}_{34} \mathrm{H}_{26} \mathrm{Al}_{2} \mathrm{I}_{2} \mathrm{~N}_{4} \mathrm{O}_{4}$ & $F(000)$ & 1688 \\
Formula weight $\left[\mathrm{g} \mathrm{mol}^{-1}\right]$ & 862.35 & Crystal size $\left[\mathrm{mm}^{3}\right]$ & $0.064 \times 0.118 \times 0.245$ \\
Temperature $[\mathrm{K}]$ & $100(2)$ & $\theta$ range $\left[^{\circ}\right]$ & 1.799 to 21.102 \\
Wavelength $[\AA]$ & 0.5608 & Reflections collected & 77576 \\
Crystal system & Monoclinic & Unique Reflections & 7098 \\
Space group & $C 2$ & $R_{\text {int }}$ & 0.0635 \\
Unit cell parameters & $\mathrm{a}=17.501(2) \AA$ & Completeness to $\theta_{\max }[\%]$ & 99.9 \\
& $b=10.390(2) \AA$ & Restraints / parameters & $1 / 420$ \\
& $c=17.692(3) \AA$ & Goodness-of-fit on $\mathrm{F}^{2}$ & 1.057 \\
& $\alpha=90^{\circ}$ & $R 1[\mathrm{I}>2 \sigma(\mathrm{I})]$ & 0.0266 \\
& $\beta=90.10(2)^{\circ}$ & wR2 (all data) & 0.0603 \\
Volume $\left[\AA^{3}\right]$ & $\gamma=90^{\circ}$ & Max. diff. peak / hole $\left[\mathrm{e} \AA^{-3}\right]$ & $1.023 /-0.769$ \\
$Z$ & $3217.0(9)$ & Absolute structure & $0.001(10)$ \\
\hline & & parameter & \\
\hline
\end{tabular}




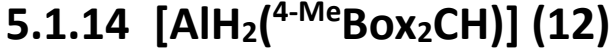

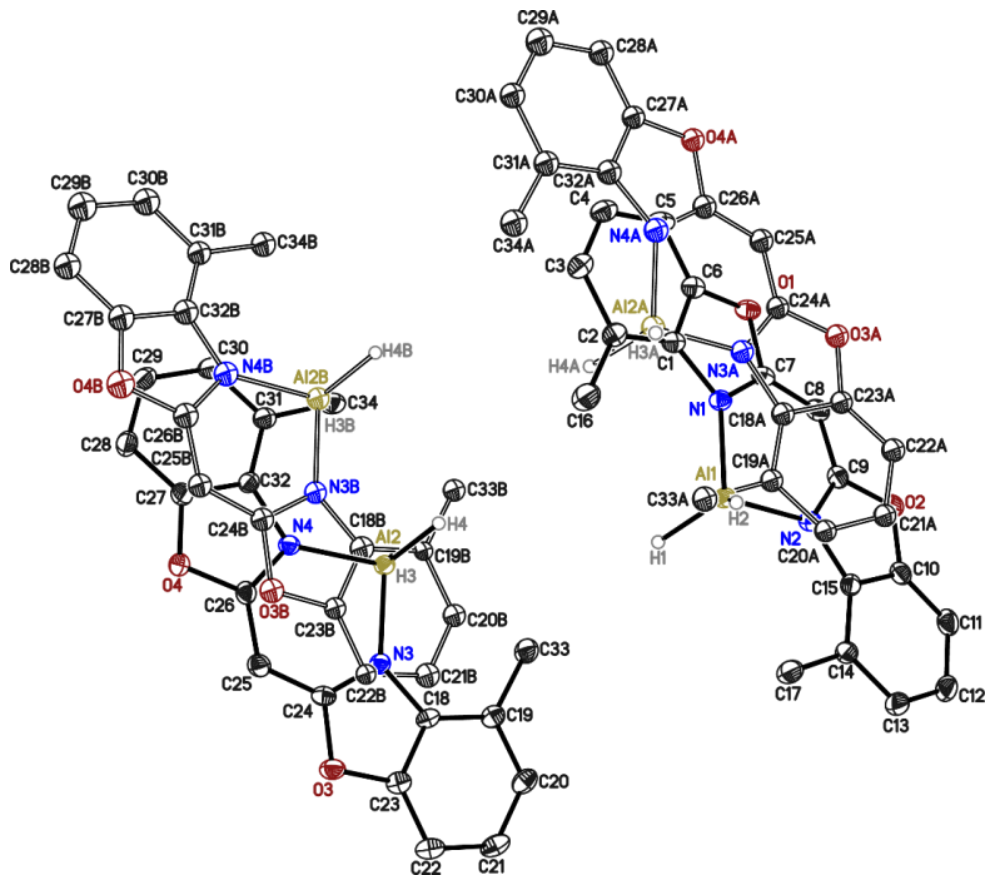

Figure 5-14. Asymmetric unit of 12 . Displacement parameters are depicted at 50\% probability. Hydrogen atoms except the hydrogen atoms bound to aluminium atoms are omitted for clarity. The compound crystalizes in space group $P 2_{1} / c$ containing two molecules in the asymmetric unit. Both molecules are disordered about two positions. The occupancy of the minor positions (A and B) refines to $0.0398(10)$ and $0.0422(10)$. These minor positions are refined as rigid group with isotropic displacement parameters. All displacement parameters are refined with similarity restraints. Reprinted with permission from reference [4]. Copyright 2020, American Chemical Society.

Table 5-14. Crystallographic data of 12.

\begin{tabular}{ll|ll}
\hline Structure code & $\mathrm{JK} 236$ & $\rho_{\text {calcd. }}\left[\mathrm{Mg} \cdot \mathrm{m}^{-3}\right]$ & 1.387 \\
CCDC no. & 2013457 & $\mu\left[\mathrm{mm}^{-1}\right]$ & 0.147 \\
Empirical formula & $\mathrm{C}_{17} \mathrm{H}_{15} \mathrm{AlN}_{2} \mathrm{O}_{2}$ & $F(000)$ & 1280 \\
Formula weight $\left[\mathrm{g} \mathrm{mol}^{-1}\right]$ & 306.29 & Crystal size $\left[\mathrm{mm}^{3}\right]$ & $0.303 \times 0.297 \times 0.206$ \\
Temperature $[\mathrm{K}]$ & $100(2)$ & $\theta$ range $\left[{ }^{\circ}\right]$ & 1.354 to 26.558 \\
Wavelength $[\AA]$ & 0.71073 & Reflections collected & 89814 \\
Crystal system & Monoclinic & Unique Reflections & 6095 \\
Space group & $P 2_{1} / \mathrm{c}$ & $R_{\text {int }}$ & 0.0420 \\
Unit cell parameters & $\mathrm{a}=15.078(3) \AA$ & Completeness to $\theta_{\max }[\%]$ & 100.0 \\
& $b=13.726(2) \AA$ & Restraints / parameters & $970 / 475$ \\
& $c=14.209(3) \AA$ & Goodness-of-fit on $\mathrm{F}^{2}$ & 1.029 \\
& $\alpha=90^{\circ}$ & $R 1[\mathrm{I}>2 \sigma(\mathrm{I})]$ & 0.0378 \\
& $\beta=94.18(2)^{\circ}$ & wR2 (all data) & 0.0434 \\
Volume $\left[\AA^{3}\right]$ & $\gamma=90^{\circ}$ & Max. diff. peak / hole $\left[\mathrm{e} \AA^{-3}\right]$ & $0.312 /-0.359$ \\
$Z$ & $2932.9(10)$ & Absolute structure & - \\
\hline
\end{tabular}




\subsubsection{5 [( $\left.\left.{ }^{4-M e} \mathrm{Box}_{2} \mathrm{CH}\right) \mathrm{Li}(\mu-\mathrm{H}) \mathrm{AlH}\left({ }^{4-\mathrm{Me}} \mathrm{Box}_{2} \mathrm{CH}\right)\right](12 \mathrm{a})$}

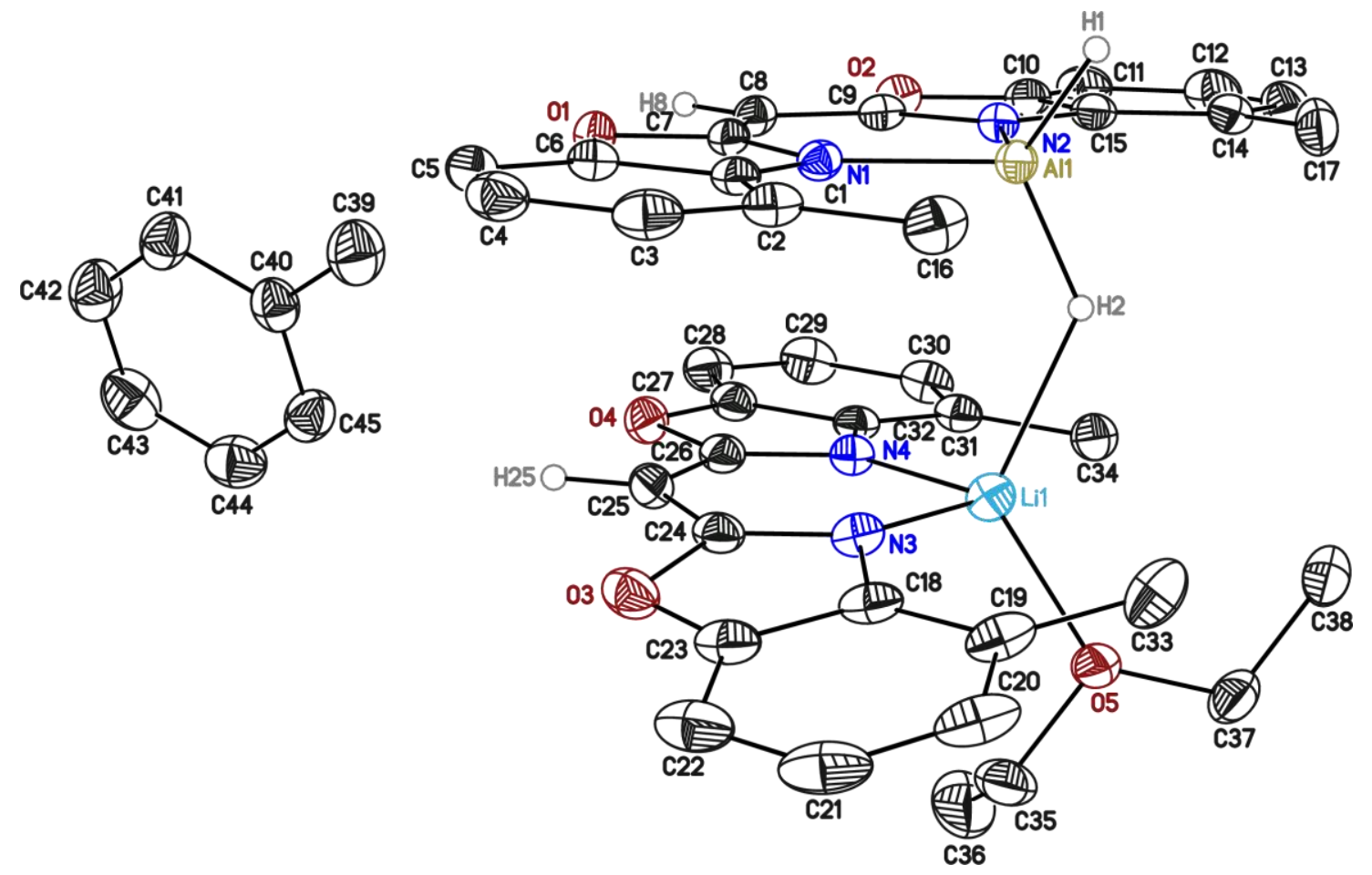

Figure 5-15. Molecular structure of 12a. Anisotropic displacement parameters are depicted at the 50\% probability level. Hydrogen atoms are omitted for clarity.

Table 5-15. Crystallographic data of 12a.

\begin{tabular}{ll|ll}
\hline Structure code & $\mathrm{JK} 232$ & $\rho_{\text {calcd. }\left[\mathrm{Mg} \cdot \mathrm{m}^{-3}\right]}$ & 1.269 \\
CCDC no. & - & $\mu\left[\mathrm{mm}^{-1}\right]$ & 0.103 \\
Empirical formula & $\mathrm{C}_{45} \mathrm{H}_{46} \mathrm{AlLiH}_{2} \mathrm{~N}_{4} \mathrm{O}_{4}$ & $F(000)$ & 1600 \\
Formula weight $\left[\mathrm{g} \mathrm{mol}^{-1}\right]$ & 756.78 & Crystal size $\left[\mathrm{mm}^{3}\right]$ & $0.193 \times 0.162 \times 0.133$ \\
Temperature $[\mathrm{K}]$ & $100(2)$ & $\theta$ range $\left[{ }^{\circ}\right]$ & 1.454 to 28.403 \\
Wavelength $[\AA]$ & 0.71073 & Reflections collected & 198955 \\
Crystal system & Monoclinic & Unique Reflections & 9916 \\
Space group & $P 2_{1} / n$ & $R_{\text {int }}$ & 0.0749 \\
Unit cell parameters & $\mathrm{a}=15.966(3) \AA$ & Completeness to $\theta_{\max }[\%]$ & 100.0 \\
& $b=14.774(2) \AA$ & Restraints / parameters & $0 / 520$ \\
& $c=18.107(3) \AA$ & Goodness-of-fit on $\mathrm{F}^{2}$ & 1.028 \\
& $\alpha=90^{\circ}$ & $R 1[\mathrm{I}>2 \sigma(\mathrm{I})]$ & 0.0386 \\
& $\beta=111.95(2)^{\circ}$ & wR2 (all data) & 0.1023 \\
Volume $\left[\AA^{3}\right]$ & $\gamma=90^{\circ}$ & Max. diff. peak / hole $\left[\mathrm{e} \AA^{-3}\right]$ & $0.397 /-0.247$ \\
$Z$ & $3961.5(12)$ & Absolute structure & - \\
& & parameter ${ }^{235]}$ & \\
\hline
\end{tabular}




\subsubsection{6 [( $\left.{ }^{\text {Dipp }} \mathrm{NacNac}\right) \mathrm{HAl}$ "-Al" $\left.\mathrm{H}\left({ }^{4-\mathrm{Me}}{ }^{\mathrm{Box}}{ }_{2} \mathrm{CH}\right)\right](13)$}

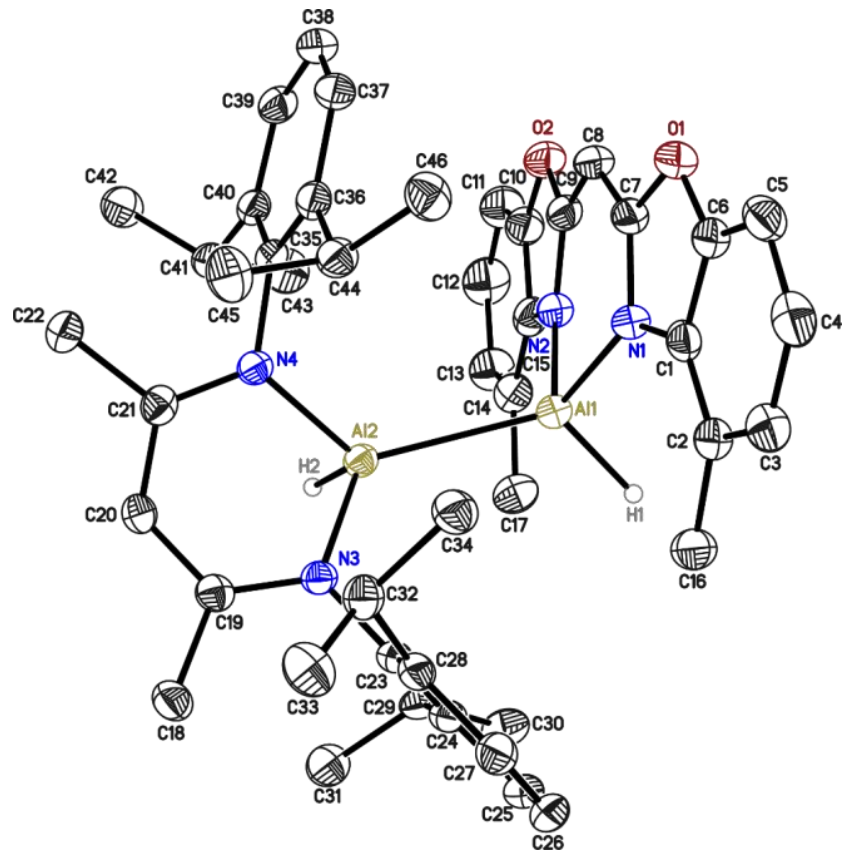

Figure 5-16. Asymmetric unit of 13. Displacement parameters are depicted at 50\% probability. Hydrogen atoms except the hydrogen atoms bound to aluminium atoms are omitted for clarity. The data were collected on a split crystal. They were integrated with two orientation matrices and then detwinned with TWINABS. The fractional contribution of the minor domain was refined to 0.4255 . Reprinted with permission from reference [4]. Copyright 2020, American Chemical Society.

Table 5-16. Crystallographic data of 13.

\begin{tabular}{|c|c|c|c|}
\hline Structure code & JK333 & $\rho_{\text {calcd. }}\left[\mathrm{Mg} \cdot \mathrm{m}^{-3}\right]$ & 1.184 \\
\hline CCDC no. & 2013458 & $\mu\left[\mathrm{mm}^{-1}\right]$ & 0.111 \\
\hline Empirical formula & $\mathrm{C}_{46} \mathrm{H}_{56} \mathrm{Al}_{2} \mathrm{~N}_{4} \mathrm{O}_{2}$ & $F(000)$ & 804 \\
\hline Formula weight $\left[\mathrm{g} \mathrm{mol}^{-1}\right]$ & 750.90 & Crystal size $\left[\mathrm{mm}^{3}\right]$ & $0.391 \times 0.155 \times 0.132$ \\
\hline Temperature $[\mathrm{K}]$ & $100(2)$ & $\theta$ range $\left[{ }^{\circ}\right]$ & 1.735 to 26.517 \\
\hline Wavelength $[\AA]$ & 0.71073 & Reflections collected & 166654 \\
\hline Crystal system & Triclinic & Unique Reflections & 8669 \\
\hline Space group & $P \overline{1}$ & $R_{\text {int }}$ & 0.1103 \\
\hline \multirow[t]{6}{*}{ Unit cell parameters } & $a=11.911(5) \AA$ & Completeness to $\theta_{\max }[\%]$ & 100.0 \\
\hline & $b=13.296(5) \AA$ & Restraints / parameters & $1 / 510$ \\
\hline & $c=13.725(6) \AA$ & Goodness-of-fit on $\mathrm{F}^{2}$ & 1.083 \\
\hline & $\alpha=79.45(2)^{\circ}$ & $R 1[\mathrm{I}>2 \sigma(\mathrm{I})]$ & 0.0494 \\
\hline & $\beta=87.14(3)^{\circ}$ & $\mathrm{w} R 2$ (all data) & 0.1320 \\
\hline & $\gamma=80.36(2)^{\circ}$ & Max. diff. peak / hole $\left[\mathrm{e} \AA^{-3}\right]$ & $0.341 /-0.331$ \\
\hline Volume $\left[\AA^{3}\right]$ & 2106.3(15) & $\begin{array}{l}\text { Absolute structure } \\
\text { parameter }^{[235]}\end{array}$ & - \\
\hline$Z$ & 2 & Extinction coefficient & - \\
\hline
\end{tabular}




\subsubsection{7 [( $\left.\left.{ }^{\text {Dipp }} \mathrm{NacNac}\right) A I^{\prime \prime}-\mathrm{Al}{ }^{\prime \prime} \mathrm{H}\left({ }^{4-\mathrm{Me}} \mathrm{Box}_{2} \mathrm{CH}\right)\right]\left[\mathrm{B}\left(\mathrm{C}_{6} \mathrm{~F}_{5}\right)_{4}\right](14)$}

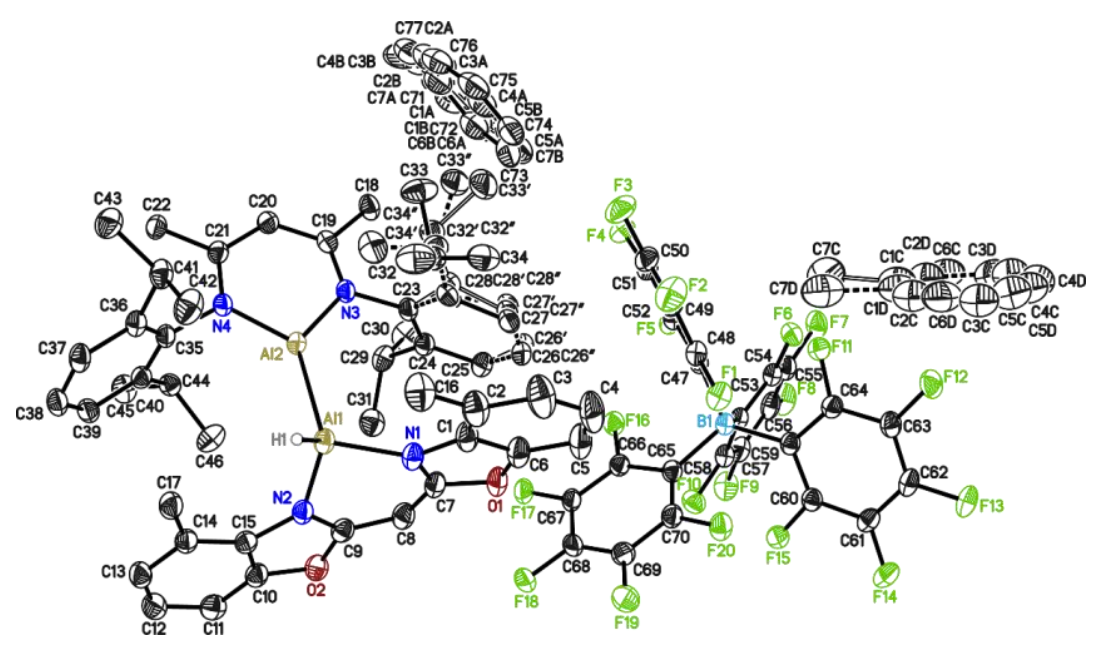

Figure 5-17. Asymmetric unit of 14. Displacement parameters are depicted at 50\% probability. Hydrogen atoms except the hydrogen atoms bound to aluminium atoms are omitted for clarity. The carbon atoms (C26, C27, C28, C32 to C34) are disordered about three positions, the occupancies of the minor positions refines to 0.308 (3) and 0.195(3). The toluene molecule C1C to C7C are disordered about an inversion centre, while the second toluene molecule is disordered about three positons, the occupancies of the minor positions refines to 0.246(2) and 0.082(2). All disordered groups are refined with distance restraints and restraints for the anisotropic displacement parameter, whereas the anisotropic displacement parameters of atomic posistions very close to each other are constrained to be identical. Reprinted with permission from reference [4]. Copyright 2020, American Chemical Society.

Table 5-17. Crystallographic data of 14.

\begin{tabular}{ll|ll}
\hline Structure code & $\mathrm{JK} 450$ & $\rho_{\text {calcd. }}\left[\mathrm{Mg} \cdot \mathrm{m}^{-3}\right]$ & 1.424 \\
CCDC no. & 2013459 & $\mu\left[\mathrm{mm}^{-1}\right]$ & 0.143 \\
Empirical formula & $\mathrm{C}_{80.50} \mathrm{H}_{67} \mathrm{Al}_{2} \mathrm{BF}_{20} \mathrm{~N}_{4} \mathrm{O}_{2}$ & $F(000)$ & 1610 \\
Formula weight $\left[\mathrm{g} \mathrm{mol}^{-1}\right]$ & 1567.15 & Crystal size $\left[\mathrm{mm}^{3}\right]$ & $0.435 \times 0.383 \times 0.230$ \\
Temperature $[\mathrm{K}]$ & $100(2)$ & $\theta$ range $\left[^{\circ}\right]$ & 1.802 to 30.627 \\
Wavelength $[\AA]$ & 0.71073 & Reflections collected & 156011 \\
Crystal system & Triclinic & Unique Reflections & 22359 \\
Space group & $\overline{1}$ & $R_{\text {int }}$ & 0.0582 \\
Unit cell parameters & $a=11.336(2) \AA$ & Completeness to $\theta_{\max }[\%]$ & 100.0 \\
& $b=16.822(2) \AA$ & Restraints / parameters & $2542 / 1288$ \\
& $c=20.432(3) \AA$ & Goodness-of-fit on $\mathrm{F}^{2}$ & 1.038 \\
& $\alpha=76.78(2)^{\circ}$ & $R 1[$ I>2 $\sigma(\mathrm{I})]$ & 0.0418 \\
& $\beta=74.55(2)^{\circ}$ & wR2 (all data) & 0.1180 \\
Volume $\left[\AA^{3}\right]$ & $\gamma=86.07(3)^{\circ}$ & Max. diff. peak / hole $\left[\mathrm{e} \AA^{-3}\right]$ & $0.405 /-0.349$ \\
$Z$ & $3655.8(11)$ & Absolute structure & - \\
\hline & 2 & parameter ${ }^{[235]}$ & \\
\hline
\end{tabular}




\subsubsection{8 $\left[\mathrm{Al} " \mathrm{H}\left({ }^{4-\mathrm{Me}}{ }^{\mathrm{Box}}{ }_{2} \mathrm{CH}\right)\right]_{2}(15 \mathrm{a} / 15 \mathrm{~b})$}

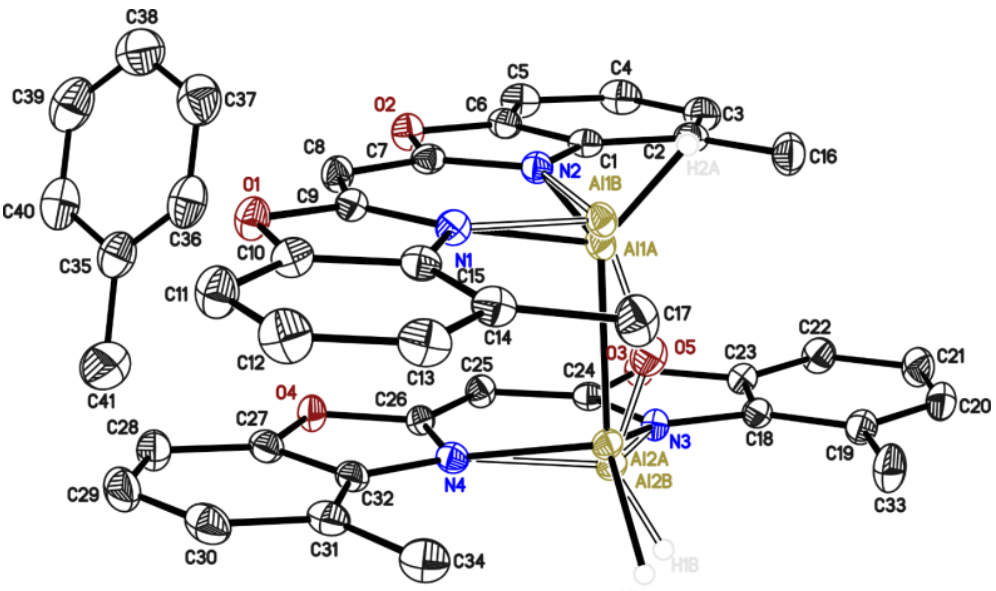

Figure 5-18. Asymmetric unit of $15 \mathrm{a} / \mathbf{1 5 b}$. Displacement parameters are depicted at 50\% probability. Hydrogen atoms except the hydrogen atoms bound to aluminium atoms are omitted for clarity. Molecule 15a and $15 \mathrm{~b}$ co-crystallised. The occupancy of $\mathbf{1 5 b}$ refined to $0.335(4)$. The disordered part is refined with distance restraints and restraints for the anisotropic displacement parameters. Reprinted with permission from reference [4]. Copyright 2020, American Chemical Society.

Table 5-18. Crystallographic data of 15a/15b.

\begin{tabular}{ll|ll}
\hline Structure code & $\mathrm{JK} 477$ & $\rho_{\text {calcd. }\left[\mathrm{Mg} \cdot \mathrm{m}^{-3}\right]}$ & 1.338 \\
CCDC no. & 2013460 & $\mu\left[\mathrm{mm}^{-1}\right]$ & 0.133 \\
Empirical formula & $\mathrm{C}_{41} \mathrm{H}_{36} \mathrm{Al}_{2} \mathrm{~N}_{4} \mathrm{O}_{4.34}$ & $F(000)$ & 1438 \\
Formula weight $\left[\mathrm{g} \mathrm{mol}^{-1}\right]$ & 708.06 & Crystal size $\left[\mathrm{mm}^{3}\right]$ & $0.234 \times 0.188 \times 0.127$ \\
Temperature $[\mathrm{K}]$ & $100(2)$ & $\theta$ range $\left[{ }^{\circ}\right]$ & 1.793 to 27.111 \\
Wavelength $[\AA]$ & 0.71073 & Reflections collected & 143627 \\
Crystal system & Monoclinic & Unique Reflections & 7762 \\
Space group & $P 2_{1} / n$ & $R_{\text {int }}$ & 0.0315 \\
Unit cell parameters & $a=14.543(2) \AA$ & Completeness to $\theta_{\max }[\%]$ & 100.0 \\
& $b=13.350(2) \AA$ & Restraints / parameters & $45 / 497$ \\
& $c=18.104(3) \AA$ & Goodness-of-fit on $\mathrm{F}^{2}$ & 1.044 \\
& $\alpha=90^{\circ}$ & $R 1[\mathrm{I}>2 \sigma(\mathrm{I})]$ & 0.0332 \\
& $\beta=90.23(2)^{\circ}$ & wR2 (all data) & 0.0952 \\
Volume $\left[\AA^{3}\right]$ & $\gamma=90^{\circ}$ & Max. diff. peak / hole $\left[\mathrm{e} \AA^{-3}\right]$ & $0.335 /-0.256$ \\
$Z$ & $3514.8(9)$ & Absolute structure & - \\
\hline & 4 & parameter & \\
\hline
\end{tabular}




\subsubsection{9 [(\{( $\left.\left.\left.\left.{ }^{\mathrm{Mes}} \mathrm{NacNac}\right) \mathrm{Mg}\right\}_{2}(\mu-\mathrm{H})\right)-\left\{\left.\mathrm{H}_{3} \mathrm{Al}\right|^{\prime \prime}-\mathrm{Al}{ }^{\prime \prime} \mathrm{H}\left({ }^{4-M e}{ }^{-} \mathrm{Box}_{2} \mathrm{CH}\right)\right\}\right](15 \mathrm{c})$}

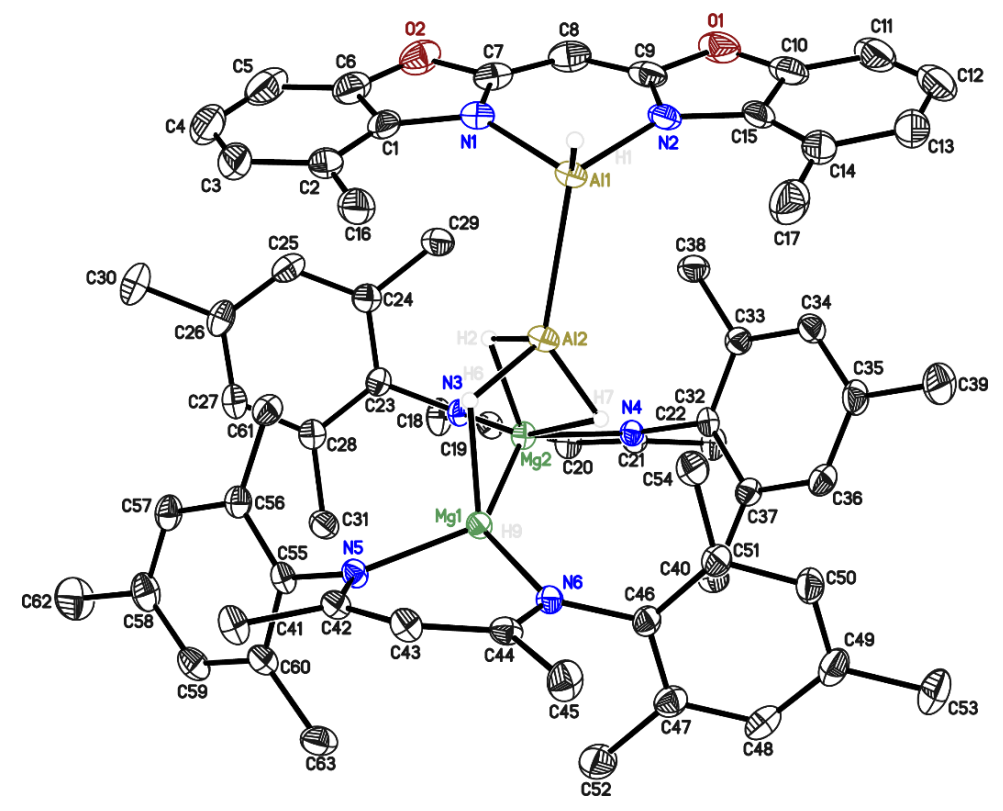

Figure 5-19. Asymmetric unit of 15c. Displacement parameters are depicted at 50\% probability. Hydrogen atoms except the hydrogen atoms bound to metal atoms are omitted for clarity. Reprinted with permission from reference [4]. Copyright 2020, American Chemical Society.

Table 5-19. Crystallographic data of 15c.

\begin{tabular}{ll|ll}
\hline Structure code & $\mathrm{JKMgAl}$ & $\rho_{\text {calcd. }}\left[\mathrm{Mg} \cdot \mathrm{m}^{-3}\right]$ & 1.175 \\
CCDC no. & 2013461 & $\mu\left[\mathrm{mm}^{-1}\right]$ & 0.117 \\
Empirical formula & $\mathrm{C}_{63} \mathrm{H}_{76} \mathrm{Al}_{2} \mathrm{Mg}_{2} \mathrm{~N}_{6} \mathrm{O}_{2}$ & $F(000)$ & 1124 \\
Formula weight $\left[\mathrm{g} \mathrm{mol}^{-1}\right]$ & 1051.87 & Crystal size $\left[\mathrm{mm}^{3}\right]$ & $0.209 \times 0.166 \times 0.106$ \\
Temperature $[\mathrm{K}]$ & $100(2)$ & $\theta$ range $\left[^{\circ}\right]$ & 1.665 to 27.172 \\
Wavelength $[\AA]$ & 0.71073 & Reflections collected & 51036 \\
Crystal system & Triclinic & Unique Reflections & 13171 \\
Space group & $P \overline{1}$ & $R_{\text {int }}$ & 0.0348 \\
Unit cell parameters & $a=10.716(2) \AA$ & Completeness to $\theta_{\max }[\%]$ & 100.0 \\
& $b=13.462(2) \AA$ & Restraints / parameters & $0 / 714$ \\
& $c=23.155(3) \AA$ & Goodness-of-fit on $\mathrm{F}^{2}$ & 1.030 \\
& $\alpha=97.83(2)^{\circ}$ & $R 1[\mathrm{I}>2 \sigma(\mathrm{I})]$ & 0.0426 \\
& $\beta=101.56(2)^{\circ}$ & wR2 (all data) & 0.1130 \\
Volume $\left[\AA^{3}\right]$ & $\gamma=111.07(3)^{\circ}$ & Max. diff. peak / hole $\left[\mathrm{e} \AA^{-3}\right]$ & $0.376 /-0.291$ \\
$Z$ & $2973.5(10)$ & Absolute structure & - \\
\hline & & parameter & \\
\hline
\end{tabular}




\subsubsection{0 [AlH(ODipp) $\left.\left.{ }^{4-M e} \mathrm{Box}_{2} \mathrm{CH}\right)\right](16)$}

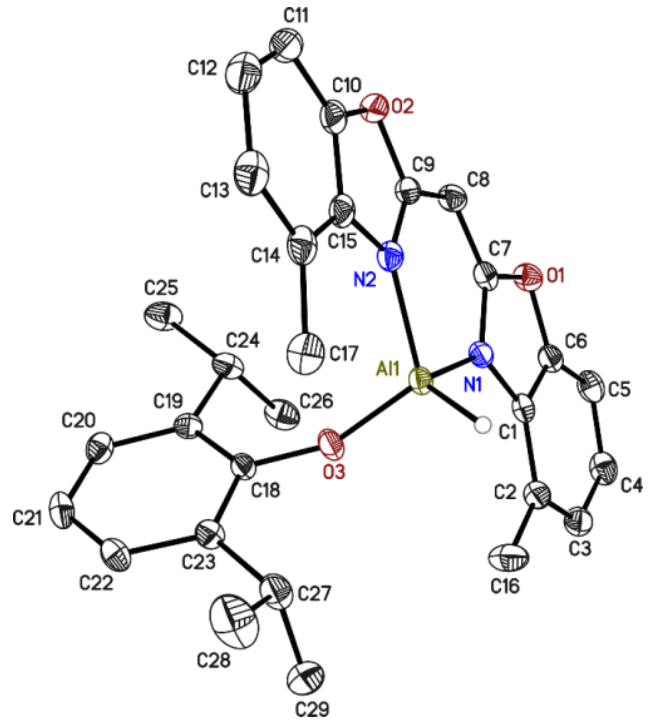

Figure 5-20. Asymmetric unit of 16. Displacement parameters are depicted at 50\% probability. Hydrogen atoms except the hydrogen atom bound to the aluminium atom are omitted for clarity. Reprinted with permission from reference [4]. Copyright 2020, American Chemical Society.

Table 5-20. Crystallographic data of 16.

\begin{tabular}{ll|ll}
\hline Structure code & $\mathrm{JK} 482$ & $\rho_{\text {calcd. }}\left[\mathrm{Mg} \cdot \mathrm{m}^{-3}\right]$ & 1.271 \\
CCDC no. & 2013462 & $\mu\left[\mathrm{mm}^{-1}\right]$ & 0.114 \\
Empirical formula & $\mathrm{C}_{29} \mathrm{H}_{31} \mathrm{AlN}_{2} \mathrm{O}_{3}$ & $F(000)$ & 512 \\
Formula weight $\left[\mathrm{g} \mathrm{mol}^{-1}\right]$ & 482.54 & Crystal size $\left[\mathrm{mm}^{3}\right]$ & $0.342 \times 0.224 \times 0.195$ \\
Temperature $[\mathrm{K}]$ & $100(2)$ & $\theta$ range $\left[^{\circ}\right]$ & 1.940 to 27.498 \\
Wavelength $[\AA]$ & 0.71073 & Reflections collected & 37784 \\
Crystal system & Triclinic & Unique Reflections & 5798 \\
Space group & $P \overline{1}$ & $R_{\text {int }}$ & 0.0250 \\
Unit cell parameters & $a=10.372(2) \AA$ & Completeness to $\theta_{\text {max }}[\%]$ & 100.0 \\
& $b=11.879(2) \AA$ & Restraints / parameters & $0 / 326$ \\
& $c=12.629(3) \AA$ & Goodness-of-fit on $\mathrm{F}^{2}$ & 1.028 \\
& $\alpha=116.29(3)^{\circ}$ & $R 1[\mathrm{I}>2 \sigma(\mathrm{I})]$ & 0.0332 \\
& $\beta=103.19(2)^{\circ}$ & wR2 (all data) & 0.0890 \\
& $\gamma=102.91(2)^{\circ}$ & Max. diff. peak / hole $\left[\mathrm{e} \AA^{-3}\right]$ & $0.361 /-0.279$ \\
Volume $\left[\AA^{3}\right]$ & $1260.9(5)$ & Absolute structure & - \\
$Z$ & 2 & parameter & \\
\hline
\end{tabular}




\subsubsection{1 [( $\mu$-O) $\left.\left\{\mathrm{Al}(\mathrm{ODipp})\left({ }^{4-\mathrm{Me}} \mathrm{Box}_{2} \mathrm{CH}\right)\right\}_{2}\right](17)$}

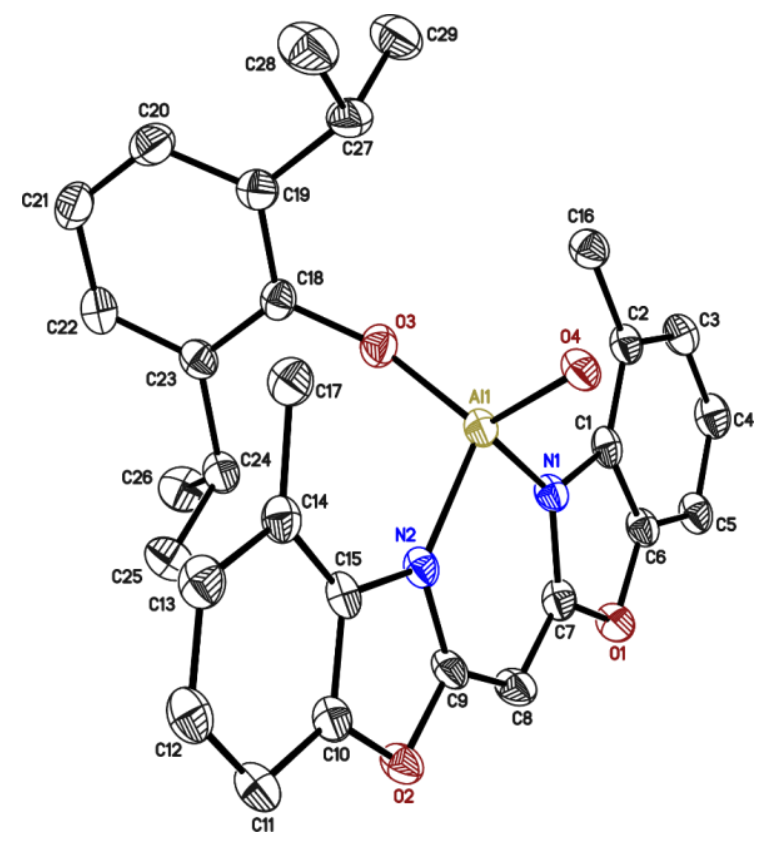

Figure 5-21. Asymmetric unit of 17. Displacement parameters are depicted at 50\% probability. Hydrogen atoms are omitted for clarity. Reprinted with permission from reference [4]. Copyright 2020, American Chemical Society.

Table 5-21. Crystallographic data of 17.

\begin{tabular}{|c|c|c|c|}
\hline Structure code & JK484 & $\rho_{\text {calcd. }}\left[\mathrm{Mg} \cdot \mathrm{m}^{-3}\right]$ & 1.306 \\
\hline CCDC no. & 2013463 & $\mu\left[\mathrm{mm}^{-1}\right]$ & 0.118 \\
\hline Empirical formula & $\mathrm{C}_{58} \mathrm{H}_{60} \mathrm{Al}_{2} \mathrm{~N}_{4} \mathrm{O}_{7}$ & $F(000)$ & 1036 \\
\hline Formula weight $\left[\mathrm{g} \mathrm{mol}^{-1}\right]$ & 979.06 & Crystal size $\left[\mathrm{mm}^{3}\right]$ & $0.156 \times 0.080 \times 0.055$ \\
\hline Temperature $[\mathrm{K}]$ & $100(2)$ & $\theta$ range $\left[^{\circ}\right]$ & 1.996 to 27.513 \\
\hline Wavelength $[\AA]$ & 0.71073 & Reflections collected & 63575 \\
\hline Crystal system & Monoclinic & Unique Reflections & 5711 \\
\hline Space group & $P 21 / n$ & $R_{\text {int }}$ & 0.1075 \\
\hline \multirow[t]{6}{*}{ Unit cell parameters } & $a=12.319(2) \AA$ & Completeness to $\theta_{\max }[\%]$ & 100.0 \\
\hline & $b=11.116(2) \AA$ & Restraints / parameters & $0 / 328$ \\
\hline & $c=18.186(3) \AA$ & Goodness-of-fit on $\mathrm{F}^{2}$ & 1.022 \\
\hline & $\alpha=90^{\circ}$ & $R 1[\mathrm{I}>2 \sigma(\mathrm{I})]$ & 0.0465 \\
\hline & $\beta=90.04(2)^{\circ}$ & $\mathrm{w} R 2$ (all data) & 0.1193 \\
\hline & $\gamma=90^{\circ}$ & Max. diff. peak / hole $\left[\mathrm{e}^{-3}\right]$ & $0.265 /-0.330$ \\
\hline Volume $\left[\AA^{3}\right]$ & $2490.4(7)$ & $\begin{array}{l}\text { Absolute structure } \\
\text { parameter }^{[235]}\end{array}$ & - \\
\hline$Z$ & 2 & Extinction coefficient & - \\
\hline
\end{tabular}




\subsubsection{Bis(4-benzhydrylbenzoxazol-2-yl)methane (23)}

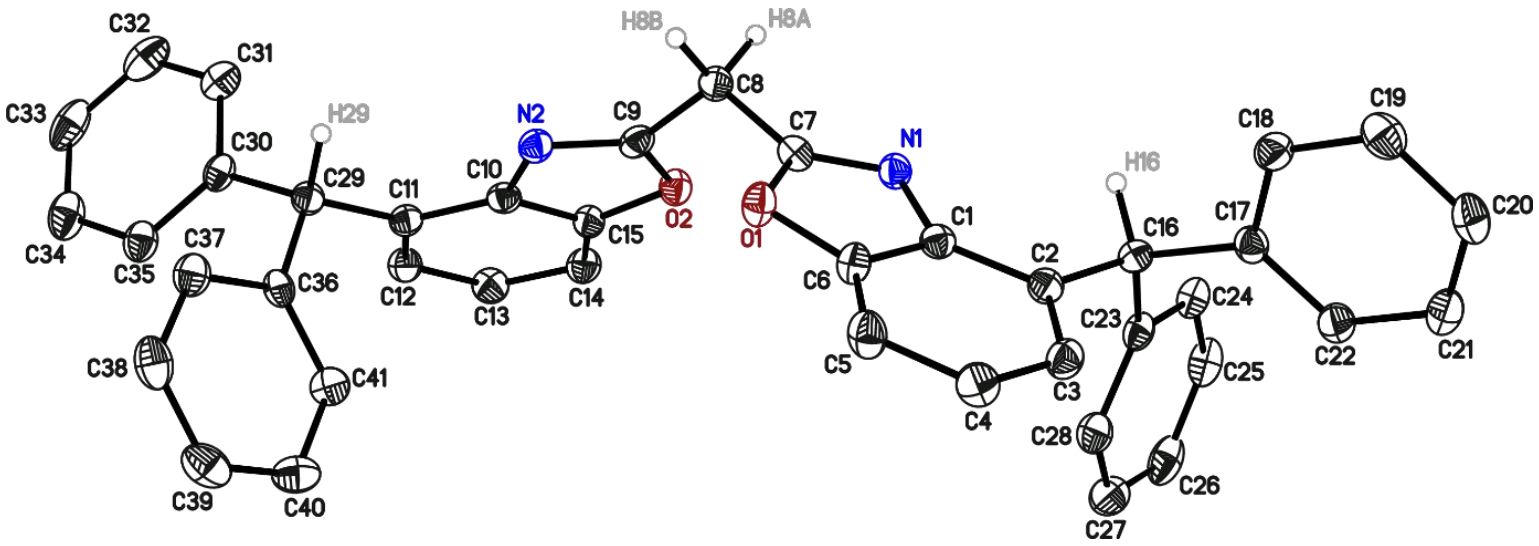

Figure 5-22. Asymmetric unit of 23. Displacement parameters are depicted at 50\% probability. Hydrogen atoms except the hydrogen atoms bound to the methylene backbone (H8) and benzylic groups (H16, H29) are omitted for clarity. Reprinted with permission from reference [5]. Copyright 2021, John Wiley and Sons.

Table 5-22. Crystallographic data of 23.

\begin{tabular}{ll|ll}
\hline Structure code & $\mathrm{JK} 252$ & $\rho_{\text {calcd. }}\left[\mathrm{Mg} \cdot \mathrm{m}^{-3}\right]$ & 1.298 \\
CCDC no. & 2031907 & $\mu\left[\mathrm{mm}^{-1}\right]$ & 0.080 \\
Empirical formula & $\mathrm{C}_{41} \mathrm{H}_{30} \mathrm{~N}_{2} \mathrm{O}_{2}$ & $F(000)$ & 1224 \\
Formula weight $\left[\mathrm{g} \mathrm{mol}^{-1}\right]$ & 582.67 & Crystal size $\left[\mathrm{mm}^{3}\right]$ & $0.179 \times 0.142 \times 0.085$ \\
Temperature $[\mathrm{K}]$ & $100(2)$ & $\theta$ range $\left[{ }^{\circ}\right]$ & 1.353 to 25.349 \\
Wavelength $[\AA]$ & 0.71073 & Reflections collected & 57812 \\
Crystal system & Monoclinic & Unique Reflections & 5458 \\
Space group & $P 2_{1} / \mathrm{c}$ & $R_{\text {int }}$ & 0.0786 \\
Unit cell parameters & $a=13.281(3) \AA$ & Completeness to $\theta_{\max }[\%]$ & 100.0 \\
& $b=30.091(6) \AA$ & Restraints / parameters & $0 / 407$ \\
& $c=7.754(2) \AA$ & Goodness-of-fit on $\mathrm{F}^{2}$ & 1.028 \\
& $\alpha=90^{\circ}$ & $R 1[\mathrm{I}>2 \sigma(\mathrm{I})]$ & 0.0403 \\
& $\beta=105.81(2)^{\circ}$ & wR2 (all data) & 0.0955 \\
Volume $\left[\AA^{3}\right]$ & $\gamma=90^{\circ}$ & Max. diff. peak / hole $\left[\mathrm{e} \AA^{-3}\right]$ & $0.288 /-0.330$ \\
& $2981.6(12)$ & Absolute structure & - \\
$Z$ & & parameter & \\
\hline
\end{tabular}




\subsubsection{3 $\left[\mathrm{Na}\left({ }^{4-\mathrm{BrhH} 2} \mathrm{Box}_{2} \mathrm{CH}\right)\right](24)$}

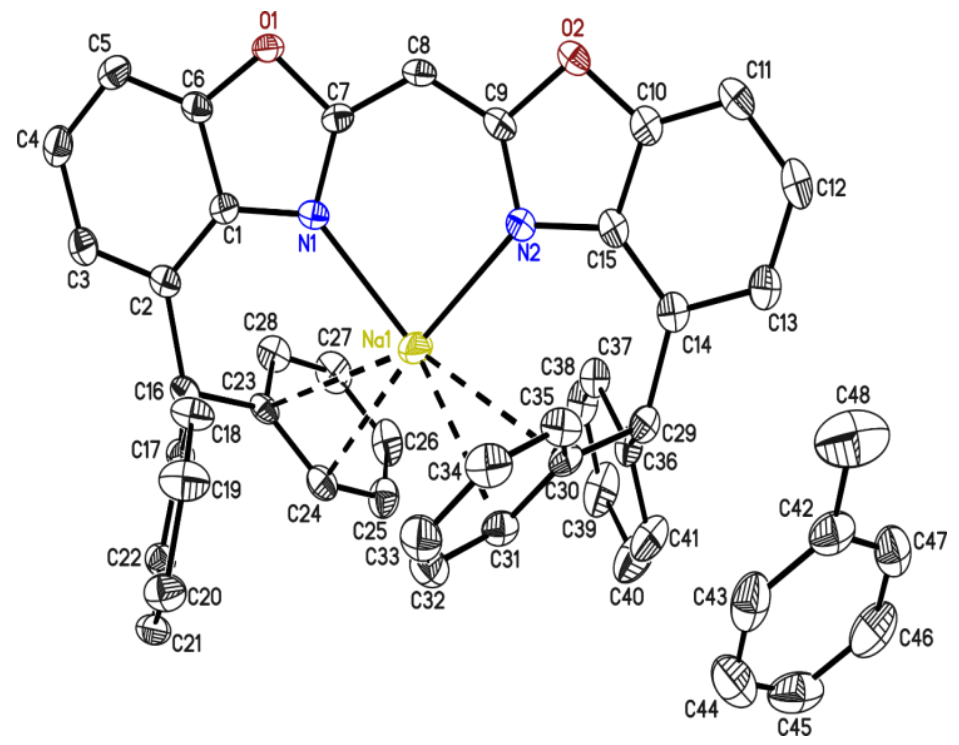

Figure 5-23. Asymmetric unit of 24. Displacement parameters are depicted at 50\% probability. Hydrogen atoms are omitted for clarity. Reprinted with permission from reference [5]. Copyright 2021, John Wiley and Sons.

Table 5-23. Crystallographic data of 24.

\begin{tabular}{ll|ll}
\hline Structure code & $\mathrm{JK} 301$ & $\rho_{\text {calcd. }\left[\mathrm{Mg} \cdot \mathrm{m}^{-3}\right]}$ & 1.289 \\
CCDC no. & 2031908 & $\mu\left[\mathrm{mm}^{-1}\right]$ & 0.056 \\
Empirical formula & $\mathrm{C}_{48} \mathrm{H}_{37} \mathrm{NaN}_{2} \mathrm{O}_{2}$ & $F(000)$ & 1464 \\
Formula weight $\left[\mathrm{g} \mathrm{mol}^{-1}\right]$ & 696.78 & Crystal size $\left[\mathrm{mm}^{3}\right]$ & $0.291 \times 0.285 \times 0.213$ \\
Temperature $[\mathrm{K}]$ & $100(2)$ & $\theta$ range $\left[^{\circ}\right]$ & 1.340 to 20.068 \\
Wavelength $[\AA]$ & 0.56086 & Reflections collected & 89033 \\
Crystal system & Monoclinic & Unique Reflections & 6854 \\
Space group & $P 2_{1} / n$ & $R_{\text {int }}$ & 0.0682 \\
Unit cell parameters & $\mathrm{a}=15.287(2) \AA$ & Completeness to $\theta_{\max }[\%]$ & 100.0 \\
& $b=9.789(2) \AA$ & Restraints / parameters & $0 / 479$ \\
& $c=23.990(3) \AA$ & Goodness-of-fit on $\mathrm{F}^{2}$ & 1.055 \\
& $\alpha=90^{\circ}$ & $R 1[\mathrm{I}>2 \sigma(\mathrm{I})]$ & 0.0415 \\
& $\beta=90.16(3)^{\circ}$ & wR2 (all data) & 0.1002 \\
Volume $\left[\AA^{3}\right]$ & $\gamma=90^{\circ}$ & Max. diff. peak / hole $\left[\mathrm{e} \AA^{-3}\right]$ & $0.241 /-0.304$ \\
& $3590.0(10)$ & Absolute structure & - \\
$Z$ & & parameter & \\
\hline
\end{tabular}




\subsubsection{4 $\left[K\left({ }^{4-\mathrm{BzhH}^{2}} \mathrm{Box}_{2} \mathrm{CH}\right)\right]\left(25_{1}\right)$}

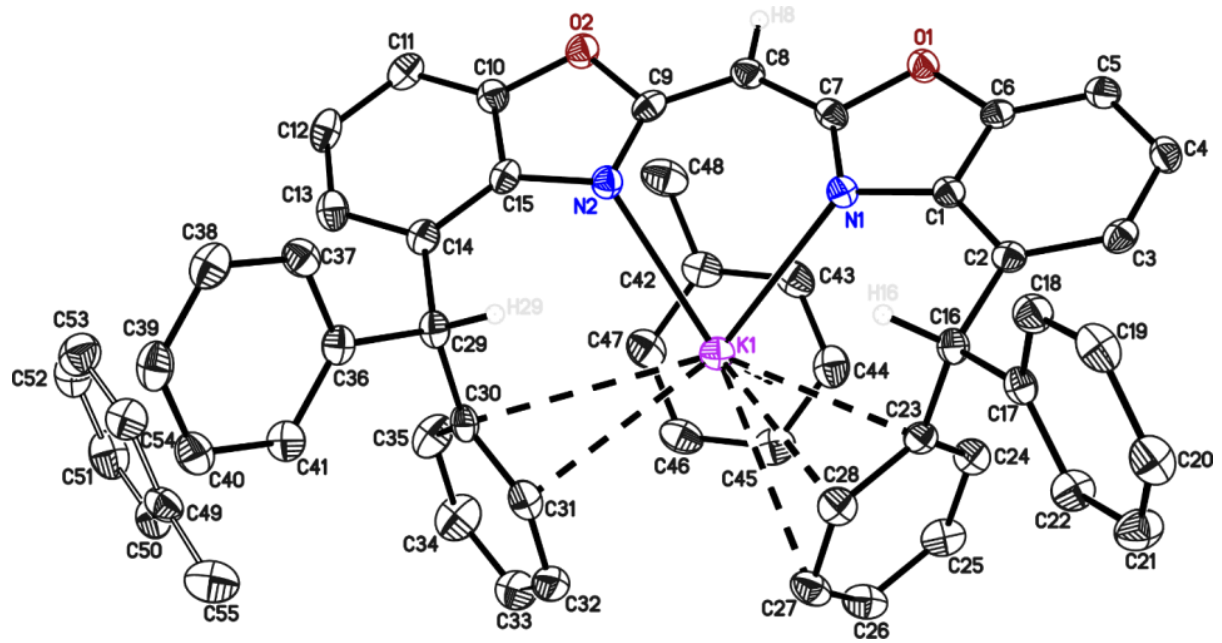

Figure 5-24. Asymmetric unit of $25_{1}$. Displacement parameters are depicted at 50\% probability. Hydrogen atoms except the hydrogen atoms bound to the methylene backbone (H8) and benzylic groups (H16, H29) are omitted for clarity. The toluene molecule C49 to C55 is disordered about an inversion centre. The disordered group was refined with distance restraints and restraints for the anisotropic displacement parameter. Reprinted with permission from reference [5]. Copyright 2021, John Wiley and Sons.

Table 5-24. Crystallographic data of $25_{1}$.

\begin{tabular}{ll|ll}
\hline Structure code & $\mathrm{JKPhBoxK}$ & $\rho_{\text {calcd. }}\left[\mathrm{Mg} \cdot \mathrm{m}^{-3}\right]$ & 1.299 \\
CCDC no. & 2031909 & $\mu\left[\mathrm{mm}^{-1}\right]$ & 0.183 \\
Empirical formula & $\mathrm{C}_{51.50} \mathrm{H}_{41} \mathrm{KN}_{2} \mathrm{O}_{2}$ & $F(000)$ & 798 \\
Formula weight $\left[\mathrm{g} \mathrm{mol}^{-1}\right]$ & 758.96 & Crystal size $\left[\mathrm{mm}^{3}\right]$ & $0.220 \times 0.113 \times 0.073$ \\
Temperature $[\mathrm{K}]$ & $100(2)$ & $\theta$ range $\left.{ }^{\circ}\right]$ & 1.523 to 26.028 \\
Wavelength $[\AA]$ & 0.71073 & Reflections collected & 39440 \\
Crystal system & Triclinic & Unique Reflections & 7636 \\
Space group & $P \overline{1}$ & $R_{\text {int }}$ & 0.0647 \\
Unit cell parameters & $\mathrm{a}=8.225(2) \AA$ & Completeness to $\theta_{\max }[\%]$ & 100.0 \\
& $b=9.434(2) \AA$ & Restraints / parameters & $84 / 543$ \\
& $c=27.089(3) \AA$ & Goodness-of-fit on $\mathrm{F}^{2}$ & 1.028 \\
& $\alpha=82.78(3)^{\circ}$ & $R 1[\mathrm{I}>2 \sigma(\mathrm{I})]$ & 0.0436 \\
& $\beta=82.16(2)^{\circ}$ & wR2 (all data) & 0.0980 \\
Volume $\left[\AA^{3}\right]$ & $\gamma=69.27(2)^{\circ}$ & Max. diff. peak / hole $\left[\mathrm{e} \AA^{-3}\right]$ & $0.248 /-0.328$ \\
$Z$ & $1940.7(7)$ & Absolute structure & - \\
\hline
\end{tabular}




\subsubsection{5 $\left[\mathrm{K}\left({ }^{4-\mathrm{BzhH} 2} \mathrm{Box}_{2} \mathrm{CH}\right)\right]_{2}\left(25_{2}\right)$}

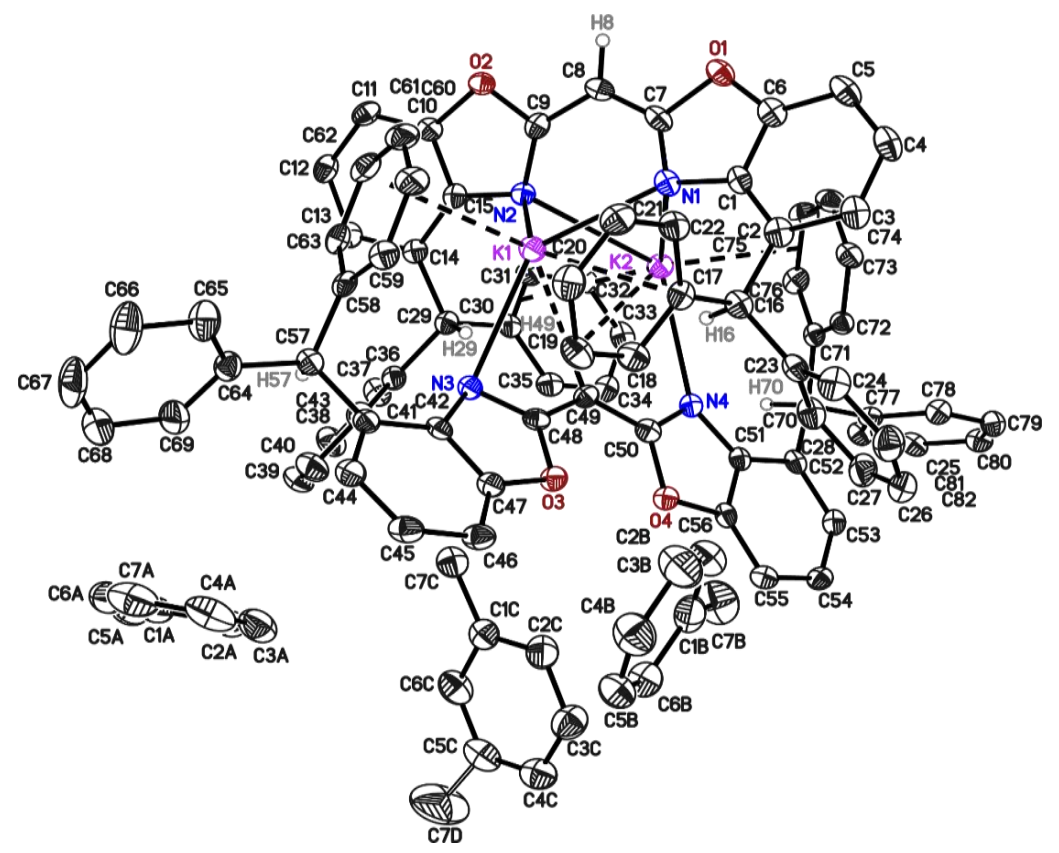

Figure 5-25. Asymmetric unit of 25. Displacement parameters are depicted at 50\% probability. Hydrogen atoms except the hydrogen atoms bound to the methylene backbone (H8, H49) and benzylic groups (H16, H29, $\mathrm{H} 57, \mathrm{H} 70$ ) are omitted for clarity. The methyl group of the toluene molecule $\mathrm{C} 1 \mathrm{C}$ to $\mathrm{C} 7 \mathrm{C}$ is disordered over two postions. The occupancy of the minor position refined to 0.150(8). All toluene molecules are refined with distance restraints and the disordered one additionally with restraints for the anisotropic displacement parameter. The hydrogen atom $\mathrm{H} 49$ was refined without any restraints or constraints. Reprinted with permission from reference [5]. Copyright 2021, John Wiley and Sons.

Table 5-25. Crystallographic data of $25_{2}$.

\begin{tabular}{ll|ll}
\hline Structure code & $\mathrm{JK} 295$ & $\rho_{\text {calcd. }}\left[\mathrm{Mg} \cdot \mathrm{m}^{-3}\right]$ & 1.286 \\
CCDC no. & 2031910 & $\mu\left[\mathrm{mm}^{-1}\right]$ & 0.102 \\
Empirical formula & $\mathrm{C}_{103} \mathrm{H}_{82} \mathrm{~K}_{2} \mathrm{~N}_{4} \mathrm{O}_{4}$ & $F(000)$ & 3192 \\
Formula weight $\left[\mathrm{g} \mathrm{mol}^{-1}\right]$ & 1517.92 & Crystal size $\left[\mathrm{mm}^{3}\right]$ & $0.219 \times 0.114 \times 0.076$ \\
Temperature $[\mathrm{K}]$ & $100(2)$ & $\theta$ range $\left[^{\circ}\right]$ & 1.286 to 19.932 \\
Wavelength $[\AA]$ & 0.56086 & Reflections collected & 207083 \\
Crystal system & Monoclinic & Unique Reflections & 14566 \\
Space group & $P 2_{1} / \mathrm{c}$ & $R_{\text {int }}$ & 0.1415 \\
Unit cell parameters & $a=13.806(2) \AA$ & Completeness to $\theta_{\max }[\%]$ & 100.0 \\
& $b=21.863(4) \AA$ & Restraints / parameters & $455 / 1035$ \\
& $c=26.528(4) \AA$ & Goodness-of-fit on $\mathrm{F}^{2}$ & 1.044 \\
& $\alpha=90^{\circ}$ & $R 1[\mathrm{I}>2 \sigma(\mathrm{I})]$ & 0.0570 \\
& $\beta=101.79(3)^{\circ}$ & wR2 (all data) & 0.1596 \\
Volume $\left[\AA^{3}\right]$ & $\gamma=90^{\circ}$ & Max. diff. peak / hole $\left[\mathrm{e} \AA^{-3}\right]$ & $0.530 /-0.518$ \\
$Z$ & $7838(2)$ & Absolute structure & - \\
& & parameter & \\
\hline
\end{tabular}




\subsubsection{6 $\left[\mathrm{Rb}\left({ }^{4-\mathrm{BrhH}}{ }^{\mathrm{BOO}}{ }_{2} \mathrm{CH}\right)\right]_{2}(26)$}

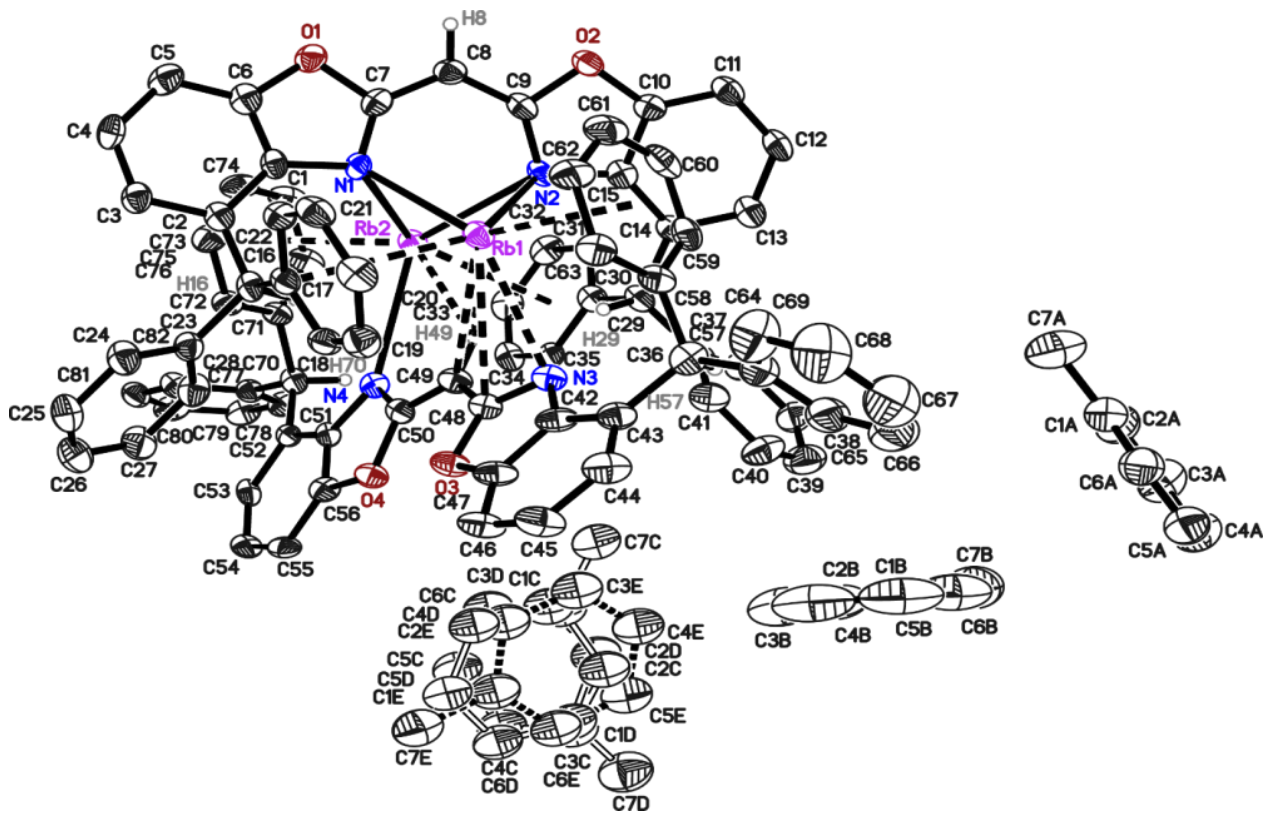

Figure 5-26. Asymmetric unit of 26. Displacement parameters are depicted at 50\% probability. Hydrogen atoms except the hydrogen atoms bound to the methylene backbone (H8, H49) and benzylic groups (H16, H29, $\mathrm{H} 57, \mathrm{H} 70$ ) are omitted for clarity. One of the three toluene molecules is disordered over three positions. The occupancies refined to 0.549 (3), 0.351 (3) and 0.100(3), respectively. All toluene molecules were refined with distance restraints and with restraints for the anisotropic displacement parameter. The data were collected on a split crystal. An integration with two orientation matrices did not improve the model. Therefore, relatively high residual remained close to the $\mathrm{Rb}$ positions. Reprinted with permission from reference [5]. Copyright 2021, John Wiley and Sons.

Table 5-26. Crystallographic data of 26.

\begin{tabular}{|c|c|c|c|}
\hline Structure code & $\mathrm{JKRb}$ & $\rho_{\text {calcd. }}\left[{\left.\mathrm{Mg} \cdot \mathrm{m}^{-3}\right]}\right.$ & 1.358 \\
\hline CCDC no. & 2031911 & $\mu\left[\mathrm{mm}^{-1}\right]$ & 1.302 \\
\hline Empirical formula & $\mathrm{C}_{103} \mathrm{H}_{82} \mathrm{Rb}_{2} \mathrm{~N}_{4} \mathrm{O}_{4}$ & $F(000)$ & 3336 \\
\hline Formula weight $\left[\mathrm{g} \mathrm{mol}^{-1}\right]$ & 1610.66 & Crystal size $\left[\mathrm{mm}^{3}\right]$ & $0.256 \times 0.131 \times 0.085$ \\
\hline Temperature $[\mathrm{K}]$ & $100(2)$ & $\theta$ range $\left[^{\circ}\right]$ & 1.218 to 25.594 \\
\hline Wavelength $[\AA ̊]$ & 0.71073 & Reflections collected & 97550 \\
\hline Crystal system & Monoclinic & Unique Reflections & 14651 \\
\hline Space group & $P 2_{1} / \mathrm{c}$ & $R_{\text {int }}$ & 0.0850 \\
\hline \multirow[t]{6}{*}{ Unit cell parameters } & $a=13.848(2) \AA$ & Completeness to $\theta_{\max }[\%]$ & 100.0 \\
\hline & $b=21.699(3) \AA$ & Restraints / parameters & $1747 / 1149$ \\
\hline & $c=26.849(3) \AA$ & Goodness-of-fit on $\mathrm{F}^{2}$ & 1.133 \\
\hline & $\alpha=90^{\circ}$ & $R 1[\mathrm{I}>2 \sigma(\mathrm{I})]$ & 0.0787 \\
\hline & $\beta=102.48(3)^{\circ}$ & $\mathrm{w} R 2$ (all data) & 0.1958 \\
\hline & $\gamma=90^{\circ}$ & Max. diff. peak / hole $\left[\mathrm{e} \AA^{-3}\right]$ & $2.874 /-0.942$ \\
\hline Volume $\left[\AA^{3}\right]$ & $7877(2)$ & $\begin{array}{l}\text { Absolute structure } \\
\text { parameter }^{[235]}\end{array}$ & - \\
\hline$Z$ & 4 & Extinction coefficient & - \\
\hline
\end{tabular}




\subsubsection{7 $\left[\mathrm{Cs}\left({ }^{4-\mathrm{BzhH} 2} \mathrm{Box}_{2} \mathrm{CH}\right)\right]_{2}(27)$}

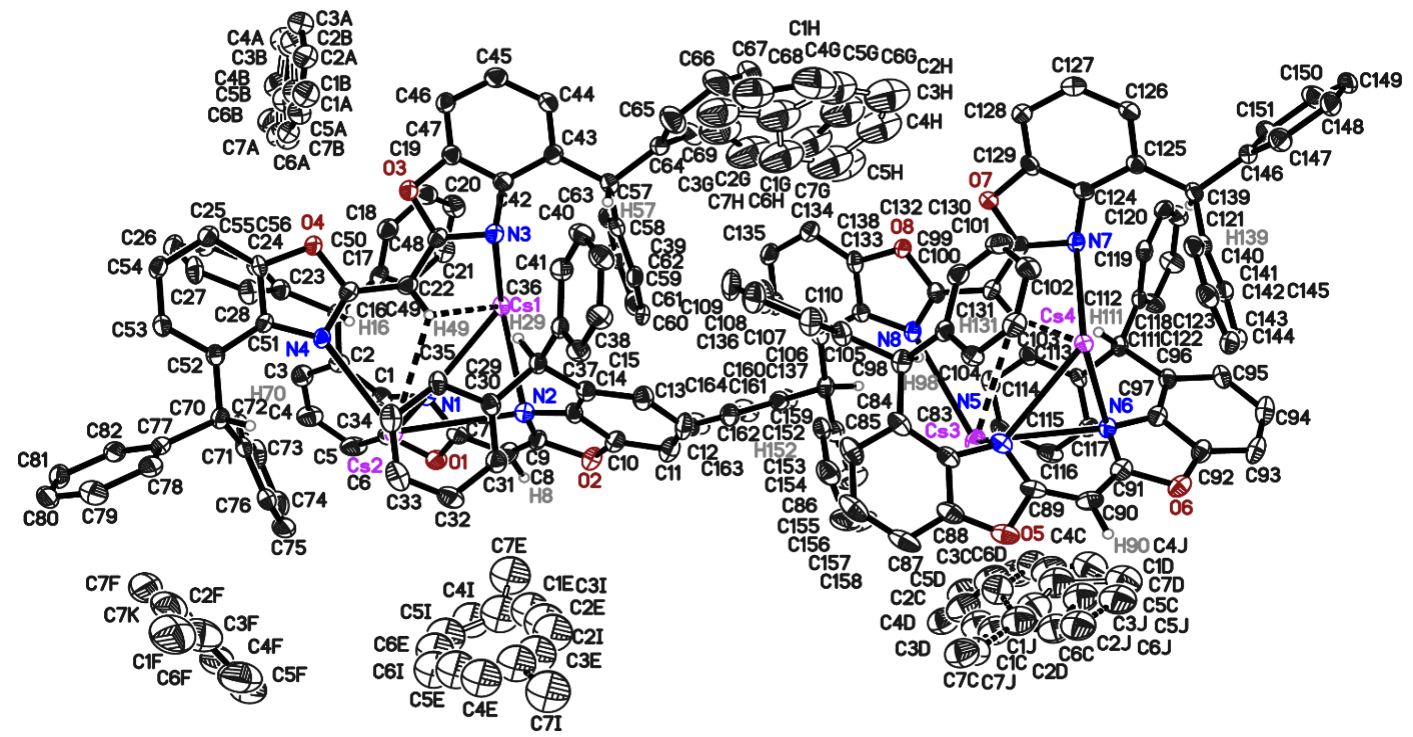

Figure 5-27. Asymmetric unit of 27. Displacement parameters are depicted at 50\% probability. Hydrogen atoms except the hydrogen atoms bound to the methylene backbone (H8, H49, H90, H131) and benzylic groups (H16, H29, H57, H70, H98, H111, H139, H152) are omitted for clarity. All toluene molecule are disordered over two or even three positions. The occupancies refined to 0.733(5) / 0.267(5) (molecule A / B), 0.347(3) / $0.345(3) / 0.309(3)$ (molecule C / D / J), 0.190(6) / 0.310(6) (molecule I / E with additional disorder over an inversion center), and 0.747(8)/ 0.253(8) (molecule F / K). All toluene molecules were refined with distance restraints and restraints for the anisotropic displacement parameters. The positions of the hydrogen atoms $\mathrm{H} 49$ and H131 were refined without any constraint or restraint. Reprinted with permission from reference [5]. Copyright 2021, John Wiley and Sons.

Table 5-27. Crystallographic data of 27.

\begin{tabular}{ll|ll}
\hline Structure code & $\mathrm{JKCs}$ & $\rho_{\text {calcd. }\left[\mathrm{Mg} \cdot \mathrm{m}^{-3}\right]}$ & 1.409 \\
CCDC no. & 2031912 & $\mu\left[\mathrm{mm}^{-1}\right]$ & 1.003 \\
Empirical formula & $\mathrm{C}_{97.75} \mathrm{H}_{76} \mathrm{Cs}_{2} \mathrm{~N}_{4} \mathrm{O}_{4}$ & $F(000)$ & 6660 \\
Formula weight $\left[\mathrm{g} \mathrm{mol}^{-1}\right]$ & 1636.44 & Crystal size $\left[\mathrm{mm}^{3}\right]$ & $0.215 \times 0.117 \times 0.085$ \\
Temperature $[\mathrm{K}]$ & $100(2)$ & $\theta$ range $\left[{ }^{\circ}\right]$ & 0.764 to 25.381 \\
Wavelength $[\AA]$ & 0.71073 & Reflections collected & 341920 \\
Crystal system & Monoclinic & Unique Reflections & 28314 \\
Space group & $P 2_{1} / c$ & $R_{\text {int }}$ & 0.1293 \\
Unit cell parameters & $\mathrm{a}=27.438(4) \AA$ & Completeness to $\theta_{\max }[\%]$ & 100.0 \\
& $b=21.780(3) \AA$ & Restraints / parameters & $5263 / 2224$ \\
& $c=26.586(3) \AA$ & Goodness-of-fit on $\mathrm{F}^{2}$ & 1.012 \\
& $\alpha=90^{\circ}$ & $R 1[\mathrm{I}>2 \sigma(\mathrm{I})]$ & 0.0407 \\
& $\beta=103.84(2)^{\circ}$ & wR2 (all data) & 0.0914 \\
Volume $\left[\AA^{3}\right]$ & $\gamma=90^{\circ}$ & Max. diff. peak / hole $\left[\mathrm{e} \AA^{-3}\right]$ & $0.699 /-0.618$ \\
$Z$ & $15427(4)$ & Absolute structure & - \\
\hline & & parameter ${ }^{[235]}$ & \\
\hline
\end{tabular}




\subsubsection{8 $\left[(\mathrm{THF})_{2} \mathrm{~K} @\left(18-\right.\right.$ crown-6) $^{+}\left[\left(^{4-\mathrm{Bzh}} \mathrm{Box}_{2} \mathrm{CH}\right)\right]^{-}(28)$}

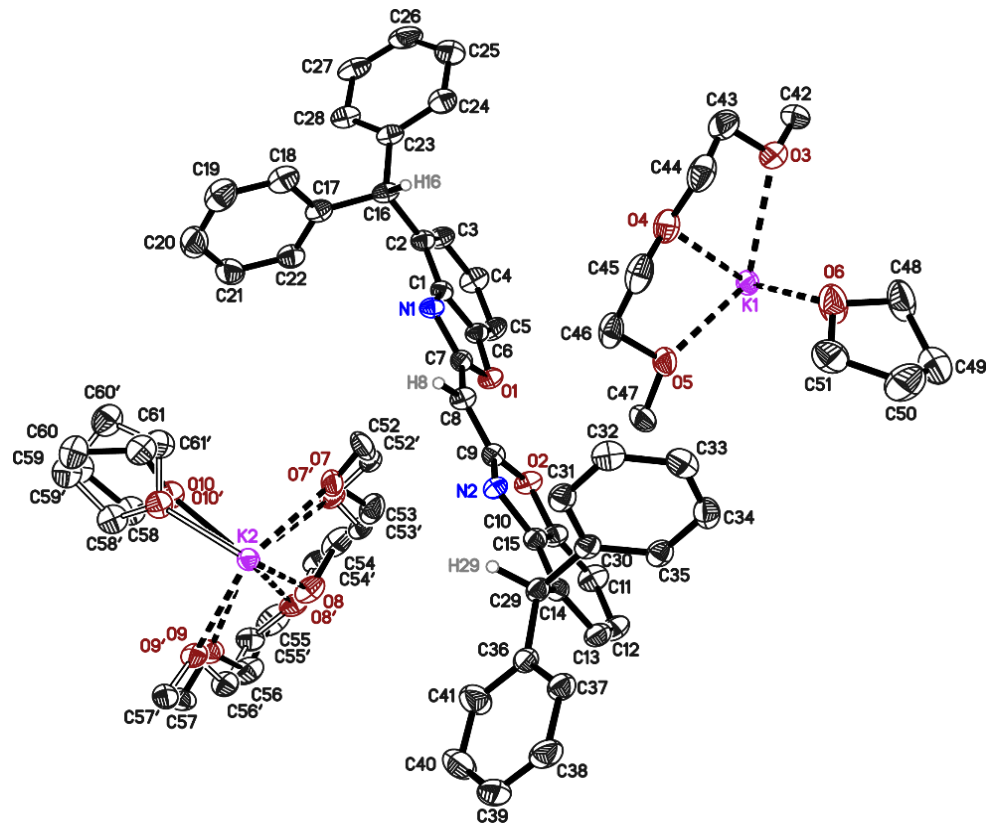

Figure 5-28. Asymmetric unit of 28. Displacement parameters are depicted at 50\% probability. Hydrogen atoms except the hydrogen atoms bound to the methylene backbone (H8) and benzylic groups (H16, H29) are omitted for clarity. The THF molecule and the crown coordinated to $\mathrm{K} 2$ are disordered about two positions. The occupancy of the minor position refined to $0.232(3)$. The disordered groups are refined with distance restraints and restraints for the anisotropic displacement parameter. Reprinted with permission from reference [5]. Copyright 2021, John Wiley and Sons.

Table 5-28. Crystallographic data of 28.

\begin{tabular}{ll|ll}
\hline Structure code & $\mathrm{JK} 502$ & $\rho_{\text {calcd. }}\left[\mathrm{Mg} \cdot \mathrm{m}^{-3}\right]$ & 1.235 \\
CCDC no. & 2031913 & $\mu\left[\mathrm{mm}^{-1}\right]$ & 0.156 \\
Empirical formula & $\mathrm{C}_{61} \mathrm{H}_{69} \mathrm{KN}_{2} \mathrm{O}_{10}$ & $F(000)$ & 1096 \\
Formula weight $\left[\mathrm{g} \mathrm{mol}^{-1}\right]$ & 1029.28 & Crystal size $\left[\mathrm{mm}^{3}\right]$ & $0.253 \times 0.141 \times 0.075$ \\
Temperature $[\mathrm{K}]$ & $100(2)$ & $\theta$ range $\left[{ }^{\circ}\right]$ & 1.140 to 26.392 \\
Wavelength $[\AA]$ & 0.71073 & Reflections collected & 57066 \\
Crystal system & Triclinic & Unique Reflections & 11321 \\
Space group & $P \overline{1}$ & $R_{\text {int }}$ & 0.0418 \\
Unit cell parameters & $a=10.519(2) \AA$ & Completeness to $\theta_{\max }[\%]$ & 100.0 \\
& $b=14.871(2) \AA$ & Restraints / parameters & $1038 / 779$ \\
& $c=19.043(3) \AA$ & Goodness-of-fit on $\mathrm{F}^{2}$ & 1.021 \\
& $\alpha=72.70(2)^{\circ}$ & $R 1[\mathrm{I}>2 \sigma(\mathrm{I})]$ & 0.0415 \\
& $\beta=77.38(3)^{\circ}$ & wR2 (all data) & 0.1081 \\
Volume $\left[\AA^{3}\right]$ & $\gamma=82.15(2)$ & Max. diff. peak / hole $\left[\mathrm{e} \AA^{-3}\right]$ & $0.474 /-0.360$ \\
& $2767.2(9)$ & Absolute structure & - \\
$Z$ & & parameter & \\
\hline
\end{tabular}




\subsubsection{9 $\left[\left\{(T H F)_{2} K @(18-c r o w n-6)\right\}\left\{K @(18-c r o w n-6) K\left({ }^{4-B z h} B^{2}{ }_{2} \mathrm{CH}\right)\right\}\right]_{n}(29)$}

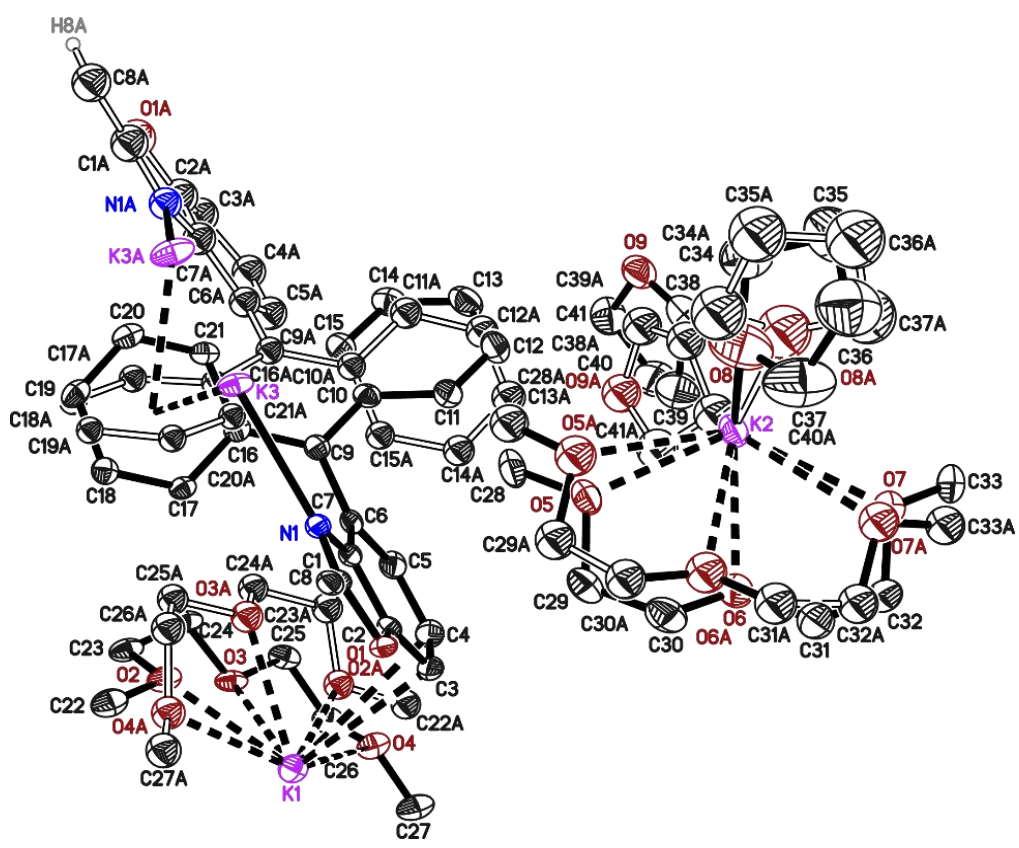

Figure 5-29. Asymmetric unit of 29. Displacement parameters are depicted at 50\% probability. Hydrogen atoms except the hydrogen atoms bound to the methylene backbone (H8, H8A) are omitted for clarity. The compound crystalises in space group $P / n$ containing one half of a formula unit in the asymmetric unit. The whole unit except atoms $\mathrm{K} 2$ and $\mathrm{K} 3$ is disordered over two positions and was refined with distance restraints and restraints for the displacement parameter. The occupancy of the minor position refined to 0.0943(14). All atoms of this position except atom K1' were refined isotropically. Reprinted with permission from reference [5]. Copyright 2021, John Wiley and Sons.

Table 5-29. Crystallographic data of 28.

\begin{tabular}{|c|c|c|c|}
\hline Structure code & K3 & $\rho_{\text {calcd. }}\left[\mathrm{Mg} \cdot \mathrm{m}^{-3}\right]$ & 1.297 \\
\hline CCDC no. & 2031914 & $\mu\left[\mathrm{mm}^{-1}\right]$ & 0.135 \\
\hline Empirical formula & $\mathrm{C}_{81} \mathrm{H}_{107} \mathrm{~K}_{3} \mathrm{~N}_{2} \mathrm{O}_{18}$ & $F(000)$ & 1616 \\
\hline Formula weight $\left[\mathrm{g} \mathrm{mol}^{-1}\right]$ & 1513.98 & Crystal size $\left[\mathrm{mm}^{3}\right]$ & $0.300 \times 0.268 \times 0.172$ \\
\hline Temperature $[\mathrm{K}]$ & $100(2)$ & $\theta$ range $\left[^{\circ}\right]$ & 1.615 to 19.826 \\
\hline Wavelength $[\AA]$ & 0.56086 & Reflections collected & 169763 \\
\hline Crystal system & Monoclinic & Unique Reflections & 7151 \\
\hline Space group & $P 2 / n$ & $R_{\text {int }}$ & 0.0885 \\
\hline \multirow[t]{6}{*}{ Unit cell parameters } & $a=18.494(3) \AA$ & Completeness to $\theta_{\max }[\%]$ & 100.0 \\
\hline & $b=10.533(2) \AA$ & Restraints / parameters & $2461 / 681$ \\
\hline & $c=19.977(3) \AA$ & Goodness-of-fit on $\mathrm{F}^{2}$ & 1.116 \\
\hline & $\alpha=90^{\circ}$ & $R 1[\mathrm{I}>2 \sigma(\mathrm{I})]$ & 0.0627 \\
\hline & $\beta=94.83(2)^{\circ}$ & $\mathrm{w} R 2$ (all data) & 0.1854 \\
\hline & $\gamma=90^{\circ}$ & Max. diff. peak / hole $\left[\mathrm{e}^{\AA^{-3}}\right]$ & $0.534 /-0.379$ \\
\hline Volume $\left[\AA^{3}\right]$ & $3877.6(11)$ & $\begin{array}{l}\text { Absolute structure } \\
\text { parameter }^{[235]}\end{array}$ & - \\
\hline$Z$ & 2 & Extinction coefficient & - \\
\hline
\end{tabular}




\subsubsection{0 [K@(18-crown-6) $\left.(\mu-\mathrm{Cl}) \operatorname{In}\left({ }^{4-B z h} \mathrm{Box}_{2} \mathrm{CH}\right)\right]_{2}(30)$}
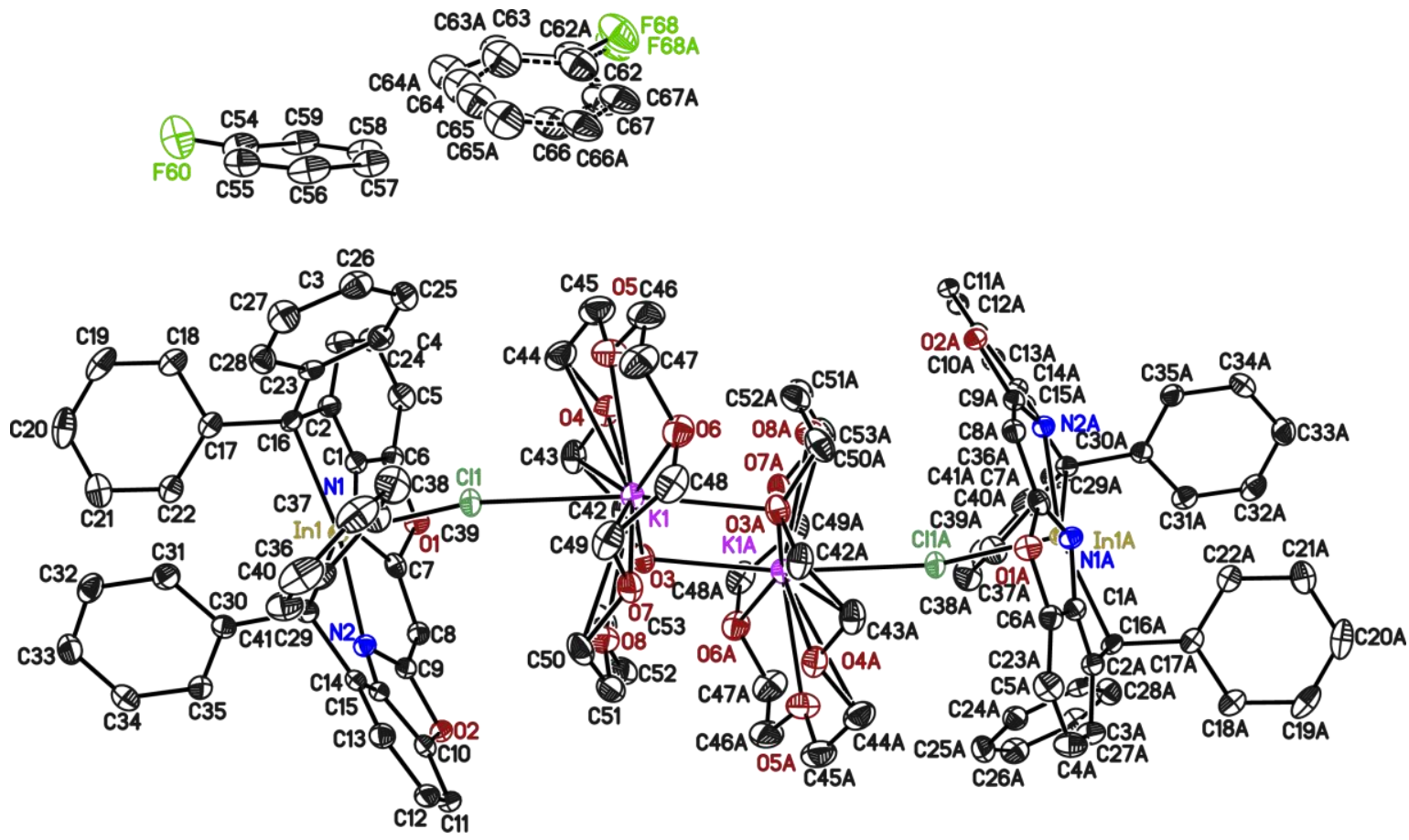

Figure 5-30. Asymmetric unit of 30. Displacement parameters are depicted at 50\% probability. Hydrogen atoms are omitted for clarity. The fluorobenzene molecule C62 to C68 and F68 is disordered about two positions and an inversion centre, the occupancies of the minor positions refine to 0.49 (3). The second fluorobenzene molecule C54 to C59 and F60 is disordered about an inversion center. All disordered groups are refined with distance restraints and restraints for the anisotropic displacement parameters.

Table 5-30. Crystallographic data of 30.

\begin{tabular}{ll|ll}
\hline Structure code & $\mathrm{JK} 595$ & $\rho_{\text {calcd. }}\left[\mathrm{Mg} \cdot \mathrm{m}^{-3}\right]$ & 1.451 \\
CCDC no. & - & $\mu\left[\mathrm{mm}^{-1}\right]$ & 0.651 \\
Empirical formula & $\mathrm{C}_{118} \mathrm{H}_{112} \mathrm{Cl}_{2} \mathrm{~F}_{2} \mathrm{In}_{2} \mathrm{~K}_{2} \mathrm{~N}_{4} \mathrm{O}_{16}$ & $F(000)$ & 1164 \\
Formula weight $\left[\mathrm{g} \mathrm{mol}^{-1}\right]$ & 2258.85 & Crystal size $\left[\mathrm{mm}^{3}\right]$ & $0.306 \times 0.200 \times 0.164$ \\
Temperature $[\mathrm{K}]$ & $100(2)$ & $\theta$ range [ $\left.{ }^{\circ}\right]$ & 1.104 to 29.248 \\
Wavelength $[\AA]$ & 0.71073 & Reflections collected & 41063 \\
Crystal system & Triclinic & Unique Reflections & 12701 \\
Space group & $P \overline{1}$ & $R_{\text {int }}$ & 0.0535 \\
Unit cell parameters & $a=11.476(2) \AA$ & Completeness to $\theta_{\max }[\%]$ & 100.0 \\
& $b=12.258(2) \AA$ & Restraints / parameters & $717 / 785$ \\
& $c=18.824(3) \AA$ & Goodness-of-fit on $\mathrm{F}^{2}$ & 1.035 \\
& $\alpha=98.78(3)^{\circ}$ & $R 1[\mathrm{I}>2 \sigma(\mathrm{I})]$ & 0.0390 \\
& $\beta=96.85(2)^{\circ}$ & wR2 (all data) & 0.0775 \\
Volume $\left[\AA^{3}\right]$ & $\gamma=94.49(2)^{\circ}$ & Max. diff. peak / hole $[\mathrm{e} \AA$ & $0.607 /-0.447$ \\
$Z$ & $2585.7(8)$ & Absolute structure & - \\
\hline & & parameter & \\
\hline
\end{tabular}




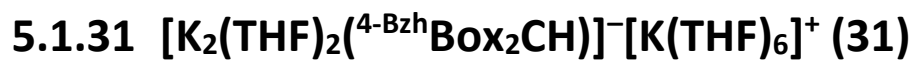

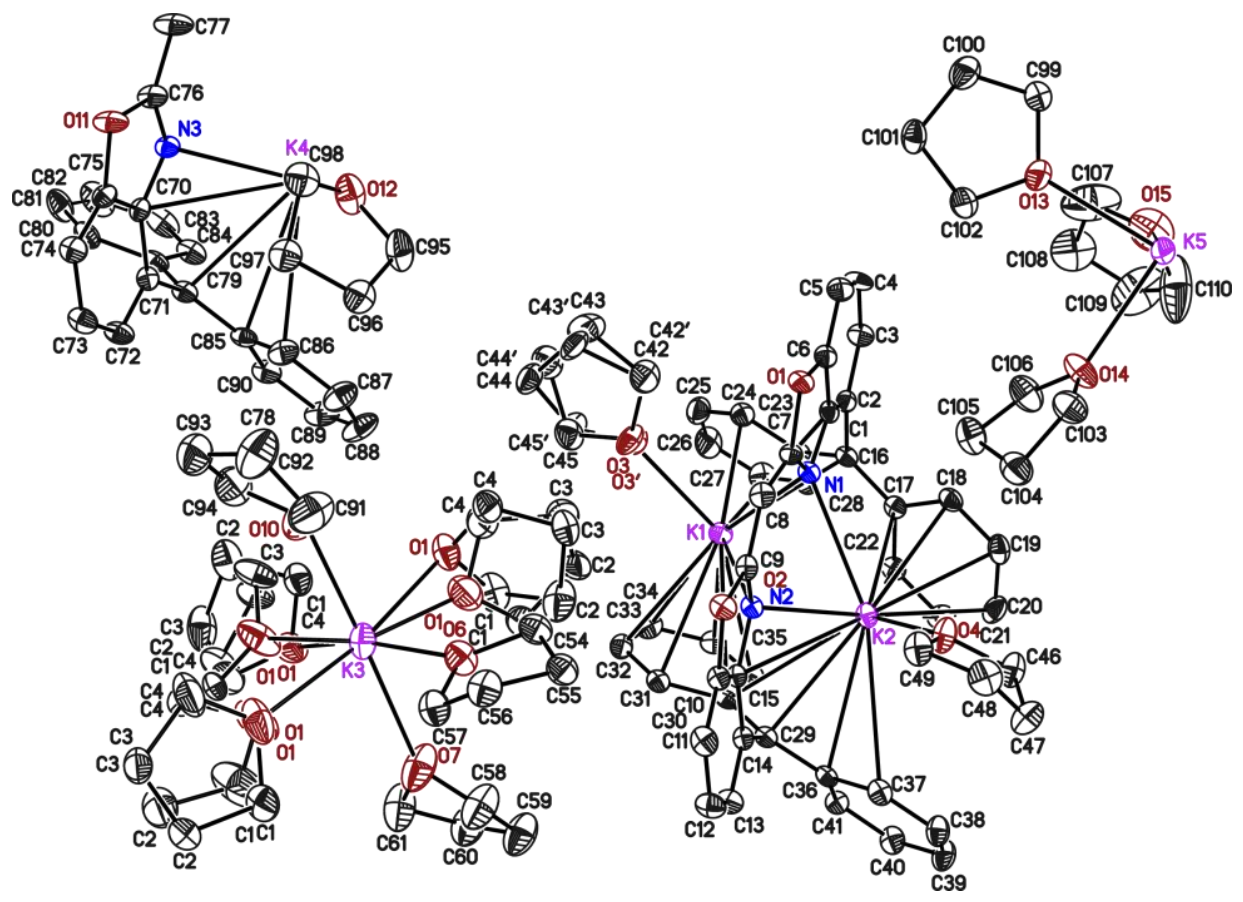

Figure 5-31. Asymmetric unit of 31. Displacement parameters are depicted at 50\% probability. Hydrogen atoms are omitted for clarity. The THF molecule $\mathrm{C} 42$ to $\mathrm{C} 45$ and $\mathrm{O} 3$ is disordered about two positions, while the occupancy of the minor positions is refined to $0.381(14)$. Furthermore, three THF molecules of $\left[\mathrm{K}(\mathrm{THF})_{6}\right]^{+}$ ( $\mathrm{C} 1$ to $\mathrm{C} 4$ and $\mathrm{O} 1$ ) disordered about two positions. The occupancy of the minor positions is refined to $0.431(8)$, 0.491(9), and 0.096(7), respectively. The disordered groups are refined with distance restraints and restraints for the anisotropic displacement parameter.

Table 5-31. Crystallographic data of 31.

\begin{tabular}{|c|c|c|c|}
\hline Structure code & JK639 & $\rho_{\text {calcd. }}\left[{\left.\mathrm{Mg} \cdot \mathrm{m}^{-3}\right]}\right.$ & 1.261 \\
\hline CCDC no. & - & $\mu\left[\mathrm{mm}^{-1}\right]$ & 0.263 \\
\hline Empirical formula & $\mathrm{C}_{219} \mathrm{H}_{273} \mathrm{~K}_{9} \mathrm{~N}_{6} \mathrm{O}_{30}$ & $F(000)$ & 8160 \\
\hline Formula weight $\left[\mathrm{g} \mathrm{mol}^{-1}\right]$ & 3821.32 & Crystal size $\left[\mathrm{mm}^{3}\right]$ & $0.288 \times 0.238 \times 0.131$ \\
\hline Temperature $[\mathrm{K}]$ & $100(2)$ & $\theta$ range $\left[^{\circ}\right]$ & 1.145 to 25.737 \\
\hline Wavelength $[\AA]$ & 0.71073 & Reflections collected & 190770 \\
\hline Crystal system & Monoclinic & Unique Reflections & 19179 \\
\hline Space group & $C 2 / c$ & $R_{\text {int }}$ & 0.0701 \\
\hline \multirow[t]{6}{*}{ Unit cell parameters } & $a=73.65(2) \AA$ & Completeness to $\theta_{\max }[\%]$ & 99.9 \\
\hline & $b=9.927(2) \AA$ & Restraints / parameters & $1202 / 1375$ \\
\hline & $c=28.499(5) \AA$ & Goodness-of-fit on $\mathrm{F}^{2}$ & 1.157 \\
\hline & $\alpha=90^{\circ}$ & $R 1[\mathrm{I}>2 \sigma(\mathrm{I})]$ & 0.0601 \\
\hline & $\beta=104.95(3)^{\circ}$ & $\mathrm{w} R 2$ (all data) & 0.1428 \\
\hline & $\gamma=90^{\circ}$ & Max. diff. peak / hole $\left[\mathrm{e}^{-3}\right]$ & $0.751 /-0.634$ \\
\hline Volume $\left[\AA^{3}\right]$ & 20131(8) & $\begin{array}{l}\text { Absolute structure } \\
\text { parameter }^{[235]}\end{array}$ & - \\
\hline$Z$ & 4 & Extinction coefficient & - \\
\hline
\end{tabular}




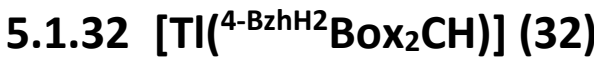

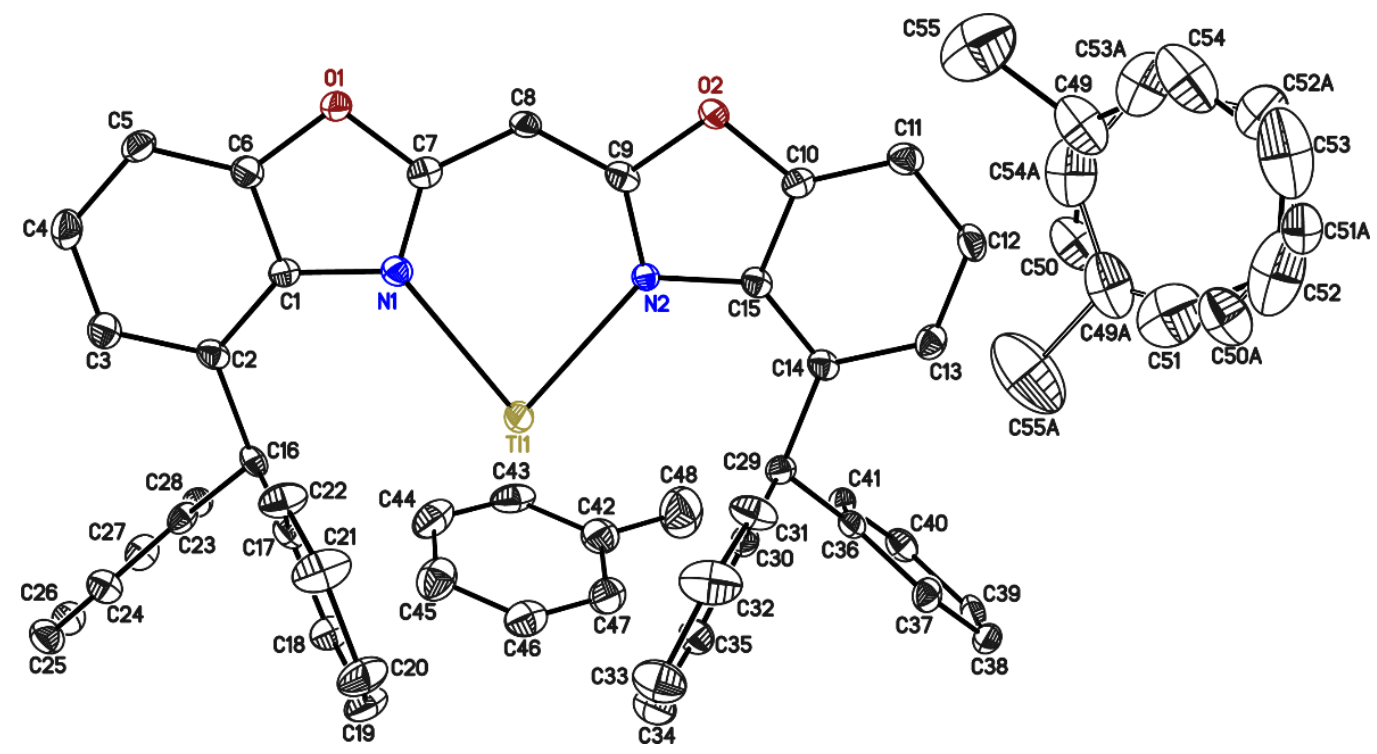

Figure 5-32. Asymmetric unit of 32. Displacement parameters are depicted at 50\% probability. Hydrogen atoms are omitted for clarity. One toluene molecule is disordered about two positions. The occupancy of the minor position refines to $0.215(8)$. It is refined with distance restraints and restraints for the anisotropic displacement parameters. Reprinted with permission from reference [6]. Copyright 2021, American Chemical Society.

Table 5-32. Crystallographic data of 32.

\begin{tabular}{ll|ll}
\hline Structure code & $\mathrm{JK} 654$ & $\rho_{\text {calcd. }}\left[\mathrm{Mg} \cdot \mathrm{m}^{-3}\right]$ & 1.539 \\
CCDC no. & 2065071 & $\mu\left[\mathrm{mm}^{-1}\right]$ & 3.903 \\
Empirical formula & $\mathrm{C}_{55} \mathrm{H}_{45} \mathrm{~N}_{2} \mathrm{O}_{2} \mathrm{Tl}$ & $F(000)$ & 972 \\
Formula weight $\left[\mathrm{g} \mathrm{mol}^{-1}\right]$ & 970.30 & Crystal size $\left[\mathrm{mm}^{3}\right]$ & $0.057 \times 0.094 \times 0.147$ \\
Temperature $[\mathrm{K}]$ & $100(2)$ & $\theta$ range $\left[^{\circ}\right]$ & 1.424 to 26.484 \\
Wavelength $[\AA]$ & 0.71073 & Reflections collected & 27286 \\
Crystal system & Triclinic & Unique Reflections & 8567 \\
Space group & $P \overline{1}$ & $R_{\text {int }}$ & 0.0516 \\
Unit cell parameters & $a=10.747(2) \AA$ & Completeness to $\theta_{\max }[\%]$ & 100.0 \\
& $b=14.395(3) \AA$ & Restraints / parameters & $363 / 608$ \\
& $c=14.542(3) \AA$ & Goodness-of-fit on $\mathrm{F}^{2}$ & 1.029 \\
& $\alpha=86.82(3)^{\circ}$ & $R 1[\mathrm{I}>2 \sigma(\mathrm{I})]$ & 0.0330 \\
& $\beta=69.61(2)^{\circ}$ & wR2 (all data) & 0.0688 \\
& $\gamma=83.35(2)^{\circ}$ & Max. diff. peak / hole $\left[\mathrm{e} \AA^{-3}\right]$ & $1.507 /-1.070$ \\
Volume $\left[\AA^{3}\right]$ & $2094.3(8)$ & Absolute structure & - \\
& & parameter & \\
$Z$ & 2 & Extinction coefficient & - \\
\hline
\end{tabular}




\subsubsection{3 $\left[\ln \left({ }^{4-B z h H} 2 \mathrm{Box}_{2} \mathrm{CH}\right)\right](33)$}

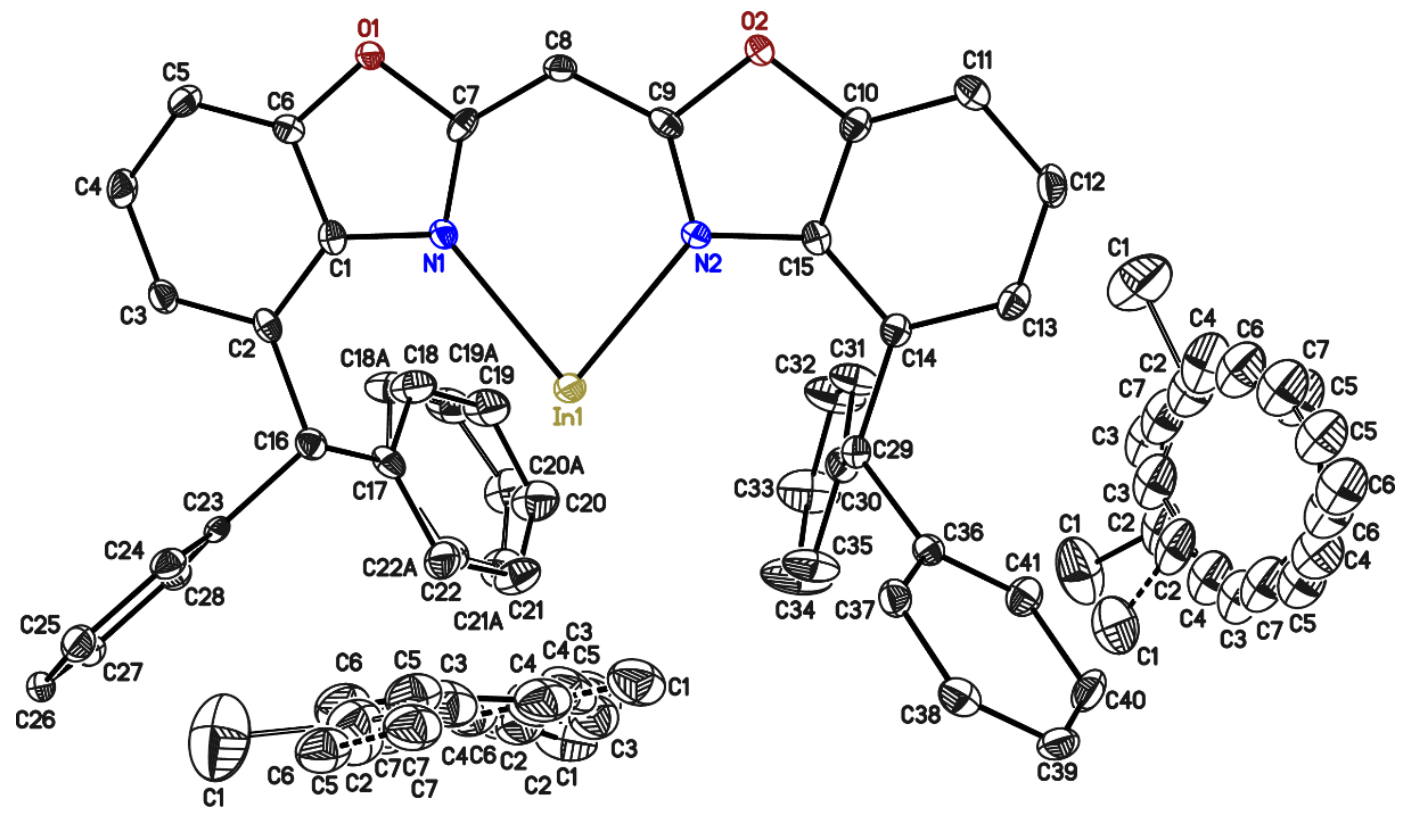

Figure 5-33. Asymmetric unit of 33. Displacement parameters are depicted at 50\% probability. Hydrogen atoms are omitted for clarity. The phenyl carbon atoms (C18, C19, C20, C21, C22) are disordered about two positions, the occupancy of the minor position refines to $0.30(3)$. Both toluene molecules are disordered about three positions, the occupancies of the minor positions refine to $0.429(3)$ and $0.106(3)$, and to $0.327(3)$ and $0.179(3)$, respectively. All disordered groups are refined with distance restraints and restraints for the anisotropic displacement parameters. Reprinted with permission from reference [6]. Copyright 2021, American Chemical Society.

Table 5-33. Crystallographic data of 33.

\begin{tabular}{ll|ll}
\hline Structure code & $J$ KPhBoxCHIn & $\rho_{\text {calcd. }}\left[\mathrm{Mg} \cdot \mathrm{m}^{-3}\right]$ & 1.392 \\
CCDC no. & 2065072 & $\mu\left[\mathrm{mm}^{-1}\right]$ & 0.330 \\
Empirical formula & $\mathrm{C}_{81} \mathrm{H}_{107} \mathrm{~K}_{3} \mathrm{~N}_{2} \mathrm{O}_{18}$ & $F(000)$ & 908 \\
Formula weight $\left[\mathrm{g} \mathrm{mol}^{-1}\right]$ & 880.75 & Crystal size $\left[\mathrm{mm}^{3}\right]$ & $0.089 \times 0.053 \times 0.047$ \\
Temperature $[\mathrm{K}]$ & $100(2)$ & $\theta$ range $\left[{ }^{\circ}\right]$ & 1.630 to 19.807 \\
Wavelength $[\AA]$ & 0.56086 & Reflections collected & 77100 \\
Crystal system & Triclinic & Unique Reflections & 7744 \\
Space group & $P \overline{1}$ & $R_{\text {int }}$ & 0.1035 \\
Unit cell parameters & $a=10.880(2) \AA$ & Completeness to $\theta_{\text {max }}[\%]$ & 100.0 \\
& $b=14.194(3) \AA$ & Restraints / parameters & $2467 / 845$ \\
& $c=14.651(3) \AA$ & Goodness-of-fit on $\mathrm{F}^{2}$ & 1.017 \\
& $\alpha=87.31(3)^{\circ}$ & $R 1[\mathrm{I}>2 \sigma(\mathrm{I})]$ & 0.0364 \\
& $\beta=69.17(2)^{\circ}$ & wR2 (all data) & 0.0766 \\
Volume $\left[\AA^{3}\right]$ & $\gamma=83.48(3)^{\circ}$ & Max. diff. peak / hole $\left[\mathrm{e} \AA^{-3}\right]$ & $0.329 /-0$. \\
& $2101.0(8)$ & Absolute structure & - \\
$Z$ & & parameter & \\
\hline
\end{tabular}




\subsubsection{4 $\left[\mathrm{Ga}\left({ }^{4-\mathrm{BzhH}} \mathrm{Box}_{2} \mathrm{CH}\right)\right](34)$}

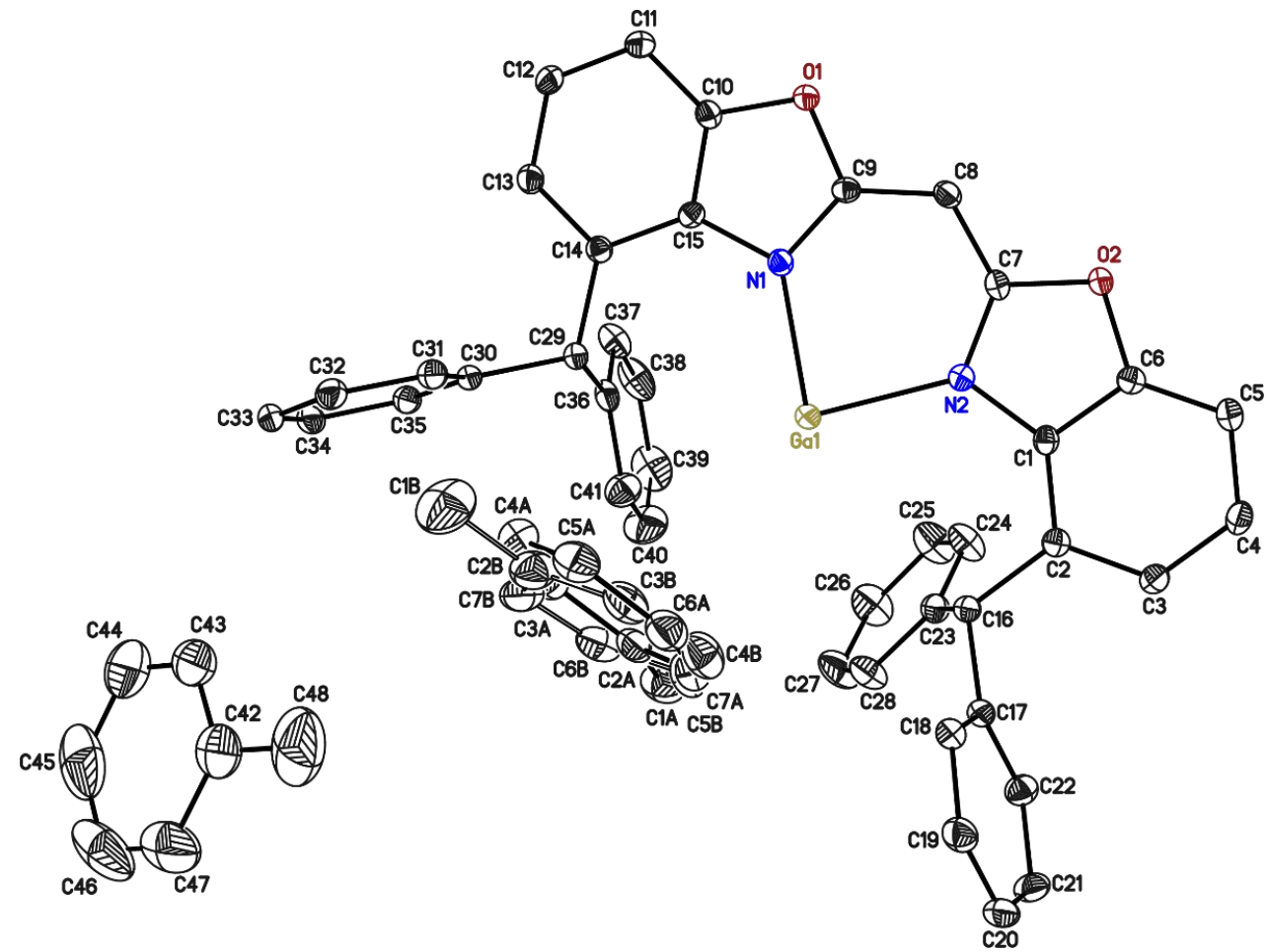

Figure 5-34. Asymmetric unit of 34. Displacement parameters are depicted at 50\% probability. Hydrogen atoms are omitted for clarity. One toluene molecule is disordered about two positions. The occupancy of the minor position refines to $0.484(4)$. It is refined with distance restraints and restraints for the anisotropic displacement parameters. Reprinted with permission from reference [6]. Copyright 2021, American Chemical Society.

Table 5-34. Crystallographic data of 34.

\begin{tabular}{ll|ll}
\hline Structure code & JK_BZHGaTol & $\rho_{\text {calcd. }\left[\mathrm{Mg} \cdot \mathrm{m}^{-3}\right]}$ & 1.327 \\
CCDC no. & 2065073 & $\mu\left[\mathrm{mm}^{-1}\right]$ & 0.704 \\
Empirical formula & $\mathrm{C}_{55} \mathrm{H}_{45} \mathrm{GaN}_{2} \mathrm{O}_{2}$ & $F(000)$ & 872 \\
Formula weight $\left[\mathrm{g} \mathrm{mol}^{-1}\right]$ & 835.65 & Crystal size $\left[\mathrm{mm}^{3}\right]$ & $0.237 \times 0.213 \times 0.190$ \\
Temperature $[\mathrm{K}]$ & $100(2)$ & $\theta$ range $\left[^{\circ}\right]$ & 1.479 to 29.256 \\
Wavelength $[\AA]$ & 0.71073 & Reflections collected & 69736 \\
Crystal system & Triclinic & Unique Reflections & 11327 \\
Space group & $P \overline{1}$ & $R_{\text {int }}$ & 0.0351 \\
Unit cell parameters & $\mathrm{a}=11.276(2) \AA$ & Completeness to $\theta_{\max }[\%]$ & 100.0 \\
& $b=13.848(2) \AA$ & Restraints / parameters & $286 / 608$ \\
& $c=14.513(3) \AA$ & Goodness-of-fit on $\mathrm{F}^{2}$ & 1.039 \\
& $\alpha=87.03(3)^{\circ}$ & $R 1[\mathrm{I}>2 \sigma(\mathrm{I})]$ & 0.0324 \\
& $\beta=68.13(2)^{\circ}$ & wR2 (all data) & 0.0852 \\
Volume $\left[\AA^{3}\right]$ & $\gamma=83.90(2)^{\circ}$ & Max. diff. peak / hole $\left[\mathrm{e} \AA^{\circ}{ }^{\circ}\right]$ & $0.699 /-0.476$ \\
& $2091.0(7)$ & Absolute structure & - \\
$Z$ & & parameter & \\
\hline
\end{tabular}




\subsubsection{5 $\left[\mathrm{Gal}_{2}\left({ }^{4-\mathrm{BrhH}^{2}} \mathrm{Box}_{2} \mathrm{CH}\right)\right](34 \mathrm{a})$}

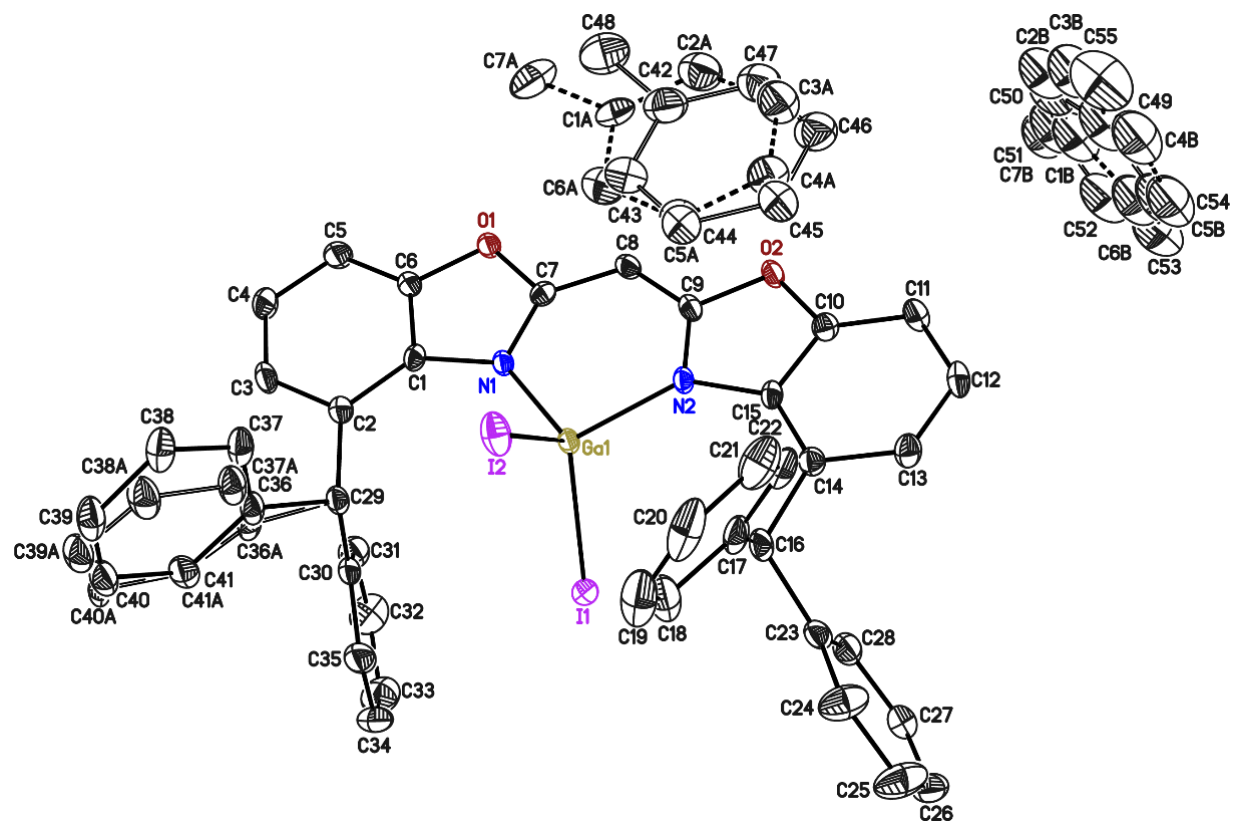

Figure 5-35. Asymmetric unit of 34a. Displacement parameters are depicted at 50\% probability. Hydrogen atoms are omitted for clarity. The phenyl carbon atoms (C36, C37, C38, C39, C40, C41) are disordered about two positions, the occupancy of the minor position refines to $0.147(8)$. Both toluene molecules are disordered about an inversion center and about two positions, the occupancy of the minor position refines to $0.109(5)$ and 0.202(5), respectively. All disordered groups are refined with distance restraints and restraints for the anisotropic displacement parameters. Reprinted with permission from reference [6]. Copyright 2021, American Chemical Society.

Table 5-35. Crystallographic data of 34a.

\begin{tabular}{ll|ll}
\hline Structure code & $\mathrm{JK} 266$ & $\rho_{\text {calcd. }}\left[\mathrm{Mg} \cdot \mathrm{m}^{-3}\right]$ & 1.626 \\
CCDC no. & 2065074 & $\mu\left[\mathrm{mm}^{-1}\right]$ & 1.186 \\
Empirical formula & $\mathrm{C}_{48} \mathrm{H}_{37} \mathrm{GaI}_{2} \mathrm{~N}_{2} \mathrm{O}_{2}$ & $F(000)$ & 984 \\
Formula weight $\left[\mathrm{g} \mathrm{mol}^{-1}\right]$ & 997.31 & Crystal size $\left[\mathrm{mm}^{3}\right]$ & $0.276 \times 0.134 \times 0.072$ \\
Temperature $[\mathrm{K}]$ & $100(2)$ & $\theta$ range $\left[{ }^{\circ}\right]$ & 1.839 to 20.203 \\
Wavelength $[\AA]$ & 0.56086 & Reflections collected & 103136 \\
Crystal system & Triclinic & Unique Reflections & 7928 \\
Space group & $P \overline{1}$ & $R_{\text {int }}$ & 0.0470 \\
Unit cell parameters & $\mathrm{a}=11.628(3) \AA$ & Completeness to $\theta_{\max }[\%]$ & 100.0 \\
& $b=13.845(3) \AA$ & Restraints / parameters & $1731 / 742$ \\
& $c=14.418(4) \AA$ & Goodness-of-fit on $\mathrm{F}^{2}$ & 1.035 \\
& $\alpha=61.52(2)^{\circ}$ & $R 1[\mathrm{I}>2 \sigma(\mathrm{I})]$ & 0.0242 \\
& $\beta=86.90(2)^{\circ}$ & wR2 (all data) & 0.0600 \\
& $\gamma=87.78(3)^{\circ}$ & Max. diff. peak / hole $\left[\mathrm{e} \AA^{-3}\right]$ & $0.800 /-0.691$ \\
Volume $\left[\AA^{3}\right]$ & $2037.4(10)$ & Absolute structure & - \\
$Z$ & 2 & parameter ${ }^{[235]}$ & - \\
\hline
\end{tabular}




\subsubsection{6 [AIMe $\left.\left.2{ }^{4-B z h H 2} \mathrm{Box}_{2} \mathrm{CH}\right)\right](35)$}

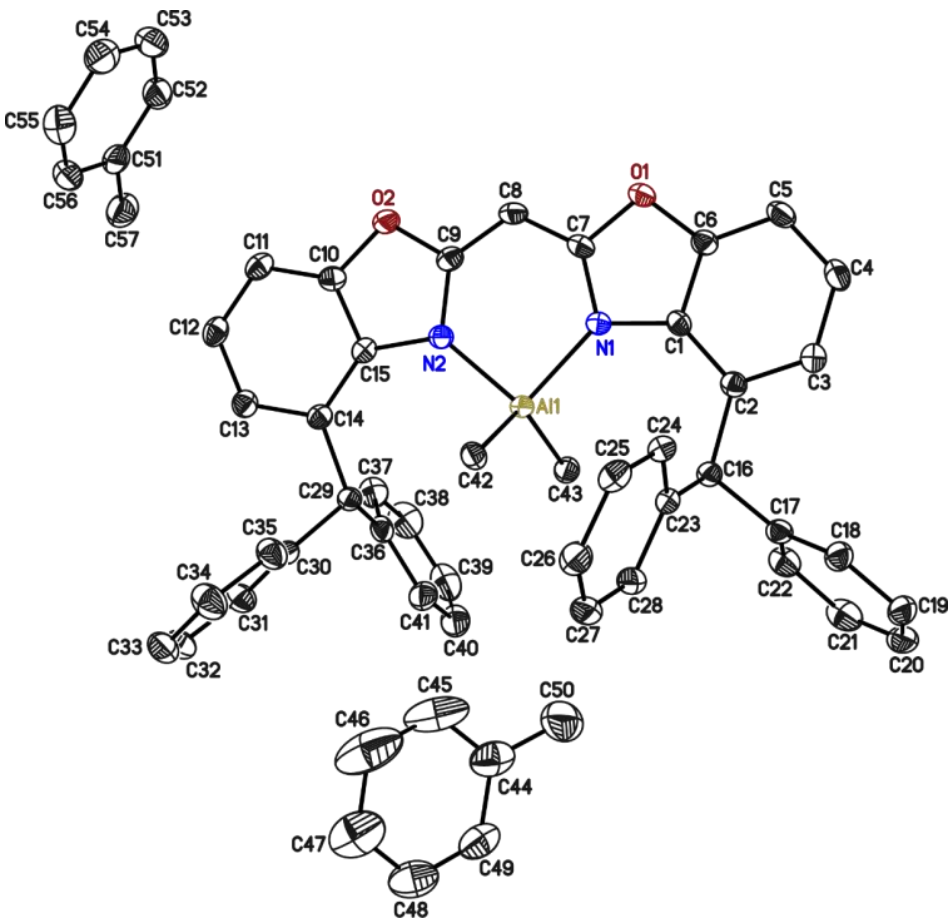

Figure 5-36. Asymmetric unit of 35. Displacement parameters are depicted at 50\% probability. Hydrogen atoms are omitted for clarity. Reprinted with permission from reference [6]. Copyright 2021, American Chemical Society.

Table 5-36. Crystallographic data of 35.

\begin{tabular}{ll|ll}
\hline Structure code & $\mathrm{JK} 320$ & $\rho_{\text {calcd. }}\left[\mathrm{Mg} \cdot \mathrm{m}^{-3}\right]$ & 1.226 \\
CCDC no. & 2065075 & $\mu\left[\mathrm{mm}^{-1}\right]$ & 0.092 \\
Empirical formula & $\mathrm{C}_{57} \mathrm{H}_{51} \mathrm{AlN}_{2} \mathrm{O}_{2}$ & $F(000)$ & 872 \\
Formula weight $\left[\mathrm{g} \mathrm{mol}^{-1}\right]$ & 822.97 & Crystal size $\left[\mathrm{mm}^{3}\right]$ & $0.394 \times 0.231 \times 0.166$ \\
Temperature $[\mathrm{K}]$ & $100(2)$ & $\theta$ range $\left[{ }^{\circ}\right]$ & 1.661 to 28.795 \\
Wavelength $[\AA]$ & 0.71073 & Reflections collected & 63788 \\
Crystal system & Triclinic & Unique Reflections & 11586 \\
Space group & $P \overline{1}$ & $R_{\text {int }}$ & 0.0406 \\
Unit cell parameters & $a=10.606(2) \AA$ & Completeness to $\theta_{\max }[\%]$ & 100.0 \\
& $b=13.187(2) \AA$ & Restraints / parameters & $0 / 563$ \\
& $c=17.633(3) \AA$ & Goodness-of-fit on $\mathrm{F}^{2}$ & 1.029 \\
& $\alpha=68.64(2)^{\circ}$ & $R 1[\mathrm{I}>2 \sigma(\mathrm{I})]$ & 0.0408 \\
& $\beta=76.44(3)^{\circ}$ & wR2 (all data) & 0.1071 \\
Volume $\left[\AA^{3}\right]$ & $\gamma=88.22(2)^{\circ}$ & Max. diff. peak / hole $\left[\mathrm{e} \AA^{-3}\right]$ & $0.352 /-0.264$ \\
$Z$ & $2228.7(8)$ & Absolute structure & - \\
\hline & 2 & parameter & \\
\hline
\end{tabular}




\subsubsection{7 [AIMel(4-BzhH2 $\left.{ }^{-} \mathrm{Box}_{2} \mathrm{CH}\right)$ ] (36)}

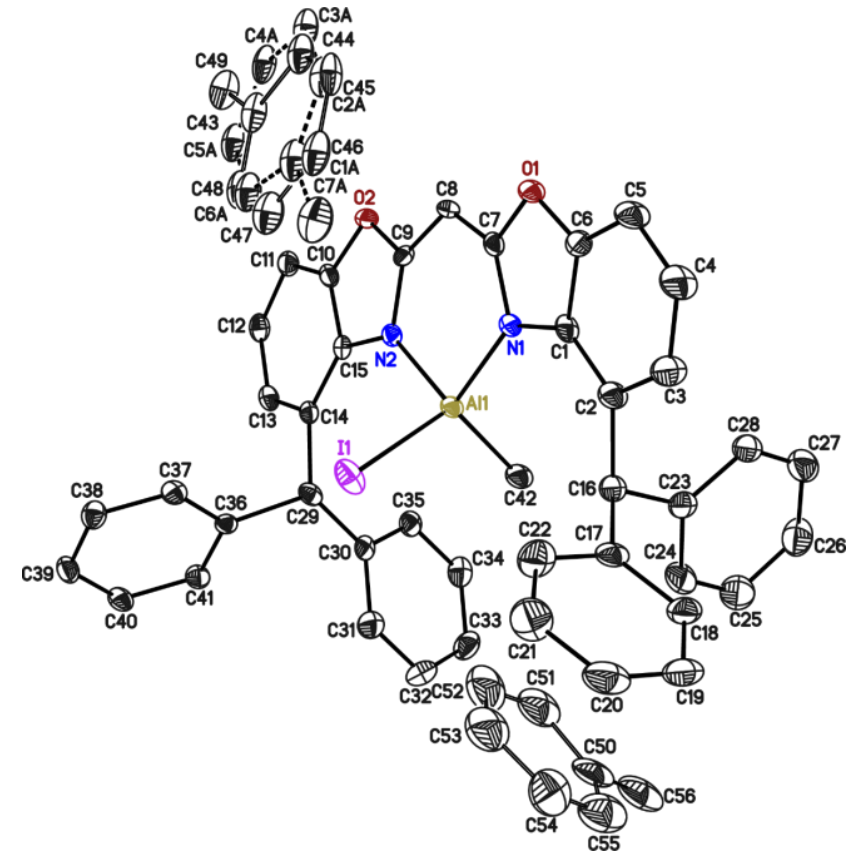

Figure 5-37. Asymmetric unit of 36. Displacement parameters are depicted at 50\% probability. Hydrogen atoms are omitted for clarity. The toluene molecule C43 to C49 are disordered about an inversion center as well as about two positions, the occupancy of the minor position refines to $0.105(5)$. The second toluene molecule C50 to C56 is disordered about an inversion center. All disordered groups are refined with distance restraints and restraints for the anisotropic displacement parameters. Reprinted with permission from reference [6]. Copyright 2021, American Chemical Society.

Table 5-37. Crystallographic data of 36.

\begin{tabular}{|c|c|c|c|}
\hline Structure code & JK_BZHAlMeI & $\rho_{\text {calcd. }}\left[\mathrm{Mg} \cdot \mathrm{m}^{-3}\right]$ & 1.420 \\
\hline CCDC no. & 2065076 & $\mu\left[\mathrm{mm}^{-1}\right]$ & 0.878 \\
\hline Empirical formula & $\mathrm{C}_{49} \mathrm{H}_{40} \mathrm{Al}_{3} \mathrm{IN}_{2} \mathrm{O}_{18}$ & $F(000)$ & 860 \\
\hline Formula weight $\left[\mathrm{g} \mathrm{mol}^{-1}\right]$ & 842.71 & Crystal size $\left[\mathrm{mm}^{3}\right]$ & $0.208 \times 0.197 \times 0.056$ \\
\hline Temperature $[\mathrm{K}]$ & $100(2)$ & $\theta$ range $\left[^{\circ}\right]$ & 1.321 to 25.463 \\
\hline Wavelength $[\AA]$ & 0.71073 & Reflections collected & 23684 \\
\hline Crystal system & Triclinic & Unique Reflections & 7295 \\
\hline Space group & $P \overline{1}$ & $R_{\text {int }}$ & 0.0384 \\
\hline \multirow[t]{6}{*}{ Unit cell parameters } & $a=9.654(2) \AA$ & Completeness to $\theta_{\max }[\%]$ & 100.0 \\
\hline & $b=13.610(2) \AA$ & Restraints / parameters & $719 / 625$ \\
\hline & $c=16.586(3) \AA$ & Goodness-of-fit on $\mathrm{F}^{2}$ & 1.060 \\
\hline & $\alpha=107.83(3)^{\circ}$ & $R 1[\mathrm{I}>2 \sigma(\mathrm{I})]$ & 0.0350 \\
\hline & $\beta=97.55(2)^{\circ}$ & wR2 (all data) & 0.0902 \\
\hline & $\gamma=103.31(2)^{\circ}$ & Max. diff. peak / hole $\left[\mathrm{e}^{-3}\right]$ & $1.360 /-0.616$ \\
\hline Volume $\left[\AA^{3}\right]$ & $1970.3(7)$ & $\begin{array}{l}\text { Absolute structure } \\
\text { parameter }{ }^{[235]}\end{array}$ & - \\
\hline$Z$ & 2 & Extinction coefficient & - \\
\hline
\end{tabular}




\subsubsection{8 $\left[\mathrm{All}_{2}\left({ }^{4-\mathrm{BrhH}^{2}} \mathrm{Box}_{2} \mathrm{CH}\right)\right](37)$}

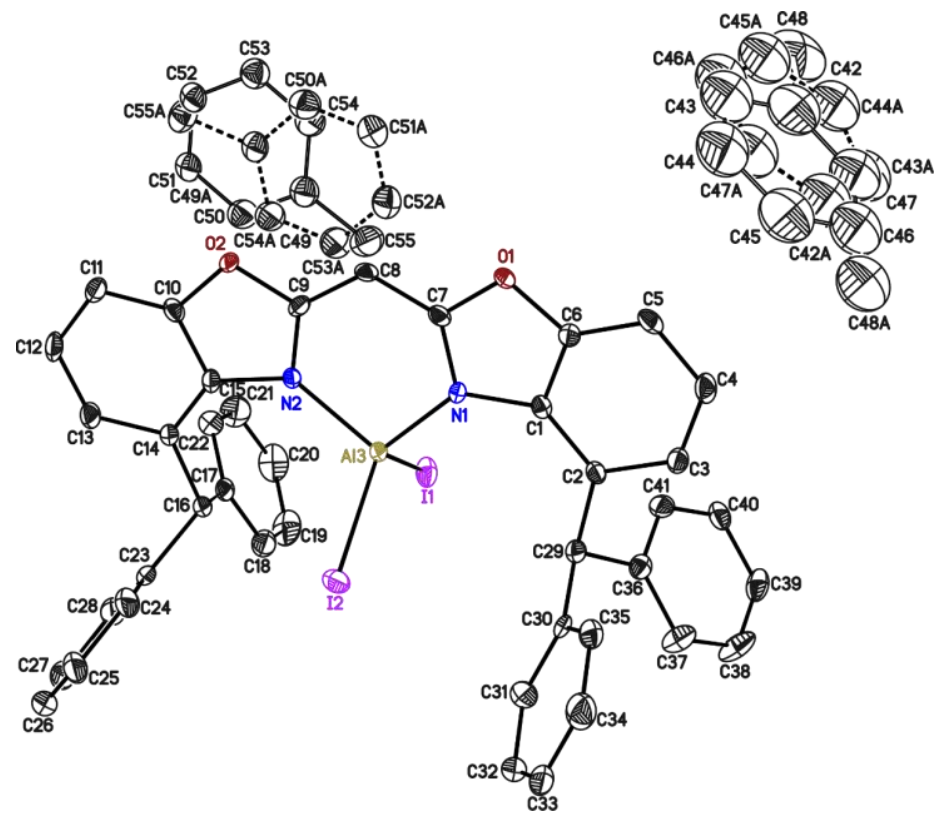

Figure 5-38. Asymmetric unit of 37 . Displacement parameters are depicted at 50\% probability. Hydrogen atoms are omitted for clarity. Both toluene molecule are disordered about an inversion center and about two positions, the occupancies of the minor position refine to $0.080(6)$ and $0.174(6)$, respectively. All disordered groups are refined with distance restraints and restraints for the anisotropic displacement parameters. Reprinted with permission from reference [6]. Copyright 2021, American Chemical Society.

Table 5-38. Crystallographic data of 37.

\begin{tabular}{ll|ll}
\hline Structure code & JKPhBoxAlI2 & $\rho_{\text {calc. }}\left[\mathrm{Mg} \cdot \mathrm{m}^{-3}\right]$ & 1.565 \\
CCDC no. & 2065077 & $\mu\left[\mathrm{mm}^{-1}\right]$ & 0.862 \\
Empirical formula & $\mathrm{C}_{48} \mathrm{H}_{37} \mathrm{AlI}_{2} \mathrm{~N}_{2} \mathrm{O}_{2}$ & $F(000)$ & 948 \\
Formula weight $\left[\mathrm{g} \mathrm{mol}^{-1}\right]$ & 954.57 & Crystal size $\left[\mathrm{mm}^{3}\right]$ & $0.146 \times 0.140 \times 0.061$ \\
Temperature $[\mathrm{K}]$ & $100(2)$ & $\theta$ range $\left.{ }^{\circ}\right]$ & 1.842 to 20.569 \\
Wavelength $[\AA]$ & 0.56086 & Reflections collected & 59841 \\
Crystal system & Triclinic & Unique Reflections & 8318 \\
Space group & $P \overline{1}$ & $R_{\text {int }}$ & 0.0706 \\
Unit cell parameters & $a=11.626(2) \AA$ & Completeness to $\theta_{\max }[\%]$ & 100.0 \\
& $b=13.775(2) \AA$ & Restraints / parameters & $1320 / 687$ \\
& $c=14.367(3) \AA$ & Goodness-of-fit on $\mathrm{F}^{2}$ & 1.024 \\
& $\alpha=61.89(2)^{\circ}$ & $R 1[\mathrm{I}>2 \sigma(\mathrm{I})]$ & 0.0319 \\
& $\beta=86.94(3)^{\circ}$ & wR2 (all data) & 0.0728 \\
Volume $\left[\AA^{3}\right]$ & $\gamma=87.63(3)^{\circ}$ & Max. diff. peak / hole $\left[\mathrm{e} \AA^{-3}\right]$ & $0.609 /-0.815$ \\
$Z$ & $2026.7(7)$ & Absolute structure & - \\
\hline
\end{tabular}




\subsubsection{9 $\left[\mathrm{AlH}_{2}\left({ }^{4-\mathrm{BrhH}}{ }^{\mathrm{BOOX}}{ }_{2} \mathrm{CH}\right)\right](38)$}

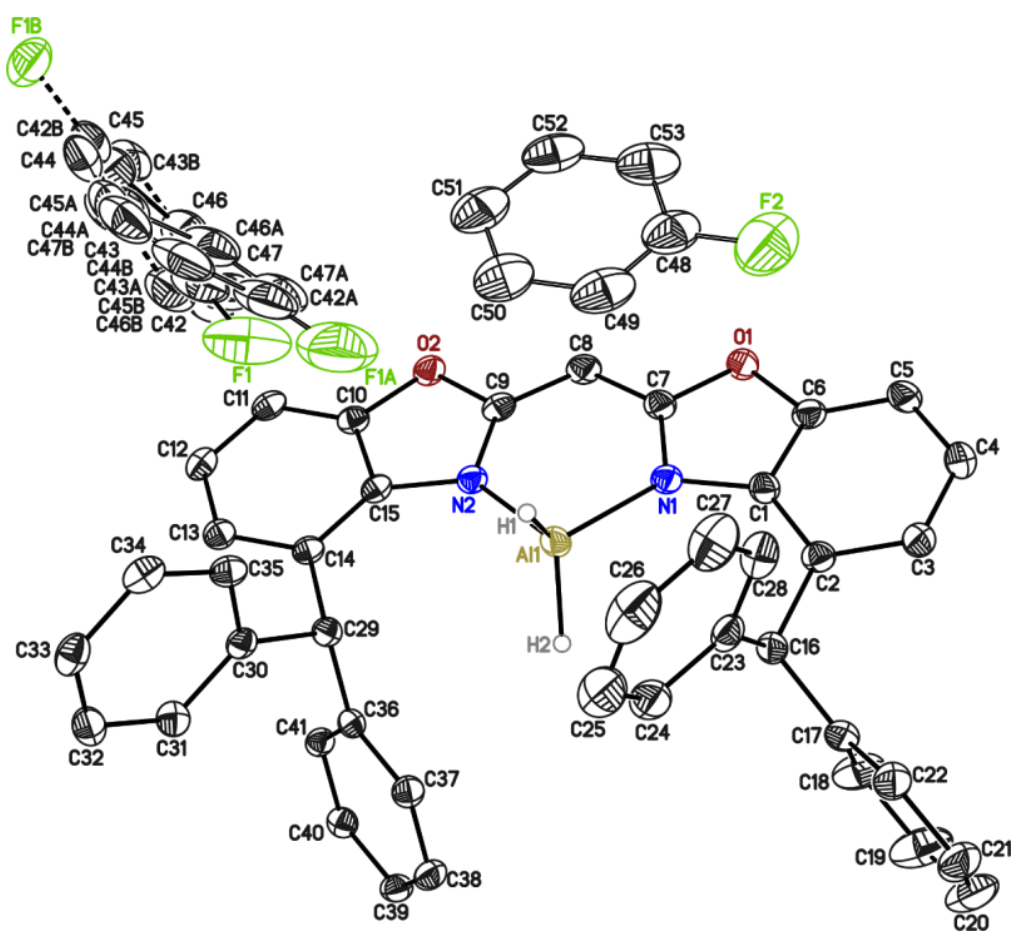

Figure 5-39. Asymmetric unit of 38. Displacement parameters are depicted at 50\% probability. Hydrogen atoms except those connected to the aluminum atom are omitted for clarity. The fluorobenzene molecule $\mathrm{C} 42$ to $\mathrm{C} 47$ and $\mathrm{F} 1$ is disordered about three positions, the occupancies of the minor positions refine to $0.266(2)$ and 0.237(2). The second fluorobenzene molecule C48 to C53 and F2 is disordered about an inversion center. All disordered groups are refined with distance restraints and restraints for the anisotropic displacement parameters. Reprinted with permission from reference [6]. Copyright 2021, American Chemical Society.

Table 5-39. Crystallographic data of 38.

\begin{tabular}{ll|ll}
\hline Structure code & JKBZHAlH2 & $\rho_{\text {calcd. }\left[\mathrm{Mg} \cdot \mathrm{m}^{-3}\right]}$ & 1.264 \\
CCDC no. & 2065078 & $\mu\left[\mathrm{mm}^{-1}\right]$ & 0.102 \\
Empirical formula & $\mathrm{C}_{50} \mathrm{H}_{38.50} \mathrm{AlF}_{1.50} \mathrm{~N}_{2} \mathrm{O}_{2}$ & $F(000)$ & 790 \\
Formula weight $\left[\mathrm{g} \mathrm{mol}^{-1}\right]$ & 754.81 & Crystal size $\left[\mathrm{mm}^{3}\right]$ & $0.109 \times 0.158 \times 0.281$ \\
Temperature $[\mathrm{K}]$ & $100(2)$ & $\theta$ range $\left[{ }^{\circ}\right]$ & 1.284 to 26.426 \\
Wavelength $[\AA]$ & 0.71073 & Reflections collected & 89347 \\
Crystal system & Triclinic & Unique Reflections & 8139 \\
Space group & $P \overline{1}$ & $R_{\text {int }}$ & 0.0671 \\
Unit cell parameters & $a=10.975(2) \AA$ & Completeness to $\theta_{\max }[\%]$ & 100.0 \\
& $b=11.688(2) \AA$ & Restraints / parameters & $1324 / 679$ \\
& $c=16.668(3) \AA$ & Goodness-of-fit on $\mathrm{F}^{2}$ & 1.024 \\
& $\alpha=104.91(3)^{\circ}$ & $R 1$ [I>2 $(\mathrm{I})]$ & 0.0406 \\
& $\beta=96.06(2)^{\circ}$ & wR2 (all data) & 0.1063 \\
& $\gamma=102.88(2)^{\circ}$ & Max. diff. peak / hole $\left[\mathrm{e} \AA^{-3}\right]$ & $0.369 /-0.353$ \\
Volume $\left[\AA^{3}\right]$ & $1983.8(7)$ & Absolute structure & - \\
& & parameter ${ }^{[235]}$ & \\
$Z$ & 2 & Extinction coefficient & - \\
\hline
\end{tabular}




\subsubsection{0 [AlHI( $\left.\left.{ }^{4-\mathrm{BrhH}}{ }^{\mathrm{BOOx}}{ }_{2} \mathrm{CH}\right)\right](39)$}
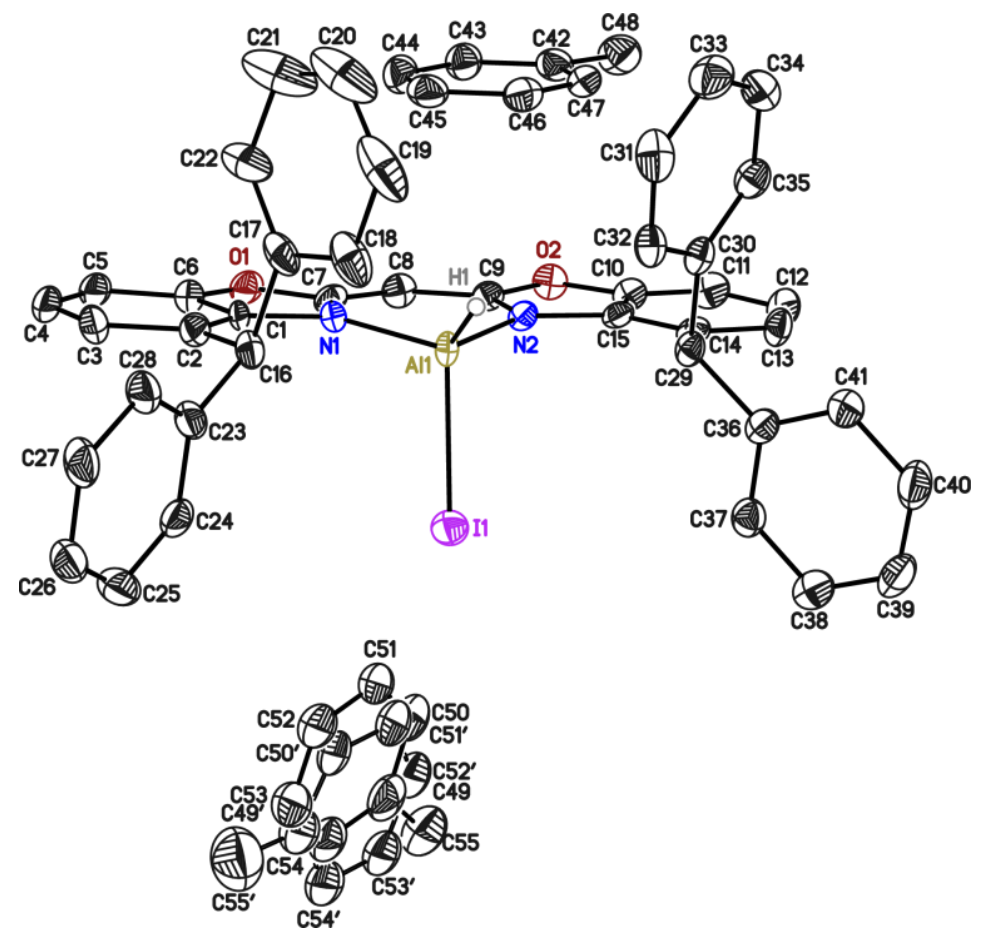

Figure 5-40. Asymmetric unit of 39. Displacement parameters are depicted at 50\% probability. Hydrogen atoms except those connected to the aluminum atom are omitted for clarity. The toluene molecule is disordered about two positions, while occupancies of the minor position refine to $0.293(10)$. All disordered groups are refined with distance restraints and restraints for the anisotropic displacement parameters.

Table 5-40. Crystallographic data of 39.

\begin{tabular}{ll|ll}
\hline Structure code & $\mathrm{JK} 615$ & $\rho_{\text {calcd. }\left[\mathrm{Mg} \cdot \mathrm{m}^{-3}\right]}$ & 1.357 \\
CCDC no. & - & $\mu\left[\mathrm{mm}^{-1}\right]$ & 0.774 \\
Empirical formula & $\mathrm{C}_{55} \mathrm{H}_{46} \mathrm{AlIN}_{2} \mathrm{O}_{2}$ & $F(000)$ & 1888 \\
Formula weight $\left[\mathrm{g} \mathrm{mol}^{-1}\right]$ & 920.82 & Crystal size $\left[\mathrm{mm}^{3}\right]$ & $0.312 \times 0.162 \times 0.112$ \\
Temperature $[\mathrm{K}]$ & $100(2)$ & $\theta$ range $\left[{ }^{\circ}\right]$ & 1.312 to 28.291 \\
Wavelength $[\AA]$ & 0.71073 & Reflections collected & 222995 \\
Crystal system & Orthorhombic & Unique Reflections & 11197 \\
Space group & $P n 2_{1}$ & $R_{\text {int }}$ & 0.0648 \\
Unit cell parameters & $a=10.040(6) \AA$ & Completeness to $\theta_{\max }[\%]$ & 100.0 \\
& $b=31.040(17) \AA$ & Restraints / parameters & $631 / 620$ \\
& $c=14.464(8) \AA$ & Goodness-of-fit on $\mathrm{F}^{2}$ & 1.263 \\
& $\alpha=90^{\circ}$ & $R 1[\mathrm{I}>2 \sigma(\mathrm{I})]$ & 0.0474 \\
& $\beta=90^{\circ}$ & wR2 (all data) & 0.1238 \\
Volume $\left[\AA^{3}\right]$ & $\gamma=90^{\circ}$ & Max. diff. peak / hole $\left[\mathrm{e} \AA^{-3}\right]$ & $0.986 /-0.921$ \\
& $4508(4)$ & Absolute structure & $0.41(3)$ \\
$Z$ & & parameter ${ }^{[235]}$ & \\
\hline
\end{tabular}




\subsection{Crystallographic Cooperation}

Reference: S. Kundu, C. Mohapatra, P. P. Samuel, J. Kretsch, M. G. Walawalkar, R. Herbst-Irmer, D. Stalke, S. De, D. Koley, H. W. Roesky, "An unprecedented 1,4-diphospha-2,3-disilabutadiene $(-P=S i-S i=P-)$ derivative and a 1,3-diphospha-2-silaallyl anion, each stabilized by the amidinate ligand", Chem. Commun. 2017, 53, 192-195; DOI: 10.1039/c6cc09171g. ${ }^{[236]}$

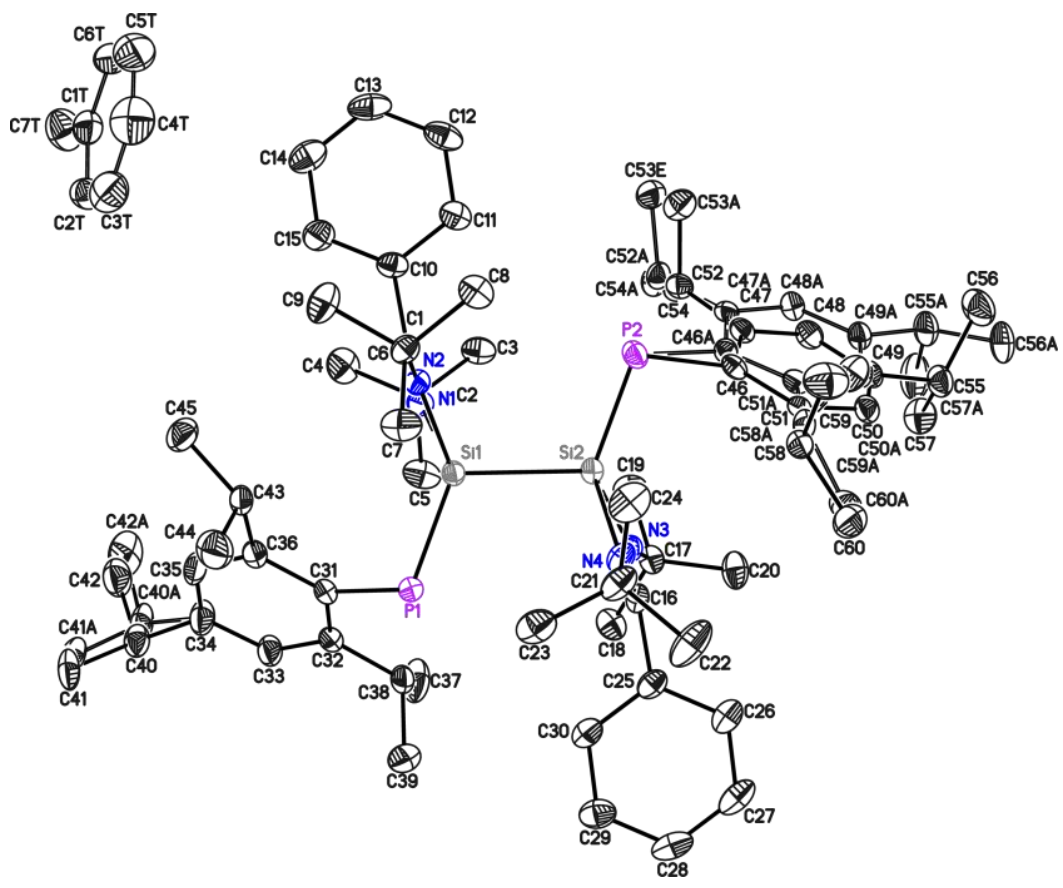

Figure 5-41. Asymmetric unit of CCDC no. 1507708. The anisotropic displacement parameters are depicted at the $50 \%$ probability level. The hydrogen atoms are omitted for clarity.

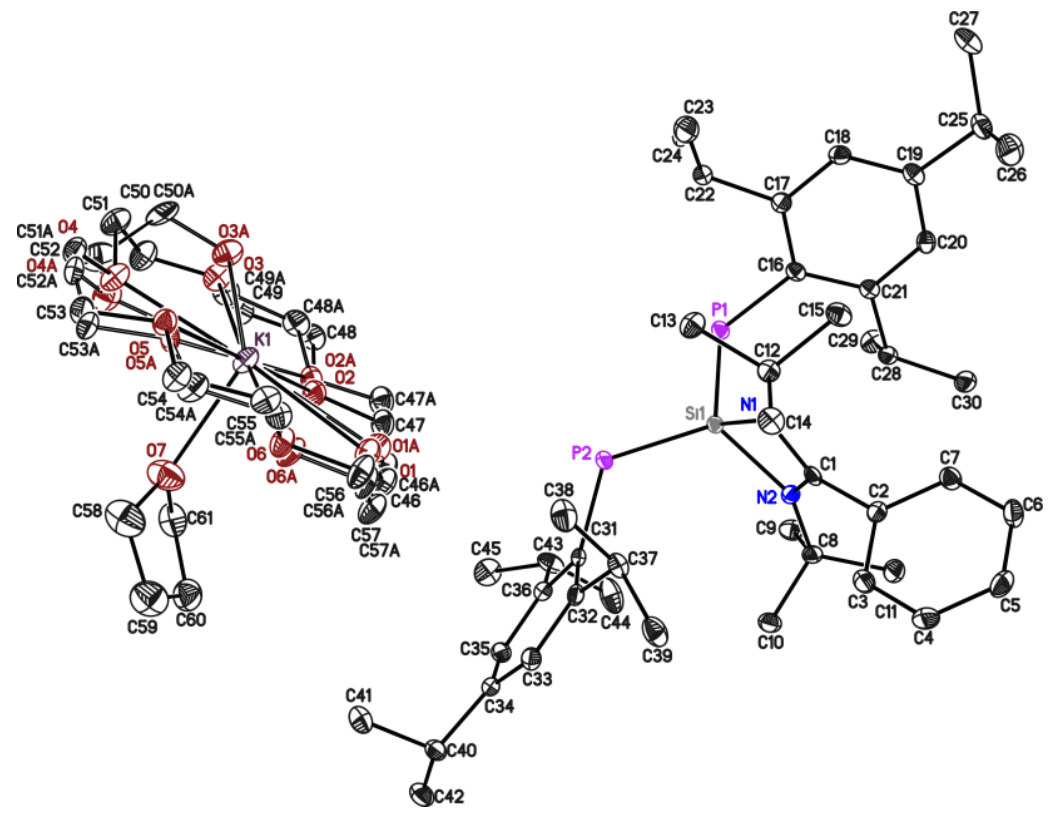

Figure 5-42: Asymmetric unit of CCDC no. 1507709. The anisotropic displacement parameters are depicted at the $50 \%$ probability level. The hydrogen atoms are omitted for clarity. 
Reference: S. Kundu, B. Li, J. Kretsch, R. Herbst-Irmer, D. M. Andrada, G. Frenking, D. Stalke, H. W. Roesky, "An Electrophilic Carbene-Anchored Silylene-Phosphinidene", Angew. Chem. Int. Ed. 2017, 56, 4219-4223; Angew. Chem. 2017, 129, 4283-4287; DOI: 10.1002/anie.201700420; 10.1002 /ange.201700420. ${ }^{[237]}$

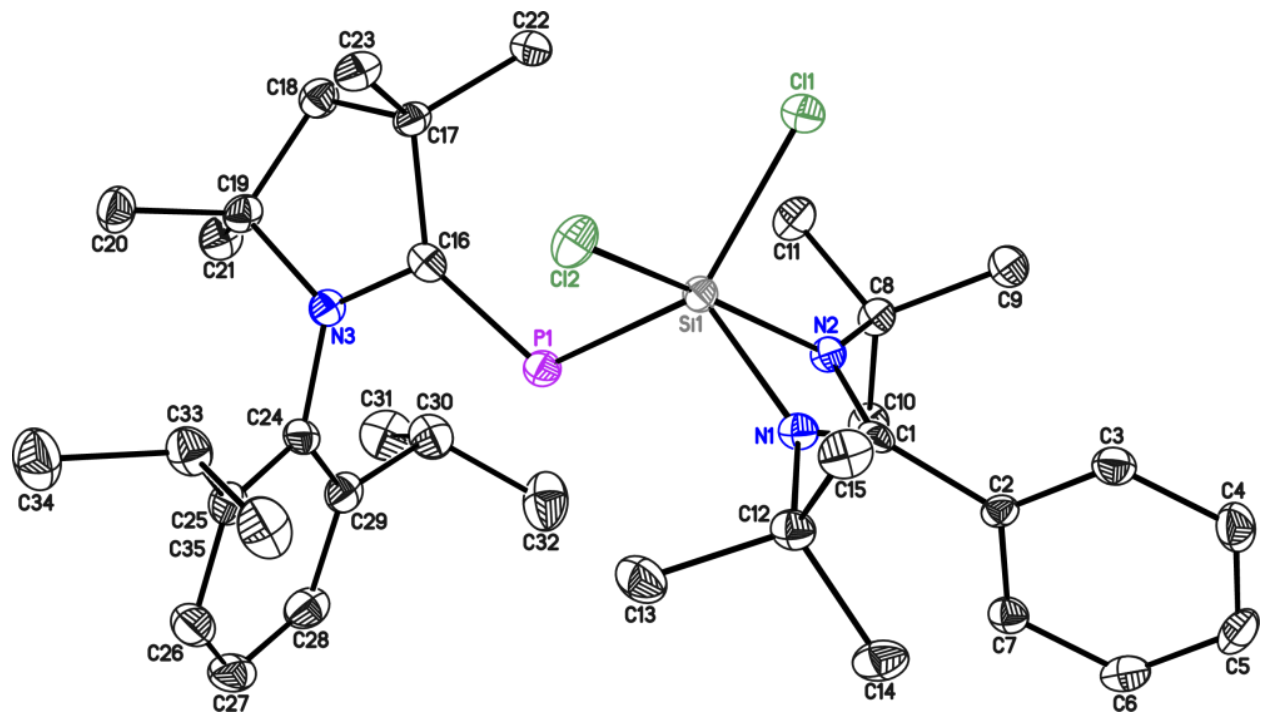

Figure 5-43: Asymmetric unit of CCDC no. 1526893. The anisotropic displacement parameters are depicted at the $50 \%$ probability level. The hydrogen atoms are omitted for clarity.
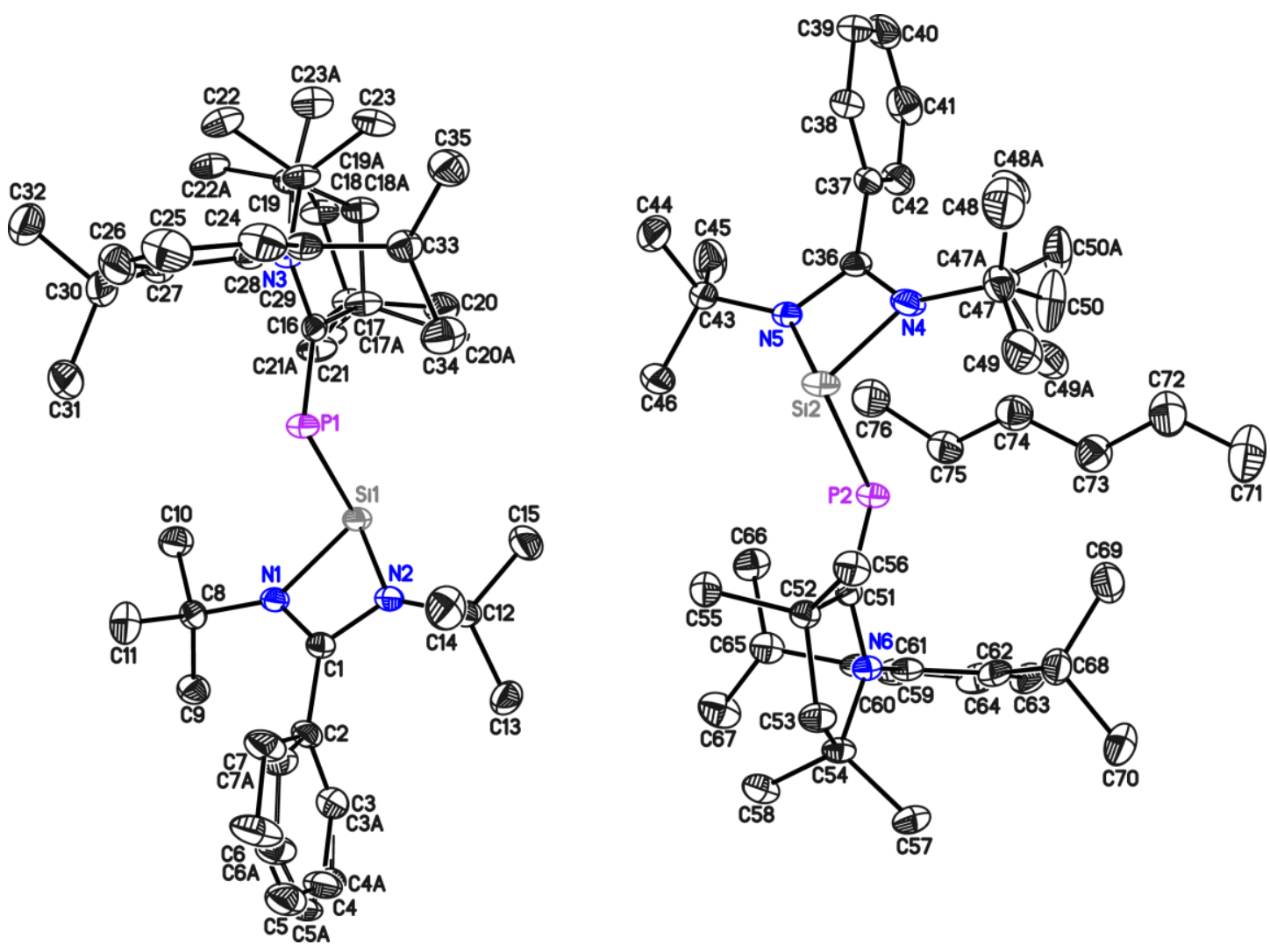

Figure 5-44: Asymmetric unit of CCDC no. 1526893. The anisotropic displacement parameters are depicted at the $50 \%$ probability level. The hydrogen atoms are omitted for clarity. 
Reference: S. K. Sarkar, M. M. Siddiqui, S. Kundu, M. Ghosh, J. Kretsch, P. Stollberg, R. HerbstIrmer, D. Stalke, A. C. Stückl, B. Schwederski, W. Kaim, S. Ghorai, E. D. Jemmis, H. W. Roesky, "Isolation of base stabilized fluoroborylene and its radical cation", Dalton Trans. 2019, 48, 85518555; DOI: 10.1039/c9dt01899a. ${ }^{[238]}$
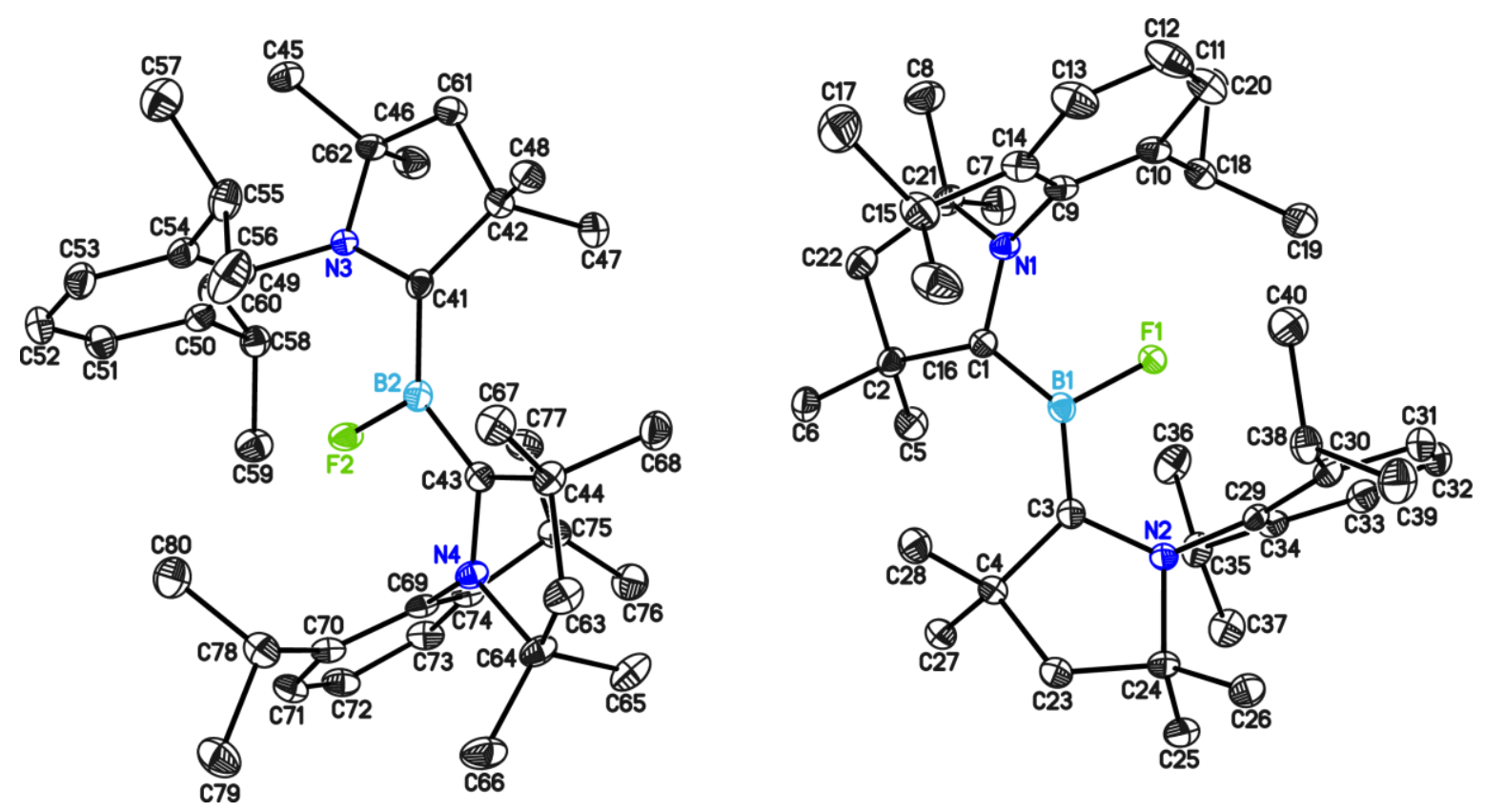

Figure 5-45. Asymmetric unit of CCDC no. 1900360. The anisotropic displacement parameters are depicted at the $50 \%$ probability level. The hydrogen atoms are omitted for clarity.

Reference: M. M. Siddiqui, S. Banerjee, S. Bose, S. K. Sarkar, S. K. Gupta, J. Kretsch, N. Graw, R. Herbst-Irmer, D. Stalke, S. Dutta, D. Koley, H. W. Roesky, "Cyclic (Alkyl)(Amino)CarbeneStabilized Aluminum and Gallium Radicals Based on Amidinate Scaffolds”, Inorg. Chem. 2020, 59, 11253. ${ }^{[239]}$
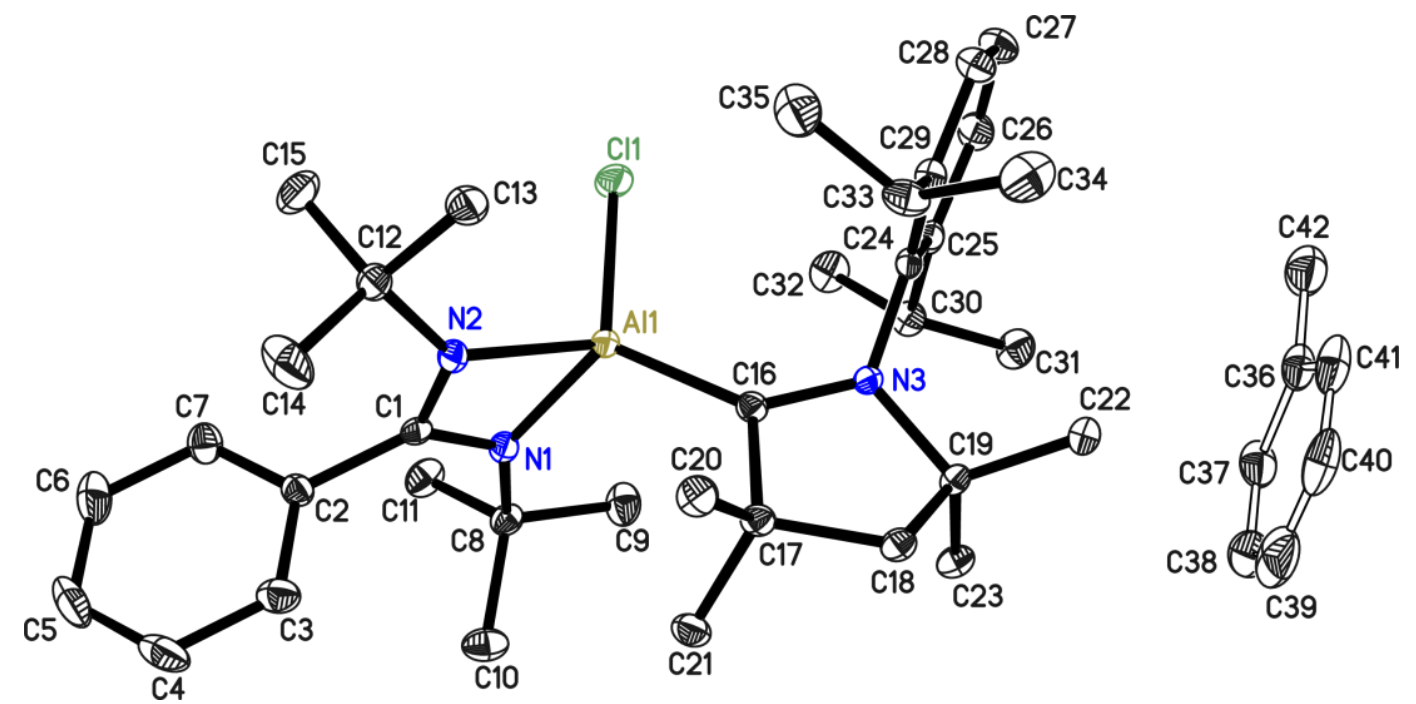

Figure 5-46. Asymmetric unit of CCDC no. 2010643. Anisotropic displacement parameters are depicted at the $50 \%$ probability level. Hydrogen atoms are omitted for clarity. 


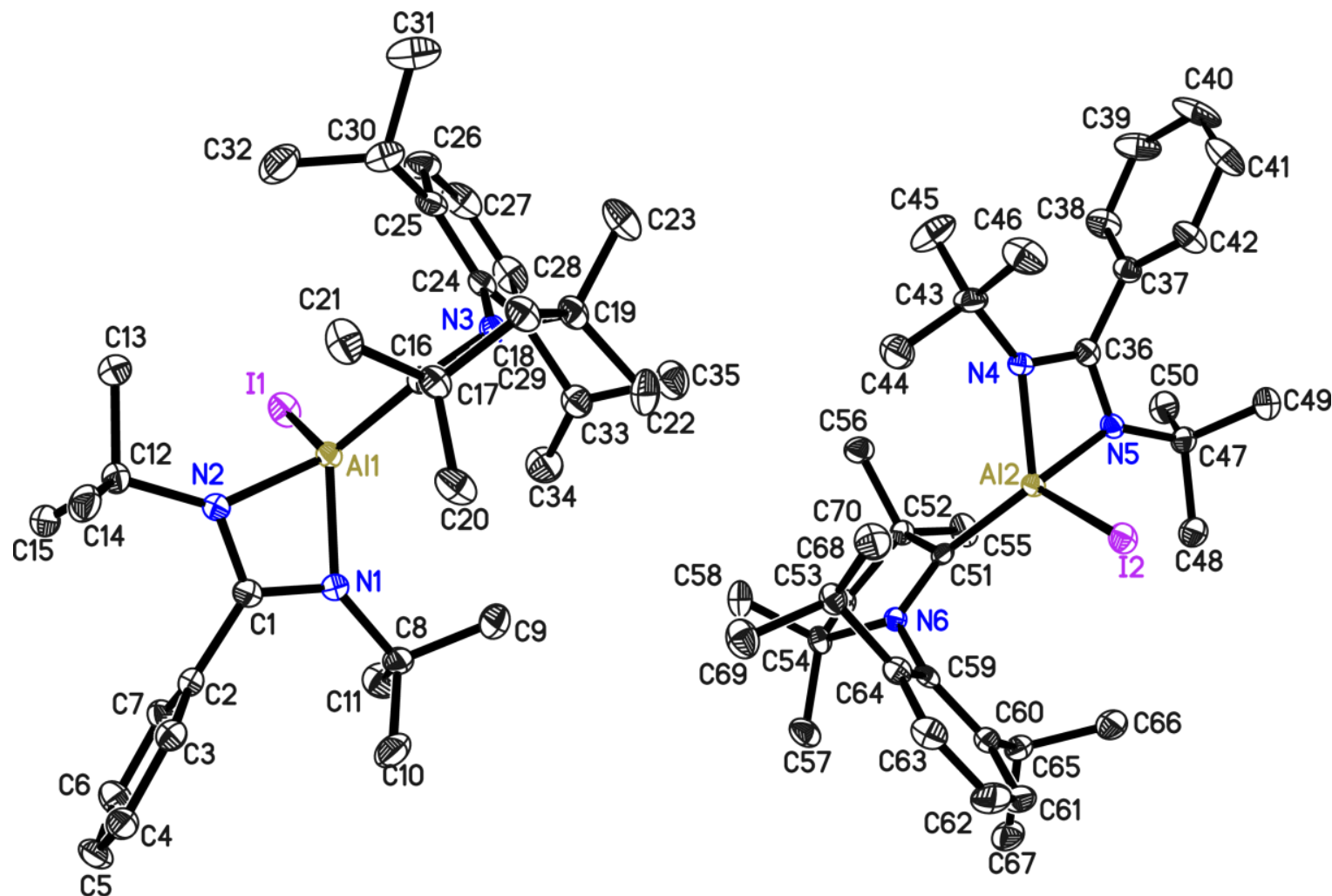

Figure 5-47. Asymmetric unit of CCDC no. 2010645. Anisotropic displacement parameters are depicted at the $50 \%$ probability level. Hydrogen atoms are omitted for clarity. 


\subsection{DOSY Data}

NMR spectra were carried out on a Bruker Ascend III $400 \mathrm{MHz}$ spectrometer equipped with an inverse broadband probe and $z$-gradient (maximum gradient strength: $51 \mathrm{G} / \mathrm{cm}$ ). If not indicated otherwise experiments were done at ambient temperature and without spinning. DOSY-Experiments were performed with the dstebpgp3s-pulseprogram with gradient pulses $(\delta)$ for ${ }^{1} \mathrm{H}$-diffusion in a range from 0.8 up to $1.3 \mathrm{~ms}$ and a diffusion time $(\Delta)$ of $0.1 \mathrm{~s}$. Spectra processing and calculation of the diffusion coefficients were carried out using the T1/T2 software of Topspin 4.0.7. Data evaluation was performed using the $M W$ Estimation Software Version 1.3.

Table 5-41. ${ }^{1} \mathrm{H}-\mathrm{DOSY}-\mathrm{ECC}-\mathrm{MW}$ estimation of $\left[\left\{\left({ }^{4-\mathrm{Me}} \mathrm{Box}_{2} \mathrm{CH}\right) \mathrm{HAl}{ }^{\mathrm{II}}\right\}-\left\{\mathrm{Al}^{\mathrm{II}} \mathrm{H}\left({ }^{\mathrm{Dipp} N a c N a c}\right)\right\}\right] \quad$ (13) in $\left[\mathrm{D}_{8}\right]$ toluene. $\mathrm{ADAM}\left(\log D_{\text {reffix }}=-8.8454\right)$ was used as internal reference. Hypothetical aggregates are given below. However, calculations confirm the successful syntheses of the proposed dimer dialane 13.

\begin{tabular}{|c|c|c|c|c|c|}
\hline & & Aggregate & $M W_{\text {det }}\left[\mathrm{gmol}^{-1}\right]$ & $M W_{\text {dif }}[\%]$ & $M D_{\mathrm{W}}\left[\mathrm{gmol}^{-1} \mathrm{~m}^{-3}\right]$ \\
\hline $\log \left(D_{\mathrm{x}}\right)$ & -9.2402 & $13\left(751 \mathrm{gmol}^{-1}\right)$ & 695 & 8 & $4.49 \mathrm{E}+29$ \\
\hline $\log \left(D_{\mathrm{x}, \text { norm }}\right)$ & -9.2353 & $12\left(306 \mathrm{gmol}^{-1}\right)$ & 695 & -56 & $4.96 \mathrm{E}+29$ \\
\hline $\log \left(D_{\text {ref }}\right)($ ADAM $)$ & -8.8502 & & & & \\
\hline $\begin{array}{l}\text { Proposed } \\
\text { Aggregates }\end{array}$ & & {$\left[\mathrm{AlH}_{2}\left({ }^{4-\mathrm{Me}} \mathrm{Box}_{2} \mathrm{CH}\right.\right.$} & $(12)$ & \multicolumn{2}{|c|}{$\begin{array}{c}{\left[\left\{{ }^{\left.\left.4-\mathrm{Me} B o x_{2} \mathrm{CH}\right) \mathrm{HAl}^{\mathrm{II}}\right\}-}\right.\right.} \\
\left.\left\{\mathrm{Al}^{\mathrm{II}} \mathrm{H}\left({ }^{\mathrm{Dipp}} \mathrm{NacNac}\right)\right\}\right](\mathbf{1 3})\end{array}$} \\
\hline
\end{tabular}




\subsection{UV/Vis Spectroscopy}

The UV/Vis spectra were recorded on an Agilent Cary 50 spectrometer using quartz cuvettes by Timo Schillmöller.

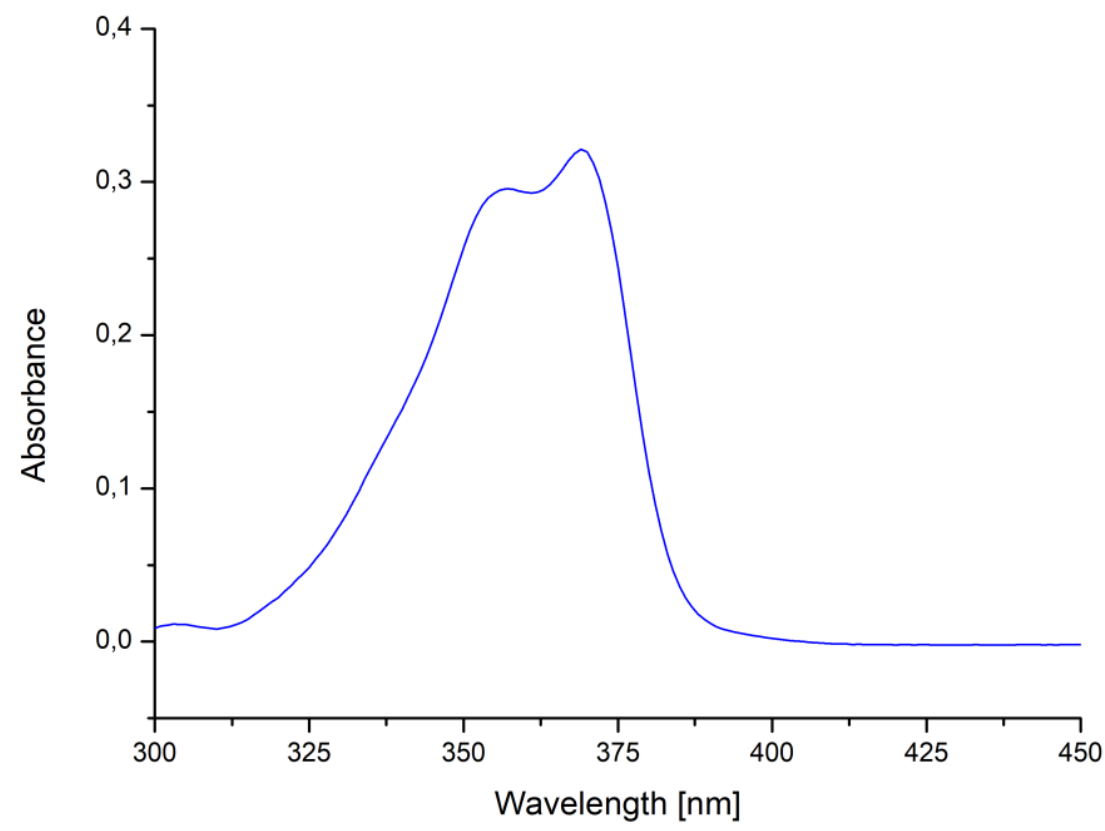

Figure 5-48. UV/Vis spectrum of $\left[\mathrm{AlH}_{2}\left({ }^{4-\mathrm{Bzh}} \mathrm{Box}_{2} \mathrm{CH}\right)\right] 38$ in diluted toluene solution $\left(10^{-5} \mathrm{M}\right)$. The figure shows an excerpt of the region around $320-475 \mathrm{~nm}$. The absorption spectra of 38 in diluted toluene solution $\left(10^{-5} \mathrm{M}\right)$ displays a maximum at $\lambda_{\max }=369 \mathrm{~nm}$ and a shoulder at $\lambda=357 \mathrm{~nm}$. 


\subsection{Fluorescence measurements}

Timo Schillmöller carried out the fluorescence measurements on a Horiba Jobin-Yvon Fluoromax4 spectrometer. The quantum yield was determined with the quanta- $\varphi$ integrating sphere. Fluorescence lifetime was estimated with the TCSPC system using a pulsed laser diode at $375 \mathrm{~nm}$ as excitation source.

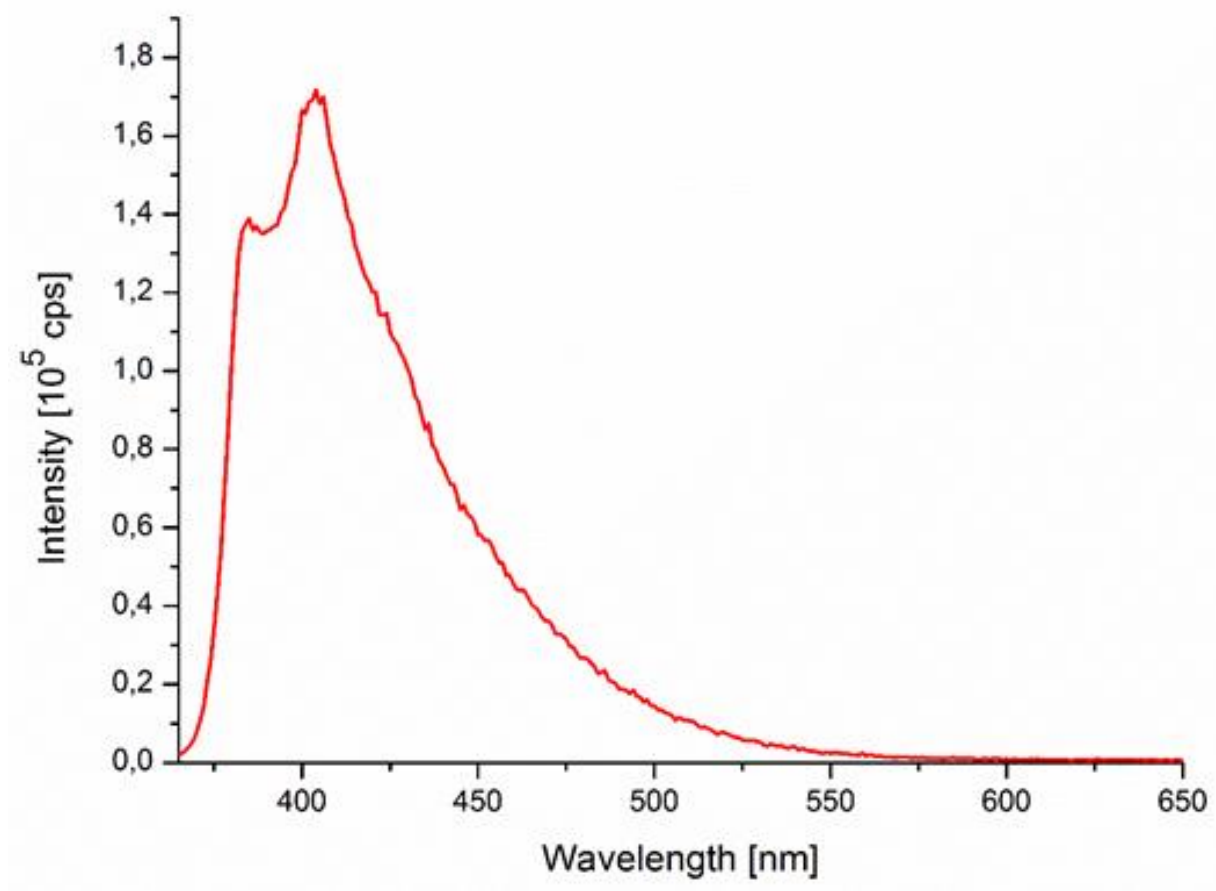

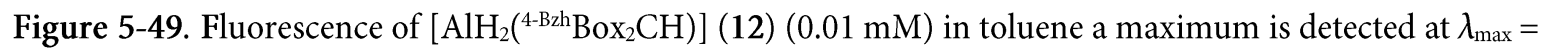
$404 \mathrm{~nm}\left(\lambda_{\mathrm{ex}}=350 \mathrm{~nm}\right)$. This might be explained by the reaction of 12 with ambient oxygen or moisture.

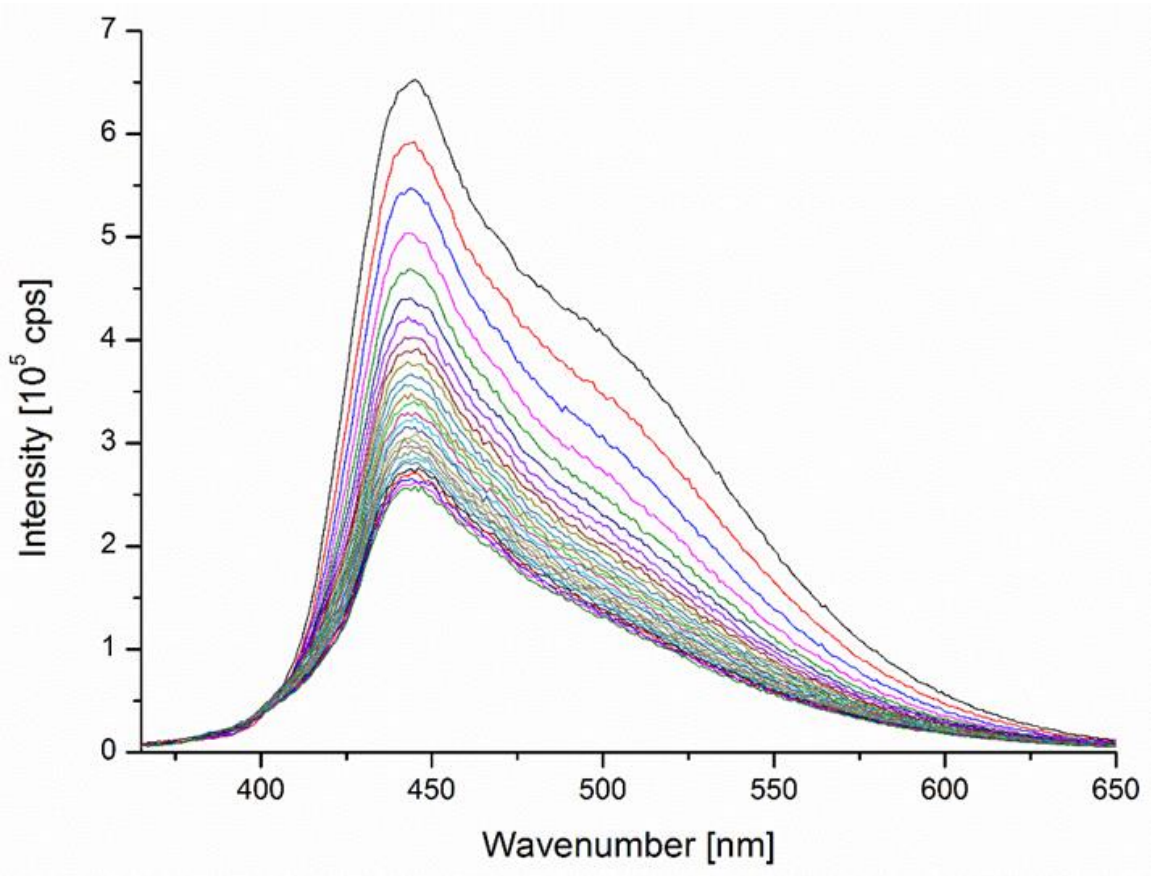

Figure 5-50. Solid-state fluorescence of crystalline $\left[\mathrm{AlH}_{2}\left({ }^{4-\mathrm{Bzh}} \mathrm{Box}_{2} \mathrm{CH}\right)\right](12)$ that were performed at ambient temperature under air showed a broad emission maximum at $\lambda_{\max }=445 \mathrm{~nm}\left(\lambda_{\mathrm{ex}}=350 \mathrm{~nm}\right)$ with a decrease in intensity overnight. 


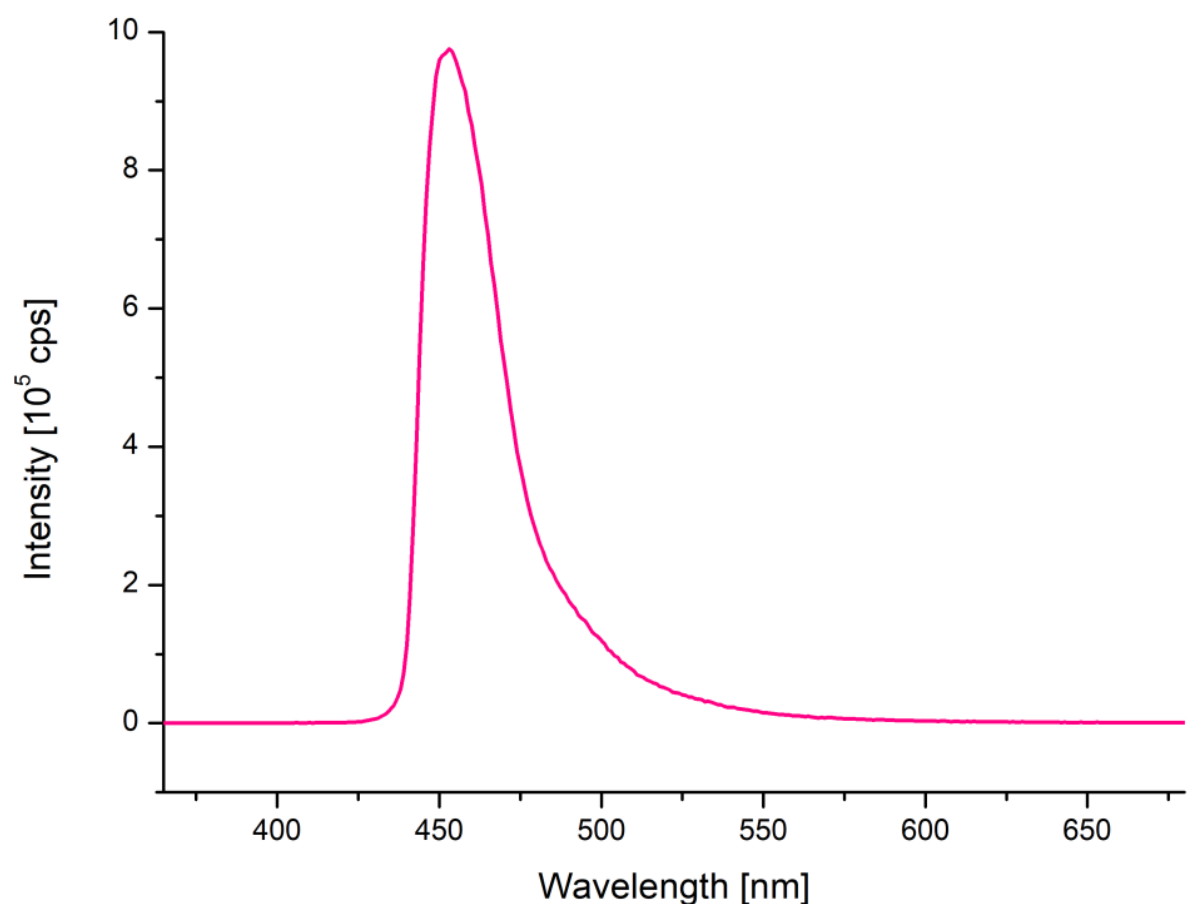

Figure 5-51. Fluorescence of $\left[(\mathrm{THF})_{2} \mathrm{~K}(18-\text { crown-6) }]^{+}\left[{ }^{4-\mathrm{BhhH}^{2}} \mathrm{Box}_{2} \mathrm{CH}\right]^{-}(\mathbf{2 8})\right.$ in THF $(1.0 \mathrm{mM})$ displays a maximum $\lambda_{\max }=454 \mathrm{~nm}\left(\lambda_{\mathrm{ex}}=350 \mathrm{~nm}\right)$.

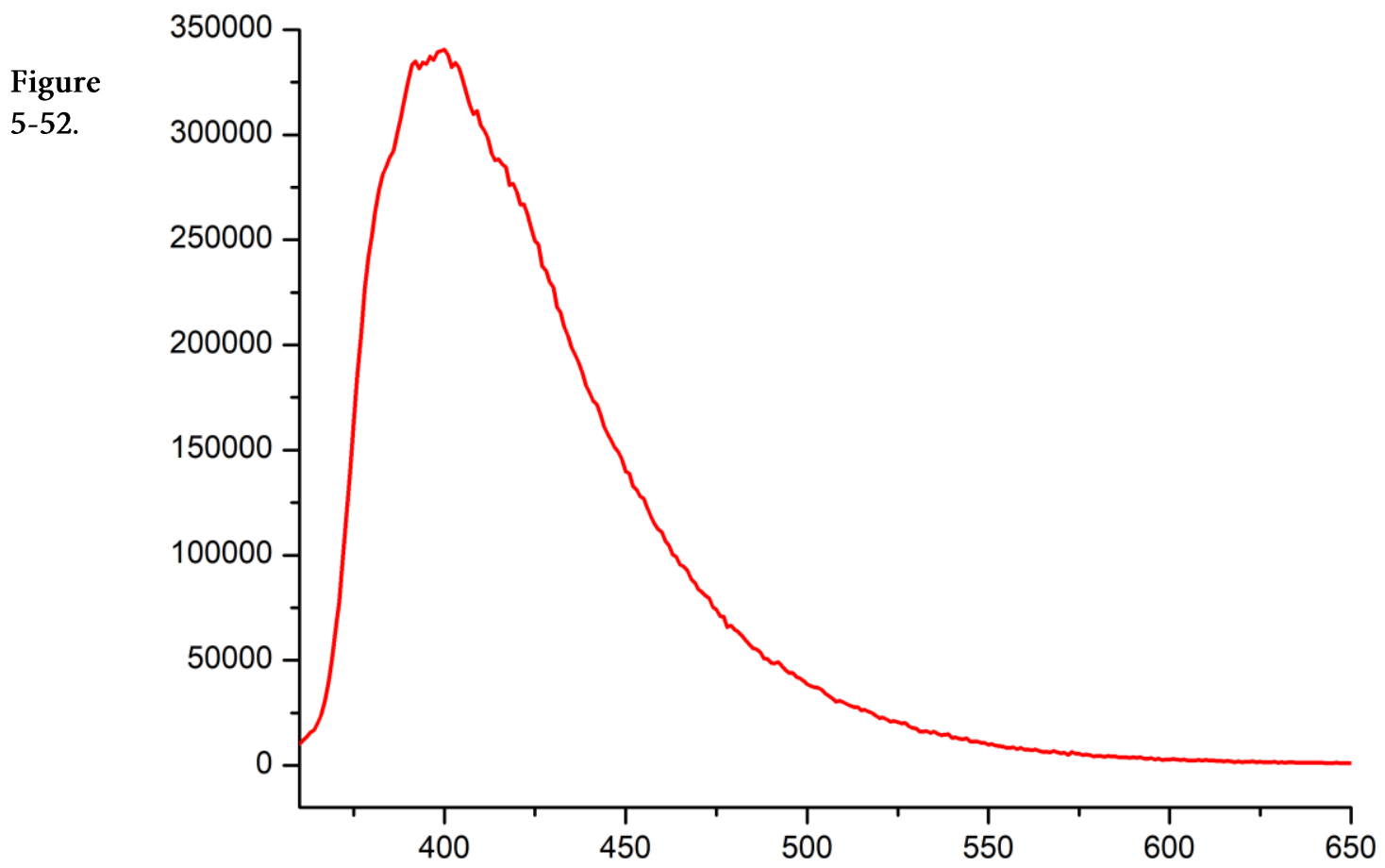

Fluorescence spectrum of 38 in diluted toluene solution $(0.01 \mathrm{mM})$ displays a emission maximum at $\lambda_{\max }=$ $400 \mathrm{~nm}\left(\lambda_{\mathrm{ex}}=350 \mathrm{~nm}\right)$. 


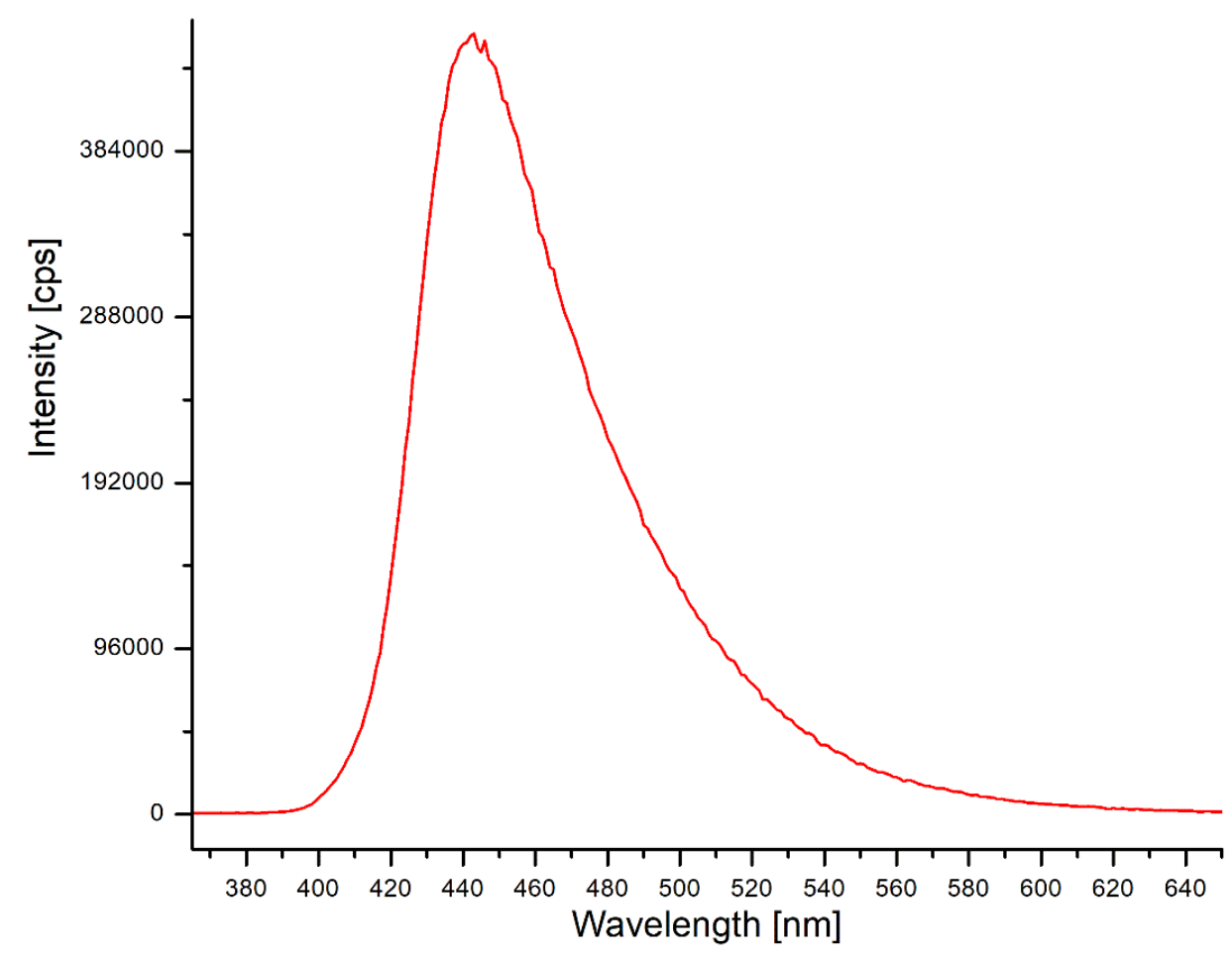

Figure 5-53.Solid-state fluorescence spectrum of $\left[\mathrm{AlH}_{2}\left({ }^{4-\mathrm{BrhH}^{2}} \mathrm{Box}_{2} \mathrm{CH}\right)\right] 38$ shows a emission maximum at $\lambda_{\max }=$ $442 \mathrm{~nm}\left(\lambda_{\mathrm{ex}}=350 \mathrm{~nm}\right)$.

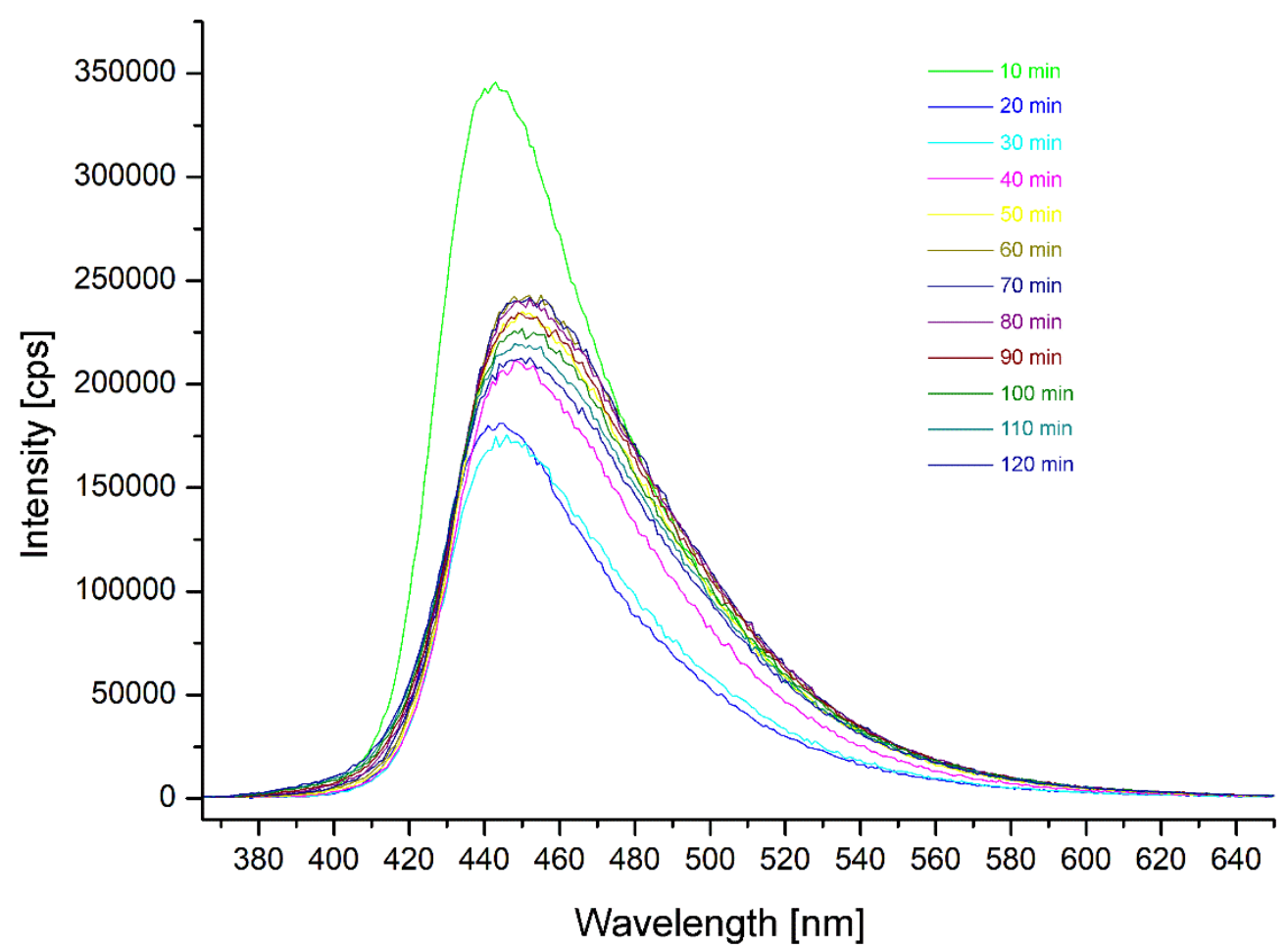

Figure 5-54. Multiple fluorescence spectra reveal the decomposition of $\left[\mathrm{AlH}_{2}\left({ }^{4-\mathrm{BzhH}^{2}} \mathrm{Box}_{2} \mathrm{CH}\right)\right] 38$ by a decrease of intensity over $2 \mathrm{~h}$. 


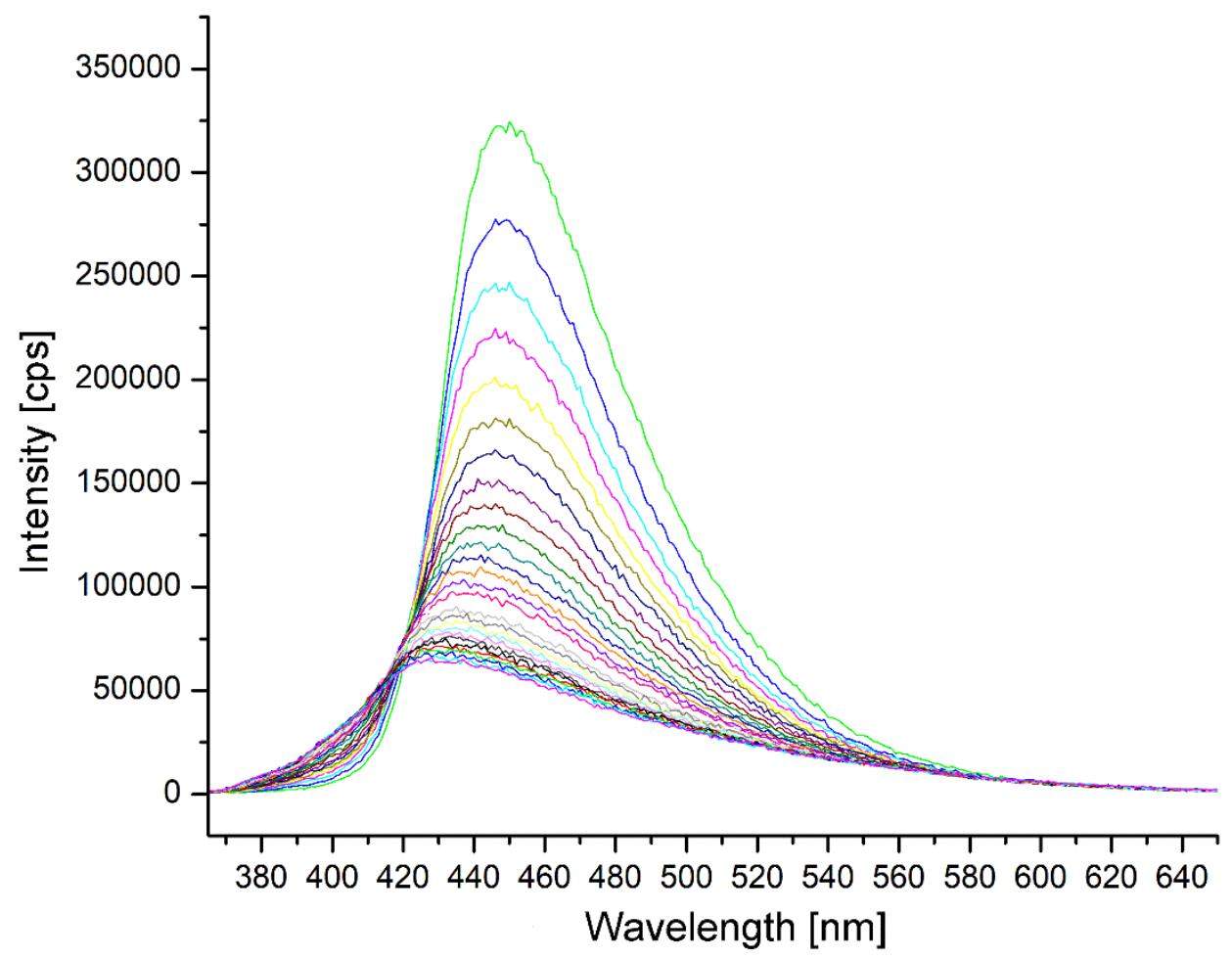

Figure 5-55. Overnight measured fluorescence spectra of $\left[\mathrm{AlH}_{2}\left({ }^{4-\mathrm{BhhH}^{2}} \mathrm{Box}_{2} \mathrm{CH}\right)\right] 38$ after the first $2 \mathrm{~h}$.

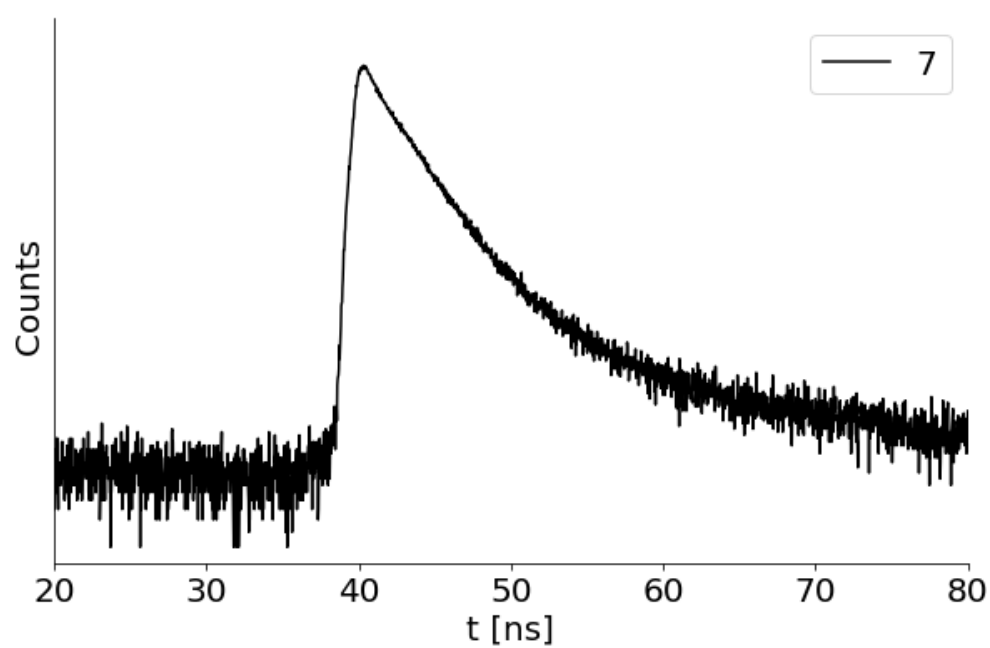

Figure 5-56. Fluorescence lifetime decay plot of $\left[\mathrm{AlH}_{2}\left({ }^{4-\mathrm{BhhH}^{2}} \mathrm{Box}_{2} \mathrm{CH}\right)\right] 38$. 


\subsection{Experimental setup and methodology for $p K_{a}$ determination}

The experimental setup and methodology for the $\mathrm{p} K_{\mathrm{a}}$ determination of $\mathrm{Box}_{2} \mathrm{CH}_{2},{ }^{4-\mathrm{Me}} \mathrm{Box}_{2} \mathrm{CH}_{2}$, or ${ }^{4-B z h} \mathrm{Box}_{2} \mathrm{CH}_{2}$ (23) were carried out by Dr. Märt Lõkov and Prof. Dr. Ivo Leito in acetonitrile according to previous publications. ${ }^{[114 b, 240]} \mathrm{A}$ brief description will follow.

The $\mathrm{p} K_{\mathrm{a}}$ determinations in acetonitrile are based on the determination of differences of $\mathrm{p} K_{\mathrm{a}}$ values of two acids. One compound is a reference acid with a previously known $\mathrm{p} K_{\mathrm{a}}$ value, and the other acid

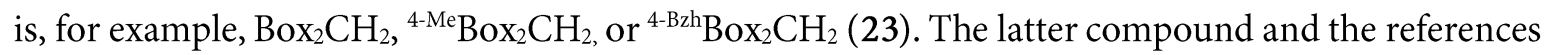
are separately titrated in order to obtain the UV/Vis spectra of the free acids and their deprotonated forms. Subsequently, the same titration is done with a mixture of the compound ${ }^{4-R}{ }^{-} \mathrm{Box}_{2} \mathrm{CH}_{2}, \mathrm{R}=\mathrm{H}$, $\mathrm{Me}, \mathrm{Bzh})$ ) and a reference acid in the same solution. After mathematically treating the spectral data obtained from the titration of the mixture at multiple wavelengths using multilinear regression analysis, the dissociation levels $(\alpha)$ of both acids in all the mixtures formed during titration are calculated. They are then in turn used to calculate the differences of $\mathrm{p} K_{\mathrm{a}}$ values $\left(\Delta \mathrm{p} K_{\mathrm{a}}\right)$ of ${ }^{4-R} \mathrm{Box}_{2} \mathrm{CH}_{2}$ and the used reference acids according to the following equation:

$$
\Delta \mathrm{p} K_{a}=\log \frac{\alpha_{1}\left(1-\alpha_{2}\right)}{\alpha_{2}\left(1-\alpha_{1}\right)}
$$

The $\mathrm{p} K_{\mathrm{a}}$ value of ${ }^{4-R} \mathrm{Box}_{2} \mathrm{CH}_{2}$ in acetonitrile is estimated as a result of $\Delta \mathrm{p} K_{\mathrm{a}}$ measurements against four different reference acids with previously published $\mathrm{p} K_{\mathrm{a}}$ values in the literature. ${ }^{[3,113]} \mathrm{All} \mathrm{p} K_{\mathrm{a}}$ determination results are presented in Table 5-42.

Table 5-42. $\mathrm{p} K_{\mathrm{a}}$ measurements results in acetonitrile.

\begin{tabular}{|c|c|c|c|c|c|}
\hline Acid & Reference Acid & $\mathrm{p} K_{\mathrm{a}}($ Ref) & $\Delta \mathrm{p} K_{\mathrm{a}}$ & $\overline{\mathrm{p}} K_{\mathrm{a}}$ (Acid) & Assigned $\mathrm{p} K_{\mathrm{a}}$ \\
\hline \multirow{4}{*}{$\mathrm{Box}_{2} \mathrm{CH}_{2}$} & 9- $\mathrm{C}_{6} \mathrm{~F}_{5}$-fluorene & 28.14 & 1.20 & 26.94 & \multirow{4}{*}{$26.89(6)$} \\
\hline & $\left(4-\mathrm{Me}-\mathrm{C}_{6} \mathrm{~F}_{4}\right)\left(\mathrm{C}_{6} \mathrm{H}_{5}\right) \mathrm{CHCN}$ & 26.98 & 0.41 & 26.84 & \\
\hline & $\mathrm{C}_{6} \mathrm{~F}_{5}-\mathrm{NHCOCH}_{3}$ & 26.45 & -0.14 & 26.86 & \\
\hline & $\left(\mathrm{C}_{6} \mathrm{H}_{5}\right)\left(\mathrm{C}_{6} \mathrm{~F}_{5}\right) \mathrm{CHCN}$ & 26.14 & -0.72 & 26.86 & \\
\hline \multirow{4}{*}{ 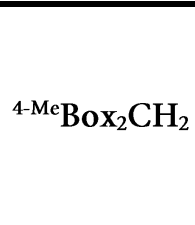 } & 9- $\mathrm{C}_{6} \mathrm{~F}_{5}$-fluorene & 28.14 & -0.58 & 27.56 & \multirow{4}{*}{$27.59(6)$} \\
\hline & $\left(4-\mathrm{Me}-\mathrm{C}_{6} \mathrm{~F}_{4}\right)\left(\mathrm{C}_{6} \mathrm{H}_{5}\right) \mathrm{CHCN}$ & 26.98 & 0.64 & 27.62 & \\
\hline & $\mathrm{C}_{6} \mathrm{~F}_{5}-\mathrm{NHCOCH}_{3}$ & 26.45 & 1.21 & 27.66 & \\
\hline & $4-\mathrm{CN}-\mathrm{C}_{6} \mathrm{~F}_{4}-\mathrm{NH}_{2}$ & 28.78 & -1.14 & 27.64 & \\
\hline \multirow{4}{*}{$\begin{array}{c}{ }^{4-\mathrm{Bzh}} \mathrm{Box}_{2} \mathrm{CH}_{2} \\
\text { (23) }\end{array}$} & $4-\mathrm{CN}-\mathrm{C}_{6} \mathrm{~F}_{4}-\mathrm{NH}_{2}$ & 28.76 & 2.20 & 26.56 & \multirow{4}{*}{$26.59(6)$} \\
\hline & $\left(4-\mathrm{Me}-\mathrm{C}_{6} \mathrm{~F}_{4}\right)\left(\mathrm{C}_{6} \mathrm{H}_{5}\right) \mathrm{CHCN}$ & 26.96 & 0.40 & 26.56 & \\
\hline & $\mathrm{C}_{6} \mathrm{~F}_{5}-\mathrm{NHCOCH}_{3}$ & 26.43 & -0.17 & 26.60 & \\
\hline & $\left(\mathrm{C}_{6} \mathrm{H}_{5}\right)\left(\mathrm{C}_{6} \mathrm{~F}_{5}\right) \mathrm{CHCN}$ & 26.14 & -0.50 & 26.64 & \\
\hline
\end{tabular}


An AGILENT Cary 60 spectrophotometer connected with optical fibre cables to an external cell compartment inside a MBRAUN Unilab glovebox filled with $99.999 \%$ pure argon was used for the spectrophotometric titrations. This setup ensured that during all titrations the moisture and oxygen contents in the argon atmosphere inside the glovebox were always under $10 \mathrm{ppm}$.

Trifluoromethanesulfonic acid (ALDRICH, 99+\%) and tert-butylimino-tris(pyrrolidino)phosphorane (ALDRICH, $\geq 97 \%$ ) were used to prepare the acidic and basic titrant solutions, respectively. For the titration involving 4-CN-C $\mathrm{C}_{4}-\mathrm{NH}_{2}$, a stronger Phosphazene base $\mathrm{P}_{2}$-Et (CAS number 165535-45-5, ALDRICH, 98\%) was used as the basic titrant. The concentrations of the titrant solutions were in the range of $1-4 \cdot 10^{-3} \mathrm{~mol} \cdot \mathrm{L}^{-1}$ and the concentrations of the studied and reference acids were between $0.6-9 \cdot 10^{-5} \mathrm{~mol} \cdot \mathrm{L}^{-1}$ during the titrations. Acetonitrile (ROMIL $190 \mathrm{SpS}$ far UV/gradient quality) was used as solvent after drying with molecular sieves ( $3 \AA$ ) for at least $12 \mathrm{~h}$, which lowered the water content to under $6 \mathrm{ppm}$. 


\subsection{Differential Scanning Calorimetry (DSC)}

Differential scanning calorimetry (DSC) was performed on a Netzsch DSC 214 DSC21400A-0867-L under a nitrogen atmosphere in cooperation with Dr. Judith Rauschendorfer.

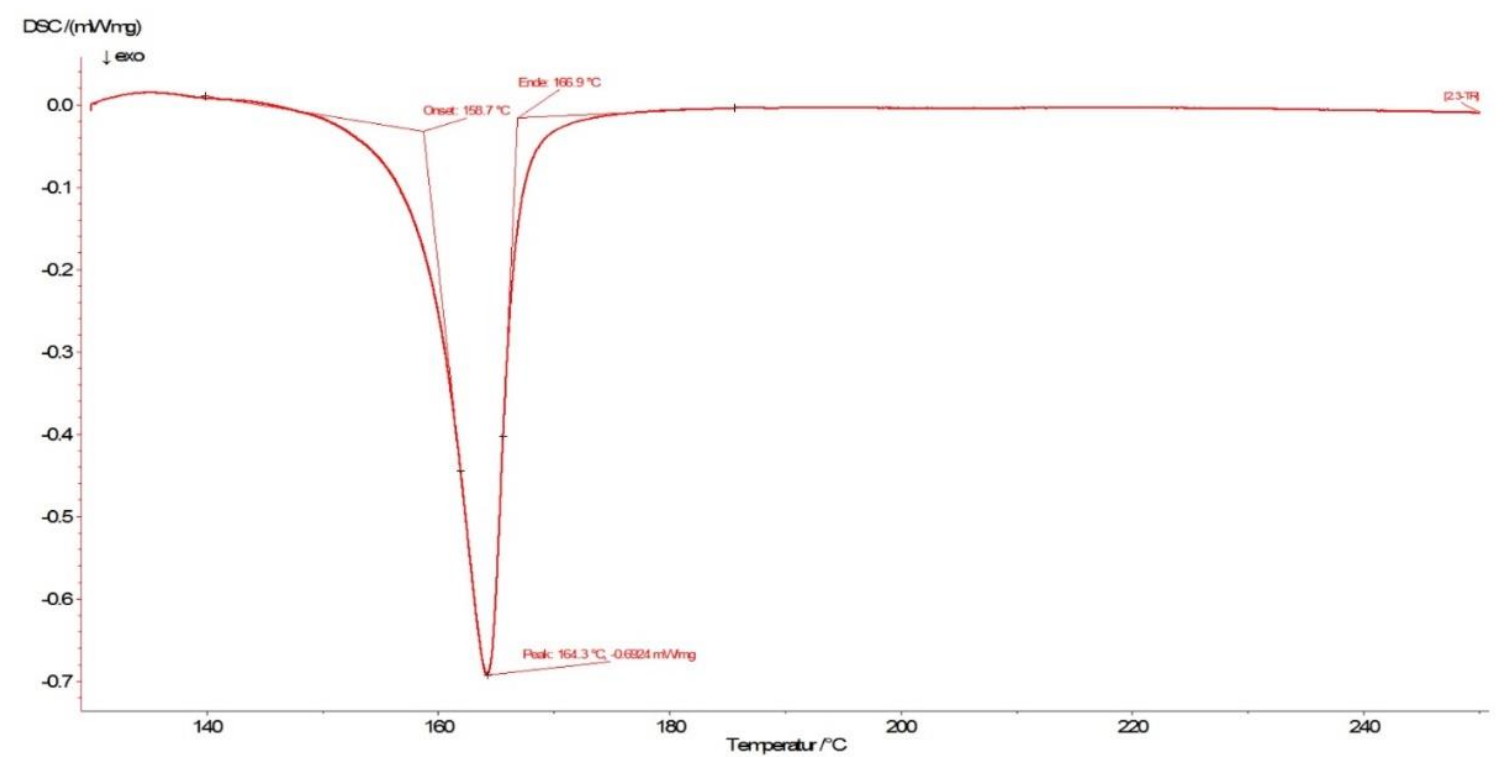

Figure 5-57. Differential scanning calorimetry (DSC) plot of crystalline $\left[\mathrm{AlH}_{2}\left({ }^{4-\mathrm{Me}} \mathrm{Box}_{2} \mathrm{CH}\right)\right] 12\left(25-130^{\circ} \mathrm{C}\right.$ $\left.(10.0 \mathrm{~K} / \mathrm{min}) ; 130-250^{\circ} \mathrm{C}(0,5 \mathrm{~K} / \mathrm{min})\right)$. Decomposition of alane 12 was detected at $\geq 158^{\circ} \mathrm{C}$.

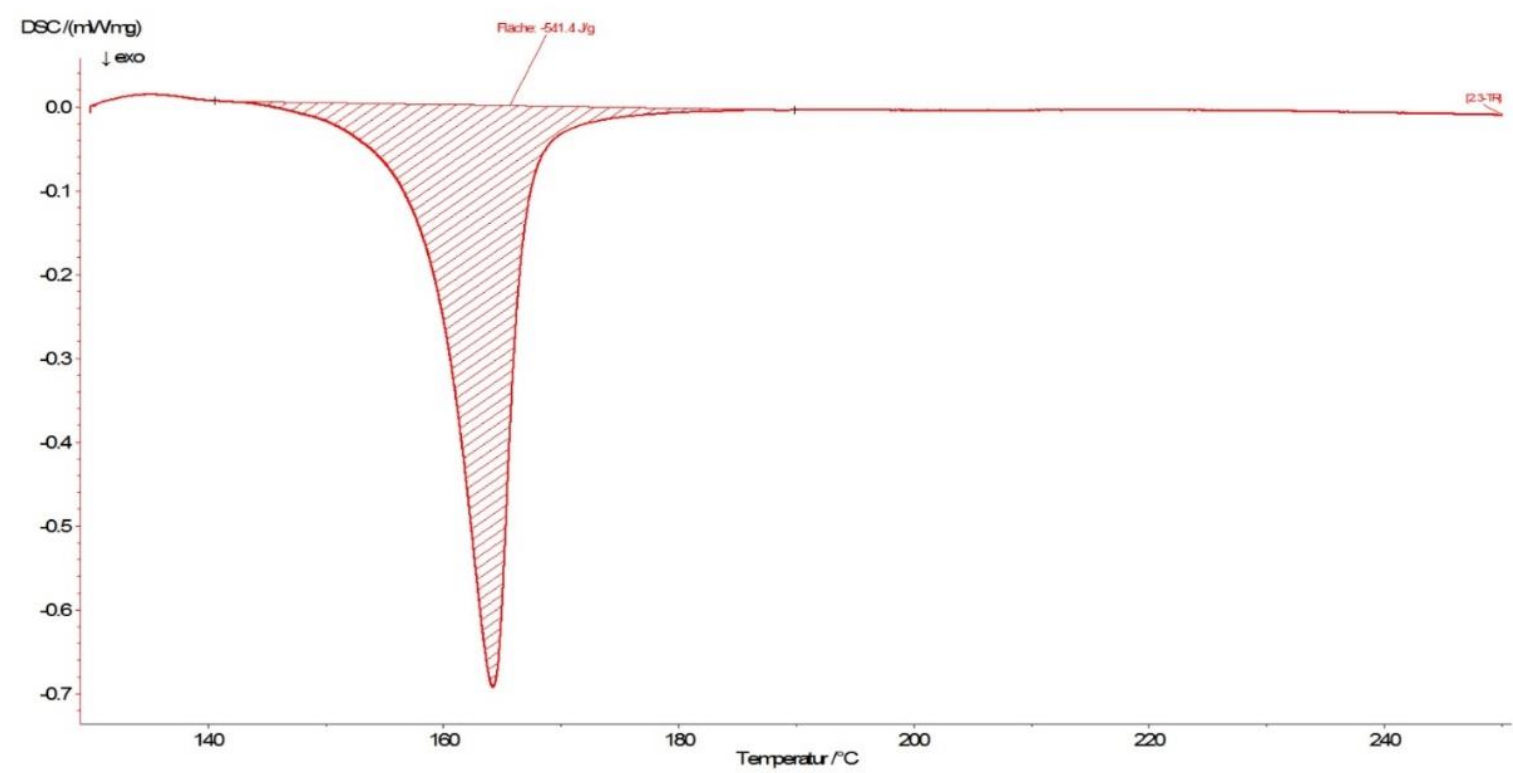

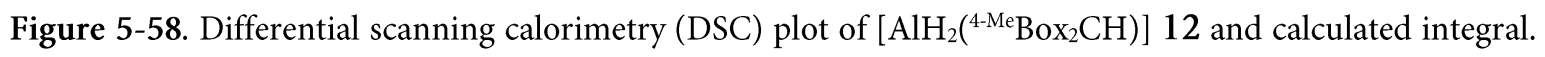
Determined enthalpy of about $\Delta H_{\text {dec }}=-166 \mathrm{~kJ} / \mathrm{mol}$. 


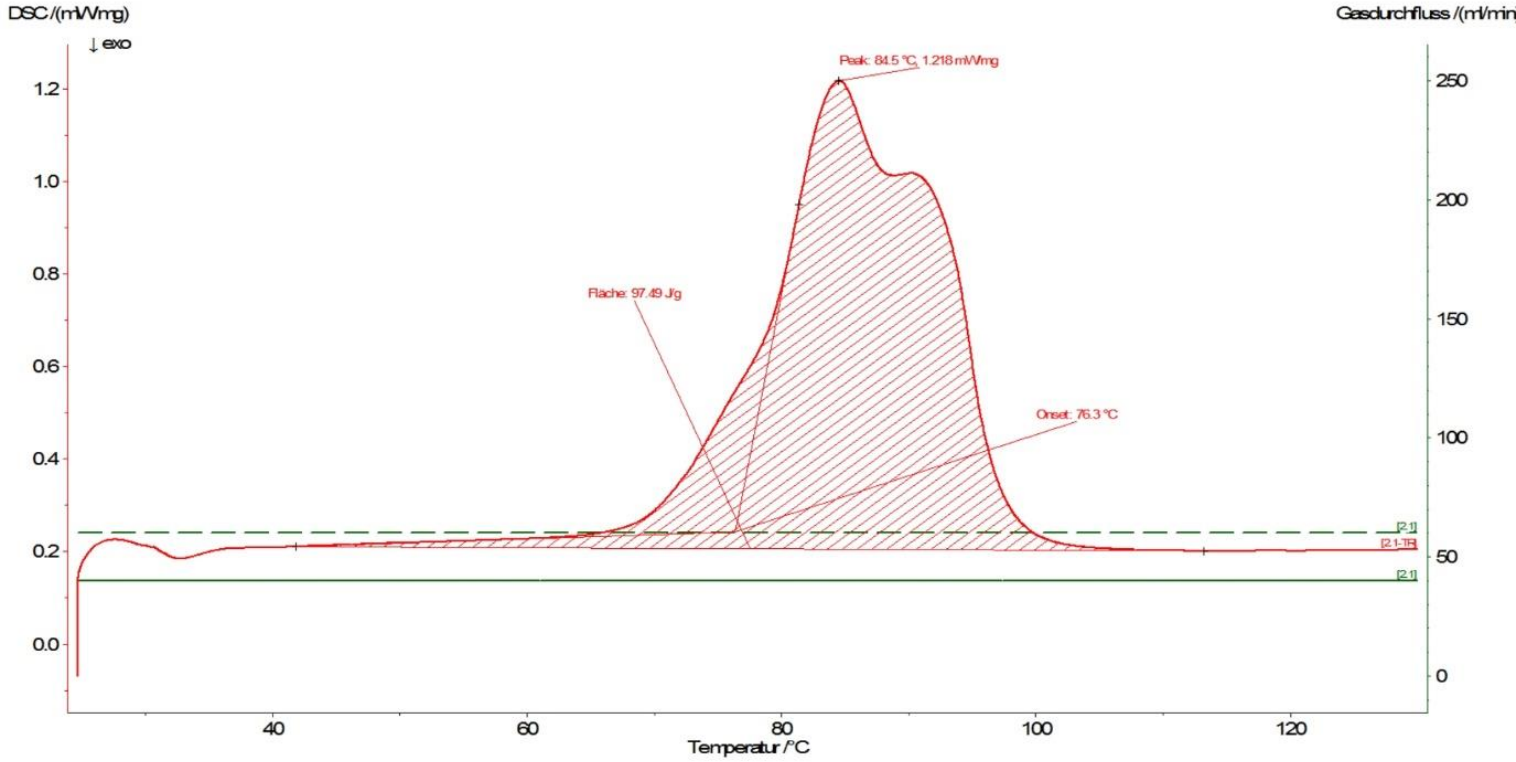

Figure 5-59. DSC curve $\left(25-130^{\circ} \mathrm{C}(10.0 \mathrm{~K} / \mathrm{min})\right)$ of crystalline $\left[\mathrm{AlH}_{2}\left({ }^{4-\mathrm{BrhH}^{2}} \mathrm{Box}_{2} \mathrm{CH}\right)\right] 38$ showing the evaporation of co-crystallized fluorobenzene at $\geq 76^{\circ} \mathrm{C}$.

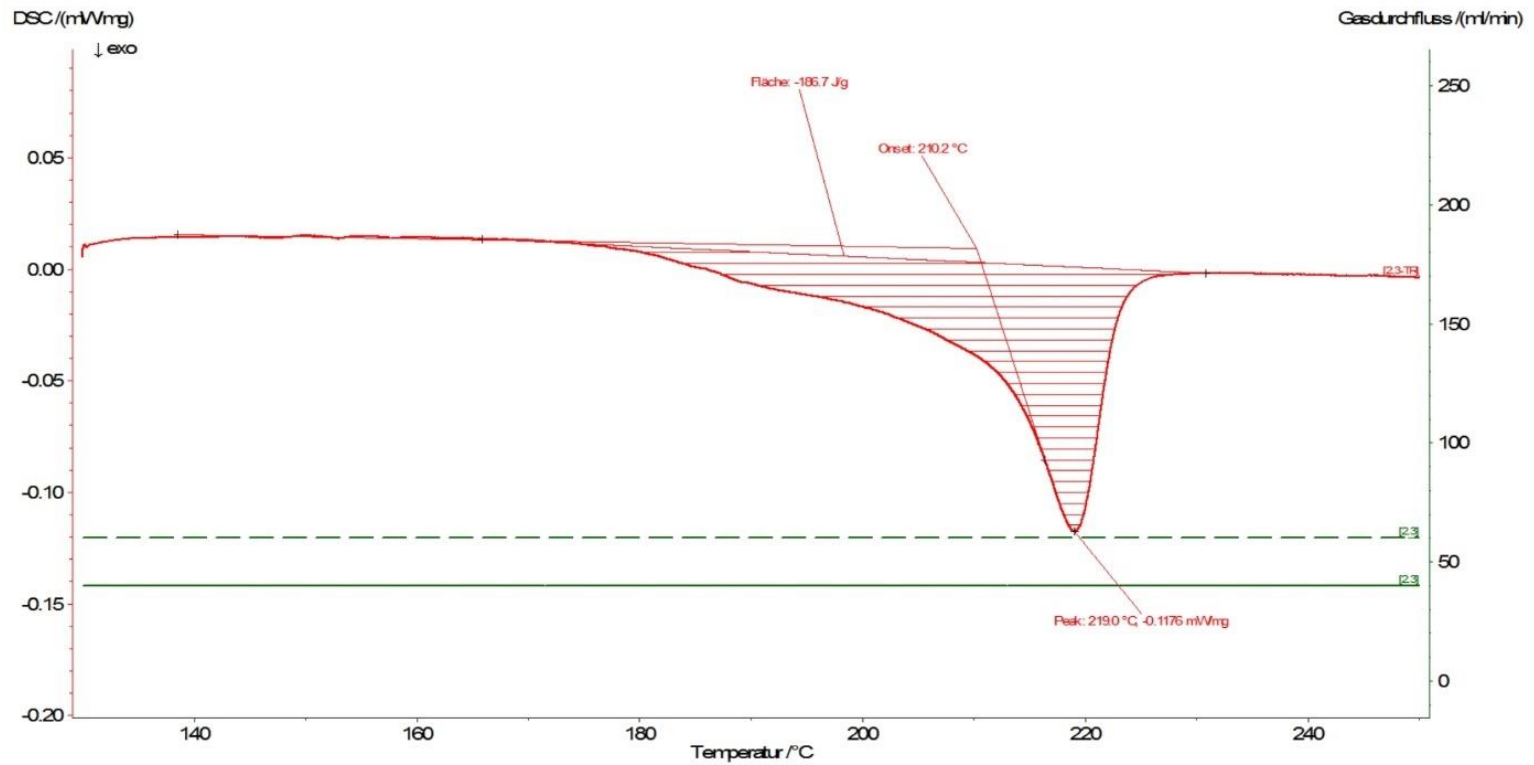

Figure 5-60. DSC curve $\left(130-250^{\circ} \mathrm{C}(0.5 \mathrm{~K} / \mathrm{min})\right)$ of crystalline $\left[\mathrm{AlH}_{2}\left({ }^{4-\mathrm{BhhH}^{2}} \mathrm{Box}_{2} \mathrm{CH}\right)\right] 38$ displaying its decomposition at $\geq 210^{\circ} \mathrm{C}$. 


\subsection{Monoanionic $(E, E)-,(Z, E / E, Z)-$ or $(E, E)-\left({ }^{4-\mathrm{Bzh}^{-}} \mathrm{Box}_{2} \mathrm{CH}\right)$ isomers of 28a-i}

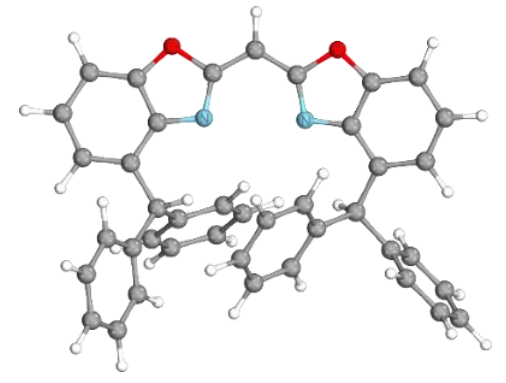

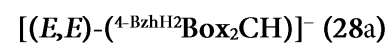

$\left(\mathrm{G}=-1838.81947112 E_{\mathrm{h}}\right)$

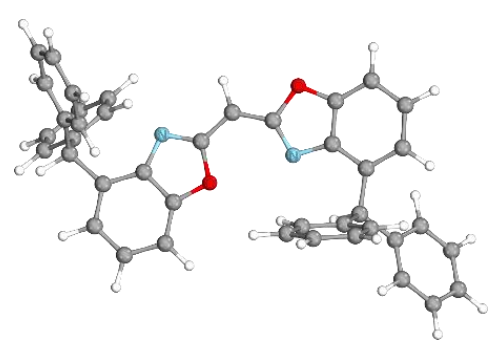

$\left[(Z, E)-\left({ }^{4-B_{2 h H}} \mathrm{Box}_{2} \mathrm{CH}\right)\right]^{-}$(28d)

$\left(\mathrm{G}=-1838.81572179 E_{\mathrm{h}}\right)$

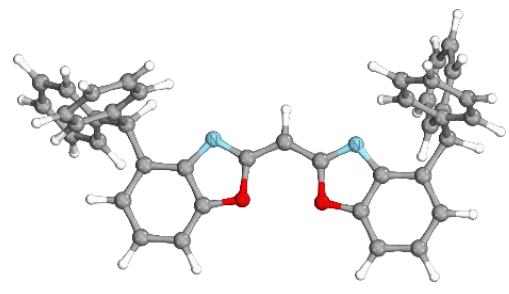

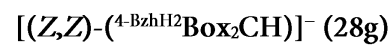

$\left(\mathrm{G}=-1838.81589933 E_{\mathrm{h}}\right)$

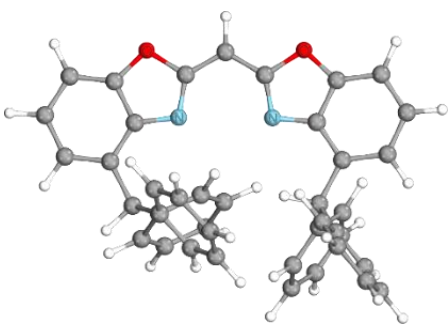

$\left[(E, E)-\left({ }^{4-\mathrm{BrhH}^{2}} \mathrm{Box}_{2} \mathrm{CH}\right)\right]^{-}(\mathbf{2 8 b})$

$\left(\mathrm{G}=-1838.82344912 E_{\mathrm{h}}\right)$

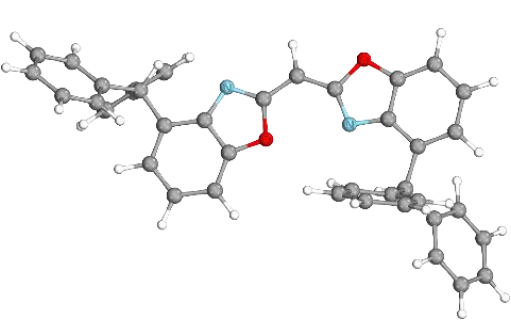

$\left[(Z, E)-\left({ }^{4-\mathrm{BzhH}^{2}} \mathrm{Box}_{2} \mathrm{CH}\right)\right]^{-}(\mathbf{2 8 e})$

$\left(\mathrm{G}=-1838.81481865 E_{\mathrm{h}}\right)$

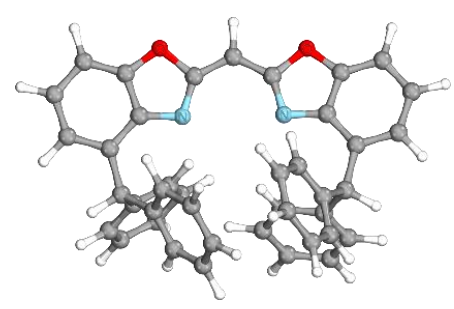

$\left[(E, E)-\left({ }^{4-\mathrm{BrhH}^{2}} \mathrm{Box}_{2} \mathrm{CH}\right)\right]^{-}(\mathbf{2 8 c})$

$\left(\mathrm{G}=-1838.80202399 E_{\mathrm{h}}\right)$

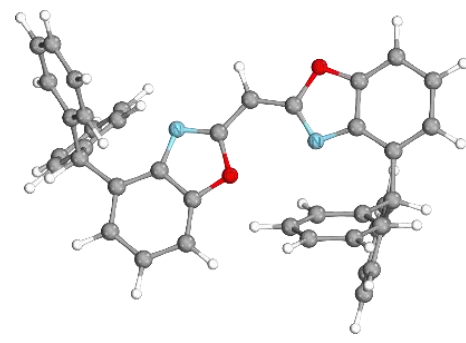

$\left[(Z, E)-\left({ }^{\left(4-\mathrm{BhH}^{2}\right.} \mathrm{Box}_{2} \mathrm{CH}\right)\right]^{-}(\mathbf{2 8 f})$

$\left(\mathrm{G}=-1838.81659250 E_{\mathrm{h}}\right)$

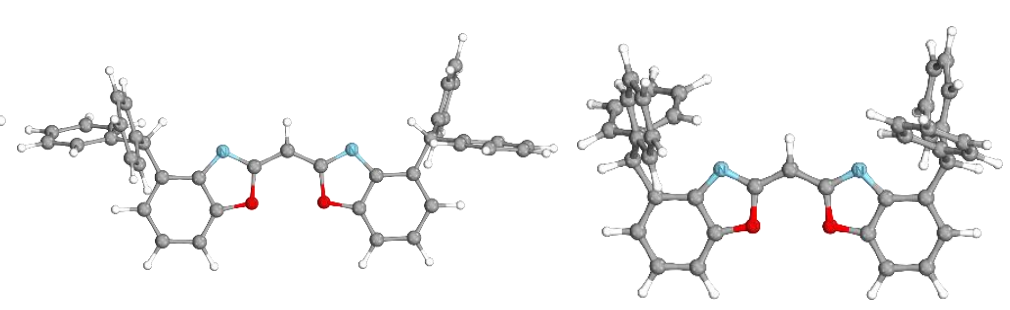

$\left[(Z, Z)-\left(4-\mathrm{BhhH}^{2} \mathrm{Box}_{2} \mathrm{CH}\right)\right]^{-}(\mathbf{2 8 h})$

$\left(\mathrm{G}=-1838.81756699 E_{\mathrm{h}}\right)$
$\left[(Z, Z)-\left({ }^{4-\mathrm{BzhH}^{2}} \mathrm{Box}_{2} \mathrm{CH}\right)\right]^{-}(\mathbf{2 8 i})$

$\left(\mathrm{G}=-1838.81127688 E_{\mathrm{h}}\right)$ 


\section{REFERENCES}

[1] J. Kretsch, A. Kreyenschmidt, R. Herbst-Irmer, D. Stalke, Dalton Trans. 2018, 47, 12606-12612.

[2] J. Kretsch, R. Herbst-Irmer, D. Stalke, Z. Anorg. Allg. Chem. 2018, 644, 657-660.

[3] J. Kretsch, I. Koehne, M. Lõkov, I. Leito, D. Stalke, Eur. J. Inorg. Chem. 2019, 2019, 3258-3264.

[4] J. Kretsch, A. Kreyenschmidt, T. Schillmöller, R. Herbst-Irmer, D. Stalke, Inorg. Chem. 2020, 59, 13690-13699.

[5] J. Kretsch, A.-K. Kreyenschmidt, T. Schillmöller, M. Lõkov, R. Herbst-Irmer, I. Leito, D. Stalke, Chem. Eur. J. 2021, 27, 9858-9865.

[6] J. Kretsch, A. Kreyenschmidt, T. Schillmöller, C. Sindlinger, R. Herbst-Irmer, D. Stalke, Inorg. Chem. 2021, 60, 7389-7398.

[7] N. N. Greenwood, A. Earnshaw, Chemistry of the elements; Butterworth-Heinemann, Oxford, 1997.

[8] E. Wiberg, A. F. Holleman, Lehrbuch der Anorganischen Chemie; De Gruyter, Inc, Berlin/Boston, 2019.

[9] G. E. Totten, Ed, Handbook of aluminum: Volume 2: Alloy Production and Materials Manufacturing; Dekker, New York, 2003.

[10] International Aluminium Institute, "World Aluminium Statistics", to be found under http://www.world-aluminium.org/statistics/, (09.06.2021).

[11] BP, Statistical Review of World Energy: $2020 \mid 6^{\text {th }}$ edition, 2020.

[12] a) H. Hoberg, S. Krause, Angew. Chem. Int. Ed. 1976, 15, 694; b) H. Hoberg, S. Krause, Angew. Chem. Int. Ed. 1978, 17, 949-950; c) W. Uhl, A. Vester, Chem. Ber. 1993, 126, 941-945; d) M. Mocker, C. Robl, H. Schnöckel, Angew. Chem. Int. Ed. 1994, 33, 862-863.

[13] a) C. Dohmeier, C. Robl, M. Tacke, H. Schnöckel, Angew. Chem. Int. Ed. 1991, 30, 564-565; b) W. Uhl, Angew. Chem. Int. Ed. 1993, 32, 1386-1397; c) W. Uhl, Angew. Chem. Int. Ed. 1993, 32, 1386-1397; d) C. Dohmeier, D. Loos, H. Schnöckel, Angew. Chem. Int. Ed. 1996, 35, 129149; e) P. Bag, C. Weetman, S. Inoue, Angew. Chem. Int. Ed. 2018, 57, 14394-14413.

[14] a) C. Cui, H. W. Roesky, H.-G. Schmidt, M. Noltemeyer, H. Hao, F. Cimpoesu, Angew. Chem. Int. Ed. 2000, 39, 4274-4276; b) X. Li, X. Cheng, H. Song, C. Cui, Organometallics 2007, 26, 1039-1043; c) J. D. Queen, A. Lehmann, J. C. Fettinger, H. M. Tuononen, P. P. Power, J. Am. Chem. Soc. 2020, 142, 20554-20559.

[15] a) N. Wiberg, K. Amelunxen, T. Blank, H. Nöth, J. Knizek, Organometallics 1998, 17, 54315433; b) N. Wiberg, T. Blank, W. Kaim, B. Schwederski, G. Linti, Chem. Ber. 2000, 2000, 14751481; c) R. J. Wright, A. D. Phillips, P. P. Power, J. Am. Chem. Soc. 2003, 125, 10784-10785; d) R. J. Wright, M. Brynda, P. P. Power, Angew. Chem. Int. Ed. 2006, 45, 5953-5956; e) T. Agou, K. Nagata, H. Sakai, Y. Furukawa, N. Tokitoh, Organometallics 2012, 31, 3806-3809; f) X. Li, J. Sun, Y. Zeng, Z. Sun, S. Zheng, L. Meng, J. Phys. Chem. A 2012, 116, 5491-5496; g) T. Agou, K. Nagata, N. Tokitoh, Angew. Chem. Int. Ed. 2013, 52, 10818-10821; h) P. Bag, A. Porzelt, P. J. 
Altmann, S. Inoue, J. Am. Chem. Soc. 2017, 139, 14384-14387; i) C. Weetman, P. Bag, T. Szilvási, C. Jandl, S. Inoue, Angew. Chem. Int. Ed. 2019, 58, 10961-10965.

[16] a) J. Hicks, P. Vasko, J. M. Goicoechea, S. Aldridge, Nature 2018, 557, 92-95; b) J. Hicks, P. Vasko, J. M. Goicoechea, S. Aldridge, J. Am. Chem. Soc. 2019, 141, 11000-11003; c) R. J. Schwamm, M. D. Anker, M. Lein, M. P. Coles, Angew. Chem. Int. Ed. 2019, 58, 1489-1493; d) R. J. Schwamm, M. P. Coles, M. S. Hill, M. F. Mahon, C. L. McMullin, N. A. Rajabi, A. S. S. Wilson, Angew. Chem. Int. Ed. 2020, 59, 3928-3932; e) S. Kurumada, S. Takamori, M. Yamashita, Nat. Chem. 2020, 12, 36-39; f) K. Koshino, R. Kinjo, J. Am. Chem. Soc. 2020, 142, 9057-9062; g) J. Hicks, P. Vasko, J. M. Goicoechea, S. Aldridge, Angew. Chem. Int. Ed. 2021, $60,1702-1713$.

[17] a) N. J. Hardman, A. D. Phillips, P. P. Power in Group 13 chemistry. From fundamentals to applications, ACS Symposium Series, Vol. 822; American Chemical Society, Washington, DC, 2002. b) M. Reiher, A. Sundermann, Chem. Ber. 2002, 2002, 1854-1863; c) M. S. Hill, P. B. Hitchcock, R. Pongtavornpinyo, Dalton Trans. 2005, 273-277. d) C.-H. Chen, M.-L. Tsai, M.D. Su, Organometallics 2006, 25, 2766-2773.

[18] M. Asay, C. Jones, M. Driess, Chem. Rev. 2011, 111, 354-396.

[19] R. Y. Kong, M. R. Crimmin, J. Am. Chem. Soc. 2018, 140, 13614-13617.

[20] C. Bakewell, A. J. P. White, M. R. Crimmin, Angew. Chem. Int. Ed. 2018, 57, 6638-6642.

[21] M. Zhong, S. Sinhababu, H. W. Roesky, Dalton Trans. 2020, 49, 1351-1364.

[22] T. Chu, Y. Boyko, I. Korobkov, G. I. Nikonov, Organometallics 2015, 34, 5363-5365.

[23] M. R. Crimmin, M. J. Butler, A. J. P. White, Chem. Commun. 2015, 51, 15994-15996.

[24] T. Chu, Y. Boyko, I. Korobkov, L. G. Kuzmina, J. A. K. Howard, G. I. Nikonov, Inorg. Chem. 2016, 55, 9099-9104.

[25] L. Kong, R. Ganguly, Y. Li, R. Kinjo, Chem. Eur. J. 2016, 22, 1922-1925.

[26] T. Chu, S. F. Vyboishchikov, B. M. Gabidullin, G. I. Nikonov, Inorg. Chem. 2017, 56, 59935997.

[27] A. Dmitrienko, J. F. Britten, D. Spasyuk, G. I. Nikonov, Chem. Eur. J. 2020, 26, 206-211.

[28] T. Chu, S. F. Vyboishchikov, B. Gabidullin, G. I. Nikonov, Angew. Chem. Int. Ed. 2016, 55, 13306-13311.

[29] T. Chu, S. F. Vyboishchikov, B. M. Gabidullin, G. I. Nikonov, J. Am. Chem. Soc. 2017, 139, 8804-8807.

[30] L. L. Liu, J. Zhou, L. L. Cao, D. W. Stephan, J. Am. Chem. Soc. 2019, 141, 16971-16982.

[31] Z. Yang, X. Ma, R. B. Oswald, H. W. Roesky, H. Zhu, C. Schulzke, K. Starke, M. Baldus, H.-G. Schmidt, M. Noltemeyer, Angew. Chem. Int. Ed. 2005, 44, 7072-7074.

[32] a) A. Kempter, C. Gemel, R. A. Fischer, Chem. Commun. 2006, 1551-1553; b) A. Kempter, C. Gemel, R. A. Fischer, Chem. Eur. J. 2007, 13, 2990-3000.

[33] A. Paparo, C. D. Smith, C. Jones, Angew. Chem. Int. Ed. 2019, 58, 11459-11463.

[34] S. Brand, H. Elsen, J. Langer, W. A. Donaubauer, F. Hampel, S. Harder, Angew. Chem. Int. Ed. 2018, 57, 14169-14173. 
[35] B. Li, S. Kundu, H. Zhu, H. Keil, R. Herbst-Irmer, D. Stalke, G. Frenking, D. M. Andrada, H. W. Roesky, Chem. Commun. 2017, 53, 2543-2546.

[36] W. Uhl, Z. Naturforsch. B 1988, 43, 1113-1118.

[37] a) C. Schnitter, H. W. Roesky, C. Röpken, R. Herbst-Irmer, H.-G. Schmidt, M. Noltemeyer, Angew. Chem. Int. Ed. 1998, 37, 1952-1955; b) A. Purath, C. Dohmeier, A. Ecker, H. Schnöckel, K. Amelunxen, T. Passler, N. Wiberg, Organometallics 1998, 17, 1894-1896; c) A. Purath, H. Schnöckel, J. Organomet. Chem. 1999, 579, 373-375; d) M. Schiefer, N. D. Reddy, H. W. Roesky, D. Vidovic, Organometallics 2003, 22, 3637-3638; e) C. Ganesamoorthy, S. Loerke, C. Gemel, P. Jerabek, M. Winter, G. Frenking, R. A. Fischer, Chem. Commun. 2013, 49, 2858-2860.

[38] a) R. J. Wehmschulte, K. Ruhlandt-Senge, M. M. Olmstead, H. Hope, B. E. Sturgeon, P. P. Power, Inorg. Chem. 1993, 32, 2983-2984; b) K. S. Klimek, C. Cui, H. W. Roesky, M. Noltemeyer, H.G. Schmidt, Organometallics 2000, 19, 3085-3090.

[39] C. Klemp, C. Üffing, E. Baum, H. Schnöckel, Z. Anorg. Allg. Chem. 2000, 626, 1787-1791.

[40] a) J. D. Gorden, C. L. B. Macdonald, A. H. Cowley, Chem. Commun. 2001, 75-76; b) A. Y. Timoshkin, G. Frenking, J. Am. Chem. Soc. 2002, 124, 7240-7248.

[41] a) S. Nagendran, H. W. Roesky, Organometallics 2008, 27, 457-492; b) K. R. Compaan, J. J. Wilke, H. F. Schaefer, J. Am. Chem. Soc. 2011, 133, 13387-13396.

[42] a) S. P. Green, C. Jones, A. Stasch, Science 2007, 318, 1754-1757; b) S. J. Bonyhady, D. Collis, G. Frenking, N. Holzmann, C. Jones, A. Stasch, Nat. Chem. 2010, 2, 865-869.

[43] S. J. Bonyhady, N. Holzmann, G. Frenking, A. Stasch, C. Jones, Angew. Chem. Int. Ed. 2016, 56, 8527-8531.

[44] S. J. Bonyhady, D. Collis, N. Holzmann, A. J. Edwards, R. O. Piltz, G. Frenking, A. Stasch, C. Jones, Nat. Commun. 2018, 9, 1-6.

[45] C. Pluta, K.-R. Pörschke, C. Krüger, K. Hildenbrand, Angew. Chem. Int. Ed. 1993, 32, 388-390.

[46] J. Hicks, A. Heilmann, P. Vasko, J. M. Goicoechea, S. Aldridge, Angew. Chem. Int. Ed. 2019, 58, $17265-17268$.

[47] A. Hofmann, C. Pranckevicius, T. Tröster, H. Braunschweig, Angew. Chem. Int. Ed. 2019, 58, 3625-3629.

[48] S. K. Mellerup, Y. Cui, F. Fantuzzi, P. Schmid, J. T. Goettel, G. Bélanger-Chabot, M. Arrowsmith, I. Krummenacher, Q. Ye, V. Engel, B. Engels, H. Braunschweig, J. Am. Chem. Soc. 2019, 141, 16954-16960.

[49] a) D. Loos, H. Schnöckel, J. Gauss, U. Schneider, Angew. Chem. Int. Ed. 1992, 31, 1362-1364; b) D. Loos, H. Schnöckel, J. Organomet. Chem. 1993, 463, 37-40; c) G. Linti, H. Schnöckel, Coord. Chem. Rev. 2000, 206-207, 285-319; d) A. J. Downs, S. Aldridge, The chemistry of the group 13 metals Aluminium, Gallium, Indium, and Thallium: Chemical patterns and peculiarities; Wiley, Hoboken, N.J, 2011.

[50] M. L.H. Green, P. Mountford, G. J. Smout, S.R. Speel, Polyhedron 1990, 9, 2763-2765.

[51] R. J. Baker, C. Jones, Dalton Trans. 2005, 1341-1348. 
[52] a) C. Jones, P. C. Junk, J. A. Platts, A. Stasch, J. Am. Chem. Soc. 2006, 128, 2206-2207; b) J. Overgaard, C. Jones, D. Dange, J. A. Platts, Inorg. Chem. 2011, 50, 8418-8426; c) A. L. Hawley, C. A. Ohlin, L. Fohlmeister, A. Stasch, Chem. Eur. J. 2017, 23, 447-455.

[53] a) G. Linti, T. Zessin, Dalton Trans. 2011, 40, 5591-5598; b) T. Zessin, J. Anton, G. Linti, Z. Anorg. Allg. Chem. 2013, 639, 2224-2232.

[54] D. Dange, S. L. Choong, C. Schenk, A. Stasch, C. Jones, Dalton Trans. 2012, 41, 9304-9315.

[55] N. J. Hardman, B. E. Eichler, P. P. Power, Chem. Commun. 2000, 1991-1992.

[56] C. P. Sindlinger, S. R. Lawrence, S. Acharya, C. A. Ohlin, A. Stasch, Dalton Trans. 2017, 46, 16872-16877.

[57] M. Asay, S. Inoue, M. Driess, Angew. Chem, Int. Ed. 2011, 50, 9589-9592.

[58] a) N. J. Hardman, P. P. Power, J. D. Gorden, C. L. Macdonald, A. H. Cowley, Chem. Commun. 2001, 1866-1867; b) N. J. Hardman, R. J. Wright, A. D. Phillips, P. P. Power, J. Am. Chem. Soc. 2003, 125, 2667-2679.

[59] N. J. Hardman, C. Cui, H. W. Roesky, W. H. Fink, P. P. Power, Angew. Chem. Int. Ed. 2001, 40, 2172-2174.

[60] G. Prabusankar, C. Gemel, P. Parameswaran, C. Flener, G. Frenking, R. A. Fischer, Angew. Chem. Int. Ed. 2009, 48, 5526-5529.

[61] a) L. Tuscher, C. Ganesamoorthy, D. Bläser, C. Wölper, S. Schulz, Angew. Chem. Int. Ed. 2015, 54, 10657-10661; b) L. Tuscher, C. Helling, C. Ganesamoorthy, J. Krüger, C. Wölper, W. Frank, A. S. Nizovtsev, S. Schulz, Chem. Eur. J. 2017, 23, 12297-12304.

[62] C. Ganesamoorthy, D. Bläser, C. Wölper, S. Schulz, Angew. Chem. Int. Ed. 2014, 53, 1158711591.

[63] C. Ganesamoorthy, C. Helling, C. Wölper, W. Frank, E. Bill, G. E. Cutsail, S. Schulz, Nat. Commun. 2018, 9, 1-8.

[64] T. Bollermann, G. Prabusankar, C. Gemel, R. W. Seidel, M. Winter, R. A. Fischer, Chem. Eur. J. 2010, 16, 8846-8853.

[65] U. Chakraborty, B. Mühldorf, N. J. C. van Velzen, B. d. Bruin, S. Harder, R. Wolf, Inorg. Chem. 2016, 55, 3075-3078.

[66] A. Seifert, D. Scheid, G. Linti, T. Zessin, Chem. Eur. J. 2009, 15, 12114-12120.

[67] A. Kassymbek, S. F. Vyboishchikov, B. M. Gabidullin, D. Spasyuk, M. Pilkington, G. I. Nikonov, Angew. Chem. Int. Ed. 2019, 58, 18102-18107.

[68] O. Kysliak, H. Görls, R. Kretschmer, J. Am. Chem. Soc. 2021, 143, 142-148.

[69] N. Saito, J. Takaya, N. Iwasawa, Angew. Chem. Int. Ed. 2019, 58, 9998-10002.

[70] a) C. Peppe, D. G. Tuck, L. Victoriano, J. Chem. Soc, Dalton Trans. 1982, 2165; b) D. G. Tuck, Chem. Soc. Rev. 1993, 22, 269; c) R. J. Wright, A. D. Phillips, N. J. Hardman, P. P. Power, J. Am. Chem. Soc. 2002, 124, 8538-8539; d) S. P. Green, C. Jones, A. Stasch, Angew. Chem. Int. Ed. 2007, 46, 8618-8621; e) S. P. Green, C. Jones, A. Stasch, Chem. Commun. 2008, 6285-6287.

[71] a) C. L. B. Macdonald, A. M. Corrente, C. G. Andrews, A. Taylor, B. D. Ellis, Chem. Commun. 2004, 250-251; b) Z. Mazej, Chem. Ber. 2005, 2005, 3983-3987; c) C. G. Andrews, C. L. B. 
Macdonald, Angew. Chem. Int. Ed. 2005, 44, 7453-7456; d) B. F.T. Cooper, C. L.B. Macdonald, J. Organomet. Chem. 2008, 693, 1707-1711.

[72] M. S. Hill, P. B. Hitchcock, Chem. Commun. 2004, 1818-1819.

[73] a) M. S. Hill, P. B. Hitchcock, R. Pongtavornpinyo, Angew. Chem. Int. Ed. 2005, 44, 4231-4235;

b) M. S. Hill, P. B. Hitchcock, R. Pongtavornpinyo, Dalton Trans. 2007, 731-733.

[74] M. S. Hill, P. B. Hitchcock, R. Pongtavornpinyo, Science 2006, 311, 1904-1907.

[75] W. W. Schoeller, Inorg. Chem. 2011, 50, 2629-2633.

[76] M. S. Hill, P. B. Hitchcock, R. Pongtavornpinyo, Dalton Trans. 2008, 2854-2860.

[77] M. S. Hill, P. B. Hitchcock, R. Pongtavornpinyo, Inorg. Chem. 2007, 46, 3783-3788.

[78] M. E. Desat, S. Gärtner, R. Kretschmer, Chem. Commun. 2017, 53, 1510-1513.

[79] M. E. Desat, R. Kretschmer, Dalton Trans. 2019, 48, 17718-17722.

[80] R. J. Schwamm, M. D. Anker, M. Lein, M. P. Coles, C. M. Fitchett, Angew. Chem. Int. Ed. 2018, $57,5885-5887$.

[81] M. D. Anker, Y. Altaf, M. Lein, M. P. Coles, Dalton Trans. 2019, 48, 16588-16594.

[82] C. Jones, P. C. Junk, J. A. Platts, D. Rathmann, A. Stasch, Dalton Trans. 2005, 2497-2499.

[83] a) H. S. Lee, S.-O. Hauber, D. Vindus, M. Niemeyer, Inorg. Chem. 2008, 47, 4401-4412; b) T. Jurca, I. Korobkov, S. I. Gorelsky, D. S. Richeson, Inorg. Chem. 2013, 52, 5749-5756.

[84] Y. Cheng, P. B. Hitchcock, M. F. Lappert, M. Zhou, Chem. Commun. 2005, 752-754.

[85] M. S. Hill, R. Pongtavornpinyo, P. B. Hitchcock, Chem. Commun. 2006, 3720-3722.

[86] a) M. E. Desat, R. Kretschmer, Chem. Eur. J. 2018, 24, 12397-12404; b) R. Wörner, O. F. Schirmer, Solid State Commun. 1984, 51, 665-669.

[87] a) X. Dai, T. H. Warren, Chem. Commun. 2001, 1998-1999; b) J. A. Kessler, V. M. Iluc, Inorg. Chem. 2014, 53, 12360-12371.

[88] C. Osuch, R. Levine, J. Am. Chem. Soc. 1956, 78, 1723-1725.

[89] H. Gornitzka, D. Stalke, Angew. Chem. Int. Ed. 1994, 33, 693-695.

[90] H. Gornitzka, D. Stalke, Organometallics 1994, 13, 4398-4405.

[91] a) T. Kottke, D. Stalke, Chem. Ber. 1997, 130, 1365-1374; b) H. Gornitzka, C. Hemmert, G. Bertrand, M. Pfeiffer, D. Stalke, Organometallics 2000, 19, 112-114.

[92] P. Vasko, V. Kinnunen, J. O. Moilanen, T. L. Roemmele, R. T. Boere, J. Konu, H. M. Tuononen, Dalton Trans. 2015, 44, 18247-18259.

[93] a) H. Gornitzka, D. Stalke, Eur. J. Inorg. Chem. 1998, 3, 311-317; b) M. Pfeiffer, F. Baier, T. Stey, D. Leusser, D. Stalke, B. Engels, D. Moigno, W. Kiefer, J. Mol. Model. 2000, 6, 299-311; c) M. Pfeiffer, A. Murso, L. Mahalakshmi, D. Moigno, W. Kiefer, D. Stalke, Eur. J. Inorg. Chem. 2002, 2002, 3222-3234.

[94] a) A. Steiner, D. Stalke, Chem. Commun. 1993, 444-446; b) M. Pfeiffer, T. Stey, H. Jehle, B. Klüpfel, W. Malisch, V. Chandrasekhar, D. Stalke, Chem. Commun. 2001, 337-338; c) F. Baier, Z. Fei, H. Gornitzka, A. Murso, S. Neufeld, M. Pfeiffer, I. Rüdenauer, A. Steiner, T. Stey, D. Stalke, J. Organomet. Chem. 2002, 661, 111-127; d) J. Henn, K. Meindl, A. Oechsner, G. Schwab, T. Koritsanszky, D. Stalke, Angew. Chem. Int. Ed. 2010, 49, 2422-2426.

[95] A. Steiner, D. Stalke, Organometallics 1995, 14, 2422-2429. 
[96] a) R. G. Pearson, J. Am. Chem. Soc. 1963, 85, 3533-3539; b) R. G. Pearson, Comput. Theor. Chem. 1983, 103, 25-34; c) R. G. Pearson, J. Am. Chem. Soc. 1985, 107, 6801-6806.

[97] a) Dr. Theodor Papenfuhs. Verfahren zur Herstellung von 2-Hydroxybenzthiazolen(0039483), 21.11.84; b) D.-R. Dauer, M. Flügge, R. Herbst-Irmer, D. Stalke, Dalton Trans. 2016, 45, 61366148.

[98] F. Téllez, A. Peña-Hueso, N. Barba-Behrens, R. Contreras, A. Flores-Parra, Polyhedron 2006, $25,2363-2374$.

[99] K. Saha, R. Ramalakshmi, R. Borthakur, S. Gomosta, K. Pathak, V. Dorcet, T. Roisnel, J.-F. Halet, S. Ghosh, Chem. Eur. J. 2017, 23, 18264-18275.

[100] K. Saha, R. Ramalakshmi, S. Gomosta, K. Pathak, V. Dorcet, T. Roisnel, J.-F. Halet, S. Ghosh, Chem. Eur. J. 2017, 23, 9812-9820.

[101] C. Nandi, K. Saha, S. Gomosta, V. Dorcet, S. Ghosh, Polyhedron 2019, 172, 191-197.

[102] W. H. Mills, Dalton Trans. 1922, 121, 455-466.

[103] a) S. Florio, F. Babudri, G. Ingrosso, A. Maria Turco, Heterocycles 1986, 24, 2215; b) D. M. McKinnon, P. Spevack, G. Tipples, Can. J. Chem. 1988, 66, 2339-2344; c) Luciano Forlani, Carla Boga, Erminia Del Vecchio, Michela Padovani, Arkivoc 2003, 2003, 75; d) H. A. Elagab, H. G. Alt, Inorg. Chim. Acta 2015, 437, 26-35; e) H. Elagab, Orient. J. Chem 2016, 32, 681700.

[104] D.-R. Dauer, D. Stalke, Dalton Trans. 2014, 43, 14432-14439.

[105] D.-R. Dauer, I. Koehne, R. Herbst-Irmer, D. Stalke, Eur. J. Inorg. Chem. 2017, 2017, 19661978.

[106] D.-R. Dauer, M. Flügge, R. Herbst-Irmer, D. Stalke, Dalton Trans. 2016, 45, 6149-6158.

[107] D.-R. Dauer, Studies of group 13 metal complexes bearing nacnac-mimetic bisheterocyclo methanides and amides; Cuvillier Verlag, Göttingen, 2016.

[108] a) I. Koehne, S. Bachmann, T. Niklas, R. Herbst-Irmer, D. Stalke, Chem. Eur. J. 2017, 23, 13141-13149; b) I. Koehne, N. Graw, T. Teuteberg, R. Herbst-Irmer, D. Stalke, Inorg. Chem. 2017, 56, 14968-14978; c) Ingo Koehne, Dissertation, Georg-Augsut-Universität Göttingen, 2018.

[109] Y. Xiong, S. Yao, M. Driess, Chem.: Asian J. 2009, 4, 1323-1328.

[110] M. Stender, R. J. Wright, B. E. Eichler, J. Prust, M. M. Olmstead, H. W. Roesky, P. P. Power, J. Dalton Trans. 2001, 3465-3469.

[111] D. C. H. Do, A. Keyser, A. V. Protchenko, B. Maitland, I. Pernik, H. Niu, E. L. Kolychev, A. Rit, D. Vidovic, A. Stasch, C. Jones, S. Aldridge, Chem. Eur. J. 2017, 23, 5830-5841.

[112] I. Koehne, S. Bachmann, R. Herbst-Irmer, D. Stalke, Angew. Chem. Int. Ed. 2017, 56, 1514115145 .

[113] A. Kütt, S. Tshepelevitsh, J. Saame, M. Lõkov, I. Kaljurand, S. Selberg, I. Leito, Eur. J. Org. Chem. 2021, 2021, 1407-1419.

[114] a) I. Kaljurand, A. Kütt, L. Sooväli, T. Rodima, V. Mäemets, I. Leito, I. A. Koppel, J. Org. Chem. 2005, 70, 1019-1028; b) A. Kütt, I. Leito, I. Kaljurand, L. Sooväli, V. M. Vlasov, L. M. Yagupolskii, I. A. Koppel, J. Org. Chem. 2006, 71, 2829-2838. 
[115] F. Bernardi, I. G. Csizmadia, H. B. Schlegel, S. Wolfe, Can. J. Chem. 1975, 53, 1144-1153.

[116] F. Ragaini, M. Pizzotti, S. Cenini, A. Abbotto, G. A. Pagani, F. Demartin, J. Organomet. Chem. 1995, 489, 107-112.

[117] F. G. Bordwell, Acc. Chem. Res. 1988, 21, 456-463.

[118] A. Kütt, S. Selberg, I. Kaljurand, S. Tshepelevitsh, A. Heering, A. Darnell, K. Kaupmees, M. Piirsalu, I. Leito, Tetrahedron Lett. 2018, 59, 3738-3748.

[119] R. Tandon, T. A. Nigst, H. Zipse, Eur. J. Org. Chem. 2013, 2013, 5423-5430.

[120] R. Shannon, Acta Crystallogr. A 1976, 32, 751-767.

[121] H. Ben Ammar, J. Le Nôtre, M. Salem, M. T. Kaddachi, P. H. Dixneuf, J. Organomet. Chem. $2002,662,63-69$.

[122] a) D. Akalay, G. Dürner, J. W. Bats, M. Bolte, M. W. Göbel, J. Org. Chem. 2007, 72, 56185624; b) J. S. Wixey, B. D. Ward, Dalton Trans. 2011, 40, 7693-7696.

[123] P. Rademacher, Strukturen organischer Moleküle; Wiley-VCH, Weinheim, 1987.

[124] F. Engelhardt, C. Maaß, D. M. Andrada, R. Herbst-Irmer, D. Stalke, Chem. Sci. 2018, 9, 31113121.

[125] N. Hu, L. Gong, Z. Jin, W. Chen, J. Organomet. Chem. 1988, 352, 61-66.

[126] T. A. Scott, B. A. Ooro, D. J. Collins, M. Shatruk, A. Yakovenko, K. R. Dunbar, H.-C. Zhou, Chem. Commun. 2009, 65-67.

[127] K. V. Vasudevan, N. C. Smythe, B. L. Scott, J. C. Gordon, Dalton Trans. 2013, 42, 4768-4771.

[128] I. Koehne, R. Herbst-Irmer, D. Stalke, Eur. J. Inorg. Chem. 2017, 2017, 3322-3326.

[129] M. H. Mazor, J. A. McCammon, T. P. Lybrand, J. Am. Chem. Soc. 1989, 111, 55-56.

[130] a) C. Schade, P. von Ragué Schleyer in Advances in Organometallic Chemistry, Academic Press, 1966. b) J. David Smith in Advances in Organometallic Chemistry, Academic Press, 1966, pp. 267-348; c) Rolf W. Saalfrank, Norbert Löw, Sabine Kareth, Verena Seitz, Frank Hampel, Dietmar Stalke, Markus Teichert, Angew. Chem. Int. Ed. 1998, 37, 172-175.

[131] Y. Gimbert, D. Lesage, C. Fressigné, J. Maddaluno, J. Org. Chem. 2017, 82, 8141-8147.

[132] a) J. Saame, T. Rodima, S. Tshepelevitsh, A. Kütt, I. Kaljurand, T. Haljasorg, I. A. Koppel, I. Leito, J. Org. Chem. 2016, 81, 7349-7361; b) S. Tshepelevitsh, A. Kütt, M. Lõkov, I. Kaljurand, J. Saame, A. Heering, P. G. Plieger, R. Vianello, I. Leito, Eur. J. Org. Chem. 2019, 2019, 67356748 .

[133] a) M. Remko, D. Fitz, B. M. Rode, Amino Acids 2010, 39, 1309-1319; b) P. Umadevi, L. Senthilkumar, RSC Adv 2014, 4, 49040-49052.

[134] W. N. Olmstead, F. G. Bordwell, J. Org. Chem. 1980, 45, 3299-3305.

[135] a) M. Stender, B. E. Eichler, N. J. Hardman, P. P. Power, J. Prust, M. Noltemeyer, H. W. Roesky, Inorg. Chem. 2001, 40, 2794-2799; b) N. Burford, M. D'eon, P. J. Ragogna, R. McDonald, M. J. Ferguson, Inorg. Chem. 2004, 43, 734-738; c) M. S. Hill, P. B. Hitchcock, S. M.A. Karagouni, J. Organomet. Chem. 2004, 689, 722-730; d) J. Koller, R. G. Bergman, Organometallics 2010, $29,3350-3356$.

[136] A. F. Holleman, E. Wiberg, N. Wiberg, G. Fischer, Anorganische Chemie; de Gruyter, Berlin, Boston, 2017. 
[137] P. Müller, R. Herbst-Irmer, A. Spek, T. Schneider, M. Sawaya, Crystal Structure Refinement: A crystallographer's guide to Shelxl; Oxford University Press, 2006.

[138] C. Janiak, R. Hoffmann, J. Am. Chem. Soc. 1990, 112, 5924-5946.

[139] C. Jones, P. C. Junk, M. Kloth, K. M. Proctor, A. Stasch, Polyhedron 2006, 25, 1592-1600.

[140] a) R. J. Baker, R. D. Farley, C. Jones, M. Kloth, D. M. Murphy, Dalton Trans. 2002, 20, 3844;

b) R. J. Baker, R. D. Farley, C. Jones, D. P. Mills, M. Kloth, D. M. Murphy, Chem. Eur. J. 2005, 11, 2972-2982.

[141] R. Laubenstein, M. Ahrens, T. Braun, Z. Anorg. Allg. Chem. 2017, 643, 1723-1729.

[142] a) J. P. Perdew, Phys. Rev. B 1986, 8822; b) A. D. Becke, Phys. Rev. A 1988, 38, 3098-3100; c) A. Schäfer, C. Huber, R. Ahlrichs, J. Chem. Phys. 1994, 100, 5829-5835; d) K. Eichkorn, F. Weigend, O. Treutler, R. Ahlrichs, Theor. Chem. Acc. 1997, 97, 119-124; e) C. Adamo, V. Barone, J. Chem. Phys. 1999, 110, 6158-6170. f) F. Weigend, R. Ahlrichs, Phys. Chem. Chem. Phys. 2005, 7, 3297-3305; g) S. Grimme, S. Ehrlich, L. Goerigk, J. Comp. Chem. 2011, 32, 1456-1465; h) F. Neese, Wiley Interdiscip. Rev. Comput. Mol. Sci. 2012, 2, 73-78; i) F. Neese, Wiley Interdiscip. Rev. Comput. Mol. Sci. 2017, 8, 1-6.

[143] E. D. Glendening, J, K. Badenhoop, A. E. Reed, J. E. Carpenter, J. A. Bohmann, C. M. Morales, P. Karafiloglou, C. R. Landis, and F. Weinhold, NBO 7.0, Theoretical Chemistry Institute, University of Wisconsin, Madison, 2018.

[144] A. Schnepf, C. Doriat, Chem. Commun. 1997, 2111-2112.

[145] A. Kempter, C. Gemel, R. A. Fischer, Inorg. Chem. 2008, 47, 7279-7285.

[146] a) H. A. Bent, J. Chem. Educ. 1960, 37, 616; b) H. A. Bent, Chem. Rev. 1961, 61, 275-311.

[147] M. Schormann, K. S. Klimek, H. Hatop, S. P. Varkey, H. W. Roesky, C. Lehmann, C. Röpken, R. Herbst-Irmer, M. Noltemeyer, J. Solid State Chem. 2001, 162, 225-236.

[148] Y. Zhao, Y. Liu, B. Wu, X.-J. Yang, Dalton Trans. 2015, 44, 13671-13680.

[149] C. Jones, Nat. Rev. Chem. 2017, 1, 1-9.

[150] H. Haraguchi, S. Fujiwara, J. Phys. Chem. 1969, 73, 3467-3473.

[151] C. Martineau, F. Taulelle, M. Haouas in PATAI'S Chemistry of Functional Groups, John Wiley \& Sons, Ltd, 2009.

[152] a) S. J. Bonyhady, C. Jones, S. Nembenna, A. Stasch, A. J. Edwards, G. J. McIntyre, Chem. Eur. J. 2010, 16, 938-955; b) J. Hicks, M. Juckel, A. Paparo, D. Dange, C. Jones, Organometallics 2018, 37, 4810-4813.

[153] S. J. Bonyhady, D. Collis, G. Frenking, N. Holzmann, C. Jones, A. Stasch, Nat. Chem. 2010, 2, 865-869.

154]a) A. Ecker, E. Baum, M. A. Friesen, M. A. Junker, C. Üffing, R. Köppe, H. Schnöckel, Z. Anorg. Allg. Chem. 1998, 624, 513-516; b) C. Klemp, G. Stößer, I. Krossing, H. Schnöckel, Angew. Chem. Int. Ed. 2000, 39, 3691-3694.

[155] S. G. Minasian, J. Arnold, Chem. Commun. 2008, 4043-4045.

[156] S. J. Bonyhady, S. P. Green, C. Jones, S. Nembenna, A. Stasch, Angew. Chem. Int. Ed. 2009, 48, 2973-2977.

[157] L. Pauling, J. Am. Chem. Soc. 1932, 54, 3570-3582. 
[158] a) F. Schüth, B. Bogdanović, M. Felderhoff, Chem. Commun. 2004, 2249-2258; b) J. Graetz, Chem. Soc. Rev. 2009, 38, 73-82.

[159] W. Li, X. Ma, M. G. Walawalkar, Z. Yang, H. W. Roesky, Coord. Chem. Rev. 2017, 350, 1429.

[160] a) J. K. Ruff, M. F. Hawthorne, J. Am. Chem. Soc. 1960, 82, 2141-2144; b) T. D. Humphries, P. Sirsch, A. Decken, G. Sean McGrady, J. Mol. Struct. 2009, 923, 13-18.

[161] a) C. Cui, H. W. Roesky, H. Hao, H.-G. Schmidt, M. Noltemeyer, Angew. Chem. Int. Ed. 2000, 39, 1815-1817; b) Y. Yang, H. Li, C. Wang, H. W. Roesky, Inorg. Chem. 2012, 51, 2204-2211; c) Z. Yang, M. Zhong, X. Ma, K. Nijesh, S. De, P. Parameswaran, H. W. Roesky, J. Am. Chem. Soc. 2016, 138, 2548-2551; d) S. Ito, K. Tanaka, Y. Chujo, Inorganics 2019, 7, 100.

[162] A. Caise, D. Jones, E. L. Kolychev, J. Hicks, J. M. Goicoechea, S. Aldridge, Chem. Eur. J. 2018, $24,13624-13635$.

[163] a) A. Reiser, L. J. Leyshon, D. Saunders, M. V. Mijovic, A. Bright, J. Bogie, J. Am. Chem. Soc. 1972, 94, 2414-2421; b) C. Carayon, S. Fery-Forgues, Photochem. \& Photobiol. Sci. 2017, 16, 1020-1035.

[164] T. Chu, I. Korobkov, G. I. Nikonov, J. Am. Chem. Soc. 2014, 136, 9195-9202.

[165] B. Twamley, N. J. Hardman, P. P. Power, Acta Crystallogr. E 2001, 57, m227-m228.

[166] R. Neufeld, D. Stalke, Chem. Sci. 2015, 6, 3354-3364.

[167] T. R. Crompton, Comprehensive Organometallic Analysis; Springer US, Boston, MA, 1987.

[168] T. W. Myers, L. A. Berben, Organometallics 2013, 32, 6647-6649.

[169] A. C. Stelzer, P. Hrobárik, T. Braun, M. Kaupp, B. Braun-Cula, Inorg. Chem. 2016, 55, 49154923.

[170] H. Zhu, J. Chai, V. Jancik, H. W. Roesky, W. A. Merrill, P. P. Power, J. Am. Chem. Soc. 2005, 127, 10170-10171.

[171] S. González-Gallardo, V. Jancik, R. Cea-Olivares, R. A. Toscano, M. Moya-Cabrera, Angew. Chem. Int. Ed. 2007, 46, 2895-2898.

[172] M. R. Mason, J. M. Smith, S. G. Bott, A. R. Barron, J. Am. Chem. Soc. 1993, 115, 4971-4984.

[173] L. K. Keyes, A. D. K. Todd, N. A. Giffin, A. J. Veinot, A. D. Hendsbee, K. N. Robertson, S. J. Geier, J. D. Masuda, RSC Adv. 2017, 7, 37315-37323.

[174] T. J. Hadlington, M. Hermann, G. Frenking, C. Jones, J. Am. Chem. Soc. 2014, 136, 30283031.

[175] A. K. Maity, S. Fortier, L. Griego, A. J. Metta-Magaña, Inorg. Chem. 2014, 53, 8155-8164.

[176] L. Quaranta, O. Corminboeuf, P. Renaud, Org. Lett. 2002, 4, 39-42.

[177] Y. Kondo, S. Kojima, T. Sakamoto, J. Org. Chem. 1997, 62, 6507-6511.

[178] a) C. M. Coleman, D. F. O'Shea, J. Am. Chem. Soc. 2003, 125, 4054-4055; b) D. M. Shendage, R. Fröhlich, G. Haufe, Org. Lett. 2004, 6, 3675-3678.

[179] J.-i. Kuroyanagi, K. Kanai, Y. Sugimoto, T. Horiuchi, I. Achiwa, H. Takeshita, K. Kawakami, Bioorg. Med. Chem. 2010, 18, 7593-7606.

[180] R. Breslow, W. Chu, J. Am. Chem. Soc. 1970, 92, 2165.

[181] M. Á. Fuentes, A. Zabala, A. R. Kennedy, R. E. Mulvey, Chem. Eur. J. 2016, 22, 14968-14978. 
[182] M. de Tullio, A. Hernán-Gómez, Z. Livingstone, W. Clegg, A. R. Kennedy, R. W. Harrington, A. Antiñolo, A. Martínez, F. Carrillo-Hermosilla, E. Hevia, Chem. Eur. J. 2016, 22, 1764617656.

[183] C. Lambert, P. von Ragué Schleyer, Angew. Chem. Int. Ed. 1994, 33, 1129-1140.

[184] G. Rabe, H. W. Roesky, D. Stalke, F. Pauer, G. M. Sheldrick, J. Organomet. Chem. 1991, 403, $11-19$.

[185] U. Pieper, D. Stalke, Organometallics 1993, 12, 1201-1206.

[186] F. Antolini, P. B. Hitchcock, M. F. Lappert, P. Merle, Chem. Commun. 2000, 1301-1302.

[187] S.-D. Bai, J.-P. Guo, D.-S. Liu, Dalton Trans. 2006, 2244-2250.

[188] a) C. R. Groom, I. J. Bruno, M. P. Lightfoot, S. C. Ward, Acta Cryst. B 2016, 72, 171-179; b) I. J. Bruno, J. C. Cole, P. R. Edgington, M. Kessler, C. F. Macrae, P. McCabe, J. Pearson, R. Taylor, Acta Cryst. B 2002, 58, 389-397.

[189] D. Hoffmann, W. Bauer, P. v. R. Schleyer, U. Pieper, D. Stalke, Organometallics 1993, 12, 1193-1200.

[190] A. G. Avent, M. R. Crimmin, M. S. Hill, P. B. Hitchcock, J. Organomet. Chem. 2006, 691, $1242-1250$.

[191] a) W. Scherer, V. Herz, A. Brück, C. Hauf, F. Reiner, S. Altmannshofer, D. Leusser, D. Stalke, Angew. Chem. Int. Ed. 2011, 50, 2845-2849; b) W. Scherer, A. C. Dunbar, J. E. BarqueraLozada, D. Schmitz, G. Eickerling, D. Kratzert, D. Stalke, A. Lanza, P. Macchi, N. P. M. Casati, J. Ebad-Allah, C. Kuntscher, Angew. Chem, Int. Ed. 2015, 54, 2505-2509.

[192] X. Chen, S. Lim, C. E. Plecnik, S. Liu, B. Du, E. A. Meyers, S. G. Shore, Inorg. Chem. 2005, 44, 6052-6061.

[193] G. C. Forbes, A. R. Kennedy, R. E. Mulvey, B. A. Roberts, R. B. Rowlings, Organometallics 2002, 21, 5115-5121.

[194] T. L. Brown, Chemistry. The central science; Prentice Hall, Upper Saddle River, NJ, 2003.

[195] C. A. Brown, J. Org. Chem. 1974, 39, 3913-3918.

[196] E. Buncel, B. Menon, Chem. Commun. 1976, 648-649.

[197] R. E. Gawley, X. Zhang, Q. Wang in Encyclopedia of reagents for organic synthesis; (Ed. L. A. Paquette), Wiley, Chichester, 1995.

[198] H. Viebrock, T. Panther, U. Behrens, E. Weiss, J. Organomet. Chem. 1995, 491, 19-25.

[199] a) R. A. Bartlett, H. V. R. Dias, P. P. Power, J. Organomet. Chem. 1988, 341, 1-9; b) A. C. Benniston, A. Harriman, Chem. Soc. Rev. 2006, 35, 169-179; c) R. M. Williams, Photochem. Photobiol. Sci. 2010, 9, 1018-1026.

[200] a) H. Hope, P. P. Power, J. Am. Chem. Soc. 1983, 105, 5320-5324; b) D. Stalke, K. H. Whitmire, Chem. Commun. 1990, 833-834; c) S. Harder, P. F. Ekhart, L. Brandsma, J. A. Kanters, A. J. M. Duisenberg, P. v. R. Schleyer, Organometallics 1992, 11, 2623-2627.

[201] U. Schümann, U. Behrens, E. Weiss, Angew. Chem. Int. Ed. 1989, 28, 476-477.

[202] J. D. Wallis, J. D. Dunitz, Helv. Chim. Acta 1984, 67, 1374-1378.

[203] M. Arrowsmith, M. S. Hill, G. Kociok-Köhn, D. J. MacDougall, M. F. Mahon, I. Mallov, Inorg. Chem. 2012, 51, 13408-13418. 
[204] a) M. Khan, R. C. Steevensz, D. G. Tuck, J. G. Noltes, P. W. R. Corfield, Inorg. Chem. 1980, 19, 3407-3411; b) Christoph Kümmel, Anton Meller, Mathias Noltemeyer, Z. Naturforsch. B, 1996, 51b, 209-219; c) E. Iravani, B. Neumüller, Z. Anorg. Allg. Chem. 2003, 629, 2509-2515.

[205] J. D. Hoefelmeyer, M. Schulte, F. P. Gabbaï, Inorg. Chem. 2001, 40, 3833-3834.

[206] a) L. Lochmann, J. Pospísil, D. Lím, Tetrahedron Lett. 1966, 7, 257-262; b) L. Lochmann, J. Petránek, Tetrahedron Lett. 1991, 32, 1483-1488; c) L. Lochmann, J. Trekoval, J. Organomet. Chem. 1987, 326, 1-7.

[207] S. L. Choong, W. D. Woodul, A. Stasch, C. Schenk, C. Jones, Aust. J. Chem. 2011, 64, $1173-$ 1176.

[208] A. E. Reed, R. B. Weinstock, F. Weinhold, J. Chem. Phys. 1985, 83, 735-746.

[209] a) L. A. Berben, Chem. Eur. J. 2015, 21, 2734-2742; b) F. Ebner, H. Wadepohl, L. Greb, J. Am. Chem. Soc. 2019, 141, 18009-18012; c) L. M. Sigmund, L. Greb, Chem. Sci. 2020, 11, $9611-$ 9616; d) L. M. Sigmund, C. Ehlert, M. Enders, J. Graf, G. Gryn'ova, L. Greb, Angew. Chem. Int. Ed. 2021.

[210] a) W. Schlenk, A. Thal, Chem. Ber. 1913, 46, 2840-2854; b) T. T. Tidwell, Angew. Chem. Int. Ed. 2001, 40, 331-337; c) Georg-August-University, "Virtuelles Labor I", to be found under http://www.stalke.chemie.uni-goettingen.de/virtuelles_labor/advanced/13_de.html, 2014.

[211] W. Uhlig, Z. Naturforsch. B 1995, 1674-1678.

[212] A. F. Burchat, J. Michael Chong, N. Nielsen, J. Organomet. Chem. 1997, 542, 281-283.

[213] H. J. Svec, Int. J. Mass Spectrom. 1985, 66, 3-29.

[214] Mora, Juan Fernandez de la, G. J. van Berkel, C. G. Enke, R. B. Cole, M. Martinez-Sanchez, J. B. Fenn, J. Mass Spectrom. 2000, 35, 939-952.

[215] a) H. B. Linden, Eur. J. Mass Spectrom. 2004, 10, 459-468; b) J. H. Gross, N. Nieth, H. B. Linden, U. Blumbach, F. J. Richter, M. E. Tauchert, R. Tompers, P. Hofmann, Anal. Bioanal. Chem. 2006, 386, 52-58.

[216] a) G. R. Fulmer, Alexander J. M. Miller, N. H. Sherden, H. E. Gottlieb, A. Nudelman, B. M. Stoltz, J. E. Bercaw, K. I. Goldberg, Organometallics 2010, 29, 2176-2179; b) Georg-AugustUniversity, "Virtuelles Labor II", to be found under http://www.stalke.chemie.unigoettingen.de/virtuelles_labor/nmr/de.html, 2014.

[217] G. Bodenhausen, D. J. Ruben, Chem. Phys. Lett. 1980, 69, 185-189.

[218] A. Bax, M. F. Summers, J. Am. Chem. Soc. 1986, 108, 2093-2094.

[219] a) S. Bachmann, R. Neufeld, M. Dzemski, D. Stalke, Chem. Eur. J. 2016, 22, 8462-8465; b) S. Bachmann, B. Gernert, D. Stalke, Chem. Commun. 2016, 52, 12861-12864.

[220] R. Neufeld, M. John, D. Stalke, Angew. Chem. Int. Ed. 2015, 54, 6994-6998.

[221] a) A. Jerschow, N. Müller, J. Magn. Reson. Ser. A 1996, 123, 222-225; b) A. Jerschow, N. Müller, J. Magn. Reson. 1997, 125, 372-375.

[222] G. A. Zhurko, ChemCraft, http://www.chemcraftprog.com, 2016.

[223] a) T. Kottke, D. Stalke, J. Appl. Cryst. 1993, 26, 615-619; b) D. Stalke, Chem. Soc. Rev. 1998, $27,171-178$; c) Georg-August-University, "Virtuelles Labor III", to be found under http://www.stalke.chemie.uni-goettingen.de/virtuelleslabor/special/22de.html, 2014. 
[224] T. Schulz, K. Meindl, D. Leusser, D. Stern, J. Graf, C. Michaelsen, M. Ruf, G. M. Sheldrick, D. Stalke, J. Appl. Cryst. 2009, 42, 885-891.

[225] Bruker AXS Inc, APEX2 v2012/2: Crystallographic Software Suite, Madison, WI, USA, 2012.

[226] Bruker AXS Inc, APEX3: Crystallographic Software Suite, Madison, WI, USA, 2016.

[227] Bruker AXS Inc, SAINT v8.30C, Madison, USA, 2013.

[228] L. Krause, R. Herbst-Irmer, G. M. Sheldrick, D. Stalke, J. Appl. Cryst. 2015, 48, 3-10.

[229] G. M. Sheldrick, TWINABS 2012/1: TWINABS 2012/1, Göttingen, 2012.

[230] L. Krause, R. Herbst-Irmer, D. Stalke, J. Appl. Cryst. 2015, 48, 1907-1913.

[231] G. M. Sheldrick, XPREP in SHELXTL 2014/2, Göttingen, 2014.

[232] G. Sheldrick, Acta Cryst. 2008, 64, 112-122.

[233] C. B. Hübschle, B. Dittrich, J. Appl. Cryst. 2011, 44, 238-240.

[234] G. M. Sheldrick, SHELXL in SHELXTL v2014/7; WI, USA, Madison, 2014.

[235] S. Parsons, H. D. Flack, T. Wagner, Acta Cryst. B 2013, 69, 249-259.

[236] S. Kundu, C. Mohapatra, P. P. Samuel, J. Kretsch, M. G. Walawalkar, R. Herbst-Irmer, D. Stalke, S. De, D. Koley, H. W. Roesky, Chem. Commun. 2017, 53, 192-195.

[237] S. Kundu, B. Li, J. Kretsch, R. Herbst-Irmer, D. M. Andrada, G. Frenking, D. Stalke, H. W. Roesky, Angew. Chem. Int. Ed. 2017, 56, 4219-4223.

[238] S. K. Sarkar, M. M. Siddiqui, S. Kundu, M. Ghosh, J. Kretsch, P. Stollberg, R. Herbst-Irmer, D. Stalke, A. C. Stückl, B. Schwederski, W. Kaim, S. Ghorai, E. D. Jemmis, H. W. Roesky, Dalton Trans. 2019, 48, 8551-8555.

[239] M. M. Siddiqui, S. Banerjee, S. Bose, S. K. Sarkar, S. K. Gupta, J. Kretsch, N. Graw, R. HerbstIrmer, D. Stalke, S. Dutta, D. Koley, H. W. Roesky, Inorg. Chem. 2020, 59, 11253-11258.

[240] I. Leito, T. Rodima, I. A. Koppel, R. Schwesinger, V. M. Vlasov, The Journal of organic chemistry 1997, 62, 8479-8483. 